INTERNATIONAL SERIES ON

APPLIED SYSTEMS ANALYSIS
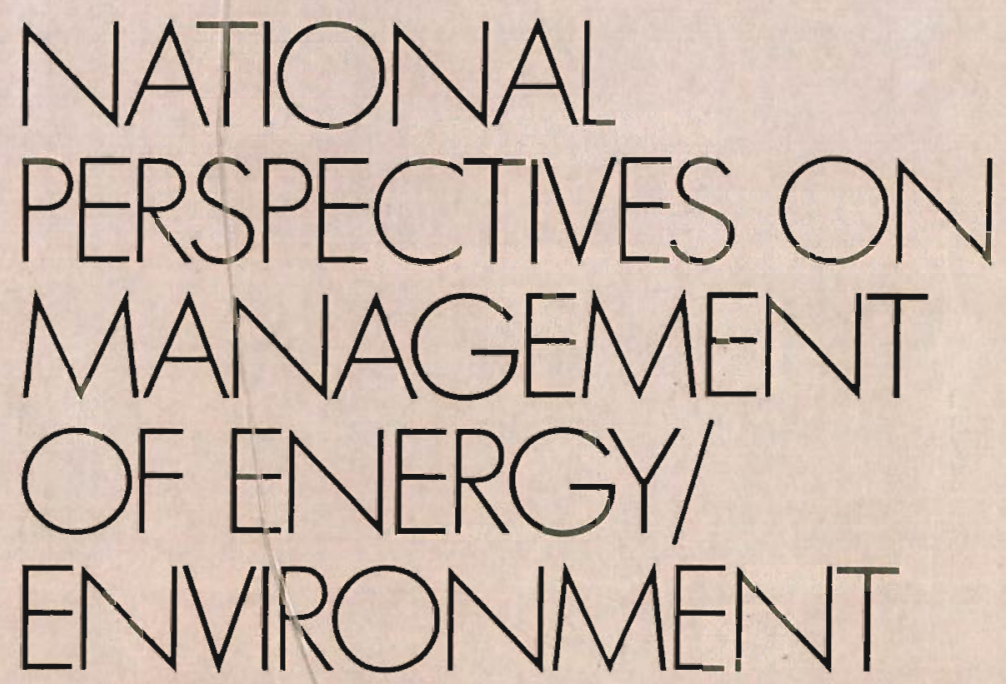

SYSTEMS

Edited by

WESLEY K. FOELL.

LORETTA A. HERVEY

International Institute for Applied Systems Analysis 


\title{
NATIONAL PERSPECTIVES ON MANAGEMENT OF ENERGY/ENVIRONMENT SYSTEMS
}

\author{
Edited by \\ Wesley K. Foell \\ Energy Research Center \\ University of Wisconsin-Madison \\ and
}

\section{Loretta A. Hervey}

International Institute for Applied Systems Analysis Laxenburg, Austria

The first part of this book is composed of a set of chapters on the management and planning of energy/ environment systems in twelve different countries both East and West. The term 'energy/environment systems' here describes the socioeconomic and technological aspects of energy and their relationship to the natural and man-made environments. The basic philosophy is that there is a very close relationship between the methods employed in the management of these systems and the institutional framework within which they must operate. By studying the way in which energy/environment problems are tackled in one country, it is hoped not only to identify the management and planning tools being used, but also to see whether they could be applied with equal success in countries with a different social, economic, and political structure. The approach is therefore both methodological and policy-oriented. Each chapter is written by an energy/environment expert from the country concerned, and in addition to a description of the management and planning techniques used includes an analysis of national energy supply and demand, an assessment of the environmental effects of energy systems, and an explanation of how these analyses are incorporated in the decision-making process.

The second part of the book takes a retrospective look at the IIASA case studies of four regions already described in Volume 5 of this series and elsewhere. The main features of the energy/environment scenarios developed for these four regions are summarized, important issues treated in the scenarios are discussed (energy conservation, energy supply strategies, air pollution, and the coal option), and representatives from the four regions assess, retrospectively, the value of the IIASA study.

\section{Contents}

\section{Introduction}

Part I. Energy/Environment Management and Planning in Twelve Countries

\section{A Comparative Overview} W. K. Foell 


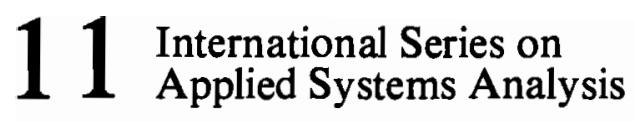

\section{National Perspectives on Management of Energy/Environment Systems}

Edited by

Wesley K. Foell

Energy Research Center,

University of Wisconsin-Madison

Loretta A. Hervey

International Institute for Applied Systems Analysis, Laxenburg, Austria

A Wiley-Interscience Publication

International Institute for Applied Systems Analysis

JOHN WILEY \& SONS

Chichester-New York-Brisbane-Toronto-Singapore 
Copyright @ 1983 International Institute for Applied Systems Analysis

All rights reserved.

No part of this book may be reproduced by any means, nor transmitted, nor translated into a machine language without the written permission of the publisher.

\section{Library of Congress Cataloging in Publication Data}

Main entry under title:

National perspectives on management of energy/ environment systems.

(International series on applied systems analysis; 11)

Continues: Management of energy/environment systems. c1979.

"A Wiley-Interscience publication. International

Institute for Applied Systems Analysis."

Includes index.

1. Environmental policy-Case studies.

2. Energy policy - Case studies. I. Foell, Wesley K. II. Hervey, Loretta A. III. International Institute for Applied Systems Analysis. IV. Series.

$\begin{array}{llll}\text { HC79.E } 5 N 348 & 1982 & 333.79^{\prime} 16 & 82-7025\end{array}$

ISBN 0471100226

\section{British Library Cataloguing in Publication Data}

Foell, Wesley K.

National perspectives on management of energy/ environment systems.- (Wiley IIASA international series on applied systems analysis; 11)
1. Energy conservation
2. Energy development

-Environmental aspects
1. Title
II. Hervey, Loretta A.

III. Series

$333.79^{\prime} 16$

HD9502

ISBN 0471100226

Illustrations prepared by Oxford Illustrators Ltd., Oxford, England Typeset by Pintail Studios Ltd., Ringwood, Hants., and printed at The Pitman Press, Bath, Avon 
To the spirit of international cooperation upon which IIASA was founded. May this spirit and her creators' ideals sustain her through times of difficulty, while preserving and nurturing the vital networks of scientists created through a common desire to improve man's management of the world's resources. 



\section{Foreword}

This book is the second of two volumes produced by the IIASA project on Management of Regional Energy/Environment Systems. The first* described the results of a collaborative three-year comparative energy study of three regions, namely, the German Democratic Republic, the Rhône-Alpes region of France, and the federal state of Wisconsin in the United States of America. That first volume concentrated on methods, quantitative analysis of the three regions, and building scenarios for their energy/environment systems. In the course of the study and during the preparation of the earlier volume, it became apparent to the IIASA team that the socioeconomic, political, and institutional differences among the regions are at least as important as their physical and technical differences for the analysis and planning of energy/environment strategies. An analysis of the management tools used in a country or region is greatly enhanced by an understanding of the institutional context within which they operate. This institutional structure, in turn, is best viewed within the overall economic and political framework of the region. This new awareness was to a large degree responsible for the IIASA "capstone" conference on Management of Regional Energy/Environment Systems, which gave rise to the present volume.

The main part of this book presents a description of management and planning of energy/environment systems in twelve widely differing countries. An expert from each of the countries describes the techniques used to analyze national energy demand and supply, and to assess the environmental effects of the country's energy systems, explaining how these are incorporated into the decisionmaking process. Each of these experts draws upon considerable experience in energy policy analysis and planning in his or her native country.

* W. K. Foell (Ed.), Management of Energy/Environment Systems: Methods and Case Studies, Wiley, 1979. 
Institutions and their analytical tools change and adapt to the perceived issues and problems of the day. This is as it should be, and the institutions and tools of energy policy and planning are no exception. A cross-section through the twelve countries described here reveals tremendous diversity in both structure and tools. Some of the centrally planned countries favor highly structured organizations and planning instruments. These contrast sharply with their counterparts in some of the market economies, where frequently the agencies and methods deal with narrower or more limited issues. In many of these countries the situation has been changing very rapidly, with institutions and tools evolving continuously through the 1970s. We believe that it is still too early to tell which of these tools and institutions will endure through the 1980s. Failures in both analysis and planning are still at least as common as successes. Energy policy analysis remains a craft: but we hope that this volume will help to move it at least one small step closer to being a science. 


\section{Preface}

The goal of this book is to further international discussion of national and regional strategies for the management of energy resources and the protection of the environment. Government agencies with special responsibility for energy and the environment are being created with increasing frequency throughout the world. At the same time, research workers and policy analysts are being asked to forecast long-term energy demands, to formulate strategies for coping with increasingly severe energy supply constraints, and to balance the need to supply energy to consumers and the desire to protect the quality of the environment. Though the sense of urgency may differ among nations, action is being taken; new administrative mechanisms are being implemented and quantitative techniques specifically addressing energy/environment problems are being developed. Each nation sees the situation in the light of a unique political, economic, social, and scientific tradition, producing a multitude of approaches to the solution of a common problem. This diversity of reactions has created a tremendous potential for crossfertilization of ideas among nations.

In 1975, the International Institute for Applied Systems Analysis (IIASA) initiated an international collaborative research project on management and planning of energy/environment systems. The energy/environment system was taken to include the overall institutional framework in which energy/environment policy making and analysis are carried out, as well as the traditional areas of energy supply, demand, and environmental impact. This ensured that the existing management and planning tools would be examined, and new methods developed, with an understanding of the institutional structure within which they must operate.

The project began with case studies of the management of energy/environment systems in the German Democratic Republic, the Rhône-Alpes region of France, and the state of Wisconsin in the United States. The objectives were: 
1. To study the institutional structure of each region, as it related to energy/environment management and planning

2. To disseminate information about the management and analysis techniques currently employed in each region

3. To develop and apply new tools for energy/environment management and analysis

These tools took the form of scenario-building and analysis for a planning horizon of 40-50 years. The results for the three regions mentioned above were described in detail in an earlier volume of the Wiley IIASA International Series on Applied Systems Analysis, Management of Energy/Environment Systems: Methods and Case Studies, edited by W.K. Foell.

This volume extends the earlier work by presenting the progress made in energy/environment management and planning in nine additional countries. Part I contains papers on the energy/environment situation in Austria, the Federal Republic of Germany, Finland, Hungary, Italy, Japan, Poland, Sweden, the Union of Soviet Socialist Republics, and the United States of America. Also included are discussions of the work done in the German Democratic Republic and France (based primarily upon the earlier book).

This book also seeks to reflect the process of active communication between the IIASA research team, the collaborating regions, and the IIASA National Member Organization (NMO) countries. Part II presents an overview of the structure and main issues treated in the energy/environment scenarios developed for the three initial regions and for Austria, which was taken as a study region in 1977-1978. This overview was produced for a 1978 "capstone" conference, to which representatives from the four regions studied and 14 NMO countries were invited. The reactions from the regions on the value and applicability of the methods and studies developed by IIASA are presented in Part II in the form of retrospective comments. The collaborative process also included panel discussions and the formation of working groups to examine salient issues in the energy/environment field: energy-economy interactions, energy and the environment, and the embedding of analysis into real-world decision making. Their conclusions are presented in the Appendixes.

The aim of this book, therefore, is to share the energy/environment experience of many nations with a wider audience, to illustrate the collaboration between the IIASA team and potential users in developing and assessing analytical methods, and, finally, to obtain an outline of the state of the art and research directions for the future from an international group of experts. This book is a product of work carried out in many countries, with IIASA serving as a catalyst and host; it has been prepared in the hope that the international cooperation that made it possible will continue unabated in the future. 


\section{Acknowledgments}

This book would not have been possible without the contributions made both by colleagues at IIASA and by researchers from collaborating institutions. Their individual contributions are too numerous to list here, but are described in detail in the articles cited in the text and in other publications resulting from this study.

Howard Raiffa, IIASA's first director, and Buzz Holling, initial leader of the IIASA Energy/Environment group, were vital catalysts for the study and were very supportive in the early stages of research. Roger Levien, IIASA's second director, also gave much encouragement in subsequent stages of the work.

Faith Worzala and Gundega Korsts of the University of Wisconsin provided expert and thorough assistance in the preparation of the final manuscript, which Helen Gasking of IIASA then edited with great skill. Finally, the Editors are indebted to Hugh Miser, IIASA's Executive Editor, for his encouragement and unswerving support in the publication of this second volume on management of energy/environment systems. 


\section{Contents}

1 Introduction

PART I: ENERGY/ENVIRONMENT MANAGEMENT AND PLANNING IN TWELVE COUNTRIES

2 A Comparative Overview

W.K. Foell

3 Management and Planning of Energy/Environment

Systems in Austria

Eduard G. Fraunbaum

4 Management and Planning of Energy/Environment

Systems in the Federal Republic of Germany

Edgar Geißler and Kjell Wiik

5 Management and Planning of Energy/Environment

Systems in Finland

Seppo Hannus

6 Management and Planning of Energy/Environment

Systems in France

Dominique Finon and Jean-Marie Martin

7 Management and Planning of Energy/Environment

Systems in the German Democratic Republic

Dietmar Ufer and Peter Hedrich

8 Management and Planning of Energy/Environment

Systems in Hungary

Gÿla Czipper, György Földvary, and Edit Unk 
9 Management and Planning of Energy/Environment Systems in Italy

Oliviero Bernardini

10 Management and Planning of Energy/Environment Systems in Japan

Takao Tomitate

11 Management and Planning of Energy/Environment

Systems in Poland

Wiestaw Ciechanowicz and Marek Makowski

12 Management and Planning of Energy/Environment

Systems in Sweden

Torgny Schütt and Lars Bergman

13 Management and Planning of Energy/Environment Systems in the Union of Soviet Socialist Republics A.S. Nekrasov

14 Management and Planning of Energy/Environment Systems in the United States of America Peter House

PART II: A RETROSPECTIVE LOOK AT THE FOUR IIASA REGIONAL ANALYSES OF ENERGY/ENVIRONMENT SYSTEMS

15 A Four-Region Overview 203 $W . K$. Foell

16 Issues Emerging from the Scenarios

M.E. Hanson, A. Hölzl, E. Pönitz, L.A. Hervey, R. Dennis, and W.A. Buehring

17 Retrospective Views from the Four Regions Helmut Hirsch, Wolfgang Kluge, Dietmar Ufer, Bertrand Chateau, and Charles Cicchetti

\section{APPENDIXES}

A The IIASA Conference on Management of

Regional Energy/Environment Systems

B Reports of the Working Groups 299

C Summaries of the Panel Discussions 309

Name Index

Subject Index 


\section{Introduction}

\section{ENERGY AND THE ENVIRONMENT}

As the 1980 s progress, the 1970 s may be retrospectively characterized as the decade which produced a worldwide realization of the need to manage energy resources. The economic shocks produced by recurring petroleum shortfalls and price increases, coupled with growing public awareness of environmental issues, have demonstrated all too clearly the importance of energy in the industrialized world and its growing role in the developing world. At the same time, controversy over nuclear power has shown that high-level technological innovation alone may not suffice to meet the demands of an energy-hungry society.

However, the past decade has also produced a cautious but steadily growing hope that renewable resources could be important in meeting the world's future energy needs. The large sums of money now spent on solar research and development demonstrate that the idea of a solar-powered society is no longer just an academic's dream. But there is also a growing realization that, if a transition to renewable resources is actually going to occur, it will be neither quick nor easy. A major effort will be required to manage our remaining fossil fuel resources prudently.

The emergence of energy and its environmental implications as crucial issues during the past decade has led to the foundation of institutions concerned with energy and the environment at local, national, and international levels. These range from institutions concerned with essentially micro-economic issues, e.g., firms or business enterprises, to new departments or ministries of energy with national responsibilities, to institutions involved with global issues, such as the International Fuel Cycle Evaluation group (INFCE), which has examined weapon proliferation and other issues associated with the nuclear fuel cycle.

Complementary to the development of these institutions, the need for improved methods of analysis, planning, and management of energy resources at each level, 
from local to international, has been recognized during the past decade. This is reflected in the number of research projects undertaken in the energy/environment field over this period.

One of these, the Workshop on Alternative Energy Strategies ${ }^{1}$, has produced scenarios of energy supply and demand in 13 market economies, on an aggregated level, up to the year 2000. The study group examined the possible ranges of total energy supply and demand, and attempted to assess the effect of variations in economic growth rates, energy policies, availability of replacement fuels, and energy coefficients in the energy demand sectors. The Energy Systems Program Group at the International Institute for Applied Systems Analysis (IIASA) has spent 7 years studying the possible evolution of global levels of energy supply and demand, up to the year $2030^{2}$. This time horizon permitted the research group to focus its attention on the "energy transition" from the present dependence on depletable resources to the use of renewable or "sustainable" resources.

Other studies carried out during the 1970s focused on the disaggregation of national energy consumption data by demand sectors or processes, in an effort to explain international differences in per capita energy consumption and to identify energy-conserving practices which could be transferred from one country to another. Schippers and Lichtenberg's comparison of energy use in the USA and Sweden ${ }^{3}$, and the cross-national study of energy consumption patterns in nine highly developed western countries carried out by Darmstadter et al. ${ }^{4}$ fall into this category.

The work of the IIASA project on Management of Regional Energy/Environment Systems may be distinguished from both global studies and international comparisons of energy use by its focus on the application of methodological tools within the specific institutional or decision-making context of a region or nation. Planning and management tools in operation in a given country or region reflect existing institutional structures, and the application of new tools must be compatible with such structures.

The IIASA study on Management of Regional Energy/Environment Systems therefore:

1. Undertook case studies in which it applied a set of energy demand, energy supply, and environmental impact models in selected regions

2. Surveyed existing planning and management tools in a variety of countries

The initial case studies of planning and management of energy/environment systems in the German Democratic Republic, the Rhône-Alpes region of France, and the state of Wisconsin in the USA have been reported in detail in an earlier publication ${ }^{5}$. A case study of Austria has also been carried out, and the results published separately ${ }^{6}$. This volume is composed largely of papers surveying the state of the art of energy/environment management in twelve of IIASA's National 
Member Organization countries. The papers are built on the framework which has guided the work of the project as a whole, i.e., discussion of the socioeconomic and institutional setting, analysis of energy demand, analysis of energy supply, examination of environmental impacts, and integration of decision making and analysis.

The rest of this chapter sets the national studies in perspective by sketching the Project's history and aims and by summarizing other aspects of its research activities, and concludes with a discussion of the aims and scope of the present volume, as reflected in its structure and contents.

\section{THE IIASA RESEARCH PROGRAM: ITS HISTORY AND AIMS}

The first steps toward organizing an international collaborative study on the management of regional energy/environment systems were taken at IIASA in early 1975 . The research team immediately focused on two related tasks. First, they wished to study current patterns of energy supply and demand, environmental management techniques, and planning tools in operation in a variety of regions. Second, they wished to develop and disseminate a set of general tools to analyze the possible evolution of energy/environment systems in the regions over the next 40-50 years. But broadening the information base and developing general planning methods represented only one side of the coin. Just as important was the collaborative nature of the project - the participation of experts from the study regions in the collection of data, in the discussion of issues, constraints, and policies which should be taken into consideration in analyzing alternative regional futures, and in the evaluation of the results.

Several criteria were used in choosing the study areas. First, the geographical region should be appropriately bounded so that it is possible to speak of energy/environment systems which are self-contained from a physical, a socioeconomic, or an administrative standpoint, or some combination of these. The regional focus makes it possible to examine the physical and institutional infrastructure in which the energy/environment system is embedded; this includes not only the characteristics of the region itself, but also its political or economic ties to the nation or supranational unit of which it is a part. Second, it was important that the regions chosen for study should contain an institute already engaged in policy-oriented research and interested in actively collaborating with IIASA. Finally, the regions chosen should have widely differing socioeconomic and political structures, geographic and environmental characteristics, and institutional approaches to energy and environmental management. This diversity promised to produce a wide range of approaches to the common problem of maintaining the supply of energy while protecting the quality of the environment.

The Rhône-Alpes region of France, a composite region of the German Democratic Republic ("Bezirk-X"), and the state of Wisconsin in the United States were chosen as the initial study regions. During the spring and summer of 
1975 the staff of energy research institutes in each of the regions provided the IIASA team with information on the geography, climate, population, transportation networks, economic structure, energy resources, and energy consumption patterns in each region. They also supplied information on the institutional settings for energy planning and decision making, local air-quality. management, energy-related building practices, and energy/environment models then in use in each of the regions. The IIASA group used the data as a basis for examining alternative energy/environment futures with the aid of a set of scenario-building techniques and simulation models. [These are discussed briefly in the following section; for more information see Chapter 3 of Management of Energy/Environment Systems: Methods and Case Studies, by Foell ${ }^{5}$, and ref. 7.] Preliminary scenarios were presented to analysts and policy makers from each of the regions at a conference held at IIASA in 1975. The final versions of the scenarios, together with a large amount of related information on the energy/environment systems of the regions, have already been published ${ }^{5}$.

In 1976 a fourth case study, Austria, was added to the project. The research focused heavily on the examination of alternative energy/environment futures for Austria and involved frequent evaluation by Austrian energy analysts and policy makers. The collaborative process included three joint workshops with analysts from Austrian institutes and a final Executive Briefing Session, during which the results of the study were summarized for national and provincial decision makers. A detailed description of the Austrian case study has been published as an IIASA research report ${ }^{6}$ Assessment of Alternative Energy/Environment Futures for Austria: 1977-2015.

A "capstone" conference, held in May 1978, represented the final phase of the IIASA project. The conference was designed not only to summarize the results of the four case studies for representatives of IIASA's 17 National Member Organizations (NMOs), but also to define priorities for future research in this field and to survey related work underway in IIASA NMO countries.

A large part of this book is composed of papers presented at the May 1978 conference. Each of these contributions, from twelve different nations, summarizes the planning and management of energy/environment systems in the home country of the author. Together with an overview written by W. K. Foell, the project leader and conference chairman, these papers represent an extension of the task originally set in the four regional case studies: to investigate the structure and management of regional energy/environment systems, and plan their future development. It is hoped that the various approaches to energy/environment planning documented here will provide a basis for exchange of ideas and possible joint ventures in this field in the future.

\section{RESEARCH ACTIVITIES OF THE IIASA PROJECT}

This volume is best viewed in the light of the work of the IIASA project on Management of Regional Energy/Environment Systems as a whole. The main 
aims of the research program are listed below and are then discussed briefly in later sections.

1. Detailed description of the energy/environment systems in selected regions. This includes a picture of past and present energy use, models of energy supply and demand, indices of environmental quality, economic activity, demography, and patterns of human settlement.

2. Development of alternative futures (scenarios) for each region to examine different energy/environment policies and strategies.

3. Analysis of the regional institutions and organizations which control energy/environment planning, management, and policy.

4. Description of the energy/environment modeling tools used in each of the regions, with special reference to methodology, fields of application in policy and planning, relation to the decision-making structure, and transferability to other regions.

5. Development of methods and concepts for communicating and evaluating energy/environment strategies and options.

6. Survey of the methods used to analyze energy/environment policy in the IIASA National Member Organization countries.

7. Determination of needs and priorities in policy analysis and planning of regional energy/environment systems, in collaboration with experts in the energy/environment sphere from each of the countries.

The first five components have been reported in detail in an earlier volume ${ }^{5}$ of the Wiley International Series on Applied Systems Analysis and are outlined below. The last two components form the basis of the present volume.

\section{Description of the energy/environment systems}

The energy/environment system in a region is a function of the various physical, socioeconomic, and energy characteristics which influence current and future patterns of energy supply and demand. An intensive data-gathering network was therefore set up to provide the project with information on local physical features, such as geography, climate, and population distribution; economic factors, such as the type of transportation network, the level of economic activity, and the structure of industrial and commercial/service sectors; and energy use, such as sources of supply and current energy consumption patterns. These data were used to define the initial conditions for the alternative energy/environment futures (or scenarios) developed for the regions under study.

\section{Development of alternative futures (scenarios)}

The IIASA research team developed a set of alternative futures (scenarios) in order to analyze the effects of different energy and environment policies and 
strategies in the regions. Scenario-building involves a detailed examination of possible futures and the consequences of assumptions made to produce these futures, and provides a formal quantitative framework for the examination and discussion of policy options. First, a set of conditions and constraints based on the data for each region is built up. Second, the implementation of various energy/environment measures is simulated within the framework. Finally, the resulting evolution of the region is analyzed.

Policy issues. The policy issues chosen were of common interest to the regions and relevant over the mid-to-long term (5-50 years). Features examined included the relationships between the environment, the size and density of urban settlements, types of housing, and energy supply technology; the energy and environmental implications of present trends in intercity and intracity passenger transportation; the possibility of satisfying future energy demand using various energy sources, such as coal, gas, nuclear and solar power; and the effects of various pollution control policies associated with alternative energy strategies.

Scenario structure. The scenarios were developed in two specific stages. First, alternative "policy sets" were devised for each region and the resulting scenarios were investigated. Second, "sensitivity studies" were conducted to evaluate the effects of varying a small number of policy variables while holding the others constant.

In order to build a scenario within the constraints of a specific set of policies, it was necessary to express each policy in terms of a limited number of characteristics. The variables chosen were:

- Population

- Structure and growth of the economy

- Location and size of urban settlements

- Technologies of energy use

- Transportation systems (for people and goods)

- Technologies of primary energy conversion and supply (including electricity generation)

- Control and protection of the environment

This general framework then provided the exogenous functions and constraints for the models used to build the scenarios. Tables 15.8-15.11 in Part II of this volume give overviews of the scenarios developed for Austria, Bezirk-X of the GDR, the Rhône-Alpes region of France, and the state of Wisconsin in the USA. It must be stressed that the energy futures were not intended as predictions but as demonstrations of the long-run consequences of different policy actions.

Some characteristics were common to the scenarios developed for all regions, e.g., stronger conservation measures, greater emphasis on renewable energy sources. High, medium, and low energy scenarios were considered for all regions. 
Analytic tools. One of the main analytic tools used to examine the scenarios was a set of simulation models originally developed at the University of Wisconsin-Madison and extended at IIASA to treat different regional energy/environment systems. The models simulate an energy system within a framework that includes energy demand, regional supply systems, and environmental impacts. Most of the models are based on descriptions of engineering processes. The socioeconomic aspects, e.g., population, settlement patterns, and economic activity, were modeled differently in each of the regions. More detailed information on the demand, supply, and environmental impact models used in examining the scenarios may be found in the earlier book ${ }^{5}$ by Foell and the related IIASA research report ${ }^{7}$.

In brief, the energy/environment system of each region was described using the following components:

- Socioeconomic activities

- Energy demand

- Energy conversion and supply

- Primary energy sources

- Environmental parameters

This structure was used throughout the project to organize primary data collection, make scenario assumptions, and classify the output and results of models. The same framework was also used as a basis for the papers summarizing management and planning of energy/environment systems in the IIASA NMO countries, and therefore provides a strong link between the four case studies undertaken previously and the national descriptions which form the core of this book.

Results. Alternative energy/environment futures (scenarios) extending over the next 40-50 years were constructed using the methods outlined above. The results obtained include annual end-use energy demand by sector and energy source; annual primary energy requirements by energy source; and the effects of the various energy scenarios on the environment.

A comparison of the results produced by different scenarios for a given region shows that the future energy demand depends strongly on the assumptions made about economic growth, changes in lifestyle, advances in technology, and conservation measures. The environmental impacts associated with the level of energy demand and the mix of energy technologies may also be compared between scenarios.

The results produced by similar scenarios in different regions demonstrate the similarities and differences in energy/environment development between the various regions. For instance, it is possible to examine the projected per capita energy consumption in each of the regions 40-50 years in the future. However, any comparisons of this nature must be made with great care. The regions enter 
the scenario at different states of development, with different socioeconomic structures, and with different expectations of the future, and it would therefore be unrealistic to expect these differences to disappear by the end of the scenario period.

Many of the findings of this study have clear policy implications. For instance, it was possible to identify the potential for energy conservation in each region by comparing the level of end-use energy demand in a scenario reflecting current patterns of use (S1) with that suggested by a "low energy" scenario (S3). In the case of Austria, the "low energy" scenario S3 was also compared with scenario S4, which assumed considerable energy conservation. An examination of the factors responsible for the difference in energy demand makes it possible to identify areas where policy measures could be effective. It is clear that greater attention should be paid to constructing energy-efficient housing, reducing the level of gasoline use in automobiles, and examining the energy-intensiveness of industrial processes. Analysis of the effects of different regional energy futures on the environment pinpoints the areas and people most affected in each case, and provides a basis for comparing the environmental impacts of various mixes of energy technologies.

Selected results for Austria, Bezirk-X of the German Democratic Republic, the Rhône-Alpes region of France, and the state of Wisconsin in the USA are summarized in Part II of the present volume. The inclusion of the Austrian case study brings the results obtained for all four regions together for the first time.

\section{Analysis of the regional institutional structure}

The internal structure and bureaucracy of a region shape the tools used to manage local energy/environment systems. It is therefore important to analyze the institutional structure of the region, since only then can the general applicability of the tools developed within it be assessed. For instance, formal mathematical models which have been integrated into the decision-making process of a centrally planned region may be difficult to transfer and implement in a region with a highly decentralized tradition of government. To provide background for the discussion of modeling tools, the coliaborating institutes in the study regions provided IIASA with information on the regional decision-making structure related to energy/environment planning. These data revealed a wide range of planning and decision-making traditions: in the GDR, for instance, energy policy is implemented through a formal energy plan, and authority for the provision of energy is vested in clearly defined government agencies. Within this well-articulated planning process, it is possible to vary the emphasis on the balance of energy supply and demand, economic requirements, and economic potential. At the other extreme, the responsibility for energy/environment matters in the state of Wisconsin is shared very widely, making coordinated planning and policy implementation difficult. It is therefore important to understand the decision-making 
structure in a given region so that planning tools can be implemented at the most effective level (local, regional, or national).

\section{Energy/environment modeling techniques}

Having analyzed the institutional background, the collaborating organizations supplied IIASA with information on the energy/environment models used in their home regions. Each group was asked to assess the models of the other regions from the perspective of their own methodological requirements for planning and policy analysis. This exchange of ideas was meant to demonstrate the range of models currently in use, and to identify the elements from each model which were considered of general relevance. These elements could then be combined to produce a set of models capable of more general application.

\section{Communicating and evaluating energy/environment strategies and options}

Much of the value of this research would be lost if decision makers were not informed of the results or if they were unable to transiate the findings into actual policy decisions. This last step is often the most difficult. In order to evaluate data on alternative futures, it is essential that decision makers should have a clear picture of what constitutes a desirable future, and the relative importance of each component to the whole. They must be able to assess the role of energy technologies in achieving policy objectives and to strike a balance between economic growth and environmental protection.

In an attempt to quantify the preferences of decision makers with regard to energy/environment futures, the IIASA team adopted a model based on multiattribute decision analysis. The model makes use of multiattribute utility functions to help decision makers to identify their own preferred energy/environment future, and is described in detail in an IIASA research report ${ }^{8}$.

The main aim of the preference model is not to provide decision makers with "answers", but to supply a basis for discussion of alternative decision strategies, to make decision makers aware of their own preferences, and to resolve conflict in decision-making groups by revealing differences in preferences among the members.

In addition to this quantitative evaluation, the IIASA team arranged opportunities for qualitative assessment of the study by policy analysts and decision makers from each of the regions. Workshops were held at important points during the program, not only to discuss methodology and research strategy, but also to give the case studies the widest possible exposure to potential "clients".

The process of communication and evaluation can best be illustrated by reference to the Austrian case study, which was begun in the autumn of 1976 . A workshop held in January 1977 identified the issues which Austrian decision makers and analysts wished to build into the scenarios. Preliminary results were 
presented to the same audience at a workshop in July 1977; it was then possible to discuss the scenarios with Austrian representatives, to assess the feasibility of the results obtained for energy demand and environmental impact, and to clarify the procedures used by the IIASA team. In October 1977, top-level Austrian decision makers were invited to an Executive Briefing Session, and presented with a concise summary (in German) of the results of the study. A third workshop, held in November 1977, was attended by a large audience of middle-level Austrian decision makers and technical analysts. The series of workshops seems to have been a successful medium both for adapting the IIASA analysis to the needs of particular regions and for publicizing the methods and results of the study among the target sector - managers, planners, and decision makers.

\section{THE PRESENT FOCUS: NATIONAL PERSPECTIVES ON MANAGEMENT OF ENERGY/ENVIRONMENT SYSTEMS}

The present volume is based on a project "capstone" conference held at IIASA in May 1978. Experts on energy and the environment from twelve of IIASA's National Member Organization countries convened to analyze energy/environment management and planning in their home countries, and to assess the regional case studies carried out by the IIASA team. The goals of the conference and of this book may be summarized as follows:

1. To expand from the regional case studies with a state-of-the-art review of energy/environment management over a wide spectrum of countries.

2. To present the methods and results of IIASA case studies to an international audience for assessment.

3. To provide a forum for informed discussion of current issues and future research in the energy/environment field.

This volume summarizes the progress made toward fulfilling these three goals.

The state of the art of energy/environment management

IIASA requested the representatives of each National Member Organization (NMO) to prepare a written statement summarizing the methods and models used for planning and analysis of energy/environment systems in their country. The following guidelines were suggested:

- Overview of energy systems planning

- Energy demand analysis

- Energy supply analysis

- Environmental analysis

- Integration of decision making and analysis 
These topics formed the basis of the four previous IIASA case studies. The use of this common framework makes it possible to compare the analytical tools employed in energy/environment management in the various countries, the institutional structures which shaped them, and the implementation of their findings as actual policy decisions. The resulting papers, submitted by ten countries, are presented in Part I of this volume. Part I also contains sections of papers on the energy/environment situation in the German Democratic Republic and France which have been largely based on chapters in Management of Energy/Environment Systems: Methods and Case Studies by Foell ${ }^{5}$. Thus all of the national studies have been brought together in one place.

This exercise in international collaborative research was successful on a number of levels. On the most elementary level, collaboration with national experts produced a bank of information which would otherwise have been inaccessible to the IIASA team. The resulting set of papers, written in a common format by representatives of twelve countries, illustrates the role which an organization like IIASA can play in coordinating an international attack on a problem of mutual interest.

The examination of national experiences in the energy/environment field also represents a preliminary exploration of the relation of planning and management techniques to the social system in which they have evolved. It must be stressed that this research is only exploratory; no attempt is made to test hypotheses linking a given national political system, as an independent variable, to analysis tools, as dependent variables. However, it is hoped that the qualitative information presented here will provide the basis for a more quantitative approach in this area in the future. At the present level of analysis, the national papers serve to identify the social and institutional contexts in which planning and management tools have developed and are applied. A knowledge of the background against which planning techniques have evolved should highlight the problems which may arise in transferring a technique from one culture to another.

In a more constructive sense, the national papers demonstrate the different approaches to a common problem which have been developed by various nations. To use the terminology of the social sciences, the planning and management tools may to some extent be considered as operational alternatives for carrying out similar functions. It is hoped that publicizing the details of energy/environment planning in twelve different countries will encourage the relevant authorities to examine the experience of other nations, and to learn from their various failures and successes in this field. Charles Cicchetti, of the Wisconsin Public Service Commission, gives an example of this process at work in his retrospective report on the Wisconsin case study (p. 291 of this volume); he reports that learning about the extensive use of waste heat in the German Democratic Republic stimulated more serious consideration of this possibility in Wisconsin. The sharing of knowledge about energy/environment practices which have evolved in a few nations, but which could have much wider application in other countries, may be one of the most important contributions of the IIASA research project. 


\section{Summary and assessment of the IIASA case studies}

Part II of this volume contains a summary overview of the scenarios developed for the IIASA regional case studies; four papers highlighting important issues treated in the scenarios (energy conservation, energy supply strategies, air pollution, and the coal option); and retrospective reports on the case studies as seen by representatives from each of the four regions involved.

\section{An international forum}

During the "capstone" conference upon which this volume is based, representatives from IIASA's NMO countries and several international organizations participated in discussions and working groups on issues of current interest in the energy/environment field. The reports of working groups and panel discussions are summarized in Appendixes $B$ and $C$ under the headings: "Energy/Economy Interactions"; "Environmental and Energy Strategies"; "Energy Conservation and Alternative Supply Strategies"; and "Embedding the Results of Energy/Environment Systems Analysis: Planning, Management, and the Real World".

It is hoped that this state-of-the-art presentation of energy/environment planning in a variety of national and regional contexts combined with a discussion of research priorities will provide both an impetus and a framework for structuring future research in this field.

\section{REFERENCES}

1 C.L. Wilson. Energy: Global Prospects 1985-2000. Report of the Workshop on Alternative Energy Strategies. McGraw-Hill, New York, 1977.

2 W. Häfele. Energy in a Finite World: Vol. 2. A Global Systems Analysis. Ballinger, Cambridge, Mass., USA, 1981.

3 L. Schippers and A.J. Lichtenberg. Efficient energy use and well-being: the Swedish example. Science 194 (1976) 4269.

4 J. Darmstadter, J. Dunkerley, and J. Alterman. How Industrial Societies Use Energy: A Comparative Analysis. Johns Hopkins University Press, Baltimore, USA, 1977.

5 W.K. Foell (Ed.). Management of Energy/Environment Systems: Methods and Case Studies. Wiley, Chichester, UK, 1979.

6 W.K. Foell, R.L. Dennis, M.E. Hanson, L.A. Hervey, A. Hölzl, J.P. Peerenboom, and E. Pönitz. Assessment of Alternative Energy/Environment Futures for Austria: 1977-2015. RR-79-7, International Institute for Applied Systems Analysis, Laxenburg, Austria, 1979.

7 W.K. Foell, J.S. Buehring, W.A. Buehring, R.L. Dennis, M.E. Hanson, L.A. Hervey, A. Hölzl, K. Ito, R.L. Keeney, J.P. Peerenboom, E. Pönitz, J. Richter, and A. Toifelhardt. The Wisconsin-IIASA Set of Energy/Environment (WISE) Models for Regional Planning and Management: An Overview. RR-81-17, International Institute for Applied Systems Analysis, Laxenburg, Austria, 1981.

8 W.A. Buehring, W.K. Foell, and R.L. Keeney. Energy/Environment Management: Application of Decision Analysis. RR-76-14, International Institute for Applied Systems Analysis, Laxenburg, Austria, 1976. 
Part I

Energy/Environment Management and Planning in Twelve Countries 



\title{
2 A Comparative Overview
}

\author{
W.K. Foell*
}

Part I comprises a set of papers on energy/environment management and planning in twelve different countries. The approaches made to the problem are as varied as the countries themselves, depending to a very great extent on the economic, technical, political, and social structure of the region in which they must operate. Each paper was written by an expert in the energy/environment field from the country under consideration: these include Austria, the Federal Republic of Germany, Finland, France, the German Democratic Republic, Hungary, Italy, Japan, Poland, Sweden, the Union of Soviet Socialist Republics, and the United States of America. For ease of comparison, IIASA suggested that all the papers should have the same basic structure:

1. General discussion of energy system planning and management in the country, with a review of the issues of greatest interest

2. Energy demand analysis

3. Energy supply analysis

4. Environmental analysis

5. Integration of decision making and analysis (embedding)

Each of these points is discussed briefly below, with reference to the national descriptions which follow this overview.

\section{ENERGY SYSTEM PLANNING AND MANAGEMENT}

There is a very close relationship between the methods employed in management of energy systems and the institutional framework within which they must

\footnotetext{
* International Institute for Applied Systems Analysis, Laxenburg, Austria, and the University of Wisconsin-Madison, Madison, Wisconsin.
} 
operate. The economic and political structure of a country has a profound influence on the national planning and decision-making processes, and the tools which may be used for analysis.

The paper by Ufer and Hedrich shows that the highly centralized planning system of the German Democratic Republic has given rise to a complex, interdependent set of data-intensive models at the national level. The introduction and application of these models are direct results of energy policy implemented through the state's most important economic instrument, the Plan (primarily the one- and the five-year plans).

In direct contrast to the GDR (which has the most highly formalized system of energy planning models considered in the national studies), is Austria. Eduard Fraunbaum explains that energy laws are not recognized as a special regulatory domain by the Austrian constitution. All forms of energy, except for electricity, fall within the jurisdiction of the provinces, unless there are any special circumstances which prevent this. National planning is therefore limited to advising on policy and action; it appears that although mid-term prognosis techniques are used in Austria, there are no formal planning models at the national level. In most of the countries considered here, the only regional analysis took place during the siting of facilities. Notable exceptions to this are the USA and the USSR, large countries where some of the states or republics conduct their own analyses, and have some planning or regulatory responsibility.

\section{ENERGY DEMAND ANALYSIS}

It is pointed out by Torgny Schütt and Lars Bergman in their study of energy/environment systems in Sweden that good demand predictions seem to be more valuable in the energy sector than in any other part of the economy. This is largely a function of the long gestation period and high capital intensity of this sector. Since the social costs of inaccurate projections can be relatively high, most countries are investing considerable effort in improving their forecasts of energy demand.

Although several of the papers describe models based upon conventional and formal methods for forecasting, it is clear that scenario building, employing sensitivity analysis and a wide range of exogenous variables, is playing an increasing role in energy demand analysis. Even in areas where formalized mathematical techniques have long been emphasized, e.g., the French electricity sector, the realization of fundamental changes in the demand patterns has brought scenario building to the fore. Demand uncertainty is viewed by Seppo Hannus as the major problem in energy planning in Finland, and is again approached through scenario building.

In several countries attempts are being made to develop linked energy/economy models with feedback loops from the energy sector to the other parts of the economy. However, there seems to be general agreement with the view expressed 
by Edgar Geißler and Kjell Wiik in their paper on the Federal Republic of Germany that the completely endogenous energy demand model is still only a dream, and a confused one at that.

Peter House discusses the energy/economy feedback mechanism for four major models in use in the USA. In particular, he summarizes the Data Resources, Inc. economic model system which can be used to examine the economic effects of energy development. This consistent linking of the energy sector with the rest of the economy is one of the major advances of the past few years. Unfortunately, however, the resource and data requirements of a system of models of this type may put it beyond the reach of many smaller countries.

\section{ENERGY SUPPLY ANALYSIS}

There are several common threads running through the energy supply analyses outlined in the national studies. The larger countries, in particular those with market economies, preferred a reference energy system which provided a unified framework for analysis of the entire energy chain. In a number of cases, e.g., France, the Federal Republic of Germany, and the USA, this framework was then coupled with a larger scale "prescriptive model" (such as an optimization model based on linear or dynamic programming) to examine alternative energy supply strategies. The reference energy systems provide a convenient framework for a large, technology-oriented energy information base. The results obtained on applying these systems to large technical models have been quite useful, but nevertheless frequently appear to lack behavioral, institutional, and geographical detail.

A second common thread through many of the national energy supply analyses was the heavy emphasis on the need to restrict petroleum imports. Takao Tomitate describes a Japanese approach in which energy is first supplied by sources that function as petroleum alternatives, and the shortfall is met by petroleum. The entire energy chain can then be checked through a fuel option model incorporating these constraints.

A thread common to the centrally planned economies was the key role played by an iterative balancing process in the whole planning procedure. In both the GDR and the USSR the starting point is taken to be the demand for energy. This is followed by a complex operation in which the supply and demand capacity and the economic requirements and potentials are assessed, adjusted, and balanced.

\section{ENVIRONMENTAL ANALYSIS}

The joint analysis of energy systems and their related environmental effects did not become common until the 1970s. Much of the previous work considered individual facilities rather than the country or the region, and concentrated on the energy aspect rather than considering the energy/environment system as a whole. 
In general, the countries which adopted the "reference energy system" approach to analyze supply used a similar method for assessing the effect of energy systems on the environment. Large data bases of environmental impact coefficients have been collected in the USA and FRG for this purpose. However, in recent years there seems to have been a tendency toward regional rather than national analysis of environmental systems. In Japan, local and regional governments have adopted even more stringent environmental restraints than the central government, and models/analyses are usually carried out at the regional level. Gÿla Czipper, György Földvary, and Edit Unk emphasize that long-range energy planning in Hungary is now being tied to a land development program. The future of the energy sector and its implications for the rest of the economy also form an important part of the 30-year National Physical Plan now being prepared in Hungary.

Many aspects of energy-related environmental damage are discussed in the national studies, though air pollution remained a dominant theme. This is presumably because it is relatively easy to link calculations of pollutant emission with energy system models. Wiestaw Ciechanowicz and Marek Makowski discuss the planning model developed for this purpose at the Systems Research Institute of the Polish Academy of Sciences. Polish legislation limits the concentration of 185 pollutants in the atmosphere, taking a weighted sum of individual pollution concentrations as an index which is used for control. However, the authors emphasize that the level at which pollution limits should be set remains a topic of much discussion in Poland. They suggest that financial estimates of the damage caused to the environment by pollution are needed to solve this problem. However, the IIASA group has found that a single consideration such as cost is not generally sufficient to incorporate environmental impacts into formal energy system analysis; it is usually necessary to include a number of other factors '.

\section{INTEGRATION OF DECISION MAKING AND ANALYSIS (EMBEDDING)}

We use the word "embedding" to describe the communication of the concepts, objectives, results, and significance of the energy/environment analysis to its users or clients. These "users" or "clients" may be government decision or policy makers, planners, corporate planners, or ordinary citizens. All too often models and other planning/management tools are designed for nonexistent decisions to be made by nonexistent decision makers. A successful model should fulfil three major criteria: it should be usable, useful, and used!

Oliviero Bernardini, in his paper on the methods and models used in energy/environment management in Italy, discusses this issue in relation to the decision-making system in Italy. He identifies the system's major elements as the information flows, the decision-making levels, and the channels for feedback between these levels. His description of the "major actors" in the Italian 
energy/environment field underlines the needs, weaknesses, and strengths of the various methods of analysis.

Most of the national papers describe the techniques used in embedding, such as workshops, gaming techniques, executive reports and briefings, and public participation projects. One feature which emerged from the discussions at the conference was the difficulty of first quantifying uncertainty, and then communicating it. Many of the participants saw this as one of the major problems associated with the use of formal techniques in systems analysis.

The embedding process was undoubtedly the most heatedly discussed and most controversial issue raised at the workshop. Those readers interested in the problems associated with integrating the results of systems analysis with the situations existing in the real world are referred to the relevant working group reports and panel discussions given in Appendixes B and C.

The general conclusion to be drawn from the twelve national studies is that, although there is still no common approach to management of energy/environment systems, the paths taken converge sufficiently to suggest a common goal. It is hoped that these studies will lead to the development of a new and lasting science: that of energy systems analysis.

\section{REFERENCE}

1 W.A. Buehring, W.K. Foell, and R.L. Keeney. Examining energy/environment policy using decision analysis. Energy Systems and Policy, Spring 1978. 


\title{
3 Management and Planning of \\ 3 Energy/Environment Systems in Austria*
}

\author{
Eduard G. Fraunbaum**
}

\section{INTRODUCTION}

Since the so-called energy crisis in the winter of $1973 / 1974$, energy policy has become a central political issue in Austria, and the environmental impact of energy supply systems has also come to play an important role in political discussion. This resulted in a public referendum on the issue of whether the first Austrian nuclear power plant should be put into operation. Austria was thus the first nation in the world to formally consult its people on the peaceful use of nuclear power. The referendum, held on 5 November 1978 , attracted $65 \%$ of the population eligible to vote and resulted in a narrow majority against putting the nuclear plant into operation $(50.5 \%$ of the voters were against, and $49.5 \%$ for, the use of the nuclear plant).

Other environmental effects of the energy supply system play a less important role in public discussion, although the impact of hydroelectric facilities on the landscape, especially in the Danube valley and alpine regions, has been the cause of some concern. Hydropower is much more important in Austria than in most other countries-about $60 \%$ of the hydropower which it is considered economical to exploit is currently used for electricity production. The impact of proposed new hydropower plants on the environment and the landscape is being considered in a number of ecological assessments, which may be used to achieve integrated landscape planning in the future.

Before discussing the potential for energy management and planning, it is first necessary to describe briefly the legal and administrative situations in Austria. In the draft energy proposal ${ }^{1}$ presented by the national government to Parliament in

\footnotetext{
* This chapter was originally written in 1978. It has been updated by the Editors, using recently published statistical information.

** Austrian Federal Ministry of Trade, Commerce, and Industry.
} 
1969 , it was noted that "the concept of 'energy affairs' does not appear in the constitution. From the standpoint of jurisdictional responsibilities, as set forth in constitutional law, the expression 'energy affairs' is exceedingly complex." This means that in general energy laws are not recognized as a special regulatory domain by the Austrian constitution. The relevant parts of the constitution were written in 1925, before the advent of many of the energy technologies, notably nuclear power, currently in use, and was therefore designed to deal with a situation completely different to that existing today. Not surprisingly, the article does not consider any of the environmental or social consequences of national energy policy which have become important in recent years.

The 1929 version of the national constitution deals with the division of responsibility between the national government and the local governments of the nine provinces (Articles 10-15, the so-called "articles of jurisdiction"). Matters which are not explicitly within the jurisdiction of the national government in Articles 10,11 , and 12 are delegated to the provinces. This means that management of all forms of energy, except for electricity, falls within the jurisdiction of the provinces, unless there are exceptional circumstances, such as foreign trade, which prevent this.

The legal base for management in times of crisis was created in 1976 with the so-called "energy crisis laws"; these laws contain provisions for constitutional changes of limited duration.

Because of the legal preconditions described above, a complex mechanism is required to coordinate the actions of the national government and the governments of the iline provinces. This is independent of the actual organization of the energy industries, which may be wholly or partly nationalized (on a national or provincial level), municipally or privately owned.

The energy supply crisis of $1973 / 1974$ provoked the preparation of the first national energy plan ${ }^{2}$ in 1975. In the foreword to this plan, the Austrian government set the following goals:

- Identification of future patterns of energy consumption in Austria

- Investigation of ways of meeting future energy demand

- Analysis of the degree to which the energy supply system is prone to crises

- Identification of desirable changes in the patterns of consumption and methods which could be used to achieve these changes

- Improvement of the supply structure

The next national plan ${ }^{3}$ (1976) put forward the following guidelines:

- Indicative planning should be used to provide a direction for policy and action which harmonizes with the public interest. It should give the national authorities a sound basis for making decisions on a wide variety of related subjects 
- Long-term goals are to be constantly revised in the light of changing socioeconomic conditions and target-setting

- The approach adopted should be acceptable to the public and as many interest groups as possible to ensure maximum cooperation

To a large extent these criteria also indicate the scope of Austrian energy policy at the national level.

Other editions* of the national energy plan were published in April $1979^{4}$ and November $1980^{5}$. Here the goals put forward for the energy sector included optimal use of domestic energy reserves, substitution of more reliable energy sources for petroleum, and ensuring the availability of energy imports. The report foresaw the growing importance of coal, wood, and alternative energy sources such as solar power.

Several Austrian provinces have also prepared their own energy plans, drafts, or catalogues of problems to be tackled in energy management ${ }^{6-8}$.

There are important regional differences in the availability of petroleum products and natural gas in Austria. Only a small fraction of the petroleum products needed for western Austria is supplied by Austria's only refinery, located east of Vienna. The provinces of Salzburg, Tyrol, and Vorarlberg are largely supplied with products refined in neighboring countries. Tyrol is the only province which is not connected to the network of natural gas pipelines?.

The very large and complex area of environmental protection is similar to that of energy matters as regards the constitution. The provinces possess fundamental control over the making and execution of laws. Matters which require nationwide cooperation, such as controlling the admissible level of pollutants in the atmosphere, may be approached through a series of agreements between national and provincial governments.

The regional policy and planning laws provide a legal basis for the systematic and integrated management of energy and environmental problems. Sectoral landuse plans and programs issued on the basis of these laws would be binding at least at the provincial level. Several provinces have already taken preliminary steps toward the provision of such schemes. However, one of the prerequisites for work of this type is an adequate data base; as yet no such data base exists. The Federal Ministry of Trade, Commerce, and Industry**, which is responsible for energy matters, intends to aid the provinces by funding cooperative surveys and analyses.

\footnotetext{
"These new editions were called "energy reports" (Energieberichte) rather than "energy plans" (Energiepläne). The new terminology reflects the content of the publications more accurately than the old.

** The titles of all official bodies, government departments, etc., have been translated into English in the text for the benefit of non-German-speakers - the official German titles are given (together with the translations) in Appendix 3A.
} 
The use of such detailed regional plans and programs should make it possible to integrate environmental and energy planning.

The principles and goals on which Austrian energy/environment policy is based are outlined below.

1. Principles of energy policy resolved by the Austrian national government ${ }^{10}$ in January 1974:

- Maximum use of domestic energy resources

- Protection of indispensable imports

- Development of stockpiles

2. Principles on energy and the environment, as set forth by the Austrian national government ${ }^{10}$ :

"In many respects the adoption of binding regulations and strict standards (especially for emissions of harmful substances, waste heat, and noise) depends on the signing of international agreements. The national government will strive for the realization of such agreements."

3. Goals agreed upon at the Austrian Regional Policy Conference* ${ }^{11}$ :

- Improvement and equalization of living conditions

- Fostering the development of the individual within society

\section{ANALYSIS OF ENERGY DEMAND}

It should be stated at the outset that the degree of geographical aggregation of the Austrian data base is relatively high, though the methods discussed above should help to make regionally differentiated data available in the future. Information on the supply of petroleum products was particularly difficult to obtain. This lack of data has led to the suggestion (made by the provinces) that the Austrian energy plan should be regionalized.

Austria's primary energy consumption of fossil fuels was $856.1 \times 10^{15}$ Joules in $1978^{12}$. This figure can be broken down into three major categories:

$\begin{array}{ll}\text { Petroleum products } & 60.1 \% \\ \text { Gases } & 21.3 \% \\ \text { Coal } & 18.5 \%\end{array}$

\footnotetext{
* The participants at the Regional Policy Conference (OROK) include the Chancellor, Federal Ministers, the State Secretary responsible for regional policy, the nine Provincial Leaders, two representatives from the association of towns, and two representatives from the association of communities.
} 
In the same year 113.2 Joules of hydropower was generated.

Since the spring of 1974 the Austrian Institute for Economic Research has prepared an annual long-term prediction of energy demand at the request of the Federal Ministry of Trade, Commerce, and Industry. In the issue ${ }^{12}$ of the Energy Prognosis to 1990 that appeared in November 1980, data going back to 1955 were employed in the prediction, which is based upon a formal mathematical model using three methods:

1. Extrapolation of past relationships between energy consumption and its determinants

2. Assessment of technological, sociological, and economic information

3. Assessment of predictions from other sources

The results of this November prognosis are summarized in Tables 3.1, 3.2, and 3.3. The prognosis took into account the results of the 1979 referendum and did not assume that nuclear-generated electricity would be available. It predicted that natural gas and hydropower would be increasingly used to meet growth in demand during the 1980 s. It is interesting to note that the estimate of future energy consumption has tended to decline in successive prognoses.

The Federal Economics Board has also produced a prognosis ${ }^{13}$ for the Austrian economy up to the year 1985. The economy was disaggregated into 31 economic sectors and analyzed with the aid of the Austria II input-output model.

TABLE 3.1 Selected figures from the Austrian national energy balance. The data are given in $10^{12}$ Joules. The figures for 1978 and 1979 are observed values and the figures for 1985 and 1990 are prognoses ${ }^{a}$.

\begin{tabular}{llrrr}
\hline Energy category & 1978 & 1979 & 1985 & \multicolumn{1}{c}{1990} \\
\hline $\begin{array}{l}\text { Total primary energy } \\
\quad \text { consumption }\end{array}$ & 953,571 & $1,010,190$ & $1,158,160$ & $1,293,833$ \\
$\begin{array}{l}\text { Conversion } \\
\text { Production of derived } \\
\quad \text { energy sources, non- }\end{array}$ & 752,802 & 804,996 & 911,556 & 993,118 \\
$\quad$ energy use, energy & & & & \\
$\quad$ consumption by energy & & & & \\
$\quad$ sector, transmission & & & & \\
losses & 767,287 & 821,051 & 927,103 & $1,023,096$ \\
End-use energy & & & & \\
$\quad$ consumption & 721,219 & 768,962 & 879,621 & 981,611 \\
$\quad$ Industry & 243,222 & 263,918 & 280,795 & 303,063 \\
$\quad$ Transportation & 176,563 & 184,783 & 207,575 & 224,069 \\
$\quad$ Small consumers & & & & \\
\hline
\end{tabular}

${ }^{a}$ Taken from ref. 12.

${ }^{b}$ Households, commerce, agriculture, public administration, services. 
TABLE 3.2 Development and structure of end-use energy consumption in Austria. The figures are given in $10^{12}$ Joules and as a percentage of the total (in parentheses). The figures for 1978 and 1979 are observed values and the figures for 1985 and 1990 are prognoses ${ }^{a}$.

\begin{tabular}{|c|c|c|c|c|c|c|c|c|}
\hline \multirow[t]{2}{*}{ Energy form } & \multicolumn{8}{|c|}{ End-use consumption } \\
\hline & 1978 & & 1979 & & 1985 & & 1990 & \\
\hline \multirow{4}{*}{$\begin{array}{l}\text { Hard coal } \\
\text { Coke } \\
\text { Lignite } \\
\text { Petroleum }\end{array}$} & 10,687 & & 13,280 & & 8,300 & & 6,150 & \\
\hline & 51,533 & $(11.0)$ & 65,282 & $(12.5)$ & 64,053 & $(9.4)$ & 59,334 & $(7.6)$ \\
\hline & 11,001 & & 11,338 & & 7,500 & & $7,100 J$ & \\
\hline & & & & & & & & \\
\hline products & 377,825 & $(52.4)$ & 388,987 & $(50.6)$ & 470,605 & $(53.5)$ & 506,801 & $(51.6)$ \\
\hline Gases & 108,581 & $(15.0)$ & 117,343 & $(15.3)$ & 124,604 & (14.2) & 158,658 & $(16.2)$ \\
\hline Electricity & 109,930 & $(15.3)$ & 114,865 & $(15.0)$ & 150,134 & (17.1) & 181,613 & $(18.5)$ \\
\hline District heat & 13,578 & (1.9) & 14,179 & $(1.8)$ & 20,462 & $(2.3)$ & 27,487 & $(2.8)$ \\
\hline Other $b$ & 38,085 & $(5.3)$ & 43,688 & $(5.7)$ & 33,962 & (3.9) & 34,468 & $(3.5)$ \\
\hline Total & 721,219 & & 768,962 & & 879,620 & & 981,611 & \\
\hline
\end{tabular}

${ }^{a}$ Taken from ref. 12.

${ }^{b}$ Hydropower, wood, etc.

TABLE 3.3 Predicted changes in energy consumption ${ }^{a}$.

\begin{tabular}{llc}
\hline Energy category & \multicolumn{2}{c}{ Annual change (\%) } \\
\cline { 2 - 3 } & $1978-1985$ & $1985-1990$ \\
\hline Total primary energy consumption & +2.8 & +2.2 \\
End-use energy consumption & +2.9 & +2.2 \\
Conversion, energy consumption by energy sector, & & +2.3 \\
$\quad$ transmission losses, nonenergy use & +2.6 & +1.5 \\
Industry & +2.1 & +1.5 \\
Transportation & +2.3 & +3.0 \\
Small consumers $b$ & +3.8 & -0.0 \\
Total consumption of: & & +1.5 \\
$\quad$ Heating oil (including gas oil for heating plants) & +3.1 & +3.6 \\
$\quad$ Gasoline & +2.2 & +4.6 \\
$\quad$ Electricity (with pumped storage) & & \\
\hline
\end{tabular}

${ }^{a}$ Taken from ref. 12.

${ }^{b}$ Households, commerce, agriculture, public administration, services. 
The Austria II model (which was also used in the IIASA study of Energy/Environment Management in Austria ${ }^{14}$ ) assumes that the present national and world economic structure will remain unchanged. It must be noted, however, that the model was not developed specifically for the energy sector.

\section{ANALYSIS OF ENERGY SUPPLY}

Until about 1955 Austria was virtually self-sufficient in energy. This was largely due to the petroleum resources in eastern Austria which, although small in absolute terms, were quite significant for a middle-European country. However, with the explosive increase in petroleum consumption and the growing dependence on petroleum products, Austria became highly reliant on imported petroleum and related products (in 1979, 86.1\% of liquid fuels were imported).

The most recent comprehensive energy balance for Austria ${ }^{15}$, showing both energy and monetary flows, was prepared for the year 1959. In later years less detailed energy balances were produced ${ }^{16}$.

With the exception of the electricity sector, energy flows in Austria are analyzed at a relatively high level of aggregation. The energy planning methods used in the coal-mining and electricity sectors are summarized below ${ }^{17-20}$.

\section{Coal-mining sector}

Only lignite is currently mined in Austria. The mining conditions are difficult and it is therefore important to use exact planning techniques such as the Critical Path Method (CPM) to achieve the best results. This method makes it possible to coordinate legal affairs and administration as well as the actual mining activities.

\section{Electricity sector}

Because electricity cannot be stored, it is particularly important to plan the construction of plants and distribution networks on the basis of a reliable estimate of future electricity demand. Planning for plant construction is carried out both by individual companies and by the Association of Austrian Electricity-Generating Companies, the latter through the Committee for Coordinating Public Electricity Supply.

There are two major approaches to planning the construction of electricity plants in Austria:

- Planning for the best mixture of generating capacity

- Planning for adjustment to variations in demand

In the past, energy systems have generally been modeled as a subsector of the economy. However, legal, environmental, and market factors should now all be 
taken into consideration in planning the future energy strategy of the country. The political feasibility of a solution could be assessed in terms of minimizing the impact of possible future energy crises. However, there will always be potential conflict between the short-term aims of the energy sector ("security of supply") and the longer-term goals reflected in the national energy plan.

\section{ENVIRONMENTAL ANALYSIS}

The most important environmental impact connected with energy use in Austria is pollution of the atmosphere, primarily through combustion of fossil fuels. However, it is extremely difficult to demonstrate the consequences of atmospheric pollution for human health. There are thought to be a number of effects which may be distinguished ${ }^{17}$ as follows:

- Short-term exposure resulting in an increase in the number of deaths (mortality)

- Short-term exposure resulting in an increase in the incidence of disease (morbidity)

- Long-term exposure resulting in an increase in the number of deaths (mortality)

- Long-term exposure resulting in an increase in the incidence of disease (morbidity) in larger populations

- Long-term effects on the health of children

The maximum recommended concentrations of pollutants in the atmosphere and in the place of work are recognized threshold values for the protection of human health, although they are not legally binding. Because of the constitutional situation in Austria, regulation of air quality is within the jurisdiction of the provinces. Uniform national standards could only be set through special agreements between the national government and the provincial administrations. The Austrian government is attempting to reduce the sulfur content of heating oil through just such an agreement. In May 1981 the maximum sulfur content of heavy heating oil was set at $3.5 \%$, that of medium heating oil at $2.5 \%$, and that of light heating oil at $1.5 \%$.

There are currently no Austrian laws or recommendations governing the level of sulfur dioxide $\left(\mathrm{SO}_{2}\right)$ in the atmosphere. In actual administrative decisions, however, reference is most often made to the West German standards given in the Technical Introduction to Air Quality Protection ${ }^{21}$, which is now being revised.

The average emissions of pollutants produced through the combustion of fossil fuels in 1976 are given in Table 3.4. Since these values are averages, the actual emissions in particular regions or districts may be considerably higher or lower than the figures given in the table. Table 3.4 also shows the cost of damage caused to buildings, facilities, health, and vegetation by atmospheric pollution in $1970^{22}$. 
TABLE 3.4 The level and cost of air pollution in Austria.

\begin{tabular}{lccc}
\hline Pollutant & Chemical description & $\begin{array}{c}\text { Quantity }^{a} \\
\left.\text { (tonnes } / \mathrm{km}^{2}\right)\end{array}$ & $\begin{array}{c}\text { Cost }^{b} \\
\left(10^{6} \text { AS) }\right.\end{array}$ \\
\hline Sulfur oxides & & 3.1 & 1809 \\
Nitrogen oxides & $\mathrm{SO}_{x}$ & 1.4 & 77 \\
Hydrocarbons & $\mathrm{NO}_{x}$ & 0.5 & - \\
Carbon monoxide & $\mathrm{C}_{x} \mathrm{H}_{y}$ & 11.9 & - \\
Particulates & $\mathrm{CO}$ & 0.7 & 238 \\
\hline
\end{tabular}

${ }^{a}$ Quantity of atmospheric pollutants produced through the combustion of fossil fuels in 1976.

${ }^{b}$ Cost of damage caused to buildings, facilities, health, and vegetation by atmospheric pollution in $1970^{22}$.

Several provinces have already undertaken studies of atmospheric pollution, established monitoring stations, and passed legislation to protect the quality of the air. One of the aims of energy/environment management in Austria is to keep the emission of harmful substances constant despite increased energy use. This could be achieved through:

- Energy conservation

- Use of energy sources which are less harmful to the environment

- Efficient combustion of fuels

The costs of such measures are somewhat uncertain. The transportation sector, for example, is responsible for most of the emission of $\mathrm{NO}_{2}$ but no estimates of the costs of reducing this pollution are available.

Power plants pollute not only the air, but also the water. The Federal Ministry for Agriculture and Forestry, which is responsible for protecting water quality, has carried out a series of studies ${ }^{23}$ on thermal pollution in the Austrian water system. There is a great need for international standards and criteria with which to assess thermal pollution of water, especially in the case of rivers and streams which cross international boundaries*. At the national level these criteria could also control the use of water from rivers and streams by power plants. Research into thermal pollution should be carried out as part of a water resources planning program. Most of the Austrian waters affected by thermal pollution are rivers and streams which would otherwise remain cool in the summer**. It has been suggested ${ }^{24}$ that thermal pollution of these waters should be subject to the following controls:

- Waste heat input must not cause a temperature increase exceeding $3^{\circ} \mathrm{C}$

- Water temperature must not exceed $25^{\circ} \mathrm{C}$

* International considerations are especially important in the case of the Danube.

** This is also true of the Danube. 
In a country in which tourism is very important, such as Austria, the impact of hydroelectric facilities on the landscape assumes great significance. Though this effect is difficult to quantify, it has been studied in a number of cases ${ }^{25}$.

\section{INTEGRATION OF DECISION MAKING AND ANALYSIS}

Policy and decision making in Austria depend to a considerable extent on the economic and social partnership between government, employers, and workers ${ }^{26}$.

"The successful Austrian system of economic and social partnership is receiv-
ing increasing respect in the international community. The partnership shows
that, in modern industrialized countries, economic policy cannot be developed
or implemented without, or in opposition to, the organization of employers and
workers. The Equality Commission, which meets once a month on average, is
the highest institutional expression of the Austrian partnership of government,
employers, and workers in all areas of social and economic policy. Without
great publicity, decisions about prices and wages are made by this Commission
or its subcommittees which shape to a great degree economic and social life in
Austria. Problems of particular significance are discussed in the debate on
economic policy which takes place four times a year."

However, the so-called economic and social partnership has its critics. Elements within the political establishment have suggested that the institution may be used to circumvent the parliamentary system". The phrase "Without great publicity, decisions ... are made" quoted above is in itself the cause of some concern.

The economic and social partnership does not only influence the wage and price structure in Austria but its members are also represented on the various official bodies concerned with energy and the environment. All of these bodies (working groups, groups of experts, committees, project teams, advisory boards, etc.) are listed in Appendix 3B.

The social partners are also represented on the advisory boards which deal with energy policy. Though these boards perform only advisory functions, they are quite important: the desire of the national government to achieve the greatest possible consensus was expressed in the introduction to the 1976 energy plan.

A regional element is also present in these advisory boards through the participation of the provinces, either directly or through the provincial liaison office. (The liaison office of the provinces is located in the Bureau of the Provincial Government of Lower Austria in Vienna, and represents the interests of the provinces in relation to the central government.)

As far as is known, the economic and social partnership has not yet taken an active interest in environmental protection.

\footnotetext{
* The results of the nuclear power referendum partly reflect popular opposition to the social partnership.
} 
The above discussion illustrates how decisions and policy are made in Austria. The system of social partnership is also implicit within the political parties and has been integrated into the parliamentary procedure.

Apart from the social partnership, there are groups, in universities and elsewhere, which gather data and issue independent reports on energy/environment management in Austria. However, it is difficult to estimate the influence of these groups on the people who actually take the decisions.

The general conclusion appears to be that the potential for public participation in energy/environment management has not been fully exploited in Austria, nor has the responsibility for making decisions in this field been sufficiently clearly defined.

\section{REFERENCES}

1 Federal Ministry of Trade, Commerce, and Industry. Draft Energy Proposals of the Austrian Federal Government. Vienna, May 1969. (Bundesministerium für Handel, Gewerbe und Industrie. Energiekonzept der österreichischen Bundesregierung. Wien, Mai 1969.)

2 Federal Ministry of Trade, Commerce, and Industry. Energy Plan for 1975. Vienna, 1975. (Bundesministerium für Handel, Gewerbe und Industrie. Energieplan 1975. Wien, 1975.)

3 Federal Ministry of Trade, Commerce, and Industry. Energy Plan for 1976. Vienna, 1976. (Bundesministerium für Handel, Gewerbe und Industrie. Energieplan 1976. Wien, 1976.)

4 Federal Ministry of Trade, Commerce, and Industry. Energy Report for 1979. Vienna, April 1979. (Bundesministerium für Handel, Gewerbe und Industrie. Energiebericht 1979. Wien, April 1979.)

5 Federal Ministry of Trade, Commerce, and Industry. Energy Report for 1980. Vienna, November 1980. (Bundesministerium für Handel, Gewerbe und Industrie. Energiebericht 1980. Wien, November 1980.)

6 Bureau of the Provincial Government of Tyrol. Problems of Energy Management in Tyrol. Innsbruck, February 1975. (Amt der Tiroler Landesregierung. Energiewirtschaflicher Problemkatalog Tirol. Innsbruck Februar 1975.)

7 City of Vienna Public Works Department. Basis of an Energy Plan for the City of Vienna. Vienna, April 1975. (Wiener Stadtwerke. Grundlagen für ein Energiekonzept der Stadt Wien. Wien, April 1975.)

8 Bureau of the Provincial Government of Styria. Energy Plan for the Province of Styria. Graz, February 1976. (Amt der steiermärkischen Landesregierung. Energieplan für das Land Steiermark. Graz, Februar 1976.)

9 F. Heeb and J. Schwarzmayr. Supplying the energy needs of western Austria with production of petroleum and natural gas. Volume 1 of Contributions to Regional Energy Policy in Austria, published by the Federal Ministry of Trade, Commerce, and Industry, Vienna, 1977. (F. Heeb und J. Schwarzmayr. Die Energieversorgung Westösterreichs mit Erdölprodukten und Erdgas. Band 1 der Beiträge zur regionalen Energiepolitik Österreichs. Bundesministerium für Handel, Gewerbe und Industrie, Wien, 1977.)

10 Federal Ministry of Trade, Commerce, and Industry. Directions for an Austrian Energy Plan. Vienna, January 1974. (Bundesministerium für Handel, Gewerbe und Industrie. Leillinien für einen österreichischen Energieplan. Wien, Januar 1974.)

11 Austrian Regional Policy Conference. The Proceedings of the 6th Session of the Austrian Regional Policy Conference, 20 June 1975, Vienna. Published by the Bureau of the Austrian Regional Policy Conference, Vienna. (Osterreichische Raumordnungskonferenz (OROK). 
Beschlußprotokol der 6. Sitzung der Österreichischen Raumordnungskonferenz, 20. Juni 1975, Wien. Geschäftsstelle der OROK, Wien.)

12 K. Musil. A new version of the energy prognosis up to the year 1990. WIFO Monthly Reports 10(1980)543-553. (K. Musil. Neufassung der Energieprognose bis 1990. WIFO Monatsberichte 10 (1980) 543-553.)

$13 \mathrm{~J}$. Teufelsbauer. The Austrian Economy up to the Year 1985. Buka Research Report 10, March 1978. (J. Teufelsbauer. Österreichische Wirtschaft bis 1985. Buka Forschungsbericht 10, März 1978.)

14 W.K. Foell, R.L. Dennis, M.E. Hanson, L.A. Hervey, A. Hölzl, J.P. Peerenboom, and E. Pönitz. Assessment of Alternative Energy/Environment Futures for Austria: 1977-2015. RR79-7, International Institute for Applied Systems Analysis, Laxenburg, Austria, 1979.

15 Federal Ministry of Trade and Reconstruction. The Austrian Energy Balance for the Year 1959. Vienna, 1961. (Bundesministerium für Handel und Wiederaufbau. Osterreichische Energiebilanz für das Jahr 1959. Wien, 1961.)

16 K. Musil. Energy Balance for the Year 1976: Full Documentation. Published by the Austrian Institute for Economic Research, Vienna, August 1977. (K. Musil. Energiebilanz für das Jahr 1976: einschliefliche Dokumentation. Herausgegeben vom Osterreichischen Institut für Wirtschaftsforschung, Wien, August 1977.)

17 Austrian Electricity Board. Existing Statistics on the Plants and Power Stations in Austria, Base Date 1, January 1974. Federal statistics of the Austrian Electricity Board, published by the Federal Ministry of Trade, Commerce, and Industry in collaboration with the Federal Department for Load Distribution, the Provincial Departments for Load Distribution, and the Association of Austrian Electricity-Generating Companies. (Osterreichische Elektrizitätswirtschaft. Bestandsstatistik der Unternehmen und Kraftwerke in Österreich, Stichtag 1. Jänner 1974. Bundesstatistik des österreichischen Elektrizitätswirtschaft, herausgegeben vom Bundesministerium für Handel, Gewerbe und Industrie unter Mitarbeit des Bundeslastverteilers, der Landeslastverteiler und des Verbandes der Elektrizitätswerke Osterreichs.)

18 Federal Ministry of Trade, Commerce, and Industry. Statistics Concerning the Fuel Used by Conventional Power Stations for Public Electricity Supply in Austria in 1975. In collaboration with the Federal Department for Load Distribution, the Provincial Departments for Load Distribution, and the Austrian Electricity Board. (Bundesministerium für Handel, Gewerbe und Industrie. Brennstoffstatistik 1975 der Wärmekraftwerke für die öffentliche Elektrizitätsversorgung in Österreich. Bundesministerium für Handel, Gewerbe und Industrie, Bundeslastverteiler unter Mitarbeit der Landeslastverteiler und der Österreichischen Elektrizitätswirtschaft AG.)

19 Federal Department for Load Distribution. Operating Statistics, Generation, and Consumption of Electrical Energy in Austria in 1976, parts I and II. Commissioned by the Federal Ministry of Trade, Commerce, and Industry with the collaboration of the Austrian Electricity Board, the Provincial Departments for Load Distribution, and the Association of Austrian ElectricityGenerating Companies. (Bundeslastverteiler. Betriebsstatistik, Erzeugung und Verbrauch elektrischer Energie in Österreich 1976, Teil I und II. Im Auftrag des Bundesministerium für Handel, Gewerbe und Industrie unter Mitarbeit der Osterreichischen Elektrizitätswirtschaft AG, der Landeslastverteiler und des Verbandes der Elektrizitätswerke Osterreichs.)

20 Federal Ministry of Trade, Commerce, and Industry. Planning Methodologies in the Energy Sector. Volume 2 of the series on the Politics of Energy produced by the Federal Ministry, Vienna, 1976. (Bundesministerium für Handel, Gewerbe und Industrie. Planungsmethodik in der Energiewirtschaft. Band 2 der energiepolitischen Schriftreihe vom Bundesministerium, Wien, 1976.)

21 H. Dreißigacker, F. Surendorf, and E. Weber. Technical Introduction to Air Quality Protection (TI-A ir), Heymanns, Cologne, 1974. (H. Dreißigacker, F. Surendorf und E. Weber. Technische Anleitung zur Reinhaltung der Luft (TA-Luft), Heymanns Verlag, Köln, 1974.) 
22 O. Preining. The Cost of Air Pollution Damage in Austria in 1970. Vienna, 1974.

23 Federal Ministry of Agriculture and Forestry. Thermal Pollution of the Austrian Water System. Water-Management Land Register, part II, Vienna, 1977. (Bundesministerium für Landund Forstwirtschaft. Wärmeeinbringung in den österreichischen Gewässer. Wasserwirtschaftskataster Teil II, Wien, 1977.)

24 Federal Ministry of Agriculture and Forestry. Foundations of Water Planning for Thermal Balance and Thermal Load Distribution-Reference Standards for the Austrian Section of the Danube. Vienna, 1974. (Bundesministerium für Land- und Forstwirtschaft. Wasserwirtschaftliche Grundlagen für Wärmebilanz und Wärmelastplan-Maßgebliche Komponente für die österreichische Donaustrecke. Wien, 1974.)

25 O.J. Rescher and G. Wendelberger. Completion of the Wachau Canal-a Comprehensive Evaluation of Various Proposed Projects. Published by the Federal Ministry of Trade, Commerce, and Industry and the Federal Ministry of Building and Technology, Vienna, 1978. (O.J. Rescher und G. Wendelberger. Ausbau der Wachau zu einer Wasserstraße-zusammenfassende Beurteilung der Varianten zum Projektsvorhaben. Herausgegeben vom Bundesministerium für Handel, Gewerbe und Industrie und dem Bundesministerium für Bauten and Technik, Wien, 1978.)

26 Federal Ministry of Finance. Successes, Problems and Prospects-the Austrian Economy up to the Middle of 1977. Vienna, 1977. (Bundesministerium für Finanzen. Erfolge, Probleme und Chancen-Österreichs Wirtschaft zur Mitte 1977. Wien, 1977.)

\section{APPENDIX 3A}

Official (German) titles of bodies quoted in English in the text.

English translation used in text

Association of Austrian ElectricityGenerating Companies

Austrian Institute for Economic Research

Austrian Regional Policy Conference

Bureau of the Provincial Government of Lower Austria

Committee for Coordinating Public Electricity Supply

Equality Commission

Federal Economics Board

Federal Ministry for Agriculture and Forestry

Federal Ministry of Trade, Commerce, and Industry
Official titles

Verband der Elektrizitätswerke Osterreichs

Österreichisches Institut für Wirtschaftsforschung

Österreichische Raumordnungskonferenz

Amt der Niederösterreichischen Landesregierung

Koordinierungsausschu $\beta$ für die öfentliche Stromversorgung

Paritätische Kommission

Bundeskammer für gewerblichen Wirtschaft

Bundesministerium für Land- und Forstwirtschaft

Bundesministerium für Handel, Gewerbe und Industrie 


\section{APPENDIX 3B}

Committees, working groups, and advisory boards within the Federal Ministry of Trade, Commerce, and Industry.

\begin{tabular}{lc}
\hline Committees & Komitees \\
\hline $\begin{array}{l}\text { Committee for the coordination of } \\
\text { prospecting and exploration for }\end{array}$ & $\begin{array}{c}\text { Ausschu } \beta \text { zur Koordinierung der } \\
\text { Prospektion und Exploration von } \\
\text { raw materials containing }\end{array}$ \\
uranium and thorium & uran- und thoriumhältigen \\
coal & Rohstoffen \\
in Austria & Kohle \\
Interministerial committee of civil & Interministerielles Beamtenkomitee \\
servants for the creation of a & für die Erstellung eines Konzeptes \\
framework in which to coordinate & zur Koordinierung der \\
the search for fossil fuels & Aufsuchungstätigkeiten bei fossilen \\
& Energieträgern \\
Interministerial committee of civil & Interministerielles Beamtenkomitee zu \\
servants for questions of energy & Fragen der Energieeinsparung \\
conservation & \\
Interministerial committee of civil & Interministerielles Beamtenkomitee \\
servants for the preparation of & für die Vorbereitung der \\
the information campaign on the & Aufklärungskampagne über Vor- \\
advantages and disadvantages of & und Nachteile von Kernkraftwerken \\
nuclear power plants & \\
\hline
\end{tabular}

\begin{tabular}{|c|c|}
\hline Working groups & Arbeitsgruppen \\
\hline $\begin{array}{l}\text { Working group for the electricity } \\
\text { sector of the energy plan }\end{array}$ & $\begin{array}{l}\text { Arbeitsgruppe Elektrizitätswirtschaft } \\
\text { des Energieplänes }\end{array}$ \\
\hline $\begin{array}{l}\text { Working group for the petroleum } \\
\text { sector }\end{array}$ & Arbeitsgruppe Erdölwirtschaft \\
\hline Working group for the gas sector & Arbeitsgruppe Gaswirtschaft \\
\hline $\begin{array}{l}\text { Working group for the solid-fuel } \\
\text { sector }\end{array}$ & Arbeitsgruppe feste Brennstoffe \\
\hline Working group for district heat & Arbeitsgruppe Fernwärme \\
\hline Working group for energy prognoses & Arbeitsgruppe Energieprognose \\
\hline $\begin{array}{l}\text { Working group for methods of } \\
\text { prognosis }\end{array}$ & Arbeitsgruppe Prognosenmethodik \\
\hline $\begin{array}{l}\text { Working group for planning } \\
\text { methodologies }\end{array}$ & Arbeitsgruppe Planungsmethodik \\
\hline $\begin{array}{l}\text { Working group for the efficiency of } \\
\text { room-heating units }\end{array}$ & $\begin{array}{l}\text { Arbeitsgruppe Wirkungsgrad von } \\
\text { Raumheizanlagen }\end{array}$ \\
\hline
\end{tabular}

(Appendix 3B continued overleaf) 
APPENDIX 3B (continued)

\begin{tabular}{ll}
\hline Advisory boards & Beirate \\
\hline $\begin{array}{l}\text { Advisory board for directing } \\
\text { energy affairs }\end{array}$ & Energielenkungsbeirat \\
$\begin{array}{l}\text { Advisory board for load distribution } \\
\begin{array}{l}\text { Advisory board for the promotion } \\
\text { of electricity }\end{array}\end{array}$ & Lastverteilungsbeirat \\
$\begin{array}{l}\text { Advisory board for energy } \\
\begin{array}{l}\text { Advisory board for energy } \\
\text { conservation }\end{array}\end{array}$ & Elektrizitätsforderungsbeirat \\
\end{tabular}

The provinces and "social partnership" are represented on all of these boards, the provincial electricity companies participating on behalf of the provinces on the advisory board for load distribution and the advisory board for the promotion of electricity. 


\title{
4 Management and Planning of Federal Republic of Germany
}

\author{
Edgar Geißler* and Kjell Wiik**
}

\section{INTRODUCTION}

The management and planning of energy systems in the Federal Republic of Germany is characterized by cooperation between federal and state government authorities, public services, energy supply companies, and the power industry. Scientific workers employed by these groups and the staff of several research institutes provide advice on policy planning. The national energy policy is an essential component of the overall economic policy, which is based on a rather liberal market system.

There are many forms of business organization and ownership in the energy sector. The extremes are represented by the privately owned oil companies, which sell their products on the free market, and the electrical power utilities, which are largely municipally owned and are subject to effective public control (e.g., through prices); these utilities also have guaranteed regional monopolies. Thus the energy system is regulated by both free and planned market economy mechanisms, which are sometimes totally independent of each other, sometimes complementary to one another, and in some cases quite contradictory.

National energy policies are developed on the basis of the energy demand, supply, and resource situation of the nation, its federal structure, and its economic links with other countries (Tables 4.1, 4.2, and 4.3). The principal guidelines and main objectives are formulated in the Energy Program of the Federal Government ${ }^{1}$, which has been revised several times since $1974^{2}$. The main objectives of national energy policy have, however, remained unchanged:

1. Adequate and reasonably priced energy for consumers in all regions of the Federal Republic of Germany

*ASA Program Directorate (Programmleitung Angewandte Systemanalyse), Cologne.

"*University of Münster. 
2. Security and reliability of energy supply in the medium- and long-term

3. Availability of energy at favorable gross national costs

4. Compatibility of all consequences of energy production with the requirements of environmental protection and regional development

The background against which energy planning and management in the Federal Republic of Germany must take place is illustrated by the data given in Tables 4.1, 4.2, and 4.3. Since the late fifties there has been a strong structural change in the sources of primary energy; coal has been displaced to a considerable extent in the energy market, both in absolute and relative terms, by oil and natural gas. However, the domestic reserves of oil and natural gas are insignificant compared to those of coal. Today more than $60 \%$ of the primary energy consumed in the FRG has to be imported; oil, which is used to meet over half of the total energy demand, is almost all imported. Consequently, the energy program gives high priority to actions which reduce the sensitivity of the energy system to foreseeable developments in the international oil market, and which protect domestic coal against a further loss in its share of the home market.

The energy program calls for actions that will result in further structural changes in the sources of primary energy. The long-term implications of these changes must be studied, as must their regional significance, their impacts on the socioeconomic system as a whole, and their actual effects in practice. A step-bystep planning procedure is desirable in order to minimize the risk of failure, to preserve flexibility, and to assess various options realistically. This is also true of any theoretical, methodological, or formal approaches adopted. Various studies, reports, and surveys commissioned by officials on energy-related questions have used this type of step-by-step procedure. Even general academic investigations and computerized modeling projects are based on quite well-defined topics and groups of questions.

The energy program is quite highly integrated with environmental protection and regional planning activities. This is very important since, due to the high

TABLE 4.1 Economic and physical characteristics of the Federal Republic of Germany in 1975 .

\begin{tabular}{lrc}
\hline Characteristic & FRG value & \% of world value \\
\hline Population & $61.48 \times 10^{6}$ & 1.52 \\
Area & $248.61 \times 10^{3} \mathrm{~km}^{2}$ & 0.18 \\
Population density & $247.29 \mathrm{~km}^{-2}$ & - \\
GNP & $\$ 408.75 \times 10^{9}$ & 6.1 \\
GNP per capita & $\$ 6.65 \times 10^{3}$ & - \\
Imports & $\$ 87.57 \times 10^{9}$ & 9.7 \\
Exports & $\$ 101.85 \times 10^{9}$ & 11.3 \\
\hline
\end{tabular}


TABLE 4.2 Energy situation in the Federal Republic of Germany in 1975.

\begin{tabular}{|c|c|c|c|c|c|c|}
\hline \multirow[t]{2}{*}{$\begin{array}{l}\text { Energy } \\
\text { source }\end{array}$} & \multicolumn{2}{|c|}{$\begin{array}{l}\text { Primary energy } \\
\text { consumption }\end{array}$} & \multicolumn{2}{|c|}{$\begin{array}{l}\text { Primary energy } \\
\text { production }\end{array}$} & \multicolumn{2}{|c|}{$\begin{array}{l}\text { Economically viable } \\
\text { reserves }\end{array}$} \\
\hline & $\begin{array}{l}\text { FRG value } \\
\left(10^{6} \text { tce }\right)\end{array}$ & $\begin{array}{l}\% \text { of world } \\
\text { value }\end{array}$ & $\begin{array}{l}\text { FRG value } \\
\left(10^{6} \text { tce }\right)\end{array}$ & $\begin{array}{l}\% \text { of world } \\
\text { value }\end{array}$ & $\begin{array}{l}\text { FRG value } \\
\left(10^{6} \text { tce }\right)\end{array}$ & $\begin{array}{l}\% \text { of world } \\
\text { value }\end{array}$ \\
\hline Coal & 66.5 & 4.56 & 95.4 & 3.98 & 24,000 & 4.87 \\
\hline Lignite & 34.4 & 14.22 & 34.4 & 14.22 & 10,500 & 7.31 \\
\hline Oil & 181.0 & 4.56 & 8.45 & 0.21 & 57 & 0.06 \\
\hline & 48.7 & 2.86 & 22.87 & 1.38 & 283 & 0.34 \\
\hline Other $^{a}$ & 17.1 & 3.42 & 17.1 & 3.42 & - & - \\
\hline Total & $347.7^{b}$ & 4.19 & 178.22 & 2.02 & 34,840 & - \\
\hline
\end{tabular}

${ }^{a}$ This includes nuclear power, hydroelectricity, solar power, etc.

${ }^{b}$ Per capita primary energy consumption $=5.65$ tce.

TABLE 4.3 Development of energy input and use in the Federal Republic of Germany between 1960 and 1975 .

\begin{tabular}{|c|c|c|c|c|}
\hline \multirow[t]{2}{*}{ Energy balance } & \multicolumn{2}{|l|}{1960} & \multicolumn{2}{|l|}{1975} \\
\hline & $\begin{array}{l}\text { Absolute value } \\
\left(10^{6} \text { tce }\right)\end{array}$ & $\begin{array}{l}\text { Percentage } \\
\text { of total }\end{array}$ & $\begin{array}{l}\text { Absolute value } \\
\left(10^{6} \text { tce }\right)\end{array}$ & $\begin{array}{l}\text { Percentage } \\
\text { of total }\end{array}$ \\
\hline \multicolumn{5}{|l|}{ Energy input } \\
\hline $\begin{array}{l}\text { Coal } \\
\text { Lignite } \\
\text { Oil } \\
\text { Gas } \\
\text { Other }^{a}\end{array}$ & $\begin{array}{r}121.0 \\
28.8 \\
52.7 \\
1.0 \\
8.0\end{array}$ & $\begin{array}{r}57.2 \\
13.6 \\
24.9 \\
0.5 \\
3.8\end{array}$ & $\begin{array}{r}66.5 \\
34.4 \\
181.0 \\
48.7 \\
17.1\end{array}$ & $\begin{array}{r}19.1 \\
9.9 \\
52.1 \\
14.0 \\
4.9\end{array}$ \\
\hline Total & 211.5 & 100.0 & 347.7 & 100.0 \\
\hline \multicolumn{5}{|l|}{ Energy use } \\
\hline $\begin{array}{l}\text { Losses and consumption in } \\
\text { the transformation sector, } \\
\text { statistical differences } \\
\text { Input for non-energy purposes } \\
\text { Industry } \\
\text { Transportation }\end{array}$ & $\begin{array}{r}58.9 \\
6.9 \\
70.7 \\
22.6\end{array}$ & $\begin{array}{r}27.8 \\
3.3 \\
33.4 \\
10.7\end{array}$ & $\begin{array}{l}90.2 \\
23.5 \\
84.0 \\
46.2\end{array}$ & $\begin{array}{r}25.9 \\
6.8 \\
24.2 \\
13.3\end{array}$ \\
\hline $\begin{array}{l}\text { Residential and other small } \\
\text { consumers }\end{array}$ & 52.4 & 24.8 & 103.8 & 29.8 \\
\hline Total & 211.5 & 100.0 & 347.7 & 100.0 \\
\hline
\end{tabular}

${ }^{a}$ This includes nuclear power, hydroelectricity, solar power, etc. 
density of both population and economic activity in the Federal Republic of Germany, the use of land, air, and water is much more intensive than in many other countries (Table 4.4).

It is evident that there is potential for conflict between the various interests, standards, and objectives of such a dense, agglomerated economy. This gives rise to a broad spectrum of problems, many in the sphere of environmental protection. It is generally agreed that further expansion of industry, transportation, agriculture, public services, and housing requires area-wide planning and coordination of all activities and projects to avoid reducing the general standard of living. The relevant political framework, objectives, and guidelines are given by a regional policy law ${ }^{3}$, a regional policy program ${ }^{4,5}$, and a medium-term research program ${ }^{6}$ at the national level.

The main points of FRG policy are:

1. To make public the regional policy objectives for urban and rural subsystems and large metropolitan areas

2. To coordinate important planning and management activities through interdepartmental cooperation

3. To improve the fundamental structure of the system (infrastructure), especially with regard to employment, living standards, income, and mobility

4. To assess the possibility of introducing national standards and policies

5. To forecast levels of population and employment on a regional basis

Human settlement policy management falls within the jurisdiction of state and local government. Several state development plans are being drawn up, in which

TABLE 4.4 Density of land use ${ }^{a}$ in the Federal Republic of Germany (1975).

\begin{tabular}{lll}
\hline Indicator & $\begin{array}{l}\text { Annual value per unit } \\
\text { area }\left(\mathrm{km}^{2}\right)\end{array}$ & World position \\
\cline { 2 - 3 } Population & 247 & 9 \\
GNP & $\$ 1.64 \times 10^{6}$ & 3 \\
Production of grain & 81 tonnes & 1 \\
Production of meat & 16 tonnes & 4 \\
Production of steel & 162 tonnes & 1 \\
Production of cars & 16 & 2 \\
Production of plastics & 20 tonnes & 3 \\
Production of electricity & $1215 \mathrm{MWh}$ & 3 \\
Endenergy use & 941 tce & 1 \\
\hline
\end{tabular}

\footnotetext{
${ }^{a}$ The density values are calculated using the total area of the country; real production densities are much higher.

${ }^{b}$ Position in world table in terms of density per square kilometer.
} 
concrete details of future regional developments (including siting of individual plants) are worked out by experts, officials, representatives of state, local, and federal authorities, regional federations, businesses, and the general public. Particular areas can be set aside for specific purposes on the basis of these plans; any other country or state affected by a new project must also be consulted. Issues are settled using a variety of special field studies, which consider the judicial, administrative, design planning, topographical, and geographical aspects of the proposed development ${ }^{7}$.

The procedure for authorizing the selection, erection, and operation of an industrial facility is not the same in all parts of the Federal Republic of Germany. The procedure is lengthy and difficult due to the many agencies and legal prescriptions involved. The procedure is especially complicated in the case of energyrelated projects, such as power plants and energy-transmission lines. At the moment the siting of facilities is largely planned by individual enterprises, while the state sets up conditions and constraints related to the environment, safety, and the law. Improvements in this procedure are generally desired; better provisional location planning is increasingly considered to be a task needing joint management by the state and the relevant industrial companies.

While the authorization of a new plant is under consideration, technical factors are not the only features examined. Also under scrutiny are:

- Distance between proposed site and human settlements

- Degree of development in the region of the site

- Ambient air quality

- Topographical, geographical, and seismological features of the site

- Development of the economic structure of the surrounding region

- Capacity for employment

Research and scientific assistance in this field is primarily concerned with formalizing and improving the availability of reliable information by means of electronic data processing.

In its 1971 environmental program, the federal government put forward the basis for a long-term national environmental policy ${ }^{8}$. The main objectives of this policy are:

1. Environmental planning through legislation, the establishment of efficient advisory procedures for decision making, the concentration of administrative staffs in suitable organizations, and the integration of environmental planning into regional regulatory policies

2. Enforcement of the "originator principle", according to which the cost of environmental damage and the necessary repairs can be charged to those responsible for the damage

3. Development of technologies for protecting the environment 
4. Training the public in environmental awareness

5. More international cooperation in environmental matters

The Federal Environment Board was established to collate and distribute data relevant to the environment. It runs an information system (UMPLIS) and has produced a catalogue of environmental research activities ${ }^{9,10}$.

The environmental protection standards have many implications for energy supply and consumption, while the energy regulations may well have a considerable influence on the environment. The federal government has pointed out clearly that both objectives-a sufficient supply of energy at reasonable costs on the one hand, and adequate protection of the population against the undesirable consequences of energy production and use on the other-are of equal importance. This indicates that compromises should not be made at the expense of either objective. The number of environmental factors linked to the energy system, the standards imposed, and the high density of energy use in the Federal Republic, especially in urban settlements, could limit energy use in the future if no structural changes were to occur. Such changes would require capital investments, which would result in higher energy costs. Because of stagnating demand for energy in all sectors, the badly maladjusted capacity of the supply system, and the stiff competition between suppliers for a share in the energy market (Table 4.5), both at the present time and in the foreseeable future, it would be unrealistic to expect changes to come from free market forces. Numerous investigations, using various modeling techniques, are examining possible courses of government action, ranging from administrative regulations to carefully directed support and promotion.

A federal transportation plan ${ }^{11,12}$ was drawn up for the first time in 1973, and is still in effect. The forecasts of developments in this sector are continually revised

TABLE 4.5 Contribution of seven large-scale suppliers in meeting primary energy demand.

\begin{tabular}{llcc}
\hline Supplier & Form of energy supplied & \multicolumn{2}{c}{ Percentage share of market } \\
& & 1975 & 1976 \\
\hline Ruhrkohle AG & & 14.7 & 12.6 \\
Shell AG & Coal & 10.1 & 9.8 \\
Ruhrgas AG & Oil/gas & 8.6 & 8.7 \\
Rheinbraun (RWE) & Gas & 8.5 & 9.1 \\
Veba AG & Lignite & 8.4 & 7.8 \\
Mobil Oil & Oil/lignite & 7.2 & 7.1 \\
Deutsche BP AG & Oil/gas & 5.7 & 5.9 \\
Total & Oil/gas & 63.2 & 61.0 \\
\hline
\end{tabular}


to integrate them with the structural changes in economic, demographic, and energy development. Public transport over short distances is the main subject of this policy. Financial support is also given to the construction of roads, in particular the elimination of dangerous stretches where accidents are common. Money is provided for the protection of the environment, the maintenance of existing communication links, and the improvement of transportation in disadvantaged regions. This type of planning requires extensive data systems and accurate assessment methods. Environmental constraints and guidelines for regional development are also receiving increasing attention.

The energy consumption of the transportation sector amounts to $20 \%$ of the total end-use energy; this sector therefore has a strong influence on the type of oil products consumed, and, through this, refinery production and the use of refinery capacity. Motor vehicles make a significant contribution to environmental problems, especially in urban areas; a great deal of damage, and many injuries $(457,800)$ and deaths $(14,370)$ are caused each year by accidents on the roads $(1,264,700)$. (The data are for the year 1975 ; accidents are defined as those events in which the damage was costed at more than 1000 DM.) Nonetheless, the effects of motor vehicles on the environment have failed to produce the public protest observed in other related areas, especially in the energy sector.

It is clear that a heading such as energy and the environment covers a wide range of topics. Energy is, in many respects, a prerequisite for most current human activities, and this will probably remain true in the future. The social concensus will always be in favor of improving living conditions, which may involve some limitations on economic activity and the energy use linked with it. The federal and state government programs therefore see the problem of energy management in the light of this consensus.

\section{ANALYSIS OF ENERGY DEMAND}

Energy input and flow, grouped for the industrial, housing, and transportation subsectors, and broken down by type of energy (electricity, coal, etc.), are given in the energy balances prepared for the Federal Republic and most of its states. The level of aggregation is very high, however, especially in the housing sector, which is partly combined with trade, business, and public services. Much work has been done to improve the analysis, either by disaggregation or by direct census of relevant data ${ }^{13-15}$. From an analysis of energy patterns observed in the past, and influences expected for the future, energy demand has been estimated in a number of studies using different methodologies ${ }^{15-18}$. The energy forecasting data cited in the federal energy program, for example, were produced by a joint study carried out by three institutes. Forecasts were made by extrapolation of trends and correlation with indicators of economic production. The effects of technological developments were taken into account in a more qualitative way. One study ${ }^{14}$ was 
primarily devoted to the technical aspects of energy use, in particular the improvement of technical efficiency factors. In addition, a very detailed analysis of the potential of new forms of energy (district heat and energy produced by gasification and liquefaction of coal) was performed at the request of the Federal Ministry of Research and Technology in 1975 by two groups using different methodologies ${ }^{19,20}$. Linear or quasi-linear curves have been popular as pure trend extrapolation techniques for a long time; however, more thorough analysis of growth rates has indicated little justification for their use, at least as regards the past ${ }^{21}$. In correlating the energy demand with economic development, economicsbased models are used to calculate the most important factors by taking into account the interrelationships between the method of energy production and the sectoral or functional distributions of GNP. Thus, if the energy sector itself is regarded as a sector of the total economy, linked with the other sectors (for example, by means of input-output techniques), feedback from the energy sector to the economy may be studied. Input-output tables currently in use differ widely in terms of size, content, and degree of aggregation.

The completely endogenous energy demand model has been increasingly recognized as a dream, and a confused dream at that. Scenario building with plausible (or arbitrary) assumptions about the behavior of exogenous variables has become an attractive alternative. The conventional analyses and forecasts of energy demand include parameters describing changes in variables such as GNP, imports, and structure of industrial production. Foreign trade has been coupled to a regionalized world model of the Mesarovich-Pestel type ${ }^{18}$. Similarly, regional analysis and forecasts are often linked with scenarios at the federal levei ${ }^{22,23}$.

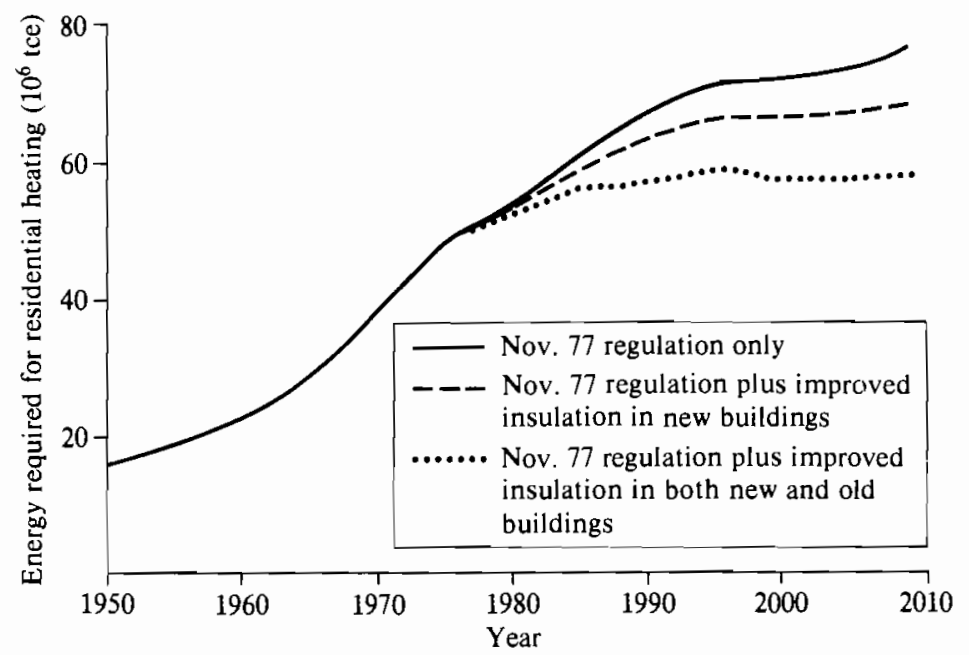

FIGURE 4.1 The energy required to heat residential buildings under three different scenarios. 


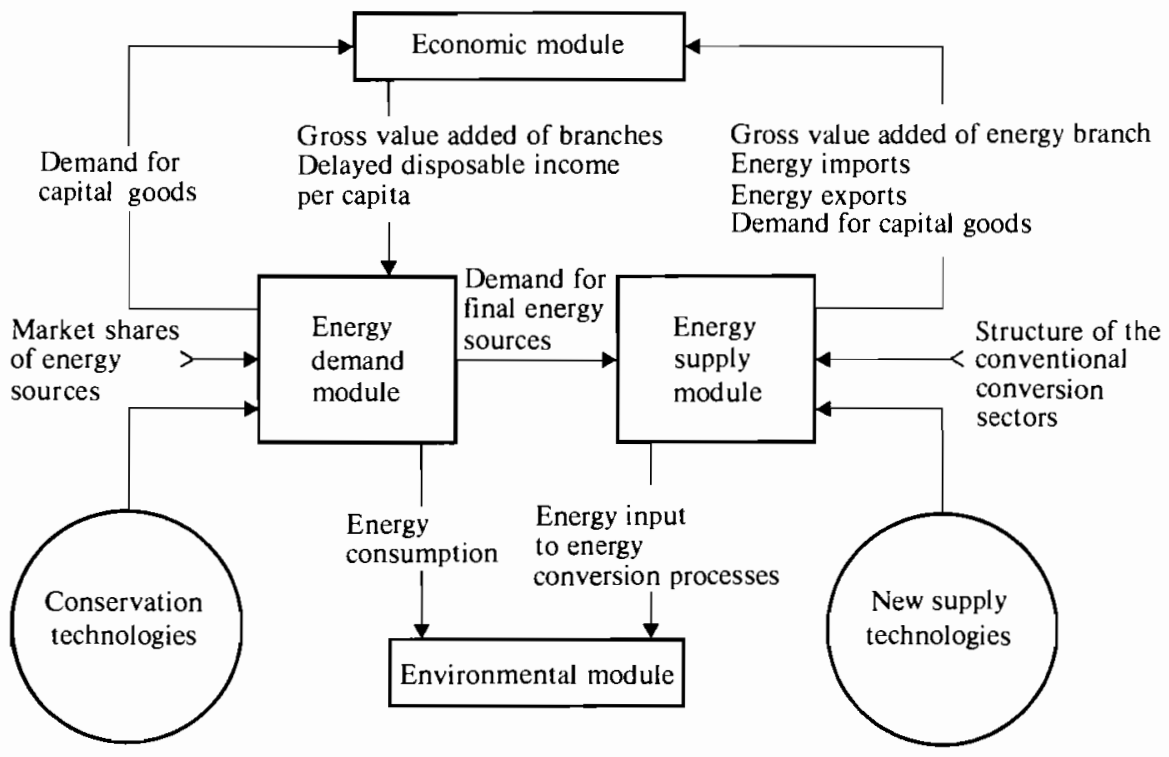

FIGURE 4.2 The structure of the KFA/STE model.

Particular issues raised by government programs or everyday problems are often studied by means of reference scenario construction. This technique is used to investigate the implementation and consequences of special policy measures, for example new administrative regulations, financial supports, or price alterations. Figure 4.1 shows the energy consumed by residential heating, calculated on the basis of three strategies for reducing heat loss through insulation.

The solid curve shows the energy used in residential heating before and after the implementation of a November 1977 building regulation designed to reduce heat losses in new buildings. If insulation levels were higher than those specified in the 1977 regulation, even greater energy savings would be possible. Heat losses could be reduced by up to $50 \%$ in new buildings and $40 \%$ in old buildings. The dashed curve corresponds to the total energy consumed in heating, assuming very high levels of insulation in new buildings, while the dotted curve assumes that both new and old buildings have improved insulation. The structure of the model used for this and similar investigations is shown in Figure 4.2.

\section{ANALYSIS OF ENERGY SUPPLY}

The form of the energy supply system cannot be unambiguously defined by primary energy input and end use. The remaining degrees of freedom provide a certain amount of flexibility in the supply structure. One approach to studying energy supply is first to separate supply from demand. This was done in the 
energy program developed by the ASA (Angewandte Systemanalyse), a joint study group formed by twelve research centers in the Federal Republic of Germany. The project deals with the complete energy chain, though some sectors are also treated individually ${ }^{17,21,24}$ (see also Figure 4.2). Energy models which consider the entire chain (including environmental pollution) and which are linked to a greater or lesser degree with economic variables have also been developed by several other institutes. The formal structures of these models, their formulation of the basic questions, and the program libraries are very similar, largely as a result of scientific cooperation and exchange ${ }^{25-28}$. It has already been noted that the approach discussed in ref. 18 includes a model describing world trade; this model also reflects the demographic and employment patterns of the national economy. Some investigations assess world energy markets and potential primary supply from specified resources (including all world deposits), and the results of these investigations are then used as numerical parameters in models of the national energy system. Detailed studies of world primary energy resources and their implications for the national supply system (including renewable resources) were the basis of the ASA program ${ }^{21,29,30}$. The results obtained by the Bundesanstalt für Geowissenschaften und Rohstoffe ${ }^{31}$, a federal economic geology board, had a considerable influence on the form of the federal energy program. "Bergbau Forschung", a research institute associated with the coal-mining industry, prepared a report on coal resources for the World Energy Conference of $1977^{32}$.

One of the main difficulties in modeling the supply system is to reduce the uncertainty associated with the transportation and energy transformation sectors. Problems also arise in developing an appropriate formal description of the system and its various elements. Attempts have been made to optimize the system, for instance by minimizing the total emission of pollutants associated with conversion processes $^{25}$, or by minimizing the total social cost of damage caused to the environment by the industrial economy. These costs have been assessed in terms of opportunity costs and shadow prices ${ }^{33,34}$ by a model discussed in more detail in Appendix 4A. Other formal approaches employ linear programming and simulation techniques, using environmental standards or the change in GNP or profits as constraints. It is very difficult, if not impossible, to obtain the optimum characteristics of the supply system as a whole through optimization techniques, since it is necessary to take into account all of the qualities and interrelations of the physical system, and its effect on factors such as regional development or regional competition between different energy forms. It is increasingly being recognized that conflict potential in very complex systems cannot be treated appropriately by simple optimization techniques. However, in the electricitygenerating sector these methods were successfully applied to the integrated operation of future power stations, taking into account the different types of power plants and the fluctuating characteristics of power demand ${ }^{35}$. The advantages of the different types of plants for peak-, medium-, and base-load operation were used to determine the minimum of the objective function represented by the 
discounted total cost of electricity generation. Thus it was possible to determine the optimum mixture of energy technologies to match a particular pattern of demand.

\section{ENVIRONMENTAL ANALYSIS}

In the Federal Republic of Germany, energy-related environmental analysis is conducted on a national, regional, or local level, according to the subject of investigation, the questions of the party commissioning the research, and the applications intended. It must be emphasized that modeling environmental effects at specific locations is more difficult than working at the national level since the basic relations and interdependences of the system must be known to a much greater degree of accuracy.

The main effects of the energy system on the environment are seen in the following areas: emission of pollutants; siting of facilities; social indicators (employment, income, etc.); regional imbalance; sensitivity of infrastructure, and supply policies.

A number of federal plans have been drawn up to help to protect the environment. These deal with solid-waste management, waste-water management, landscape preservation, and air quality. Within the framework of these schemes, the states are free to make adjustments to comply with existing regulations, to reach specific targets and to supply particular needs.

\section{Air pollution}

The urgency of the air pollution problem in the Federal Republic of Germany is reflected in the air quality management plan. This plan sets out standards and restrictions affecting the quality of the air, including limits for the ten most common noxious materials, 170 standards controlling the emission of particulates and gases, and several air-quality-related conditions which must be met by about 50 different types of industrial plants (including energy plants) before they may start production ${ }^{36}$.

Air pollution problems are sometimes analyzed by the simulation of ambient air quality in cities and near large industrial complexes, using multisource mathematical diffusion models. These models can provide the decision maker with an indication of the effects of introducing, changing, or removing a source of pollution, and can also be used to compare various strategies for combatting air pollution. Models of this type have been used in the cities of Bremen, Düsseldorf, and Frankfurt, as well as for several large refineries planned in the northwestern and western parts of the country. The model used in these investigations may be characterized as a continuous Gaussian dispersion model for multiple effective point sources and for locally homogenous meteorological conditions ${ }^{37}$. The structure of the model ${ }^{37}$ used in the Frankfurt metropolitan area is shown in 
Meteorological data (Jan. 1967-Dec. 1970)

(e.g., clouds, wind velocity, temperature)

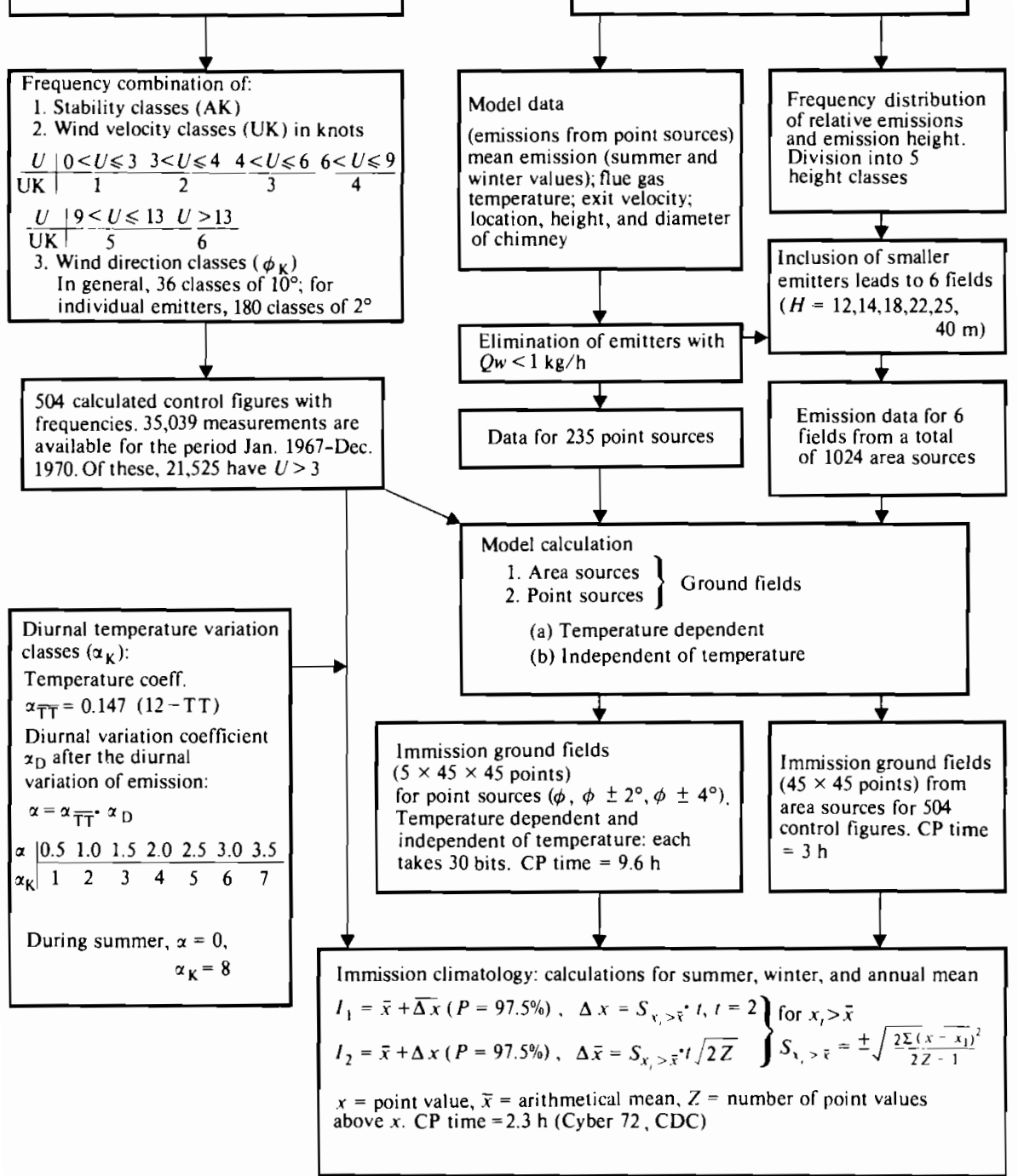

FIGURE 4.3 The emission model applied to the Frankfurt metropolitan area.

Figure 4.3. The left-hand side of the figure shows the meteorological input, the right-hand side the emission input.

This model is now being extended by the addition of two submodels, one describing topographical diffusion processes within the system, and the other describing meteorological diffusion in calm conditions with little air exchange. The 
extended model will be used by Hessian authorities to analyze air quality in this heavily polluted area ${ }^{38}$.

Until now, the federal air quality management plan has not required the use of air pollution models for planning the location of heavy pollution sources like energy plants, but it points out that such methods ought to be used in heavily polluted areas in future. The plan has three main stages ${ }^{39}$ :

- Survey of emissions, ambient air quality, effects on the environment, and analysis of causes

- Prediction of future levels of emission and ambient air quality

- Decision on a course of action

The first planning program of this kind in the FRG was developed for Cologne in North Rhine-Westphalia. A standardized Gaussian dispersion model was used to analyze the effects of the location of important pollution sources like energy plants and refineries ${ }^{39}$. When the program is fully developed, it will consider not only the local effects of pollution, but also the impact over a larger area, such as the region or state. Other states in Germany are following the example of North Rhine-Westphalia in developing air-pollution planning programs.

\section{Thermal pollution of water}

Thermal pollution of rivers has been at a critical level in the FRG for about 10 years. The main sources of this pollution are the thermal power plants, which have increased in number and size in response to the growing demand for electrical energy. The Rjver Rhine and River Main are particularly badly affected.

Simulation models have been developed to aid in planning the thermal load. A model of special interest ${ }^{40}$ was developed for the Rhine in 1971. It considered the following elements of the heat-exchange process:

- Amount of heat discharged directly

- Solar radiation balance

- Evaporation or condensation

- Convection

Four cases of thermal pollution were studied with this model: natural conditions, without artificial heat discharge; the thermal pollution existing in 1970; the thermal pollution expected in 1975; and the thermal pollution expected in 1985. The results obtained from the model had a clear impact on policy: in the same year the states along the Rhine imposed a requirement that in future all large-scale power plants to be sited near the river must be equipped with cooling towers.

Another type of model has been used to investigate the interaction between the ecological limits of thermal pollution of water and economic activity ${ }^{41}$. This multisectoral and multiregional linear decision model simulates the thermal load of a 
section of the River Rhine, taking into account both the natural temperature of the water and the waste heat discharged by electrical power plants and other industries. The model derives the optimum combination of measures to control thermal pollution in the area under investigation, and analyzes in detail the effects of different water flows, standards controlling the increase in water temperature, previous thermal inputs, and the effects of various industrial wastes. Possible systems of waste-heat removal-open-circuit cooling, semi and completely closed-circuit cooling, and dry cooling-are represented in the model by means of a special mixed-integer programming module which uses integer zero/one variables. The branch and bound method was used to optimize cooling controls for 14 important waste-water outputs. The advantage of mixed-integer programming lies in the simultaneous optimization of alternative waste-heat removal strategies in one single computation. Conventional methods using continuous variables could produce similar results only after a comprehensive comparison of all possible combinations, involving a great deal of computing.

\section{Nuclear power plants}

The environmental effects associated with nuclear facilities are receiving a great deal of attention at nuclear research centers. Both general questions ${ }^{42}$ and regional issues ${ }^{43,44}$ are being studied. Special attention is given to reducing the pollution of the atmosphere and water by waste heat ${ }^{44,45}$ and limiting the level of radioactive pollution ${ }^{46}$, using models which are not specific to nuclear power. The environmental impacts and associated legislation related to the energy sector are discussed in ref. 47.

The possibility of supplying district heat from a nuclear power plant has been investigated for the specific case of the KRB Grundremmingen reactor ${ }^{48}$; it is estimated that enough heat for 55,000 people could be supplied.

Regionalized data systems ${ }^{49,50}$ which assemble and process data with a high degree of geographical resolution have been set up at the Nuclear Research Center in Jülich and the Institute for Nuclear Energy in Stuttgart. The data sets at Jülich refer to the whole country, using raster sizes of $1 \mathrm{~km} \times 1 \mathrm{~km}$, while those at Stuttgart apply only to the state of Baden-Württemberg, with raster sizes of $0.5 \mathrm{~km} \times 0.5 \mathrm{~km}$.

Investigations based on these data sets could have a great impact on the procedure used to authorize the siting of industrial facilities (i.e., nuclear power plants, refineries, manufacturing industries, etc.).

There should always be a dialogue between planners and scientific data processors; the subjective element marking planning activities could be reduced by such collaboration.

The long-term goals of energy systems planning and preferred methods of development have recently been receiving increasing attention ${ }^{51}$. The ASA program considers various aspects of the supply system in relation to the type of 
area supplied (rural, metropolitan, or dense urban zones). Classical work in urban and regional planning is being carried out by several institutes at the request of a number of local councils - the work of Thoss and Wiik ${ }^{52}$ at the University of Münster provides a good example.

\section{INTEGRATION OF DECISION MAKING AND ANALYSIS}

Urban and regional planning is characterized by the complexity and multitude of relevant demographic, economic, ecological, and technical factors on the one hand, and the uncertainties of evaluation and judgment on the other. In this situation the problem of finding compromises in a system of different and partly conflicting interests is viewed as more important than the problem of optimizing an objective function. Certain developments are currently underway which should make regional planning (considered as the transformation of competing ambitions and objectives into a form which will benefit the region as a whole) a more comprehensible and reproducible process ${ }^{53}$. The essential features of such planning systems are:

- Knowledge of the objectives of different groups, interests, and programs

- Information and data on a regional and sectoral level, with the required degree of disaggregation

- Logical connection of cause and effect, to assess alternative solutions

- Methods with which to transform the results of the assessment into physical proposals acceptable to the majority

In the past, systems analysts were a very vocal group, often presenting their ideas and opinions before they had obtained any results. An attentive audience of potential users tended to demand results immediately. However, many of the present "users" in government, community, industry, or administrative circles have now been cooperating with systems analysts for a number of years, commissioning projects and providing financial support. Those who have done so are as familiar with the difficulties and uncertainties of systems analysis as the analysts themselves. The results produced by systems analysis have received close attention: the programs and actions of the federal and state governments and regional planners are based for the most part on results and conclusions drawn from this work; the need for further analysis is evident.

The general procedure for implementing the results of systems studies is described below. Any project which is supported by the analysis must be broken down into its component stages, each of which is presented in detail. It is also possible to introduce new objectives which deviate from the original plan at this point. The final results are published and, if necessary, publicized to gauge public opinion. Difficulties sometimes arise with results which are not applicable from a practical point of view. Systems analysts and decision makers would both 
benefit from analyzing these results in terms of their own different perceptions of reality-to attribute the fault solely to superficial factors would be quite misleading.

\section{REFERENCES}

1 Federal Ministry of the Economy. Energy Program of the Federal Government (1973); First Extension of the Energy Program (1974); Second Extension of the Energy Program (1977). Bonn. (Bundesministerium für Wirtschaft. Energieprogramm der Bundesregierung (1973); Erste Fortschreibung (1974); Zweite Fortschreibung (1977). Bonn.)

2 Press and Information Office of the Federal Government. Principles and Reference Values for the Extension of the Energy Program. Bulletin 30, p. 265, 1977. (Presse- und Informationsamt der Bundesregierung. Grundlinien und Eckwerte für die Fortschreibung des Energieprogramms. Bulletin 30, s. 265, 1977.)

3 Regional Policy Law of 8 April 1965. Federal Law Register, Part 1, No. 16, p. 306, Bonn, 21 April 1965. (Raumordnungsgesetz vom 8. April 1965. Bundesgesetzblatt, Teil 1, Nr. 16, s. 306, Bonn, 21. April 1965.)

4 Federal Ministry for Regional Policy, Construction, and City Planning. Regional Policy Program for the Extensive Development of National Territory (Federal Regional Policy Program). Second issue in the series "Regional Policy" produced by the Federal Ministry for Regional Policy, Construction, and City Planning, Bonn, 1974. (Bundesministerium für Raumordnung, Bauwesen und Städtebau. Raumordnungsprogramm für die grossräumige Entwicklung des Bundesgebietes (Bundesraumordnungsprogramm). Heft Nr. 2 in der Schriftenreihe "Raumordnung" des Bundesministeriums für Raumordnung, Bauwesen und Städtebau, Bonn, 1974.)

5 Federal Diet of the Federal Republic of Germany. 1974 Report on Regional Policy. Publication No. 7/3582, Bonn, 1974. (Deutscher Bundestag. Raumordnungsbericht 1974. Drucksache Nr. $7 / 3582$, Bonn, 1974.)

6 National Institute for Geography and Regional Policy. Research on Territorial Development and Settlement Patterns: Documentation for First Publication 1975. Bonn-Bad Godesberg, 1975. (Bundesanstalt für Landeskunde und Raumordnung. Forschungen für Raumentwicklung und Siedlungsentwicklung, Dokumentation zur 1. Ausschreibung 1975. Bonn-Bad Godesberg, 1975.)

7 W. Blümel. Preliminary Plans for the Siting of Nuclear Power Plants and other Important Proposals with Significance for the Environment in the Federal Republic of Germany. Register of Administrative Acts, Volume 92, Issue 7, p. 301, 1977. (W. Blümel. Die Standortvorsorgeplanung für Kernkraftwerke und andere umweltrelevante Großvorhaben in der Bundesrepublik Deutschland. Deutsches Verwaltungsblatt, 92. Jahrgang, Heft 7, s. 301, 1977.)

8 Government of the Federal Republic of Germany. Environmental Policies and the Environmental Program of the Federal Government. 4th edn., W. Kohlhammer, Stuttgart, 1975. (Bundesregierung der Bundesrepublik Deutschland. Umweltpolitik, das Umweltprogramm der Bundesregierung. 4. Auflage, Verlag W. Kohh ammer GmbH, Stuttgart, 1975.)

9 Federal Environment Board. 1976 Catalogue of Environmental Research. Erich Schmidt, Berlin (West), 1976. (Umweltbundesamt. Umwellforschungskatalog 1976 (UFOKAT 76). Erich Schmidt Verlag, Berlin (West), 1976.)

10 Federal Environment Board. UMPLIS, an Information and Documentation System for the Environmental Sector, 1977 Catalogue of Authorities. Erich Schmidt, Berlin (West), 1978. (Umweltbundesamt. UMPLIS, Informations- und Dokumentationssystem Umwelt, Behördenverzeichnis 1977. Erich Schmidt Verlag, Berlin (West), 1978.) 
11 Federal Ministry of Transportation. Step 1 of the Federal Transportation Plan. Bonn, 1973. (Bundesministerium für Verkehr. Bundesverkehrswegeplan, 1. Stufe. Bonn, 1973.)

12 Federal Ministry of Research and Technology. Research on Short-Distance Traffic in 1977. Bonn, 1977. (Bundesministerium für Forschung und Technologie. Nahverkehrsforschung 1977. Bonn, 1977.)

13 H. Reents. The Development of Sectoral Requirements for Final Energy and Useful Energy in the Federal Republic of Germany. Report Jül-1452, Jülich Nuclear Research Center, 1977. (H. Reents. Die Entwicklung des sektoralen End- und Nutzenergiebedarfs in der Bundesrepublik Deutschland. Bericht Jül-1452, Kernforschungsanlage Jülich, 1977.)

14 Federal Ministry of Research and Technology. Summary and Explanation of the Technical Section of the Study on Technologies for the Conservation of Energy. Report BMFT-FT T 7736, July 1977. (Bundesministerium für Forschung und Technologie. Kurzfassung und Erläuterung des technischen Teils der Studie über Technologien zur Einsparung von Energie. Bericht BMFT-FT T 77-36, Juli, 1977.)

15 Association of Electricity Companies of the Federal Republic of Germany. Consideration of the Future Development of Electricity Consumption by Private Households in the Federal Republic of Germany up to 1990. Frankfurt, 1977. (Vereinigung Deutscher Elektrizitätswerke (VDEW). Überlegungen zur künftigen Entwicklung des Stromverbrauchs privater Haushalte in der Bundesrepublik Deutschland bis 1990. Frankfurt, 1977.)

16 DIW-EWI-RWI Institute. The Future Development of Energy Demand and Supply-Perspectives up to the Year 2000. Part I. Study commissioned by the Federal Ministry of the Economy, Bonn, 1977. (DIW-EWI-RWI Institute. Die künftige Entwicklung der Energienachfrage und ihrer Deckung-Perspektiven bis zum Jahr 2000. Teil I. Studie im Auftrag des Bundesministeriums für Wirtschaft, Bonn, 1977.)

17 K. Schmitz et al. Development Possibilities of the Energy Economy in the Federal Republic of Germany-an Investigation Carried Out With the Help of a Dynamic Simulation Model. Report Jül-Spez-1, Vois. I and II, No. 1 in the series on Applied Systems Analysis, Jülich Nuclear Research Center, 1977. (K. Schmitz et al. Die Entwicklungsmöglichkeiten der Energiewirtschaft in der Bundesrepublik Deutschland-Untersuchung mit Hilfe eines dynamischen Simulationsmodells. Bericht Jül-Spez-1, Bds. I und II, in der Reihe Angewandte Systemanalyse, Kernforschungsanlage Jülich, 1977.)

18 Systems Research Group. Adaptation of the Mesarovic-Pestel World Model to Formulate Questions Relevant to Research and Technology in the Federal Republic of Germany. Chair A for Mechanics, Technical University, Hannover, 1977. (Gruppe Systemforschung. Anpassung des Mesarovic-Pestel Weltmodells zur Anwendung auf Forschungs- und technologierelevante Fragestellungen aus der Sicht der Bundesrepublik Deutschland. Lehrstuhl A für Mechanik, Technische Universität, Hannover, 1977.)

19 Jülich Nuclear Research Center. Possibilities for Utilizing New Energy Systems. Study commissioned by the Federal Ministry of Research and Technology, Report Jül-1148-SE, Jülich Nuclear Research Center, 1975. (Kernforschungsanlage Jülich. Einsatzmöglichkeiten neuer Energiesysteme. Programmstudie im Auftrag des Bundesministeriums für Forschung und Technologie, Bericht Jül-1 148-SE, Kernforschungsanlage Jülich, 1975.)

20 Federal Ministry of Research and Technology. Toward New Energy Systems. Study commissioned by the Federal Ministry of Research and Technology, Bonn, 1975. (Bundesministerium für Forschung und Technologie. Auf dem Wege zu neuen Energiesystemen. Programmstudie im Auftrag des Bundesministeriums für Forschung und Technologie, Bonn, 1975.)

21 E. Geißler (Ed.). 1976 A nnual Report of the ASA Program Directorate within the Study Group of the Major Research Institutions, Appendix 1: Energy Systems. ASA Program Directorate, Cologne, 1977. (E. Geißler (Hrg.). Jahresbericht 1976 der Programmleitung ASA in der Arbeitsgemeinschaft der Großforschungseinrichtungen, Anlagenband I: Energiesysteme. Programmleitung Angewandte Systemanalyse, Köln, 1977.) 
22 Baden-Württemberg Ministry for the Economy and Transportation. Energy Program 1975. Stuttgart, 1975. (Ministerium für Wirtschaft, Mittelstand und Verkehr des Landes BadenWürttemberg. Energieprogramm 1975. Stuttgart, 1975.)

23 Minister-President of the State of North Rhine-Westphalia, State Planning Council. Commentary to the Sixth State Development Plan. State Planning Council, Düsseldorf, 1976. (Ministerpräsident des Landes Nordrhein-Westfalen, Landesplanungsbehörde. Erläuterungsbericht zum Landesentwicklungsplan VI. Landesplanungsbehörde, Düsseldorf, 1976.)

24 W. Grasse. Applied Systems Analysis. In E. Geißler (Ed.), 1976 Annual Report of the ASA Program Directorate within the Study Group of the Major Research Institutions. ASA Program Directorate, Cologne, 1977. (W. Grasse. Angewandte Systemanalyse. In E. Geißler (Hrg.), Jahresbericht 1976 der Programmleitung ASA in der Arbeitsgemeinschaft der Großforschungseinrichtungen. Programmleitung Angewandte Systemanalyse, Köln, 1977.)

$25 \mathrm{~J}$. Bürstenbinder et al. ENIS: an Information System for the Energy Sector. Federal Ministry of Research and Technology, Report DV-75-09, Bonn, 1976. (J. Bürstenbinder et al. ENIS, Energiesektorales Informationssystem. Bundesministerium für Forschung und Technologie, Bericht DV-75-09, Bonn, 1976.)

26 H. Bossel, P. u.d. Hijden, W. Hudetz, and R. v. Denton. Interactive program for the development and testing of long-term strategies for the energy supply system and for applications within the Federal Republic of Germany. In Ch. König (Ed.), Energy Models for the Federal Republic of Germany. Birkhäuser, Basel, 1977. (H. Bossel, P. u.d. Hijden, W. Hudetz, und R. v. Denton. Dialogprogramm zur Entwicklung und Uberprüfung von Langfristkonzepten für das Energieversorgungssystem und Anwendung auf die Bundesrepublik Deutschland. In Ch. König (Hrg.), Energiemodell für die Bundesrepublik Deutschland. Birkhäuser Verlag, Basil, 1977.)

27 Institute for Nuclear Energy. Simulation of the Energy-Environment-Economy System. IKE Reports K-51-1, K-51-3, K-53-1, K-54-5. Stuttgart, 1977, 1978. (Institut für Kernenergetik. Simulation des Systems Energie-Umwelt-Wirtschaft. IKE Berichte K-51-1, K-51-3, K-53-1, K-54-5. Stuttgart, 1977, 1978.)

28 Jülich Nuclear Research Center. Task Force on Energy Models for the Federal Republic of Germany. 30-31 January 1975. Report Jül-Conf.15, 1975. (Kernforschungsanlage Jülich. Arbeitsseminar: Energiemodelle für die Bundesrepublik Deutschland, 30-31 Januar 1975. Bericht Jül-Conf.-15, 1975.)

29 ASA Program Directorate. Energy Sources for Tomorrow? Meeting Future Energy Requirements: The Significance of Nonfossil and Nonnuclear Energy Sources. Umschau Publications, Frankfurt, 1976. (Programmleitung Angewandte Systemanalyse. Energiequellen für Morgen? $Z u$ künftige Energie bedarfsdeckung und die Bedeutung der nicht-fossilen und nicht-nukleare Primärenergieträger. Umschau Verlag, Frankfurt, 1976.)

30 J. Kern and L. Oedekoven. Fossil Primary Energy Sources-Data on Hard Coal and Lignite. Report ASA-I/28/77, ASA Program Directorate within the Study Group of the Major Research Institutions, Cologne, 1977. (J. Kern und L. Oedekoven. Fossile Primärenergieträger-Datensammlung Stein- und Braunkohle. Bericht ASA-I/28/77, Programmleitung Angewandte Systemanalyse in der Arbeitsgemeinschaft der Großforsch ungseinrichtungen, Köln, 1977.)

31 Federal Institute for Geological Sciences and Raw Materials. The Future Development of Energy Demand and Supply-Perspectives to the Year 2000. Part III: the Supply of Energy Resources. Hannover, 1976. (Bundesanstalt für Geowissenschaften und Rohstoffe. Die künftige Entwicklung der Energienachfrage und ihrer Deckung-Perspektiven bis zum Jahr 2000. Teil 111: Das Angebot von Energierohstoffen. Hannover, 1976.)

32 Mining Research Limited. Estimation of World Coal Reserves and their Future Availability. Essen, 1977. (Bergbau-Forschung GmbH. Abschätzung der Weltkohlereserven und ihrer zukünftigen Verfügbarkeit. Essen, 1977.) 
33 R. Thoss. A generalized input-output model for residuals management. In K.R. Polenska and J. Skolke (Eds.), Advances in Input-Output Analysis. Proceedings of the Sixth International Conference on Input-Output Techniques, Vienna, 22-26 April 1974. Ballinger, Cambridge, Massachusetts, 1976.

34 H.P. Döllekes. Emission of Pollutants from those Fossil-Fuel-Fired Power Plants that are most Cost-Efficient in Meeting the Demand for Electrical Energy. Institute for the Study of Settlements and the Residential Sector, University of Münster, 1975. (H.P. Döllekes. Schadstoffemission von fossilen Kraftwerken, die den Bedarf an elektrischer Energie kostenoptimal decken. Institut für Siedlungs- und Wohnungswesen, Universität Münster, 1975.)

35 P. Winske et al. Future Requirements for Electrical Energy and Supply Options, with special reference to Nuclear Energy. Report K 76-03, Federal Ministry of Research and Technology, Bonn, 1976. (P. Winske et al. Künftiger Bedarf an elektrischer Energie und dessen Deckung, insbesondere mit Hilfe der Kernenergie. Bericht K 76-03, Bundesministerium für Forschung und Technologie, Bonn, 1976.)

36 H.L. Dreißigacher, F. Surendorf, and E. Weber. Technical Introduction to Air Quality Protection. Heymanns, Cologne, 1974. (H.L. Dreißigacher, F. Surendorf, and E. Weber. Technische Anleitung zur Reinhaltung der Luft. Heymanns Verlag, Köln, 1974.)

37 H. Fortak. Model for the determination of air quality. In Lower Main Regional Planning Cooperative (Ed.), An Air Quality-Meteorological Model Investigation of the Lower Main Region. Lower Main Planning Cooperative, Frankfurt am Main, 1974. (H. Fortak. Model for the determination of air quality (in English). In Regionale Planungsgemeinschaft Untermain (Hrg.), Luft-hygienisch-meteorologische Modelluntersuchung in der Region Untermain. Regionale Planungsgemeinschaft Untermain, Frankfurt am Main, 1974.)

38 Hessian State Government. Report on the Environment. Hessian Ministry for Rural Areas and the Environment, Wiesbaden, 1976. (Hessische Landesregierung. Umweltbericht. Hessisches Ministerium für Landschaft und Umwelt, Wiesbaden, 1976.)

39 F.J. Dreyhaupt. New planning tools for environmental protection. In Ch. König (Ed.), Energy and the Environment. Vuikan Publishers, Essen, 1977. (F.J. Dreyhaupt. Neue planerische Instrumente des Umweltschutzes. In Ch. König (Hrg.), Energie und Umwelt, Vulkan Verlag, Essen, 1977.)

40 D. Flinspack. Thermal pollution control of the Rhine. Progress in Water Technology 10, 1978.

41 J. Muddemann. Waste heat and environmental protection in the Upper Rhine: A decision model for the optimal economic utilization of cooling capacity. In R. Thoss and W. Ernst (Eds.), Contributions to Settlement and Housing Issues and to Regional Planning, Volume 52. Münster, 1978. (J. Muddemann. Abwärme und Umweltschutz am Oberrhein: Ein Entscheidungsmodell zur optimalen wirtschaftlichen Nutzung der Kühlkapazitat. In R. Thoss und W. Ernst ( $\mathrm{Hrg}$.), Beiträge zum Siedlungs und Wohnungswesen und zur Raumplanung, Band 52. Münster, 1978.)

42 Federal Ministry of Research and Technology. On the Peaceful Use of Nuclear Energy, Federal Government Report. Bonn, 1977. (Bundesministerium für Forschung und Technologie. Zur friedlichen Nutzung der Kernenergie, eine Dokumentation der Bundesregierung. Bonn, 1977.)

43 A. Bayer. Radiological Effects of Nuclear Power Plants in the Upper Rhine Region. KFK News Bulletin 3/1974, Karlsruhe Nuclear Research Center, 1974. (A. Bayer. Radiologische Belastung im Oberrheingebiet durch kerntechnische Anlagen. KFK-Nachrichten 3/1974, Kernforschungszentrum Karlsruhe, 1974.)

44 W. Kinzelbach. Cooling management on the Upper Rhine. Journal of Fuel, Heat, and Power 28, 1976. (W. Kinzelbach. Kühlregie am Oberrhein. Brennstoff-Wärme-Kraft 28, 1976.)

45 H.G. Fortak. Impacts on the local climate arising from large centers of energy production and consumption. In Ch. König (Ed.), Energy and the Environment. Vulkan Publishers, Essen, 
1977. (H.G. Fortak. Beeinflussung des Lokalklimas durch große Energieerzeugungs- und Verbrauchszentren. In Ch. König (Hrg.), Energie und Umwelt, Vulkan Verlag, Essen, 1977.)

46 H. Bonka, R. Bieselt, and D. Brenk. Future Environmental Impacts in the Federal Republic of Germany of Radionuclides Emitted from Nuclear Power Plants during Normal Operation. Report Jül-1220. Jülich Nuclear Research Center, 1975. (H. Bonka, R. Bieselt, und D. Brenk. Zukünftige radioaktive Umweltbelastung in der Bundesrepublik Deutschiand durch Radionuklide aus Kerntechnischen Anlagen im Normalbetrieb. Bericht Jül-1220, Kernforschungsanlage Jülich, 1975.)

47 G. Haury, W. Schikarski, and E. Thorne. Compilation of Environmental Impacts arising from the Production and Consumption of Energy in the Federal Republic of Germany and Legislative and Technical Measures for their Reduction. Report KFK 2103 UF, Karlsruhe Nuciear Research Center, 1974. (G. Haury, W. Schikarski, und E. Thone. Zusammenstellung der in der Bundesrepublik Deutschland durch die Erzeugung und den Verbrauch von Energie bedingten Auswirkungen auf die Umwelt und der legislativen und technischen Massnahmen zu ihrer Verminderung. Bericht KFK 2103 UF, Kernforschungsanlage Karlsruhe, 1974.)

48 Jülich Nuclear Research Center. Supply of District Heat to the Villages near the KRB Grundremmingen Nuclear Power Plant. Study commissioned by the Federal Ministry of Research and Technology, Report Jül 1283, Jülich Nuclear Research Center, 1976. (Kernforschungsanlage Jülich. Fernwärmeversorgung der um das Kernkraftwerk KRB Grundremmingen liegenden Ortschaften. Studie im Auftrag des Bundesministeriums für Forschung und Technologie, Bericht Jül-1283, Kernforschungsanlage Jülich, 1976.)

49 W. Hensel. Contribution to the Standardization of Siting Criteria for Nuclear Power Plants. Report Jül-Spez-0012, Jülich Nuclear Research Center, 1978. (W. Hensel. Beitrag zur Standardisierung der Standortbestimmung von Kernkraftwerken. Bericht Jül-Spez-0012, Kernforschungsanlage Jülich, 1978.)

50 ASA Program Directorate. Exploratory Analysis of the Possibility of Extensive Utilization of Nuclear Power in the Federal Republic of Germany. Report ASA-PE/04/76, Cologne, 1976. (Programmleitung Angewandte Systemanalyse. Orientierungsanalyse zur Problematik einer umfassenden Kernenergienutzung in der Bundesrepublik Deutschland. Bericht ASAPE/04/76, Köln, 1976.)

51 Federal Ministry for Regional Policy, Construction, and City Planning. The Effect of Developments in the Energy Sector on Land Use and Settlement Structures. Issue II in the series "Regional Policy" produced by the Federal Ministry for Regional Policy, Construction, and City Planning, Bonn, 1977. (Bundesministerium für Raumordnung, Bauwesen und Städtebau. A uswirkungen von Entwicklungen im Energiesektor auf die Raum und Siedlungsstruktur. Heft 11 in der Schriftenreihe "Raumordnung" des Bundesministeriums für Raumordnung, Bauwesen und Städtebau, Bonn, 1977.)

52 R. Thoss and K. Wïk. Optimal Allocation of Economic Activities under Environmental Constraints in the Frankfurt Metropolitan A rea. Internal report, University of Münster, 1976.

53 Federal Ministry for Regional Policy, Construction, and City Planning. The PRO-REGIO Planning System. Issue 7 in the series "Regional Policy" produced by the Federal Ministry for Regional Policy, Construction, and City Planning, Bonn, 1976. (Bundesministerium für Raumordnung, Bauwesen und Städtebau. Planungssystem PRO-REGIO. Heft Nr. 7 in der Schriftenreihe "Raumplanung" des Bundesministeriums für Raumordnung, Bauwesen und Städtebau, Bonn, 1976.)

54 R. Thoss, P. Brasse, W. Burgbacher, and K. Wiik. Environmental policy and regional planning in the Lower Main area: A decision model for socioeconomic-ecological guidance to development planning. In German National Committee for the UNESCO "Man and the Biosphere Program" (Ed.), Ecology and Planning in an Urban Area: The Studies on MAB Project 11 in the Lower Main Region. Report No. 2, MAB-Information, Bonn, 1978. 
55 H.P. Döllekes. Planning of Energy and Environmental Policies. Dissertation, University of Münster, 1976. (H.P. Döilekes. Planung der Energie- und Umweltpolitik. Dissertation, Universität Münster, 1976.)

56 N. Wippo. Distribution of Traffic and Environmental Protection. Dissertation, University of Göttingẹn, 1976. (N. Wippo. Verkehrsteilung und Umweltschutz. Dissertation, Universität Göttingen, 1976.)

\section{APPENDIX 4A}

A multiregional, multisectoral decision model for the analysis and coordination of economic and environmental policy ${ }^{54}$

A decision model which allows economic and environmental factors to be treated simultaneously is being developed at the University of Münster as a contribution to the UNESCO "Man and the Biosphere" program. The model is designed for application in the Frankfurt metropolitan area, and its object is to help identify a "generally accepted" set of targets, and the levels of instrumental variables (charges, air pollution standards, etc.) required to reach these targets. The Frankfurt area has been divided into 21 subregions, while the rest of the FRG serves as the 22 nd region for import-export purposes. The model is based on recursive linear programming, and consists of six subsystems:

1. Socioeconomic relations

2. Energy and air pollution

3. Water pollution and water quality

4. Solid wastes and recycling

5. Regional policy

6. Transport

Because energy planning and its effects on the environment are of particular interest here, subsystems 1 and 2 will be examined in detail.

An input-output matrix constitutes the main part of subsystem 1 (socioeconomic relations) ${ }^{33}$. For the purpose of the model, this matrix has been extended: 21 types of treatment of residuals with their intermediate and primary input demands have been added to the original 56 sectors. Further, a choice between several production processes has been made possible by introducing alternative processes for electricity generation as well as for several recycling technologies. The economic part of the model deals with the relative shares of private and public consumption, private and public investment, and export surplus. Labor balances and sectoral constraints on employment are used to define the scope of economic production and to provide targets for employment.

The impact of economic activities on air pollution cannot be studied without a detailed description of the consumption and conversion of energy, because much of the problem results from energy use. Therefore the energy sector in the second submodel was further disaggregated into commodities (coal, gas, etc.). This model contains energy balances for 34 forms of energy, which may be produced (either as main products or as byproducts) by six sectors using 15 different processes.

First the energy balances may be used to determine the necessary output levels for each commodity if demand (and trade) are known. The next step is to determine the demand using another set of relations. To permit substitution in the electricity sector, the total 
demand for energy commodities is split into two parts. The first comprises the energy used in the electricity-producing sector. Unlimited substitution of energy inputs in four different methods of electricity production has been taken into account in this sector by defining activities which convert energy of different types into substitutable inputs for electricity generation. Choice of energy inputs means choice between these activities. The second part of the energy demand comes from all of the other sectors.

Energy of each type is supplied either by domestic production or imported. The amount supplied must be equal to the (substitutable) demand for electricity production plus the (fixed) demand for all other purposes. The supply part of the submodel also includes constraints on the supply of energy from "outside" sources (imports).

Thus energy demand and energy supply are treated within a single framework. The effects on the environment are modeled by considering eight types of air pollutant. The sources of these unwanted byproducts may be either production activities or the consumption of different types of energy. Air quality standards for each of the pollutants are used to specify the upper limits of pollution, which again imposes limits on regional growth. It should be noted that the model deals simultaneously with the three states of matter (solids, liquids, and gases) and the three environmental media (land, water, and air). The water quality management model contains dispersion and transformation models for five different rivers in the area under investigation. The solid-waste submodel contains 16 material balances and 19 treatment and recycling activities. The land-use model considers 23 different uses of land. The transport model considers seven different kinds of transport, and five types of air pollutant.

Environmental constraints are considered to be the "limits to growth" in the area. Within these limits, however, there is no reason why industrial growth should not continue. One of the objectives of economic-ecological development planning in our regional system must therefore be to maximize production in all subregions subject to socioeconomic and ecological constraints. Of course, other objectives can be introduced as flexible targets (objective functions) depending on the problem under investigation.

This model can be used to examine both energy and environmental strategies. The results of possible courses of action taken to protect the environment (and their repercussions on the total system) can be tested and analyzed. Some of the possibilities are as follows:

- Adjustment of the level of production

- Substitution of processes or inputs

- Changing the site of production or encouraging the population to move

- Recycling of materials

- Antipollution investment

- Environmental preservation

This approach can be used to determine the "optimal" regional environmental and economic strategy, in which energy plays a very important role.

Three of the submodels discussed above (as well as the economic part of the model) have been implemented for the Frankfurt metropolitan area. The energy and transport models, which have both been run for the FRG, are now being adapted for regional and local use ${ }^{55.56}$. It is also planned to incorporate the results of the air pollution research project (discussed on page 45 ) into the model. 


\title{
5 Management and Planning of \\ $\mathcal{S}$ Energy/Environment Systems in Finland
}

\author{
Seppo Hannus*
}

\section{INTRODUCTION}

The management and planning of energy systems in Finland is influenced by groups operating on a number of hierarchical levels. These include energy consumers and producers and local and national governments. Some of the energy producers are responsible for supplying a certain geographical area, and are therefore interested in regional energy planning, although most of the management and planning of energy systems is carried out at the national level.

Environmental planning is designed to minimize the environmental effects of social or economic growth, and is therefore intrinsically concerned with all sectors of the economy. This means that environmental aspects are taken into account while, for example, making plans about energy supply. In this case the analysis is carried out partly by energy authorities, and partly by the authorities responsible for the environment and natural resources.

The energy issues of concern in Finland are those common to the oil-importing, industrialized nations: high energy demand combined with low indigenous energy resources. The environmental issues are, however, somewhat different. Finland is very sparsely populated, and so the environmental impacts can perhaps be more easily controlled than in other countries. On the other hand, the Finnish environment is rather vulnerable because of its northern location, and does not adapt well to change. One of the most important issues is transnational pollution, which accounts for almost half of the air pollution in Finland.

\footnotetext{
* Energy Division, Ministry of Trade and Industry, Helsinki.
} 


\section{ANALYSIS OF ENERGY DEMAND}

The method used to calculate energy demand is based on the simple formula

$$
\text { Energy demand }=\text { Economic activity } \times \text { Specific consumption }
$$

This is very similar to the approach used by the Workshop on Alternative Energy Strategies (WAES) ${ }^{1}$, and is applied separately to different consumption sectors for different types of fuel. The level of disaggregation depends on the range of the analysis. Medium-term analysis (10-15 years) includes 30 demand sectors and 18 types of fuel, while long-term analysis (20-25 years) considers only 9 demand sectors and 9 types of fuel.

The analysis of energy demand therefore leads to a matrix in which each element describes the demand for one type of secondary energy by one particular sector. The total demand for each type of secondary energy is then calculated by adding the sectoral demands. This matrix is estimated for each time point assessed: every year in the medium-term analysis, and every five years in the longterm analysis.

The demand for energy is calculated for a number of different scenarios. The scenarios are defined by a set of variables which take different values in each case; the procedure used for analysis is the same in all cases.

The starting point of the analysis is the estimation of economic activity, which is carried out manually. There are two determinants which are allowed to vary:

1. Annual rate of growth of GNP

2. Structure of this growth, i.e., the relative growth of different sectors

Economic activity is generally measured by the value added in the production sectors. In some cases the level of economic activity is expressed in physical units, for example the volume of living space that must be heated.

A coefficient of specific energy consumption is determined for each sector. This is defined as an energy demand per unit of economic activity, for example process heat demand per unit of value added in production, or heat demand per cubic meter of space in buildings. The base scenarios assume that the current trends in these coefficients will continue unchanged.

The trends in these sectoral coefficients may be altered by varying two determinants:

1. Price of energy imports

2. Energy conservation policy

There are therefore four main factors that determine the energy demand. These were allocated the following values in the scenarios under investigation: 
1. Annual rate of growth of GNP

- $0 \%$

- $2 \%$

- $3 \%$

- $4 \%$

- $5 \%$

2. Structure of growth in GNP

- Extrapolation of present structure

- Increased growth in the service sector, less growth in the industrial sector

- Less growth in the energy-intensive industries

3. Price of energy imports

- Constant price level

- Prices doubling by the year 2000

4. Energy conservation policy

- Present policy

- Policy of increased energy conservation

Thus there are $5 \times 3 \times 2 \times 2=60$ possible cases of demand, or scenarios, but only the most relevant of these have been analyzed.

Conservation is regarded as an energy policy variable while all of the other factors are considered exogenous to the energy sector. The main purpose of this analysis is therefore to study how the demand is determined by exogenous and policy variables. Having analyzed the scenarios as outlined above, it was found that the exogenous variables have a much greater effect on the level of demand in Finland than the endogenous policy variables. Thus uncertainty is seen as the major problem in energy planning.

\section{ANALYSIS OF ENERGY SUPPLY}

The analysis of energy supply takes place in two phases:

1. Investigation of available supplies

2. Determination of suitable uses for supplies ("supply-demand integration")

The availability of the various sources of energy is very different, and so each of these has been determined individually. The fact that there are no high-grade fossil fuel reserves in Finland simplifies the analysis to some extent, the main indigenous energy sources being wood, peat, wastes, and hydropower. The term "available supplies" also includes imported energy.

Energy supply analysis, like energy demand analysis, is based on the use of scenarios. Each scenario consists of a set of assumptions concerning the supply of 
each possible energy source. The energy sources are divided into two categories: indigenous and imported. Supply is in principle also dependent on factors like economic growth and the price of energy, but these relationships have not been quantitatively investigated. It has been assumed that sources like wood, peat, and imported coal will not be constrained by supply during this century. This means that the supply of these fuels is larger than the demand predicted by any of the scenarios so that their use is determined only by future demand and the choice of fuel mix. On the other hand, sources like hydropower, waste materials, imported oil, gas, and electricity are or may become constrained by supply before the end of this century. This means that the supply of this type of energy may not be sufficient to meet the demand.

There are an infinite number of possible supply scenarios, only two of which will be considered here. One is a conventional unconstrained supply scenario, in which most of the additional demand is met by oil and nuclear energy. In the other scenario the oil supply is assumed sufficient to meet only half of the demand and the use of nuclear energy is constrained to the present level.

The integration of supply and demand is simple in the case of unconstrained supply since all of the energy required is assumed to be available. The case of constrained supply is more complicated, since the energy sources which have been limited must be partly replaced by more readily available supplies. However, not all sources of energy are suitable for all purposes, so that the choice of fuel mix has to be considered very carefully.

The optimization approach to determining energy use has not been used here since it was felt that it would not produce useful results. All energy allocation and fuel mix assumptions are made explicitly by the planner and not by mathematical algorithms, which makes the analysis more realistic. These assumptions are then fed into automatic programs which produce the final supply-demand integrations in the form of energy balances. Energy policy issues are considered to be so complex that they cannot be represented by numerical objective functions.

\section{ENVIRONMENTAL ANALYSIS}

The analyses of energy supply and demand are carried out on such a high level of aggregation that they do not provide very much operational information about environmental impacts, though certain parameters representing total emissions can be and are calculated. Since Finland is a small country there are not very many major energy supply installations and the environmental impact of each of them can be analyzed individually. The local conditions have a considerable effect on the environmental impact of each plant. It appears that the quality of the fuels and the methods used to burn them have a greater effect on the emission rates than the choice of fuels, when viewed at the national level. These are again factors that cannot be determined in an aggregate, long-range supply-demand analysis. 
The environmental impacts are very different in type, and are usually introduced into the decision-making framework in different ways. Each problem is solved individually - it does not seem sensible to develop a general procedure for dealing with situations that have very little in common, and which cannot be quantified.

\section{INTEGRATION OF DECISION MAKING AND ANALYSIS}

It seems obvious that when central energy policy issues are assessed there should be no organizational barriers between the analysts and those who actually apply the results. This implies that systems analysis should be directly embedded within the organizations responsible for the planning of energy systems - this is the only way to avoid the classical information gap between systems analysts and "decision makers". There are several ways of obtaining and producing information for decisions on energy policy, and these can collectively be called the information system for energy policy assessment. Systems analysis is only one part of the information system, which also requires other procedures to provide a complete background for decision making. If systems analysis is organizationally and functionally separated from the other parts of the information network, the results will hardly ever be used.

There is no master plan controlling the use of systems-analytical techniques in energy-oriented decision making. Methods are considered to be tools and used only when necessary. The approach has been very problem-oriented, the energy planners responsible for preparing the issues for the decision makers using the means at their disposal to obtain their results. This often involves large amounts of data but seldom any sophisticated mathematics. The methods developed at IIASA have also been studied in Finland, but have not been put into practice. This is partly because the resources for energy planning in Finland are very limited and the work carried out therefore has to be very practical. However, the results of the IIASA studies have provided a sound basis for the estimation of factors exogenous to Finland, and have been followed closely by the Finnish energy planners and analysts. The results obtained in other countries also provide an interesting background for a general study of the characteristics of energy systems.

\section{REFERENCE}

1 C.L. Wilson. Energy: Global Prospects 1985-2000. Report of the Workshop on Alternative Energy Strategies. McGraw-Hill, New York, 1977. 


\title{
6 Management and Planning of Energy/Environment Systems in France
}

\author{
Dominique Finon* and Jean-Marie Martin*
}

\section{INTRODUCTION}

This discussion begins with a brief description of the energy situation in Rhône-Alpes, one of the 21 regions of France, and is then broadened to include national energy policy and planning. There are several reasons for a preliminary examination of the Rhône-Alpes region. First, this area was the subject of one of the IIASA case studies on regional energy/environment systems ${ }^{1}$. A discussion of energy matters in this region should provide an interesting background to the Rhône-Alpes scenarios discussed in Part II of this volume. Second, recent plans for constructing a large number of nuclear plants on the banks of the River Rhône have brought the region to the fore in the national energy picture. Finally, a discussion of regional energy management demonstrates the centralized nature of decision making in France and points to the need for a national analysis of the management and planning of energy systems.

\section{The Rhône-Alpes region}

In 1975, the Rhône-Alpes region contained $9.1 \%$ of the total population of France and accounted for $10 \%$ of the total energy consumed-about $15 \mathrm{mtpe}$ (million tonnes of petroleum equivalent). This relatively large share is principally due to industrial consumption ( $45 \%$ of the total); this in turn is related to growth in the energy-intensive chemical, electrochemical, and metallurgical industries.

The region itself produces primary energy in the form of 500,000 tonnes of coal and $20,000 \mathrm{GWh}$ of hydropower per year, and there is also a petroleum refinery at Feyzin. However, the energy situation is changing. Future proposed develop-

\footnotetext{
* Institute for the Economic and Judicial Study of Energy, CNRS, Grenoble.
} 
ment includes the construction of a large number of nuclear power plants in the Rhône-Alpes region by 1985. Fifteen plants are planned, 12 of $900 \mathrm{MWe}$ capacity, two of $1300 \mathrm{MWe}$ capacity, and one $1200 \mathrm{MWe}$ fast breeder reactor. This very rapid development of nuclear power will create numerous environmental problems in addition to those already present in Rhône-Alpes, one of the most industrialized regions of France. There is already concern over the thermal pollution of rivers, the emission of sulfur dioxide and carbon dioxide, the land required for electricity distribution, the loss of open space near cities, and so on. The conflicts between those interested in producing more energy and those wishing to protect the quality of life have become increasingly numerous and more violent in recent years*. However, these problems cannot be resolved locally, because although Rhône-Alpes, like all French regions, has an Economic and Social Council**, it has no control over the decisions taken at the national level. This is reflected in the analysis which follows.

\section{The energy industry and the decision-making system $\dagger$}

For historical reasons, decisions on energy policy and planning are taken by small groups of people concentrated in and around Paris. This is reflected in the structure of the organizations which produce, import, transport, and distribute energy and energy-producing materials.

Coal. A single, publicly owned enterprise (Charbonnages de France, or CDF) and its subsidiary companies (Houillères de Bassin) annually produce 25 million tonnes of coal which are sold directly or through wholesale dealers. Almost the same quantity of coal is imported each year by wholesale dealers, or ordered directly by the biggest consumers. These imports must pass through the Technical Association for Coal Imports (ATIC).

Natural gas. The Sociéte Nationale Elf-Aquitaine (SNEA), most of which is publicly owned, produces about 6 billion $\mathrm{m}^{3}$ of natural gas per year at Lacq, in southwestern France. This gas, plus the gas which is imported from The Netherlands and Algeria (about 13 billion $\mathrm{m}^{3}$ per year), is transported and distributed by Gaz de France (GDF), a publicly owned monopoly.

\footnotetext{
* To the point of provoking one death at the site of the fast breeder reactor (Creys-Malville) in July 1977.

** However, this council has discussed the energy problems of the region and has published an interesting report on the subject ${ }^{2}$.

† The names of all administrative, regulatory, and consultative bodies will be cited in English in the text-their original French titles are given in Appendix 6A. The names of the energy-producing companies will, however, remain in the original French.
} 
Petroleum. This is the only branch of the energy industry in which several largescale enterprises coexist, and handle both production and distribution. National companies, such as the largely privately owned Compagnie Française de Pétroles (CFP), and the largely publicly owned Societe Nationale Elf-Aquitaine (SNEA), control about $40 \%$ of the refinery capacity and market distribution, and deal with about 100 million tonnes of various petroleum products. All of the other companies are subsidiaries of large foreign concerns (Shell, Esso, BP, Mobil, Petrofina), and there are also about 70 groups which import and distribute refined products but do not possess industrial facilities. All of these companies operate within the limits of the 1928 legislation, which gave the State the sole right to import petroleum (both crude and refined products). The State, in turn, delegates its monopoly to companies by granting authorizations to import, which must be renewed periodically.

Electricity. Electricité de France (EDF), a publicly owned enterprise created, like CDF and GDF, shortly after World War II, has a monopoly over electricity transmission and distribution. The only exceptions to this are a few cities which have retained their own municipal companies. EDF also produces $80 \%$ of the $200 \mathrm{TWh}$ of electricity consumed annually in France, using hydropower stations, nuclear power stations, and thermal plants. The remainder is provided by the CDF, the Compagnie Nationale du Rhône (CNR), and several self-producers (notably in the metallurgy and electrochemical industries).

Nuclear power. Any nuclear power plants constructed and put into operation by the EDF will rely on the Commission for Atomic Energy (CEA) for the supply (production and importing) of natural uranium, its enrichment, and the reprocessing of spent fuel elements.

This brief outline demonstrates the important role played by the State in the operation and development of the French energy industry. (A more detailed description is given in ref. 3.) The public character of the major coal, electricity, and gas companies, and the 1928 legislation limiting petroleum imports means that the State possesses a control over energy industries which is not found in other capitalist economies. No decisions of importance are taken without its knowledge and approval: however, this does not necessarily mean that the aims of government and industry are opposed.

The central administration dealing with energy matters is quite small, and concentrated in Paris. The government has assigned two directorates to prepare and implement energy legislation and regulations, one dealing with petroleum products, and the other with gas, electricity, and coal.

The directorate in charge of petroleum products (DICA) is responsible for the development and implementation of all measures concerned with liquid and gaseous hydrocarbons: research, extraction techniques, the safety of facilities, and the organization of the market. 
The directorate in charge of gas, electricity, and coal (DIGEC) carries out the same functions as the petroleum directorate but for different forms of energy, and is also responsible for the publicly owned companies operating in this field.

Since 1974, a number of new administrative bodies have been set up to develop and coordinate national energy policy ${ }^{4}$. The most important of these is the General Delegation for Energy, which advises the government on the measures necessary to keep France adequately supplied with energy. The Delegation also coordinates the activities of the DICA, the DIGEC, and the new agencies which have been set up in recent years. One of these, the Agency for Energy Conservation, is not only responsible for advising the government on energy conservation but is also an industrial and commercial agency in its own right, with a budget used to develop and promote new technologies. Another organization, the Delegation for New Energy Sources, is an offshoot of the recent Commission for Solar Energy. It was developed to stimulate research into new sources of energy at various agencies (CNRS, CEA, etc.), and to introduce these new techniques to energy consumers.

The administrative structure described above is organized at the national level in Paris. The 21 regions are represented by about 90 departments (4-10 per region) and are not autonomous in energy management. The central administrative agencies dealing with energy problems have one representative in each region, designated by legislation passed on 12 May 1976 as the head of the interdepartmental service for industry and mining. This official is responsible for applying national regulations at the regional level, and for gathering the local data needed by the central administration for national energy planning.

It is important to understand the processes involved in national energy planning to appreciate the analyses of energy supply and demand which follow, and the position accorded to environmental protection in energy management.

A new national plan is prepared every five years. The General Commissariat for Planning first convenes an Energy Commission, which is generally made up of representatives of all bodies dealing with energy supply in France. These include not only representatives of the Ministry of Industry (DICA, DIGEC, etc.), the Ministry of Finance, and the Ministry for the Protection of Nature and the Environment, but also the largest energy producers (EDF, CDF, GDF, and petroleum companies) and the principal energy consumers (essentially industry). This Commission produces a 15-year prognosis of supply and demand, which is the result of compromises between the projections (more or less contradictory) of various industries. Theoretically, at this very general stage in the development of energy policy, the Ministry for the Protection of Nature and the Environment is supposed to present its case. However, this Ministry generally finds itself at a disadvantage when faced with the principal energy producers and with representatives of other sectors who have much more power, either because they are involved in financing energy-related projects (the Ministry of Finance), or because they have a greater knowledge of the problems of the sector (the Ministry of Industry). 
The same is true of all other interagency bodies consulted in government decisions on energy, e.g., the Consultative Committee for the Utilization of Energy (CCUE), which examines all projects involving regulatory measures in the field of energy use. However, the Agency for Energy Conservation often stresses better protection of the environment, and the objectives of this group are strongly defended within the Energy Commission.

The conclusions of the consultative commission for the Production of Nuclear Energy (PEON) have always had a strong influence on government decisions. A recent work ${ }^{5}$ has revealed that the Ministry for the Protection of Nature and the Environment carries very little weight in this commission, which is dominated by EDF, the CEA, and the constructors of nuclear installations.

Finally, regulations setting standards for energy-related activities or an investment program requiring state authorization and/or state financing are prepared within the Ministry of Industry and finalized by the government at an interministerial council or by the Council of Ministers. The weight of the Ministry for the Protection of Nature and the Environment at these Councils depends on numerous variables, the personality and politics of the Minister himself playing a major role. From this point of view the situation in France seems to have deteriorated since the creation of the Ministry for the Protection of Nature and the Environment*. Certain decisions may take the form of a law and be passed by Parliament, where concern for the environment may still be expressed. The lack of parliamentary debate on environmental issues is largely a reflection of the scant interest shown by the French public in this subject.

This, then, is the outline of the institutional system which produces French energy policy. Since 1974 this policy has been dominated by one central preoccupation: the need to meet the energy demands of the French economy during the coming decades, while decreasing the national dependence on imported petroleum (more than $60 \%$ of the primary energy consumed in France is derived from imported petroleum). In the absence of abundant high-quality coal or hydrocarbon reserves, France has chosen large-scale rapid nuclear development. Goals set at the beginning of 1975 suggest that nuclear power should provide about $25 \%$ of the primary energy consumed in 1985 , this figure rising to $40-45 \%$ in the year 2000. Electricity does not cause any pollution at the point of consumption, but its production in very large nuclear parks (containing up to five 1300 MW reactors) raises numerous problems:

- Safety at the plants

- Thermal pollution, especially of water

- Transport, storage, and reprocessing of wastes

- Right of way for the electricity transmission network

* The first Minister was Robert Poujade, who belonged to a very powerful political group. 
The sites chosen for nuclear plants have also been the cause of heated debate, especially the site chosen for the construction of the first fast breeder reactor, Super-Phênix, at Creys-Malville.

The next section shows how the supply of, and demand for, energy have been affected by these factors, and the degree to which they are (or are not) influenced by concern for the quality of the environment.

\section{ANALYSIS OF ENERGY SUPPLY AND DEMAND*}

This section considers the national models used to analyze energy supply and demand in France. Most of these models are very specific and are concerned with operational research or the simple administration of enterprises.

\section{Oil branch models ${ }^{6}$}

The oil companies have developed models of two main types ${ }^{7}$ :

1. Models which optimize the administration and the operation of a refinery, taking into account its technical characteristics, the quality of oil supplied to the refinery, the production program imposed by company headquarters, and the company's market in the area of the refinery. In order to do this, the variable expenses are minimized using programming techniques; the specific characteristics of products are also taken into account.

2. Models of transport and distribution which minimize transport expenses; also models of the availability of different oil products, taking into account the sites of refineries, of storage places, and of main areas of consumption. These models are regional and also use programming or variational algorithms.

There are also more general models, which attempt to optimize the strategy of oil companies by planning their investments in exploration, refining, and distribution, and by optimizing their strategy of acquiring markets (heavy oils, light oils, and so on). Again, it is necessary to remember that half of the French oil market is controlled by multinational firms whose investment policy depends on the strategy of all other multinational firms. There are no strategic models at the national level in this branch.

* This section is based on pp. $420-427$ of Management of Energy/Environment Systems: Methods and Case Studies, edited by W.K. Foell. It appears here with the kind permission of the publisher, John Wiley and Sons. 


\section{Gas branch models}

Except for the models that optimize the management of gas pipelines by considering the possible growth of different regional markets and the availability of gas (national resources, import contracts), and the models that manage reservoirs with underground storage in order to handle peak demand, few models for gas have been developed by Gaz de France. However, it should be noted that other methodologies have been used in place of formal models, both to analyze the competitiveness of gas, and to help in choosing investments.

To analyze competitiveness, the markets for gas have been studied case by case in the different domains where it is or could be used*; an equivalent price for gas is determined from the price of competing fuels, taking into account the profit of utilization, costs of equipment, and costs to gas users. To help in the choice of investment, Gaz de France studies the potential profits of possible investment projects; it determines from a number of profitable operations those which produce the best forecasted financial result ${ }^{8}$. It is in effect necessary to cut down on less profitable projects because investment credits granted by public authorities are limited.

\section{Electricity branch models}

This branch has been a subject of particular interest to modelers: the first linear programming models used in France were developed in 1954 by Electricite de France (EDF) for the purpose of choosing investments. Since this time, the company's researchers have been making progress in utilizing new computation techniques (nonlinear programming, dynamic programming, the theory of optimal control, and so on). Although very specific models have been developed, e.g., for optimizing nuclear fuel cycles ${ }^{9,10}$, for optimizing the electricity transmission network, and for maximizing the reliability of this network ${ }^{11}$, we shall concentrate here on the more general models, in particular models for demand forecasting and for choosing between investments.

The models used by EDF for forecasting electricity demand are relatively simple and based upon extrapolation of past trends, using statistical relations of the simple or multiple regression type ${ }^{12}$. These relations (generally logarithmic) are used to calculate the demand for electrical energy at the national level (or at the level of highly aggregated ${ }^{* *}$ sectors such as the residential, commercial, or industrial sector) at time $t$, as follows:

$$
\log C_{t}=\mathrm{a}+\mathrm{b} \cdot t
$$

Alternatively, the models relate the demand for electrical energy to the level of

* Specific domains include tubular boilers, different types of drying, and the baking of clay.

** Aggregation may be according to the level of voltage required (high or low). 
economic activity as represented by an operational economic index of the gross national product (Product National Brut or PNB) or industrial value added (Valeur Ajoutée Industrielle or VAI):

$$
\log C_{t}=\mathrm{a}+\mathrm{b} \log \mathrm{PNB}_{t}
$$

Forecasters at EDF have concluded that these models provide the best results and that all efforts to link electricity consumption with other variables (such as the price of capital, labor, or fuels relative to that of electricity in industry, or such as income) prove to be unsatisfactory ${ }^{13}$. It should be pointed out that this econometric approach assumes that the consumption of electricity is inelastic with respect to price, and that the market for electricity has developed in a relatively autonomous manner in each domain. The new commercial strategy of EDF and the great increase in the price of petroleum products, however, makes compartmentalization of markets impossible, and casts some doubt on the continued validity of these methods. At the present time it is necessary to supplement econometric forecasts with information on commercial objectives; the forecasts should also consider various scenarios for the future. Extrapolation techniques can never be completely discarded, but beyond a horizon of five years such projections should be used with much caution.

In addition, a short-to-medium-term forecasting model of the daily load curve is used to define the output power required in every hour of each day of the week for every month, by extrapolating various coefficients which characterize important parameters ${ }^{13}$.

Let us now consider the models for the choice of investments; much work has been done on this subject ${ }^{14-16}$. These models minimize the costs of electricity production over a long period of time (1975-2000), in accordance with given production objectives. The objectives are determined by projections of total electricity demand that are arrived at (1) with the aid of the econometric models discussed above, and (2) by a representation of this demand as weekly load curves. The different types of equipment used for electricity production, including hydroelectric equipment, are explicitly taken into account and are characterized both by their capacity and by their level of operation during the different hours of the load curve. The risks associated with hydropower and hourly electricity consumption are assessed with the help of probabilities established from past samples; it is then possible to take into consideration possible failures of the production system.

The new national model of investment ${ }^{17}$ uses the theory of optimal control. The objective function is minimization of a cost function composed of three terms: investment, operating cost, and cost of failure*. The control variables are the

* The cost of power failure is a nonlinear function increasing with the duration and the amplitude of the power failure. 
quantities of equipment to be installed each year, and the constraints express an obligation to satisfy future demand as well as to develop certain types of equipment. The algorithm has two parts: in the first the control variables are determined and in the second the best investment strategy for a given power output is defined. The program makes it possible to obtain the optimal investment plan at the national level, the economic lifetime of equipment, the probability of power failure, the marginal costs of production of a kilowatt-hour (according to the hour, day, and month), and so on. The marginal costs determined in this way are then used as a basis for electricity tariffs, adding on the marginal costs of transport and distribution calculated elsewhere and a "toll" which permits EDF to balance its budget and even to make a small profit ${ }^{18,19}$. The utilities determined by the model can be used to compare individual hydroelectric projects with conventional thermal or nuclear power plants of the same capacity in order to study their profitability ${ }^{20}$.

These nonlinear programming models of investment choices are particularly complex because the system of French electricity production involves hydropower plants, conventional thermal plants, and nuclear plants. This necessitates a detailed representation of the state of hydropower equipment (water flows, locks, reservoirs, pumps, etc.) during different hours in the year, taking into account the daily, weekly, or seasonal carry-overs which are available. In the model now in use, a submodel simulates the management of the electrical capacity in such a manner that the weekly (or monthly) load of the conventional thermal capacity is as steady as possible. It is necessary to stress that, of the investment models considered here, only the model "Investments 85" constructed in 1965 was disaggregated into regions; the Rhône-Alpes region together with the Mediterranean-Côte d'Azur region constituted the southwestern region in this model. The southwestern region was linked with other regions by variables describing interregional exchanges. The objective was not to determine transportation routes but rather to try to outline a preliminary scheme for the siting of production equipment, taking into consideration the location of hydropower resources and consumers.

It is necessary to point out that these investment models deal only with private costs and not with the social costs arising from the degradation of the environment through atmospheric or water pollution or land use. In other words, not a single environmental constraint has been taken into account. From a practical point of view, for example, these models have never explicitly considered the siting of electricity installations since almost all of the models are not disaggregated into regions*. In France there are only a few rivers with a flow sufficient to act as a coolant for a number of power plants, and therefore this tends to influence the location of plants more than, say, transmission costs.

* The regionalization included in the model "Investments 85 " was not fine enough for this problem to be considered. 
However, this does not mean that EDF is not concerned with the environmental effects of electricity generation, which include the effects of radioactivity, noise, electrical disturbances, and RF interference. These effects have been evaluated with reference to a group of factors from fields as varied as physics, medicine, biology, and psychology. Some of the elements are purely qualitative or subjective and represent judgments or explicit or implicit choices made by individuals who are assumed to express the attitudes and aspirations of the community. The relative importance of the ecological problems posed by different production techniques has been calculated by means of "ecological points". Seven types of ecological problem have been catalogued for a reference plant (a 600MW unit in a conventional thermal plant). The impacts of the various production techniques are then evaluated in terms of the severity of each ecological problem caused. Finally, comparing the different types of impacts with the help of a preference function*, the total value of impacts of different installations can be calculated in terms of "ecological points". Similarly, it is possible to evaluate the ecological gain of each action undertaken to reduce harmful effects to the environment. This technique can also yield an implicit evaluation in monetary terms of an "ecological point", an evaluation which must, however, remain more or less inexact.

At the sectoral level, there is no comprehensive decision model designed to influence public authorities or related bodies. This also applies to the regional energy system. A method of energy planning was used in the past within the framework of the IV French Plan (1961-1965) and the V French Plan (1966-1970). This method included an informal model which was designed to determine how France could achieve a reliable energy supply at the lowest cost. However, this method was abandoned in 1970 when the VI French Plan was conceived, for the public authorities no longer controlled the energy system.

There is also a simulation model ${ }^{* *}$ which forecasts the medium- and long-term consequences of changes in energy policy (tariffs, taxes, investments, regulation) for the financing, employment, annual investment needs, and budgets of enterprises in the energy sector.

\section{Cognitive models}

Very few efforts have been made in France to understand and explore the French energy system with the help of models. In this context the scenario method is particularly interesting, in that it is possible to reduce the complexity of the system

\footnotetext{
* This preference function expresses the level of concern attached to each category of harmful effects and is based on subjective considerations (acceptable levels of change in the natural environment, quality of the atmosphere, and so forth).
}

** FINER's model, constructed by D. Blain, Ministry of Industry. 
studied through the selection of the most important factors, and to trace different options for the development of nuclear energy up to the year 2000.

At the Institute for the Economic and Judicial Study of Energy (IEJE) in Grenoble, an optimization model for the energy sector without any ties to the public authorities has been developed ${ }^{21,22}$. Its aim is to test the reaction of the French energy system to changes in the political and economic environment, i.e., changes in factors such as the following:

Price of oil
- Cost of nuclear facilities
- Pevelopment of certain technologies
- Policy of protecting the environment

The linear programming model considers the period up to 2020 for the French energy system as a whole.

The system is described by means of a network in which the nodes represent all of the energy-related activities (extraction, importing, processing, transformation, transport, consumption) on French territory. It disaggregates the total consumption of energy into the various forms of end use (electricity, coal, etc.). In the current version, the only environmental impact considered is the emission of sulfur dioxide, but the method of formalization could easily be extended to include other environmental effects.

The model chooses between the different processes for producing various types of energy on the basis of minimizing the cost while both satisfying demand and obeying various political constraints (limitation of dependence on oil, possible acceleration of the nuclear program, limitation of the levels of emissions, and so on). The variables of the model are therefore the flows through the network in different years (exploitation variables) and the capacities to be created in the future (equipment variables). The model is then divided into two subsystems which deal with consumption and production separately.

Consumption subsystem. Demand is partly endogenous to the model. Disregarding consumption in the energy sector, demand is disaggregated into three groups of consumers (industrial, transport, and domestic) and nine types of final energy (coke, coal, gas, electricity, motor fuels for transport systems, naphthalene for the chemical industry, domestic fuel oil, fuel oil with a high sulfur content, and heavy fuel oil with a low sulfur content). The model also distinguishes between two types of use, substitutable and nonsubstitutable. Substitutable use is characteristic of situations where there is competition between different forms of energy.

Suppose $c$ is a group of consumers and $\phi$ is a form of final energy. 
Then

$x^{1}(\phi, c)$ are the flows of $\phi$ directed toward nonsubstitutable use

$x^{\prime \prime}(\phi, c)$ are the flows of $\phi$ directed toward thermal use

$r(\phi, c)$ is the profit from utilizing $\phi$ in the equipment of the consumer

$D(\phi, c)$ are the specific energy needs of the consumers

$U_{c}$ is the consumers' need for useful thermal energy

$T(\phi, c)$ is the initial capacity of the energy-using equipment of the consumer for thermal purposes

$X(\phi, c)$ is the capacity created between the starting date and the date under consideration

The need to meet energy demand subject to limited capacity leads to three constraints:

Specific needs: $x^{1}(\phi, c)>D(\phi, c)$ for all $\phi$

Substitutable needs: $\sum_{\phi} r(\phi, c) \cdot x^{11}(\phi, c) \geqslant U_{c}$

Capacity constraints: $x^{11}(\phi, c) \leqslant T(\phi, c)+X(\phi, c)$

The objective function of this subsystem is a part of the objective function of the total system and includes the cost of the equipment utilized and the cost of purchasing energy. We should stress the fact that the model integrates the possible choices of various energy forms at the level of final consumption, parallel to the decisions of the energy production system. This representation of substitution between types of energy has nothing to do with price elasticities of consumption, which should be included in every long-term model.

Production subsystem. This submodel connects different subsystems of production (coal, gas, electricity, and oil). The network illustrates the interdependence of the operations and suggests how the installations should be operated to achieve maximum overall production efficiency. The version of the model currently in use also considers low enthalpy geothermal and solar energy for the heating of buildings and the recovery of heat from power plants.

Optimization techniques may be used to choose among:

- Competing energy forms in different domains

- Processes having different capital requirements

- Types of energy to be imported and types of energy which should be produced locally

- Various degrees of energy-related pollution*

\footnotetext{
* The emission of pollutants is controlled at the national level in France. This procedure may seem unreasonable, especially if only a single impact is considered. However, at the national level it is possible to fix thresholds of emissions or of waste materials which may not be exceeded, and which could be defined in such a way that harmful effects would be at an acceptable level in the most polluted geographical sectors ${ }^{23}$.
} 
It is thus possible for the years 1975-2020 to calculate:

- The balance of primary energy

- The national or disaggregated balance of final energy consumption

- The supply of equipment for production and consumption

- The activity of the various plants

- The increase in investments necessary for changes in the energy capacity

- The total cost of fuel imports

- The total expenses from year to year (whether realized or not)

- The emission of the pollutants considered by the model

This type of model, which is by no means intended to replace decision makers, makes it possible to analyze the rigidity of the energy structure, the competition between types of energy in certain domains, and possibly their operating margins. This is the ideal tool for obtaining some idea of the use of a particular type of energy or new technology (for instance, solar energy, geothermal energy, hydrogen, or recovery of heat from power plants) 15-25 years hence*. In the future the model will be revised to study specifically these new energies and techniques; it will also be improved at the level of the consumers by a disaggregation based more on the type of use and other factors**.

This type of model is suitable for analyzing three fundamental elements of the energy policy:

- Energy economy

- Development of national resources

- Sources of imported fuels

on the basis of various criteria: the lowest cost for the community, the least economic dependence on other countries, the reliability of supplies, and finally, the ecological consequences $\dagger$.

\footnotetext{
- Others have a much more normative concept of this type of tool and would like to see it used to calculate the optimal distribution of the various energies and to deduce optimal prices and tariffs (with the help of dual variables) which would guide consumers in the direction best for society as a whole. We prefer to use it as an exploratory tool.

The new version of the model is actually used in a very pragmatic manner in the energy sector of nine countries of the European Economic Community (EEC), adopting a network general enough to be applied to all nine nations. The goal is to calculate simultaneously the annual needs for investments and imports up to 1985 and to trace various energy futures up to 2000-2020. It is likely that there will be a further study of the compatibility of the EEC optimum with the national optima of the nine countries considered.

** Demand was studied from an analytical point of view in the consumption sector in connection with research carried out at the Institute for the Economic and Judicial Study of Energy ${ }^{24}$.

† The criterion of cost minimization limits the degree to which foreign dependence can be reduced through the development of national resources.
} 
To summarize, there are no specific models for individual regions, but there are models covering all French activities in each branch or sector. This is mainly a reflection of the institutional and economic centralization of France.

The most numerous of the existing models are decision models covering one particular sector. Most of these are based on optimization techniques. The only formalized model that exists at the national level is without any real ties with the centers of public or private decision making.

\section{ENVIRONMENTAL ANALYSIS}

Until the beginning of the 1970 s, decisions on energy policy were taken with very little regard for their environmental consequences. There was no systematic evaluation of the effects of increased energy production on the quality of the environment; it was sufficient for a particular industrial installation (e.g., a petroleum refinery) to remain within certain legal limits concerned with health and safety*.

One of the first significant public reactions against energy installations seems to have been the refusal of the local communities to permit the construction of a new refinery** in the Lyon region in July 1971. At about the same time, a "Restricted Council" on energy matters asked the new Ministry for the Protection of Nature and the Environment to prepare a report on energy and the environment. The conclusions of this report formed the basis for the first decisions linking energy and the environment to be made by the Interministerial Action Committee for Nature and the Environment (CIANE) on 20 July 1972.

These decisions were mainly concerned with atmospheric pollution caused by the combustion of hydrocarbons. Since 1972, many other aspects of environmental damage have been considered, and steps taken to remedy them. A number of these are discussed below.

The maximum sulfur content of domestic fuel oil was lowered from $0.7 \%$ to $0.3 \%$ on 1 January 1978 , a measure which was expected to reduce the total emission of sulfur dioxide in France by half. The emission of sulfur dioxide by industrial installations and thermal power plants is still under study-this is particularly important in the Fos-sur-Mer industrial complex, where the problem has become acute.

The maximum lead content of gasoline was reduced from 0.64 to 0.55 grams per liter on $1 \mathrm{January} 1974$, and to 0.45 grams per liter on 1 January 1976. This meant that certain refineries had to be modified to produce petroleum of a different quality.

The procedures governing the authorization of energy facilities are under

\footnotetext{
* The basic regulations governing the operation of industrial plants were passed on 19 December 1917 and 2 August 1961.

** The humorous adjective "baladeuse" (wandering) was applied to the plant.
} 
review-this is especially urgent in the case of petroleum refineries, for which the most recent legislation was passed on 1 April 1939. It is likely that new measures will include the reduction of waste discharge limits, and the compulsory installation of filters to reduce the amount of pollutants discharged into water. The regulations dealing with flared gas will also probably be changed.

The original report paid little attention to nuclear energy, i.e., nuclear-fueled electricity-generating plants, except to conclude that the existing measures were satisfactory. The report stated that transporting radioactive wastes poses no serious problems, that cases of thermal pollution by nuclear power plants should be considered individually, and that it would cost too much to consider laying subterranean electricity lines.

There are already regulations controlling nuclear safety and protection. These deal with both the setting-up and surveillance of nuclear plants (legislation dated 11 December 1963 and 27 March 1973) and the disposal of wastes (legislation dated 11 November 1974 (gaseous wastes), 31 December 1974 (liquid wastes), and 20 June 1976 (radioactive wastes)).

Since 1973 the Higher Council on Nuclear Safety has been responsible for putting this legislation into effect. The Council is composed of representatives of the various public bodies and ministries dealing with nuclear power, a member of the Senate, and various experts in related fields. The decisions of this Council are reflected in the work of the Central Authority for the Safety of Nuclear Plants (SCSIN), which, in conjunction with the Central Radiation Protection Authority (SCPRI), oversees the authorization and safety of nuclear plants, and controls the disposal of waste. The Central Radiation Protection Authority is associated with the Ministry of Public Health.

The very rapid development of nuclear power has been the subject of mounting opposition since 1975. The most controversial issue seems to be the sites chosen for plant construction--people living near the proposed sites are generally strongly opposed to the project. To overcome this difficulty and provide a forum for discussion, the government has introduced a planning procedure with three main stages:

1. A certain number of sites which seem suitable for nuclear power plants are selected. The recommendations are issued by the national electricity company (EDF) at interministerial meetings attended by representatives of the Ministry of Industry, the Ministry for the Protection of Nature and the Environment, and the Delegation for Regional Planning. During these meetings, representatives of the SCSIN, the SCPRI, and the Ministry for the Protection of Nature and the Environment must ensure that the electricity company complies adequately with safety regulations and environmental legislation.

2. The site proposed for the construction of a nuclear plant is then discussed at regional and local leveis. This consultation is organized by the government 
representative in each department and takes the form of debates in regional and departmental assemblies. It is at this stage that the River Basin Agencies present their analysis of the effect of plant construction on the quality of the water in local rivers. The conclusions of an environmental impact study should also be taken into consideration at this point. Legislation passed on 10 July 1976 makes it necessary to carry out this type of study to ensure that large industrial projects do not cause undue damage to flora, fauna, water quality, air quality, or other aspects of the environment. At the conclusion of this second stage, the government decides whether to permit the electricity company to proceed with its proposed plant on the site under consideration.

3. It is then necessary to obtain a "Declaration of Public Utility". This stage is principally administrative. A complete dossier on the project is circulated among all institutions which have displayed interest: local groups, cham-bers of agriculture, commerce, and industry, regional representatives of the Ministry of Industry, and so on. The electricity company is required to respond to all enquiries made by institutions or persons who receive the dossier. The feelings of the local population are also taken into account in a regional inquiry. At the successful conclusion of this stage, the Minister for Industry declares the proposed facilities to be of public utility; this means that private citizens can no longer use their property rights to oppose the construction of the electricity plant.

There have been great advances in integrating environmental analysis with energy planning in France since 1972. Stricter limits have been set and a systematic procedure for evaluating possible sites has been introduced. The Ministry for the Protection of Nature and the Environment plays an important role in this evaluation, and can now challenge the views of the electricity company (EDF) and the Ministry of Industry during regional debates.

However, the legislation passed on 10 July 1976 making an environmental impact study mandatory has not yet achieved its full power. This is very unfortunate, because it is through these impact studies that environmental groups and local associations attempt to counterbalance the arguments of the national electricity company and the Ministry of Industry for increased energy production.

\section{REFERENCES}

1 W.K. Foell (Ed.). Management of Energy/Environment Systems: Methods and Case Studies. Wiley, Chichester, UK, 1979.

2 Economic and Social Council. Rhône-Alpes faces Energy. Workshop, 26 April 1977. (Conseil Economique et Social. Rhöne-Alpes face à l'energie. Workshop, 26 avril 1977.)

3 J.-M. Martin. The energy industries in France. Social Chronicle of France 3 (1975) 35-54. (J.-M. Martin. Les industries de l'énergie en France. Chronique Sociale de France 3 (1975) 35-54.) 
4 V. Dallemagne and P.Y. Maurice. The case of the French energy administration. In The Administrative Implications of a New International Order, Sousse Colloquium, 1976. (V. Dallemagne et P.Y. Maurice. Le cas de l'administration française de l'énergie. Dans Les Implications Administratives d'un Nouvel Ordre International, Sousse Colloquium, 1976.)

5 P. Simonnot. The Nucleocrats. Grenoble, 1978. (P. Simonnot. Les Nucleocrates. Grenoble, 1978.)

6 J. P. Charpentier. A Review of Energy Models. RR-75-35, International Institute for Applied Systems Analysis, Laxenburg, Austria, 1975.

7 H. Maurin. Applied Linear Programming. Technip, Paris, 1967. (H. Maurin. Progammation Linéaire Appliquee. Technip, Paris, 1967.)

8 M. Toromanoff. The investment choices of Gaz de France. French Energy Review 260, 1974. (M. Toromanoff. Le choix des investissements au Gaz de France. Revue Française de l'Energie 260, 1974.)

9 J.P. Charpentier, G. Naudet, and A. Paillot. Simulation Model of the Nuclear Fuel Cycle. Commission for Atomic Energy, Paris, 1973.

10 Department of Nuclear Studies. The SEPTEN Model. Directorate of Equipment of the EDF, Paris, 1972. (Service des Etudes Nucléaires. Model SEPTEN. Direction de l'équipement de l'EDF, Paris, 1972.)

11 J.C. Dodu. Probability Model for the Study of the Security of Supply from a Transport Network. Electricité de France, 1973.

12 D. Finon. Forecasting the consumption of energy and electricity: the methods used in France. In C.J. Cicchetti and W.K. Foell (Eds.), Energy Systems Forecasting, Planning, and Pricing. Proceedings of a French-American Conference, University of Wisconsin-Madison, Madison, Wisconsin, 1975.

13 Y. Pioger. Forecasting power consumption and models for constructing load curves. In C.J. Cicchetti and W.K. Foell (Eds.), Energy Systems Forecasting, Planning, and Pricing. Proceedings of a French-American Conference, University of Wisconsin-Madison, Madison, Wisconsin, 1975.

14 P. Masse and R. Gibrat. Application of linear programming to investments in the electric power industry. Management Science 3, 1957.

15 F. Bessiere. Methods of choosing production equipment at Electricite de France. European Economic Review, 1969.

16 F. Bessiere. Methods of choosing equipment at Electricité de France: development and presentday concepts. In C.J. Cicchetti and W.K. Foell (Eds.), Energy Systems Forecasting, Planning, and Pricing. Proceedings of a French-American Conference, University of WisconsinMadison, Madison, Wisconsin, 1975.

17 D. Levi and D. Saumon. Description of the New National Model of Investment. Internal memo of Electricité de France, 1973.

18 P. Stasi. The rational use of electricity: the contribution of tariffing. In Symposium on the Rationalization of the Consumption of Electrical Energy, Varsovie, 1962.

19 C. Berthomieu. Theory and practice of electricity pricing in France. In C. J. Cicchetti and W.K. Foell (Eds.), Energy Systems Forecasting, Planning, and Pricing. Proceedings of a French-American Conference, Unjversity of Wisconsin-Madison, Madison, Wisconsin, 1975.

$20 \mathrm{M}$. Boiteux and $\mathrm{F}$. Bessiere. The use of aggregate and marginal methods in choosing investments. In J.R. Nelson (Ed.), Optimal Investment Decisions. Prentice-Hall, Englewood Cliffs, New Jersey, 1962.

21 D. Finon. The Energy Model-Optimization of the French Energy Sector Through a Global Approach. Dissertation, Grenoble, 1975.

22 D. Finon. Optimization models for the French energy sector. Energy Policy 2(1974) 136-151.

23 D. Finon. Evaluation of the costs of an environment protection policy on the French energy system. In Energy and Environment, Organization for Economic Cooperation and Develop ment (OECD), Paris, 1974. 
24 B. Chateau and B. Lapillone. The Long-Term Prediction of Energy Demand: Methodological Proposals. National Center for Scientific Research, Paris, 1977. (B. Chateau et B. Lapillone. La Prévision à Long Terme de la Demand d'Energie: Propositions Methodologiques. Centre National de la Recherche Scientifique (CNRS), Paris, 1977.)

\section{APPENDIX 6A}

Administrative, regulatory, and consultative bodies cited in English in the text and their original French titles.

Agency for Energy Conservation

Central Authority for the Safety of

Nuclear Plants

Central Radiation Protection Authority

Commission for Atomic Energy

Commission for the Production of Nuclear Energy

Commission for Solar Energy

Consultative Committee for the Utilization of Energy

Delegation for New Energy Sources

Delegation for Regional Planning

Directorate in Charge of Gas, Electricity, and Coal

Directorate in Charge of Petroleum Products

Economic and Social Council

Energy Commission

General Commissariat for Planning

General Delegation for Energy

Higher Council on Nuclear Safety

Institute for the Economic and Judicial Study of Energy

Interministerial Action Committee for Nature and the Environment

Ministry for the Protection of Nature and the Environment

Ministry of Finance

Ministry of Industry

Ministry of Public Health

River Basin Agencies

Technical Association for Coal Imports
Agence pour les Economies d'Energie

Service Central de Sûreté des Installations Nucléaires (SCSIN)

Service Central de Protection contre les Rayonnements Ionisants (SCPRI)

Commissariat à l'Energie Atomique (CEA)

Commission pour la Production d'Energie d'Origine Nucléaire (PEON)

Commissariat à l'Energie Solaire

Comité Consultative de l'Utilization d'Energie (CCUE)

Délégation aux Energies Nouvelles

Délégation à l'Amènagement du Territoire

Direction du Gas, de l'Electricité et du Charbon (DIGEC)

Direction des Carburants (DICA)

Conseil Economique et Social

Commission de l'Energie

Commissariat Générale au Plan

Délégation Générale à l'Energie

Conseil Supérieur de la Sûreté Nucléaire

Institute Economique et Juridique de l'Energie (IEJE)

Comité Interministériel d'Action pour la Nature et l'Environnement (CIANE)

Ministère Chargé de la Protection de la Nature et de l'Environnement

Ministère des Finances

Ministère de l'Industrie

Ministère de la Santé Publique

Agences de Bassin

Association Technique de l'Importation Charbonnière (ATIC)

(Appendix 6A continued overleaf) 


\section{APPENDIX 6A (continued)}

The French energy industry.

Charbonnages de France (CDF)-Publicly owned coal company

Compagnie Française des Pétroles (CFP)-Largely privately owned petroleum company

Compagnie Nationale du Rhône (CNR)-Electricity company

Electricité de France (EDF)-Publicly owned electricity company

Gaz de France (GDF)--Publicly owned gas transportation and distribution company Houillères de Bassin-Subsidiaries of CDF

Société Nationale Elf-Aquitaine (SNEA)-Largely publicly owned natural gas and petroleum company 


\title{
7 Management and Planning of Energy/Environment Systems in the German Democratic Republic*
}

\author{
Dietmar Ufer** and Peter Hedrich**
}

\section{INTRODUCTION}

In the German Democratic Republic (GDR) the people own the productive equipment in all industries. The fact that the socialist title to the means of production is undivided renders product-line planning possible, but makes it necessary, at the same time, to organize, plan, and control the socialist development according to consistent principles. The energy sector must also be planned; full details of the energy industry of the GDR are given below. First, however, the organizational structure of the energy industries must be outlined so that the planning policy adopted in the GDR may be understood more readily.

The energy economy includes all the utilities and facilities for the production, conversion, transportation, and use of all forms of energy (see Figure 7.1). The energy system penetrates all aspects of public life, and is therefore planned with great care. The Ministry for Coal and Energy $\dagger$ is responsible for working out and implementing the national energy policy, which is based on decisions made by the United Socialist Party of the GDR. The Ministry for Coal and Energy operates according to the principles of the national economic policy accepted by the Council of Ministers and is subordinate to this Council. The structure of the GDR hierarchy is shown in Figure 7.2. The State Planning Commission, also subordinate to the Council of Ministers, is the most important staff organization; it outlines the development strategy for national industry and is therefore important in planning for the energy industry.

\footnotetext{
* This chapter is a revised version of a paper prepared in 1975, and is based on pp. 337-345 and pp. 414-415 of Management of Energy/Enviranment Systems: Methods and Case Studies, edited by W.K. Foell. It appears here with the kind permission of the publisher, John Wiley and Sons.

** Institute of Energetics, Leipzig.

† The names of all administrative, regulatory, and consultative bodies will be cited in English in the text-their original German titles are given in A ppendix 7A.
} 


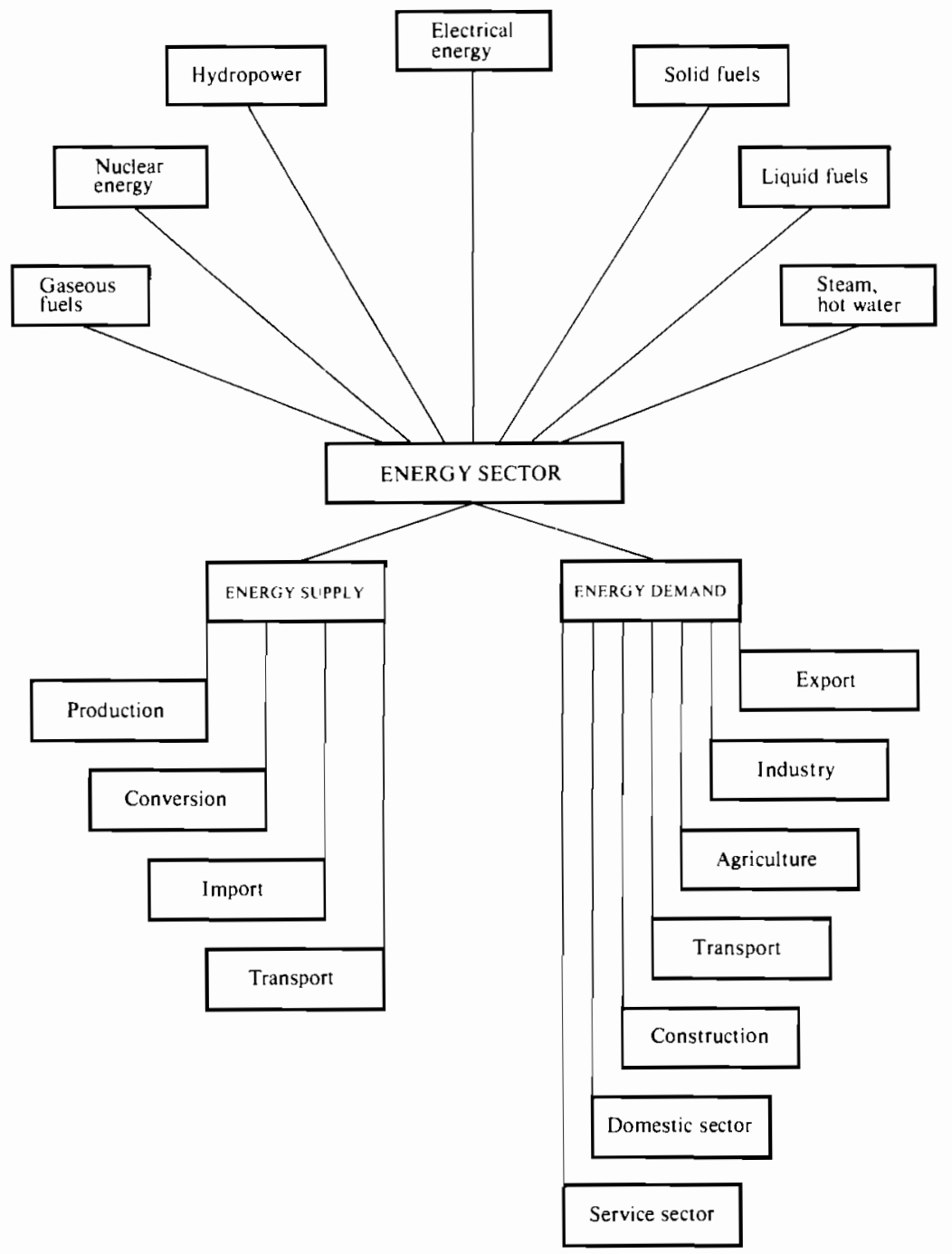

FIGURE 7.1 The energy sector in the GDR.

All of the authorities that regulate the economy are subordinate to the Ministries of Industries. In the case of the Ministry for Coal and Energy, these authorities include the Kombinat* of nuclear power plants, the Kombinat of lignite-fired power plants, the "Black Pump" gas Kombinat, the Senftenberg and Bitterfeld lignite Kombinate and the energy Kombinate of individual districts. The

* A Kombinat is an industrial complex which consists of an integrated set of plants or works involved in the production of a particular type of good. 
Institute of Energetics is also under the direct control of the Ministry for Coal and Energy.

The Ministry for Coal and Energy is therefore responsible for the greatest part of the energy supply. The main exceptions are (1) the primary processing of petroleum, which falls within the sphere of the Ministry for Chemical Industry; (2) the extraction of natural gas, which is controlled by the Ministry for Geology; and (3) the industrial power plants in the various branches of industry, the municipally owned heating plants, and other plants of only local importance. The Ministry for Coal and Energy performs a dual function with regard to development strategies for the energy industry:

- It is responsible for the supply of energy by the economic units under its control, i.e., about $78 \%$ of the total primary energy supply.

- It is responsible for the implementation of rational principles of energy use, and thus for energy policy in all spheres of national industry and social life.

In recent years a system of executive bodies has been set up to put the second of these functions into practice, as follows:

- In all of the Ministries controlling industry, and in the authorities controlling the economy, there are energy specialists supervising the economical use of energy who are also responsible for the development of energy plans. Managers and ministers are of course assumed to take overall responsibility for energy consumption in their own sectors.

- Under the direction of the deputy chairmen of the District Councils, energy commissions have been set up to implement national energy policy in the administrative regions of the GDR. They cooperate closely with the regional energy supply authorities and central government authorities.

The most important instrument for implementing energy policy is the Energy Plan. This plan covers a period of ten years and is developed by all energyintensive large-scale enterprises and facilities in conjunction with the one-year and five-year plans. The plans are coordinated centrally and reported on annually. The implementation of the policy for efficient energy use is supported by a pricing policy for various forms of energy.

It is not possible here to describe the overall planning process in detail, but the main principles of socialist planning, and some phases of long-range energy planning will be outlined. The planning of the energy economy forms part of the overall plan for the national economy. Its goals are the consolidation and steady development of the socialist community, the continual supply of the growing necessities of life, and the fulfillment of the intellectual desires of its members by a continuous and rapid rise in production in all sectors. Since the objectives of the planning process are important to the whole community, the process is controlled centrally 


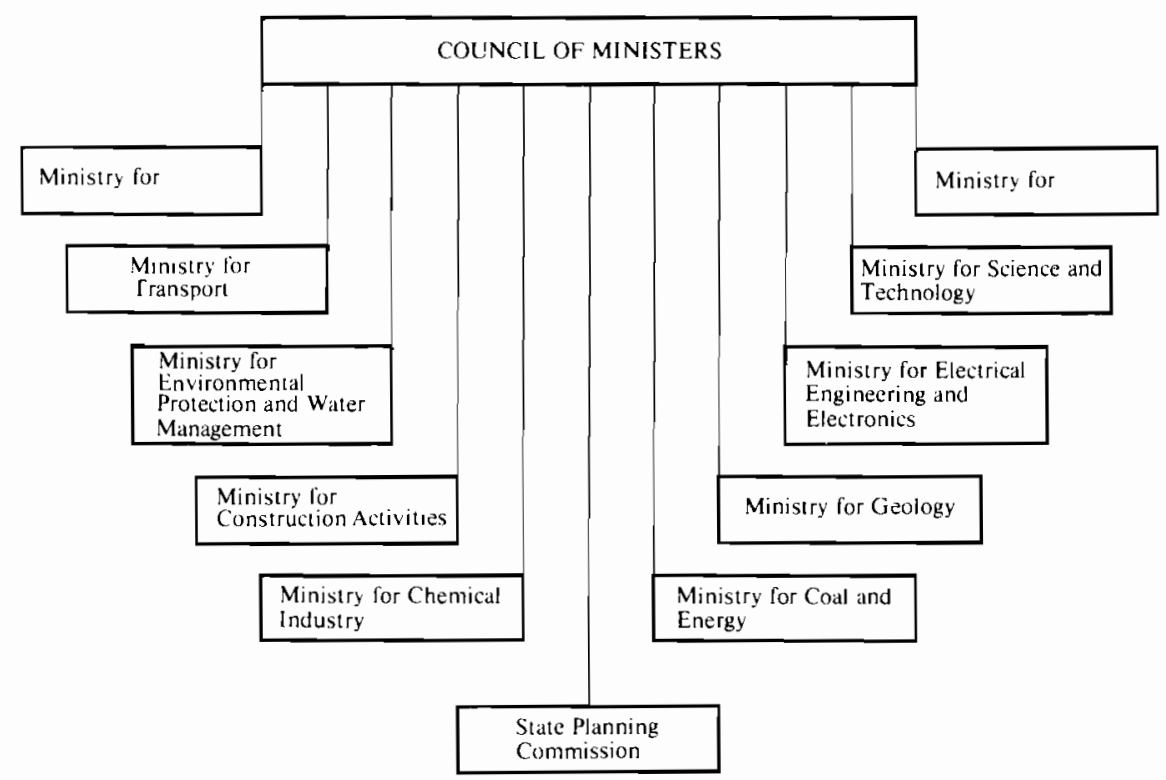

FIGURE 7.2 The structure of the government in the GDR.

by the government. It is reviewed at all levels of the government up to the Enterprise Associations, where the employees participate in the development of Enterprise Plans.

The GDR is a member of the Council of Mutual Economic Assistance (CMEA). The plans of the member countries, especially the five-year plans, are closely coordinated to encourage a steady and rapid development of national industries in all socialist countries.

Planning is carried out and coordinated for different periods: for one year, five years, or for the longer term. Long-term planning usually covers several decades and is especially important in the energy industry. The forecasting of the scientific and technical development of individual processes and procedures within them is given great importance. The planning for one- and five-year periods is based on a central design which is also the basis for energy planning. The methods of longrange planning vary and depend on the economic sphere and time horizon of the analysis, although they are all based on three principles:

- The starting point is the demand, which may be either national or regional depending on the type of planning.

- The main consideration in planning is balancing, i.e., to balance the demand and supply capacity, the economic requirements, and the economic potentials. 
- Planning is carried out with due regard for the essential interrelations between activities.

\section{ANALYSIS OF ENERGY SUPPLY AND DEMAND}

The forecasting of the demand for energy is the starting point for energy planning. The quantity and structure (mix) of the energy supplied depends to a great extent on the development of the national economy and on living standards. The forecasting of energy demand requires both an awareness of future economic trends, especially in the production of energy-intensive products, such as steel, aluminum, and glass, and some information on the trends in specific energy consumption in both production and service sectors. For this purpose, investigations into the technological and economic development of individual processes are carried out in cooperation with experts from the appropriate sectors. In longrange planning (10-20 years ahead), approximately $40 \%$ of the total demand for energy is estimated with the aid of detailed data on specific consumption. This percentage, of course, decreases as the length of the planning period increases. The remaining demand for energy is assessed using methods such as trend and correlation calculations.

The selection of the most effective alternative is of special significance in the long-range planning of energy supply. With the advanced development of production techniques such as those used in the steel or cement industries, the consumer has considerable scope in his choice of technological options. However, the aim is not simply to minimize demand but to choose the option that meets all requirements at the least social cost. This is also in the interests of the national economy.

The isolated calculation of alternatives for individual processes has the drawback that combinations of energy sources which are not feasible for the economy as a whole may result (e.g., an excessive demand for natural gas or another limited energy source). For this reason we have developed a model (substitution optimization model or SOM) that takes into consideration the substitution of different forms of energy. This makes it possible to distribute the forms of energy among the individual processes such that there will be maximum economic benefit not for each process individually but for the system as a whole.

Apart from these detailed techniques for determining the energy consumption associated with individual processes and services, global methods are also used to calculate the total consumption and demand of the different sectors. These methods have priority over mere trend determinations derived from correlations of production, national income, and other economic variables with energy consumption. These global methods should be used in conjunction with consumption data and then verified using other methods. They must also be considered the only methods suitable for the calculation of consumption variables over very long periods.

The total production and importing of all energy forms is calculated in the next phase of the planning process. A production optimization model (POM) is used in 
long-term planning to take into account the interdependence of the various forms of energy. This model is designed to select the combination of energy forms and extraction and conversion systems by which the demand for energy can be met at the lowest social cost. These calculations are supplemented by computations with global methods (methods which handle all energy-related problems), especially for forecasting beyond the year 2000. Ignoring the interdependence of energy forms can lead to inaccurate analysis: a pure trend extrapolation of energy consumption will produce results which are both technologically and economically untenable.

This phase in the planning process is linked with studies of the scientific and technological development of energy production, energy transportation, and power conversion systems. The computations require considerable knowledge about available energy resources, both domestic and foreign; economic variables such as the amount invested, the level of wages, and the prices of imported energy are also important. The process of long-range energy planning has not yet been completed and so it is not possible to calculate the optimum structure of the energy industry. The two phases of the planning process-the calculation of energy demand, and subsequently the calculation of primary energy consumption-must be constantly repeated (Figure 7.3). This is necessary for two reasons:

- The basic data of these two planning phases change, largely due to longrange planning in other sectors of the national economy.

- The results obtained in long-range energy planning must be screened to ensure that they are compatible with national economic planning.

This implies that the results obtained from the production optimization model or other methods used in the first phase of planning may call for investments or manpower for the energy industry which cannot be satisfied by the national economy. It is also possible that the recommended level or structure of energy demand could not be satisfied at some future time, because, for example, the power capacity will not develop rapidly enough or it is impossible to import enough crude oil. Similarly, the level or structure of energy demand suggested in the first phase may be rejected if the resulting environmental damage would contravene the government's environmental protection policy.

The studies performed after the optimization calculation are extremely important in the long-range planning of energy systems. Since a balance between energy/economic requirements is rarely achieved immediately, it is usually necessary to make certain changes before continuing. These may include the use of new systems or techniques with greater efficiency in energy conversion, the use of indigenous rather than imported fuels, or even changing the national economic structure so that certain energy-intensive processes can be excluded. The twostage iteration is then repeated until a suitable solution is reached.

Some parts of the feedback can be simulated using mathematical models, e.g., linking the substitution optimization model with the production optimization 


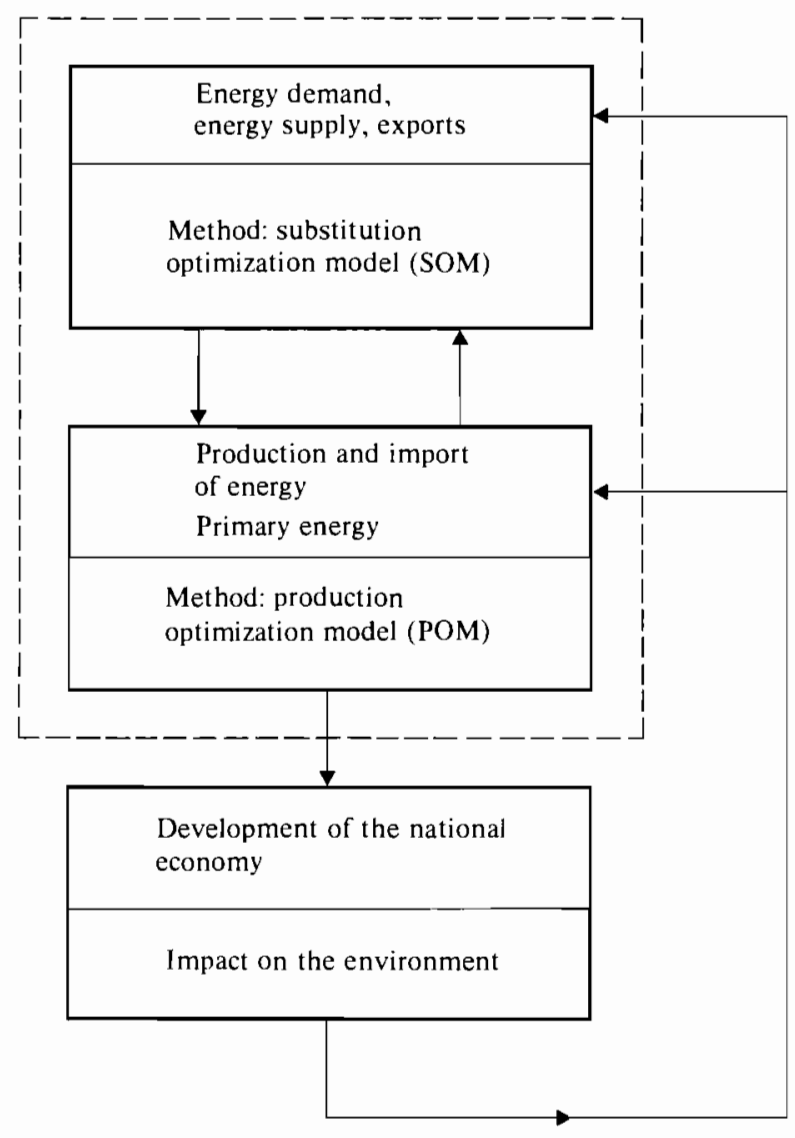

FIGURE 7.3 Energy planning in the GDR.

model. This makes it possible to calculate the optimum distribution of limited fuel resources over the energy sector as a whole.

\section{ENVIRONMENTAL ANALYSIS}

Special attention is paid to the relationship between the energy industry and the environment in the GDR. Measures for environmental protection are systematically included in plans for national economic development as an effective safeguard of social welfare. The Ministry for Environmental Protection and Water Management has issued certain directives concerning environmental protection measures, and these are used to formulate programs (based on socialist legislation) for environmental conservation in industrial districts. A program of this type has already been implemented by the Council of the District of Leipzig.

In 1975, two-thirds of the financial investment in environmental protection was 
spent in industrial districts where energy plants are one of the greatest sources of pollution-19\% of the particulate emissions in the GDR are produced by power plants in the districts of Halle and Cottbus. In the same year, $34 \%$ of the financial investment in environmental protection was spent on controlling air pollution*, $47 \%$ on controlling water pollution (an important problem since the GDR has very few lakes and rivers), $15 \%$ on the utilization and removal of wastes, and $4 \%$ on noise abatement measures. The main aim of environmental protection in the GDR is to produce an immediate improvement in the living conditions of the population.

\section{INTEGRATING DECISION MAKING AND ANALYSIS}

The description of the models given earlier in this chapter emphasized that a stepwise procedure should be followed, not only in developing tools for decision making, but also in their application. This is important from several viewpoints. No given tool used in the process of planning can automatically be generalized to make a practical algorithm, even if it is highly practical and flexible in itself. This sounds contradictory, but it is certainly true with respect to the application of the models. It takes several years of practical experience for those who run the models as well as for those who have to interpret the results, i.e., the decision makers in the government and the authorities leading the individual branches, to find the best way of dealing with mathematical/economic calculation procedures of this kind. And even this statement is valid only if the appropriate level of aggregation has been found. The main problem is the correct interpretation of the results of the models. The decision maker must be able to extract from the results the essential features of the real world, taking into consideration the various aggregations that have been made to obtain the results, and use them to make the right decision.

The application of models and model systems should by no means be understood to imply that, with the help of these modern tools, final plans can be produced by computers. Only by creative processing of the results by experts can plans and other decision fundamentals be determined. These plans are, however, superior in every respect to plans calculated in the conventional way, due to the greater level of balance and optimality as well as to the governing role of the "objective function" which guarantees that subjective elements are eliminated in the planning process. Quite often, teams of scientists or operations research groups are commissioned not only to construct and apply models, but also to define the objective function and interpret the results. However, these are only the first steps. Efficient decision making is only possible when there is close cooperation between decision makers and modelers, and when there is a mutual understanding of the two (necessarily) different ways of viewing the given * See pp. $357-370$ in ref. 1 for a more detailed discussion of air quality management practices in the
GDR. 
problems. By merging the two viewpoints the technique may be seen as something that is to be neither glorified nor rejected, and ways can then be found for its effective use.

The fact that a model system is available does not necessarily mean that one should refrain from using its submodels. On the contrary, a model is only used effectively in solving the specific problems for which it was developed. Depending on the type of problem and its complexity, either the entire system or a subsystem may be more appropriate for finding a solution. Overuse of a model prevents, rather than promotes, successful utilization, since the optimization itself should be done in an optimal way. Although the human element seems to be decreasing with the increasing computerization of data preparation and the use of mathematical evaluation (which is only possible with a computer), the creative capacity of the system is increased through the possibility of man-machine-man dialogue. However, this is only achieved if people understand this process and analyze, evaluate, and give directions at various intermediate stages, or, in other words, behave in a creative controlling manner. This is possible, but only after extensive experience. A simple and efficient coupling algorithm that has been developed in the GDR is especially suitable for this purpose. It may be used to control the collaboration of all branches of the energy sector, and to utilize to the full the advantages of such collaboration. Previous experience has shown that the coupling algorithm may be used to couple systems with quite different structures, if the models are adjusted in a consistent manner. From a mathematicalmethodological point of view, we believe that it is possible to incorporate the energy sectors of several countries into one model system. The main difficulty in doing this lies in the fact that economic conditions differ significantly between individual countries. However, with the progress of economic integration of socialist countries, increasingly favorable conditions for such coupling will appear inside the Council of Mutual Economic Assistance (CMEA). In future work on balancing and optimizing the energy sector, the problem of differing economic conditions should receive special attention.

\section{CONCLUSIONS}

In summary, the methods used in recent years for long-range energy planning in the GDR seem to have been quite successful. The development strategy for the energy industry derived from long-range planning is used as the basis for the fiveyear plans, and the success in fulfilling these plans may be regarded as one of the benefits of good long-range planning.

The main features of the energy system are summarized below.

1. The energy system of the GDR must be considered highly developed, ranking third in Europe in terms of primary energy production (about 44 Gcal per capita), and ninth in Europe in terms of electricity production 
(4000 kWh per capita). The GDR is the largest producer of lignite in the world.

2. Planning of energy intensiveness has been entirely successful. This is demonstrated by the average $4.5 \%$ annual reduction in the intensiveness of energy supplied in recent years.

3. The proportion of high-grade forms of energy supplied has been corrected so that electricity, for example, now constitutes $12 \%$ of the total supply.

4. Policy has been consistently based on maximum utilization of primary energy, especially in the case of lignite. More than $90 \%$ of imported energy comes from socialist countries (mainly from the Soviet Union). The fact that the energy industry was not directly affected by the oil crisis demonstrates the success of this policy.

5. The energy technology is developed according to centralized plans. Modern methods and modern equipment are used-for example, nuclear power stations and 500-MW turbogenerators (developed by the Soviet Union).

We are confident that good results will be obtained by improving joint planning activities with other socialist countries within the Council of Mutual Economic Assistance, and this will receive further emphasis in our future activities.

\section{REFERENCE}

1 L. Hervey and R. Dennis. Air quality management. Appendix C-I in W.K. Foell (Ed.), Management of Energy/Environment Systems: Methods and Case Studies. Wiley, Chichester, UK. 1979.

\section{APPENDIX 7A}

Administrative, regulatory, and consultative bodies cited in English in the text and their original German titles.

Institute of Energetics

Ministry for Chemical Industry

Ministry for Coal and Energy

Ministry for Environmental

Protection and Water Management

Ministry for Geology
Institut für Energetik

Ministerium für Chemische Industrien

Ministerium für Kohle und Energie

Ministerium für Umweltschutz und

Wasserwirtschaft

Ministerium für Geologie 


\title{
8 Management and Planning of Energy/Environment Systems in Hungary
}

\author{
Gÿla Czipper*, György Földvary*, and Edit Unk**
}

\section{INTRODUCTION}

Energy policy can be regarded as a system of technical and economic decisions and processes affecting the energy sector. This includes surveys of energy supply and demand, future planning, investment, industrial development, and research. The system is ultimately concerned with consumption, and its efficiency can be measured only by the extent to which the energy demand at any given time can be met economically and safely.

This report looks first at the modernization of the energy supply system in Hungary, with particular emphasis on the energy needs of settlementst. The evolution of supply strategies is traced from the post- 1945 reliance on solid fossil fuels to the increasing use of liquid hydrocarbons, particularly in the extensive natural gas system and district heating networks. Current attempts to improve the efficiency of the energy system and to implement conservation measures are then discussed. Finally, the place of energy in medium- and long-term physical planning in Hungary is outlined.

\section{THE MODERNIZATION OF THE ENERGY SUPPLY SYSTEM IN HUNGARY}

In 1945, the energy needs of settlements were met predominantly by solid fossil fuels: coal, wood, briquettes, coke, and agricultural wastes. Only a very small

\footnotetext{
* National Board for Power and Fuel Economy, Ministry for Heavy Industry, Budapest.

** VATI Hungarian Institute for Regional Planning and Research, Budapest.

† In this chapter the term "settlements" is used to describe centers which consume energy, i.e., cities, towns, and villages. While this is primarily the residential and public sectors, the term also includes the productive sectors, i.e., industry, commerce, transport, and agriculture.
} 
amount of energy was supplied through pipelines, and only $40 \%$ of the settlements within the country were supplied with electricity. Piped town gas was limited to Budapest and nine other towns; natural gas, a by-product of the modest domestic petroleum industry, was available only in the immediate neighborhood of the oil wells. There was very little use of hydrocarbons by the population, this being limited to a modest amount of propane-butane, and fuel for a small number of privately owned cars. Only a fraction of multistoried residential buildings and a few public buildings had central heating, which was based predominantly on coal or coke.

The reconstruction and development of settlements after 1945 took place in conjunction with large-scale industrialization based on traditional sources of energy. This can be explained largely by an economic policy of national selfsufficiency, the fact that the energy supply was based almost exclusively on coal, and the priority given to meeting industrial energy demands.

The domestic energy supply system and average living conditions were greatly improved by the national electrification program, which was completed in 1963. The early 1950s saw the construction of the first combined heat and power plants, which were designed to provide heating for a large proportion of the population. This was accompanied by the construction of smaller district-heating systems to supply heat to a mixture of industrial, public, and private consumers. This efficient form of coal use exploited the thermodynamic and economic advantages of utilizing heat and electrical energy produced simultaneously.

In the late 1950s and early 1960s the introduction of new economic and energy policies with the twin objectives of a safe and economic energy supply produced a major change in the pattern of energy supply. The new energy policy rested on two major factors:

1. The discovery of considerable deposits of natural gas in Hungary

2. Access to large amounts of imported energy in the form of petroleum and petroleum products, mainly from the USSR

The implementation of the new energy policy, which was designed to alter the energy supply structure, coincided with the first fifteen-year housing plan (1960-1975). Thanks to coordinated planning, the energy supply to the older settlements was improved, while the newest energy technologies were employed in the settlements under construction.

The transformation of the energy supply structure was apparent in the increasing importance of petroleum products and natural gas and the decreasing dependence on solid fuels. However, the change in the structure of the energy supplied to the settlements was not as great as the change in that supplied to industry, transport, and agriculture. The settlements sector consists largely of households, i.e., a high number of relatively scattered, small, individual consumers. The climatic conditions in Hungary are such that energy required for 
heating purposes peaks in only relatively few hours per year. This pattern of demand characterizes the energy needs of household units, commercial establishments, and other public consumers.

There is a sharp contrast between the use of new energy sources in the many agricultural and recreational settlements and the relatively few industrial and urban settlements. The low population density in agricultural and recreational settlements makes the use of piped thermal energy (natural gas, town gas, or district heating) uneconomical. The energy supply system chosen also depends on whether the aim is to modernize old districts and buildings, to provide an adequate supply of energy for new buildings, or, occasionally, to provide energy for a completely new settlement.

\section{The natural gas program}

The exploitation of domestic natural gas reserves was one of the most important factors in the transformation of energy supply systems in Hungary. In general, natural gas has been utilized not by locating industries near the sources of natural gas, but by piping the gas to industrial areas. The costs of piping gas are not too high because of the relatively small size of Hungary*. The long-distance pipelines start from the major natural gas fields in the east and southeast of the country and lead to the industrial districts in the east and northeast, as well as to the capital city, Budapest, which contains most of the nation's industry and one-fifth of the total population. Long-distance pipelines are currently being built from the gas fields to industrial regions in the center and west of the country.

The network of gas pipelines was built up according to the capacities of industrial plants and their requirements for large volumes of gas. Industries using furnaces and high-temperature technologies requiring sulfur-free fuels (the chemical, metallurgical, and building materials industries) were the first to be attached to the natural gas network. In these cases the demands of the manufacturing processes coincided with the advantages of natural gas. Plants producing coal-based low-grade gases were closed down and the organic chemical industry started to use a petrochemical base. These measures meant that energy was used more efficiently and that air pollution was reduced. Natural gas was also increasingly used in residential districts near big industrial plants for space heating, water heating, and cooking.

The existence of settlements already supplied with town gas provided an impetus for the expansion of the natural gas network. Petrol-cracking plants were established as the first stage in a program of modernization and expansion in the gas-producing industry. These plants made it possible for an increasing number of dwellings and public buildings to be heated with piped gas. The closure of a number of plants producing conventional coal-based town gas and the switch

* The area of Hungary is $93,000 \mathrm{~km}^{2}$. Nowhere does the breadth of the country exceed $500 \mathrm{~km}$. 
from this gas to natural gas (which has a higher calorific value) have brought many advantages. However, town gas will continue to be used in settlements for which a natural gas supply is not an economic proposition.

Another major impetus for the development of natural gas supply networks was the proximity of the natural gas resources to the settlements. Piped gas was used in settlements near the sources of natural gas as a matter of course. At the same time, pipelines leading to the big industrial centers passed through a whole series of smaller settlements, so that piped natural gas could be used in the residential and public sectors of these communities.

Table 8.1 shows the amount of gas consumed by the Hungarian population in the years between 1960 and 1975, while Table 8.2 gives the number of domestic consumers supplied with gas over the same period.

The government has recently made the use of natural gas a component of national economic policy by implementing a "central development program for natural gas use". Earlier moderate expenditure on supplying gas to the industrial sector brought relatively quick returns. At the present time, however, the government is seeking to supply natural gas to both residential and public sectors, and this ambitious project demands much higher investment.

A number of steps are involved in the scheme: construction of an extensive and, consequently, very costly gas distribution network; introduction of measures designed to reduce the amount of energy used for heating purposes; provision for the storage capacity required to meet peak demand; and supply of modern heating appliances and metering and regulating equipment for large numbers of small consumers.

The volume of gas supplied is limited by the size of the fields and the capacity of the pipelines; this makes it important to economize on energy use. Measures must be taken to ensure the supply of piped gas to small consumers; this is often achieved by imposing restrictions on the larger, industrial consumers (such as boiler plants) during periods of peak demand, or by requiring them to use alternative fuels. Such measures tend to protect the interests of the settlements as far as energy supply and environmental protection are concerned.

One of the most important components of the "natural gas program" concerns the capital of Hungary, Budapest. It is hoped to supply private dwellings and public facilities with natural gas, partly through conversion to natural gas in existing town gas networks, and partly through the extension of the distribution network to new consumers. The program has a number of aims:

- Household units in old multistoried buildings with individual stove heating will have kitchens and bathrooms supplied to a large extent with piped gas (an occasional alternative being electricity).

- Household units may also have individual gas heating, using either devices installed in old tile stoves or gas convectors. This method of heating will be used frequently in houses in the more sparsely populated garden suburbs of the town. 


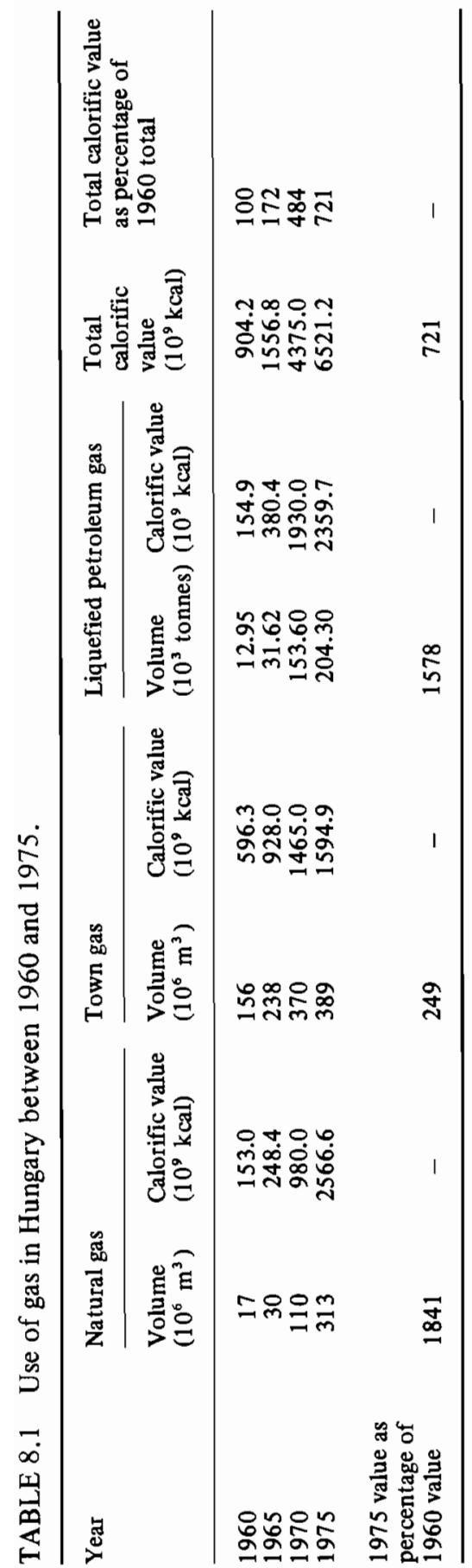


TABLE 8.2 Number of household units (thousands) using gas between 1960 and 1975.

\begin{tabular}{|c|c|c|c|c|}
\hline & 1960 & 1965 & 1970 & 1975 \\
\hline $\begin{array}{l}\text { No. of household units using natural gas } \\
\text { No. of household units using town gas } \\
\text { No. of household units using liquefied petroleum }\end{array}$ & $\begin{array}{r}8.6 \\
293.0\end{array}$ & $\begin{array}{r}22.1 \\
376.0\end{array}$ & $\begin{array}{l}131.0 \\
393.3\end{array}$ & $\begin{array}{l}350.0 \\
357.0\end{array}$ \\
\hline $\begin{array}{l}\text { gas } \\
\text { Total no. of household units supplied with gas } \\
\text { (Percentage of } 1960 \text { value) } \\
\text { (Percentage of total number of household units) }\end{array}$ & $\begin{array}{l}128.8 \\
430.4 \\
(100) \\
(15.0)\end{array}$ & $\begin{array}{l}284.0 \\
682.1 \\
(158) \\
(23.0)\end{array}$ & $\begin{array}{l}1291.0 \\
1815.3 \\
(422) \\
(57.0)\end{array}$ & $\begin{array}{l}1623.0 \\
2330.0 \\
(541) \\
(65.9)\end{array}$ \\
\hline $\begin{array}{l}\text { No. of household units heated with natural gas } \\
\text { No. of household units heated with town gas } \\
\text { Total no. of household units heated with gas } \\
\text { (Percentage of } 1960 \text { value) } \\
\text { (Percentage of household units supplied with } \\
\text { piped gas) }\end{array}$ & $\begin{array}{r}7.6 \\
0.1 \\
7.7 \\
(100) \\
(2.6)\end{array}$ & $\begin{array}{r}16.6 \\
10.6 \\
27.2 \\
(354) \\
(6.8)\end{array}$ & $\begin{array}{r}70.3 \\
87.0 \\
157.3 \\
(2045) \\
(30.0)\end{array}$ & $\begin{array}{r}174.5 \\
131.3 \\
305.8 \\
(3971) \\
(43.2)\end{array}$ \\
\hline
\end{tabular}

- Gas-fired boilers will be used in multistoried buildings with central heating (these are generally old or renovated buildings in the old parts of the town or newly constructed buildings in the city center). These boilers are often placed in the basement or, more recently, in the space just under the roof of the building. In old buildings this method of heating usually replaces coal or coke, thus reducing the need to transport solid fuels and improving air quality. The so-called "block heating" methods are also used for several adjacent buildings, and this represents the simplest version of a natural-gasbased district heating system.

- Most large-scale residential developments (built largely of prefabricated elements) will be supplied with district heating from power stations or heating plants, and will obtain hot water from the same source. The district heating plants generally employ natural gas, either exclusively or combined with oil. Natural gas is often used directly in the kitchen; electricity is employed in some cases in order to cut down investment costs and minimize air pollution.

Natural gas may be used in much the same way in country towns linked to the natural gas system as it is in Budapest. However, the restrictions connected with environmental protection are less severe in country towns than in the capital.

The natural gas program was only one of the energy supply strategies used in the development of settlements during the past fifteen years (more than one million housing units were constructed in this period). There are two competing methods of domestic heating in Hungary: individual hydrocarbon-based supply for each housing unit, and district heating. The advantages and disadvantages of these alternatives are summarized below. 


\section{Liquid petroleum products and liquefied petroleum gas}

Liquid petroleum products and bottled liquefied petroleum gas were used without geographical restrictions in the modernization of the energy supply system. These fuels are found in areas in which they have not been superseded by natural gas or where there has not been a stable market for coal or any other conventional fossil fuel (e.g., wood). Conventional fossil fuels have been popular sources of energy for a long time, due to their low prices, the large numbers of ovens, kitchen stoves, and boilers in general use, and also to the habits of the consumer.

The use of liquid petroleum products and liquefied petroleum gas spread quickly, primarily in newly constructed or renovated dwellings where no piped heat supply was possible. Interest in space heating and water heating based on oil and liquefied petroleum gas (propane-butane) has grown because of the convenience of these fuels in transport and storage, and their high energy efficiency and environmental safety - despite their relatively high prices. The number of oil stoves used in the residential and public sectors has grown to 2.2 million (1.5 million units were sold between 1970 and 1975). The penetration of these fuels started in rural settlements and the sparsely populated outskirts of towns. Together with electrification, these fuels helped to improve the standard of living of the rural population.

The growing availability of petroleum products, including gasoline and diesel fuels for internal combustion engines, opened the way for rapid development of road traffic. Between 1970 and 1975 the number of cars grew from 190,000 to 506,000 , and the number of motorcycles increased by 130,000 . This created new demands for better road systems both within and between settlements, and increased the consumption of petroleum products.

\section{District heating}

District heating represents an independent and partly competitive method of providing heat in Hungarian settlements. The enormous difficulties facing the building industry in the first 15-year housing program could be overcome efficiently and quickly only by applying entirely new concepts in building technology. These innovations included the construction of very large housing developments and the use of prefabricated components. Because of the poor insulation in such buildings, it is necessary to provide a uniform, basically continuous, and therefore reasonably centralized, heating system. Variants of individual gas heating techniques, such as gas convectors, are not suitable for multistoried buildings, for a number of reasons. District heating, however, has been shown to be a convenient method for meeting space- and water-heating requirements in large, prefabricated housing developments. As a consequence, district heating from oil-based heating plants (which produce both heat and electricity) is considered to be one of the most desirable methods of meeting heat 
TABLE 8.3 Use of district heating in Hungary between 1965 and 1975 .

\begin{tabular}{|c|c|c|c|}
\hline Use of district heating & 1965 & 1970 & 1975 \\
\hline $\begin{array}{l}\text { No. of residential buildings provided with } \\
\text { district heating }\end{array}$ & 2,375 & 5,293 & 9,162 \\
\hline No. of household units provided with & & & \\
\hline $\begin{array}{l}\text { district heating } \\
\text { (Percentage of all dwellings) }\end{array}$ & $\begin{array}{l}45,720 \\
(1.5)\end{array}$ & $\begin{array}{l}109,388 \\
(3.4)\end{array}$ & $\begin{array}{l}252,399 \\
(7.1)\end{array}$ \\
\hline $\begin{array}{l}\text { No. of household units supplied with warm water } \\
\text { (Percentage of all household units) }\end{array}$ & $\overline{(-)}$ & $\begin{array}{l}75,158 \\
(2.3)\end{array}$ & $\begin{array}{l}209,009 \\
(6.2)\end{array}$ \\
\hline
\end{tabular}

requirements in Hungary today. The data in Table 8.3 show the increasing number of housing units and residential buildings provided with district heating.

District heating is especially important in Budapest, owing to the large-scale, high-density construction of dwellings and the constraints of environmental protection. The number of household units with district heating in the capital grew from 50,000 in 1970 to 105,000 in 1975 ; this is more than $15 \%$ of the total number of household units in Budapest.

At first the competition between district heating and individual methods of heat supply increased with the growing availability of petroleum and petroleum products, which contrasted sharply with the high investment costs associated with district heating. However, the rise in the world market price of petroleum underscored the importance of high-efficiency, combined production of heat and electricity for both heating and industrial purposes. Nevertheless, the high capital costs involved in constructing energy plants and energy distribution pipelines make it necessary to examine local conditions very carefully before deciding which is the most economical heating system for each particular case.

TABLE 8.4 Forms of energy used by the Hungarian population between 1960 and 1975 .

\begin{tabular}{lrrrr}
\hline Energy form & \multicolumn{3}{c}{ Percentage of total energy use } \\
\cline { 2 - 5 } & \multicolumn{1}{c}{1960} & 1965 & 1970 & 1975 \\
\hline Solid fuels (coal, wood fuels) & 93.6 & 90.0 & 73.9 & 49.9 \\
Liquid fuels (petroleum products) & 0.9 & 1.1 & 6.0 & 15.3 \\
Motor fuels (ga soline) & 1.2 & 2.2 & 3.8 & 9.2 \\
Gaseous fuels (natural gas, town gas, LPG) & 2.7 & 3.7 & 9.5 & 13.0 \\
Heat (district heating) & - & 0.7 & 3.3 & 7.3 \\
Electrical energy & 1.6 & 2.3 & 2.5 & 5.3 \\
Total energy use (\%) & 100.0 & 100.0 & 100.0 & 100.0 \\
Total energy use (1012 kcal) & 30.2 & 37.7 & 44.7 & 51.6 \\
Percentage of 1960 total energy use & 100.0 & 124.8 & 148.0 & 170.8 \\
\hline
\end{tabular}


Table 8.4 shows the changes in the forms of energy used by the population in the period between 1960 and 1975 . Note that the total energy consumption grew by more than $70 \%$ during these 15 years.

\section{IMPROVING LONG-TERM ENERGY SUPPLY AND USE}

The considerable increases in the world market price of oil in 1973-1974 affected Hungary's energy economy, and improvements in efficiency became necessary in every area of energy use. Measures were taken to moderate energy needs, reduce energy losses, and increase energy conservation while meeting the essential needs of the settlements. The interests of small consumers, i.e., the residential and public sectors, were protected; it was regarded as important not to reverse the progress already made in providing a convenient supply of energy for the public.

These objectives mean that the modernization of the energy supply system must rely less on the increased use of hydrocarbons, and the use of light petroleum products for heating purposes will be restricted*. It is also planned to bring useful energy demands into line with real energy requirements through the careful choice of energy supply systems, introducing new technical measures to reduce losses.

Because of the growing national dependence on energy imports, efforts are being made to increase the efficient use of domestic energy sources. With this end in view, existing coal consumption will be maintained** and coal-based district heating systems will be developed to meet the demands of the residential, public, and industrial sectors simultaneously. For the same reasons, obsolete condensing power stations may be converted into heat-generating power plants if they are in appropriate locations, bearing in mind environmental requirements and the difficulty of transporting heat over long distances.

It is planned to increase the use of Hungary's geothermal energy resources for heating dwellings and communal facilities, and for agricultural purposest. This represents the only "alternative" energy source planned to be used in Hungary. Geothermal energy may be found in a usable form under nearly $70 \%$ of Hungarian territory: thermal springs at temperatures varying between 110 and $130^{\circ} \mathrm{C}$ originate at least 2000 meters below ground level and thermal water at temperatures of $80-90^{\circ} \mathrm{C}$ at depths of $1500-2000$ meters. It is not planned to supply thermal energy from nuclear power plants in the near futureई.

\footnotetext{
* This includes restricting the trade in oil-fired heating appliances.

** This implies the continued supply of good quality coal to the population, the production of modern coal-fired stoves and small boilers for heating household units, and larger boilers for centrally heated buildings.

+ Greenhouses, driers, etc.

$\S$ The Paks nuclear park is presently under construction. It is planned that two plants, with a combined capacity of $880 \mathrm{MWe}$, will be in operation by the end of 1982 . Additional plants will be added to the park during the rest of the 1980 s.
} 
The possible use of solar energy in Hungary is still under investigation. The intensity of solar radiation measured on a horizontal plane is about $140 \mathrm{~W} / \mathrm{m}^{2}$, averaged over a year; the amount of energy radiated ranges from 1160 to $1280 \mathrm{kWh} / \mathrm{m}^{2}$ per year, depending on the number of hours of sunshine. Largescale use of solar power is not expected before the year 2000 .

In the more immediate future, the efficiency of energy supply and use will be improved by means of a comprehensive energy conservation program affecting the residential and public sectors. The following measures have already been adopted or are being planned:

- The use of gasoline, diesel, and light fuel oil will increase only in those areas where they cannot be replaced by another type of energy, or where their use can be justified on the grounds of maintaining the standard of living or protecting the environment.

- Industrial consumption of light fuel oil will be reduced in order to improve the supply of light fuel oil to the population. Efforts will be made to switch to natural gas or heavy fuel oil in the industrial sector.

- State loans will be used to support investments resulting in energy conservation. This policy, which has existed for more than two decades, has now been applied to the public sector in an attempt to save light fuel oil.

- The regulations regarding the design and construction of buildings are being revised with the objective of reducing heat losses by better insulation and more up-to-date design standards, particularly in the residential sector.

- The regulations controlling the operation of district heating systems will be revised in order to eliminate waste; heat consumption will be metered and regulated so that charges for heating can be linked to actual consumption.

- The possibility of using liquefied natural gas for mass urban transport is being examined.

- State support will be available to provincial consumers who wish to utilize local energy resources (e.g., geothermal energy or small isolated natural gas reserves) for heating.

- Energy consumption in the residential and public sectors depends largely on the efficiency, ease of regulation, and automation of energy-consuming appliances. Domestic industrial enterprises will therefore be encouraged to develop and widen the range of power-driven machines, appliances, and instruments, to introduce modern imported equipment, and to take advantage of possible international cooperation.

- A new licensing system is being prepared to deal with the production, importing, and sales of energy installations, with the aim of conserving energy. Extensive information campaigns are planned, to encourage the acceptance of energy conservation measures in the residential and public sectors. 
Most of the energy conservation methods outlined above should be put into effect in the course of the 1975-1990 housing program. This program calls for the construction of nearly 1.5 million new household units, of which more than 900,000 will be built in 87 towns. Some $60 \%$ of the total number of units will be in prefabricated multistoried buildings. The construction of housing in concentrated settlements makes it possible to implement policies developed by the central government.

The long-term objectives of regional and local development are worked out through close cooperation between national authorities and local bodies. The Ministry for Building and Urban Development, which is responsible for the development of settlements and housing, and the Ministry for Heavy Industry, which is responsible for energy supply, together with city and county councils and local energy suppliers, call upon professional planners to work out compatible regional and local development plans. These plans provide the basis for mediumterm energy supply strategies, from which the principles guiding the energy supply of a given area can be determined.

These strategies are particularly important today, when more effective use of energy and increased energy conservation are vital. The development of these policies reflects the systems approach as applied to a modern energy system. Factors that must be considered in conjunction with the long-term social and economic aims of the nation are the potential for the production and purchase of energy, trends in energy technology, and the need to provide a safe and economical supply of energy. National energy policies will always be implemented with regard for local conditions and the interests of the population.

\section{ENERGY SYSTEMS AND SPATIO-PHYSICAL PLANNING IN HUNGARY}

Long-range energy planning in Hungary is closely tied to physical planning. A 30year National Physical Plan with input from all sectors has recently been prepared at the request of the national government. The plan considers the regional energy demands for various activities, the land required for energy supply systems, and the implications of developments in the energy sector. It is hoped to coordinate the development of all sectors at the regional level and ultimately to create better living conditions.

An analysis of existing settlement patterns was carried out in 1978, and preliminary ideas for future development are now being examined. These are based on the growth of human settlements, and take into account the related productive and nonproductive activities of each region and the need to provide sufficient technical infrastructure in each area. Maps showing the existing pattern of settlement and proposed centers of development have been drawn up at the VATI 


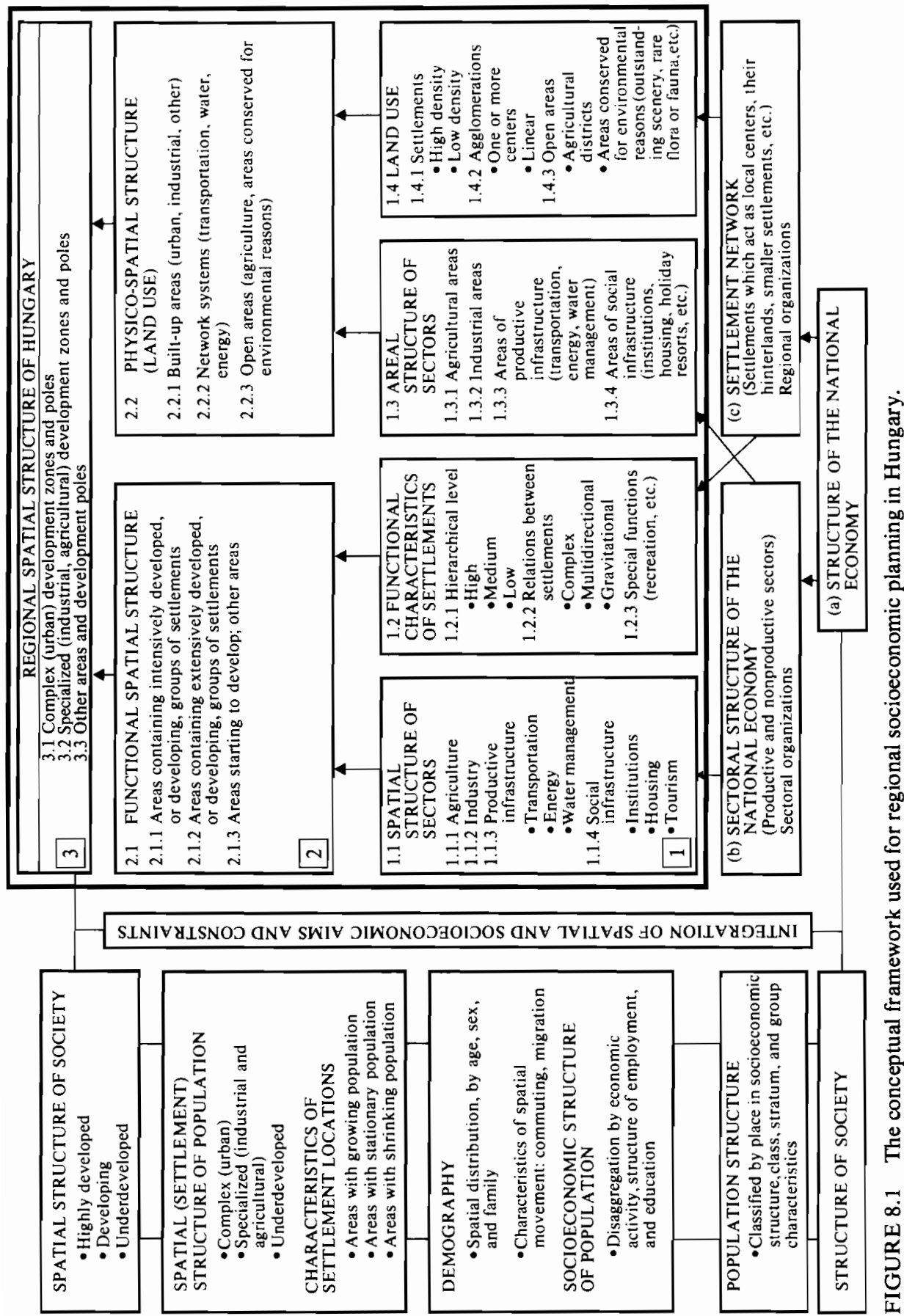


Hungarian Institute for Regional Planning and Research*. Settlements and districts which are expected to become more densely populated are distinguished from settlements which are expected to expand outwards. These maps are based on the results of numerous research projects ${ }^{1-6}$. The broad socioeconomic objectives of the nation and the regularities of regional development suggest that the concentration of centers of production will continue in the future and that patterns of development will become more complex. Of course, the pattern of settlement will also depend on the dynamics of development, economic factors, and constraints such as environmental protection.

The conceptual framework used for planning is illustrated in Figure 8.1. Important socioeconomic variables and characteristics of different types of settlements are listed on the left-hand side of the figure, while the spatial structure of the country is analyzed on three levels on the right. Level 1 provides a detailed analysis of the productive and nonproductive sectors of the economy and their associated requirements for land. The production and distribution of energy are considered under the heading "productive infrastructure" (1.1.3 and 1.3.3). Levels 2 and 3 analyze the spatial structure of Hungary at a higher level of aggregation.

Figure 8.2 shows the way in which energy planning is linked to the economic and physical development of the country. Box (b) indicates the factors which determine the structure of the energy sector; these include the availability of energy resources, the size of future demand, import policies, and the need to construct energy production and distribution facilities. On Level 1, energy planning must consider the supply requirements of the various economic sectors and the physical structure of the settlements; it must also take into consideration the location of energy resources and facilities. On Levels 2 and 3, energy planning must be compatible with existing patterns of settlement, proposed development, and prospective land use. The proposals made for the energy sector are then reviewed by all other sectors, and their comments and criticisms incorporated into the plan.

For a planning horizon of up to 15 years, the total energy requirements are estimated by aggregating the energy requirements of the individual sectors. However, for longer-term planning (the next 30 years), a completely different approach is often adopted. Total demand and the constraints on supply are taken as the starting point, and possible developments in individual sectors are then analyzed. The ability of the energy sector to meet the total requirement is assessed, and information about estimated demand is incorporated into the energy plan.

\section{Regional planning: spatio-physical planning}

Spatio-physical planning involves the disaggregation of the country into 234

* Studies carried out at the VATI Hungarian Institute for Regional Planning and Research include topics such as the following: General Regularities in Regional Development; Regions Undergoing Dynamic Development in Hungary; Groups of Settlements Limited by the Concentration of Productive Forces; Perspectives on Urbanization. 


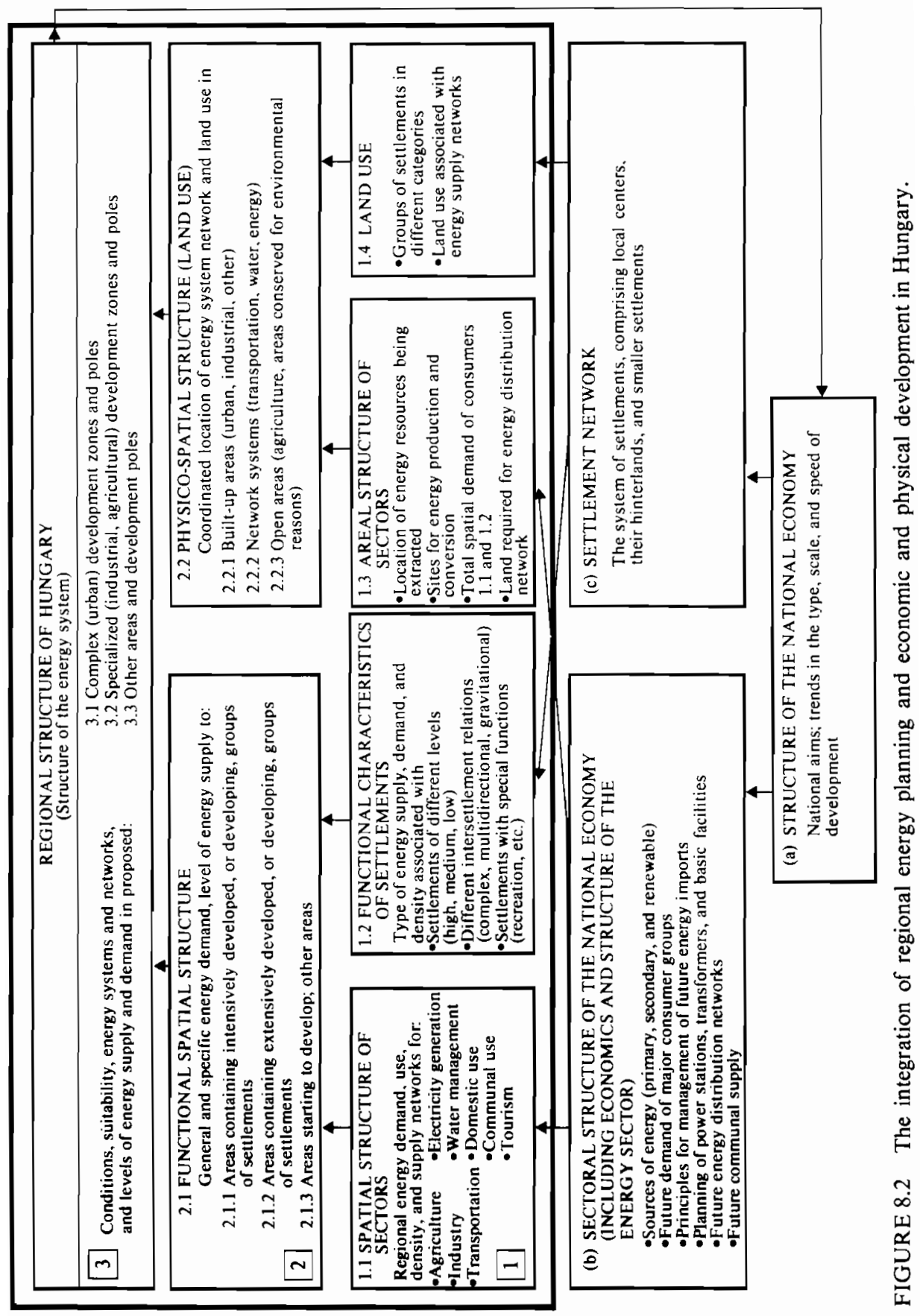


microdistricts; the centers of these districts are towns or larger villages. The socioeconomic potential of each district is then analyzed, taking into account its geographical position and importance to the economy, and evaluating its technical resources. This results in the categorization of the districts in terms of measured and estimated values; these values reveal inequalities in spatial development, some of which will never disappear completely.

The success and continuity of regional planning depend to a large extent on the availability of a system which allows spatial information to be coordinated before decisions about the differential development of the districts are taken.

\section{Analysis of regional energy demand}

The method used to estimate regional energy demand for planning purposes differs from the traditional sectoral method in that the regional energy structure is considered to be only one component of a complex socioeconomic and environmental system.

The analysis of regional energy demand begins with the classification of the districts in terms of the values of various indices. Eight of the indices refer to the occurrence of natural energy resources in the districts or connections with energy supply networks, and five refer to the energy supply to household units. These parameters and their maximum values are given in Appendix 8A.

Three main groups emerge on the basis of this classification: districts which are "average", "above average", or "below average" in terms of their energy development. The range of parameter values included in each group is listed in Appendix $8 \mathrm{~A}$, and will change over time. Figure 8.3 indicates the current status of all districts; it can be seen that more regions are "below average" than "above average" in terms of energy supply.

This method of estimation assumes a certain situation to be "desirable" and demonstrates the shortcomings of the present regime. The aim of this regional analysis is therefore to reduce inequality among the regions while bearing in mind the socioeconomic and environmental aspects of change.

National requirements are evaluated, information is gathered, and programs for the development of the major sectors are designed on the basis of long-term planning. Regional energy planners have access to official information and there is mutual feedback; this ensures that the best sites are chosen for recreation areas, medium-sized production centers, and settlement-network systems. At the same time it is possible to analyze regional energy supply and demand, and the existing and proposed distribution networks. Figure 8.4 shows the result of proposed extensions to the energy supply networks-many more districts will have an "above average" supply of energy by the year 2010. Energy planning is one of the fundamental components of the regional development program.

There are many ways of developing each district. The method of development is generally decided in the third phase of the planning procedure, when the needs of each district are balanced within the national energy plan. 

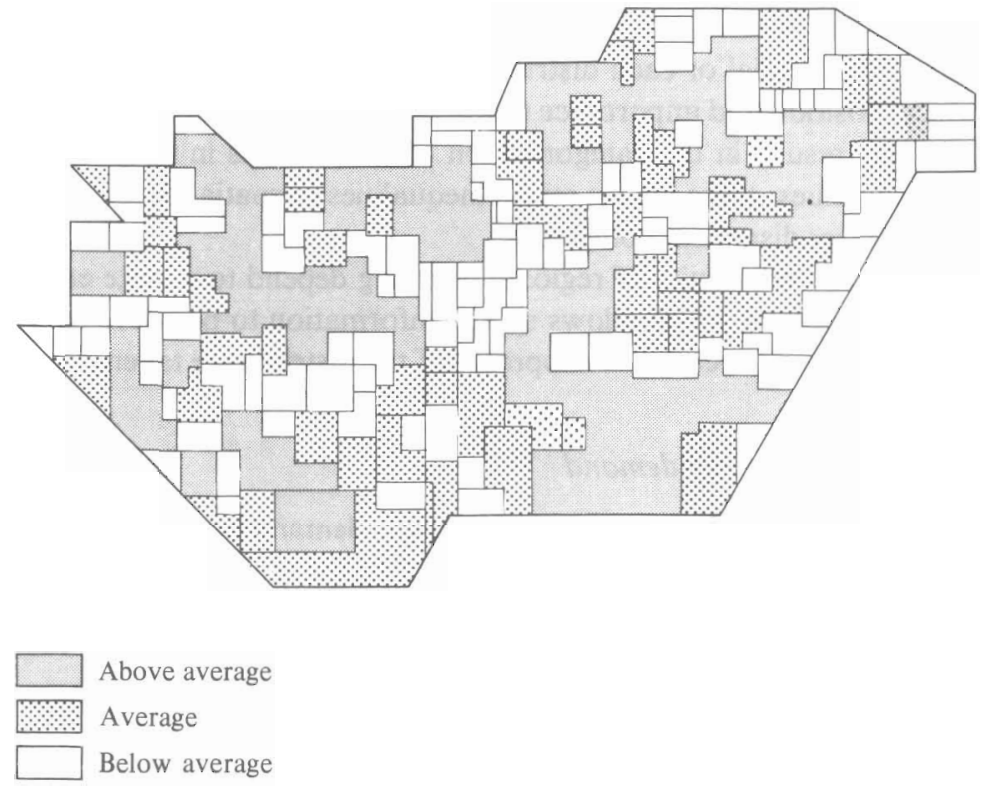

FIGURE 8.3 The present level of energy supply in the various districts of Hungary.
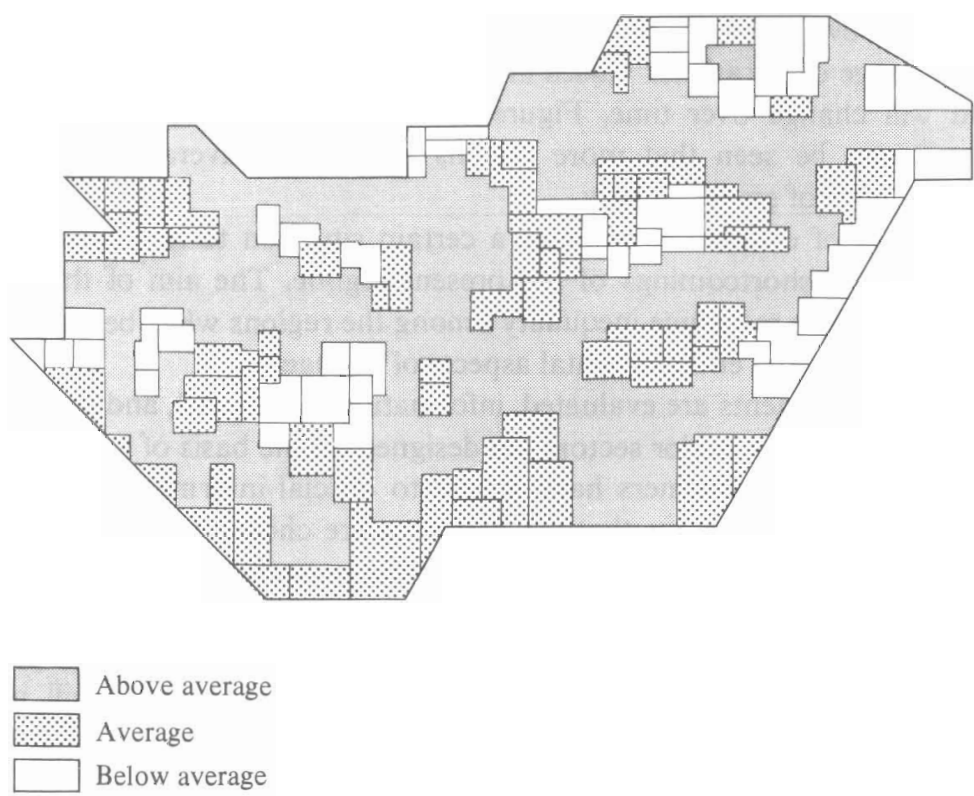

FIGURE 8.4 The levels of energy supply proposed for the year 2010. 
Energy supply analysis

Hungary finds it necessary to import large quantities of energy, largely because local production does not provide the required mixture of energy sources in sufficient quantities to meet demand. A number of different scenarios suggest that imports will provide $53-64 \%$ of the energy consumed annually up to the year 2000.

There are three main energy supply options, which involve differences in sectoral development: the "coal" version, the "sectoral optimization" mixed version, and the "technical optimization" environmental protection version (see Table 8.5). Each of these scenarios depends on increased international cooperation over the organization of energy systems, including the development of larger international networks within Europe.

The regional development program will lead to the establishment of national electricity, hydrocarbon (oil and gas), and coal networks within certain zones. These zones will be preserved as open spaces until the networks are built.

Realistic estimates show that the differences in regional energy supply will decrease in the future; by about 2010 , no more than $22 \%$ of the total area should remain underdeveloped.

The energy supply systems of the public and residential sectors are to be examined with a view to associating each settlement with one of the three supply strategies discussed above. Table 8.5 outlines the three scenarios for providing heat in Hungarian settlements, judging each in terms of availability, location, price and cost, convenience, reliability, flexibility, environmental effects, and permanence. The "technical optimization" version proves to be best in terms of the sum of the above parameters, although it is also the most expensive in terms of the "price and cost" indicator.

\section{Protection and management of the human environment}

Environmental protection is taken into consideration in the National Physical Plan at all levels (see Figure 8.1). Development must be combined with the protection of the soil, water, and air; there are national standards regulating the pollution that may be caused by various sectors (e.g., the energy industry, other industries, traffic, the public sector, residential heating, agrochemicals, etc.). Figure 8.5 shows regions which have been selected for environmental protection and improvement.

\section{Integration of decision making and analysis}

Spatio-physical planning incorporates the regional consequences of changes in all sectors, and is theoretically in harmony with economic planning and decision making at each level. 
TABLE 8.5 Three different scenarios for heating in Hungary. Each characteristic

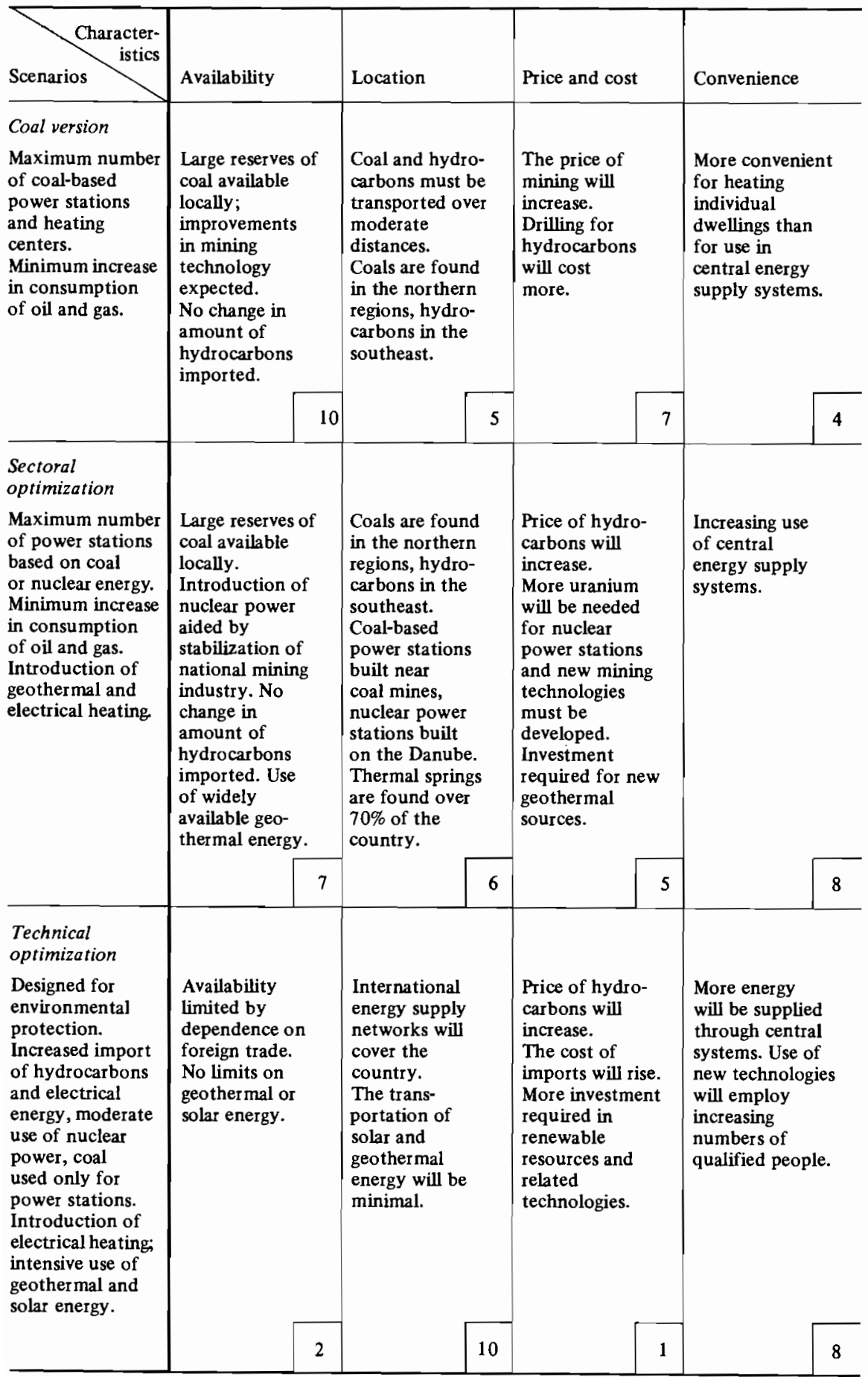


is evaluated in terms of an index which may vary between 0 and 10 .

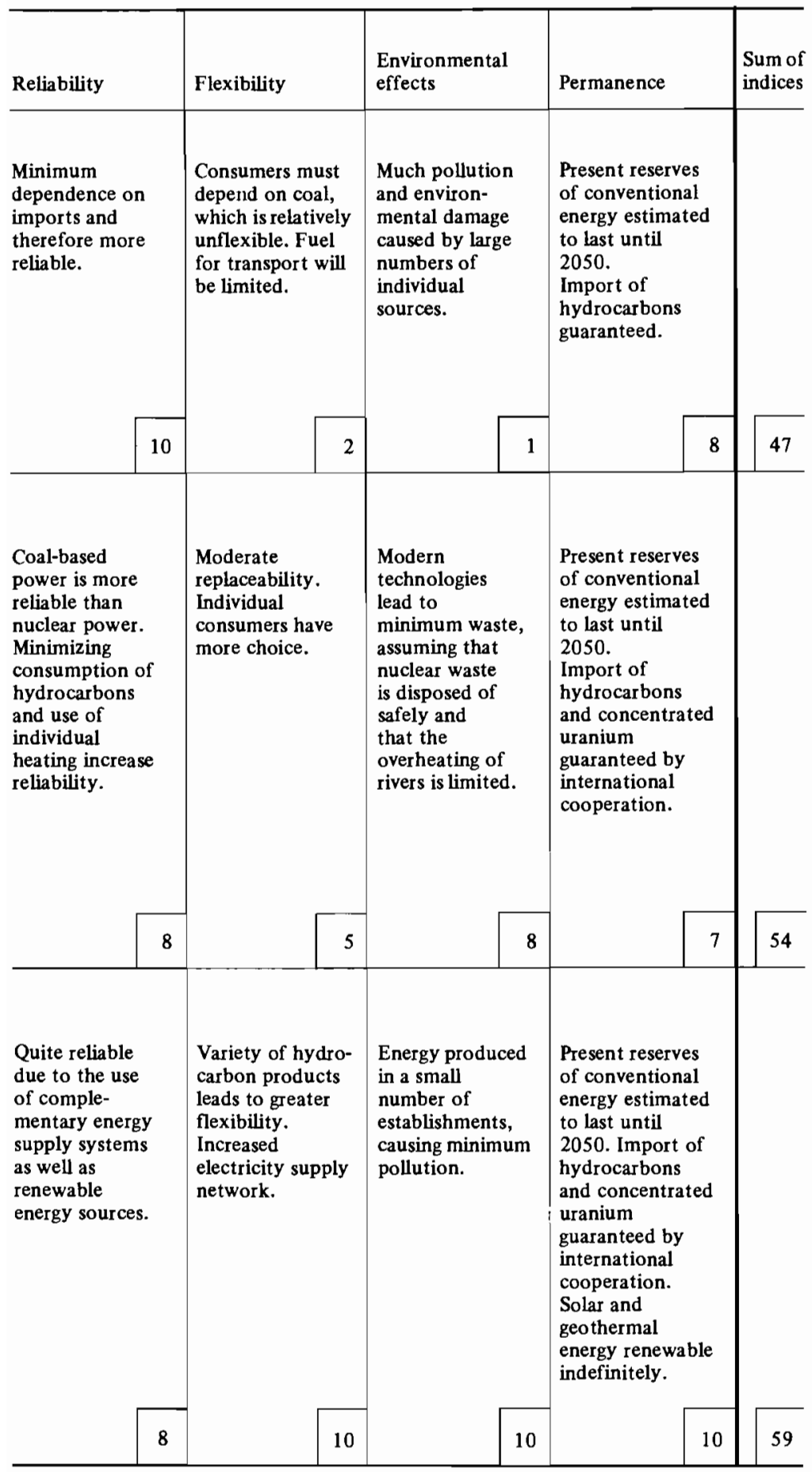




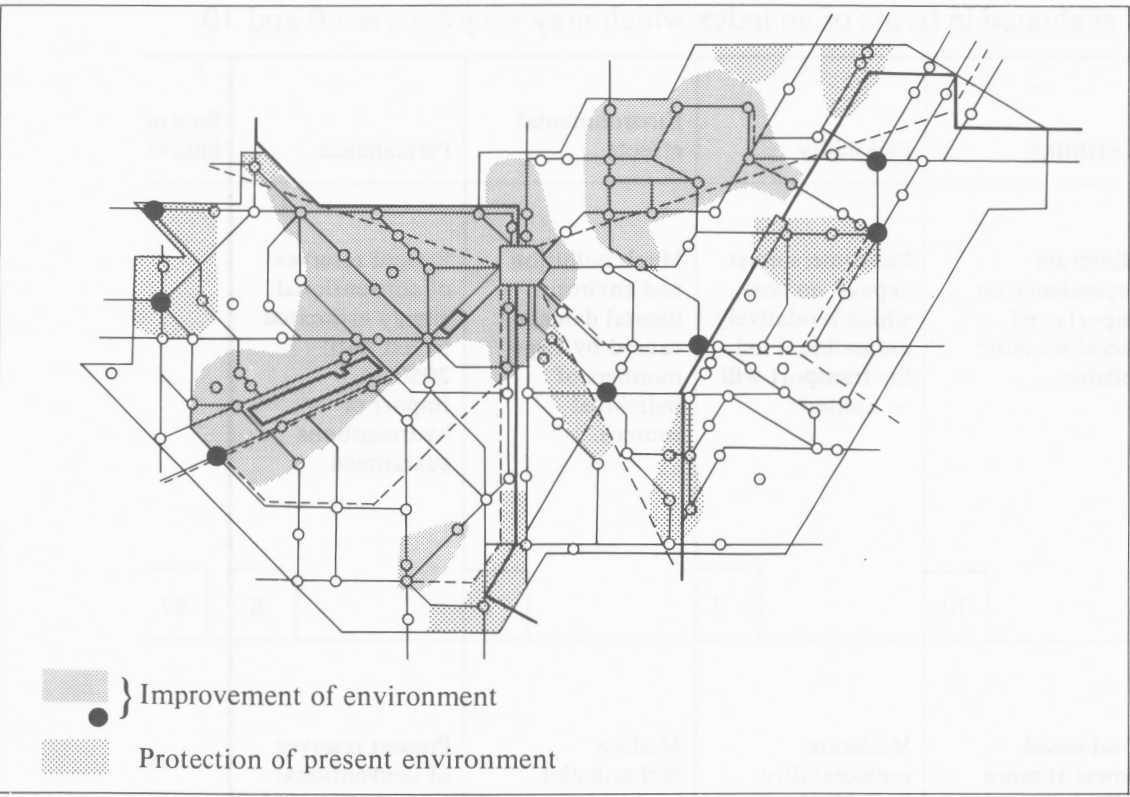

FIGURE 8.5 Regions selected for environmental protection and improvement.

Once the directives and concept of spatio-physical planning have been accepted by the government, coordinated regional development will be assured. It is hoped that this method will also prove more useful in the preparation of policies, strategies, and tactics than the techniques currently employed.

\section{REFERENCES}

1 E. Baráth. Interconnections between physical long-term and energy planning. Paper presented at the Conference of Energetics and Town and Country Planning, 5-6 May 1978, Debrecen, Hungary.

2 Gy. Szekér. Developments and perspectives in Hungarian energetics. Energie és Atomtechnika 27, 1974.

3 W. Häfele. Second Status Report of the IIASA Energy Systems Program. RR-75-1, International Institute for Applied Systems Analysis, Laxenburg, Austria, 1975.

4 Gy. Czipper. Actual tasks of energetics in Hungary. Energie és Atomtechnika 29, 1976.

5 E. Unk. Introduction of regional aspects into energetics through physical planning. Paper presented at the Conference of Energetics and Town and Country Planning, 5-6 May 1978, Debrecen, Hungary.

6 VATI Draft National Spatial Physical Plan. Chapter 1: Spatial structure. Chapter 2: Technical infrastructure and environmental protection. VATI, Budapest, 1978. 


\section{APPENDIX 8A}

Parameters used to classify microdistricts.

\section{Parameter}

Maximum value

\section{Energy resources and supply networks}

Presence of coal or lignite in proven fields

Presence of geothermal springs at a temperature greater than $35^{\circ} \mathrm{C}$

10

10

Presence of an establishment generating communal heat, with reserved capacity

Presence of high-voltage electricity distribution network

Presence of natural gas fields or connections to natural gas pipelines

Distance from a plant making oil-based products ${ }^{a}$

Distance from propane-butane supply station ${ }^{a}$

Distance from fuel shop or wood-felling area ${ }^{a}$

Energy supply to household units

Proportion of household units with electricity supply, and the extent of this supply

Proportion of household units with modern heating system

Proportion of household units with individual heating system

Proportion of household units with piped gas or propane-butane gas supply

Proportion of household units with electricity in the kitchen

${ }^{a}$ The closer the better.

The values of the parameters are summed for each district, and the total used to classify the district as "average", "above average", or "below average" in terms of energy development. The range of values included in each group varies over time, as shown below.

Classification of microdistricts into three groups in 1980,1995 , and 2010.

\begin{tabular}{llll}
\hline Classification & \multicolumn{3}{l}{ Sum of parameter values } \\
\cline { 2 - 4 } & 1980 & 1995 & 2010 \\
\hline Above average & $35-50$ & $40-60$ & $50-80$ \\
Average & $20-30$ & $25-40$ & $30-50$ \\
Below average & $10-20$ & $15-30$ & $15-35$ \\
\hline
\end{tabular}




\title{
Q Management and Planning of Energy/Environment Systems in Italy
}

\author{
Oliviero Bernardini*
}

\section{THE BACKGROUND SITUATION}

One of the most important features of the energy scene in Italy is the relatively minor role played by domestic primary energy production. Only hydropower, geothermal energy, and more recently natural gas, have had any real importance as domestic sources in Italy's energy history. A quarter of a century ago, hydropower was still a major source of energy for the country - over $25 \%$ of total primary supply measured in equivalent thermoelectric terms-and as late as 1963 it was still responsible for about $65 \%$ of electricity production. With the very rapid growth in electricity consumption, however, this contribution diminished rapidly during the sixties and seventies. The present estimate of economic resources still to be exploited has dwindled to an equivalent installed capacity of perhaps $5000 \mathrm{MW}$ at the winter peak**, although future variations in the costs of exploiting other resources could increase this estimate. Natural gas became relatively important during the fifties and sixties but domestic production from the limited reserves could hardly keep pace with demand and major import contracts were signed in the late sixties. Although substantial new discoveries have recently increased the estimate of local reserves, domestic production of natural gas remains almost unchanged at $15 \times 10^{9} \mathrm{~m}^{3} / \mathrm{yr}$ and is not expected to rise significantly. The domestic contribution to total natural gas supplies, which presently amounts to some $60 \%$, will thus continue to fall.

In the post-war period, energy consumption in Italy grew faster than in any other industrialized country except Japan, increasing at an average rate of $8.5 \%$

* Department of Technology Assessment, Research and Development Division, Montedison.

** Note that this is mostly peak capacity. The electricity produced amounts to only about 1500 hours of operation per year. 
per year in terms of primary energy between 1953 and 1972. Remarkably, Italy was one of the very few countries, and certainly the only industrialized country, in which overall energy consumption grew faster than electricity consumption: in terms of final energy use, overall consumption increased by $8.5 \%$ per year, compared with a growth in electricity use of $7.9 \%$ per year over the same period. Again remarkably, Italy was also the only industrialized country in which overall energy consumption grew substantially faster than, and even accelerated relative to, gross national product. The ratio of the growth rates increased from about 1.2 to about 1.8 between the late fifties and the late sixties, averaging some 1.6 in the 25 years following the second world war.

Petroleum was by far the major source of energy used to satisfy the very rapid increase in demand. Petroleum consumption grew at an average rate of $13 \%$ per year between 1953 and 1972; almost all of the fuel was imported. During the fifties and sixties Italy changed from a largely coal- and hydropower-based economy to a petroleum-based economy. In 1973 the consumption of petroleum accounted for $75 \%$ of total energy use, while coal, with a share of only $7 \%$, was used mostly in the steel industry. The use of coal in electricity production has on the whole been very limited and, even before the war, this fuel never achieved the importance in Italy which it attained in other industrialized countries.

Refinery capacity increased with oil consumption during the sixties and provided one of the major investment programs in this period. Much of the new capacity, however, was based on excessively optimistic forecasts of energy demand in Italy and abroad. The very rapid increase in energy demand experienced during the fifties and early sixties was part of a relatively short-lived growth phenomenon. Given the information then available, it was not easy to foresee that growth in energy demand would show saturation effects - related to the degree of maturity of the economy and independent of its rate of growth-by the late sixties. Moreover, much of the investment in new capacity grew out of a firm belief in a continuing large export market for refined petroleum products. The conditions were indeed quite favorable since, as a relatively low income country, home demand for gasoline and light distillates could be met relatively easily so that refinery parameters were determined by the production of heavy fuel oil. This was - and still is - by far the leading distillate, and is used both as a major fuel for process heat in industry and for power production.

Overinvestment in refinery capacity during the sixties also proved to be a major obstacle for the relatively new atomic power industry. Although there were other reasons underlying the long nuclear gestation period in Italy-inability to develop a commercial reactor, as well as financial and social problems-there was nevertheless a very clear conflict between rapid development in nuclear power and the large new investments in refinery capacity in the late sixties. The nascent industry was effectively slowed down, and between 1965 and 1978 there was an increase of only $850 \mathrm{MW}$ in nuclear capacity, making a total of $1400 \mathrm{MW}$. Refinery capacity will undoubtedly remain excessive for many years to come; at 
present only about $65 \%$ of the capacity is used. The increase in oil prices and the slower economic growth experienced in Italy and throughout the world after 1973 have also contributed to this situation. Exports of petroleum distillates from Italy have been diminishing rapidly since the 1973-1974 crisis and the working margins have become quite slim; it now seems advisable to close down a number of refineries and restructure others.

Following the second world war, Italy went through an exceptionally rapid period of growth. Given this circumstance, and the very profound change in the mix of primary energy sources fueling the economy, it has not been easy to match demand with supply over both the short and the long term in a coordinated strategy. These are certainly among the major reasons underlying the far from optimal situation in the energy sector, of which overcapacity in refineries, though symptomatic, is not the only example. In the early seventies it became clear that considerable advances would have to be made in energy planning if the system was to remain at all viable. The 1973 Petroleum Plan was perhaps the first major example of movement in this direction, and in the aftermath of the oil crisis the planning system was rapidly tightened up.

At about the same time the environment became a topic of major concern. The very rapid growth occurring during the fifties and sixties caused large-scale disruptions of the environmental equilibria. In very few countries in the world was so much damage done so aggressively and over such a short period of time in the name of economic growth. The basic legislation governing energy and the environment was laid down in the mid-sixties and, as energy planning and management has evolved, it has become progressively complicated by new legislative constraints.

\section{THE DECISION-MAKING SYSTEM}

The basic elements of a decision-making system are the information flows, the decision-making levels, and the feedback channels between levels. The body of this paper is a brief attempt to identify these elements as they relate to energy/environment planning and management in Italy today. In order to do this it is helpful to refer to the principal actors and their principal activities as defined in the matrix of Figure 9.1. While this identification may contain a certain degree of arbitrariness and approximation and may even be incomplete, it nevertheless provides some useful preliminary insight into and understanding of energy/ environment planning in Italy.

The discussion is divided into two parts. The first briefly describes the actors and their present and possible roles, and develops the control and feedback links between them. The second focuses on the various activities, and describes the control and flow of information within the system, highlighting the most important interactions between actors and activities. 


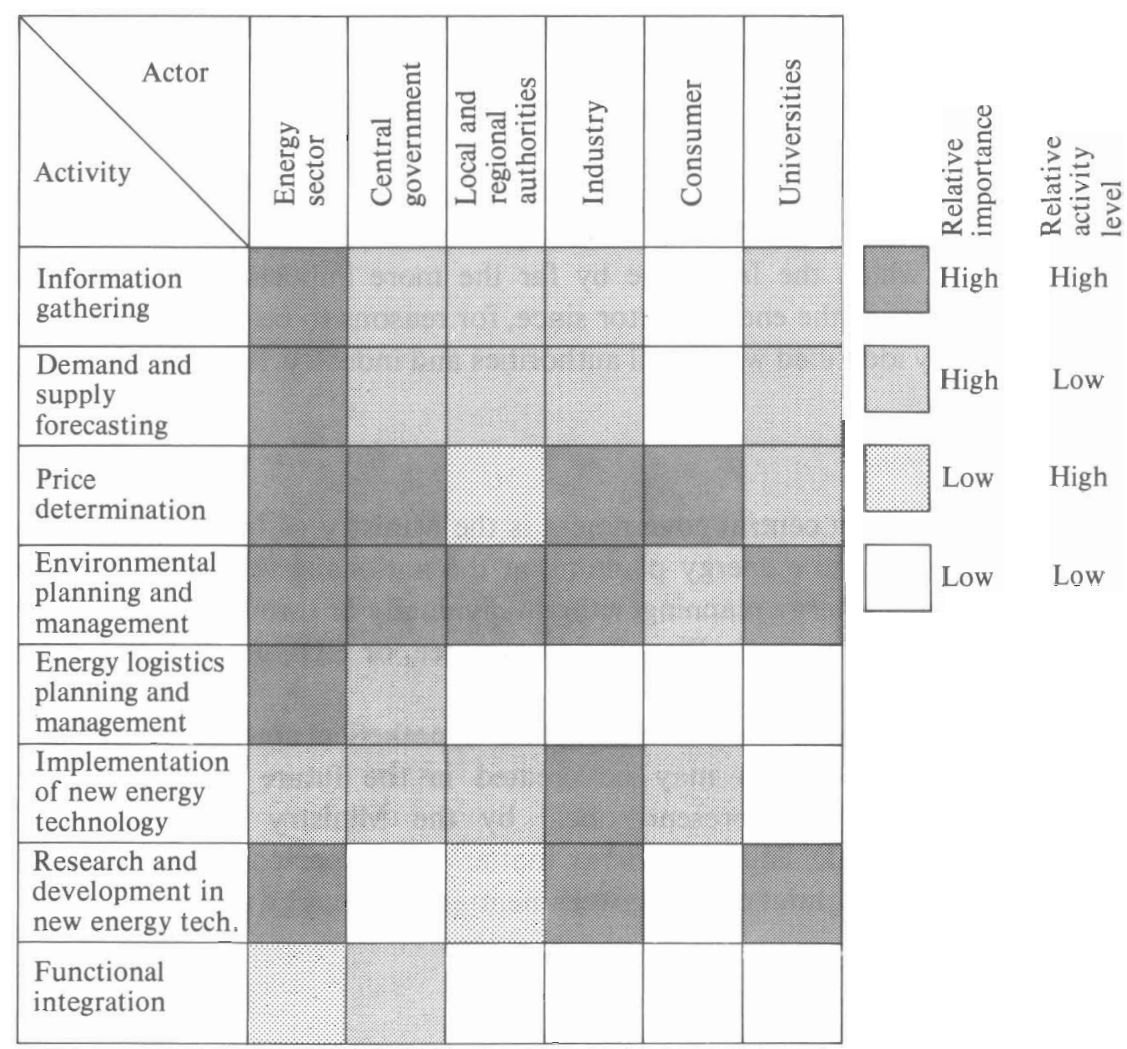

FIGURE 9.1 Decision matrix used for energy/environment management in Italy.

\section{THE ACTORS}

\section{The energy sector}

The major actors in the energy sector are ENEL and ENI*. Both are public organizations, the former being responsible for the production and distribution of electricity, while the latter is principally a supplier of hydrocarbons, but is also involved in geothermal exploration and the development of the nuclear fuel cycle. Other important public actors in the energy sector are CNEN, the nuclear energy agency dealing with research and development, safety, and regulatory questions, and IRI, the Institute for Industrial Reconstruction. Among private concerns, the

\footnotetext{
* A list of acronyms is given in Appendix 9A.
} 
principal actors are the petroleum refiners-Esso, Mobil, and numerous others-which together produce somewhat less than $70 \%$ of all refined petroleum. Other largely private actors are the nuclear and conventional power engineering industries.

A considerable proportion of electricity generation and distribution-about $25 \%$-is presently controlled by municipal concerns and private industrial enterprises, of which the latter are by far the more important. These are not included as actors in the energy sector since, for reasons to be outlined later, they are more closely identified with local authorities and industry, respectively.

\section{Central government}

The principal actor in central government is the Ministry of Industry, which has overall responsibility for energy planning at the national level. Other ministries may also influence energy planning, either individually or through interministerial organs such as the Economic Planning Committee, or CIP, a committee dealing with price administration.

Central government is also taken to include hypothetical authorities such as the Ministry of Energy, which may be created in the future to take over the responsibility for energy presently held by the Ministry of Industry. The authorities presently dealing with energy matters are dispersed in a somewhat illdefined manner throughout central government and the energy sector.

\section{Local and regional authorities}

The main actors in this category are the local authorities (basically the city councils, local boards, or equivalent governing bodies), which comprise a total of 8073 decision-making units. Though more authority has been delegated to Italy's 19 regions by a law (385) passed in 1976, neither local nor regional administrations have been assigned specific roles in energy planning. However, both local and regional authorities have jurisdiction in territorial and environmental matters-water management, local transport, and urban planning-and can therefore play a very significant role in the siting of energy production and distribution facilities.

Other very important actors at the local level are the private and public services providing electricity, gas, water, and public transport. There have been recent signs within the local power structure of a growing body of opinion in favor of delegating greater responsibility for energy planning to the local authorities ${ }^{1,2}$. It is argued that the integrated management of public services at the local level would lead to much greater operational efficiency, as demonstrated by the city of Brescia. This runs all its public services (electricity, water, natural gas, public transport, street cleaning, refuse collection, street lighting, and--unusually for Italy-district heating) as a single coordinated operation. There is much debate 
on whether energy planning should be carried out at the local level, both on technical grounds* and because of the conflict of responsibilities that would inevitably arise.

\section{Industry}

As the country's major energy consumers, manufacturing industries comprise a potentially important element of the decision-making structure. As a group, they are also important suppliers of energy: about $20 \%$ of the electricity produced in Italy comes from the manufacturing sector. Although this percentage has declined very slightly in the last ten years, the proportion of energy supplied by the manufacturing sector in the form of heat and power-about $18 \%$ in 1976 -has been consistently increasing. This is partly a result of incentives, particularly in the Mezzogiorno region in southern Italy. One of the major obstacles to improvement in this sector seems to be the price paid by ENEL for excess electricity; this is considered too low by the manufacturing industries. Centralized production and distribution of electricity clearly involve low overall economic costs, which are significantly increased on transference to the national agency. ENEL therefore maintains that the low price it is willing to pay for electricity is a measure of its effective value. Analogous difficulties surround electricity produced by municipal utilities or other independent groups.

The conflict between centralized and decentralized production is complicated by the frequent use of combined cycle engineering for power production within the manufacturing sector, with corresponding gains in local overall efficiency. ENEL is prepared to become involved with heat distribution, as recently allowed by statute, but this is frequently not cost effective given the great distances and consequent high distribution costs generally involved in centralized production of heat. Whether this conflict will be resolved in favor of centralized or decentralized production of heat is not immediately clear. In the longer term the whole issue is complicated by the territorial siting of industrial facilities and the question of power production consortia formed by separate industrial enterprises (which is presently not allowed by ENEL's charter). Given the large gains in overall efficiency which sometimes result from decentralized combined heat and power production, it is not surprising that a number of groups are now actively calling for a thorough investigation of this part of the decision-making structure.

\section{The consumer}

The consumer is not normally classified as a decision maker in the field of economic planning: the major actors mentioned above tend to regard the consumer only as a beneficiary or final recipient of goods. However, the decisions

\footnotetext{
- It is not at all clear that maximum efficiency at the local level coincides with maximum efficiency at the national level.
} 
taken by the consumer on the basis of prices and costs, disposable income, shortand long-term benefits, and personal preferences, unfailingly work their way through the market and the economic system, where they are compounded and filtered, and finally constitute a major feedback element in the overall decisionmaking structure.

"The consumer" includes the newspapers, television, and other mass media. It includes the political parties and trades unions in their attempts to identify themselves with the citizen and the worker. It also includes such groups as Italia Nostra and the Italian chapter of the World Wildlife Fund, which are active in environmental matters. It includes all citizen action groups and grass-roots movements which wish to make their voices heard on subjects more conventionally left to administrative and industrial planners and managers. Finally, "the consumer" also includes the upper and lower houses of parliament, which represent the ordinary man at the national level and which debate and pass legislation on his behalf. All of these groups clearly influence the individual's decision, and constitute a direct link between the "final recipient" and the other actors on the energy/environment stage.

One of the most difficult and, as yet, unsolved problems in energy-environment planning is the monetary evaluation of the environmental and social costs implicit in the energy production and consumption necessary for economic growth. These costs have in the past been ignored or treated as unfortunate side-effects. The cost effectiveness and greater overall efficiency of centralized energy production traditionally does not take into account the social and environmental costs of centralization and the accompanying urban growth. Although many environmental constraints have recently been introduced into energy planning*, no really convincing attempt has been made to introduce social costs into this field ${ }^{* *}$. By converting these costs intelligently into constraints, the consumer can play an extraordinarily important role in energy planning, no longer simply as a final recipient working through the market, but as one of the principal actors in the overall decision-making structure.

\section{Universities}

This group includes CNR, the central research authority responsible for allocation of public research funds, universities, and nonindustrial research institutes in general. The results of pure and applied research in fields connected with energy planning can, over the long term, influence the structure, as well as the course, of the planning process.

\footnotetext{
* In Italy, for example, ENEL has published a work ${ }^{3}$ which considers demography, hydrology, geology, seismology, infrastructures, and public services as they relate to the selection of sites for nuclear power plants.

** For example, population distribution is assigned a weight which is inversely proportional to the distance of the population from a central point. There is no accepted way of assessing the social costs of this "centralization" ideal.
} 


\section{THE ACTIVITIES}

\section{Information gathering}

The principal need of any decision maker is adequately filtered information. The gathering and preliminary analysis of data is common to all decision-making activities and is highlighted here as a separate activity because of its great importance in energy planning. Physical data on the nature of the terrain, the availability of water, logistic and commercial systems, etc., are obviously necessary, but this section will concentrate on the weaker points in the information system: economic and technical data on energy end use, and the relationship between renewable energy sources and the patterns of human settlement.

There is no coordinated information gathering and processing service which provides a consistent, wide-ranging, and up-to-date set of data with a suitable degree of sectoral, temporal, and regional disaggregation. The Energy Balances published by the Ministry of Industry since 1953 provide the most continuous source of information on energy use 4 . Though this publication has the advantage of complete coverage and uniformity, it appears only once every year and contains information which is usually a few years out of date, insufficiently disaggregated by end-use sector, and aggregated only at the national level. The Energy Balances also lack data on the relationship between energy and economic activities. The Statistical Bulletin of Energy Supply and Industrial Production, which has been published by the Ministry of Industry since 1965, contains monthly data, has much greater sectoral and territorial disaggregation, and provides a measure of economic activity by sector, but does not give complete coverage and is not uniform in its definitions of energy use. Other of ficial or semiofficial compilations do exist, each emphasizing a different aspect of the energy situation, but they are generally incomplete or discontinuous in time. Investigators are often compelled to provide their own data base, using raw information when available, and estimating, extrapolating, and interpolating when necessary. This takes a great deal of time and effort and involves large margins of error.

In the middle to late sixties there was considerable progress in the collection and pre-treatment of energy end-use data in the energy sector. Routine sampling was introduced, satisfying simultaneously many of the requirements outlined above. This improved the information base considerably, particularly in the domestic sector (space heating, appliance use, etc.), which had previously been very poorly documented. However, the information available on energy end use in certain sectors is often disaggregated only according to government-regulated differential tariff classes; this information is not always reliable because it is possible to buy fuel in one sector and use it in another*.

\footnotetext{
* Gas oil was introduced into the domestic sector in 1967, taking an increasing share of the residential market but also being used instead of the higher-priced diesel in the transport sector. This was revealed when the price of gas oil was increased to that of diesel in 1976, causing a step-like rise in the consumption of diesel and an equivalent reduction in the consumption of gas oil for domestic use.
} 
Much still remains to be done in this field. The collection and pre-treatment of raw industrial energy end-use data ordered by the Ministry of Industry for all units with more than ten employees is not yet completely automated. However, it should soon be possible to examine the role of factors such as industry size, sectoral structure, and regional distribution in energy use, with the final aim of establishing technical-economic and econometric models. Further developments in industrial end-use data collection, such as including details of process temperatures, will however require considerable collaboration with the companies furnishing the original information. It also seems unlikely that the data-processing will be extended to include all of the data available in the Ministry of Industry archives: information on more than two decades of industrial development which should be of great interest to the student of energy systems.

The residential and transport sectors remain the most poorly covered in terms of the disaggregation of energy end use by activity. The transport sector is unique in that many of the statistics which used to be quite reliable were suppressed or discontinued during the sixties*. It is of course very difficult to gather information on end uses in these sectors because of the high degree of dispersion and the complicated fine structure (different methods of transport in the transport sector; different space heating systems, electrical appliances, and types of housing in the residential sector). It would be very useful to have a standard definition of sectors and a standard method of measuring activities and energy use; this could be applied at the local level and coordinated through some central body.

Information on renewable and localized energy sources is best collected by local organizations. In terms of standard economics, local exploitation of renewable resources generally turns out to be more costly than centralized production and distribution. However, the comparison does not take into account the social costs and indirect resource costs inherent in changing the patterns of human settlement in order to satisfy the least-cost economic optimum: these include migration to cities, urbanization and its immense resource costs, and the destruction of local communities. A complete technical and economic knowledge of local renewable resources is essential from a broader point of view and should include factors such as the environment, the human element, and the indirect energy and resource costs caused by centralization. Yet, up to now, practically nothing has been achieved in this field. Although information on solar flux levels is now collected routinely, data on the average seasonal wind velocity and its duration are practically nonexistent, as is analogous information on the water flow in local rivers and streams and the availability of energy-rich forest products and biomass wastes from agriculture.

\footnotetext{
* The last year for which the Ente Autotrasporto Merci (an association of freight transporters) published information on freight transport by road was $1962^{\circ}$, and the last year for which the Ministry of Transport published information on urban and suburban public transport was $1968^{\text {? }}$.
} 


\section{Demand and supply forecasting}

It is necessary to collect information not only to provide a "snapshot" of the system at a given instant in time, but also to illustrate how the system can evolve over time. This requires observations over long periods of time and over significant variations in the main parameters of the system: per capita income, income distribution, prices, population movements, etc.

The type of continuous information on energy end use and related economic activity useful for energy demand forecasting is generally available in Italy only at rather high levels of sectoral and territorial aggregation. Although some attempts are being made-particularly by the energy sector but also within independent research groups - to provide a satisfactorily disaggregated data base as a foundation for technical-economic models, it will be many years before enough observations have been made to permit the construction of anything more complicated than simple forecasting models.

Energy planning in Italy is mostly based on demand since, except for natural gas, the distribution network reaches practically every part of the country. The models used for forecasting demand are mostly aggregated over geographic regions and over sectors, though this is not true for the natural gas forecasting model which is based on supply. Most of the models consider only one fuel, with little or no attempt at integration with other sources of energy. Though these models could frequently be made more detailed, this may not always be profitable over the 5-10-year planning horizon generally used by the energy sector. Planning of future energy supply must be based on some measure of maximum probable demand so that there is little to be gained from excessive refinements in the structure of the models at this stage.

However, the rather aggregated nature of most of the models used, their largely one-sector/one-fuel specification, their frequent lack of fine structure, their lack of regional disaggregation, and their coarse econometric form, are clearly all factors leading to an incomplete and probably misleading picture of the interaction of the various forces involved. Even when these models are computerized-which is not very frequently the case-they can be of only very limited use, for example, in determining the most appropriate price of fuels, or in examining the direct and indirect effects of energy saving policies.

Thus, while existing models may be quite adequate for planning in individual branches of the energy sector, there appears to be no satisfactory model for overall demand/supply policy planning up to the year 2000 . Some moves in this direction are being made both within the energy sector and within universities (energy modeling receives specific financing through CNR and the Progetto Finalizzato Energetica (PFE) - an applied project on energy problems), but research is proceeding very slowly. This can probably be traced to the lack of an econometric or economic modeling tradition in Italy.

Another important aspect of demand/supply modeling, and one which does not receive sufficient attention in present Italian energy planning, is the feedback 
between regional and national levels. The part of the energy sector responsible for distributing energy are fully aware of the importance of the local element in making the final decisions; feedback channels have been developed and are used routinely in energy supply planning. However the approach is quite frequently, though not always, top-down, amounting to a national supply forecast of energy allocations among regions; unfortunately a bottom-up approach is hardly possible in the absence of a regionally disaggregated data base.

Though local and regional authorities might not have any responsibility for local energy forecasting, they are responsible for planning in many fields which affect energy consumption and supply. Details of this planning should be included as input to the more standard forecasting models in the energy sector. Though this is not being done at present, it should not affect the shorter-term modeling most typical of the energy sector, since such factors as development of transport systems, changes in settlement patterns and residential structures, exploitation of local resources, and development of district heating are usually medium- to longterm phenomena. It is much easier for planners to react to a gradual long-term development than a sudden change in policy direction.

A similar situation arises between industry and the energy sector. Here again, industry's plans for expansion, exploitation of local resources, and production of heat and/or electricity can form a most important input to planning in the energy sector. Though the energy sector and the system as a whole can possibly afford to overlook the independent decisions of other actors and adjust to them gradually, there is no doubt that the system would benefit significantly from a more regular and wide-ranging flow of information between regional and national levels.

\section{Price delermination}

Basic fuel prices, like all other administered prices, are established at the central government level by an interministerial committee known as CIP (Comitato Interministeriale per i Prezzi). This committee meets regularly and attempts to control the energy used by the nation through the price of fuels in the various end-use sectors and through possible automatic mechanisms for price adjustment. The pricing decisions are made on the basis of the industrial costs to the energy sector, the product prices "acceptable" to industry, and the commodity prices "most desirable" to the final consumer.

The short- and long-term objectives of this price-setting procedure are not clearly specified and are difficult even to identify; the optimization process involved is not at all obvious. In the absence of a conventional role for the market, one would expect integrative use of economic and technical models to assist the decision maker in his choice of price and pricing mechanisms. On the whole, this is not the procedure followed in practice.

The absence of models simulating the very complex interrelations between fuel substitution, differential energy prices, and changes in sectoral activity makes it 
very difficult to adjust the pricing system quickly and accurately to changes in boundary conditions. It would certainly have helped if such models had been in existence immediately after the energy crisis, when the prices of primary inputs were changing rapidly on the international market. The Italian energy pricing system was unduly slow to adjust to the nonequilibrium situation and considerable damage was done, for example, in the natural gas sector. At the time of the crisis, most of the natural gas used in the residential sector was of Italian origin. As a result of the crisis, the price of natural gas became uncoupled from that of fuel oil, increasing only slightly from its 1973 levels while the price of heating oil, its main competitor in the residential sector, more than tripled. It was only in 1977 that the basic price of natural gas was finally increased to equilibrium level and by that time the residential market had more than doubled, growing at an average annual rate of $22 \%$, placing great strains on the energy sector, and provoking a situation of general instability in the market.

Local authorities now have a certain measure of freedom in altering the government-approved price of certain fuels, such as natural gas. This is usually done in response to pressure from various groups and represents an element in the pricing system which is difficult to control and which may damage the national economy. For example, local organizations generally sell natural gas to the residential sector at prices approximately $30 \%$ lower than the recommended price paid by the local organizations to the energy sector. The difference frequently appears as part of the deficit of the local public administration, and is then passed back to the government.

\section{Environmental planning and management}

Although energy consumption per capita is still reasonably small in Italy compared with other industrialized countries $(2.5 \mathrm{toe} / \mathrm{yr})$, the relatively high population density means that the energy density is also quite high. Italy had an energy density of 440 toe $/ \mathrm{km}^{2}$ in 1975 , compared to 600 toe $/ \mathrm{km}^{2}$ for Western Europe, 180 toe $/ \mathrm{km}^{2}$ for the United States, and 40 toe $/ \mathrm{km}^{2}$ for the world as a whole.

Most of the energy and associated pollution released into the atmosphere is a result of the widespread use of motorized transport and space heating. The very rapid growth in central heating during the fifties and sixties led to a virtually unmanageable environmental situation in the larger cities. In 1966, fairly advanced anti-smog legislation was passed, limiting the use of fuel oil for this purpose, with the result that gas oil with a low sulfur content $(0.5 \%)$ began rapidly to take its place, with a considerable improvement both in atmospheric conditions and in burner performance. It is possible that this legislation will be modified to decrease the use of fuel oil in domestic space heating still further. The increasing substitution of natural gas for gas oil is another factor which should improve atmospheric conditions in the years to come. Legislation in the transport sector now limits maximum exhaust emission from light-duty gasoline engines and diesel 
engines in new production models; the maximum lead content of gasoline is also controlled. Much of this legislation, provided for the consumer by the consumer, imposed itself in terms of constraints upon the system and significantly altered the economic and technical criteria governing refinery operation, effectively introducing the elements of "environmental cost" into energy planning and management.

About $41 \%$ of the energy released into the environment comes from the transport and domestic sectors, while manufacturing industry contributes $35 \%$. There is precise pollution abatement legislation which controls the emission of all major pollutants connected with fuel use in industrial plants; both local and regional authorities have jurisdiction in this field. Electricity production contributes $18 \%$ of the total energy released into the environment and refineries only $4 \%$; although this is a relatively small proportion it looms large in public opinion because highly centralized production can have a more significant effect on the environment than dispersed sources. It is, of course, relatively easy to control the centralized polluter and such control generally implies lower overall costs than the control of dispersed pollution. In the case of electricity, moreover, there is a significant tradeoff between the relatively high point-source emission involved in the production process and the low direct environmental impact at the point of consumption.

Modeling of the interaction between energy and the environment is quite advanced in Italy. There are already models of air and water pollution, which are used in principle, if not in practice. Everyday planning in the energy sector must take account of the environmental limits specified by law, and sophisticated models are employed in decision making. When considering the siting of power plants, for example, models are used to determine acceptable temperature profiles in rivers and coastal waters, and to simulate the normal operation of the plant.

However, all of this represents only one aspect of the decision process. Local government bodies, though they presently have no jurisdiction in energy planning, control both territorial and environmental planning so that the final decision frequently rests with these authorities and with the consumer groups which influence them. The sites of power plants proposed by the energy sector on the basis of meeting potential demand with the lowest distribution costs, have in fact been encountering increasing resistance from local and regional authorities. This is a general phenomenon which seems to be largely independent of the fuel basis of the plant, although it does reach extremes in the case of nuclear power. Resistance to the construction of new power plants seems to be increasing, despite warnings by the energy sector and others of power shortages and rationing as early as 1984 if these plants are not built.

The final decision on the siting of power plants, industrial complexes, and refineries should clearly rest with the consumer, but it is important that the consumer should be fully aware of the significance and scope of his decisions. The general feeling is that the consumer is not sufficiently well-informed to take a responsible decision and the mass media, by generally offering standard and superficial versions of the debate and not broadening the issue, are clearly not providing the public with an appropriate decision-making environment. 
In a densely populated country like Italy, it is increasingly likely that regions of energy consumption and production will not coincide. In 1976, 32\% of the electricity produced in Italy crossed regional boundaries before consumption. This percentage continues to increase and may lead to serious problems as local and national interests conflict. There are already numerous examples of local resistance to the proposed siting of power plants designed to generate electricity for export. This conflict must be resolved within the next two decades. By this time, the energy consumed by Italy's most populous and most rapidly growing region, Lombardy, will be equivalent to the combined output of all Italian electricity-generating plants in operation today ${ }^{8}$. Environmental constraints will probably prevent the production of this amount of energy ( $1250 \mathrm{toe} / \mathrm{km}^{2}$ per year) within the region since over $60 \%$ of the energy would be released into the atmosphere and local rivers. There is likely to be social resistance to new plants, regardless of whether the increase in generating capacity is nuclear or conventional. At the same time, other regions may object to producing energy for use by Lombardy, pointing out that if the overall economic system were properly optimized, jobs would be coming to them rather than going to Lombardy and the north.

Economic development has always been based on centralization of the means of production and consumption, which has also meant centralization of human settlements. The energy debate in Italy is now taking the peculiar form of a battle between centralization and decentralization. If local resistance in siting questions results in the production of insufficient energy for "satisfactory" economic growth, this shows only that the social costs related to centralization were so great that they effectively slowed down economic growth. In all cases it is the consumer who must evaluate his social costs, and not the other actors on the scene. It is therefore vital to make all relevant information available to the consumer; this would also reduce the possibility of misrepresentation through overly active pressure groups.

\section{Energy logistics planning and management}

There is clearly a connection between planning the logistics of energy systems and environmental management. Unfortunately it is quite possible that the optimal logistic system may correspond to an unacceptable environmental solution.

The Italian oil and gas system is now virtually complete and it is unlikely that major changes will be made in the rest of this century. The system was created during the last three decades using criteria and aims which do not always seem to be immediately obvious. The fact, for example, that $52 \%$ of the refinery capacity is located in southern Italy and the islands, whereas $70 \%$ of the oil consumption occurs in northern and central Italy, does not seem to correspond to any longterm logistic optimum. Every day some $3 \times 10^{5}$ tonnes of oil (mostly imported) and oil products of various specifications are transferred through an $11,000-\mathrm{km}$ network of pipelines. This distribution, through ports and storage points to the 
rest of the commercial chain, at minimal cost, would be impossible without the use of very sophisticated operating and management models. These are in fairly general use within the petroleum industry; some of them are virtually connected to the actual refining process.

In theory, considerable improvements in the operation of the system could be made through better coordination of the different concerns involved in the refining of oil. Market forces are incapable of achieving perfect coordination and an overall refinery model would be of great assistance in this field. A model of this type, based within ENI, has been in existence for a number of years. It treats the entire logistic system as a single integrated decision-making unit, rather than a combination of many independent units connected imperfectly through the market. Although it is unlikely to be used directly as an on-line management tool, this model could be very important in providing the government with information which could then be used to improve the operation of the system as a whole.

The management of the power system is aided greatly by models, and optimization is made easier by the centralized structure of the national electricity system. The Sibilla system which underlies ENEL's planning and operation deals with all major aspects of power production and distribution, including load modeling, expansion in generating capacity, optimization of the characteristics, location, and capacity of power plants, and expansion of the transmission network. The Sibilla system is well-known throughout the world ${ }^{9}$.

\section{Research and development in new energy technology}

Research and development in new energy technologies is an important strategic component of planning for the more distant future. There has not been as much activity in this field as might have been expected, considering the potentially important energy resources available to Italy, e.g., solar and geothermal energy. This does not reflect the quality or organization of the research but rather a lack of financial support in the past, though the situation seems to be improving rapidly. In 1978, the Progetto Finalizzato Energetica, which now coordinates a significant part of the country's energy research and development, assigned some 6 billion lire (about $\$ 7$ million) to research and development in new energy sources. There is also a considerable amount of independent research in this area, in both public and private sectors.

Energy can be saved by making end use more efficient, by integrating industrial processes, and by introducing economic policies designed to encourage substitution of energy sources. In all cases there is a very important connection between energy conservation and the economy. Research into methods of saving energy in Italy receives considerable financing through $\mathrm{CNR}$ and is coordinated by the Progetto Finalizzato Energetica. Much of this research involves making end use more efficient, particularly in space heating and transport, while improvements in 
end use in the industrial sector are studied mostly within industry through private financing. Most of this research is technological and largely ignores the national economic situation. In fact conservation of energy is both a technological and an economic problem, involving energy prices and income distribution, and requiring a knowledge of such factors as the relative proportions of direct and indirect energy consumed and saved, the nonequilibrium response of the consumer to monetary savings accompanying energy savings, and the short- and long-term effects of changes in the relative prices of fuels ${ }^{10,11}$. Without this knowledge, and with no long-or medium-term econometric model of the Italian economy, it would be almost impossible to study the macroeconomic consequences of energy-saving policies. This is one major element missing from effective analysis in this field.

\section{Implementation of new energy technologies}

Most of the regulations governing the use of new energy technologies are still at the policy-making stage. A relatively recent law (1975) dealing with industrial reconversion contains clauses designed to promote new energy technologies in an overall industrial development strategy. A number of committees are working on the practical applications of this law, which should aid the penetration of new energy technologies into the Italian market.

New energy technologies will also have to fit into the social and economic structures of the regions, where the roles of the various protagonists are more exactly defined than at the national level. Though there has not been very much interest in this integration in the past, developments are now taking place at the regional and local levels which may prove to be very useful as long as they do not overlap the more general type of research financed directly through central government.

\section{Functional integration}

Functional integration is basically a high-level activity which has some degree of control over the economy and can affect the direction of policy decisions. It is therefore carried out largely by central government with very little consultation at lower levels.

Functional integration should ideally be concerned with providing a long-term energy/environment plan extending up to and beyond the year 2000. Since lower levels such as the energy sector and industry are controlled by the upper levels responsible for functional integration, medium- and short-term planning of these sectors should be possible. Short- and medium-term responses from the energy sector and industry could then be used to adapt the long-term energy/environment plan to their particular requirements.

What is actually happening, however, is quite different. The lower-level actors 
are providing the central government with ideas based largely on short- to medium-term horizons. The national energy plans prepared within central government are basically the proposals put forward by the energy sector and, to a certain extent, by industry, the universities, and even the consumer*; the central government just coordinates these plans and ensures that they are compatible. The result is that national energy planning does not extend more than 10-15 years into the future - the range commonly used in the energy sector. Given the amount of time taken to develop new energy systems, a more appropriate time horizon would appear to be $20-30$ years.

Functional integration is also concerned with the international aspects of energy planning. It is impossible to carry out any long-term planning without considering its international implications. In this case, again, the reversal of roles discussed above has led to a policy based on the achievement of short-term aims. Existing energy plans have tended to emphasize the short- and medium-term commercial and strategic aspects of energy planning at the international level--supply security, geographical diversification of sources, collaboration in the nuclear fuel cycle, and so on. Of course, this is to be expected from an energy plan prepared largely by the energy sector, which is more concerned with day-to-day operation than with long-term prospects. Nevertheless, these plans do not attach sufficient weight to the strong tensions that are likely to appear in the international petroleum market within the next 10 years and in the nuclear fuel market by the turn of the century; they also fail to grasp the essential gaming nature of international energy politics. This emphasis on short-to-medium-term energy planning also means that aspects of longer-term planning, such as research and development and energy conservation, are overlooked.

Finally, functional integration includes the integration of the energy/environment strategy and the national and regional economies. Suitable energy economics models are of course vital, but have not yet been constructed because a number of very important links are missing, or are not known in sufficient detail. Integration of energy/environment planning and economic factors could be very important in view of the increasing distance between areas of electricity consumption and production** (which is related to urban migration patterns), and also the major role that local authorities can play in energy conservation and in the development of local renewable resources.

Functional integration is sufficiently important that an organization should be established to coordinate all energy-related activities; this was proposed as part of the 1975 Energy Plan.

\footnotetext{
* A very important input to the 1978 energy plan was prepared by a parliamentary commission acting on the behalf of the consumer ${ }^{12}$.

** See, for example, ref. 9. where it is stated explicitly: "In the more distant future it is possible to forecast that the increasing difficulty of installing new power plants in the vicinity of large load centers in the northern regions will make it necessary to transfer large amounts of power from a few generation areas towards these load areas, over distances that in many cases are of the order of $200-350 \mathrm{~km} . "$
} 


\section{REFERENCES}

I D. Andrioli. Energy policy and land-use management and The local authority and the problem of integrated management of energy sources. Papers presented at the meeting of the Technical Consulting Committee on The Problem of Energy for the Local A uthority: Introduction to the Analysis of Economic, Political, and Institutional Aspects, Riva del Garda, 20-21 May 1977. (D. Andrioli. Politica energetica e gestione del territorio; L'ente locale ed i problemi della gestione integrata dell'energia. Comitato Tecnico Consultivo, Giornate di studio su L'Energia a Servizio dell'Ente Locale. Introduzione all'Esame degli Aspetti Economici, Politici ed Istituzionali, Riva del Garda, 20-21 Maggio 1977.)

2 G. Girelli and R. Zenoni. The energy problem: impacts on the organization of the national, regional, and local administration. Paper presented at the CISPEL National Conference on Energy Problems and Local Authorities, Stresa, May 1978. (G. Girelli e R. Zenoni. I problemi energetici: riflessi sull'ordinamento dello stato, delle regioni e degli enti locali. Relazione presentata alla Conferenza Nazionale Energia ed Enti Locali, CISPEL, Stresa, Maggio 1978.)

3 National Electrical Energy Agency. Atlas of the Primary Territorial Characteristics of the Italian Coast. Rome, 1973. (Ente Nazionale per l'Energia Elettrica. Atlante delle Caratteristiche Territoriali Primarie delle Coste Italiane. Roma. 1973.)

4 Ministry of Industry. Energy Balances. Rome, published annually since 1953. (Ministero dell'Industria. Bilanci Energetici. Roma, publicazione annuale da 1953.)

5 Ministry of Industry. Statistical Bulletin of Energy Supply and Industrial Production. Rome, published annually since 1965. (Ministero dell'Industria. Bollettino Statistico sulle Fonti di Energia e sulla Produzione Industriale. Roma, publicazione annuale da 1965.)

6 Association of Truck Freight Transporters. National Statistics on Freight Transport. Rome, 1962. (Ente Autotrasporto Merci. Statistica Nazionale dell'Autotrasporto di Cose. Roma, 1962.)

7 Ministry of Transport. Statistics of Commissioned Public Services. Rome, 1968. (Ministero dei Trasporti. Statistica dei Servizi Pubblici in Concessione. Roma, 1968.)

8 O. Bernardini. Energy scenarios for Lombardy: conservation and alternative energy sources. Paper presented at the Conference on Conservation and Alternative Energy Sources, Milan, 23 January 1978. (O. Bernardini. Scenari energetici per la Lombardia: risparmi e fonti alternative. Relazione presentata allo Convegno sul Risparmio Energetico e Fonti Alternative, Milano, 23 Gennaio 1978.)

9 G. Manzone, L. Paris, and M. Valtorta. Power System Planning Practice in Italy. Paper presented at the Winter Meeting of the IEEE Power Engineering Society, New York, January 1978.

10 B. Hannon. Energy conservation and the consumer. Science 189 (1975) 95.

11 O. Bernardini. The role of prices in energy conservation. Paper presented at the Conference on Energy for Development, Florence, 13 May 1978. (O. Bernardini. Ruolo del prezzo per il risparmio energetico. Relazione presentata allo Convegno Energia per loa Sviluppo, Firenze, 13 Maggio 1978.)

12 Chamber of Deputies, Commission on Industry. Investigative Survey of Energy Problems. Rome, June 1977. (Commissione Industria della Camera dei Deputati. Indagine Conoscitiva sui Problemi dell'Energia. Roma, Giugno 1977.) 


\section{APPENDIX 9A}

Explanation and translation of acronyms used in the text.

\begin{tabular}{|c|c|c|}
\hline CIP & $\begin{array}{l}\text { Comitato Interministeriale } \\
\text { per i Prezzi }\end{array}$ & $\begin{array}{l}\text { Interministerial Committee for } \\
\text { Prices }\end{array}$ \\
\hline CNEN & $\begin{array}{l}\text { Comitato Nazionale per l'Energia } \\
\text { Nucleare }\end{array}$ & $\begin{array}{l}\text { National Committee for Nuclear } \\
\text { Energy }\end{array}$ \\
\hline CNR & Consiglio Nazionale della Ricerche & National Research Council \\
\hline ENEL & $\begin{array}{l}\text { Ente Nazionale per l'Energia } \\
\text { Ellectrica }\end{array}$ & $\begin{array}{l}\text { National Electrical Energy } \\
\text { Agency }\end{array}$ \\
\hline ENI & Ente Nazionale Idrocarburi & National Hydrocarbons Agency \\
\hline IRI & $\begin{array}{l}\text { Istituto per la Riconstruzione } \\
\text { Industriale }\end{array}$ & $\begin{array}{l}\text { Institute for Industrial } \\
\text { Reconstruction }\end{array}$ \\
\hline PFE & Progetto Finalizzato Energetica & Energy Project \\
\hline
\end{tabular}




\title{
$10 \begin{aligned} & \text { Management and Planning of } \\ & \text { Energy/Environment Systems }\end{aligned}$ in Japan
}

\author{
Takao Tomitate*
}

\section{INTRODUCTION}

The management and planning of energy systems in Japan is carried out independently by the national government, local authorities, and energy-related industries in their respective fields. At the same time, however, these groups cooperate widely so that their work is mutually compatible. The central government agency responsible for energy systems is the Agency of Natural Resources and Energy, part of the Ministry of International Trade and Industry. Any matters of concern are submitted by the Agency to the Advisory Committee for Energy, and management policy is based on the response. The Advisory Committee is composed of influential university professors, energy experts, journalists, and businessmen. A number of subcommittees have also been formed to investigate subjects such as supply and demand, petroleum, nuclear power, conservation, the environment, finance, and public acceptance. Under these subcommittees, in turn, are specialist committees and working groups which handle detailed tasks and analyses.

Local government bodies are concerned primarily with the planning and management connected with environmental protection and energy supply facilities. The measures introduced by the local authorities to protect the environment are often more stringent than the national regulations. These local administrations also have considerable control over the location of nuclear power plants and other energy supply facilities, as they must grant permission for the plants to be built. In cases where local residents oppose the construction of such facilities, the local government agencies often mediate between the residents and the energy companies.

Each energy industry has a trade association; these include the Petroleum Association of Japan, the Federation of Electric Companies, and the Japan Gas

\footnotetext{
* Institute of Energy Economics, Tokyo.
} 
Association. These associations conduct their own supply and demand forecasts and financial planning and analysis, but they also examine government policy and adjust their business interests accordingly.

Japan differs from most industrialized countries in having virtually no university courses, research institutes, or scholars concerned with energy issues, except in highly specialized fields such as nuclear engineering. In particular, there are no scholars specializing in the economics and politics of energy. For this reason, energy analysis and planning is conducted primarily by experts in the government agencies and industrial associations described above. The Institute of Energy Economics (IEE) is a specialized research organization established by a group of companies interested in energy systems (firms in the steel and chemical industries, trading companies, and banks). It produces analyses which are used by government and industry in energy planning and management.

There are two important environmental problems which should be considered in energy planning. One is the question of how to deal with sulfur dioxide $\left(\mathrm{SO}_{2}\right)$ and nitrogen oxides $\left(\mathrm{NO}_{x}\right)$, and the other the problem of environmental preservation in view of the increasing number of energy supply facilities. The second point is illustrated by the frequent need to compensate fishermen for damage caused to fishing grounds, since most of Japan's energy supply facilities are located along the coasts.

Japan's major aims in the energy field are as follows:

1. To build the required energy supply facilities while meeting the environmental regulations and gaining the support of local residents. The methods used to achieve this will depend on whether programs are established to develop sources as alternatives to petroleum, e.g., nuclear power, LNG, or coal.

2. Assuming that alternatives to petroleum are adopted, to achieve the best possible distribution of new fuels.

3. To balance the increasing demand for the lighter fractions of oil with the growing dependence on imported heavy crude oil.

4. To encourage energy conservation in all sectors.

5. To integrate the national energy plan and the plans for regional development (including the associated planning of regional energy systems).

6. To encourage more energy research and development.

However, none of these aims can be achieved without the expenditure of considerable amounts of time and large sums of money. It is not immediately clear who should bear the cost.

At present, the government's official supply and demand forecasts and programs (with the exception of the Sunshine program aimed at developing new energy sources) tend to concentrate around 1985, although some have 1990 as their target date (see Table 10.1 and ref. 1). In addition, a study extending to the year 2000 is now underway ${ }^{2}$. However, almost no government or private research 
has investigated possible energy strategies for the next century. Moreover, although the government's planning and management policy decisions are made public, details of the reasoning leading up to them are not. With this in mind, we shall now examine the energy situation in Japan, concentrating on studies made by the Institute of Energy Economics (IEE).

\section{ANALYSIS OF ENERGY DEMAND}

\section{Energy matrix and specific consumption}

Energy consumption statistics issued by the government and each industry are processed by the IEE to produce quarterly and yearly energy matrices ${ }^{3-5}$. The data processing is completely computerized. Each matrix consists of 36 rows representing production, imports and exports, transformation, and final consumption, and 28 columns representing energy products. These energy matrices, along with energy balance tables and industrial production indices, may be used to determine the specific consumption of each sector.

\section{Demand estimates for the industrial sector}

Energy demand forecasts for industry are generally obtained by the following method:

1. A macroeconomic model is used to estimate the relative contribution of each sector to the gross national product. (The IEE bases its analysis on two cases, one a high-growth scenario close to the government forecast and the other an independent low-growth situation.)

2. An input-output table (based on recent figures) and the results of the macroeconomic model are used to determine the amount of production in each industrial sector.

3. The energy demand in each industry is calculated using the amount of production and specific energy consumption of that industry.

4. The specific energy consumption figures are reduced by means of an energy conservation ratio.

5. The trend toward a changing industrial structure is incorporated. It is assumed that energy-intensive industries, such as the steel and petrochemicals industries, will constitute a decreasing percentage of the total energy market.

\section{Other demand}

Domestic and commercial energy demands are derived by correlating personal consumption and GNP, and by estimating the spread of energy-consuming appliances. Energy demand in the transportation sector is related to the amount of 
TABLE 10.1 Projected long-term energy supply and demand situations in Japan ${ }^{a}$.

\begin{tabular}{|c|c|c|c|c|c|c|c|c|}
\hline & \multirow{2}{*}{\multicolumn{2}{|c|}{$\begin{array}{l}\text { Fiscal year } \\
1975 \\
\text { (actual } \\
\text { situation) }\end{array}$}} & \multicolumn{4}{|c|}{$\begin{array}{l}\text { Fiscal year } \\
1985\end{array}$} & \multirow{2}{*}{\multicolumn{2}{|c|}{$\begin{array}{l}\text { Fiscal year } \\
1990 \\
\text { II }^{c}\end{array}$}} \\
\hline & & & \multicolumn{2}{|l|}{$\mathbf{I}^{b}$} & \multicolumn{2}{|l|}{$\mathrm{II}^{c}$} & & \\
\hline \multicolumn{9}{|c|}{ Projected demand $\left(10^{6} \mathrm{kloe}\right)^{d}$} \\
\hline $\begin{array}{l}\text { Demand excluding } \\
\text { energy conservation } \\
\text { Rate of energy }\end{array}$ & & & \multicolumn{2}{|l|}{740} & \multicolumn{2}{|l|}{740} & \multicolumn{2}{|l|}{916} \\
\hline $\begin{array}{l}\text { conservation } \\
\text { Demand including }\end{array}$ & & & \multicolumn{2}{|c|}{$40(5.4 \%)$} & \multicolumn{2}{|c|}{$80(10.8 \%)$} & \multicolumn{2}{|c|}{$124(13.5 \%)$} \\
\hline energy conservation & 390 & & 700 & & 660 & & 792 & \\
\hline \multicolumn{9}{|l|}{ Projected supply } \\
\hline $\begin{array}{l}\text { Hydropower } \\
\text { Ordinary } \\
\text { Pumped } \\
\left(10^{6} \mathrm{~kW}\right)\end{array}$ & $\left.\begin{array}{r}17.8 \\
7.1\end{array}\right\}$ & $(5.7)$ & $\begin{array}{l}19.5 \\
19.5\end{array}$ & $(3.3)$ & $\left.\begin{array}{l}22.5 \\
18.5\end{array}\right\}$ & (3.9) & $\begin{array}{l}26.5 \\
24.5\end{array}$ & $(3.9)$ \\
\hline $\begin{array}{c}\text { Geothermal power } \\
\qquad\left(10^{6} \mathrm{~kW}\right)\end{array}$ & 0.1 & $(0.0)$ & 0.5 & $(0.1)$ & 1.0 & $(0.3)$ & 3.0 & $(0.7)$ \\
\hline $\begin{array}{l}\text { Indigenous oil and } \\
\text { natural gas } \\
\left(10^{6} \mathrm{kloe}\right)^{d}\end{array}$ & 3.5 & $(0.9)$ & 8.0 & $(1.2)$ & 11.0 & (1.7) & 14.0 & $(1.7)$ \\
\hline $\begin{array}{l}\text { Indigenous coal } \\
\qquad\left(10^{6} \text { tonnes }\right)\end{array}$ & 18.6 & $(3.4)$ & 20.0 & $(2.0)$ & 20.0 & $(2.1)$ & 20.0 & $(1.8)$ \\
\hline $\begin{array}{l}\text { Nuclear power } \\
\qquad\left(10^{6} \mathrm{~kW}\right)\end{array}$ & 6.6 & $(1.7)$ & 26.0 & $(5.4)$ & 33.0 & $(7.4)$ & 60.0 & $(11.2)$ \\
\hline $\begin{array}{l}\text { LNG imports } \\
\qquad\left(10^{6} \text { tonnes }\right)\end{array}$ & 5.1 & (1.8) & 24.0 & (4.9) & 30.0 & (6.4) & 44.0 & $(7.7)$ \\
\hline Coal imports & 62.3 & $(13.1)$ & 93.0 & $(10.7)$ & 102.0 & (12.4) & 144.0 & $(14.1)$ \\
\hline $\begin{array}{l}\text { Steam coal } \\
\quad\left(10^{6} \text { tonnes }\right)\end{array}$ & 0.5 & & 6.0 & & 16.0 & & 40.0 & \\
\hline $\begin{array}{l}\text { New sources } \\
\qquad\left(10^{6} \mathrm{kloe}\right)^{d}\end{array}$ & - & & - & & 2.3 & $(0.4)$ & 13.0 & (1.6) \\
\hline $\begin{array}{l}\text { Total supply excluding } \\
\text { oil imports }{ }^{e} \\
\left(10^{6} \mathrm{kloe}\right)^{d}\end{array}$ & 104.0 & $(26.6)$ & 195.0 & $(27.8)$ & 228.0 & $(34.5)$ & 340.0 & $(42.9)$ \\
\hline $\begin{array}{l}\text { Oil imports } \\
\qquad\left(10^{6} \mathrm{kloc}\right)^{d}\end{array}$ & 286.0 & $(73.3)$ & 505.0 & $(72.2)$ & 432.0 & $(65.5)$ & 452.0 & $(57.1)$ \\
\hline LPG (10 tonnes) & 5.9 & & 14 & & 20 & & 25 & \\
\hline Total $^{e}\left(10^{6} \mathrm{kloe}\right)^{d}$ & 390.0 & $(100)$ & 700.0 & $(100)$ & 660.0 & $(100)$ & 792.0 & $(100)$ \\
\hline
\end{tabular}

\footnotetext{
${ }^{a}$ The data in this table were provided by the Advisory Committee for Energy. Figures in this provisional outlook may be changed in accordance with the results of future studies.

$b_{1}$ represents a reference case in which Japan pursues current energy policy.

${ }^{c}$ II represents an accelerated energy policy case, with maximum government and private sector cooperation in conserving energy.

$d$ "kloe" is $10^{3}$ liters of oil equivalent, and is calculated assuming that $9400 \mathrm{kcal}$ is equivalent to one liter. The rate of energy conservation is based on 1973 figures.

${ }^{e}$ The values in the columns have been rounded so that the figures quoted as totals may not actually equal the sums of the figures in each column.
} 


\section{TABLE 10.1 (continued)}

\section{Comments}

Fiscal year 1985 I

In view of the likely world petroleum supply and demand situation, Japan may well have difficulty in obtaining 505 million $\mathrm{kl}$ of imported oil. Thus an energy shortage is likely to develop.

Fiscal year $1985 \mathrm{II}$

The volume of imported oil quoted here (432 million $\mathrm{kl}$ ) is the minimum considered necessary if maximum energy conservation and development of new sources of energy are assumed.

Fiscal year $1990 \mathrm{II}$

The fiscal 1990 reference case shows that oil imports will reach 587 million $\mathrm{kl}$. It would be very difficult to obtain this volume with the expected constraints on world oil supply. Thus if insufficient energy is conserved, there is likely to be a greater shortfall in fiscal 1990 than in fiscal 1985.

fuel consumed. Gasoline and diesel oil consumption in the private sector is estimated using the number of automobiles on the roads and approximating the amount of fuel required. The amount of fuel used in transporting goods is deduced by estimating the volume of goods moved by each means of transport, the types of fuel used by each means of transport, and the various efficiencies of energy use.

The total energy demand is the sum of demand in the industrial, commercial, domestic, and transportation sectors, calculated as described above.

\section{Energy conservation}

The Energy Conservation Research Center of the IEE has conducted several studies on energy conservation, using sample surveys and econometric methods ${ }^{6,7}$.

\section{ANALYSIS OF ENERGY SUPPLY}

\section{Primary energy supply and the energy chain}

There are two types of energy supply analysis: those investigations conducted in parallel with demand analysis and those carried out quite separately. However, all investigations are ultimately brought together and incorporated in an overall energy supply-demand balance.

In one approach, the total primary energy requirements derived from the model described above are adjusted by an internationally accepted method: demand is first met by energy forms that function as petroleum alternatives, and the remaining shortfall is assumed to be made up by petroleum. A realistic estimate for the supply of alternative energy forms is obtained by studying the state of development of related government and industry programs. In addition, the specific consumption figures described above are then subdivided into separate figures for 
each energy form, and the demand for each type of fuel in the domestic, transport, and other sectors is calculated for each type of equipment and mode of transport. This determines the final end-use energy requirements. The electric power supply is estimated on the basis of nuclear power, LNG- and coal-fired generation capacities, while the supply of gas includes only that based on LNG and LPG. Petroleum is seen as making up the balance. The end-use demand for each category of energy is then converted back to primary energy using a conversion/allocation model.

\section{Constraints}

As already mentioned, Japan is faced with two major constraints in the energy field: restrictions on $\mathrm{NO}_{x}$ and $\mathrm{SO}_{2}$ and the need for increased importing of heavy crude oil. Both of these may have a significant effect on the energy supplydemand pattern. A fuel option model incorporating these constraints can be used to check the results of the entire energy chain. This fuel option model is a linear programming (LP) model whose objective function (aim) is minimum cost. The optimum solutions resulting from this model are used to revise the demand for each oil product in each sector and each individual industry ${ }^{8}$.

\section{Extension of framework}

Since petroleum currently meets over $70 \%$ of Japan's total energy requirements, and this figure is unlikely to fall below $60 \%$ in the future, the need to obtain oil is a major problem in national energy planning. The IEE has therefore developed a world oil trade model which has been used to investigate the varieties of crude oil and oil products that could be imported to Japan. This is an LP model with an objective function of minimum total cost which simulates the trade in 38 varieties of crude oil and 6 varieties of oil products in 19 areas of the world. Restrictions governing the sulfur content of fuel oil are treated as constraints in the more industrialized areas. An Asia-Pacific oil trade submodel has also been developed 9,10 . At a lower level of aggregation, the IEE has introduced an energy supply-demand forecasting model for 47 regions (prefectures) within Japan. This model employs fundamentally the same methods as the international model, but the movements of population and industry between regions are also included ${ }^{11}$.

\section{ENVIRONMENTAL ANALYSIS}

Japan's national atmospheric pollution controls are the strictest in the world (see Tables 10.2 and 10.3), and the local authorities have adopted even more stringent standards than the central government. As a result, only fuel with a sulfur content of less than $0.3-0.5 \mathrm{wt}$. percent can be used in the large urban centers and sur- 
TABLE 10.2 Air quality objectives in Japan and selected OECD countries, $1975^{a}$.

\begin{tabular}{lllc}
\hline Country & $\begin{array}{l}\mathrm{SO}_{2} \\
\text { (p.p.m.) }\end{array}$ & $\begin{array}{l}\text { Particulates } \\
\left(\mathrm{mg} / \mathrm{m}^{3}\right)\end{array}$ & $\begin{array}{l}\mathrm{NO}_{2} \\
\text { (p.p.m.) }\end{array}$ \\
\hline Japan & 0.04 & 0.10 & 0.02 \\
Canada & 0.06 & 0.12 & $0.10^{b}$ \\
Finland & 0.10 & 0.15 & 0.10 \\
Italy & 0.15 & 0.30 & - \\
USA & 0.14 & 0.26 & $0.13^{c}$ \\
FRG & 0.06 & - & $0.15^{d}$ \\
France & 0.38 & 0.35 & - \\
Sweden & 0.25 & - & - \\
\hline
\end{tabular}

${ }^{a}$ These data were provided by the OECD. All figures are average daily values.

${ }^{b}$ This figure is for Ontario; the figure for Saskatchewan is much lower $(0.01)$.

${ }^{c}$ The USA sets its $\mathrm{NO}_{2}$ objective in terms of an average yearly value of 0.05 p.p.m. The figure given is therefore an equivalent open to criticism.

${ }^{d}$ The FRG has two standards: 0.05 p.p.m. for long-term exposure and 0.15 p.p.m. for short-term exposure.

rounding industrial areas, and new power-generation facilities built in these areas must be LNG-fired.

Until recently, environmental policy was largely directed at reducing the emission of $\mathrm{SO}_{2}$. The action taken included a reduction in the sulfur content of imported crude oil, direct burning of low-sulfur crude oil, desulfurization at oil refineries, stack-gas desulfurization, and increased use of LNG. The air over Tokyo has become much cleaner as a result, and there is now more refinery desulfurization capacity than required.

In the future, however, the problem of nitrogen oxides $\left(\mathrm{NO}_{x}\right)$ is likely to rival or exceed that of $\mathrm{SO}_{2}$. Emission of $\mathrm{NO}_{x}$ is of two main types: stationary and non-

TABLE 10.3 Automobile emission standards in Japan and selected OECD countries $^{a}$.

\begin{tabular}{lccc}
\hline Country & $\begin{array}{l}\mathrm{CO} \\
(\mathrm{g} / \mathrm{km})\end{array}$ & $\begin{array}{l}\mathrm{C}_{x} \mathrm{H}_{y} \\
(\mathrm{~g} / \mathrm{km})\end{array}$ & $\begin{array}{l}\mathrm{NO}_{x} \\
(\mathrm{~g} / \mathrm{km})\end{array}$ \\
\hline Japan (1976) & 2.10 & 0.25 & 0.60 \\
Japan (1978) & 2.10 & 0.25 & 0.25 \\
USA (Federal government) (1975) & 9.30 & 0.93 & 1.93 \\
USA (California) (1975) & 5.60 & 0.56 & 1.24 \\
Canada (1975) & 15.62 & 1.25 & 1.94 \\
Canada (future) & 2.13 & 0.25 & 1.94 \\
Sweden (1976) & 24.20 & 2.10 & 1.90 \\
\hline
\end{tabular}

${ }^{a}$ These data were provided by the OECD. Testing methods vary from country to country and comparisons must be made with great care. 
stationary. The latter is due mainly to automobiles, and improvements in this area are being made, e.g., by engine modifications, in response to stringent emission controls. The former presents a more formidable problem over the long term.

In Japan, planning and management of energy/environment systems ultimately resolves itself into the question of what supply system to build, i.e., what fuel mix and methods of waste disposal to employ. The Environment Agency is presently conducting a wide-ranging environmental analysis which considers (among other things), the impact of energy production and consumption on human health and the economic aspects of pollution control ${ }^{12}$.

\section{National industry-wide energy analysis}

The National Institute for the Advancement of Research has conducted a study of the effect that restrictions on $\mathrm{SO}_{2}$ and $\mathrm{NO}_{x}$ may be expected to have on energy supply and demand up to the year 2000. This was one of several projects undertaken jointly by seven Japanese research organizations* including the IEE ${ }^{13}$. In addition to this study, the IEE has conducted an independent analysis of the effects of $\mathrm{NO}_{x}$ restrictions on the supply of and demand for fuel, and their effects on the refining industry. This analysis was carried out for the year 1985 using an improved version of the fuel option model described above, and covered such topics as necessary adjustments in $\mathrm{NO}_{x}$ controls, the cost of reducing $\mathrm{NO}_{x}$ emission, the increase in fuel consumption caused by installation of more flue gas denitration units, the extra cracking capacity required, and the extra investment needed to produce the lighter petroleum fractions at refineries ${ }^{14}$.

The results of this analysis demonstrate the need to install stack-gas desulfurization and flue-gas denitration facilities at power plants and factories employing coal. This would eliminate the $\mathrm{SO}_{2}$ and $\mathrm{NO}_{x}$ produced by sulfur and nitrogen in the fuel, as well as the $\mathrm{NO}_{x}$ resulting from combustion. However, it would also give rise to rapid increases in costs and lead to greater fuel consumption (due to lower combustion efficiency). If the use of coal is to increase in the future, development of new technologies would be necessary. These would include techniques for the liquefaction and gasification of coal, the use of solvent-refined coal and colloidal coal-oil mixtures, and the production of methanol from coal.

\footnotetext{
- These research organizations are investigating the following subjects: (a) Institute of Energy Economics, An Analysis of Energy Supply and Demand in 1985 and 2000; (b) Japanese Economic Research Center, $A$ Study of the Socioeconomic Framework of Energy Supply and Demand in 2000 ; (c) Institute for Future Technology, An Analysis of Environmental Restrictions on Energy Production and Consumption; (d) Japanese Industrial Policy Research Institute, An Analysis of the Effects of Heat Generated by Energy Consumption in Urban Areas: (e) Mitsubishi Research Institute, A Quantitative Analysis of Raising the Efficiency of Energy Use in Industry; ( $)$ Nomura Research Institute, A Quantitative Analysis of Raising the Efficiency of Energy Use in Transportation; (g) Industrial Research Institute, Technical and Economic Analysis and Evaluation of New Energy Supplies, including Coal and Nuclear Power. (The names of these projects have been translated from the original Japanese.)
} 
As pollution was controlled more strictly and alternatives to petroleum were adopted, the demand for increasingly lighter oil products would grow. This would result in increased costs and the need for more energy to produce lighter fractions of oil.

Such large-scale conversion would require enormous investment of funds, technological development, and the construction of new facilities. If these were not forthcoming, the domestic primary energy supply-demand balance would be disrupted at all stages, even if sufficient quantities of crude oil and coal were available from overseas. This is the most important problem that will face Japan in its planning and management of the energy/environment system up to the end of the century.

\section{Regional analysis}

A study of the possible introduction of LNG may be used to illustrate one aspect of regional energy/environment analysis ${ }^{15}$. The IEE divided Japan into 14 regions, and analyzed the competition between oil and the major alternative fuel sources in each of them. Special emphasis was placed on the maximum feasible volume of LNG that could be introduced into each of the industrial heating sectors. This was a simulation study which considered a variety of possible scenarios for the years 1985 and 2000. Three submodels were used to forecast the alternative demands for oil and gas in the 14 regions in 1985 and 2000; a macroeconomic model, a national energy supply-demand forecasting model, and a regional-sectoral energy demand forecasting model. The results of this study and the combustion efficiency ratios of the various fuels used in eight types of furnace were then used to determine the effective energy demand by region and by type of furnace. These results were finally fed into the regional LNG-oil competition model, a linear programming model with restrictions on $\mathrm{SO}_{2}$ and $\mathrm{NO}_{x}$ emission as its major constraints, and minimum cost as its objective function. This model also contains a highly detailed subroutine dealing with transportation.

Another example of regional analysis took the form of research into energy demand in urban areas and utilization of waste heat from garbage incineration ${ }^{16}$. This study was divided into two parts. The first involved an analysis of the types of energy consumed in the large cities, especially Tokyo. The food and service industries were questioned on the quantities and types of fuel that they consume, and specific consumption and other energy indicators were calculated. The second part involved an investigation of the utilization of waste heat from city garbage incinerators. Nine garbage incineration plants making some use of their waste heat were investigated; the systems employed, the volume incinerated, the costs, effectiveness, and various other factors were analyzed. In addition, forecasts of garbage production in the year 2000 were used to construct a model of an incineration plant providing regional heating and generating power in an ideal city 
of the future. The feasibility of this idea was assessed in terms of the economies of waste heat utilization and the energy balance.

\section{INTEGRATING DECISION MAKING AND ANALYSIS}

Many of the studies discussed above were carried out by the IEE, and other research organizations, under contract to the Ministry of International Trade and Industry, other central government agencies, or related bodies. The results of such studies are submitted to the government departments and advisory councils concerned with energy, for use in policy making. The studies often involve the formation of committees and discussion groups (workshops) composed of executives from the energy industry and experts in energy systems. In addition, the executives and research staff of the IEE and other research organizations concerned with energy are often leading members of government advisory councils and provide most of the experts attending the workshops. Thus the workshop is used in Japan as a means of both communicating the results of analyses to users, and obtaining feedback from those users.

Other IEE reports commissioned by the government include a systems analysis of petroleum transportation and distribution ${ }^{17}$ and a study of the impact of rising energy costs on the Japanese economy ${ }^{18}$; the Agency of Science and Technology (a branch of the IEE) has also undertaken a medium- and long-range analysis of nuclear power strategies*. Communication with industry is achieved largely through workshops set up through the Energy Strategy Committee. This committee is supported jointly by the Committee for Energy Policy Promotion (composed of top executives from all of the major industries) and the IEE. The workshops produce medium- and long-term forecasts of energy supply and demand, estimate energy funding requirements, and prepare energy policy recommendations.

The major difficulties encountered in communication are listed below.

1. Communication with the government is made difficult by frequent changes in the personnel controlling the government departments concerned with energy. Since medium- and high-level officials change approximately every two years, any continuity in communication is impossible. Moreover, the budget (prepared by the Ministry of Finance) allocated for implementing policy and administration is never sufficient, so that the recommendations of the analysts are rarely incorporated fully into the government program.

\footnotetext{
* This analysis is based upon the following studies: Strategies for a New Type of Power-Generating Reactor, Enrichment, and Spent Fuel Reprocessing in Japan (commissioned in 1975); The Security of the Supply of Nuclear Energy (commissioned in 1976); and Nuclear Fuel Supply and Demand to the Year 2000 and the Optimization of Nuclear Fuel Stockpiling (commissioned in 1978). (The names of these studies have been translated from the original Japanese.)
} 
2. When new government policy runs the risk of interfering directly or indirectly in the affairs of the energy industry, especially when the policy may interfere with vested interests or the established order, private industry reacts strongly against implementation of the analytical results suggesting this policy. In addition, it is often quite difficult to resolve conflicts of interest between the various energy industries (oil, electric power, gas, etc.) and between individual firms in each industry. Japanese industry does not seem to appreciate the full scope of systems analysis; there is a tendency for industry to be excessively concerned with the political implications of such work.

3. In the past, there was almost no direct communication between analysts and politicians. However, all six of the political parties holding seats in the Diet have recently produced their own energy supply-demand outlooks and detailed energy policy statements, showing that they have at least given serious thought to the subject. IEE researchers and energy experts are often asked by political parties to provide specialized information and to give lectures on energy matters. Nevertheless, the political parties still display little interest in the long-term aspects of energy systems, limiting themselves almost completely to policy relevant to the 20th century. This may be a result of the widening gap between the inherently long-term nature of energy planning and the relatively short-term concerns of politicians (such as winning elections).

\section{REFERENCES}

1 Ministry of International Trade and Industry. Promotion of Consistent and Comprehensive Energy Policies-Energy Program for Japan (in English). Tokyo, December 1977.

2 Ministry of International Trade and Industry, Agency of Natural Resources and Energy. Longrun Outlook for Japan's Energy Problems-Choices for the Year 2000 (in Japanese). Tokyo, October 1977.

3 Institute of Energy Economics. Energy Matrix (in Japanese and English). Tokyo, published yearly.

4 H. Izumi. An Econometric Analysis of the Recent Changes in Specific Energy Consumption in Japan (in Japanese). Institute of Energy Economics, Tokyo, August 1980.

5 Ministry of International Trade and Industry. Analysis of the 1978 MITI Input-Output Table and Energy Consumption (in Japanese). Tokyo, 1980.

6 Institute of Energy Economics. Present State and Potential of Energy Conservation in Japan (in Japanese and English). Tokyo, 1979.

7 Institute of Energy Economics. National Living Standards and Residential/Commercial Energy Demand (in Japanese and English). Tokyo, 1980.

$8 \mathrm{~K}$. Matsui. Long-term energy demand and supply forecast for Japan in a new situation, 1985-1990 (in English). Supplement to Energy in Japan Quarterly Report 36 (2), 1977.

9 T. Tomitate and K. Fujime. Future oil flow in the world and conditions for oil supply to Japan (in English). Supplement to Energy in Japan Quarterly Report 24 (2), 1974.

10 T. Tomitate. Future oil flow in the Asia-Pacific region (in English). Paper submitted to the First Conference of the ASEAN Council on Petroleum (ASCOPE), Jakarta, October 1977. 
11 Institute of Energy Economics. Systems Analysis of Future Demand for Oil Products and their Interregional Transportation (in Japanese). Report prepared by the IEE for the Ministry of International Trade and Industry, Tokyo, February 1976.

12 Environment Agency. Quality of the Environment in Japan in 1977 (in English). Printing Bureau, Ministry of Finance, Tokyo, December 1977.

13 National Institute for the Advancement of Research. Choice of a Long-Term Energy Strategy, 1985-2000 (in English). Tokyo, January 1977.

14 Y. Hara and K. Ogawa. Changes in oil supply-demand structure and problems in the refining industry--effects of reduced $\mathrm{NO}_{x}$ emissions on fuel supply and demand (in English). Energy in Japan Quarterly Report, March 1978.

15 Institute of Energy Economics. LNG Demand Structure and Supply System (in Japanese). Report SR 99, IEE, Tokyo, June 1977.

16 Institute of Energy Economics. An Analysis of Energy Consumption Structure and Utilization of Waste Heat in Large Cities in Japan (in Japanese). Report SR 102, IEE, Tokyo, March 1978.

17 Institute of Energy Economics. Systems Analyses of Transportation and Distribution of Oil Products in Japan (in Japanese). Reports prepared by the IEE for the Ministry of International Trade and Industry, Vols. 1-3, Tokyo, 1975-1977.

18 Institute of Energy Economics. An Analysis of the Impact of Rising Energy Costs on Japan's Economy and Major Industries (in Japanese). Report prepared by the IEE for the Economic Planning Agency, Tokyo, March 1977. 


\title{
11 Management and Planning of in Poland
}

\author{
Wieslaw Ciechanowicz* and Marek Makowski*
}

\section{INTRODUCTION}

This chapter describes the energy/environment research carried out at the Systems Research Institute (SRI) of the Polish Academy of Sciences. The views put forward here are solely those of the authors who, however, hope that the models described will prove useful to decision makers in Poland.

It is generally agreed that energy problems should be considered in conjunction with economic and environmental management. Similarly, environmental planning should not be separated from economic planning. It is therefore important to carry out an analysis incorporating all elements of the energy/environment/ economic system.

Since it seems unrealistic to try to construct one model representing the whole of the economy, a "core model" has been employed', and extended using a family of more detailed models. This "family" falls into two main classes: regional models and sector-specific models. Regional models are discussed in more detail in ref. 2. The sector-specific models describe those branches of the economy that must be considered in development planning, e.g., energy, food and agriculture.

The aim of this research is to develop models that can be used in energy systems planning. The analysis must therefore cover the whole energy chain from the extraction of primary energy resources to the production and consumption of energy, while ensuring that all proposals are consistent with overall economic development. We avoid the supply-oriented approach based on assumed energy demand since it is thought that problems of energy supply and demand should be considered simultaneously.

\footnotetext{
* Systems Research Institute, Polish Academy of Sciences, Warsaw.
} 
The system of models used at the Systems Research Institute has the structure shown in Figure 11.1, and involves three mutually linked models:

1. The Energy Production and Consumption System (EPCS) model which is composed of two submodels dealing with the Energy Consumption System (ECS) and the Energy Production System (EPS). These are discussed in subsequent sections.

2. A core model, which in this case includes all of the economy except for the energy sector. This model is described in the next section.

3. The Environmental Protection (EP) model, which is discussed in a later section.

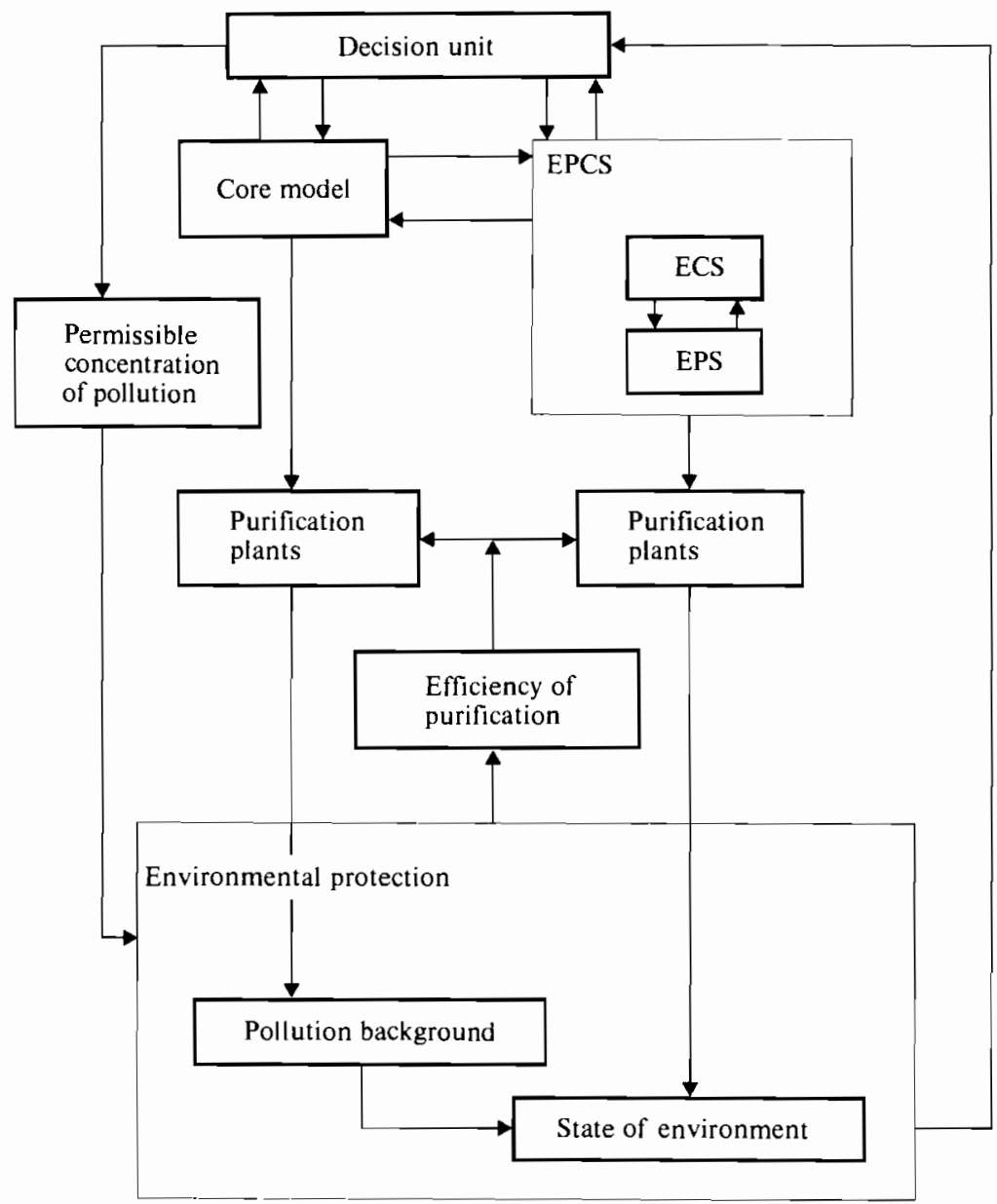

FIGURE 11.1 General structure of the SRI system of models. 
The EPCS model is constructed in such a way that it may be used as part of a larger model as well as functioning as a separate open-loop system for energyoriented studies, e.g., for preliminary selection of energy development strategies.

Using this approach, it is possible to obtain answers to many important questions, such as:

1. What would be the results of various development strategies in terms of the demand for different types of energy?

2. How should the energy system be developed so that it is compatible with a given economic development plan in terms of various targets and constraints? When should different technologies be introduced, and which technologies should they be?

3. What would be the effect of a change in energy consumption (both in the total amount and in the amounts obtained from various sources) on the possible methods and cost of supplying energy?

4. What would be the effect of a rational "chain of decisions" (concerning technology options, development strategies, location of new plants, and maximum levels of pollution) on the cost of producing energy, assuming that all pollution standards are met?

Some of these questions should be considered in planning at the national level, although most of them should also involve a regional analysis, especially if there are environmental implications.

\section{ENERGY CONSUMPTION SYSTEM (ECS)}

The ECS model involves an intensive energy-demand-oriented analysis of national economic development. The amounts of energy produced and consumed in each sector of the economy are generated by a core model and are treated as exogenous variables in the ECS model.

A normative model of complex development, e.g., one of the MRI $(I=0,1,2, \ldots)$ series $^{1}$, may be used as the core model. The MRI models are designed to derive the values of decision variables (allocation of resources and investment among different sectors, and intersectoral flows) and to forecast the most important economic variables (volumes of sectoral production and consumption, capital stock, employment, and so on). The most recent version of the MRI series, MR4, examines 15 industrial sectors and one consumption sector, the latter including both individual and aggregate consumption. A new MRI variant still being developed will make a more detailed examination of a smaller number of sectors and will also include the results of further research on the shape of the production function, the share of investments in the GNP, international trade, and other related questions. For regional planning one may adopt the model ${ }^{3-5}$ 
developed for Silesia, a highly industrialized region of Poland. This model is designed to examine regional development with special reference to the environment. The environmental consequences of development are discussed later in this chapter.

The energy consumption system is composed of a number of sectors that have been selected on the basis of their energy use. The production intensities of these sectors, as determined by the core model, are then aggregated into a vector $x(t)$. The components of this vector represent the intensity of production or other activity in each ECS sector. The energy consumption system is currently composed of three sectors: industrial, transportation, and residential. Each of these sectors may be split into a number of subsectors.

The ECS model is described by the linear input-output relation

$$
x(t)=\mathbf{A}(t) y(t)
$$

where

$\boldsymbol{x}(t)=\left[x_{1}(t), x_{2}(t), x_{3}(t)\right]$, where $x_{1}(t), x_{2}(t)$, and $x_{3}(t)$ are the intensities of production or other activity in the industrial, transportation, and residential sectors, respectively

$y(t)=\left\lfloor y_{j}(t), j=1,2, \ldots, J\right]$, where $y_{j}(t)$ denotes an amount of secondary energy source $j$, and $J$ is the number of sources considered

$A$ is a matrix of coefficients which characterize the efficiency of energy source utilization; matrix A may be optimized, as discussed later

A scenario analysis is generally carried out to investigate the various technologies used in processes that are known to be big energy consumers and/or substantial pollution sources. This evaluation of different technology options should also involve the possibility of substituting one source by another and should lead to a preliminary set of admissible combinations of technologies for energy consumption processes, i.e., different $\mathbf{A}$ matrices. This approach was used in an analysis of the transportation sector ${ }^{6}$.

The ECS model may also be used to analyze the energy demand in various scenarios assuming differential development of the sectors and different combinations of technologies. The energy demand may be defined by

$$
y(t)=\mathbf{A}^{-1}(t) x(t)
$$

Thus the energy demand can be calculated using both economics-based models and models describing selected processes. Note that "demand" is usually understood as the quantity of a commodity that a consumer would purchase at a given place, time, and price, and since future prices are unlikely to be known exactly, the energy demand calculated by the core model is not sufficiently precise to be used for supply analysis. 
In preliminary runs of the EPS model, the energy demand was based on predicted population growth and an assumed primary energy consumption per capita.

\section{ENERGY PRODUCTION SYSTEM (EPS)}

The Energy Production System (EPS) includes the entire chain from extraction of raw materials, through the transportation of energy, up to the conversion of primary energy to secondary energy forms.

The EPS may be divided into a number of subsystems: fossil fuels; substitutes for fossil fuels; electrical energy; and nuclear power. The EPS model is described by the input-output relation

$$
y(t)=\mathbf{B}(t) z(t)
$$

where

$y(t)$ is the production intensity vector identified with particular energy sources

$z(t)$ is a production intensity vector, the components of which represent the production intensities of the primary energy production sectors

$\mathbf{B}(t)$ is a matrix of coefficients which characterize the efficiency of the conversion of primary energy to secondary energy forms; the matrix $\mathbf{B}$ may be optimized, as discussed later

Two particular problems in the development of energy production systems have been studied in more detail. These are the possible expansion of the nuclear fission system ${ }^{7}$, and the coal-mining industry ${ }^{8}$.

The general structure of the energy production and consumption systems is presented in Figure 11.2.

The analysis of the fuel supply and electrical energy subsystems includes:

- Preliminary forecasts of the amounts of fossil fuel substitutes and electrical energy to be produced.

- Evaluation of development scenarios with respect to the efficiency of coal utilization and the reduction of liquid fuel and electricity shortfalls.

The following scenarios were investigated:

1. The electrical energy subsystem uses conventional power plants while the fuel supply subsystem utilizes coal directly.

2. The electrical energy subsystem is based on combined gas-steam turbine cycle plants powered by low-Btu gas, wind energy generators, and bottoming cycle technology (Rankine cycle) involving the utilization of industrial waste heat. In the fuel supply subsystem, conventional utilization of fossil fuels is replaced by use of autothermal coal gasification techniques. 


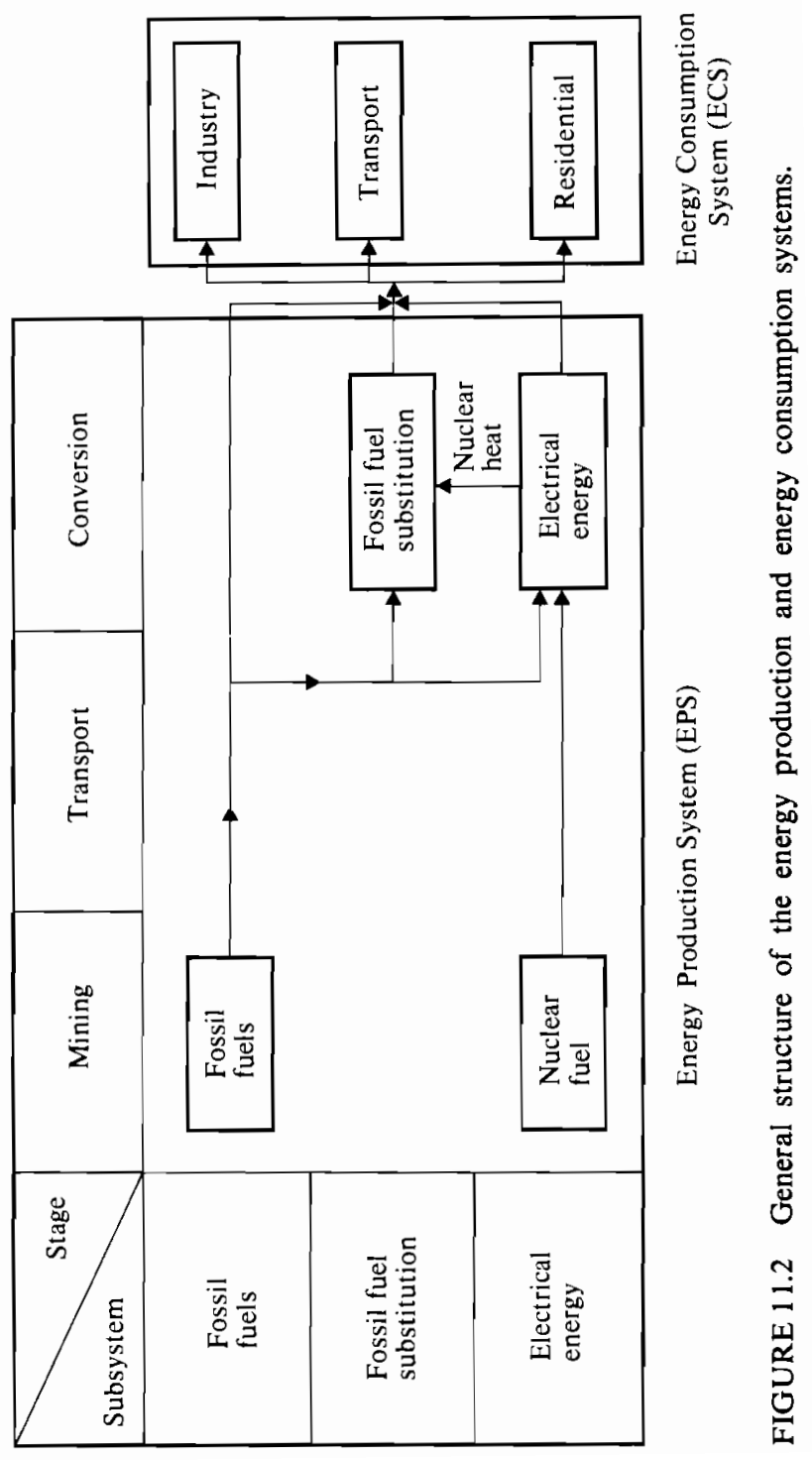


3. The electrical energy subsystem is based on conventional power plants and provides for the utilization of the low-temperature heat generated by hightemperature reactors, while the fuel supply subsystem is based on the use of high-temperature reactors (HTRs) to gasify coal.

4. The same as scenario 3 except that HTRs will be used to gasify lignite.

Because of the constraints imposed on increased mining of coal by transportation problems and environmental issues, it was assumed for all scenarios that any electrical energy shortfall would be covered by the use of light water reactors, and that any shortfall in fuels would be eliminated by importing oil and/or natural gas.

The preliminary analysis of the nuclear option was designed to provide answers to the questions:

- What is the best solution to the problem of nuclear expansion?

- What is the scale of the problem that must be faced in the future?

The nuclear system under investigation is assumed to contain a combination of light water reactors, high-temperature reactors, "near breeder" and fast breeder reactors.

\section{ENVIRONMENTAL ANALYSIS}

The approach used here to analyze the environmental consequences of economic and industrial development is described in detail in ref. 9; more recent accounts are given in refs. 10 and 11 . Only the main points of this approach are outlined below.

The quality of the environment is reflected in the Systems Research Institute model by the concentration of various air pollutants. This approach could easily be extended to water and land pollution if the relevant transportation and transformation models could be obtained. Neither risk assessment nor the question of the damage to landscape caused by mining is included in the model, although both problems can be brought into the decision-making process indirectly through adequate scenario analysis.

Polish legislation currently restricts the concentration of 185 air pollutants. If more than one pollutant is discharged into a particular area then it is necessary to check an additional index: the total annual dose of pollution in this area. The dose is the weighted sum of the concentrations of individual pollutants, where the weighting coefficient represents the toxicity of the pollutant with respect to sulfur dioxide. In general, the dose must not exceed the maximum permissible annual mean concentration of sulfur dioxide $\left(0.097 \mathrm{mg} / \mathrm{m}^{3}\right)$ by more than $50 \%{ }^{12}$. However, the maximum concentrations permitted in some parts of the country are much lower than those allowed in other areas. It is assumed that pollution concentrations are acceptable if both the direct and the indirect impacts of pollution 
on human health are small enough that the cost of reducing pollution still further would not be justified by the resulting improvements in health. However, the problem of deciding on admissible pollution concentrations is still a subject of much discussion ${ }^{12,13}$. It is generally thought that a reliable financial estimate of the environmental damage caused by pollution is needed to resolve this problem ${ }^{9}$.

The actual concentration of pollutants in the environment is determined by the level of emission, i.e., the amount of pollutants discharged into the environment. (Emission may be subject to control, while concentration reflects environmental quality.) A relationship between emission and concentration may be determined with the help of a transportation and transformation model ${ }^{12}$. An efficient set of programs has already been developed for this purpose ${ }^{14}$, though it is only possible to obtain a relationship between emission and concentration for a given set of pollution sources and meteorological conditions. This type of relationship can also be used to choose the best location for new plants and to decide when it is necessary to invest in purification devices.

For these purposes it is necessary to divide emission sources into two groups. The first one comprises emission sources whose parameters are fixed; the pollution caused by this group is called the background. The second group contains the rest of the emitters and is much smaller than the first. The model calculates total emission in two steps: the background is estimated in the first run and the emission from the other sources is calculated and added to the background in the second.

Since it is impossible to determine the concentration of pollutants without knowing the location of all the emitters, and since the location of future emitters is not known when long-term planning takes place, a new index must be introduced. This is the total amount of permissible emission (PE), a vector whose components correspond to the various types of pollutants. It is assumed, however, that the usual policy of locating new plants such that the concentration of pollutants will remain below the legal limits ${ }^{12}$ will be continued.

The permissible emission is in fact a decision variable which may be determined by taking into account the current level of emissions and the concentration of pollutants. The PE must be determined on the same basis as the admissible concentration referred to earlier.

The emission of pollutants may be adjusted in two ways:

1. Changes in levels of production and consumption throughout the economy

2. Advances in technology (e.g., increasing the efficiency of purification plants)

However, only the technological aspects of emission may be optimized in energy/environment planning. Decisions about the level of production may be made during the iterative procedure discussed in the next section. 
It is therefore assumed that the environmental constraint

$$
G(x, \mathbf{A}, \mathbf{B})=P(\mathbf{A}, x)+P(\mathbf{B}, z)+\mathbf{B E} \leqslant \mathbf{P E}
$$

must be fulfilled, where

$P(\mathbf{A}, \boldsymbol{x})$ is the pollution emitted during consumption of different forms of energy by technologies $\mathbf{A}$ with production intensities $\boldsymbol{x}$

$P(\mathbf{B}, z)$ is the total pollution emitted during production of various forms of energy by technologies $\mathbf{B}$ using volumes of primary energy sources $z$

BE is the background emission, i.e., emission by all sources with fixed parameters; the value of BE may be determined by the core model

\section{PLANNING IN THE ENERGY PRODUCTION/CONSUMPTION SYSTEM}

The development of the Energy Production and Consumption System (EPCS) is planned at four hierarchical levels ${ }^{15}$, each of which is identified with a different time horizon. These are:

- Development planning (40-50 years)

- Long-range planning (15-25 years)

- Middle-range planning (1-4 years)

- Short-range planning, which deals largely with production on a daily or weekly basis

Most of the research at the SRI has been concentrated on development planning ${ }^{16}$. This involves three main groups of problems:

- Local problems, i.e., the expansion of individual EPCS sectors

- Coordination problems, i.e., the distribution of resources between sectors or subsystems of the EPCS

- Consistency problems, i.e., the difficulty of achieving solutions of the core model and the EPCS model that are consistent with each other

The performance of the EPCS model may be measured by

where

$$
Q=\int_{0}^{T}[f(\mathbf{A}, \mathbf{B}, t)+g(\mathbf{A}, \mathbf{B}, t)] \mathrm{d} t
$$

$T$ is the time horizon (about $40-50$ years)

$f$ is a function that represents the cost intensity associated with the utilization of a specific technology, i.e., the amount of investment necessary, operating costs, research and development costs, the cost of raw materials, the cost of transportation, etc. 
$g$ is a function that expresses the profit from energy conservation, which is equivalent to the reduction in the bill for energy imports

$\mathbf{A}$ is a matrix of energy consumption coefficients, with rows which correspond to individual sectors of the ECS and columns which represent energy sources

B is a matrix of energy production coefficients, with rows which correspond to secondary energy sources and columns which represent primary sources

The decision variables are the technologies producing and consuming energy, and are represented by matrices $\mathbf{B}$ and $\mathbf{A}$, respectively. Note that $\mathbf{A}$ and $\mathbf{B}$ depend on time, i.e., the question of changing technologies over a period of time is also considered.

Any solution must therefore obey the foilowing constraints:

1. The production intensity $x(t)$ used in the ECS model must be equal to that determined by the core model

2. The environmental constraint (4) must be obeyed

3. The primary energy resources $z(t)$

$$
z(t)=\mathbf{B}(t)^{-1} \mathbf{A}(t)^{-1} \boldsymbol{x}(t)
$$

must not be greater than an assumed amount

4. The secondary energy sources $y(t)$ defined by eqn. (2) must not be greater than an assumed amount

5. The industrial capacity for new technologies is limited

6. The investment funds are limited

These constraints are explained more fully in refs. 15 and 17, and a method of solving a simplified version of the model is presented in refs. 17 and 18 .

To solve the problem presented above, it is necessary to carry out a scenario analysis for a number of subsets of the suitable sets of technologies and energy resources, and then compare the corresponding values of $Q$ (eqn. 5). This results in a choice of technologies for the conversion and utilization of energy and determines the amounts of primary and secondary energy of various forms required, as well as all costs associated with the scenario. The optimal EPCS developmentstrategy is then determined for this preliminary set of technologies.

The EPCS solution is introduced into the core model and modifies the parameters of the core model, i.e., the goal function, the production function, and the intersectoral flows. The next run of the core model then leads to the introduction of a new set of intensities of production and consumption in the ECS sectors and the modification of certain constraints, i.e., investment capacities, in the next run of the EPCS model. This iterative procedure is continued until the solutions of the EPCS model and the core model are consistent with each other. Note that the number of alternative sets of acceptable $\mathbf{A}$ and $\mathbf{B}$ matrices decreases very rapidly in consecutive runs of the EPCS model. 


\section{ACKNOWLEDGMENTS}

M. Deptuła, R. Dragg, and T. Obidziński contributed greatly to research on the EPCS model. The authors also thank T. Gawda for her assistance in the preparation of this report, and appreciate a number of valuable discussions with the staff of the Large-Scale Systems Theory Department at the Systems Research Institute (SRI) and with the staff of the International Institute for Applied Systems Analysis (IIASA). A number of papers forwarded to us by the IIASA study group on planning and management of regional energy/environment systems were also very helpful. Finally, the authors are indebted to H. Gasking for skillfully editing and clarifying the paper.

\section{REFERENCES}

1 G. Bruckmann (Ed.). SARUM and MRI: Description and Comparison of a World Model and a National Model. Proceedings of the Fourth IIASA Symposium on Global Modelling, Pergamon Press, Oxford, 1978.

2 L. Krus. Normative modelling of regional development. In A. Straszak (Ed.), Models for Regional Planning and Policy-Making. Proceedings of a Joint IBM/IIASA Conference, Vienna, 1977.

3 W. Ciechanowicz and M. Deptula. On the Expansion of the Energy Production System with Respect to the National and the Silesian Economy (in Polish). Report IBS 221, Systems Research Institute, Warsaw, 1978.

4 L. Kruś, M. Makowski, and J. Sosnowski. Optimization of development planning for the Silesia region with constraints on air pollution emission (in Polish). In R. Kulikowski (Ed.), Problems of Modelling the Economy and Environment (in Polish), PWN, Warsaw, 1979.

5 L. Krus (Ed.). A Normative Model of Silesian Development (in Polish). Internal report, Systems Research Institute, Warsaw, 1980.

6 T. Obidzinski. Expansion Strategy for the Transport Sector of the Energy System. Part I (in Polish). Report ZTSW 9-64/78, Systems Research Institute, Warsaw, 1978.

7 M. Deptuła. Nuclear Fission System Model (in Polish). Report ZTSW 10-64/78, Systems Research Institute, Warsaw, 1978.

8 M. Deptuła, R. Drąg, W. Niepostyn, and T. Obidziński. Planning the Development of an Energy System (in Polish). Report ZTSW 21-64/78, Systems Research Institute, Warsaw, 1978.

9 M. Makowski. Subsystem dealing with the environment in the normative model of complex development. In K. Cichocki and A. Straszak (Eds.), Systems Analysis Application to Complex Programs. Proceedings of the IFAC/IFORS/IIASA Workshop, Pergamon Press, Oxford, 1978.

10 T. Obidziński. Problems of air pollution and planning of coal-fired power plants (in Polish). In R. Kulikowski (Ed.), Problems of Modelling the Economy and Environment (in Polish), PWN, Warsaw, 1979.

11 W. Ciechanowicz and W. tabuda. Use of fuel and energy with regard to environmental pollution (in Polish). In R. Kulikowski (Ed.), Problems of Modelling the Economy and Environment (in Polish), PWN, Warsaw, 1979.

12 J. Pruchnicki. Air Pollution Dispersion Models as Used in Poland in Regional Development Planning. RM-77-5, International Institute for Applied Systems Analysis, Laxenburg, Austria, 1977.

13 Polish Academy of Sciences, Committee on Forecasting. Poland 2000: Current and Prospective Health Problems in Poland (in Polish). Ossolineum, Warsaw, 1975. 
14 M. Sądelski, L. Kruś, M. Makowski, and W. Olinger. Computer Programs in FORTRAN for Calculation of Air Pollution Concentrations (in Polish). Ossolineum, Wroclaw, 1976.

15 W. Ciechanowicz. Optimal investment strategy of the resource-energy system. Part I. Control and Cybernetics 3(1977)5-20.

16 W. Ciechanowicz. Expansion planning of the resource-energy system. In K. Cichocki and A. Straszak (Eds.), Systems Analysis Application to Complex Programs. Proceedings of the IFAC/IFORS/IIASA Workshop, Pergamon Press, Oxford, 1978.

17 W. Ciechanowicz. Expansion Strategies for the Energy System (in Polish). Report ZTSW 15-64/78, Systems Research Institute, Warsaw, 1978.

18 W. Ciechanowicz. Optimal investment strategy of the resource-energy system. Part II. Control and Cybernetics 1(1978)5-20. 


\title{
12 Management and Planning of Energy/Environment Systems in Sweden
}

\author{
Torgny Schütt* and Lars Bergman**
}

\section{INTRODUCTION}

During the 1970s, energy and environmental policy issues were at the forefront of political debate in Sweden. A 1975 government proposal brought about the reevaluation of national energy policy, and in May 1981 Parliament decided on the main principles of Sweden's energy policy for the 1980s and proposed programs and measures dealing with the production and use of various forms of energy ${ }^{1}$.

Background material for this energy policy decision was prepared by several parliamentary committees (see Appendix 12A) as well as by government ministries and research institutions $\dagger$. The Energy Commission is the most important of the ad hoc committees analyzing energy policy issues, and its work represents a major attempt to integrate economic, environmental, and safety factors, as well as the regional and national aspects of energy policy. The Energy Commission has recently proposed a number of options for future energy policy in Sweden.

The report issued by the Energy Commission in 1978 provides the most complete and detailed description of energy management in Sweden, including analyses of demand, supply, and social consequences ${ }^{2}$. The reports of the Energy R\&D Commission give the best account of Swedish energy research, development, and implementation planning.

These government investigations concentrate upon the health and environmental questions of energy management, and are also concerned with risk assessment. This paper describes the approach of the Energy Commission to these

\footnotetext{
* Swedish Energy Research and Development Commission.

** Stockholm School of Economics.

† Some of the more important government investigations and resolutions and parliamentary resolutions and decisions dealing with energy and the environment are listed in Appendix 12B.
} 
problems, and, although the analysis is concerned largely with national energy management, the conclusions reached regarding risks, health, and the environment are also valid at other levels (global, international, regional, and local).

The 1975 government proposal set Sweden the target of reducing the rate of growth of energy consumption from a postwar average of $5 \%$ per annum to $2 \%$ per annum between 1975 and 1985 and to zero growth from 1990. However, this reduced growth was not the primary goal of the policy, which was to transform the energy system so that both its impact on the environment and its dependence upon imported fuels would be reduced. However, this transformation should, according to the government proposal, neither conflict with important social and economic goals, nor lead to dramatic changes in the electricity supply. The reduced growth targets given above were therefore regarded as a reasonable compromise goal.

Although the basic principles put forward in the 1975 government proposal have remained essentially unaltered, much has changed in the energy sphere since the time of the proposal. First, a March 1980 referendum "resolved" the question of nuclear power after a long and sometimes heated debate. Despite strong support for the proposal to close down all nuclear plants in Sweden before 1990, about $58 \%$ of the electorate supported the continuation of the nuclear power program (i.e., the construction of six new reactors in addition to the six already in existence). Second, in view of the oil price increases during the 1970s and the resulting deterioration of Sweden's balance-of-payments position, attempts to reduce the use of imported oil have increased in importance; this is presently accepted by most parties as the main goal of Swedish energy policy and was emphasized in the government's May 1981 "Guidelines for Energy Policy" .

Apart from the problem of substituting for oil, the main energy questions facing Sweden can be summarized as follows:

1. Should the huge uranium deposits in Sweden be exploited?

2. To what extent will it be possible to produce energy biomass by shortrotation forestry? (This is currently at the research and development stage.)

3. To what extent can solar heating of houses become economically viable? (Another topic at the research and development stage.)

4. Emissions of sulfur dioxide must be controlled and restricted at the international level.

5. To what extent should the hydropower resources untouched in the past for environmental reasons be exploited in the future?

\section{ANALYSIS OF ENERGY DEMAND}

\section{Energy demand forecasting}

The long gestation periods and high capital intensity in the energy sector mean that good demand predictions are more valuable in this sector than in most other 
parts of the economy. Since the social costs of bad energy demand predictions can be relatively high, it seems reasonable that the community should become involved in energy demand forecasting. In Sweden, long-term energy demand forecasts have been published regularly since the war by various parliamentary committees and by the power industry. Since 1974, the National Industrial Board (NIB) has been responsible for preparing official energy demand forecasts, in which it collaborates closely with the Ministry of Economic Affairs (MEA).

The energy demand forecast is the result of an iterative procedure in which information is exchanged between the NIB and the MEA. The procedure can be described by the identity

$$
E \equiv \sum_{j \in 1} e_{j} x_{j}+\sum_{j \in \mathrm{T}} e_{j} x_{j}+\sum_{j \in \mathrm{M}} e_{j} x_{j}
$$

where

$E$ is the total consumption of energy in the economy

$e_{j}$ is the input of energy per unit of output in sector $j$

$x_{j}$ is the output from sector $j$

and where the set $I$ represents the industrial sector, set $T$ the transportation sector, and set $\mathbf{M}$ the rest of the economy.

Using a 24-sector model of the Swedish economy, the MEA makes a preliminary forecast of the development of each of the production sectors (including the energy sector), i.e., it predicts the development of each of the $x_{j}$ in eqn. (1) above. In the next step the NIB estimates the development of each of the $e_{j}$ in eqn. (1). If the resulting estimate of $E$ differs from the MEA's estimate of the output from the energy sector, the procedure is repeated. In this way the economic forecasts made by the MEA become consistent with the energy demand forecasts made by the NIB.

The energy input coefficients, $e_{j}$ in eqn. (1), are predicted quite simply. Thus the procedure is based not on regression equations, nor on process models, but on extrapolation of trends. The trends are adjusted for the expected impact of energy price changes, technological changes, structural changes within the aggregated production sectors, and so on. Discussions with industry representatives and experts outside the NIB play an important part in this process. The problem with this approach is, of course, that the relationship between the forecasts and the underlying assumptions is ambiguous.

The MEA economic forecasts are based on simulations using a model called LEMMA $^{3}$. This is a dynamic equilibrium model containing elements of Wairasian general equilibrium theory, neoclassical production and consumption theory, and input-output analysis à la Leontief. It is basically a multisectoral growth model of the same type as that used in prospective planning in Norway. The model is designed to provide a basis for estimating development trends and future capital and labor requirements in different parts of the economy at a point in the future when capital and labor resources may be regarded as substitutable. The analysis can be 
carried out under different assumptions about the allocation of resources between consumption and investment on the one hand, and among the public, housing, and business sectors on the other. The time perspective and structural coefficients of the model can also be varied. The present version of the model examines 24 sectors and is based on the assumption that consumers and producers act on the basis of information about prices. Producers are assumed to choose the production volume and the demand for capital, labor, and inputs that maximize their profits at given relative factor prices. Private consumption is determined by the expenditure elasticities and price elasticities of the various commodities. Consumption and production plans are made as compatible as possible (under given resource constraints) through variations in relative prices.

The model generally assumes that the so-called business sectors try to maximize their profits at given prices. The public and housing sectors are not assumed to behave in any given way - the share of total resources which goes to these sectors is determined outside the model. Development paths for production, employment, capital stock, and foreign trade are all determined within the model.

There is no regional disaggregation in LEMMA and, consequently, in the energy demand forecasts. However, the sectoral classification in the model is such that inferences about regional development can be made on the basis of data about national development. The environmental consequences of given economic development paths are not included in LEMMA.

\section{Analysis of energy policy measures}

As pointed out in the preceding section, the energy input coefficients $e_{j}$ in the production sectors were not predicted formally so that the sensitivity of the resulting forecasts to energy prices, for instance, is ambiguous. For this reason, the procedure described above is not very suitable for analyzing different energy strategies. Moreover, if these energy strategies are likely to have a significant effect on the rest of the economy, it might be better to analyze the impact of energy policy measures using a model of the whole economy. This is the idea behind the EPM (Energy Prognosis Model) ${ }^{4}$, which was developed at the Stockholm School of Economics and is now used by the NIB.

There are many similarities between the LEMMA model and the EPM. Like LEMMA, the EPM is a 24-sector representation of the entire Swedish economy. The same behavioral assumptions are used to "close" both models, and their treatment of foreign trade is practically identical. Moreover, both models concentrate on long-term development patterns in the Swedish economy, although energy production and consumption are emphasized in the EPM while LEMMA deals primarily with capital-labor substitutions, the development of labor productivity, and a number of macroeconomic variables. As in LEMMA, there is no regional dimension in the EPM, and environmental effects are considered only in the energy sector. 
However, in spite of these similarities there is a basic difference between LEMMA and the EPM in their treatment of technologies. In LEMMA the production technology is represented by continuous production functions while in the EPM it is described by a set of linear production processes. This difference (which stems from the simple fact that the models were developed for different purposes) and difficulties in providing econometric estimates of the substitutability of energy and other factors of production lead to a number of technical differences which are not discussed in this paper.

The EPM can be used to evaluate certain policy measures dealing with the production and consumption of energy. These measures are of three types:

- Measures which aim at restricting or promoting the use of particular technologies

- Measures which aim at restricting the total consumption of energy or the consumption of various kinds of energy

- Measures which affect the price of energy

The EPM consists of a core model covering the entire economy and satellite models of particular sectors. The core model can be divided into a model of the energy sector and a model covering all energy consuming sectors. The satellite models deal with the residential heating and household* sectors. The solutions from the satellite models are inserted into the core model, and then the solutions are made consistent with each other by an iterative process.

The main difference between the satellite models and the core model lies in the level of aggregation. Thus, the residential heating model considers a large number of alternative heating technologies for eight different types of dwellings. The solution of this model is the lowest-cost pattern of energy consumption and conservation for the residential sector, given the indoor temperature, the number of dwellings, and the prices of various kinds of energy and energy conservation equipment. This solution can be inserted into the core model as a part of the input-output vector of the housing services sector. Alternatively the residential heating model can be solved for various sets of relative prices and the solutions can be taken as a set of feasible input-output vectors for the aggregate residential heating sector.

Data about the substitutability of energy and other factors of production have not been available until very recently. However, the intensive research carried out in this field in Sweden during the last few years should make it possible to model the potential flexibility of the energy system more closely in the future.

\footnotetext{
* The household model is a nonlinear econometric model used to estimate the commodity composition of household final demand for goods and services as a function of total household expenditure and relative prices.
} 


\section{ANALYSIS OF ENERGY SUPPLY}

The share of imports in the total amount of energy consumed in Sweden is high and has been increasing ever since the war; about $75 \%$ of the energy currently used in Sweden is imported. The energy supply analysis has therefore focused on the world market prices and availability of oil, coal, and enriched uranium, and the capacity and operation of the electricity sector.

Energy demand is forecast in terms of secondary energy, and is independent of the energy supply analysis, though the EPM described in the previous section could be used to carry out a simultaneous analy sis of supply and demand. Higher oil prices and plans to introduce new energy sources in Sweden make it more likely that the EPM will be used in work related to energy demand forecasting in the future. The possibility of making increased use of Swedish energy resources such as uranium, wind power, solar energy, and biomass is being examined in the national $R \& D$ program.

\section{ENVIRONMENTAL ANALYSIS}

The environmental aspects (safety, health, and well-being) of possible energy strategies are regarded as very important in the overall evaluation of possible options by decision makers, although only too often economic and other factors tend to dominate the analysis.

\section{Relevant environmental impacts}

In the early stages of research, the impacts relevant to the actual decision may not be recognized by the analysts providing the information on which the decision is to be based. The systems analysts and the decision-making body must therefore compile a set of relevant impacts in an iterative (cyclic) manner throughout the decision-making procedure (Figure 12.1). Thus the systems analysts, the decision makers, and the nature of the decision all influence the choice of elements to be included in the database. Recent Swedish government investigations into national energy management have broadened the environmental database considerably, by taking into account a large number of environmental impacts occurring at various points in the fuel chain, from extraction to end use. This leads to a range of impacts sufficiently wide for many different options to be considered.

\section{From side-effects to final impacts--what to describe and evaluate?}

Figure 12.2 illustrates the factors considered in evaluating the environmental effects of energy systems.

The decision-making body is most interested in the final impacts of energy systems on human safety, health, and well-being. However, in many cases 


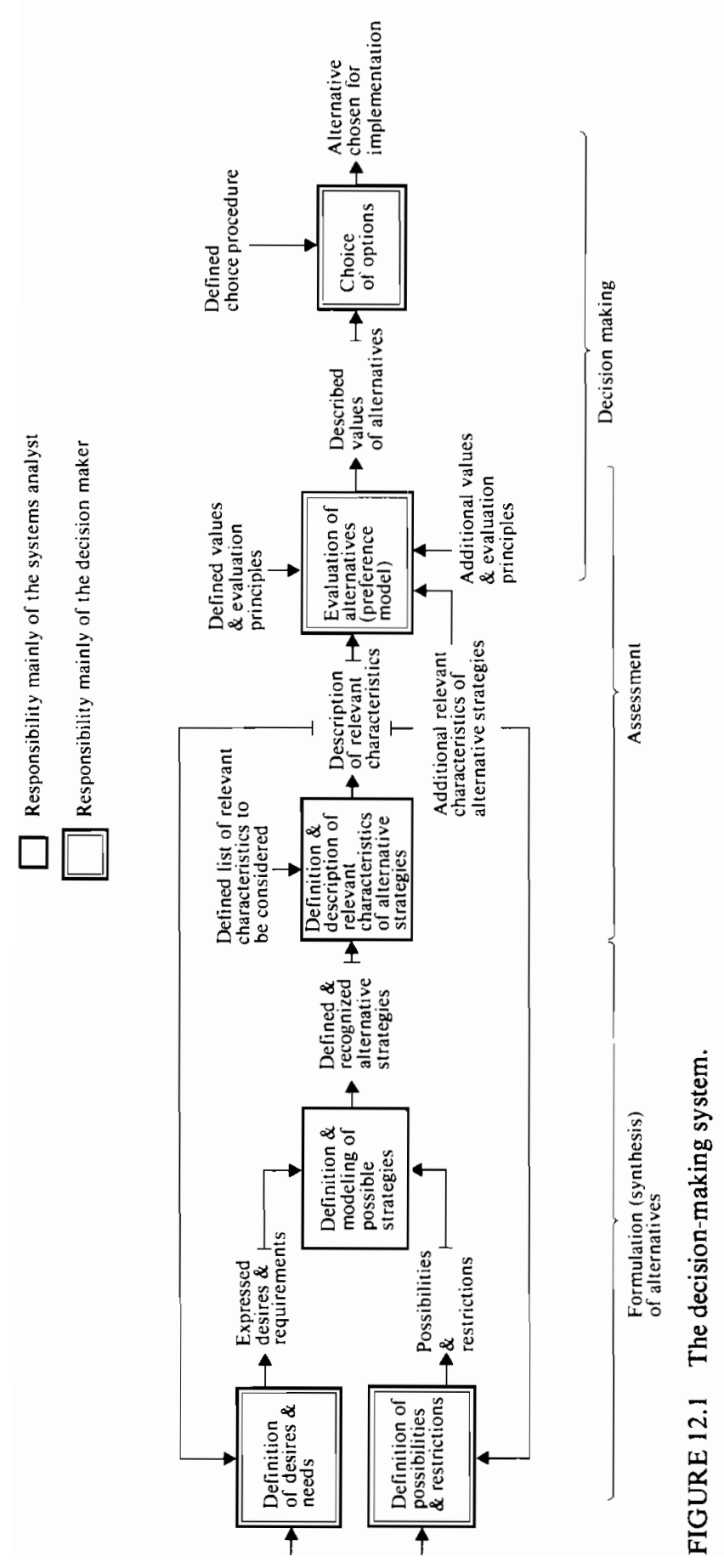




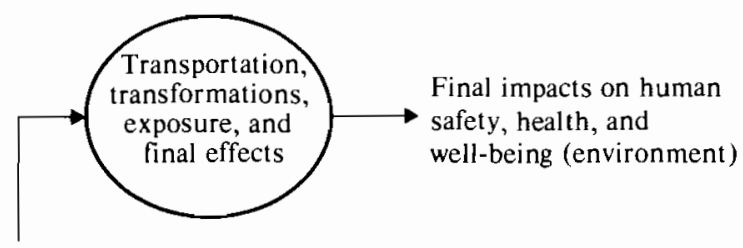

Primary side-effects

(emission of pollutants, radiation, wastes, explosions, land and water use, etc.)

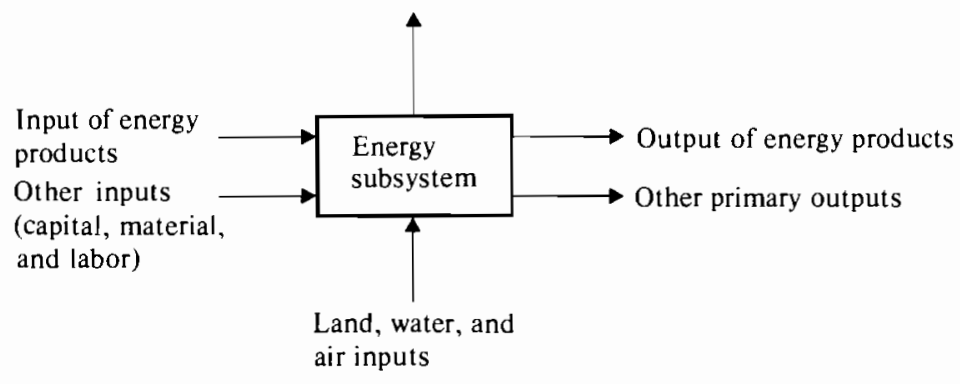

FIGURE 12.2 Factors considered in the environmental evaluation of energy systems.

the impacts associated with transportation and transformation and the dose-response relationships are only partially understood. This gives rise to many different opinions about what constitutes the final impacts, even if the primary side-effects are not in dispute, and the stochastic nature of the processes involved reinforces the uncertainty surrounding the subject. One method of circumventing these difficulties is to focus on and compare the primary sideeffects produced by similar subsystems, e.g., electricity-generating plants based on different energy sources. However, this method is unfortunately not applicable to larger energy systems including production chains.

\section{General and specific impacts}

It is useful to distinguish between the known possible impacts of energy systems in general, on the one hand, and the actual impacts caused by a particular system, on the other.

When examining the final impacts of energy systems on the environment, the decision maker needs to know:

1. What objects are influenced? (humans, physical environment, ecosystems, property)

2. How are these objects influenced? (loss of life, disablement, poorer health, lower standard of living, severe damage, etc.) 
3. Where are these objects situated? (within the energy system or outside it, in which region, in which nation, etc.)

4. When and for how long will the impacts take effect? (over the short term, medium term, or long term)

5. What are the primary causes of these impacts? (air pollution, radiation, etc.)

6. What can be done (technically, economically, socially) to avoid them?

Using the first two points given above, it is possible to classify the final impacts as follows:

1. Risks to human life and health

- Physical risks

- Danger to health, caused by intake of, or contact with, poisonous or carcinogenic substances (e.g., air pollutants)

2. Effects on the physical environment which constitute a potential risk to health

- Contamination of soil and/or water by poisonous materials (e.g., heavy metals) or radioactive substances

3. Effects on ecosystems which might be hazardous for human health, safety, or well-being

- Climatic changes (global changes caused by emission of carbon dioxide or local changes caused by emission of heat and water vapor)

- Acidification of soil and water, mainly caused by emission of sulfur dioxide

- Contamination of soil and water (through transportation of oil)

- Contamination of soil and water by heavy metals (e.g., through the emission of cadmium and mercury compounds from the combustion of fossil fuels)

- Ecological disturbances caused by the release of warm water (mainly cooling water from power stations) into local streams, lakes, or bays

- Changes in the landscape or natural systems (caused by hydropower stations, short-rotation forestry, and mining)

- Damage to property (from accidents or through normal emission of sulfur dioxide and particles)

4. Aesthetic effects

- Changes in the landscape and in ecological systems

This classification has been adopted by the Swedish Energy Commission, but is only one of many possible variants ${ }^{5}$.

When establishing a characteristic "spectrum of environmental effects" for a particular energy subsystem, production chain, national system, or strategy, it is necessary to consider the different phases in the life of the system (construction, 
operation, and demolition) and its different modes of operation (normal and exceptional). Normal operation is conveniently divided into a normal unperturbed mode, during which technical and manual imperfections give rise to normal emissions and other normal characteristics of the system, and a perturbed mode, during which technical and manual malfunctions and natural external perturbations may give rise to accidents within the system. Sabotage, terrorist actions, and war are conditions which define the exceptional mode of operation; these possibilities should also be taken into consideration.

\section{Uncertainties}

Any description or model of the chain of cause and effect, from the primary sideeffects of the system (emission of pollutants, radiation, etc.) to the final impacts on the environment, will involve uncertainty. This uncertainty has two main causes:

- Real cause-effect relationships are partly stochastic because of the stochastic behavior of external factors, such as climate

- Our knowledge of the system is imperfect, and in some areas (e.g., toxicology) quite poor

These uncertainties multiply in every step of the cause-effect chain and in some cases give embarrassingly large uncertainties in the estimates of final impacts.

It should be noted that uncertainty is not limited to environmental matters: all models and data concerning energy and other systems contain an element of uncertainty. The best way to handle uncertainty is to create flexible decision strategies (sequences of decisions) so that freedom of action is preserved as long as possible. During these prolonged decision procedures it is possible to reduce the uncertainty by further investigations.

\section{Preferences and subjectivity}

The last step in the decision-making process is to order the different alternatives relative to each other and, if possible, define a measure for the distances between them. If it is possible to do this in a formal way we say that the procedure is rational or formal. However, to order alternatives and to define distances means that values or preferences must be introduced. And preferences are virtually always subjective or relative in that they depend on the individual decision maker or the decision-making (e.g., political) body.

How can such factors as economic costs and benefits, social impacts like high or low employment, and impacts on safety, health, and the environment be combined in a formal way? How may loss of life in foreign coal mines be compared with the heavy pollution of Swedish lakes by sulfur dioxide or mercury? At the moment there is no agreed formal method for doing this, either in Sweden or 
elsewhere. The politicians have adopted a nonformal (personal or political) approach to the preference problem, illustrated in Figure 12.3. The Swedish Energy Commission also uses a nonformal procedure.

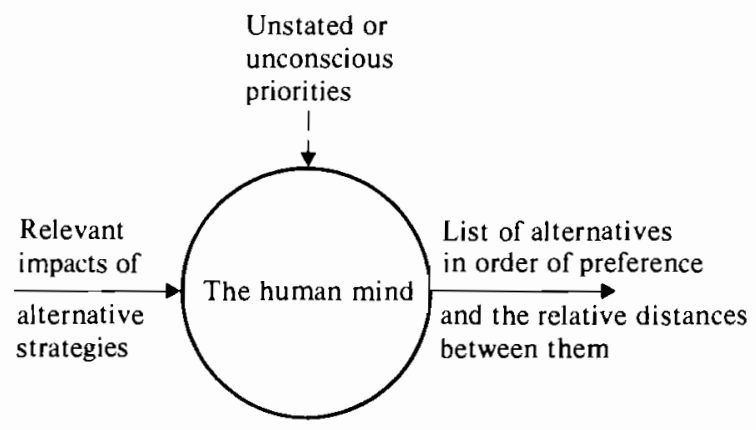

FIGURE 12.3 The nonformal approach to decision making.

To take a decision it is of course necessary to have certain preferences. There are two main reasons for not spelling out these preferences:

- The decision maker is to a large extent unconscious of his preferences. His subconscious automatically orders the options and estimates the differences between them; he will feel convinced that his decision is right without exactly knowing why.

- It is sometimes practical to employ double standards.

\section{Important environmental impacts}

The most important safety, health, and environmental impacts of energy production (as determined by several Swedish investigations) are listed in Table 12.1. The uncertainties associated with many of the impacts in Table 12.1 are considerable, e.g., the climatic effects of $\mathrm{CO}_{2}$ emission and the ecological consequences of short-rotation forestry. These uncertainties can be reduced to acceptable levels only through further research and development.

\section{INTEGRATING DECISION MAKING AND ANALYSIS}

Information generated by government institutions, universities, industry, or individuals inside or outside Sweden is communicated freely to any interested parties. (In the energy sector, as in other sectors, research and development concerning problems of national importance is mainly initiated and sponsored by ministries and other government organizations.)

The institutional structure dealing with research and development and communication of results is reasonably well established. The first condition for communication, an efficient structure of communication channels, is therefore met. 
TABLE 12.1 Some of the most important environmental impacts, their causes and scale.

\begin{tabular}{|c|c|c|c|}
\hline Impact & Direct cause & Energy system & Scale \\
\hline \multicolumn{4}{|c|}{ Risks to human life and health } \\
\hline $\begin{array}{l}\text { Occupational injuries, } \\
\text { chronic diseases, and } \\
\text { lung-cancer }\end{array}$ & $\begin{array}{l}\text { Accidents; normal } \\
\text { working } \\
\text { environment }\end{array}$ & Coal mines & Site \\
\hline Public health & Air pollution & Coal burners & Local \\
\hline $\begin{array}{l}\text { Occupational and general } \\
\text { fatalities and cancers }\end{array}$ & Radiation & $\begin{array}{l}\text { Core-melting in } \\
\text { nuclear power } \\
\text { stations }\end{array}$ & Local \\
\hline \multicolumn{4}{|c|}{ Effects on physical environment which constitute potential risks to health } \\
\hline Cancer & Radiation & $\begin{array}{l}\text { Core-melting in } \\
\text { nuclear power } \\
\text { stations }\end{array}$ & Local \\
\hline \multicolumn{4}{|c|}{ Effects on ecosystems which might be hazardous for human health, safety, or well-being } \\
\hline Public poisoning & $\begin{array}{l}\text { Cadmium and } \\
\text { mercury emissions }\end{array}$ & Coal burners & Subnational \\
\hline Public poisoning & Nitrogen leaching & $\begin{array}{l}\text { Short-rotation } \\
\text { forestry }\end{array}$ & Local \\
\hline $\begin{array}{l}\text { Severe damage to lakes } \\
\text { and soil fertility, } \\
\text { and corrosion of } \\
\text { property }\end{array}$ & $\begin{array}{l}\text { Sulfur dioxide } \\
\text { emissions }\end{array}$ & Oil and coal burners & Supranational \\
\hline $\begin{array}{l}\text { Reduction in soil } \\
\text { fertility }\end{array}$ & Vanadium emission & Oil burners & Local \\
\hline $\begin{array}{l}\text { Pollution of the sea } \\
\text { and damage to } \\
\text { property }\end{array}$ & Oil spillage & Oil transport & Local \\
\hline $\begin{array}{l}\text { Damage to ecosystems } \\
\text { and scenery }\end{array}$ & Water control & $\begin{array}{l}\text { Hydropower } \\
\text { systems }\end{array}$ & Local \\
\hline Climatic change & $\begin{array}{l}\text { Carbon dioxide } \\
\text { emissions }\end{array}$ & Fossil fuel burners & Global \\
\hline
\end{tabular}

The second condition is the existence of a common conceptual framework, and a language by which integrated social planning problems can be described, analyzed, and communicated. This condition is more difficult to fulfill. Groups such as economists, ecologists, engineers, sociologists, political scientists, corporate managers, and political decision makers seem to lack common ground. On the one hand, the traditional sciences do not have sufficient mutual overlap: scientists in different fields normally deal with only one aspect of the problem and are frequently too academic in approach. Social planners, on the other hand, are often in urgent need of a more formal and "scientific" approach to their problems. To help social planners and decision makers in this position, scientists and policy analysts should pay much more attention to the social decision-making process. There is currently an urgent need for an approach integrating economic, ecological, technological, social, and human aspects of the problem-a method for 


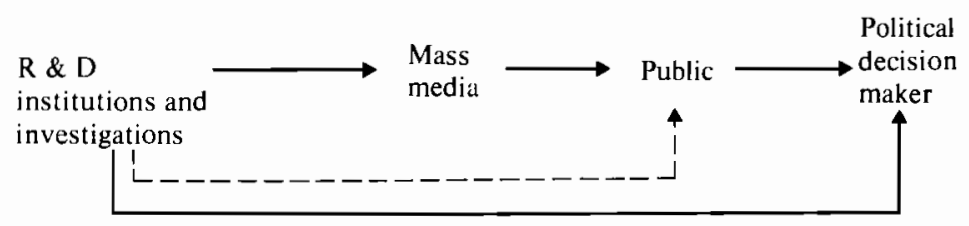

FIGURE 12.4 Important channels of communication.

evaluating human values and preferences is probably the most important single item on the agenda. Most people in the Swedish social "establishment" are willing to support a proposal of this type; the problem seems to lie in finding people capable of actually carrying it out.

The mass media (radio, television, and the press) play a major role in communicating the results of investigations, $R \& D$, and government resolutions to the public. Unfortunately the message is often heavily distorted at this stage and can even become misleading, mainly because negative impacts from technology are judged to be more newsworthy than positive impacts. Ignorance and polarization of attitudes also contribute to the distortion of factual information.

The mass media effectively influence public opinion, which in turn can influence the political decision maker. However, the decision maker also obtains information directly from the original sources, e.g., government investigations (Figure 12.4), and these two different communication channels can, and sometimes do, conflict.

One method of reducing this conflict would be to open up a new channel of communication between the experts and the public, for example, if the authors of official government reports were also to produce popular summaries of their conclusions. The public does not usually communicate directly with local and government authorities - various organizations usually act as intermediaries.

\section{REFERENCES}

1 Guidelines for Energy Policy (in Swedish). Government Bill 1980/1981:90, May 1981.

2 Energy Commission. Energy (in Swedish). SOU 1978:17, Stockholm, 1978.

3 Ministry of Finance. Medium-Term Planning in Sweden--The System of Models (in English). Stockhoim, 1976. TThe main document on LEMMA is in Swedish: Modeller for samhällsekonomisk perspektivplanering, SOU 1976:51.]

4 L. Bergman. Energy and Economic Growth in Sweden (in Swedish). Economic Research Institute, Stockholm School of Economics, Stockholm, 1977.

5 R.E. Munn (Ed.). Environmental Impact Assessment: Principles and Procedures. SCOPE Report No. 5, International Council of Scientific Unions--Scientific Committee on Problems of the Environment, Toronto, Canada, 1975. 


\section{APPENDIX 12A}

\section{Parliamentary procedure in Sweden}

Figure 12A.1 illustrates the Swedish parliamentary procedure. When the need for a government investigation has been recognized, the government normally appoints a committee of up to 50 members to make the investigation. The committee may contain politicians (parliamentary committee) or be composed purely of experts in the field under study. Within the limits of time and money set by the government, the committee prepares an official government report, which is then circulated among interested parties in nongovernmental organizations or institutions. The government then composes a resolution to set before Parliament, using the official report, the comments from nongovernmental organizations, and its own opinions as the basis for the resolution.

In a parliamentary committee the government resolution is supplemented by parliamentary motions, and is then discussed, elaborated, and transformed into a parliamentary resolution which is set before Parliament. The parliamentary decisions are sent back to the government for implementation and are thus incorporated into the fabric of society. 


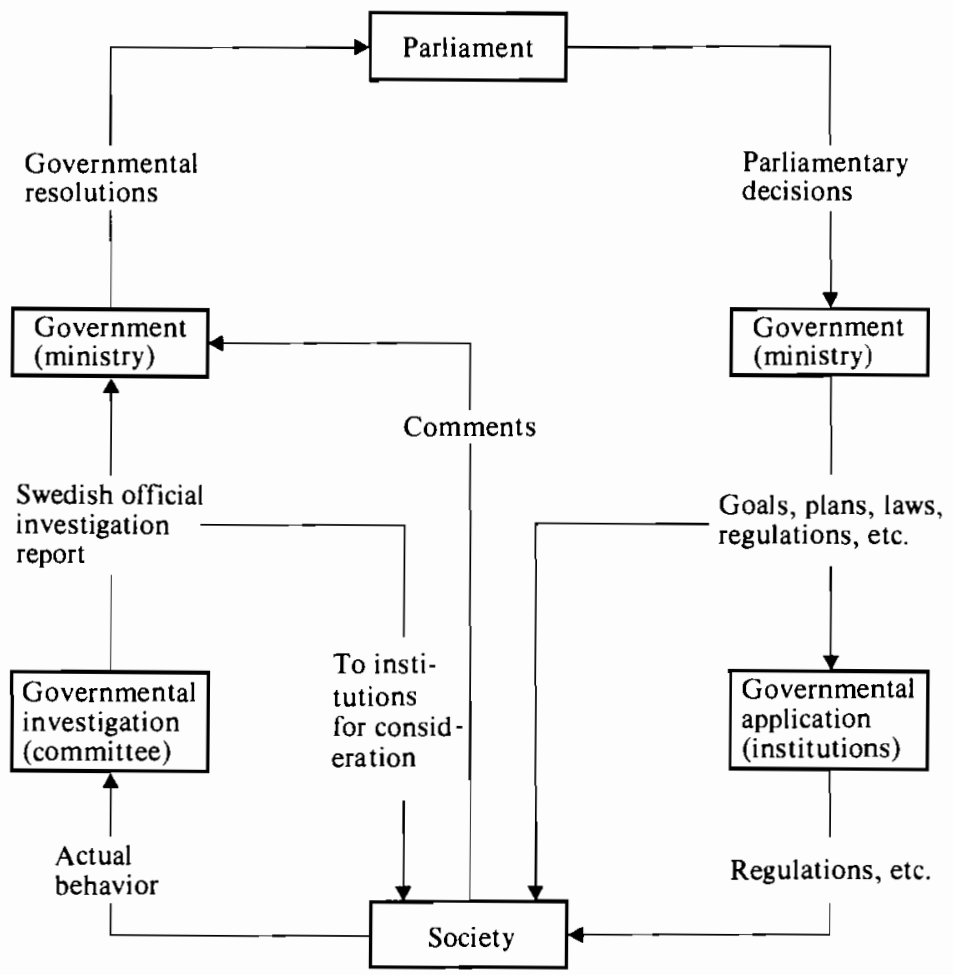

FIGURE 12A.1 Swedish parliamentary procedure. 
APPENDIX 12B

Recent government investigations into energy/environment management.

No. Ministry ${ }^{a}$ Investigation/Committee Type Period Report

\begin{tabular}{|c|c|c|c|c|c|}
\hline 1 & $\mathrm{Fi}$ & Energy Committee & Experts & $1964--1970$ & $\begin{array}{l}\text { Sweden's Energy Support } \\
\text { (Policy and Organization) }\end{array}$ \\
\hline 2 & I & & Experts & $1964-1970$ & $\begin{array}{l}\text { Sweden's Energy Support } \\
\text { (Policy and Organization) }\end{array}$ \\
\hline 3 & I & $\begin{array}{l}\text { Urban siting of } \\
\text { nuclear power stations }\end{array}$ & Experts & $1970-1974$ & Final Report \\
\hline 4 & I & $\begin{array}{l}\text { Energy forecast } \\
\text { investigation }\end{array}$ & Experts & $1972-1974$ & Intermediate Report \\
\hline 5 & & & Experts & $1972-1974$ & Energy 1985,2000 \\
\hline 6 & I & $\begin{array}{l}\text { Energy Program } \\
\text { Committee }\end{array}$ & Mixed & $1973-1975$ & Energy R\&D \\
\hline 7 & & & Mixed & $1973-1975$ & $\begin{array}{l}\text { Plan for General Energy } \\
\text { Systems Research }\end{array}$ \\
\hline 8 & $\mathrm{Fi}$ & Ministry & Experts & $1974-1975$ & $\begin{array}{l}\text { Swedish Environmental } \\
\text { Policy } 1975-1980\end{array}$ \\
\hline 9 & & Government & Political & $1974-1975$ & $\begin{array}{l}\text { Energy Management } \\
\text { Resolution }\end{array}$ \\
\hline 10 & & $\begin{array}{l}\text { Parliament (Standing } \\
\text { Committee on } \\
\text { Economic Affairs) }\end{array}$ & Political & 1975 & $\begin{array}{l}\text { Energy Management } \\
\text { Resolution }\end{array}$ \\
\hline 11 & $\mathrm{~L}$ & $\begin{array}{l}\text { Industrial injuries } \\
\text { investigation }\end{array}$ & Experts & $1973-1976$ & Industrial Injuries \\
\hline 12 & $\mathbf{H}$ & $\begin{array}{l}\text { Hydroelectric power } \\
\text { and environment }\end{array}$ & Experts & $1974-1976$ & $\begin{array}{l}\text { Hydroelectric Power } \\
\text { and Environment } 3\end{array}$ \\
\hline 13 & 1 & Radioactive waste & Mixed & $1973-1976$ & $\begin{array}{l}\text { Spent Nuclear Fuel and } \\
\text { Radioactive Waste }\end{array}$ \\
\hline 14 & 1 & $\begin{array}{l}\text { Energy R\&D } \\
\text { Commission }\end{array}$ & Mixed & $1975-1977$ & $\begin{array}{l}\text { Proposal for an Energy } \\
\text { R\&D Program 1978-1981 } \\
\text { (main report) }\end{array}$ \\
\hline 15 & & & Experts & $1975-1977$ & Industrial Processes \\
\hline 16 & & & Experts & $1975-1977$ & Transportation \\
\hline 17 & & & Experts & $1975-1977$ & Buildings \\
\hline $\begin{array}{l}18 \\
19\end{array}$ & & & $\begin{array}{l}\text { Experts } \\
\text { Experts }\end{array}$ & $\begin{array}{l}1975-1977 \\
1975-1977\end{array}$ & $\begin{array}{l}\text { Recycling and Recovery } \\
\text { Energy Supply }\end{array}$ \\
\hline 20 & & & Mixed & $1975-1977$ & $\begin{array}{l}\text { Genera1 Energy System } \\
\text { Studies }\end{array}$ \\
\hline 21 & & & Experts & $1975-1977$ & $\begin{array}{l}\text { Environmental- and Health- } \\
\text { Effects of Technical } \\
\text { Energy Systems in Normal } \\
\text { Operation }\end{array}$ \\
\hline $\begin{array}{l}22 \\
23\end{array}$ & & $\begin{array}{l}\text { Government } \\
\text { Parliament }\end{array}$ & $\begin{array}{l}\text { Political } \\
\text { Political }\end{array}$ & $\begin{array}{l}1977 \\
1978\end{array}$ & $\begin{array}{l}\text { Energy Research Resolution } \\
\text { Energy Research Resolution }\end{array}$ \\
\hline 24 & $\mathbf{A}$ & $\begin{array}{l}\text { Energy and } \\
\text { Environment } \\
\text { Committee }\end{array}$ & Mixed & $1976-1977$ & $\begin{array}{l}\text { Energy, Health, and } \\
\text { Environment }\end{array}$ \\
\hline
\end{tabular}




\begin{tabular}{|c|c|c|c|c|c|c|}
\hline \multirow[t]{2}{*}{ Official number } & \multirow{2}{*}{$\begin{array}{l}\text { Main } \\
\text { issue }^{b}\end{array}$} & \multicolumn{5}{|c|}{ Number of pages ${ }^{c}$} \\
\hline & & Total & $\begin{array}{l}\text { Emissions } \\
\text { and other } \\
\text { primary } \\
\text { effects }\end{array}$ & $\begin{array}{l}\text { Risks and } \\
\text { effects on } \\
\text { health and } \\
\text { environment }\end{array}$ & $R \& D$ & $\begin{array}{l}\text { Method- } \\
\text { ology }\end{array}$ \\
\hline Fi 1967:8 & B & 200 & - & - & - & - \\
\hline SOU $1970: 13$ & $\mathbf{B}, \mathbf{P}, \mathbf{O}$ & 130 & 10 & - & - & - \\
\hline SOU 1974:56 & RHE & 325 & $x$ & $x$ & 5 & 10 \\
\hline I 1973:2 & M, So & 200 & 15 & 1 & 5 & - \\
\hline $\begin{array}{l}\text { SOU 1974:64 } \\
\text { (and 65) }\end{array}$ & $\mathrm{B}, \mathrm{M}$, So & 300 & 10 & 1 & 10 & 5 \\
\hline $\begin{array}{l}\text { SOU 1974:72 } \\
\text { (and 74) }\end{array}$ & R\&D & 225 & - & - & $x$ & - \\
\hline I 1975:3 & $\mathbf{R} \& \mathrm{D}$ & 110 & - & 5 & $x$ & - \\
\hline SOU $1975: 98 / 6$ & RHE & 105 & $x$ & $x$ & - & - \\
\hline P 1975:30 & $\mathbf{P}$ & 600 & 10 & 5 & 80 & - \\
\hline NU 1975:30 & $\mathbf{P}$ & 130 & - & not rele & at- & - \\
\hline SOU $1976: 17$ & RHE & 295 & - & $x$ & - & $x$ \\
\hline SOU 1976:28 & So, RHE & 360 & - & $x$ & - & - \\
\hline SOU $1976: 30$ & RHE & 325 & $x$ & $x$ & 15 & - \\
\hline SOU 1977:56 & RD\&D & 415 & 10 & 5 & $x$ & 5 \\
\hline $\begin{array}{l}\text { SOU 1977:57 } \\
\text { SOU 1977:58 } \\
\text { SOU 1977:59 } \\
\text { SOU 1977:60 } \\
\text { SOU 1977:61 } \\
\text { SOU 1977:62 }\end{array}$ & $\begin{array}{l}\text { RD\&D } \\
\text { RD\&D } \\
\text { RD\&D } \\
\text { RD\&D } \\
\text { RD\&D } \\
\text { RD\&D }\end{array}$ & $\begin{array}{r}170 \\
130 \\
315 \\
60 \\
725 \\
45\end{array}$ & $\begin{array}{l}- \\
- \\
- \\
- \\
10 \\
-\end{array}$ & $\begin{array}{l}- \\
- \\
- \\
- \\
5 \\
1\end{array}$ & $\begin{array}{l}x \\
x \\
x \\
x \\
x \\
x\end{array}$ & $\begin{array}{l}- \\
- \\
- \\
- \\
- \\
1\end{array}$ \\
\hline DFE 1977:7 & RD\&D & 145 & $x$ & $x$ & $x$ & $x$ \\
\hline \multirow{2}{*}{$\begin{array}{l}\text { P } 1977-1978: 110 \\
\text { NU 1977-1978:68 } \\
\text { SOU } 1977: 67\end{array}$} & $\begin{array}{l}\text { RD\&D } \\
P\end{array}$ & $\begin{array}{r}170 \\
26\end{array}$ & \multicolumn{4}{|c|}{$\longrightarrow$ not relevant- } \\
\hline & RHE & 245 & $x$ & $x$ & $x$ & $x$ \\
\hline
\end{tabular}




\section{APPENDIX 12B (continued)}

Recent government investigations into energy/environment management.

No. Ministry ${ }^{a}$ Investigation/Committee Type Period Report

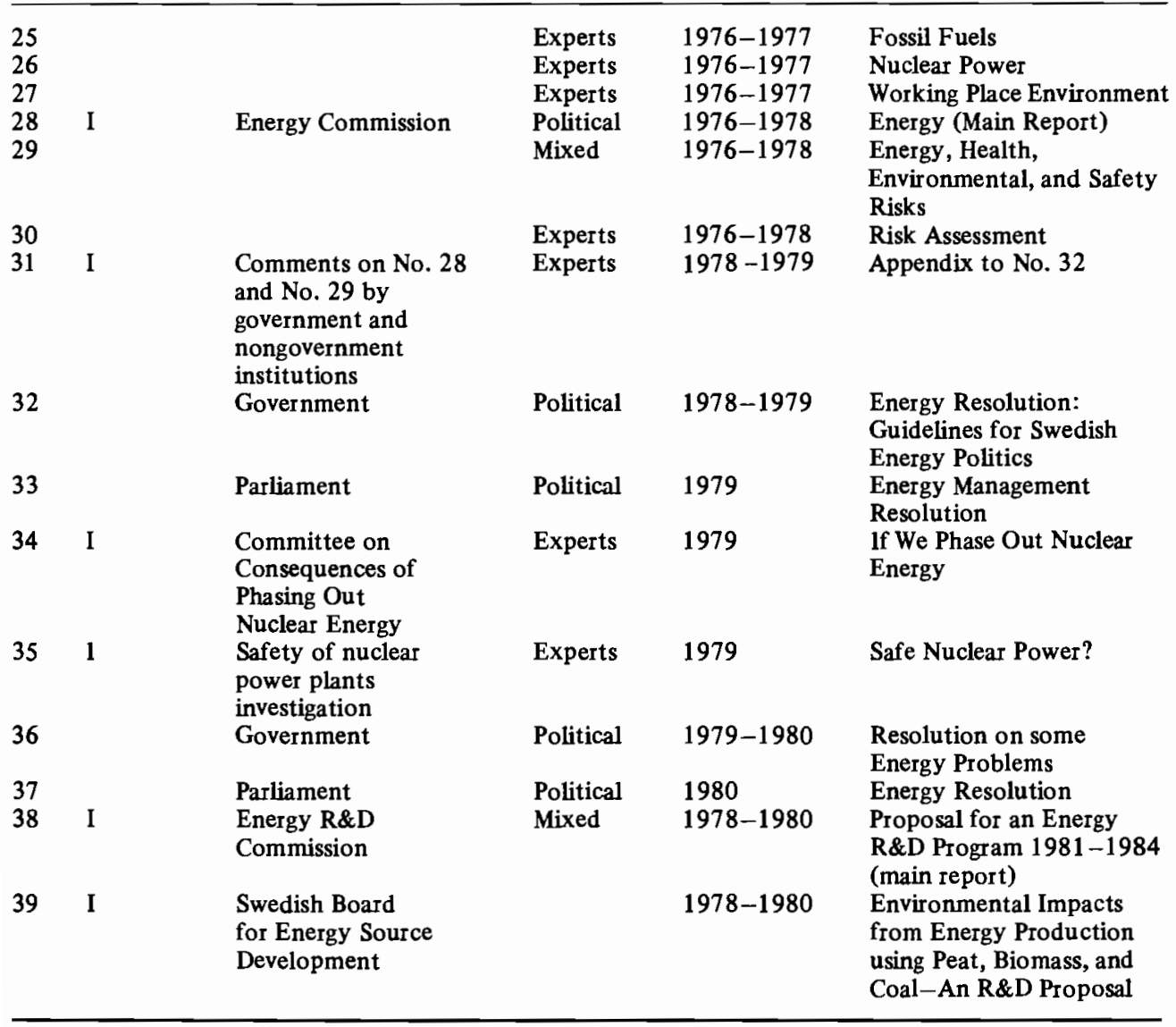

${ }^{a}$ The abbreviations used are as follows: $\mathrm{A}$, agriculture; $\mathrm{Fi}$, finance; $\mathrm{H}$, housing and physical planning; $I$, industry; $L$, labor.

${ }^{b}$ The abbreviations used are as follows: B, national energy balances (forecasts of supply and demand); $\mathbf{M}$, methodology; $\mathrm{O}$, government energy organization; $\mathrm{P}$, government energy policy, planning, and 


\begin{tabular}{|c|c|c|c|c|c|c|}
\hline \multirow[t]{2}{*}{ Official number } & \multirow{2}{*}{$\begin{array}{l}\text { Main } \\
\text { issue }^{b}\end{array}$} & \multicolumn{5}{|c|}{ Number of pages ${ }^{c}$} \\
\hline & & Total & $\begin{array}{l}\text { Emissions } \\
\text { and other } \\
\text { primary } \\
\text { effects }\end{array}$ & $\begin{array}{l}\text { Risks and } \\
\text { effects on } \\
\text { health and } \\
\text { environment }\end{array}$ & $R \& D$ & $\begin{array}{l}\text { Method- } \\
\text { ology }\end{array}$ \\
\hline SOU $1977: 68$ & RHE & 600 & $x$ & $x$ & $x$ & - \\
\hline SOU $1977: 69$ & RHE & 105 & 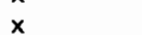 & $x$ & $\ddot{x}$ & _ \\
\hline SOU $1977: 70$ & RHE & 185 & $x$ & $x$ & $x$ & - \\
\hline SOU $1978: 17$ & $\mathbf{P}$ & 780 & $x$ & $x$ & $x$ & $x$ \\
\hline SOU 1978:49 & RHE & 250 & $x$ & $x$ & $x$ & $x$ \\
\hline I $1978: 15$ & RHE & 100 & - & - & - & $x$ \\
\hline P 1978-1979:115B & $\mathbf{P}$ & 545 & 20 & 10 & - & - \\
\hline P 1978-1979:115 & $\mathbf{P}$ & 400 & $\ldots$ & not relev & ht- & _ \\
\hline NU 1978-1979:60 & $\mathbf{P}$ & 150 & 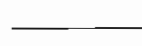 & not relev & at- & \\
\hline SOU 1979:83 & B, So & 175 & 7 & 3 & - & - \\
\hline SOU 1979:86 & RHE & 275 & $x$ & $x$ & $x$ & $x$ \\
\hline P 1979-1980:170 & $\mathbf{P}$ & 105 & 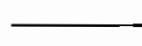 & not reler & at- & \\
\hline NU 1979-1980:70 & $\mathbf{P}$ & 80 & & -not relev & t- & \\
\hline SOU 1980 & RD\&D & 380 & 5 & 4 & $x$ & 2 \\
\hline NE 1980:15 & RHE R\&D & 200 & $x$ & $x$ & $x$ & - \\
\hline
\end{tabular}

management; R\&D, research and development; RHE, estimation and management of risks and effects on health and well-being; So, social effects (health, environment, etc.); RD\&D, research development, and demonstration.

${ }^{c}$ The symbols used are as follows: $\mathrm{x}$, main issue; - almost nothing. 


\title{
13 Management and Planning of Union of Soviet Socialist Republics
}

\author{
A.S. Nekrasov*
}

\section{INTRODUCTION}

Analysis of the energy economy in the USSR focuses upon two components of the general plan: energy consumption by sector and by region. Regional energy system planning in an economic region or union republic is designed to achieve integrated development of the energy base and the productive sectors. Planners also try to ensure that the energy demands of the industrial, transportation, construction, and service sectors, and of the urban and rural populations are met rationally.

Regional energy systems are closely connected with the national energy economy. The national-regional link may be seen in the production of energy, its interregional distribution, and its use. Regional energy planning is based on the integration of national plans for the development of particular sectors of the energy economy with local opportunities for exploiting energy resources, and local patterns of energy consumption. The "regional energy system" in this context includes both the producers and the consumers of all forms of energy in a given region. Regional planners must also consider local geographical and climatic conditions, population density, availability of labor, transportation networks, water supply, availability of land suitable for industrial development, existing plants, etc.

Energy/economic factors which have an important influence on the regional energy system include the type and number of energy consumers, the location of large energy facilities and energy-intensive industries, the existing patterns of energy consumption, the quality and quantity of local energy resources, the various types of fuel storage, and the different modes of interregional energy

\footnotetext{
* Central Institute of Economics and Mathematics, USSR Academy of Sciences, Moscow.
} 


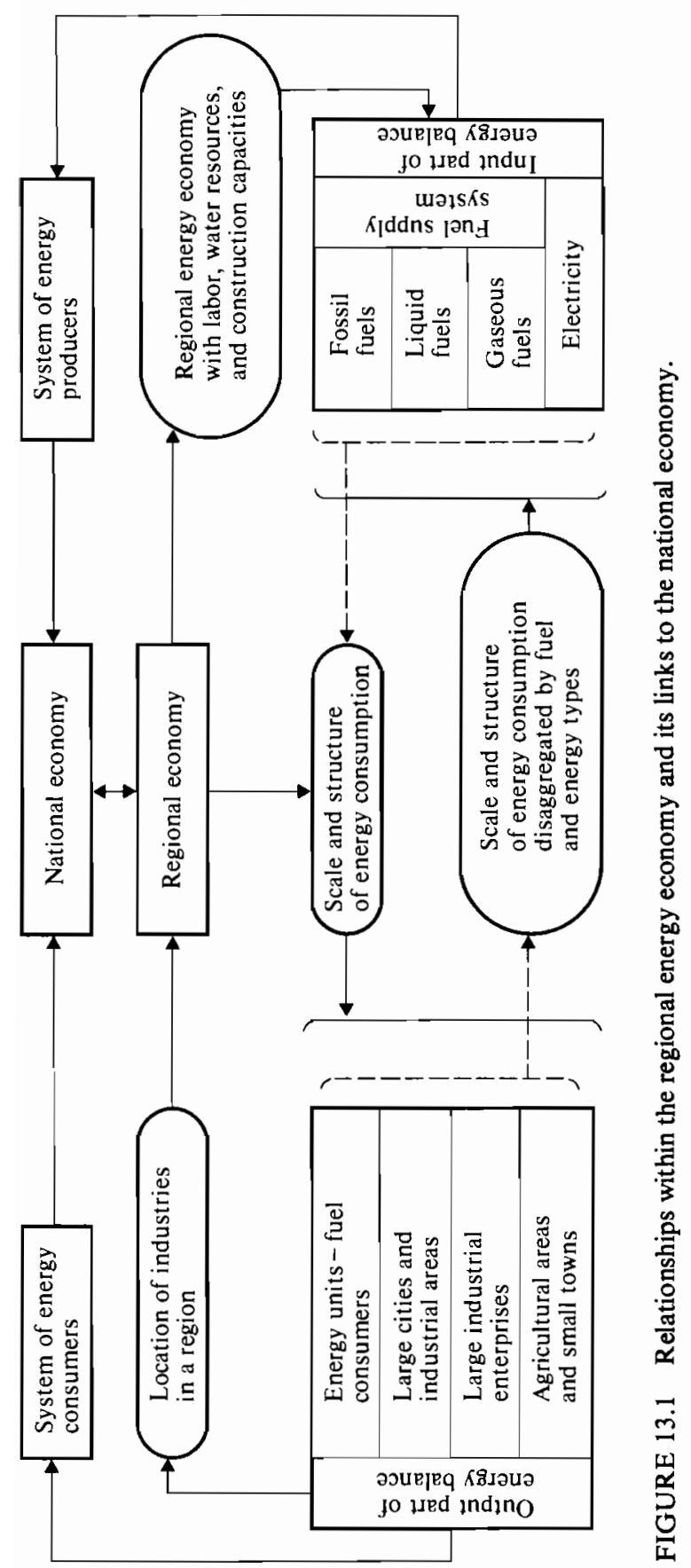


transport. The complex relationship between the regional energy system and the national economy is illustrated in Figure 13.1.

It is impossible to plan regional energy systems without coordinating the goals of national and regional economic development. Thus, the main features of regional development are obtained from national plans for the development and location of productive resources in the USSR over the next 15-20 years. The national plans describe the development and location of energy-intensive sectors, the dynamics of the labor force, and the principles behind the long-term input-output balance of the national economy. This information is used in regional planning to ensure that the development of the regional economy is compatible with the direction taken by the national economy as a whole.

Information on the existing regional energy economy, information on physical conditions, and preliminary projections of the regional economy are used to prepare a number of regional economic development scenarios. These scenarios are designed to illustrate the possible scale and pattern of regional energy consumption, and are based on estimates of the scale and structure of the regional energy supply suggested by the planned development of the national energy economy. The technological and economic characteristics of existing and planned energy facilities are also reflected in the scenarios.

The complex character of national economic development is a primary consideration in building scenarios for the development of the regional energy economy. The national development scheme provides for both the comprehensive development of regional productive resources and the specialized development of individual sectors of the national economy.

Regional energy planning requires a thorough study of physical conditions in general, and of the local climate in particular. These factors can have a strong influence on the amount of energy required for space heating or cooling and on the pattern of fuel and energy supply in the region. This is especially true in remote mountain areas, for example, where the climate and other conditions are particularly extreme. In these areas the values of planning indicators are quite different from the regional averages.

Any projections of long-term regional energy development must take into account the production, processing, and utilization of local energy resources. Local resources are those which are consumed in their region of origin; it is not economic to move them between regions because of the cost of transportation. However, the economically approved level of production, processing, and utilization of local resources in a given region may influence the scale of the interregional energy supply and ultimately the regional energy economy as a whole.

In the rural areas of some regions the use of local energy resources is influenced by traditional methods of space heating and cooking in the residential sector.

Issues such as the environmental impact of energy production, the living conditions of the population, and health and safety at work must be taken into con- 
sideration in regional energy development planning. Each scenario for the development of the regional energy system should examine these issues, since they are important in choosing appropriate technologies and patterns of energy supply, as well as in determining the degree of electrification and energy costs. The scenarios should examine the impact on the regional environment of each element included in the energy system.

\section{IMPORTANT ISSUES IN THE REGIONAL ENERGY ECONOMY}

Regional energy planning is largely concerned with the following issues:

- Siting large new industrial areas and energy-intensive enterprises in the region in accordance with plans for rational development.

- Determining the needs of the regional consumer for different types of fuel and different types of energy, taking into consideration annual and seasonal fluctuations in consumption.

- Evaluating the regional supply of different types of fuel and energy according to the principles of interregional energy distribution. The form of this distribution is given by the optimal solution of the national energy balance and the optimal development of the energy sectors.

- Planning the development of the regional energy base, bearing in mind that the regional energy base is a component of the national energy economy. The development of the regional energy base must also take into account the different types of energy consumers in the region.

- Siting, specialization, and output of the most important energy industries, as well as economic evaluation of the regional oil, gas, coal, and electricity supply systems.

- Planning the interregional distribution of energy resources and rational patterns of energy supply to large cities, industrial complexes, and agricultural areas.

- Investigating the level of industrial efficiency of, and uses for, local energy resources which it is not economic to transport to other regions.

- Assessing the environmental impacts of energy production and developing ways to eliminate them.

\section{ENERGY ECONOMY SCENARIOS}

Long-term projections cannot provide one unique recommendation for the overall development of the national energy economy, even less for the regional energy economy. The best solution to the problem of long-term energy planning can only be obtained by varying the assumptions concerning the demand for different energy sources, possible levels of fuel and energy supply, and the economics of interregional exchange. This is achieved in the preliminary stages of planning by 
means of a set of scenarios for regional energy development which have varying input data. One of the scenarios thus obtained will then suggest a development strategy which is consistent with existing regional conditions.

\section{MODELING THE REGIONAL ENERGY ECONOMY}

The regional energy economy is studied with the aid of a system of models which describe the industrial and technological characteristics of the energy sectors and their relationship to energy consumers. The system includes models representing energy consumers and oil, gas, coal, and electricity supply.

The regional energy system may be considered to contain four main groups of energy consumers:

1. Mining operations, fuel-processing plants, and electricity plants. These are represented in the models either as separate blocks or in a generalized form, depending on their size and role in regional energy production.

2. Cities and industrial areas which contain a number of industrial enterprises. Large-scale energy consumption characterizes this group.

3. Individual large industrial enterprises. This group includes the large enduse energy consumers, such as iron and steel producers and cement plants.

4. Consumers distributed relatively evenly over the region. The fuel and energy consumption of these consumers is on a much smaller scale than in any of the three groups defined above.

Depending on their location in a region and the patterns of consumption, specific consumers are linked to various parts of the energy transport and distribution system, which includes the electricity transmission network, gas pipelines, etc.

The models used to evaluate the level of electrification in each sector of the national economy make it necessary to take into account load curve characteristics. Specific methods and algorithms for modeling the long-term load duration curve of the energy system have therefore been developed and put into use. However, if no significant long-term changes in the consumption patterns of electricity consumers are expected, it is possible to use simplified methods to describe the electrical load curve.

In its static form the system of models describes the energy economy in the last year of the planning period, while in its dynamic form it describes the whole planning period, in time intervals of one year and longer. Both approaches take into account seasonal variations in the production and consumption of fuel and energy.

The form of the objective function used in modeling the regional energy economy is assumed to be similar to that employed in the system of models describing the national energy economy. The objective function of regional energy development is to minimize the capital and operating costs of: 
1. Exploration for resources

2. Fuel extraction

3. Fuel enrichment or processing

4. Conversion of fuels into other energy forms

5. Interregional transport of fuel and energy

6. Distribution of fuel and energy to consumers

7. Use of energy sources

When fuel or energy is delivered to a region as a part of an interregional energy exchange, shadow prices rather than costs are used for the first five items listed above. The derivation of the shadow prices is based on the conventional method for optimizing the long-term development and distribution of production facilities ${ }^{1}$.

The system of models used to analyze the regional energy economy contains blocks representing the energy consumers, the fuel supply system, and electricity supply system. These are discussed in more detail below.

\section{The "energy consumer" block}

Small individual consumers and industrial consumers are considered separately in this block. The populations of large cities and areas which include small towns and agricultural consumers are classified as small individual consumers, and for this group the "energy consumer" block compares various interchangeable modes of energy supply for cooking, space heating, hot water supply, and air conditioning. The construction characteristics of the dwellings (such as age or height) are important factors in choosing the best method of supply. In the industrial sector, the "energy consumer" block determines energy sources for steam-driven power plants, very large boiler plants, high-temperature production processes and average- and low-capacity industrial and space-heating boiler plants. Except for very large plants, which are considered individually, all of these consumers are represented in the models as groups with economic indicators of energy use typical of a given city or area. The models are used to forecast the maximum capacity of plants and the future consumption of energy resources by each of the specified groups of consumers; relationships between modes of heat, fuel, and electricity supply to the residential sector are also examined.

\section{The "fuel supply" block}

The system of models also contains a "fuel supply" block which is used to determine the level of development and location of fuel extraction sites and processing plants (on both a local and an interregional basis); to find the best distribution of fuels among regional consumers, taking into account seasonal variations in consumption; and to examine regional energy transport systems and their relationship 
with the national energy balance. The "fuel supply" block includes models of regional fuel supply, for coal, gas, and oil, as well as models of local fuel supply. As a whole, the "fuel supply" models describe the extraction, processing, distribution, and storage of various types of fuel at the regional level; they also take into account seasonal variations in consumption, though the actual consumption is not treated here, but in the previous block of models.

The scale and types of interregional energy transportation, and consequently the main parameters of long-distance fuel transportation, are determined through optimization of the national energy balance. The figures obtained from the optimization are used as inputs to the regional energy planning model. This applies to pipelines carrying gas, oil, and related products, as well as to the transportation of coal between regions.

\section{The "electricity supply" block}

The "electricity supply" block of models describes the development of the regional electricity supply system. The models are used to determine the need for new electrical power plants and transmission lines, the type and siting of new electrical power plants, the load curves of individual power plants and of the complete electricity network, and the type of fuel to be used in new power plants.

The models consider hydropower plants, steam-driven power plants (fossilfueled and nuclear), as well as the transmission lines connecting one transformer substation with another. The specifications of plants generating both heat and power are determined by the demand for heat, though the generating capacity and electrical output of these cogeneration plants should of course be considered when calculating the grid load. The distribution of heat and electricity to the consumer is covered in the "energy consumer" block.

The main constraints in the "electricity supply" block are equations balancing load and generating capacities, as well as electricity balances concerned with the characteristics of the load duration curves which depend on the seasons. The models also include equations describing the fuel demands of power plants; constraints on the capacities of installed power plants and transmission lines; equations describing seasonal river flow at hydropower stations; equations describing the annual output of steam-driven power plants; and constraints on the resources available for the construction of new power plants and transmission lines.

\section{ENVIRONMENTAL IMPACTS}

The environmental impacts of energy production are analyzed in two stages. First, various scenarios describing the possible development of the energy economy are selected on the basis of their ecological effects and are used in model runs. Second, the environmental significance of the results obtained from the model runs is assessed. 
This approach has been developed in the course of research into the air pollution caused by combustion products in urban areas ${ }^{2}$. The results showed that the contribution of individual industrial enterprises and sectors to the total background air pollution does not depend directly on the volume of pollutants emitted by the enterprise or sector. In a given city, joint heat and power generating plants and large boiler plants produce only a small proportion of the total background air pollution.

\section{CONCLUDING COMMENT}

The system of models described in this paper may be solved using a technique for decomposing linear programming models of large dimension. A detailed description of the system of models is given in ref. 3. Both the detailed system of models and the simplified version given in ref. 4 proved to yield reliable results that were useful in planning the regional energy economy.

\section{REFERENCES}

1 A.G. Aganbegyan, M.M. Albeger, D.M. Kazakevich, Z.A. Kozlov, V.V. Kosov, N.N. Nekrasov, N.M. Fedorenko, and V.O. Chernyabenii. Standard procedure for optimizing the development and distribution of production facilities (in Russian). Ekonomika i Matematicheskie Metody 13 (1977) 1137-1149.

2 M.A. Styrikovich, E.V. Minaev, A. Troitskii, and A.K. Vnukov. Ways of reducing urban air pollution caused by the burning of fuels (in Russian). Teploenergetika 9, 1976.

3 Scientific Council on the Complex Problem "Optimal Planning and Management of the National Economy". Systematic Recommendations for the Optimization of Regional/Republic Energy Economies on the Basis of a System of Models (in Russian). In collaboration with the Central Institute of Economics and Mathematics, USSR Academy of Sciences, the Georgian Scientific Research Institute, and the Ministry of Energy. Nauka, Moscow, 1976.

4 V.A. Razykov and A.N. Akhrorova. Economic-Mathematical Modeling of the Energy Economy of a Union Republic (in Russian). Nauka, Moscow, 1977. 


\title{
14 Management and Planning of Energy/Environment Systems in the United States of America
}

\author{
Peter House*
}

\section{INTRODUCTION}

Energy planning in the United States is clearly polynucleated. Given the ubiquity of energy use and the federal approach to problem solving, each center of interest addresses energy issues and also tends to develop individual methods for dealing with questions of energy policy. This results in a large number of energy models with different aims and capabilities.

However, this chapter will be limited to the models used by the US Department of Energy (DOE) for official planning purposes. This restricts the number of models considered, but the fact that the DOE has only been in existence since 1 October 1977 and was made up of several previously existing units means that the "official" models of the Department are still evolving. Consequently, the discussion will be limited still further to those models that were the official models of some of the organizations which constitute the present Department; specifically, the Project Independence Energy Systems (PIES) model of the former Federal Energy Administration (FEA), the Brookhaven National Laboratory (BNL) Modeling System of Energy Research and Development Administration (ERDA), the Strategic Environmental Assessment System (SEAS) of the Office of Environment, ERDA, and the model developed by the Stanford Research Institute (SRI) as part of ERDA's Market Orientation Program Planning Strategy (MOPPS) exercise.

Before discussing these models, however, it would be useful to examine the objectives of the National Energy Plan, to help to understand both what lies behind the models and what has, in part, developed from them.

Quoting from the 1977 National Energy Plan (NEP), the United States has three important energy objectives:

* Office of Technology Impacts, Department of Energy, Washington, DC. 
1. As an immediate objective, and one that will become even more important in the future, to reduce dependence on foreign oil and vulnerability to interruptions in supply.

2. In the medium term, to keep United States oil imports sufficiently low to weather the period when world oil production has reached its limit.

3. In the long term, to have renewable and essentially inexhaustible sources of energy for sustained economic growth.

The plan suggests the following measures:

- Conservation and fuel efficiency

- Rational pricing and production policies

- Reasonable certainty and stability in government policies

- Substitution of abundant energy resources for those in short supply

- Development of new energy technologies for the future

The national objectives have been embodied in a series of goals. These goals are:

- Reduce the annual growth in total energy demand to below $2 \%$

- Reduce gasoline consumption by $10 \%$ of its current level

- Reduce oil imports from a potential level of 16 million barrels per day to 6 million, which would be roughly equivalent to one-eighth of total energy consumption

- Establish a Strategic Petroleum Reserve of 1 billion barrels

- Increase coal production by two-thirds, to more than 1 billion tonnes per year

- Bring $90 \%$ of existing American homes and all new buildings up to minimum standards of energy efficiency

- Use solar energy in more than 2.5 million homes

These goals were analyzed and the detailed plan was at least partly created using two of the models discussed in this paper-the BNL model and PIES.

Further, after the plan was published, another group of analysts in the Office of the Assistant Secretary for Environment (then in ERDA) did an environmental impact analysis of the plan using a third model, the Strategic Environmental Assessment System (SEAS). Their results were given in the form of an Annual Environmental Analysis Report (AEAR).

The NEP assessments and the AEAR suggested the following R\&D priorities:

- To reduce expected short-term and long-term increases in $\mathrm{SO}_{x}$ and $\mathrm{NO}_{x}$. Pollution control technology for plants burning coal should be accelerated.

- The large quantities of sludge produced by more efficient pollution control 
systems contain trace heavy metals and other toxic chemicals. Environmentally sound methods of disposing of this sludge need to be developed to protect groundwater and public health.

- The expected increase in underground mining in the East will increase sub sidence and acid drainage problems. Improved mine-sealing techniques need to be developed to protect the environment and the public from these mining hazards.

- To ensure environmentally sound land use, water use, and water quality in the West, rapid reclamation techniques must be developed for surface mines to prevent the runoff of alkaline solids from exposed areas.

- Detailed and comprehensive research and assessment should be carried out on all energy-related factors which would affect the environment in the North Central Region (Region 8, see Fig. 14.1). The environmental quality of this region should be given special consideration.

- Reliable radioactive-waste storage systems should be developed to ensure that the environment will be protected from radioactive leaks as storage requirements increase in the near future.

The most important energy-related environmental impacts anticipated by the year 2000 are illustrated in Figure 14.1.

Future efforts to update the AEAR will involve the development of procedures for incorporating AEAR findings directly in environmental R\&D and policy recommendations for the Assistant Secretary for Environment, in the Department of Energy.

The success of these modeling activities indicates clearly that large policy models should be used in the energy-environment decision process, along with other methodologies, to link energy, economic, and environmental policies more closely together.

Table 14.1 summarizes the features of the models most relevant to energy/environment planning, though much information is necessarily lost in this form. A better comparison can be obtained by a more detailed examination of the models themselves, and this is done in the following sections*.

\section{FEDERAL ENERGY ADMINISTRATION (FEA) PROJECT INDEPENDENCE EVALUATION SYSTEM (PIES) MODEL ${ }^{1}$}

Project Independence was the generic title used to describe activities organized by the FEA in the continuing development and implementation of a national energy policy for the United States. The PIES model generates planning estimates of

\footnotetext{
* The summaries of the models are taken from reports by the groups that developed them. To minimize arguments about the content and scope of the models, great care was taken to include as much of the original descriptions as possible, though because editorial changes were made in the descriptions they are not presented as quotes. In the main, however, the reader should give the credit for the description to the original authors and the blame for any changes in their intended message to the present author.
} 


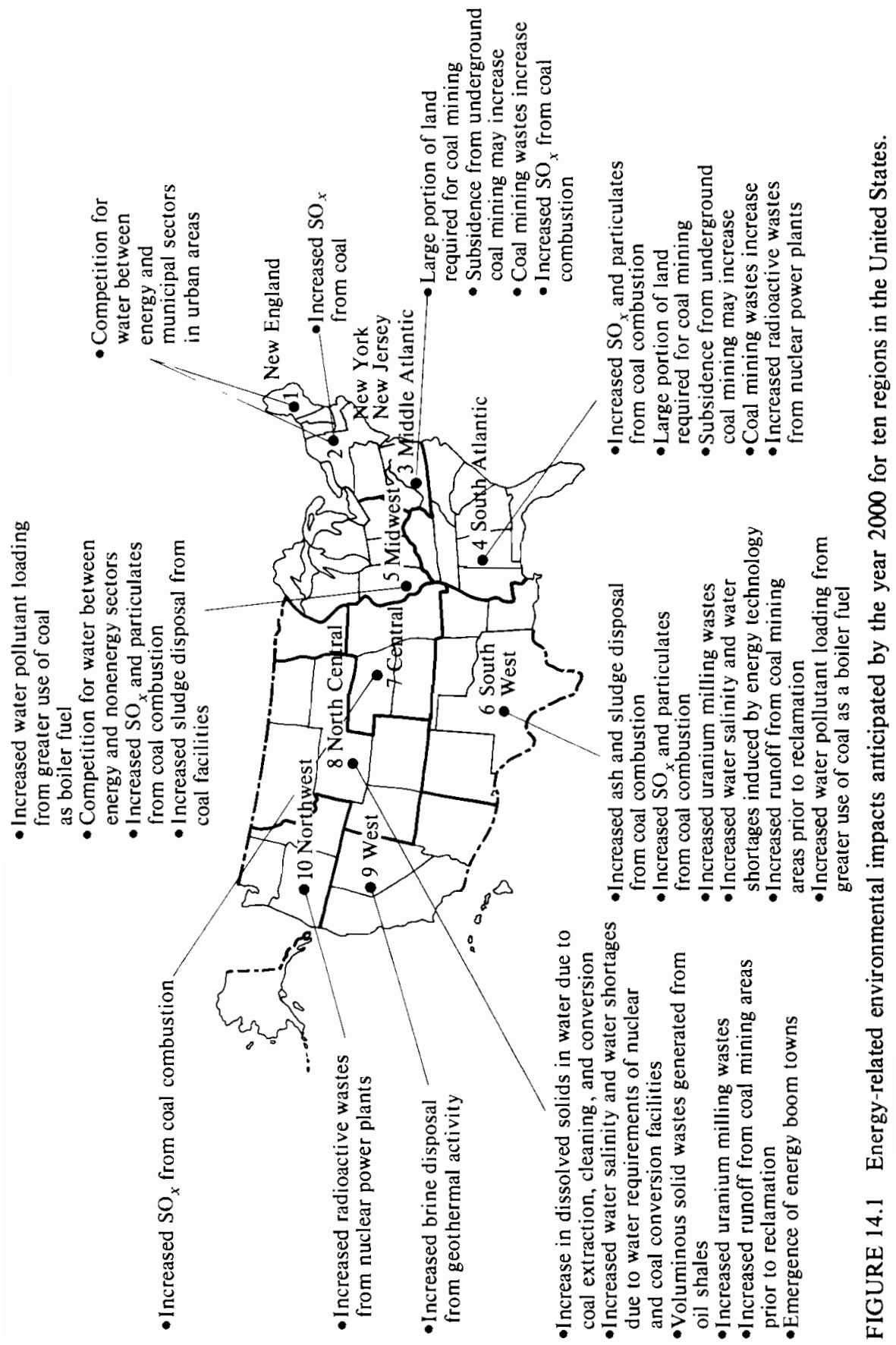


TABLE 14.1 Some basic comparisons of four energy models used at the Department of Energy.

\begin{tabular}{|c|c|c|c|c|}
\hline Characteristic & PIES & Brookhaven & SEAS & SRI \\
\hline Demand & Economic & Economic & $\begin{array}{c}\text { Technical and } \\
\text { economic }\end{array}$ & None \\
\hline $\begin{array}{l}\text { Energy-economy links } \\
\text { Energy-economy }\end{array}$ & Yes & Yes & Yes & Yes \\
\hline $\begin{array}{l}\text { feedback } \\
\text { Supply and demand }\end{array}$ & Yes & Yes & Yes & Yes \\
\hline linked & Yes & Yes & Yes & No \\
\hline Environmental impacts & Emissions & Yes & $\begin{array}{r}\text { Emissions, } \\
\text { quality } \\
\text { indices }\end{array}$ & No \\
\hline Full fuel cycle & Yes & Yes & Yes & Yes \\
\hline Regional analysis & Yes & Yes & $\begin{array}{l}\text { Yes } \\
\text { (to county) }\end{array}$ & Yes \\
\hline Type of model & Optimization & Simulation & Simulation & Simulation \\
\hline Level of analysis & County & County & $\begin{array}{l}\text { Plant, } \\
\text { county }\end{array}$ & County \\
\hline Method of use & $\begin{array}{l}\text { Via technical } \\
\text { staff }\end{array}$ & $\begin{array}{l}\text { Via technical } \\
\text { staff }\end{array}$ & $\begin{array}{l}\text { Via technical } \\
\text { staff }\end{array}$ & $\begin{array}{l}\text { Via technical } \\
\text { staff }\end{array}$ \\
\hline Time horizon & 1985 & 1985 & 2000 & 2010 \\
\hline
\end{tabular}

possible energy system variables, taking into consideration the effect of relative prices, the potential for fuel substitution, and the technological constraints inhibiting increased energy supplies.

Among the factors considered by the PIES model in analyzing alternative strategies are:

1. Price sensitivity - the impact of relative prices

2. Fuel competition - the substitution of one energy source for another

3. Technology - the variation of the production and conversion technologies within the energy system

4. Resource limitations-physical capacities and other resource limitations

5. Externalities - the byproducts or side-effects of energy production and consumption

6. Economic impacts - the effect of total energy production and consumption on the economy

7. Regional variations - the uneven geographic distribution of energy production and consumption

8. Dynamics - the lead times, capacity in previous periods, and other timedependent functions

9. Modularity - the possibility of expanding major components of the energy system or introducing new components

10. Judgment - the ability to use information and make approximations and estimates 
Thus, the energy system is depicted as a kind of network in which production, processing, conversion, distribution, transportation, and consumption activities take place. The prices of, and capacities for, these activities are presented in such a way as to be consistent with the dual objectives of preserving price sensitivity and recognizing potential constraints on the system. The supply and demand sectors are then separated from one another.

The supply system, which produces, processes, and converts energy, is represented by nodes within an energy network. These nodes are then connected by links which depict the energy transportation and distribution system.

Various activities within the energy production system are described by a set of supply curves, which identify the prices to be paid and nonenergy resources to be consumed at each possible level of operation.

Important physical or technological limitations affecting the production of energy are described within the energy transportation and distribution network. The refining and conversion facilities are included as intermediate nodes in the network, each with a description of its capacities and conversion technologies. The refining and conversion activities are connected with the demand or consumption sectors through an additional set of transportation and distribution links. These links are subject to capacity restrictions which can be modified if sufficient key resources are available. The supply curves, conversion technologies, methods of transportation, costs, and resource requirements are produced by supply submodels and linked within the overall framework of the model.

The estimates of the demand for energy are produced by a demand model. The demand for energy products is spread over different geographical regions and varies with energy prices. The choice of activities described as "demand" is somewhat arbitrary, but can be thought of as the final demand for the various energy products. Fuel substitution is simulated in the demand model through the empirical development of the relationship between demand and relative prices.

Given the prices, resource requirements, and capacity constraints, an integration model constructs a feasible set of energy flows that satisfies the final demands for energy. The energy supply system and energy prices are adjusted during this market simulation to obtain a balanced solution which is also in equilibrium. This means that no consuming sector would be willing to pay more than the prevailing market price for an additional unit of any energy product and no supplier would provide an additional unit of any energy product for less than this price.

For an arbitrary selection of prices and demands, the least-cost balancing solution may not be an equilibrium solution: there is no means of guaranteeing that an arbitrary price used to estimate the demand for a product will be equal to the price at which the product is supplied. However, the necessary adjustments in the prices are made and this process is repeated until the equilibrium solution is obtained.

The supply, demand, and equilibrium balancing components describing the energy system are combined with models of the economy, assessments of the availability of resources other than energy, and report-writing programs that 


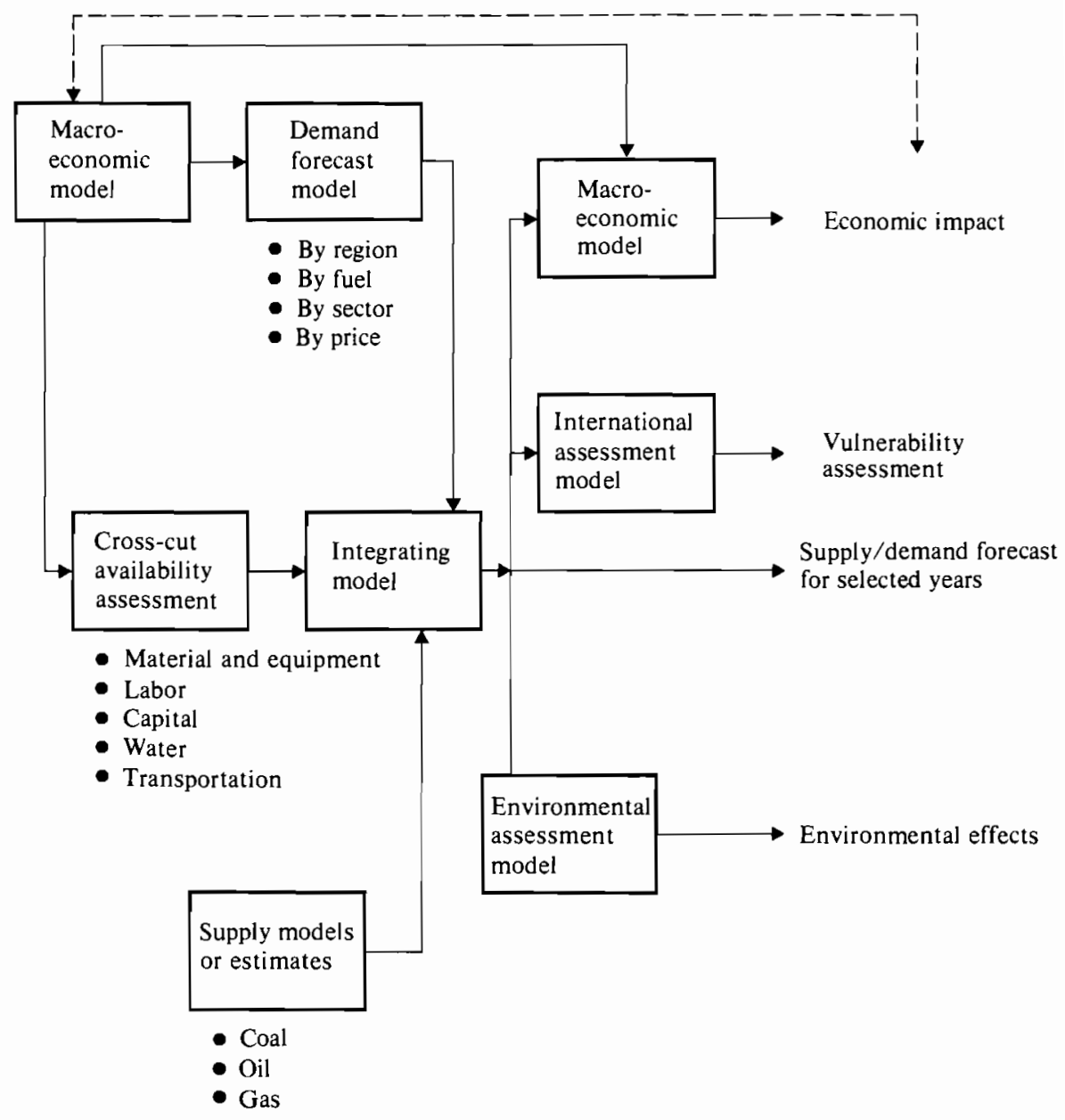

FIGURE 14.2 The FEA Project Independence Evaluation System (PIES).

evaluate energy solutions in terms of the environmental, economic, or resource impacts. Econometric, simulation, accounting, and optimization models are included in this system, each being particularly suitable for one particular aspect of the problem. The model of macroeconomic activity chosen is one of several major econometric models of the United States economy, and was developed by Data Resources, Inc. ${ }^{2}$ (see BNL description).

The resource constraints are derived from a large data base which records the coefficients of demand for nonenergy resources for the various energy activities included in the system. These coefficients are employed to construct constraints 
for the equilibrium solution, if capacities are known, or to prepare ex post summaries for off-line evaluation of potential bottlenecks. The supply model component comprises a variety of procedures used to construct stepwise approximations to the energy supply curves. These range from nonautomated engineering analysis in the case of coal to the complex software used by the National Petroleum Council to estimate the supply of oil and gas.

The demand model is a behavioral econometric model. The demand for energy is not represented in terms of its final use as energy but as the demand for the various energy products in the consumer sectors. The relationship between demand and substitution is described in terms of relative prices, and the relevant parameters are estimated using econometric techniques. The resulting system consists of over 800 behavioral relationships governing the demand for different types of energy products in each sector.

The demand, supply, and resource assessment models are combined through a series of programs known as the integrating model (Figure 14.2). A partial equilibrium is obtained by balancing prices and quantities for all energy products. The equilibrium energy flows and prices in the energy sector then provide the input to a series of evaluation or report-writing programs relating the solution to the particular problems under consideration. There are over 20 types of evaluation, ranging from an executive summary of the energy balance to a detailed list of associated waste products, an analysis of water requirements, or an examination of the implied use of nonenergy resources which have not been considered directly in the energy system network.

\section{STRATEGIC ENVIRONMENTAL ASSESSMENT SYSTEM (SEAS)}

SEAS has been described as "a system of special-purpose models linked to a macroeconometric model and an interindustry input-output model of the United States economy". Other models in this system use economic forecasts to estimate the levels of pollutants, and the cost of reducing them; energy demands; the volume of solid waste generated and associated recycling possibilities; the need for land; the amount of minerals consumed; the status of material still in the ground, and the amount stored as processed ore; the demand for transportation; and changes in the relative prices of commodities. At present, this model is used to simulate the effects of forecasts made by other government agencies in order to predict the levels of pollution, the costs of cleaning up, and other economic impacts associated with the forecast (see Figure 14.3).

\section{Economic models}

The SEAS model produces three economic forecasts at different levels of detail. The first, the macroeconomic forecast, gives the result of projecting a number of 


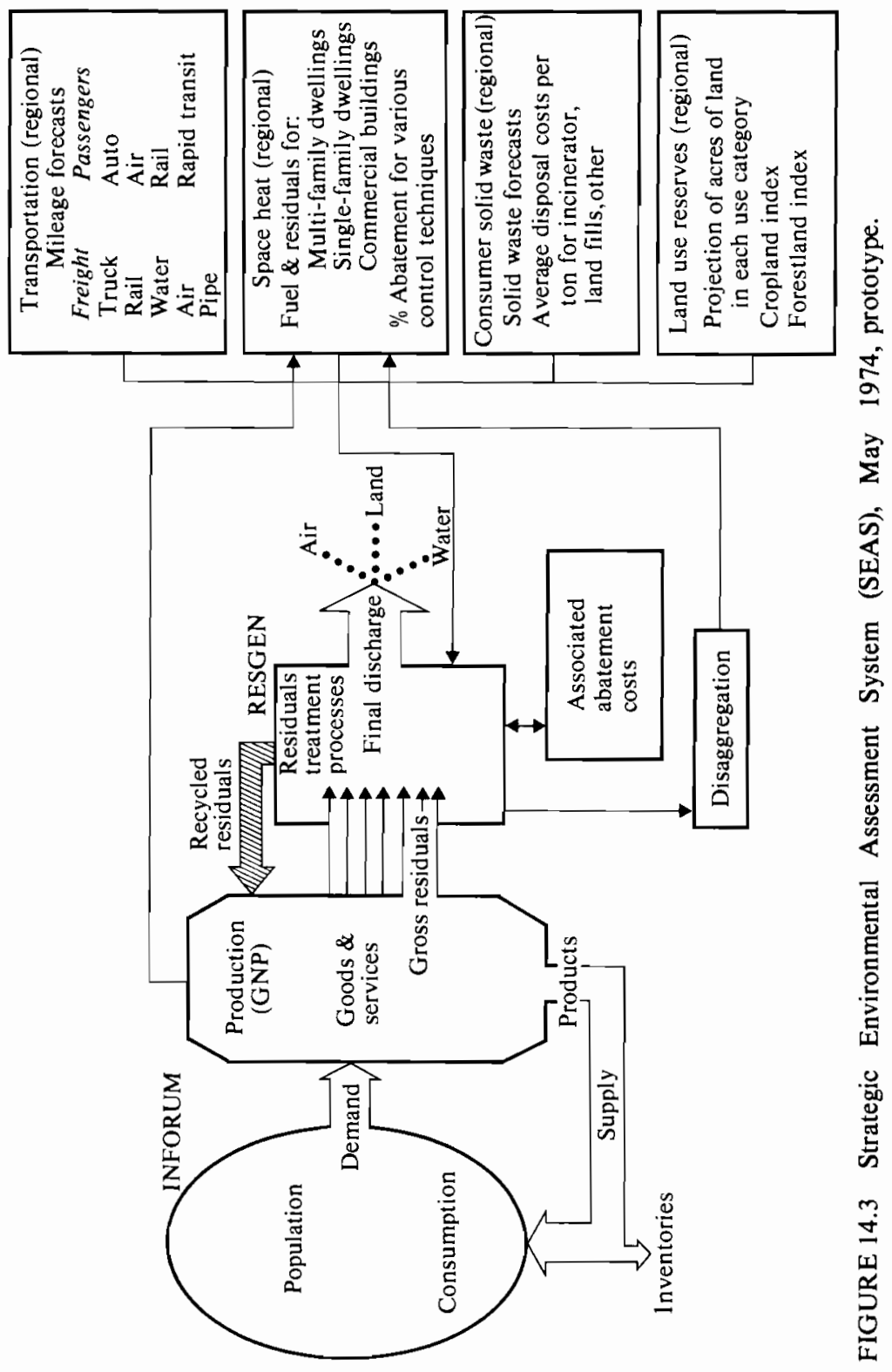


general parameters to each year up to 1985 . These parameters include employment, the output of the production sector, personal consumption, disposable income, and capital investment, and make it possible to project the general components of the GNP.

The second forecast involves the calculation of the interactions among industries required to meet the levels of output proposed by the demand forecast of the macroeconomic model. This economic input-output model, called INFORUM, provides yearly economic projections for 185 sectors of the economy, and sectoral statistics such as employment, proportion of output satisfying final demand, total output, expenditure on durable goods and construction, exports, and imports.

Economic forecasts at the third level are much more detailed and deal with procedures that break down the information obtained for the 185 sectors considered in the INFORUM model into a form more suitable for answering specific questions. Official estimates from the Departments of Commerce, Agriculture, and the Interior are used as detailed indicators of the level of economic activity. This type of SEAS economic forecast is easily expanded and contains three times more detail than the second-level forecast.

The various subroutines of this model will now be considered separately.

\section{ABATE (abatement cost feedback model)}

ABATE estimates the investment and operating and maintenance costs required to reduce the emission of pollutants by each economic sector. It also relays to INFORUM the increased demand for money and goods resulting from the introduction of pollution control measures. This demand will affect the industrial sectors which supply materials and labor for construction, equipment and chemicals for reducing pollution, and also the types of energy sources employed and the size of the workforce required.

\section{SOLID WASTE (solid waste recycling model)}

SOLID WASTE estimates the amounts of solid wastes produced by nonindustrial sources, the expected method of disposal, and the costs associated with each method. For disposal methods involving incineration and open burning, it also estimates the amount of air pollution caused annually.

\section{STOCKS (material reserves model)}

After the economic models have estimated the total annual demand for various fuels and mineral ores, and the recycling model has forecast the degree to which the demand for certain materials can be met by reprocessing, SEAS uses the STOCKS model to provide details on the sources of raw materials, the depletion 
of economic reserves, and the increased cost of production under a wide range of possible inventory/export/import assumptions.

\section{ENERGY (energy use model)}

The ENERGY estimates of energy use are based on the INFORUM forecasts of economic activity in 185 sectors of the economy. The program disaggregates energy use into a number of fuel categories, and for each category it also indicates whether the fuel is used for combustion or as a raw material in six user sectors: industrial, commercial, residential, transportation, consumption by an electric utility, and electricity generation.

\section{RESGEN (residual generation model)}

RESGEN estimates the annual emissions of air and water pollutants and the production of solid wastes by the major polluting industries. It estimates first the pollutants that would be released if no pollution abatement schemes were in force and then the emissions actually reaching the environment.

\section{TRANSPORT (transportation model)}

TRANSPORT forecasts the demand for automobiles, buses, trucks, railroads, and airplanes in terms of miles traveled for both passenger and freight transportation purposes, using the Department of Transportation forecasts of the total number of miles traveled. The program also estimates the annual volume of emissions produced by mobile sources.

\section{LAND USE (land use model)}

LAND USE estimates the amounts of land used for various activities as a function of forecasts of economic activity. It also forecasts the levels of air and water pollution and the amount of solid wastes produced by nonpoint sources in activities such as agriculture, construction, forestry, mining, and drilling, as well as the pollution caused by naturally occurring sources.

\section{REGION (assignment of processes and associated activities to subnational regions model)}

This model is designed to improve forecasting of economic and environmental impacts by predicting the distribution of industrial growth and the associated environmental effects in various types of geographical regions. The regions chosen include states, SMSAs (Standard Metropolitan Statistical Areas), river basins, air quality control areas, and "basic economic areas". 
Two important functions are performed outside the computer system. These are:

1. The development of alternative scenarios.

2. The analysis of results obtained from the scenarios. This should demonstrate the consequences of different scenarios and provide some insight into the probable effects of specific national policies and regulations, including public and institutional reactions.

\section{MODELS* EMPLOYED BY BROOKHAVEN NATIONAL LABORATORY (BNL) ${ }^{3}$}

Brookhaven National Laboratory has described its two-model system as being developed to estimate the amounts of energy produced domestically and imported in 1985, 1990, and 2000. One model, the Brookhaven Energy System Optimization Model (BESOM), has been used to estimate the least-cost mixture of energy supplies required to meet specified energy demands, while the other, the Brookhaven Energy-Economy Input-Output Model (IO), uses macroeconomic estimates from the DRI models to estimate the base case level of energy demand (Figure 14.4).

BESOM is a linear programming model which minimizes the total cost of satisfying a given set of national energy demands. Given a set of energy requirements defined by end use (i.e., motive power, space heating, electrical power, etc.) and knowing the energy resources available and the capacities of the various conversion technologies, the model determines the minimum-cost allocation of energy supplies to meet energy demands. For instance, it determines the annual coal and oil requirements of electricity-generating plants, the quantities of oil and electricity needed for space heating, and the refined oil/electricity mix required to meet the demand for motive power.

BESOM is based on the classical transportation problem of determining the best route for a product, in this case an intermediate energy form, from a set of $n$ supply nodes to $m$ demand nodes where a cost and a set of environmental impacts are associated with a unit of energy passing over each of the $n \times m$ possible paths. The typical linear programming representation of the transportation problem is modified by including efficiency coefficients in the supply and demand constraints and augmented by additional constraints reflecting environmental factors as well as certain technical features of the energy system. Given these efficiencies and constraints, the model estimates the least-cost mix of primary and converted forms of energy required to meet the specified demands, e.g., the optimal mix of electricity, gas, and oil for heating purposes. The IO model, developed jointly by Brookhaven National Laboratory and the Center for Advanced Computation at the University of Illinois, is a conventional input-output model with the following

- As with all of the models described in this paper, the description is only correct as of the time of writing. All will have evolved, been expanded, and improved since that date. 


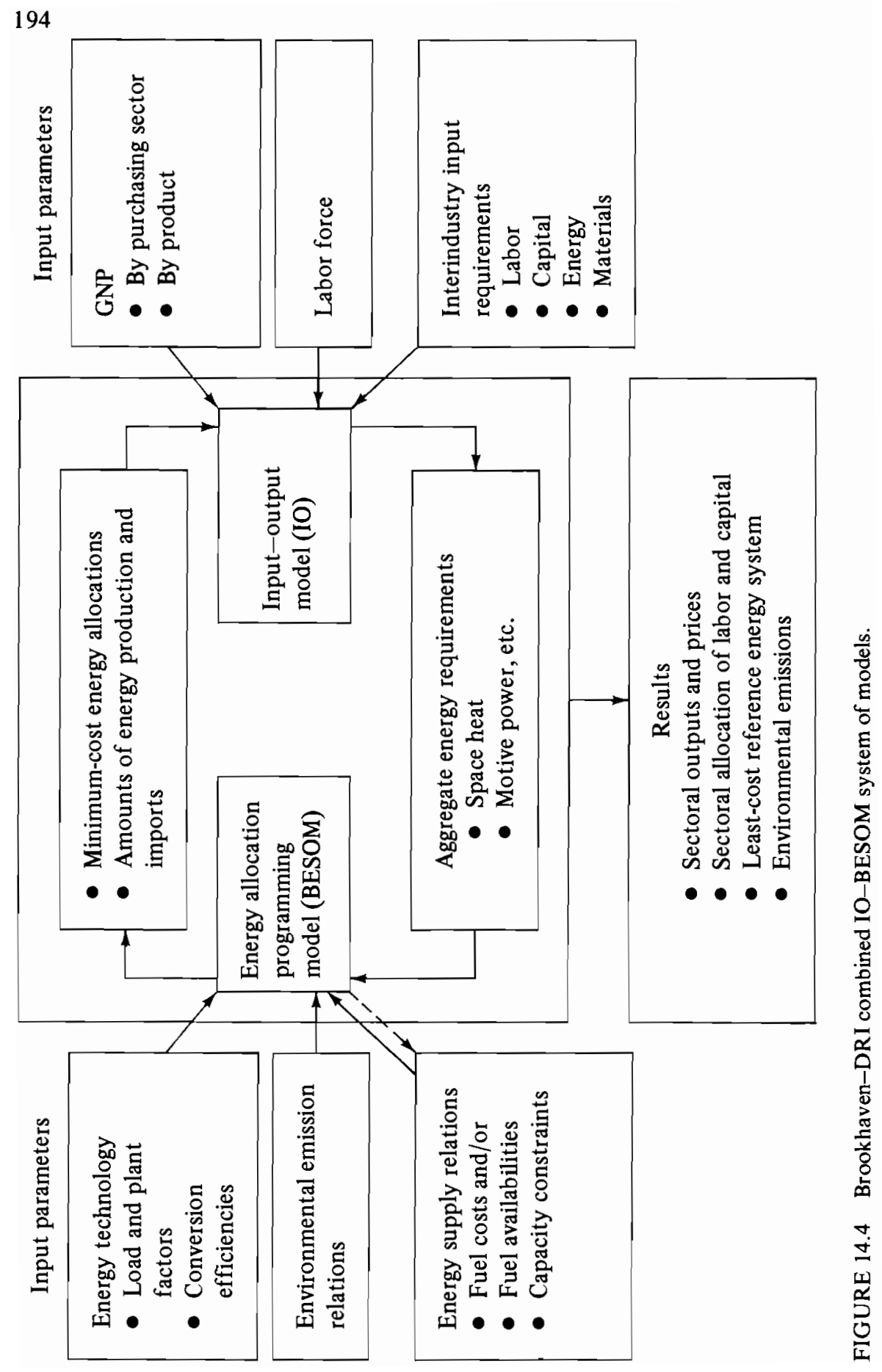


exceptions. The output of all energy sectors is expressed in physical units (Btu) rather than in dollars. In addition, the outputs of the coal, oil, gas, and electricity sectors are not distributed directly to the purchasing sectors, but to eight dummy "energy product" sectors. These product sectors are defined in the same way as the set of energy requirements in BESOM, and comprise coke, petrochemical feedstocks, motive power, process heat, water heat, space heat, air-conditioning, and electrical power. These energy products are distributed directly to the interindustry and final demand sectors. In other words, energy input to nonenergy sectors is given in terms of energy products such as space heat rather than in terms of generated electricity and specific fuels such as coal or natural gas. Specifying input requirements in terms of energy products makes it much easier to substitute fuels to meet given functional energy requirements when the input-output model is joined to BESOM.

Finally, input-output coefficients for six new energy technologies have been added to the model. These technologies are the Solvent Refined Coal (SRC) process for coal purification; the mining and retorting of shale oil; the HighTemperature Gas-Cooled Reactor (HTGR); the gasification of high-Btu coal; the gasification of low-Btu coal and the combined low-Btu coal gas and steam cycle electricity generation plant; and the Light Water Reactor (LWR). This makes it possible to analyze the economic effects of introducing new technologies which have resulted from RD\&D (research, development and demonstration) activities.

\section{MODELS EMPLOYED BY DATA RESOURCES, INC. ${ }^{2}$}

Complementing the PIES and Brookhaven systems is the DRI system of economic models, which provides an analytical framework for the examination of the economic effects of energy development. This system consists of two components: a macroeconomic growth model and a ten-sector interindustry economic model. Together these models may be used to analyze the general trends and pattern of long-run economic growth and to examine the pattern and composition of economic activity at any point in its development.

The macroeconomic forecasts consider both supply and demand, and these are maintained in equilibrium by means of a market mechanism within which both prices and quantities may vary. A detailed analysis of the pattern of economic activity at any given time can then be provided by linking the interindustry economic model with the macroeconomic growth model. The growth model determines the general nature of economic performance; the interindustry model determines the corresponding detailed pattern of expenditure and production.

\section{Linkage of BNL and DRI models}

As part of a long-term plan to integrate the pricing and output structures of all DRI and BNL models, the models have been calibrated so that they produce consistent economic output estimates for the base case. This means that each model 
should start from the same initial position with respect to the GNP, its sectoral composition and distribution to consumption, investment, government and foreign trade, and sectoral interindustry input requirements.

The need for consistency affects previously estimated exogenous inputs to the BNL and DRI models. The 90 final demands for nonenergy materials in the BNL IO model and the corresponding four final demands (agricultural, manufacturing, transportation, and services) in the DRI interindustry model have been scaled so that they agree with the corresponding "material" aggregate in the macroeconomic model. The $90 \times 90$ nonenergy-into-nonenergy input coefficients in the IO model have been scaled so that they agree with the corresponding $4 \times 4$ aggregate input-output coefficients in the DRI interindustry model.

After making the IO parameters consistent with the corresponding DRI interindustry parameters, the IO model has been solved to give the total energy demands, which in turn have been used in BESOM. Given the energy demands, BESOM estimates the least-cost level and mix of domestic energy production and imports.

Exogenous technological shift parameters in the DRI interindustry model have been adjusted so that the model yields energy estimates consistent with those produced by BESOM. The levels of imports and foreign trade have been made consistent in all models by decreasing exports by the same current dollar amounts as the decrease in imports.

The capital requirements for energy production in accordance with BESOM solutions have been estimated and yearly values calculated to yield forecasts of the investment in energy required in 1985, 1990, and 2000. These, in turn, have been introduced into the BNL IO model and the DRI interindustry model, replacing the original investment estimates.

Thus, the models have not only been calibrated using a common base case set of energy projections, they have also been made consistent with respect to changes in the pattern of energy demands arising from changes in energy prices, and with respect to changes in domestic energy supplies and capital requirements arising from the introduction of new energy technologies.

\section{SRI-GULF MODEL ${ }^{4}$}

This model has been used to analyze a wide range of corporate and government decision problems in the energy field. The structure of the current SRI-Gulf model therefore naturally reflects the decision problems to which it has recently been applied. In particular, the model has been used to analyze the policies of the government and of private industry on synthetic fuels and commercialization and on priorities in research and development of new energy supply technologies. As a result, the present model contains large amounts of information on these and other competing technologies as well as details of energy resources, markets, transportation, and end-use energy conversion, all of which determine the market for new energy supply technologies. A different emphasis would be required to 
analyze other problems, such as those concerned with regulation of energy prices, energy conservation, and environmental control (see Figure 14.5).

\section{Model structure}

The structure of the SRI-Gulf model is illustrated by the schematic network diagram shown in Figure 14.5.

The current network considers 17 end-use demands for each of the nine demand (US census) regions. The detailed structure of the demand sectors of the model is illustrated in Figure $\mathbf{1 4 . 5}$ for the residential and commercial (R/C) sectors. Note that the end-use demand for space heating is represented in terms of

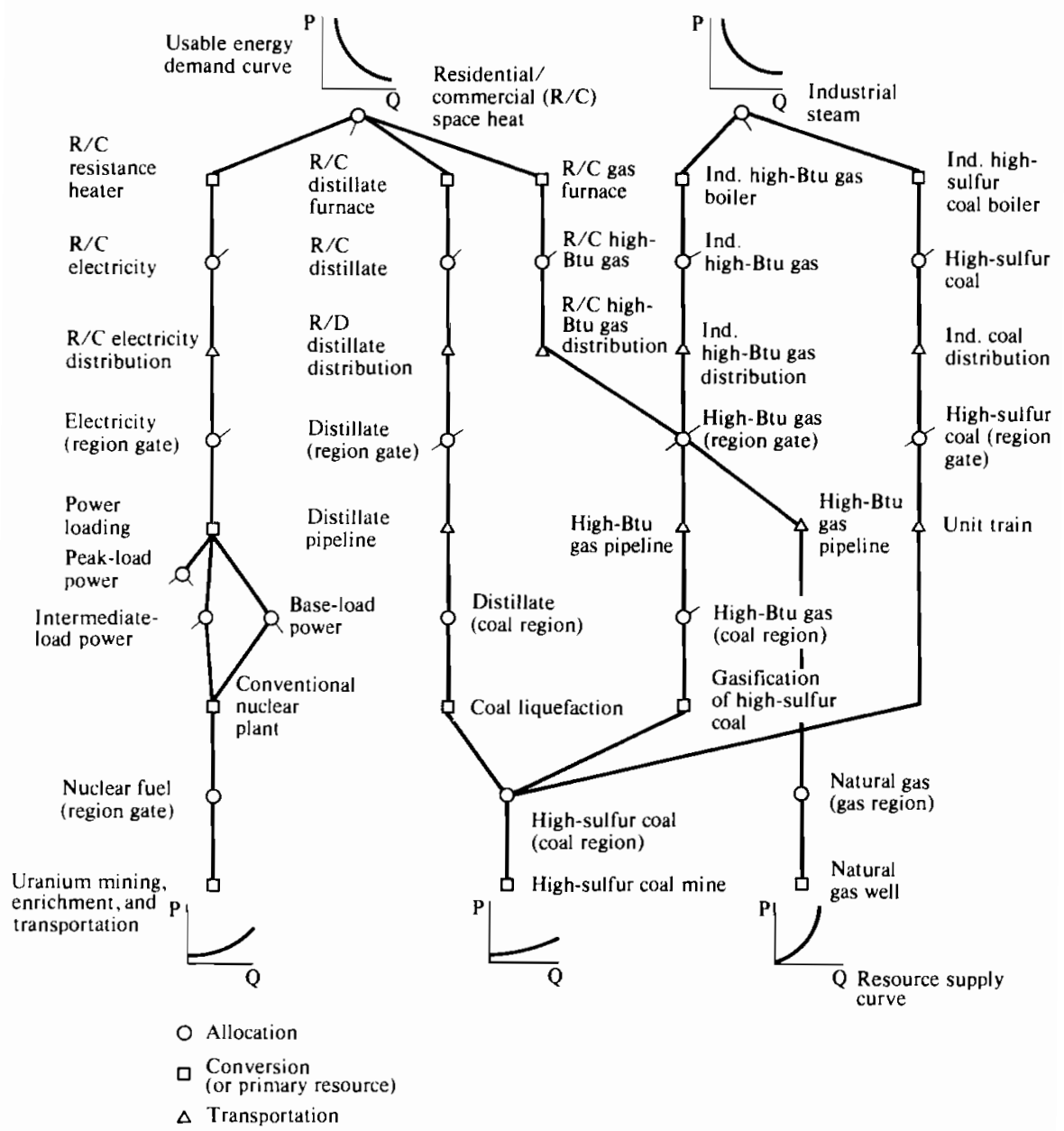

FIGURE 14.5 Schematic diagram of the network structure of the SRI-Gulf model. 
the energy output of a residential furnace and that the fuel required for space heating is assumed to be the fuel consumed in the furnace. This contrasts with most energy models, which usually treat only the demand for fuel and do not consider end-use energy demands in any detail. Moreover, the technologies and energy products shown in Figure 14.5 cover a wide range of present and future energy options. The industrial and transportation demand sectors are treated in as much detail as the residential and commercial demand sectors.

Energy is converted from natural to synthetic products in the demand regions and in some of the supply regions. Details of the conversion processes producing hydrogen, electricity, and low-Btu gas in the demand regions are given in Figure 14.5; particular attention is paid to electricity generation to meet base-load, intermediate and peak-load power demands. Synthetic high-Btu (pipeline) gas, shale, and coal-based synthetic crude oils, methanol, and other synthetic products are produced in the shale and coal supply regions.

The interregional transportation network for high-Btu gas (both natural and synthetic) includes only major current or future routes. Comparable transportation networks for all other products and resources are given in the model.

The supply of primary resources such as coal, nuclear fuels, shale, geothermal steam, crude oil, and natural gas is described by process models defined for each supply region. An important and unique feature of these models is their use of long-run supply curves such as those employed for crude oil. Within the resource process models, the prices of primary resources are defined in terms of the marginal cost from these curves plus an economic rent term that represents resource scarcity.

There are two important models which are not shown in Figure 14.5:

1. A model representing economic and population growth. This model derives the end-use demand by taking projections of aggregate economic activity and population growth and determining the activity and the price elasticity of the demand for end-use energy in each sector.

2. A model describing the factors of production or secondary materials consumed by processes. This model describes the effect of increases in the demand for secondary materials on the prices of secondary materials and hence on the prices of products.

The SRI-Gulf model spans the next 50 years. Models of each process deal with the installation and retirement of facilities over time; the depletion of primary resources over time is also modeled. The dynamic aspects of forecasting (predicting future variables) and time-lag modeling, introduced through the normal functioning of the decision processes, are particularly important in models employed in capacity expansion decisions. For example, the SRI-Gulf model uses estimates of the future prices of primary resources to determine the economic rent on resources in intervening periods. 
The SRI-Gulf model reflects the high degree of decomposition of the United States energy market in that it is composed of processes which describe the technology and decision behavior of each sector of the energy market. Because the overall model is very detailed, the structure within each of the process models is relatively simple. More importantly, model parameters can be assessed at any level of detail, depending on the expertise and data available. Thus, specialists in each sector of the energy market can provide their own inputs and use the model at any level they wish. The next section describes how the prices and quantities of energy materials and the choice of energy technologies that form a solution to the model are determined.

\section{Network iteration algorithm}

The network iteration algorithm assumes initial rough estimates of prices and quantities for all energy products in all periods considered in the model; these prices and quantities are then adjusted until all of the relations implicit in the process models are satisfied. The resulting set of prices and quantities is usually called the equilibrium solution. This solution will, however, reflect the market imperfections and aspects of human behavior built into the submodels (processes); idealized, perfect market behavior need not be assumed in a generalized equilibrium model. Moreover, the equilibrium solution is dynamic; the solution for a given time period depends on the solutions for the periods which precede and succeed it.

The algorithm in the SRI-Gulf model takes advantage of the network structure of the model in that it iterates up and down the network (see Figure 14.5), computing tentative prices on the upward iteration and quantities on the downward iteration. The upward iteration begins with estimates of the prices of primary resources and computes product prices and end-use energy costs using a subset of the relations in each process. The remaining relations in each process are used to calculate quantities on the downward iteration.

In this iterative procedure, the prices or quantities of each output or input are computed for all time periods before moving to the next output or input. An alternative iterative scheme would be to iterate back and forth through time, and within each single time period to move up and down the network only once. For the present model, the first scheme is less expensive in terms of programming and computation. The surprising feature of these iterative schemes is that they cost very little more to program and compute than algorithms that impose severe restrictions on the dynamic structure of the model.

\section{MODELS IN THE POLICY PROCESS}

Each of the four models discussed above has been used in the policy sector. It is not possible to analyze these uses here, but it is useful to understand the driving 
force behind the development of such models. For example:

- PIES was developed in response to a Presidential mandate to develop strategies that would make the USA independent of foreign energy supplies. It became the principal analytical tool of the now disbanded Federal Energy Administration and is used by the Energy Information Administration of the Department of Energy.

- SEAS was developed by the Environmental Protection Agency and is used by the Office of Research and Development. In 1976 it was introduced as the principal method of environmental analysis in the Office of the Assistant Secretary for Environment at the Department of Energy.

- The Brookhaven system was used throughout ERDA but the principal users were the Office of the Assistant Administrator for Planning and Evaluation. It provided the analytical basis for the agency's two five-year plans.

- The SRI-Gulf model was used largely for one major ERDA exercise.

In all cases, the primary use of the models was to produce annual plans or reports, and it is therefore difficult to state exactly how the models contributed to policy. To the extent that the agencies took the forecasts and goals seriously, the models can be said to have produced the framework for the specific policies of those agencies. However each of these models has also been used for a number of other policy studies, and in these cases their use has been much more directly tied to the final policy decisions.

In general, all models of the type discussed here are large forecasting systems which involve a sizable number of people and considerable maintenance costs. The policy maker is obviously not expected to interact with such systems directly; technical advisers in his office manage the system and are responsible for explaining the problem to be solved to the computer operators and interpreting the results of the analysis for the policy maker.

It is evident that energy/environment modeling is a field with a great deal of potential. The past has been exciting and fruitful--the future promises still more.

\section{REFERENCES}

1 P.W. House and J. McLeod. Large-Scale Models for Policy Evaluation. Wiley, New York, 1977.

2 Data Resources, Inc. The Data Resources Quarterly Model, Econometric Forecasting System. Equation Specifications, 1974.

3 D.J. Behling, Jr., R. Dullien, and E. Hudson. The Relationship of Energy Growth to Economic Growth Under Alternative Energy Policies. Prepared for the Office of the Assistant Administrator for Planning and Analysis, US Energy Research and Development Administration, under contract \#E(30-1)-16 by the Economic Analysis Division, Department of Applied Science, Brookhaven National Laboratory, Upton, New York, March 1976, pp. 21-36.

4 E.G. Cazalet. Final Report-Generalized Equilibrium Modeling: The Methodology of the SRI-Gulf Model. Decision Focus, Inc., Palo Alto, California and Stanford Research Institute, Menlo Park, California. Prepared for the Federal Energy Administration, Washington, DC, May 1977. 
Part II
A Retrospective Look at the
Four IIASA Regional Analyses of Energy/Environment Systems 



\section{A Four-Region Overview}

W. K. Foell*

\section{INTRODUCTION}

The IIASA research program on Management of Regional Energy/Environment Systems was designed to use methods from systems analysis to integrate the planning of energy systems with environmental management. As an experiment in East-West collaborative research, it examined areas from within both the centrally-planned and market economy sectors, in particular the German Democratic Republic, the Rhône-Alpes region of France, the state of Wisconsin in the USA, and Austria.

This chapter reports on the major objectives of the research program: the description and analysis of patterns of regional energy use and study of the relationships between energy use and socioeconomic patterns; and the examination of different possible energy futures for the regions, both from the point of view of the individual region and from a cross-regional perspective.

The next section provides a short comparison of the regions studied, and is followed by a section describing the concept of scenario use together with a brief definition of the scenarios employed. An overview of the resulting regional energy demand and supply futures is then given, and some of the environmental implications of these futures are summarized. The final section comments on planning and policy design in the regions and relates them to the results of this research.

\section{SHORT COMPARISON OF THE FOUR REGIONS}

This section summarizes and compares selected characteristics of the socioeconomic and energy systems of Austria, the German Democratic

* International Institute for Applied Systems Analysis, Laxenburg, Austria, and the University of Wisconsin-Madison, Madison, Wisconsin. 
Republic, the Rhône-Alpes region, and the state of Wisconsin to provide a background to the alternative energy futures described in the next sections. The characteristics presented here have a strong influence upon the evaluation of the energy systems in the regions and form an important part of the initial conditions of the scenarios. It should be noted that the GDR scenarios were constructed for "Bezirk-X", a composite region typical of the heavily industrialized southeast of the country*. However, the following characteristics are representative of the GDR as a whole.

The geographical locations of the four regions studied are shown in Figure 15.1. Table 15.1 compares their area, population, and population density, showing Wisconsin to be the largest of the regions. There is a striking contrast between the overall densities of sparsely settled Wisconsin and the heavily populated GDR; the population density in the GDR is more than five times greater than that in Wisconsin. Figure 15.2, a comparison of recent population figures, shows that the GDR and Austria had zero population growth between 1972 and $1978^{1,2}$, in contrast to the continuing, although modest, growth in the Rhône-Alpes region ${ }^{3,4}$, and Wisconsin ${ }^{5}$ (approximately $0.59 \%$ and $0.65 \%$ per year, respectively). In 1972 the Rhône-Alpes region had the highest birth rate, the lowest death rate, and the greatest degree of urbanization of the regions considered. Wisconsin was characterized by the relatively low median age of its inhabitants and a correspondingly low death rate. The demographic features of the GDR in 1972 included a comparatively low birth rate and a relatively high death rate, resulting from the higher median age of the population. Austria's demographic patterns are similar to those of the GDR.

\section{Transportation characteristics}

Table 15.2 compares the numbers of motor vehicles in the regions in 1972, and demonstrates the heavy reliance placed on the automobile in Wisconsin. Furthermore, the number of registered motor vehicles in Wisconsin has increased approximately three times faster than the population since 1960 . However, recent time-series studies show that automobile ownership in the GDR is increasing at an annual rate of $12 \%$ compared to $4 \%$ in Wisconsin. The heavy reliance on mass transit in the GDR is also striking. Austria's car ownership pattern falls between those of the GDR and the Rhône-Alpes region.

\section{Economic characteristics}

Industry is more important in the economies of the Rhône-Alpes region and the GDR than in Austria or Wisconsin. Table 15.3 shows the estimated proportions

\footnotetext{
" The best English translation of the German word "Bezirk" is probably "county".
} 


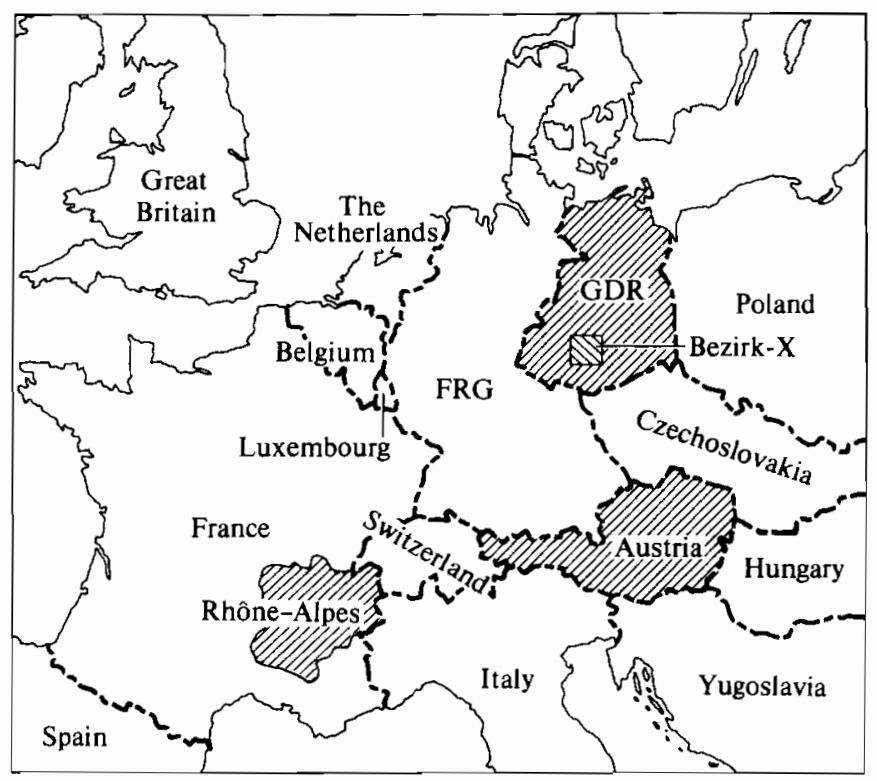

(a)

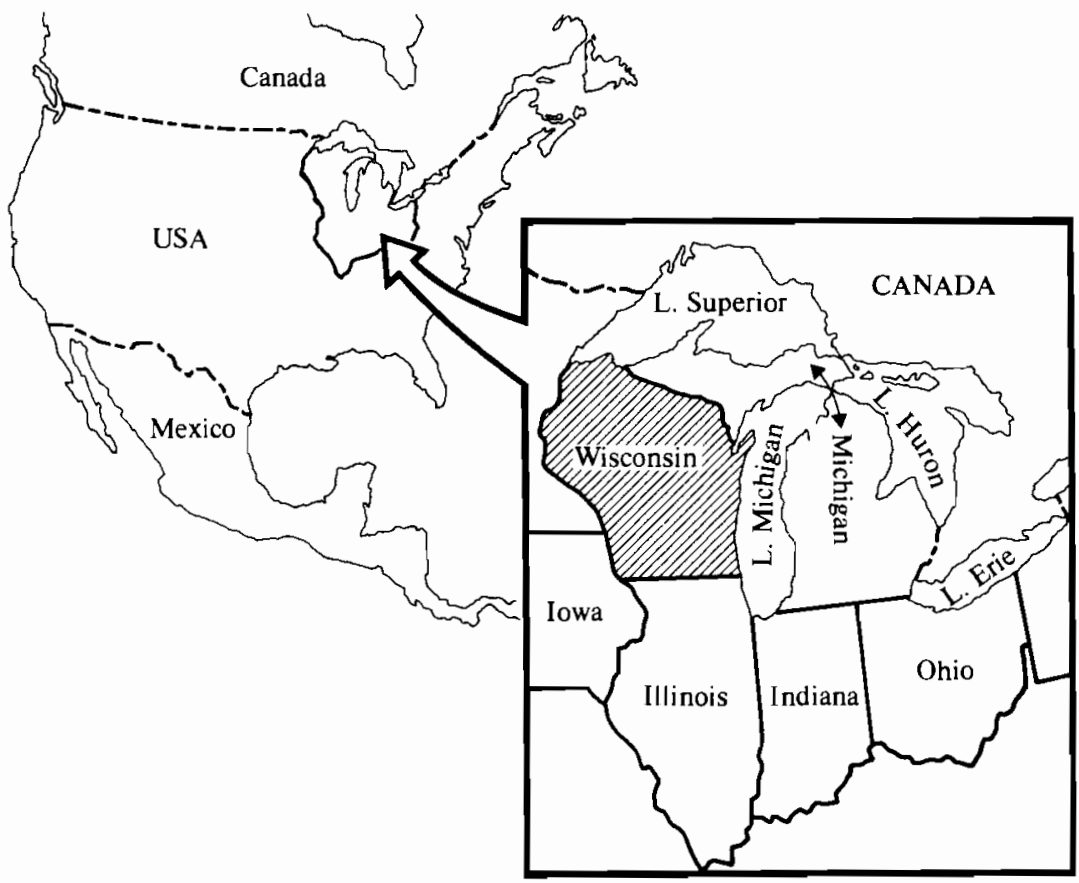

(b)

FIGURE 15.1 The geographical locations of the four regions studied. 
TABLE 15.1 Population, area, and population density of the four regions in 1972.

\begin{tabular}{lcrc}
\hline Region & $\begin{array}{l}\text { Population } \\
\left(10^{6} \text { people) }\right.\end{array}$ & $\begin{array}{l}\text { Area } \\
\left(\mathrm{km}^{2}\right)\end{array}$ & $\begin{array}{l}\text { Population } \\
\text { density } \\
\left.\text { (people } / \mathrm{km}^{2}\right)\end{array}$ \\
\hline Austria & 7.5 & 83,853 & 89 \\
GDR & 17.0 & 108,178 & 157 \\
Rhône-Alpes & 4.7 & 43,634 & 108 \\
Wisconsin & 4.5 & 145,370 & 31 \\
\hline
\end{tabular}

of the total working population occupied in each economic sector for the four regions in 1972. Although there may be some inconsistencies in the definition of sectors, Wisconsin has a significantly smaller percentage of workers in the industrial sector than have the other regions*.

Table 15.4 presents an interregional comparison of industrial activity disaggregated by sector. The greatest relative differences occur in the food and chemical sectors. Wisconsin is one of the more important food-producing states in the USA, especially in dairy products. On the other hand, it plays a relatively small part in the chemical and rubber industries, both of which are important in Austria, the GDR, and the Rhone-Alpes region.

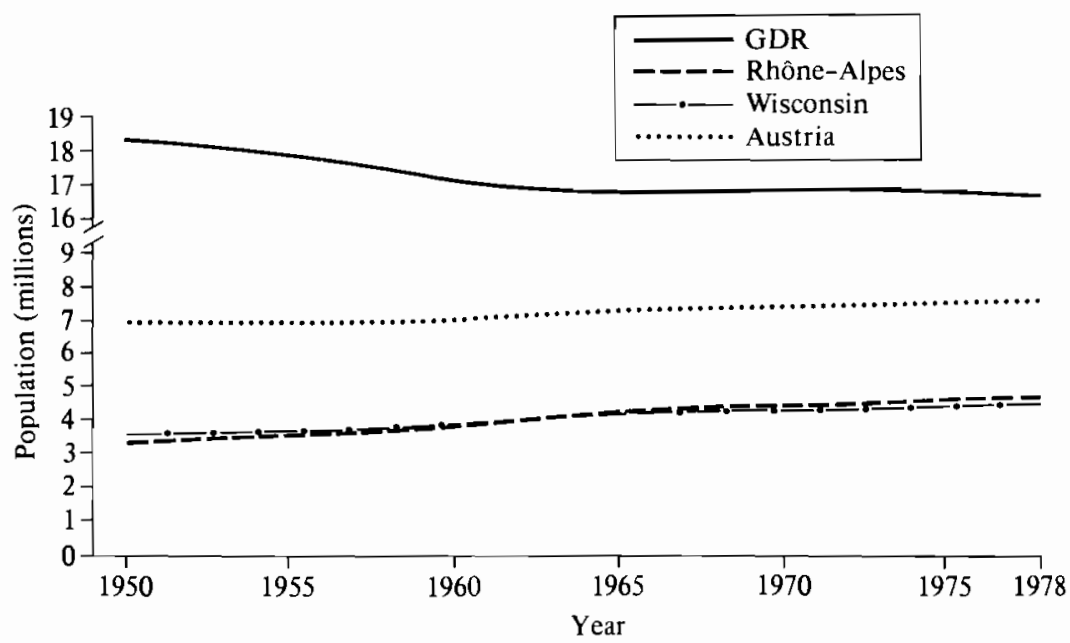

FIGURE 15.2 Evolution of the populations of the four regions studied, 1950-1978.

\footnotetext{
* Wisconsin nevertheless has the twelfth highest total industrial output of the 50 states in the USA.
} 


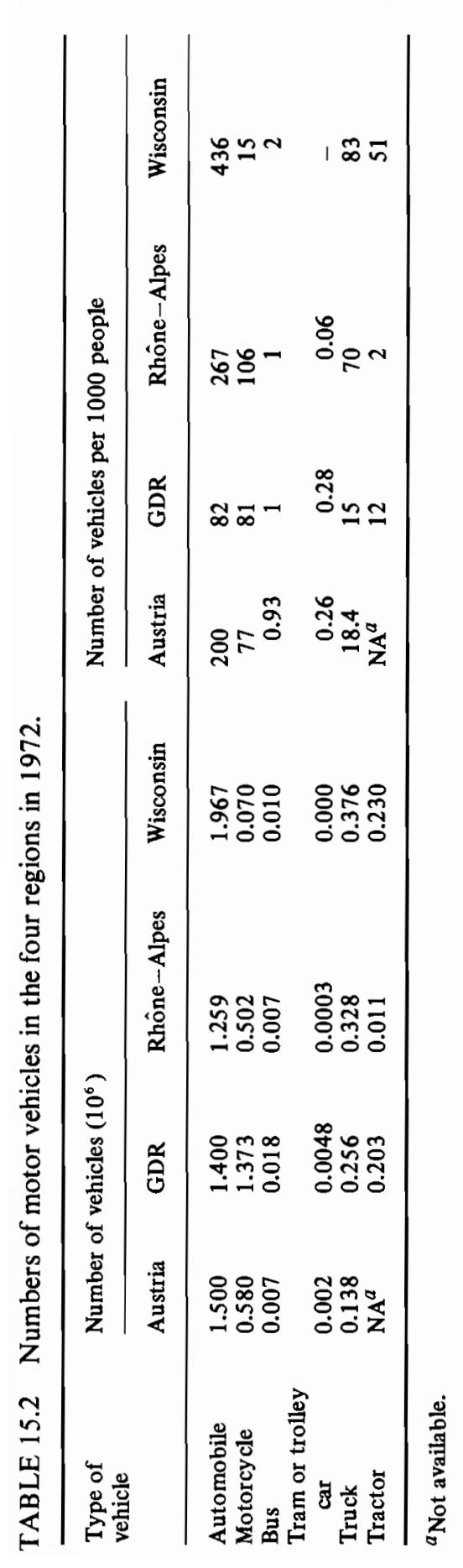

207 
TABLE 15.3 Estimated disaggregation of the working population of each region in 1972 into economic sectors.

\begin{tabular}{lcccc}
\hline Economic sector & Austria & GDR & Rhône-Alpes & Wisconsin \\
\hline Percentage of working population & employed & in each & economic sector & \\
Agriculture & 14.0 & 11.6 & 9.0 & 8.4 \\
Industry & 33.0 & 38.5 & 36.0 & 25.5 \\
$\begin{array}{l}\text { Building and public works } \\
\text { Commerce, service, and }\end{array}$ & 8.0 & 7.4 & 9.3 & 3.3 \\
$\quad$ administration & 42.0 & 42.5 & 45.7 & 62.8 \\
$\begin{array}{l}\text { Other } \\
\text { Percentage of total population assumed to be working }\end{array}$ & 3.0 & - & - & - \\
All sectors & 42.0 & 48.6 & 43.4 & 40.8 \\
\hline
\end{tabular}

\section{Energy consumption}

A comparison of past energy use in the four regions reveals some interesting differences, most of which are discussed in connection with the alternative energy futures in later sections. Table 15.5 summarizes primary energy use in the regions in 1972. Wisconsin has by far the greatest energy use per capita-almost three times that of Austria - while the density of energy use in the GDR is almost twice that of the Rhône-Alpes region and three times greater than the corresponding figures for Wisconsin and Austria. Although the energy density varies considerably within a region, the overall density nevertheless indicates the concentration of energy-related activities in that region.

TABLE 15.4 Sectoral structure of the industrial activity in the four regions in 1972.

\begin{tabular}{lcccc} 
Industrial sector & \multicolumn{3}{l}{$\begin{array}{l}\text { Percentage contribution of each industrial sector to overall } \\
\text { industrial activity }\end{array}$} \\
\cline { 2 - 5 } & Austria & GDR & Rhône-Alpes & Wisconsin \\
\cline { 2 - 5 } & 14.3 & 11.6 & 8.7 & 15.8 \\
Food & 7.3 & 2.1 & 3.5 & 1.3 \\
Building materials & 9.1 & 4.7 & 5.8 & 5.6 \\
Primary metals & & & & \\
Machinery (mechanical, & 29.7 & 42.0 & 44.5 & 49.0 \\
$\quad$ electrical, and & 18.5 & 17.0 & 14.7 & 6.0 \\
$\quad$ transportation equipment) & 21.1 & 22.6 & 22.8 & 22.3 \\
Chemicals and rubber & & & & \\
Light industry & &
\end{tabular}

${ }^{a}$ As a percentage of industrial value added for Austria, the Rhône-Alpes region, and Wisconsin, and as a percentage of net industrial production for the GDR. 
TABLE 15.5 Use of primary energy in the regions in 1972.

\begin{tabular}{llll}
\hline Region & $\begin{array}{l}\text { Annual energy } \\
\text { use } \\
\left(10^{15} \mathrm{cal}\right)\end{array}$ & $\begin{array}{l}\text { Annual energy } \\
\text { use per capita } \\
\left(10^{9} \mathrm{cal}\right)\end{array}$ & $\begin{array}{l}\text { Density of annual } \\
\text { energy use } \\
\left(10^{12} \mathrm{cal} / \mathrm{km}^{2}\right)\end{array}$ \\
\hline Austria & 181 & 24.3 & 2.2 \\
GDR & 749 & 44.0 & 6.9 \\
Rhône-Alpes & 168 & 35.7 & 3.8 \\
Wisconsin & 319 & 70.9 & 2.2 \\
\hline
\end{tabular}

Table 15.6 compares the end-use energy by each economic sector in the four regions in 1972. The percentage of end-use energy consumed by the industrial sector is far greater in the GDR (60\%) than in Austria (42\%), the Rhône-Alpes region $(40 \%)$, or Wisconsin $(29 \%)$. This in part reflects the more industrialized structure of the GDR economy, but is also related to the less energy-intensive character of the residential and transportation sectors in the GDR, compared to the other regions. For example, in Wisconsin the heavy reliance on automobiles and trucks as modes of transport means that the transportation sector consumes $29 \%$ of total end-use energy, as compared with $21 \%, 17 \%$, and $10 \%$ in Austria, the Rhone-Alpes region, and the GDR, respectively. The relatively high fraction of end-use energy supplied as electricity to industry in the Rhône-Alpes region is also striking, although not surprising since the heavy concentration of industry near the mountains was designed to take advantage of local inexpensive hydropower.

TABLE 15.6 End-use energy consumption disaggregated by sector for the regions in 1972.

\begin{tabular}{lcccc}
\hline Sector & Austria & GDR & Rhône-Alpes & Wisconsin \\
\cline { 1 - 2 } \begin{tabular}{l} 
Energy consumed in each sector \\
\multicolumn{2}{l}{$\left(10^{12}\right.$ kcal and as a percentage of the total for all sectors) }
\end{tabular} & & \\
Industrial & $61.8(42)$ & $312(60)$ & $48(40)$ & $77(29)$ \\
Residential and commercial & $49.8(34)$ & $139(27)$ & $52(43)$ & $106(39)$ \\
Transportation & $31.5(21)$ & $55(10)$ & $20(17)$ & $79(29)$ \\
Other & $5.2(3)$ & $15(3)$ & - & $8(3)$ \\
All & $148.3(100)$ & $521(100)$ & $120(100)$ & $270(100)$
\end{tabular}

Electrical energy consumed in each sector

(as a percentage of total energy consumption in that sector)

Industrial

Residential and commercial

Transportation

Other

All
19

12

4

12

13
13

12

2

31

12

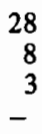

15
10

16

0

11 
One of the issues investigated was the potential need for additional electricitygenerating capacity in the regions. Table 15.7 provides an interregional comparison of recent electricity use and the annual growth in electricity consumption. Between 1972 and 1978 the rates of growth in electricity consumption were quite similar in all four regions.

A comparison of the fuels used to generate electricity, shown in Figure 15.3, illustrates the dominance of coal (lignite) in the GDR, hydropower in Austria and the Rhône-Alpes region, and coal in Wisconsin. During recent years, Wisconsin has placed much less reliance on coal; in 1976, nuclear plants provided more than $30 \%$ of all electricity generated. In all four regions, electricity growth rates have tended to decrease rather than increase in recent years.

\section{Energy supply}

The main sources of primary energy in the four regions are quite different, as illustrated in Figure 15.4. Nearly $70 \%$ of Austria's energy is provided by petroleum and natural gas. The GDR relies heavily on coal (mainly locally stripmined lignite), whereas the Rhône-Alpes region is very dependent on petroleum and hydropower. Although Wisconsin has no naturally occurring fuel resources, it has a diverse mix of energy sources based mainly on petroleum, natural gas, and coal; the proportion of Wisconsin's energy supply derived from uranium has increased in recent years (2.8\% in 1972 and $8 \%$ in 1976).

\section{Import and export of energy in the four regions}

Austria. Austria imports well over three-quarters of the primary energy it consumes, including $67 \%$ of the natural gas supply and $80 \%$ of the petroleum supply. Austria imports $8 \%$ of the electricity it consumes and exports approximately $20 \%$ of the electricity it produces (mostly hydropower).

GDR. Almost all of the hard coal, petroleum, and gas consumed in the GDR is imported; in 1972 these energy forms represented approximately one-third of the primary energy supply. There is some export of refined petroleum products (gasoline and diesel) and of lignite products. Electricity imports and exports are almost equal.

Rhône-Alpes region. The Rhône-Alpes region has to import all energy sources except for the coal and hydropower used in electricity generation. The declining use of coal means that petroleum imports represent an increasing fraction of the primary energy supply - about $50 \%$ of the petroleum products are refined within the region. In the past, the Rhône--Alpes region was a net exporter of electricity ( $20 \%$ surplus in 1972 ), but the export surplus has recently been declining. 


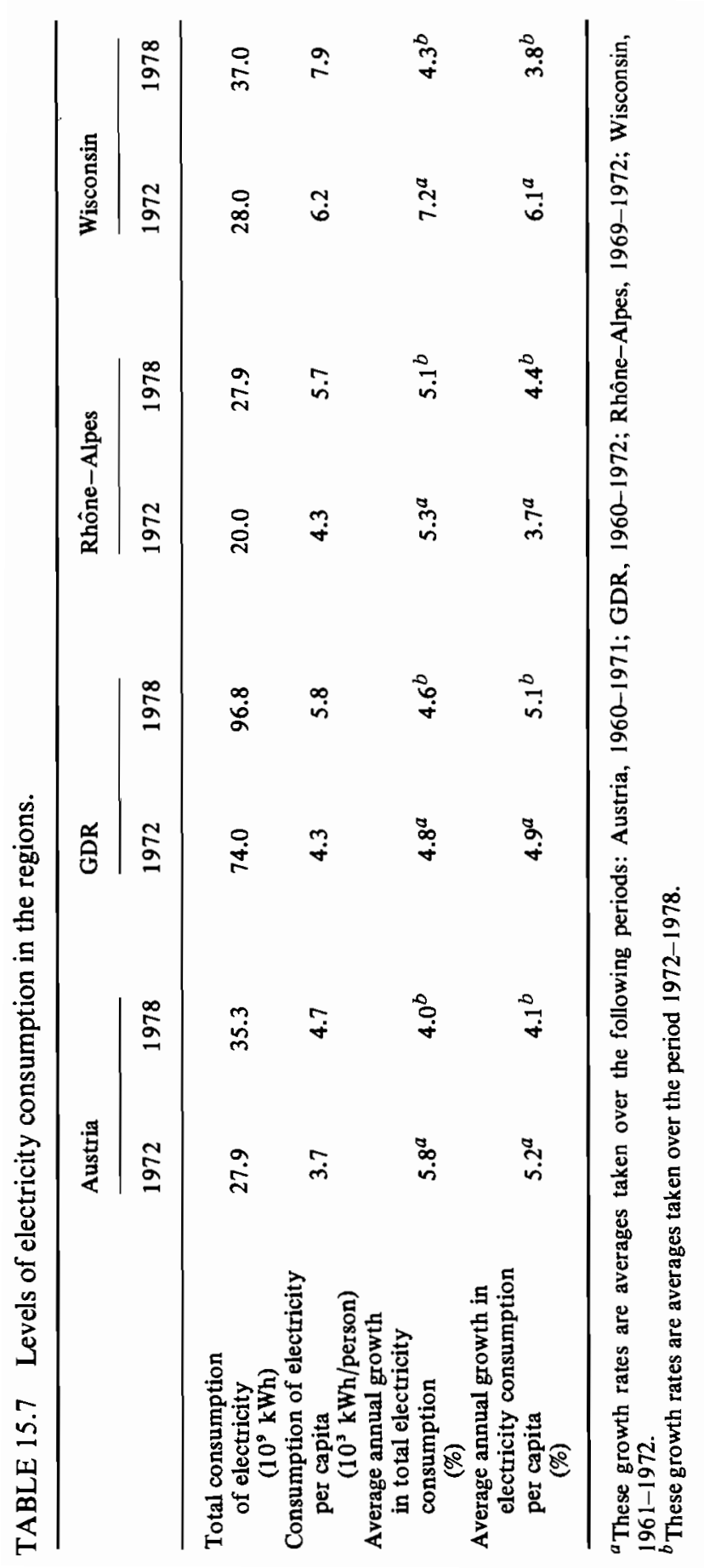



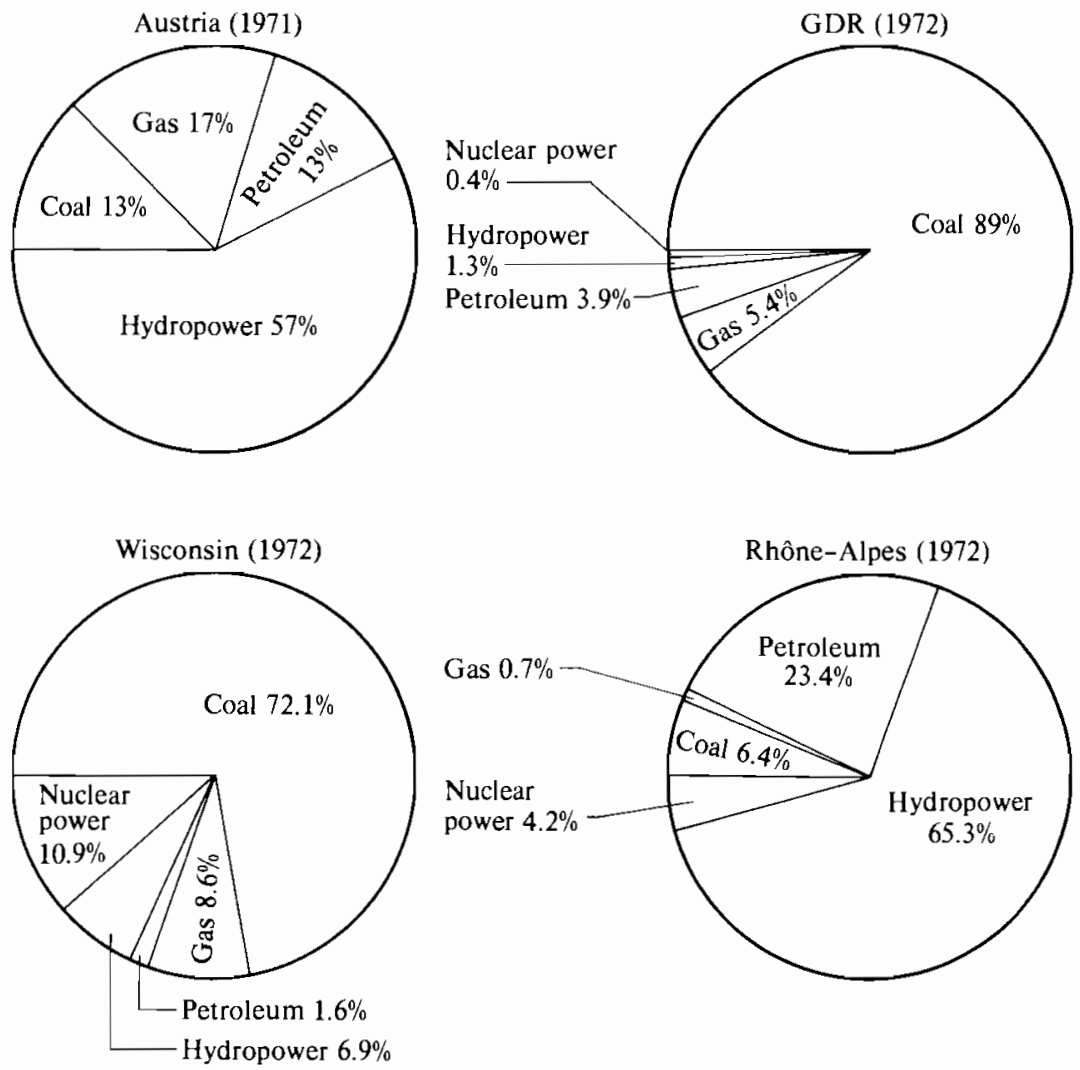

FIGURE 15.3 Interregional comparison of the fuels used for electricity generation.

Wisconsin. Wisconsin imports all of its primary energy except for a small amount of hydropower. There are some small refineries within the region. Electricity imports and exports are almost equal.

\section{THE SCENARIOS}

The IIASA study used scenario building as a formal quantitative approach to policy analysis and the examination of energy/environment strategies. This process involves two stages:

1. The assumption that specific energy/environment policies are adopted by the regions. These policies take into consideration the individual characteristics and initial constraints in the regions.

2. The modeling and evaluation of the resulting developments. 
The policies chosen were relevant to all of the regions and were basically concerned with mid-to-long-term (5-50 years) energy strategies.

A number of "policy sets" were developed for each region and the resulting scenarios were investigated. "Sensitivity studies" were then conducted to evaluate the effects of varying a small number of policy variables while holding the others constant.

The policy sets were based on possible future developments in four main areas: socioeconomic factors, lifestyle, technology, and environment. Within these four general categories, detailed assumptions about policies and/or future events were built into the scenarios. The resulting energy futures were not developed as predictions, but rather were intended as a means of evaluating the consequences of different policy decisions.

Each of the regions has a range of possible energy futures; the policies chosen here examine only a small number of options in an attempt to illustrate the possible approaches to energy/environment management. It should be
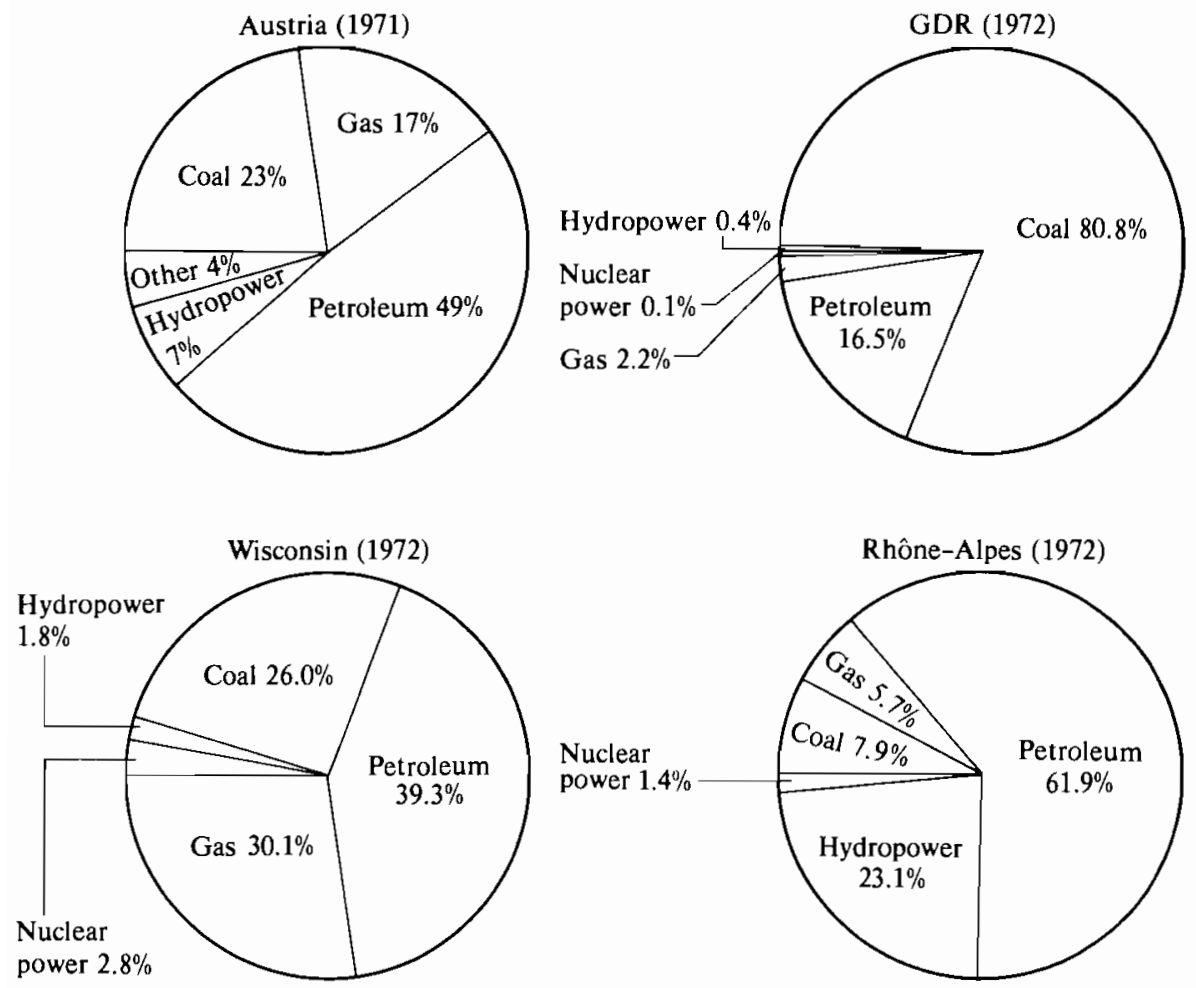

FIGURE 15.4 Interregional comparison of the sources used to provide energy. 
emphasized that the policies and assumptions were not chosen arbitrarily by the IIASA research team, but were the products of lengthy and repeated consultation with collaborating specialists in the various regions. Whenever possible, the assumptions were compared with those in other economic or technical studies, such as the GDR long-term energy outlook ${ }^{6}$, or national energy assessments for France and Austria ${ }^{7-10}$.

As noted earlier, the scenarios for the GDR were constructed for "Bezirk-X", a composite region typical of the heavily industrialized southeast of the country. A detailed comparison of the socioeconomic and energy characteristics of Bezirk-X and the GDR as a whole are given in ref. 11 . The IIASA research team felt that Bezirk-X was sufficiently representative of the GDR that an analysis of its energy system would provide considerable insight into that of the entire country.

One of the main tools used to analyze the scenarios was a family of simulation models originally developed at the University of Wisconsin-Madison ${ }^{12}$ and extended at IIASA to treat a wider range of regional energy/environment systems ${ }^{13}$. The models simulate the regional energy system within a framework that includes energy demand, regional supply systems, and environmental impacts. Most of the models are based on descriptions of engineering processes. The socioeconomic development of the regions (population growth, settlement patterns, economic activity, etc.) was modeled differently in each region; the techniques employed ranged from extrapolating the value-added variables (Wisconsin) to the use of a demand-oriented input-output model (Austria). In all cases the regional socioeconomic development scenarios were consistent with national and/or global patterns.

The studies for the GDR, the Rhône-Alpes region, and Wisconsin were conducted simultaneously and so some common characteristics could be introduced into the scenarios for all three regions, e.g., stronger conservation measures, greater emphasis on renewable energy sources, and so on ${ }^{11}$. Although the Austrian study was conducted slightly later, the scenarios were constructed on the same general basis as in the other three studies. For all regions, the scenarios could be categorized as cases of high, medium, or low energy use. The policies and assumptions in the medium (base) case (S1) are in general a continuation of past trends or trends current at the time of scenario construction, and assume no dramatic changes in energy prices. The high energy scenarios (S2) are produced by policies encouraging increased energy use; they are based on the assumption of decreasing energy costs and little incentive to improve the efficiency of energy use. The low energy scenarios (S3) are based on the assumption of higher energy costs and on the desirability of saving energy; however, as discussed later, they do not represent the lowest level of energy consumption that could reasonably be expected.

Tables 15.8-15.11 provide an overview of the scenarios investigated for each of the four regions. The scenarios all share the same basic structure: 
1. Socioeconomic factors

- Population

- Settlement patterns

- Economic activity

2. Lifestyle

- Personal consumption

- Methods and level of transportation

- Types of housing and use of appliances

3. Technology

- Industrial technology

- Technology of transportation systems

- Domestic heating and insulation technologies

- Energy supply and conversion technologies

4. Environment

- Environmental regulations

Certain factors remained constant in all scenarios for a given region. For example, the level of economic activity in Wisconsin was the same in all three scenarios. In addition, the ratio of manufacturing to service activity was not varied from scenario to scenario, although it changed over time. The population growth in a given region was also generally independent of the scenario. One example of differences between scenarios is given by the assumed evolution of human settlement patterns in Wisconsin (Table 15.11). The growth and spatial distribution of the population affects virtually all components of the energy system: for example, patterns of movement and distances traveled are strongly related to city size ${ }^{15,16}$, and the position of pollution sources relative to urban centers can affect the health of the local population ${ }^{17-19}$. Several different patterns of settlement have been suggested and these have been quantitatively incorporated into the various scenarios for Wisconsin.

Many sensitivity studies were conducted to investigate the effect of varying a single parameter within a given scenario. The parameters changed included type of housing, rate of development of domestic solar heating, insulation standards, different methods of electricity supply, and regulations controlling the emission of sulfur dioxide $\left(\mathrm{SO}_{2}\right)$.

\section{Socioeconomic factors}

Socioeconomic factors provide the main driving force for the evolution of regional energy demand; they also influence the degree and nature of the damage to human health caused by energy-related pollution. For these reasons, a brief interregional comparison of important socioeconomic factors is given below. The 


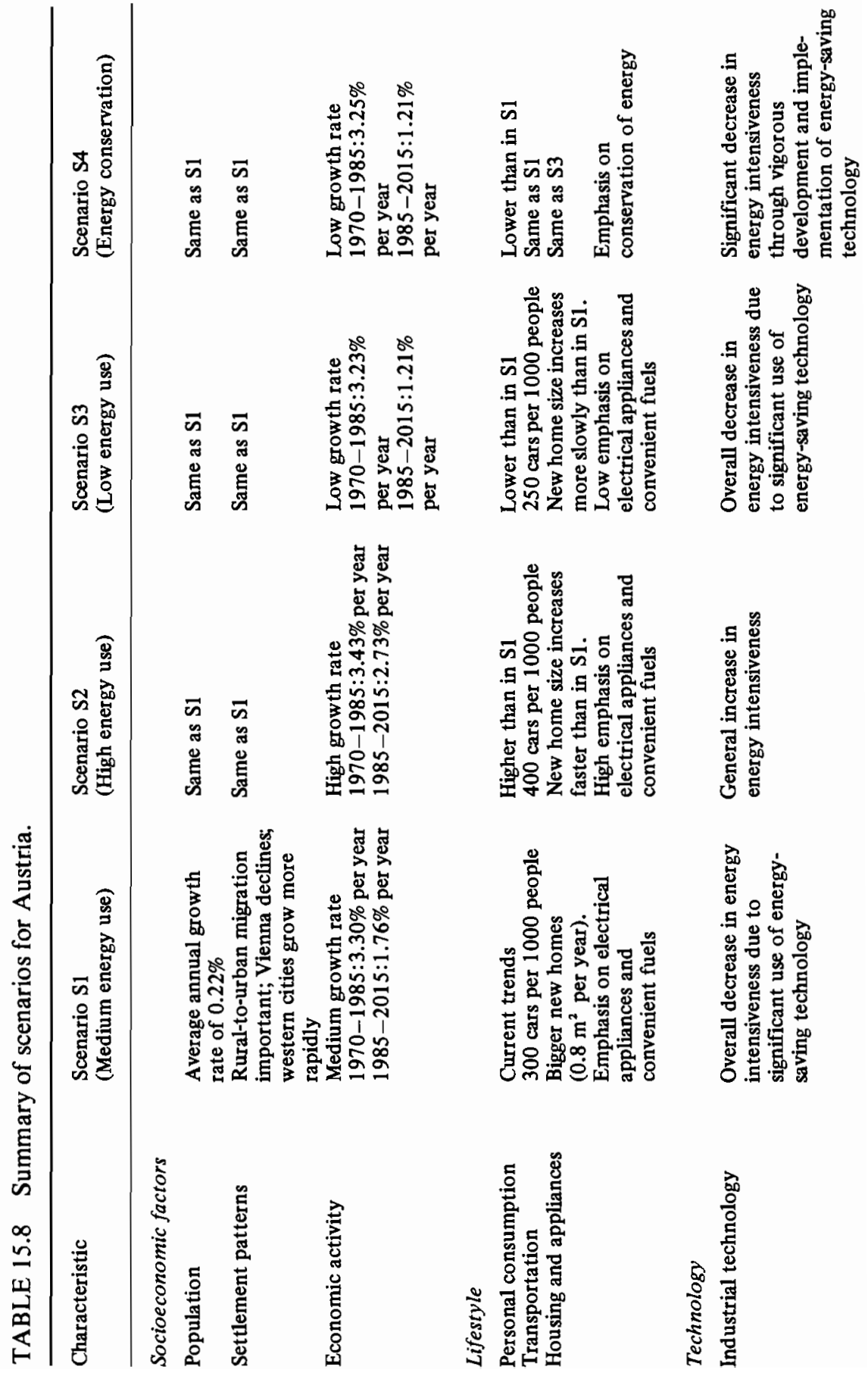


$\stackrel{-5}{8}$

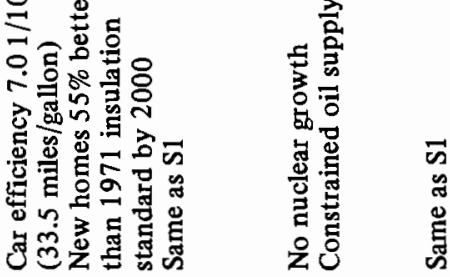

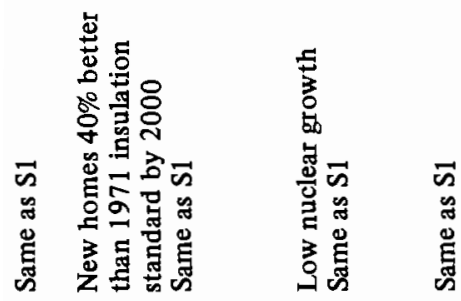

$\stackrel{\Xi}{8}$

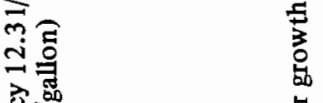

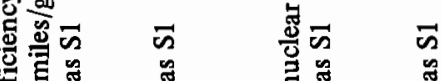

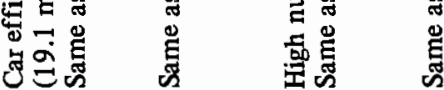

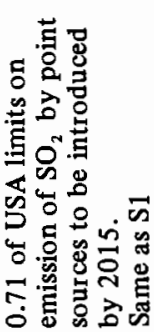

范莒焉

궁

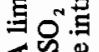

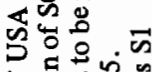

4.

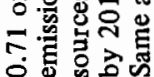

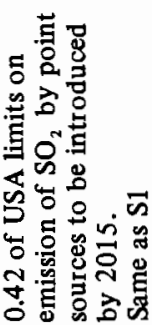

로

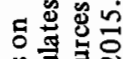

跑

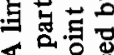

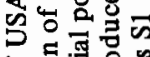

ㄴㅇㅇㄹㅇ

埩刍吉

- 5.5 .5

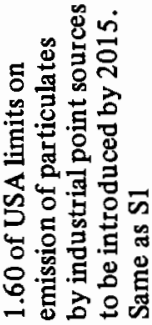

호

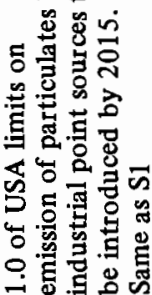

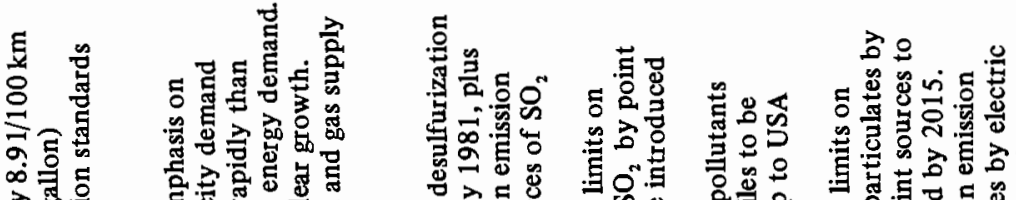

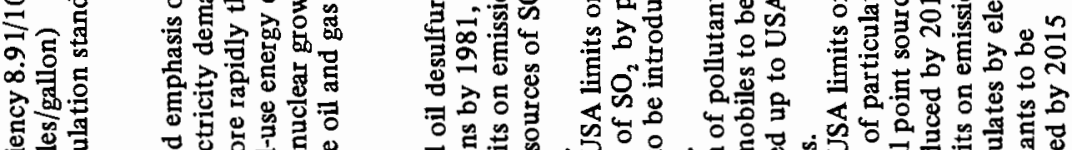

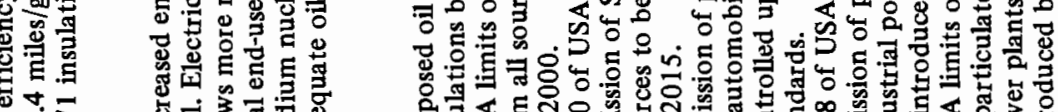

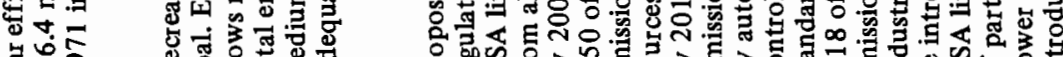

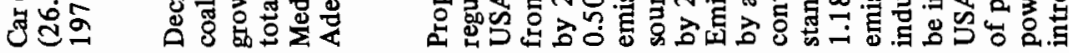

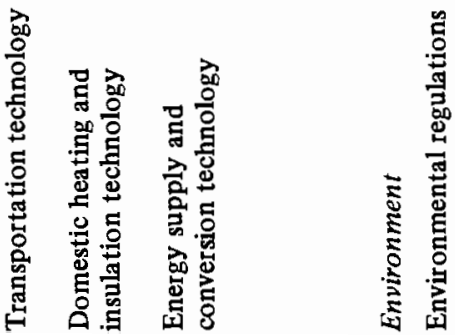




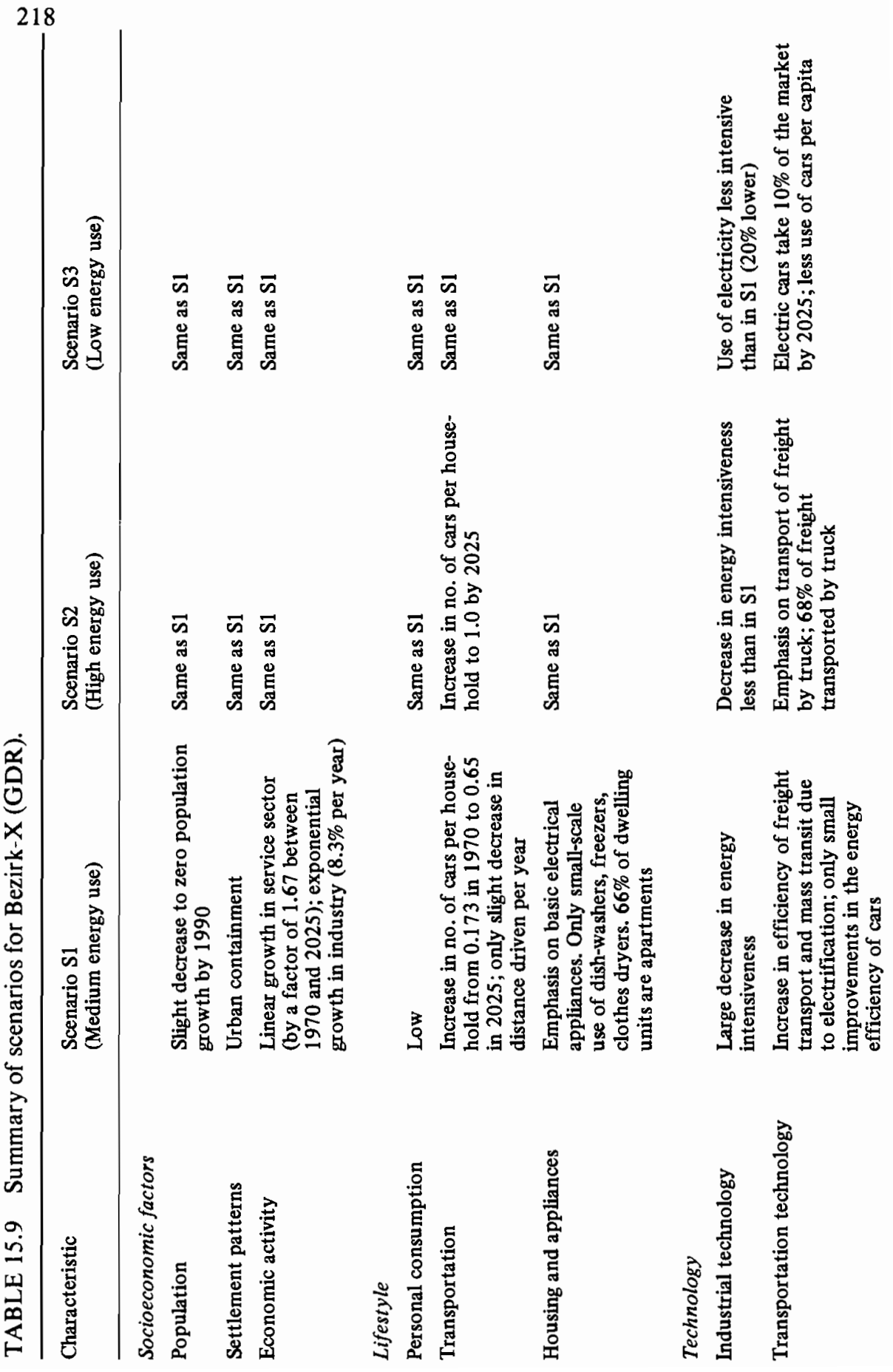




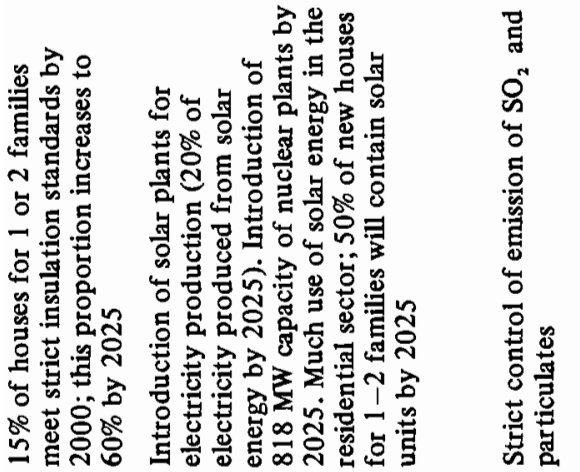

ล 믈 吾合

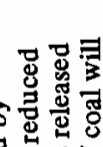

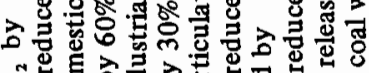

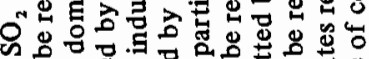

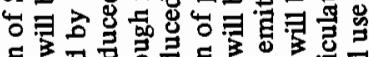

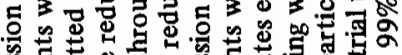

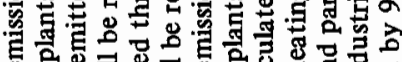

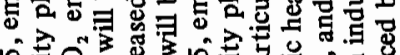

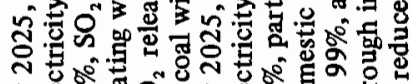

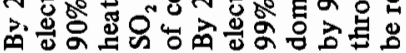
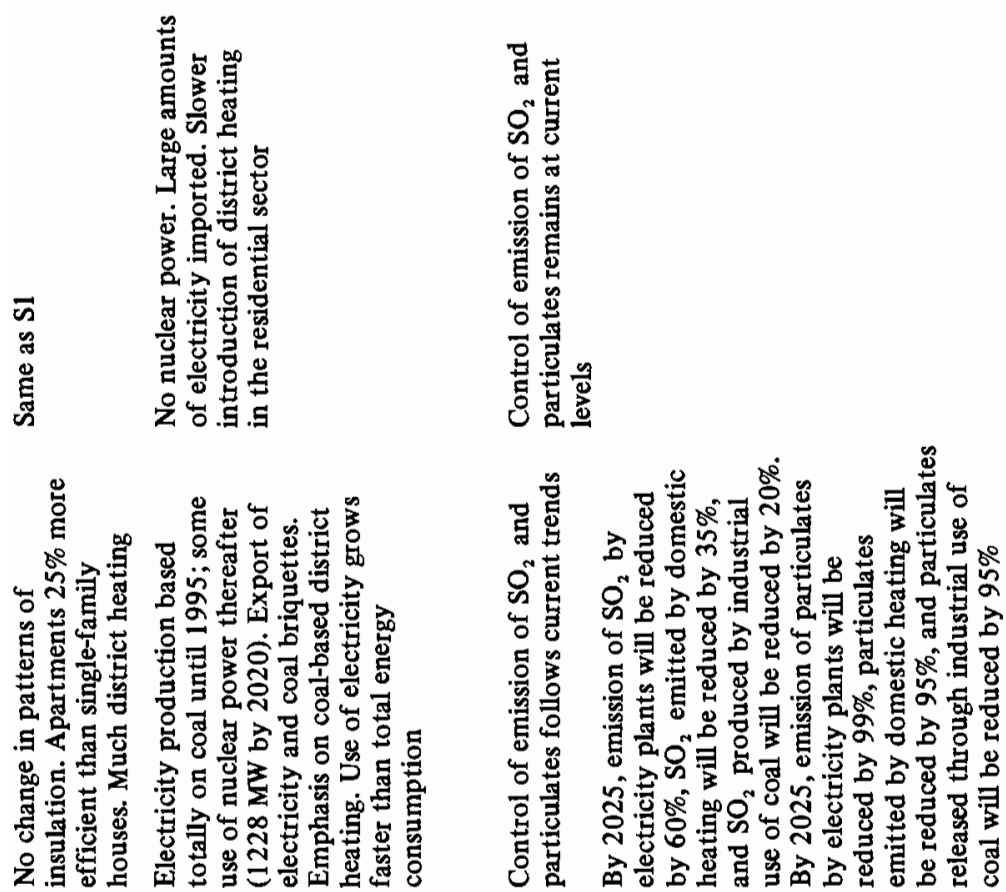

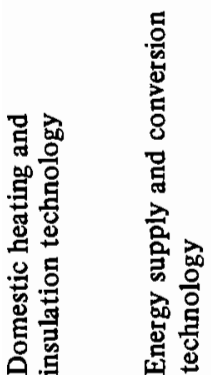

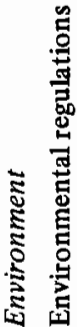




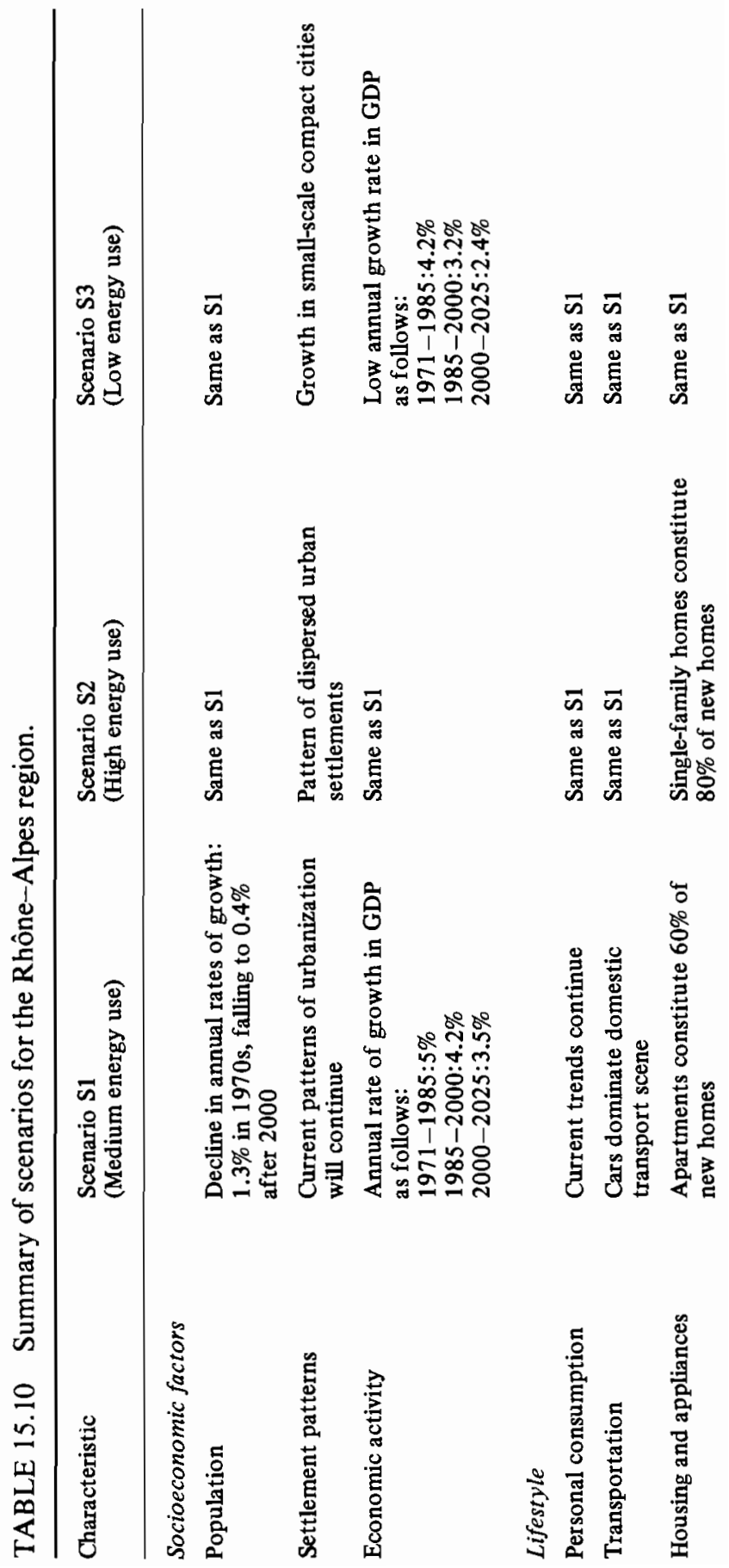



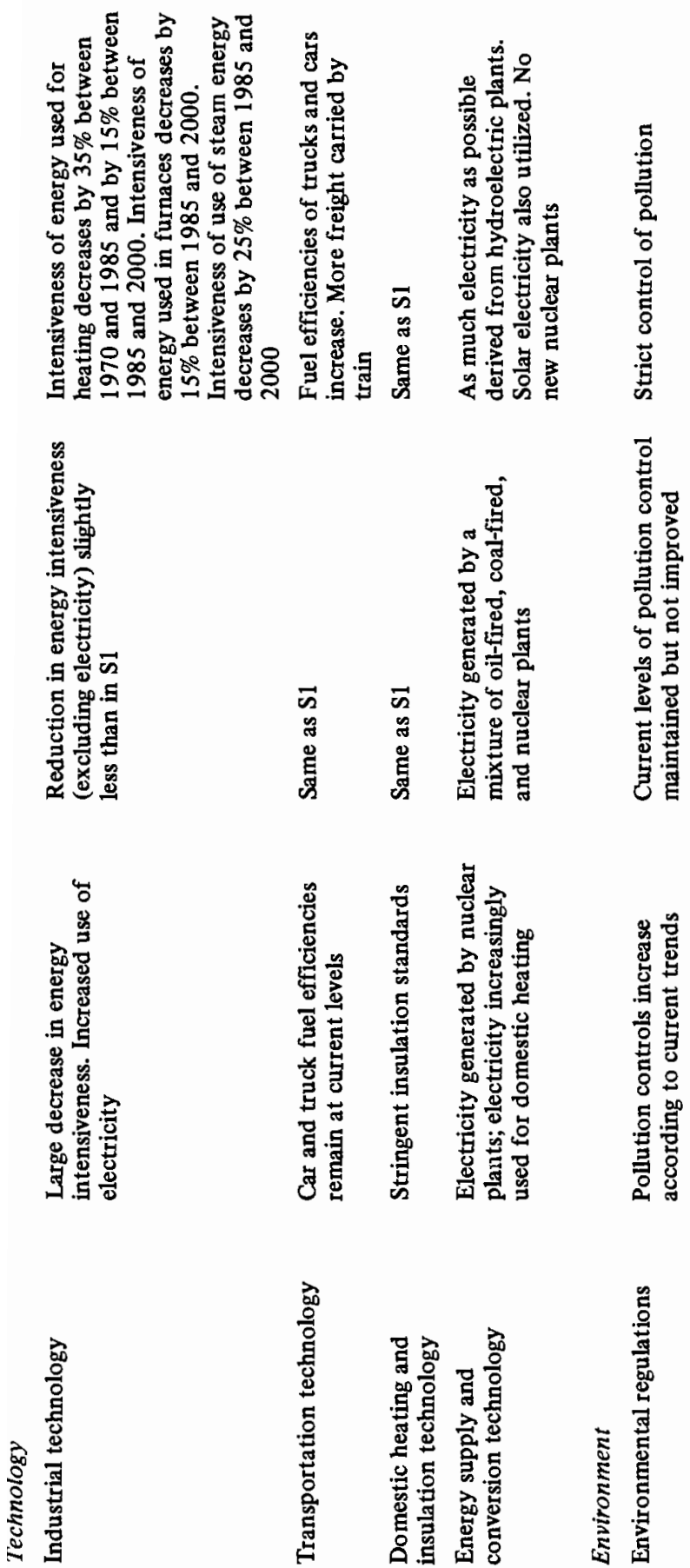


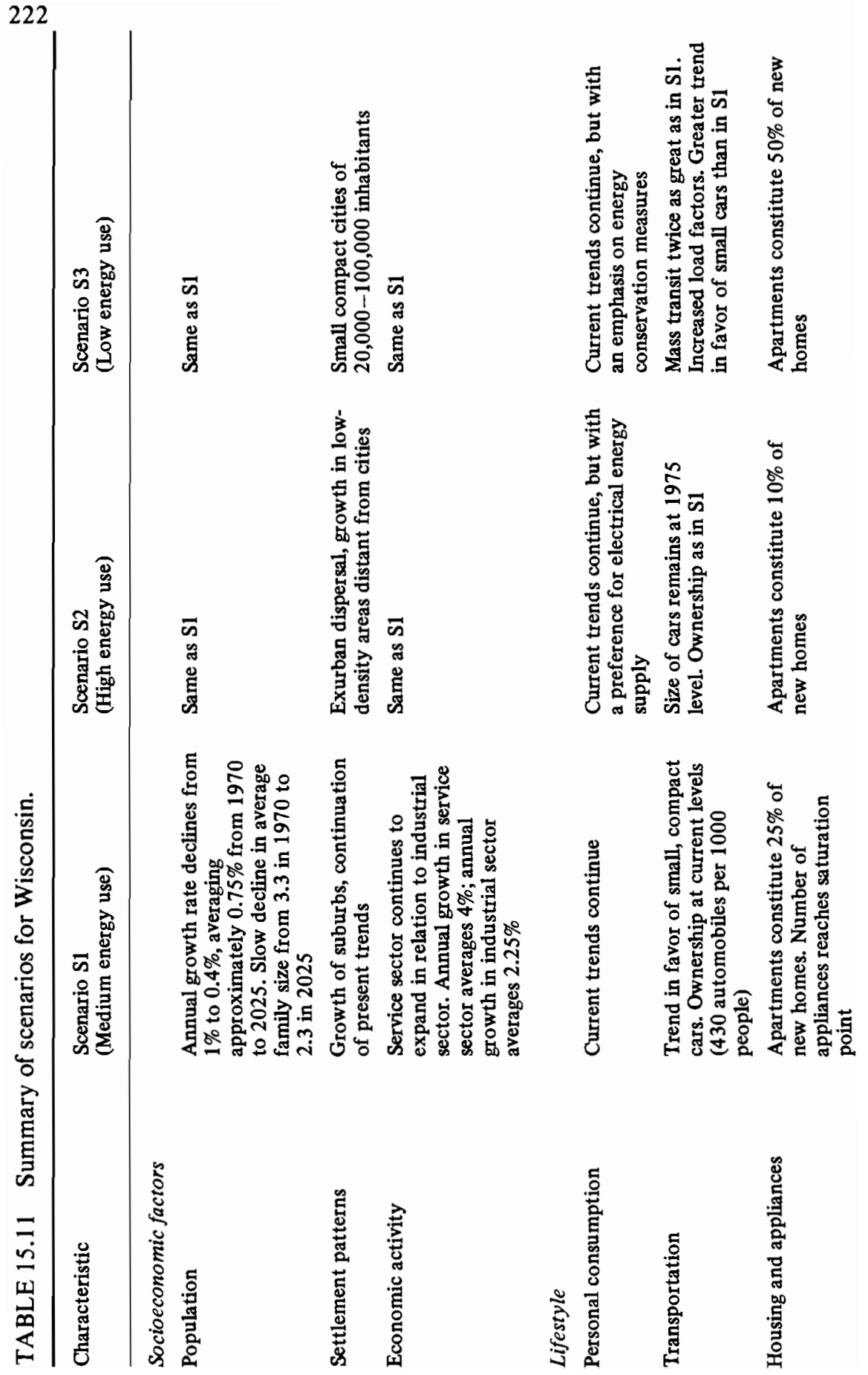




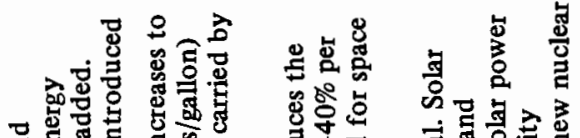

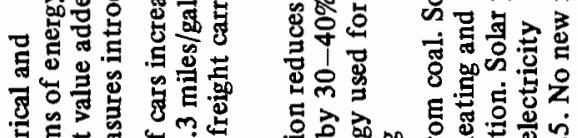

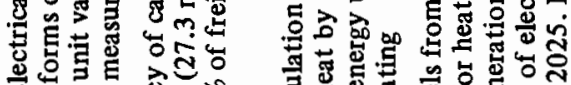
웡

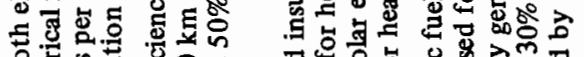

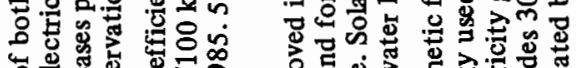

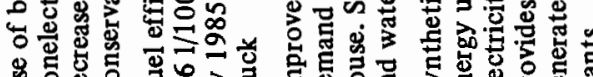

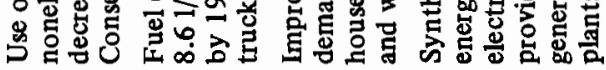
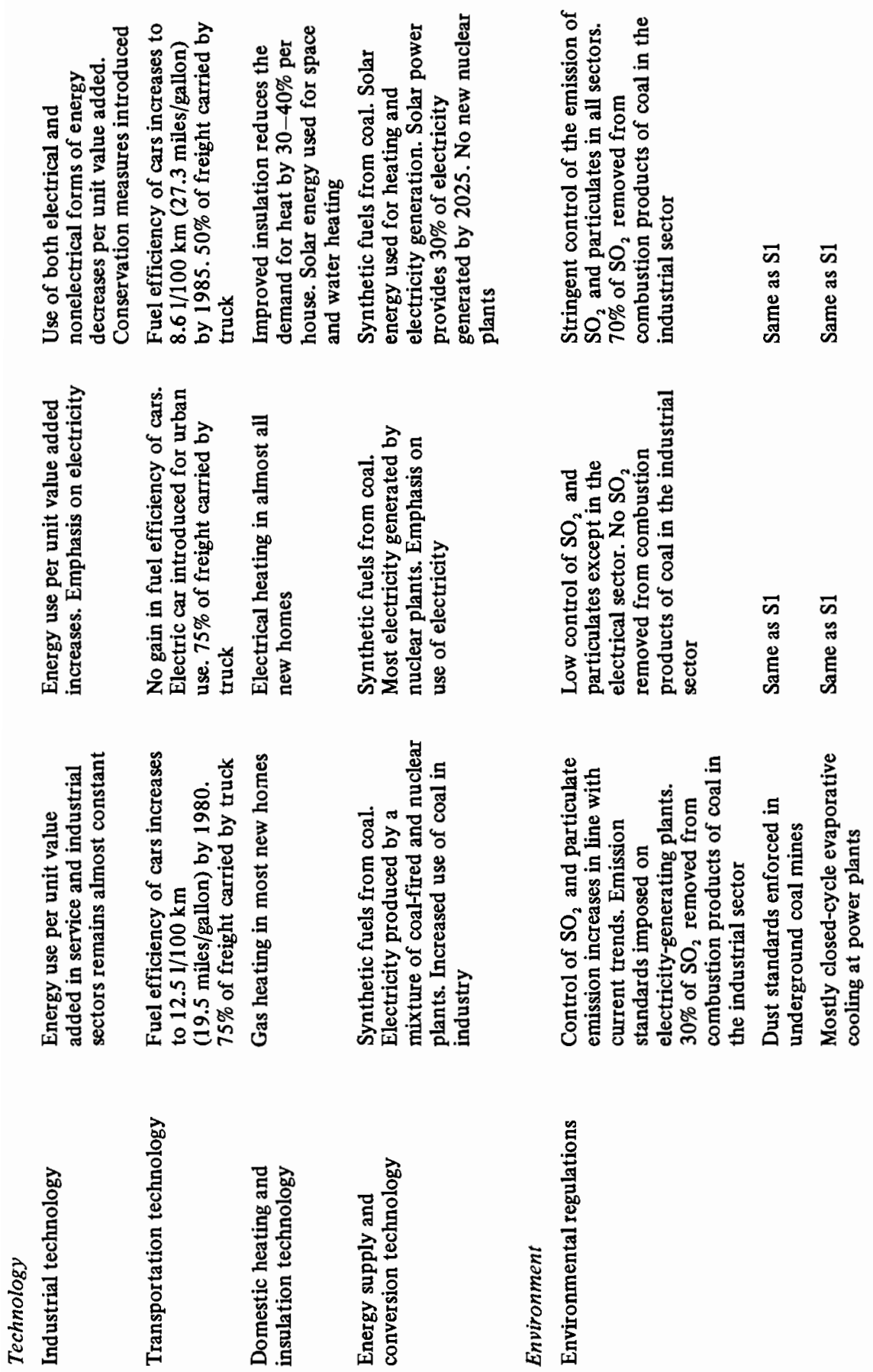
levels of most of these factors were suggested by the collaborating regional institutions and served as inputs to the energy demand, energy supply, and environmental models.

Population growth and settlement patterns. Over the 50-year period studied in the scenarios, the population of Bezirk-X remains nearly constant, that of Austria grows very slowly (an average annual growth rate of $0.22 \%$ ), while the populations of both the Rhône-Alpes region and Wisconsin grow somewhat more rapidly. The same population growth rate was used in all scenarios for a given region. Figure 15.5 displays the population forecasts and the associated population densities for the medium energy use (base) scenario for each region*. The continued very high population density in Bezirk-X plays an important role in determining energy use in both the residential and transportation sectors, while the relatively low population density in Wisconsin reinforces the heavy dependence on the automobile.

Economic activity. For the purposes of this study, regional economic activity was generally expressed in relative rather than absolute terms, i.e., economic activity was described relative to a base year. Comparisons of alternative energy futures were then analyzed in terms of economic development since the base year. This approach avoided the difficulties associated with setting appropriate
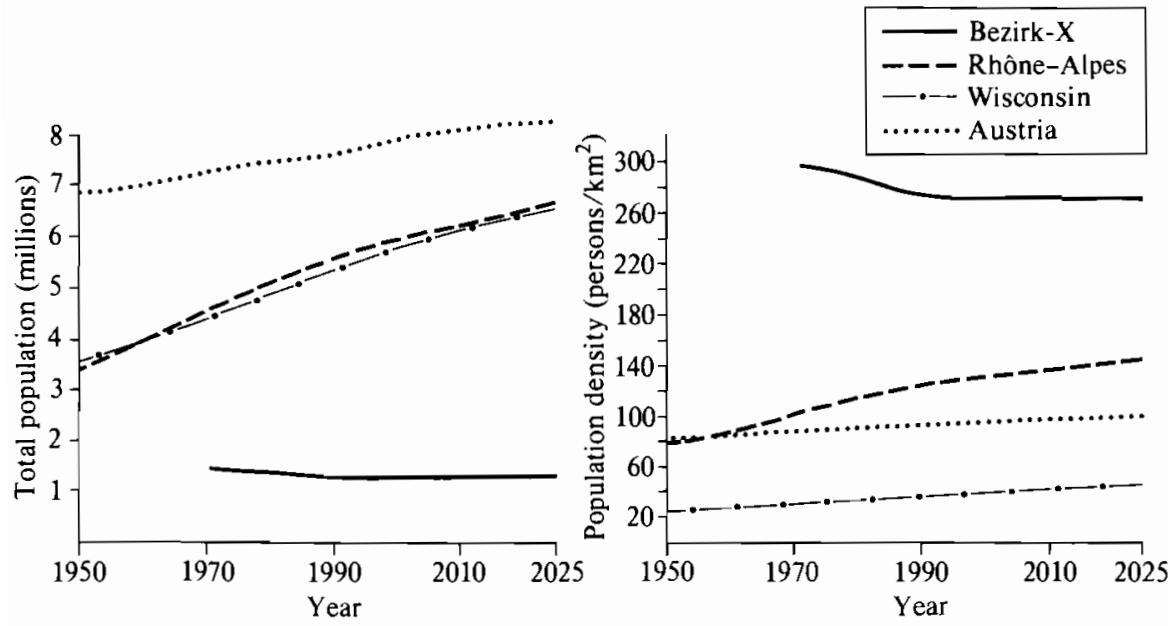

FIGURE 15.5 Forecasts of population growth and associated population densities used in scenario $\mathrm{S} 1$ (base case).

* The patterns of human settlement in Austria and Bezirk-X were the same in all scenarios. In the Rhône-Alpes region and Wisconsin, these patterns were varied as described in Tables 15.10 and 15.11 to explore the effects of different paths of urban development. 
currency exchange rates, and, although it does not permit direct regional comparisons of the ratio of gross domestic product (GDP) to energy consumption (E), it does illustrate some of the energy-related consequences of changes in the relative economic indicators.

Economic activity was measured in terms of gross national product (Austria), net national output (GDR), and value added (Rhône-Alpes region and Wisconsin). Figure 15.6 shows how the economic indicators that formed the basis for the scenarios are expected to change over time. The AUSTRIA II Model ${ }^{20}$ suggests that the Austrian GNP will grow at an annual rate of $3.3 \%$ from 1970 to 1985 , fall to $2.1 \%$ from 1985 to 2000 , and then to $1.5 \%$ from 2000 to $2015^{*}$.

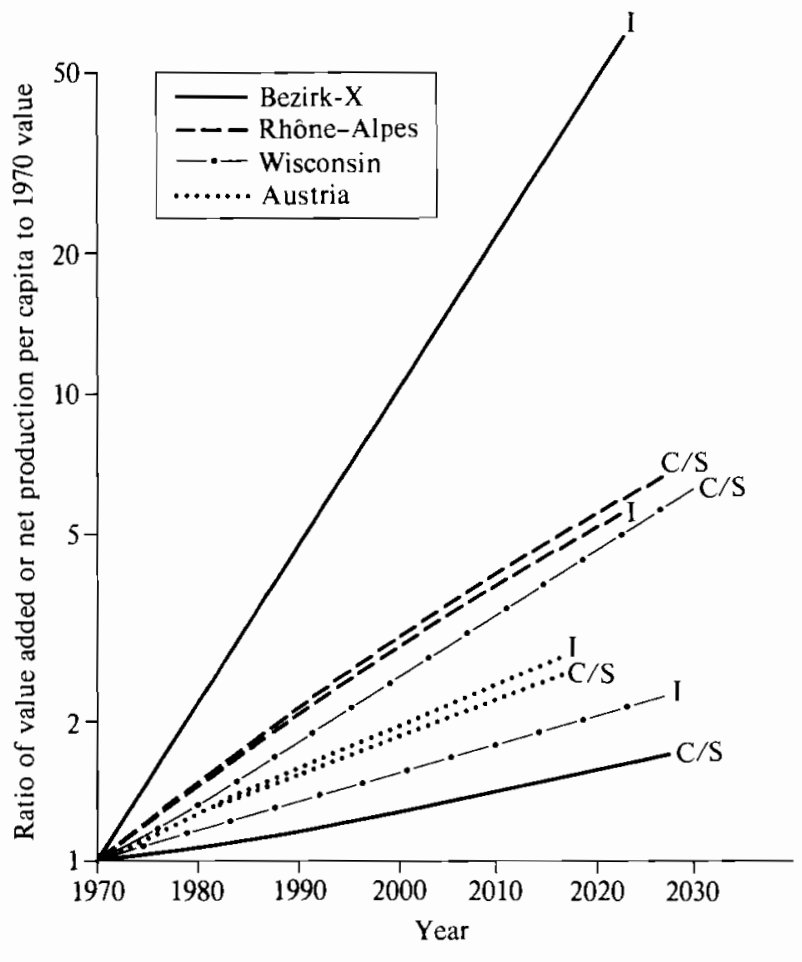

FIGURE 15.6 Projected evolution of economic indicators in industrial (I) and commercial and service $(\mathrm{C} / \mathrm{S})$ sectors over time (all regions).

\footnotetext{
* AUSTRIA II, a demand-oriented input-output model, describes the economic activity at constant prices for each year of the forecasting period ${ }^{20}$. General parameters in the model, derived from timeseries analysis, preserve a certain degree of continuity in economic policy, e.g., taxation, income distribution, conditions of investment, export promotion, etc. Assumptions regarding the economic development of Austria's trading partners are particularly important inputs to the model.
} 
(Growth in the GNP from 1954 to 1974 averaged 5.4\% per year.) The economic patterns for Bezirk-X are taken from the informal 20-year plan* up to 1995, and from an extrapolation of the plan thereafter. The industrial sector is postulated to grow at an average annual rate of $8.3 \%$; the service sector is assumed to grow more slowly. In the Rhône-Alpes region a continuation of ecurrent economic trends yields growth rates of 5\% per year in the early 1970 s, declining to $3.5 \%$ per year by 2025 . In Wisconsin the overall economic growth rate is taken to be $3.1 \%$ per year, somewhat lower than past trends would suggest, with a continuing shift toward the commercial/service sector.

The distribution of activity among the various industries was quite similar in all regions in 1970. By the year 2025, it is suggested that the proportion of energyintensive metal-processing and chemical industries will have increased slightly in Wisconsin, decreased slightly in the Rhône-Alpes region, and increased considerably in Bezirk-X. Austria should find that the chemical industry has grown relative to other industries, while all other energy-intensive activities have declined. The percentage of the population in full employment is assumed to remain fairly constant in each region. For Bezirk-X this projection, coupled with the economic growth rates shown in Figure 15.6, implies an increase in productivity to more than ten times the present level before the year 2000. This high growth rate caused much discussion at the conferences held during the project.

\section{ENERGY DEMAND}

This section discusses the energy demand implied by the scenarios summarized in Tables 15.8-15.11. An interregional comparison of annual energy use is given, and this is followed by an analysis of each sector separately.

End-use energy is the energy consumed in end-use processes; losses due to conversion and transmission, such as occur in electricity generation, are not included in this category. Table 15.12 summarizes the total end-use energy per capita implied by each of the scenarios studied. For reference, the average end-use energy consumption per capita in the USA in 1970 was about $20 \%$ greater than the corresponding average for Wisconsin in the same year. Nevertheless, Wisconsin consumed approximately twice as much energy per capita in 1970 as did the Rhône-Alpes region, and almost three times more than Austria (1971 value) and Bezirk-X. For the base case scenario $\mathrm{S} 1$, these relative positions continue unchanged up to 2000 , but the higher economic growth rate assumed for Bezirk-X means that its energy use will exceed that of the Rhône-Alpes region by 2025.

\footnotetext{
* There is no 20 -year plan for the GDR in the formal sense; these patterns are the result of informal planning procedures.
} 
TABLE 15.12 Projected evolution of annual end-use energy per capita in the four regions, assuming various scenarios.

\begin{tabular}{|c|c|c|c|c|c|}
\hline \multirow[t]{2}{*}{ Region } & \multirow[t]{2}{*}{ Year } & \multicolumn{4}{|c|}{$\begin{array}{l}\text { Annual end-use energy per capita } \\
\left(10^{\circ} \mathrm{cal}\right)\end{array}$} \\
\hline & & $\mathrm{S} 1$ & $\mathrm{~S} 2$ & S3 & S4 \\
\hline Austria & $\begin{array}{l}1971 \\
2000 \\
2015\end{array}$ & $\begin{array}{l}20 \\
30 \\
43\end{array}$ & $\begin{array}{l}20 \\
37 \\
68\end{array}$ & $\begin{array}{l}20 \\
29 \\
36\end{array}$ & $\begin{array}{l}20 \\
25 \\
30\end{array}$ \\
\hline Bezirk-X & $\begin{array}{l}1970 \\
2000 \\
2025\end{array}$ & $\begin{array}{l}20 \\
37 \\
73\end{array}$ & $\begin{array}{r}20 \\
48 \\
171\end{array}$ & $\begin{array}{l}20 \\
36 \\
61\end{array}$ & $\begin{array}{l}- \\
- \\
-\end{array}$ \\
\hline Rhône-Alpes & $\begin{array}{l}1970 \\
2000 \\
2025\end{array}$ & $\begin{array}{l}25 \\
39 \\
60\end{array}$ & $\begin{array}{l}25 \\
46 \\
76\end{array}$ & $\begin{array}{l}25 \\
40 \\
45\end{array}$ & - \\
\hline Wisconsin & $\begin{array}{l}1970 \\
2000 \\
2025\end{array}$ & $\begin{array}{r}54 \\
80 \\
130\end{array}$ & $\begin{array}{r}54 \\
78 \\
137\end{array}$ & $\begin{array}{l}54 \\
61 \\
87\end{array}$ & $\begin{array}{c}54 \\
- \\
-\end{array}$ \\
\hline
\end{tabular}

The broad range of assumptions concerning policy measures and/or economic growth in the scenarios leads to a wide range of values for future energy use in each region. Table 15.13 presents the average annual percentage increase in enduse energy over various periods of time for each scenario. In Austria, the high energy use scenario S2 produces annual growth rates slightly less than

TABLE 15.13 Projected evolution of annual increase in end-use energy in the four regions, assuming various scenarios.

\begin{tabular}{llllll}
\hline Region & Period & \multicolumn{3}{l}{$\begin{array}{l}\text { Average annual increase in end-use } \\
\text { energy (\%) }\end{array}$} \\
\cline { 4 - 6 } & & S1 & S2 & S3 & S4 \\
\hline Austria & & & & & \\
& $1960-1970$ & 5.2 & - & - & - \\
& $1971-1990$ & 2.2 & 3.3 & 2.0 & 1.2 \\
Bezirk-X & $1990-2015$ & 1.3 & 2.4 & 0.7 & 0.6 \\
& $1970-2000$ & 1.7 & 2.6 & 1.6 & - \\
Rhône-Alpes & $2000-2025$ & 2.8 & 5.2 & 2.2 & - \\
& $1970-2000$ & 2.4 & 2.9 & 2.4 & - \\
Wisconsin & $2000-2025$ & 2.1 & 2.4 & 0.9 & - \\
& $1970-2000$ & 2.3 & 2.2 & 1.3 & - \\
& $2000-2025$ & 2.5 & 2.8 & 2.0 & - \\
\hline
\end{tabular}


1960-1970 values, whereas the so-called conservation scenario S4 approaches zero energy growth by 2015 . This zero energy growth is partly a result of a declining economic growth rate, but also depends largely on the severity of the energy conservation measures assumed to be introduced. Both Wisconsin and the Rhône-Alpes region achieve growth rates somewhat lower than recent values in the medium (base) and high energy use scenarios up to the year 2000*. In contrast, the growth in end-use energy in Bezirk-X increases by more than a factor of eight between 1970 and 2025 in scenario S2; this results primarily from the assumed industrial growth rate of $8.3 \%$ per year. The dramatic increase in energy use in $\mathrm{S} 2$ as compared with $\mathrm{S} 1$ and $\mathrm{S} 3$ is a direct result of the lower efficiency of industrial energy use in S2.

Primary energy is sometimes a better indicator of certain characteristics of a regional energy system than end-use energy. Primary energy includes both enduse energy and the energy losses that occur in processing, conversion, and transport. If a region is gradually moving over to electricity and synthetic fuels (as in scenarios S1 and S2 for Wisconsin), the consumption of primary energy may increase more rapidly than the consumption of end-use energy. One interesting and much discussed parameter of regional energy systems is the ratio of primary energy consumption to regional economic output. We have investigated the relationship between economic activity and energy use by means of an inferred elasticity, $e$, where

and

$$
e=\frac{\Delta E_{\mathrm{p}} / E_{\mathrm{p}}}{\Delta G / G}
$$

$\Delta E_{\mathrm{p}} / E_{\mathrm{p}}$ is the fractional change in annual primary energy use (excluding exports, but including imports) over a given period of time

$\Delta G / G$ is the fractional change in annual economic output over a given period of time

$E_{\mathrm{p}}$ and $G$ are the values of annual primary energy use and annual economic output, respectively, at the beginning of the period concerned.

Table 15.14 presents the elasticities characteristic of each scenario for the four regions, and also the observed elasticities for Austria and Wisconsin in past years. In nearly all cases the elasticity is less than one, indicating that the ratio of primary energy use to GNP decreases over time. The notable exceptions are the high energy use scenario for Wisconsin and the later period of the medium use scenario for the same region. These high values are caused mainly by:

1. The assumed significant shifts toward electricity and/or synthetic fuels, both of which have significant energy losses in conversion

* In Wisconsin the growth in end-use energy increases slightly after the year 2000 , primarily because economic growth continues at the same rate despite lower population growth. 
TABLE 15.14 Inferred evolution of elasticity of primary energy consumption to regional economic output in the four regions, assuming various scenarios.

\begin{tabular}{|c|c|c|c|c|c|}
\hline \multirow[t]{2}{*}{ Region } & \multirow[t]{2}{*}{ Period } & \multicolumn{4}{|c|}{ Elasticity ${ }^{a}$} \\
\hline & & S1 & $\mathbf{S 2}$ & \$3 & S4 \\
\hline Austria & $\begin{array}{l}1955-1971 \\
1971-1990 \\
1990-2015\end{array}$ & $\begin{array}{l}0.86 \\
0.63 \\
0.87\end{array}$ & $\begin{array}{l}-\overline{96} \\
1.01\end{array}$ & $\begin{array}{l}- \\
0.58 \\
0.65\end{array}$ & $\begin{array}{l}-\overline{25} \\
0.52\end{array}$ \\
\hline Bezirk-X & $\begin{array}{l}1970-2000 \\
2000-2025\end{array}$ & $\begin{array}{l}0.04 \\
0.21\end{array}$ & $\begin{array}{l}0.09 \\
0.42\end{array}$ & $\begin{array}{l}0.03 \\
0.17\end{array}$ & - \\
\hline Rhône-Alpes & $\begin{array}{l}1970-2000 \\
2000-2025\end{array}$ & $\begin{array}{l}0.60 \\
0.77\end{array}$ & $\begin{array}{l}0.50 \\
0.85\end{array}$ & $\begin{array}{l}0.55 \\
0.67\end{array}$ & - \\
\hline Wisconsin & $\begin{array}{l}1960-1970 \\
1970-2000 \\
2000-2025\end{array}$ & $\begin{array}{l}1.13 \\
0.76 \\
1.29\end{array}$ & $\begin{array}{l}- \\
1.09 \\
1.35\end{array}$ & $\begin{array}{l}-\overline{46} \\
0.90\end{array}$ & $\begin{array}{l}- \\
-\end{array}$ \\
\hline
\end{tabular}

a Elasticity is defined as $\left(\Delta E_{\mathrm{p}} / E_{\mathrm{p}}\right) /(\Delta G / G)$, where $E_{\mathrm{p}}$ and $G$ represent consumption of primary energy and regional economic output, respectively, at the beginning of each period of time, and $\Delta E_{\mathrm{p}}$ and $\Delta G$ denote the changes in the parameters over this period.

2. The assumption that the proportion of the industry sector involved in energy-intensive activities will increase, or decrease only slightly (as discussed in a later section)*

In all regions except the Rhône-Alpes, the elasticity is considerably lower for the low energy use (S3) and conservation (S4) cases than for the base case (S1); this reflects the combined impact of the measures designed to conserve energy. The similarity of the inferred elasticities for all three Rhône-Alpes scenarios is in part a reflection of the judgment of the Rhône-Alpes researchers that the amount of energy conserved by future measures could not vary widely between scenarios. It is interesting to note that elasticities in general increase over time, demonstrating that the effects of conservation measures become less significant after a certain point has been reached, and also that considerable reliance is still placed on the less efficient supply technologies. The extremely low elasticities given in Table 15.14 for Bezirk-X are based on work carried out by the GDR researchers, which indicates that the region will be able to maintain high rates of industrial growth while continuously increasing its efficiency of industrial energy use.

* More recent data and analyses have indicated that this assumption has not been borne out by events. 


\section{Transportation sector}

One of the sectors in which the regions differ most markedly is transportation. Table 15.2 demonstrates one of the major differences-the wide variations in the numbers of motor vehicles in each region. The car ownership figures are even more striking, showing that in 1972 there were 82 automobiles per thousand inhabitants in the GDR and 200 per thousand in Austria, while the corresponding figures for the Rhône-Alpes region and Wisconsin were 267 and 436, respectively.

The level of car ownership strongly influences the relative importance of the transportation sector in the overall pattern of energy consumption in the region; the technical efficiency of the vehicles (in terms of distance traveled per unit of fuel) is also an important factor. High levels of ownership and low levels of efficiency have a significant effect on the end-use energy consumption in the transportation sector (given in Table 15.6).

The overall analysis is based on the influence of various socioeconomic factors, lifestyles, and technological patterns on energy consumption. In the transportation sector it is necessary to examine factors such as alternative patterns of human settlements, automobile ownership, use of mass transit, methods of transporting freight, and the technical efficiencies of various modes of transport. Comparison of the different regional patterns of transportation produces some interesting results. Figure 15.7 shows the trends in the amount of energy used for personal transportation per capita, estimated on the basis of various scenarios. The relevant features of the scenarios are:

Bezirk-X (S1). Car ownership rises to approximately 240 cars per thousand persons by 2025; efficiency of fuel consumption remains approximately constant. Austria (S1). Car ownership and fuel efficiency level off at 300 vehicles per thousand persons and 8.9 liters per $100 \mathrm{~km}$ (26.4 miles per gallon), respectively. Austria (S4). As S1, except that efficiency improves to 7.0 liters per $100 \mathrm{~km}$ (33.5 miles per gallon).

Rhône-Alpes (S1). Car ownership and fuel efficiency remain essentially unchanged.

Wisconsin (S2). Fuel efficiency remains at the level attained by cars produced in 1975 (12 liters per $100 \mathrm{~km}$ or 19.5 miles per gallon); car ownership (430 per thousand people) and distance traveled remain unchanged.

There are many differences in both the initial conditions of energy use and the scenarios suggested for the regions; with no improvements in the efficiency of fuel consumption, the amount of energy used (per capita) for personal transportation in Wisconsin would remain far higher than in the other regions. Scenario S2 for Wisconsin does not include the provisions of the US Energy Policy and Conservation Act (EPCA), which sets an average yearly standard aimed at attaining an 


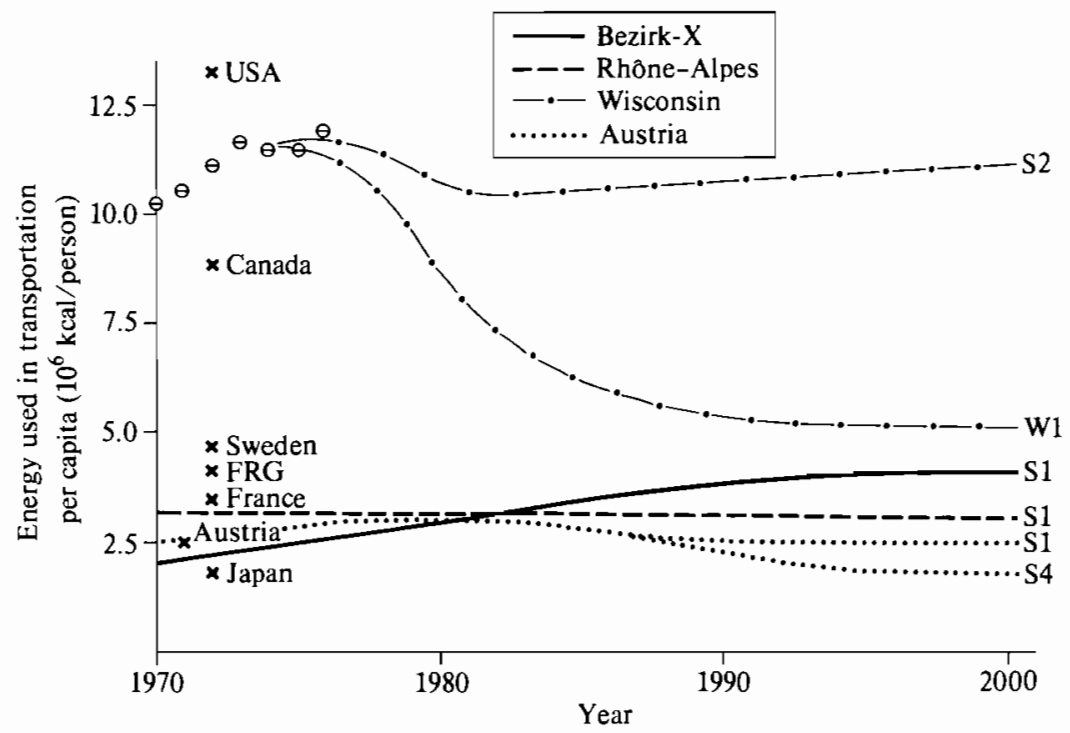

FIGURE 15.7 Amount of energy used for personal transportation per capita, assuming different scenarios.

efficiency of 8.6 liters per $100 \mathrm{~km}$ ( 27.3 miles per gallon) in cars produced in 1985. A new scenario (W1-see Figure 15.7) recently developed at the University of Wisconsin-Madison includes EPCA and some additional conservation measures ${ }^{21}$; according to this scenario, the amount of energy used for personal transportation (per capita) will be only $20 \%$ greater in Wisconsin than in Bezirk-X (scenario $\mathrm{S} 1$ ) by the year 2000 .

\section{Residential sector}

The most important factors influencing energy consumption in the residential sector are the number, size, and characteristics of dwellings, the degree of use of domestic energy-consuming appliances, and the regional climate. Table 15.15 gives an interregional comparison of some of these factors.

Space heating was found to be the largest single consumer of energy in the residential sector in all of the regions studied. The greater floor area, colder climate, and higher proportion of households with many appliances in Wisconsin combine to produce a total energy consumption in the residential sector which is between two and three times larger than that in any other region.

One of the major conclusions for the residential sector is that the demand for energy is not expected to increase significantly over the period studied, and under certain conditions may even decrease. Measures enforcing higher standards of 
TABLE 15.15 Various factors affecting energy consumption in the residential sectors of the four regions.

\begin{tabular}{|c|c|c|c|c|}
\hline Factor & $\begin{array}{l}\text { Austria } \\
\text { (1971) }\end{array}$ & $\begin{array}{l}\text { Bezirk-X } \\
(1970)\end{array}$ & $\begin{array}{l}\text { Rhône--Alpes } \\
\text { (1970) }\end{array}$ & $\begin{array}{l}\text { Wisconsin } \\
(1970)\end{array}$ \\
\hline \multicolumn{5}{|l|}{$\begin{array}{l}\text { Annual end-use energy consumption } \\
\text { per capita in the residential }\end{array}$} \\
\hline sector $\left(10^{9} \mathrm{cal}\right)$ & 4.4 & 5.6 & 7.2 & 16 \\
\hline No. of persons per housing unit & 2.94 & 2.65 & 3.12 & 3.30 \\
\hline $\begin{array}{l}\text { Average floor area of housing } \\
\text { unit }\left(\mathrm{m}^{2}\right)\end{array}$ & $68^{a}$ & $\mathbf{N A}^{b}$ & $\mathbf{N A}^{b}$ & $137^{c}$ \\
\hline No. of heating degree-days ${ }^{d}$ & 3435 & 3340 & 2264 & 4150 \\
\hline Ratio of no. of apartments to & & & & \\
\hline no. of single-family homes & $1: 1$ & $2: 1$ & $\mathrm{NA}^{b}$ & $1: 7.3$ \\
\hline \multicolumn{5}{|l|}{$\begin{array}{l}\text { Proportion of housing units with } \\
\text { selected energy-consuming } \\
\text { appliances: }\end{array}$} \\
\hline Water heating & 0.58 & $\mathrm{NA}^{b}$ & 0.77 & 0.99 \\
\hline Electric stove & 0.48 & 0.15 & $\mathbf{N A}^{b}$ & 0.49 \\
\hline Refrigerator & 0.75 & 0.66 & 0.85 & 1.00 \\
\hline Television & 0.75 & 0.60 & 0.74 & 0.97 \\
\hline Dishwasher & 0.02 & 0.00 & 0.00 & 0.17 \\
\hline Drier & 0.02 & 0.00 & $\mathbf{N A}^{b}$ & 0.44 \\
\hline
\end{tabular}

${ }^{a}$ Average floor area of a single-family house in Austria is assumed to be $83 \mathrm{~m}^{2}$; aver age floor area of an apartment is assumed to be $53 \mathrm{~m}^{2}$.

${ }^{b}$ Data not available.

${ }^{c}$ Average floor area of a single-family house in Wisconsin is assumed to be $142 \mathrm{~m}^{2}$; average floor area of an apartment is assumed to be $97 \mathrm{~m}^{2}$.

${ }^{d}$ The number of heating degree-days for any day is calculated by averaging the daily high and low temperatures and then subtracting the result from $18.3^{\circ} \mathrm{C}$, the standard used for comfortable room temperature. The degree-days are then accumulated over the heating season to obtain annual values.

insulation would result in important energy savings in all regions, particularly in Wisconsin, with its larger dwellings and colder climate.

\section{Commercial/service sector}

The definition of commercial activity varies among the regions and so it is difficult to make useful interregional comparisons in this sector. As in the residential sector, most of the energy is consumed in heating, lighting, and cooling. Consequently one of the main parameters affecting energy use in the commercial sector is the floor area of buildings, which can be estimated on the basis of either value added or employment. The scenarios suggest modest increases in commercial/service energy demand in Bezirk-X and Austria, and substantial increases in Wisconsin. This substantial growth in energy demand in Wisconsin is based upon the assumption that floor area is directly proportional to value added in the sector. 


\section{Industrial sector}

The industrial sector is a major consumer of energy in all of the four regions studied (Table 15.6) and plays an important part in the overall analysis. However, the regional institutions involved in this study held widely differing views on future industrial development and energy consumption in their respective regions. The various patterns of industrial energy demand were seen to diverge quite strongly in the long term.

Trends in industrial energy demand can be discussed in terms of three important factors:

1. The rate of industrial economic growth and the resulting mix of energyintensive and less energy-intensive industries, i.e., the relative proportions of processes which require a great deal of energy and those which do not.

2. The energy intensiveness in terms of energy consumed per unit of activity (e.g., $\mathrm{cal} / \mathrm{\$}$ or $\mathrm{cal} / \mathrm{ton}$ ) in individual industrial subsectors.

3. The proportion of the energy demand in each industrial subsector satisfied by various forms of energy (fuel mix).

The economic growth patterns have already been summarized and so this section will concentrate on the second aspect of industrial consumption: energy intensiveness. This factor was the focus of the industrial energy demand and conservation analysis, which was based partly on recent trends in energyintensiveness in the various sectors, and partly on the potential and incentives for energy conservation within the major technical processes. The energy analysts from the GDR were the most optimistic about the possibility of continuing longterm reductions in energy intensiveness. Based upon the results of the two most recent five-year plans, and their longer-term planning, they anticipate annual reductions of $5 \%$ in the overall energy intensiveness of industrial production. This suggests not only continuing implementation of currently available and new conservation measures, but also the continual development of new technologies.

Figure 15.8 shows the overall energy intensiveness in the industrial sector (enduse energy per unit of industrial activity) for the base case scenarios (S1); Figure 15.9 displays the corresponding information for the low use or conservation scenarios. It must be emphasized that these values incorporate the industrial structures and the sectoral fuel mixes assumed in the scenarios. All of the situations represented here, except for the Wisconsin S1 (base case), show that energy intensiveness will decrease over time. Subsequent analysis for Wisconsin ${ }^{22-25}$, based upon more recent data, indicates that scenario S3 (Figure 15.9) actually represents current trends somewhat better than scenario $\mathbf{S} 1$.

The base case scenarios suggest that industrial energy use will grow more slowly in the future than it has in the recent past. The only exception is the GDR, where the high economic growth rate more than compensates for the continuing 


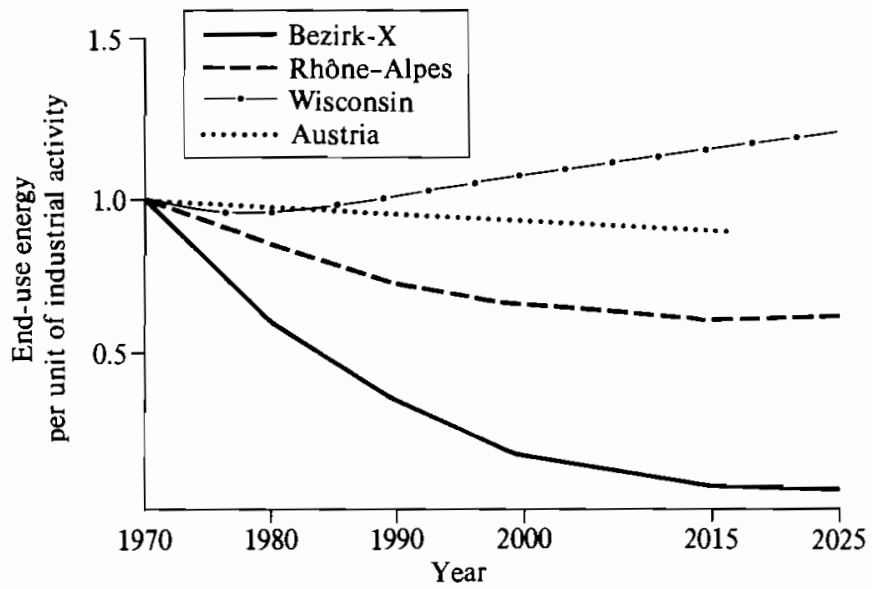

FIGURE 15.8 Interregional comparison of end-use energy consumed per unit of industrial activity under scenario S1 (base case).

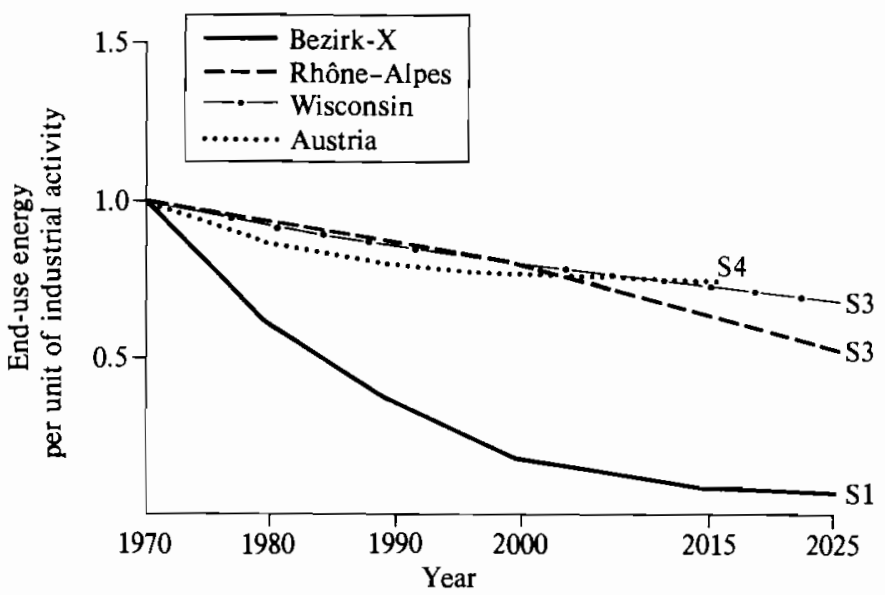

FIGURE 15.9 Interregional comparison of end-use energy consumed per unit of industrial activity under low energy use or conservation scenarios. 
reduction in energy intensiveness. The conservation scenarios all yield future increases in energy demand which are significantly lower than those experienced in the past; in Wisconsin, the projected demand for energy in the industrial sector grows less rapidly than the demand in the commercial and service sector, so that by the year 2025 the relative importance of these two sectors will have been reversed.

\section{ENERGY SUPPLY}

The choice of fuels and supply technologies is one of the most important longterm decisions facing the regions today. The availability of resources and various economic considerations played a major role in shaping the end-use energy demands described in the previous section, but they influence to perhaps an even greater degree the energy supply strategies for a region.

Two distinct approaches were used to distinguish the most important issues in energy supply and to develop a number of energy supply scenarios. The first method was to construct a supply scenario based upon:

1. Analysis of the energy supply systems used in the region in the past

2. Assessment of the mid-term development plans of domestic energy industries

3. Examination of the availability of domestic energy resources

4. General assessment of possible future fuel import and export contracts

This type of supply analysis also provided boundary conditions and constraints for the demand analysis. The second method, used only in the case of Austria, involved the use of a formal resource allocation model based upon an objective function of discounted costs.

The issues which should be considered in any analysis of energy supply include:

1. Petroleum and natural gas requirements; consideration of synthetic fuels in view of the decreasing availability of natural resources; possible fuel substitution and conservation

2. Strategies related to the use of coal

3. The likelihood and desirability of continued increases in electricity demand and production

4. Possible contributions from renewable resources

5. Contributions from district heating

The first three of these issues are discussed briefly below.

\section{Petroleum and natural gas requirements}

Recent patterns of energy supply in all of the regions except for the GDR display a very heavy dependence on petroleum and/or gas (see Figure 15.4). However, 
even in the GDR the number of automobiles is increasing rapidly and it seems likely that the demand for petroleum in this region will grow accordingly. Concern about world petroleum reserves and production rates prompted the examination of a number of energy conservation and fuel substitution strategies which could be implemented in the regions. These strategies were then evaluated in the light of various forecasts of the global availability of petroleum (for example, the assessment made by the Workshop on Alternative Energy Strategies ${ }^{26}$ ). The scenarios demonstrate that severe constraints or shortfalls in petroleum supplies could be experienced in the late 1980s or early 1990s if petroleum production peaks in this period.

\section{Strategies related to the use of coal}

A program common to all four regions is the degree to which they should rely on coal for future energy supply. Each has access to coals of different quality and each faces environmental and social constraints, and problems associated with costs and with resource availability. These issues were examined from a number of perspectives. For example, the various advantages and disadvantages of using coal rather than nuclear methods for electricity generation were considered for three of the four regions studied ${ }^{27}$. The resource requirements and some of the environmental effects of employing coal gasification in Wisconsin were examined, and the possibility of increasing Austria's reliance on lignite while decreasing its reliance on petroleum and gas was also investigated. Finally, a study was carried out to determine whether Bezirk-X will be able to sustain its current very heavy reliance on lignite over the long term.

One of the main conclusions that could be drawn from this analysis was that, although the financial and environmental costs could be considerable, coal represents one important way of reducing the regions' dependence on the diminishing supplies of petroleum and gas, as well as providing major competition to nuclear power as a means of electricity generation.

\section{Electricity}

A significant proportion of the energy consumed in the regions is supplied as electricity (Table 15.6), with electricity consumption in the 1970s growing at annual rates of $4-5 \%$ (Table 15.7). The electricity strategies considered in the scenarios ranged from continuing or increasing the level of electricity use in the residential, commercial/service, and industrial sectors (e.g., Wisconsin scenario S2), to policies which explicitly emphasize nonelectrical forms of energy such as synthetic fuels and solar energy (e.g., Wisconsin scenario S3). The electricity scenarios were based on different assumptions about cost, the technical difficulty of using electricity as a substitute for other fuels, and the time taken for electricity to gain a significant share of the energy market for new applications. 
TABLE 15.16 Projected evolution of average annual increase in electricity consumption and percentage of primary energy used for electricity generation in the four regions for all scenarios.

\begin{tabular}{llllllll}
\hline Region & Year & $\begin{array}{l}\text { Historical } \\
\text { value }\end{array}$ & Year & \multicolumn{3}{l}{\begin{tabular}{l} 
Projected value \\
\cline { 3 - 5 }
\end{tabular}} & \\
\hline
\end{tabular}

Annual average increase in electricity consumption (\%) ${ }^{a}$

$\begin{array}{lllllllc}\text { Austria } & 1960-1971 & 5.8 & 1971-2000 & 3.0 & 4.0 & 2.8 & 2.2 \\ \text { Bezirk-X } & 1960-1972 & 4.8 & 1970-2000 & 4.2 & 5.4 & 3.9 & - \\ \text { Rhône-Alpes } & 1969-1972 & 5.3 & 1970-2000 & 5.3 & 4.4 & 4.8 & - \\ \text { Wisconsin } & 1961-1972 & 7.2 & 1970-2000 & 3.6 & 6.3 & 3.3 & -\end{array}$

Proportion of primary energy used for generation of electricity $(\%)^{b}$

\begin{tabular}{llllllll} 
Austria & 1970 & 28 & 2000 & 33 & 33 & 33 & 30 \\
Bezirk-X & 1970 & 32 & 2000 & 42 & 48 & 41 & - \\
Rhône-Alpes & 1970 & 24 & 2000 & 66 & 48 & 50 & - \\
Wisconsin & 1970 & 25 & 2000 & 30 & 54 & 34 & - \\
\hline
\end{tabular}

${ }^{a}$ Excludes exports and transmission losses; includes electricity imports.

${ }^{b}$ Includes primary energy used for electricity export as well as primary energy used for electricity import.

One of the major conclusions to be drawn from the scenarios is that in the future electricity generation will grow at much slower rates than in the past. Table 15.16 shows the average annual increase in electricity consumption predicted by the scenarios and compares them with recent values. The table also shows the percentages of primary energy used for generating electricity. The significant reduction in the growth of electricity consumption expected in these industrialized regions suggests that the need for new electricity generating facilities should be kept under constant review.

\section{ENVIRONMENTAL IMPLICATIONS}

An analysis of the environmental consequences of different energy strategies was one of the major objectives of this study. This was achieved by using a wide range of "quantified" environmental indicators to describe the environmental implications of each scenario. Only those impacts included in the environmental models were "quantified"; the choice of this set is of course subjective and varying degrees of uncertainty (and, in some cases, controversy) are associated with many of the factors. Nevertheless, this approach has proved useful in planning in all four regions.

Energy systems come into contact with the environment at all stages up to and including end use. Depending on the particular fuel system, the effects of energy use within a region may be limited to that region, or may also be experienced 
elsewhere. The environmental implications of energy production and use may be divided into five main categories:

1. Effects on water, e.g., water evaporated by waste heat from power plants

2. Effects on land, e.g., land used for resource extraction and energy-related facilities

3. Effects on air, e.g., emission of sulfur dioxide

4. Effects on humans, e.g., increased incidence of disease and higher mortality rates due to accidents

5. Possible long-term effects, e.g., the dangers associated with the production of carbon dioxide and radioactive waste

A number of these points are discussed below.

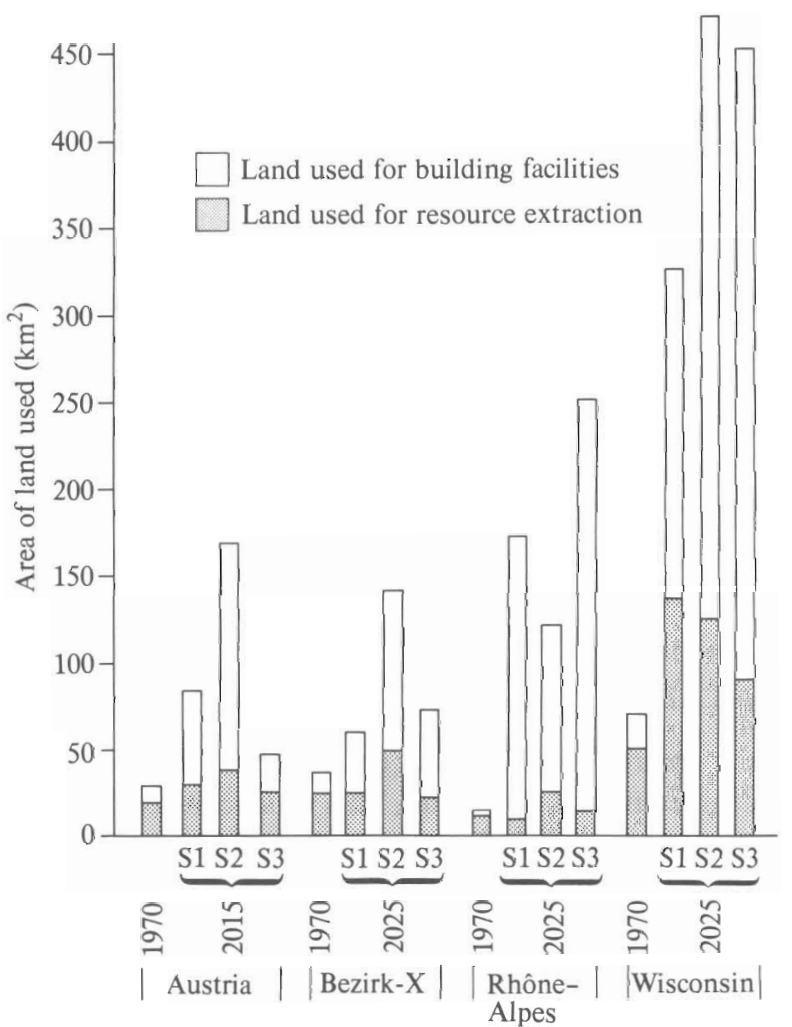

FIGURE 15.10 Interregional comparison of the land used annually for energy facilities (excluding hydropower plants) and resource extraction under various scenarios. The column labeled "1970" gives the actual amount of land involved in energy production in each region in that year. 


\section{Land use}

The amount of land used annually for energy production as predicted by various scenarios is shown in Figure 15.10. This land includes the sites of energy facilities, such as power plants, and the land used for resource extraction, such as surface mines producing uranium and coal. Note that not all of the land used for energy production lies within the region, since some of the fuel is imported. Even if it is assumed that all of the land disturbed for resource extraction in the past is reclaimed so that the total quantity of land involved in energy production is only that shown in the figure, the quantities of land used are still very significant. The scenarios suggest that in 2025 the total land area (both inside the region and elsewhere) used to produce energy for the region could reach the following percentages of the land area of each region:

$\begin{array}{ll}\text { Austria (S2) } & 0.2 \% \\ \text { Bezirk-X (S2) } & 2.9 \% \\ \text { Rhône-Alpes (S3) } & 0.6 \% \\ \text { Wisconsin (S2) } & 0.3 \%\end{array}$

The land used for producing hydropower is not included in Figure 15.10 or in the values quoted above. If it were included, the land required for energy-related facilities should be doubled or trebled in both Austria and the Rhône-Alpes region. However, it is arguable whether the land employed in generating hydropower is actually land taken from use.

\section{Emission of sulfur dioxide}

Sulfur dioxide $\left(\mathrm{SO}_{2}\right)$ is generally thought to have deleterious effects on human health, plant life, and man-made structures. Coal is the major source of atmospheric $\mathrm{SO}_{2}$ in Bezirk-X and Wisconsin, while petroleum is the major source in Austria and the Rhône-Alpes region. The chemical and thermal characteristics of various types of fuel vary widely among the regions. For example, in the absence of measures controlling $\mathrm{SO}_{2}$ emission, the low-heat-content coal from Bezirk-X produces about twice as much $\mathrm{SO}_{2}$ per unit of energy released as blended coal from the USA, and nearly five times as much as low-sulfur subbituminous coal from the western United States.

The levels of $\mathrm{SO}_{2}$ emission predicted by scenario $\mathrm{S} 1$ for the year 2025 are compared for the four regions in Figure 15.11. Four different measures of pollution are displayed: total emission of $\mathrm{SO}_{2}$, emission of $\mathrm{SO}_{2}$ per unit land area, emission of $\mathrm{SO}_{2}$ per capita, and emission of $\mathrm{SO}_{2}$ per unit of primary energy use. Austria and the Rhone-Alpes region have very similar levels of $\mathrm{SO}_{2}$ production on all four scales, Wisconsin has the highest levels of total emission, but Bezirk-X has the greatest values on the other three scales. Because Bezirk- $X$ is a highly 


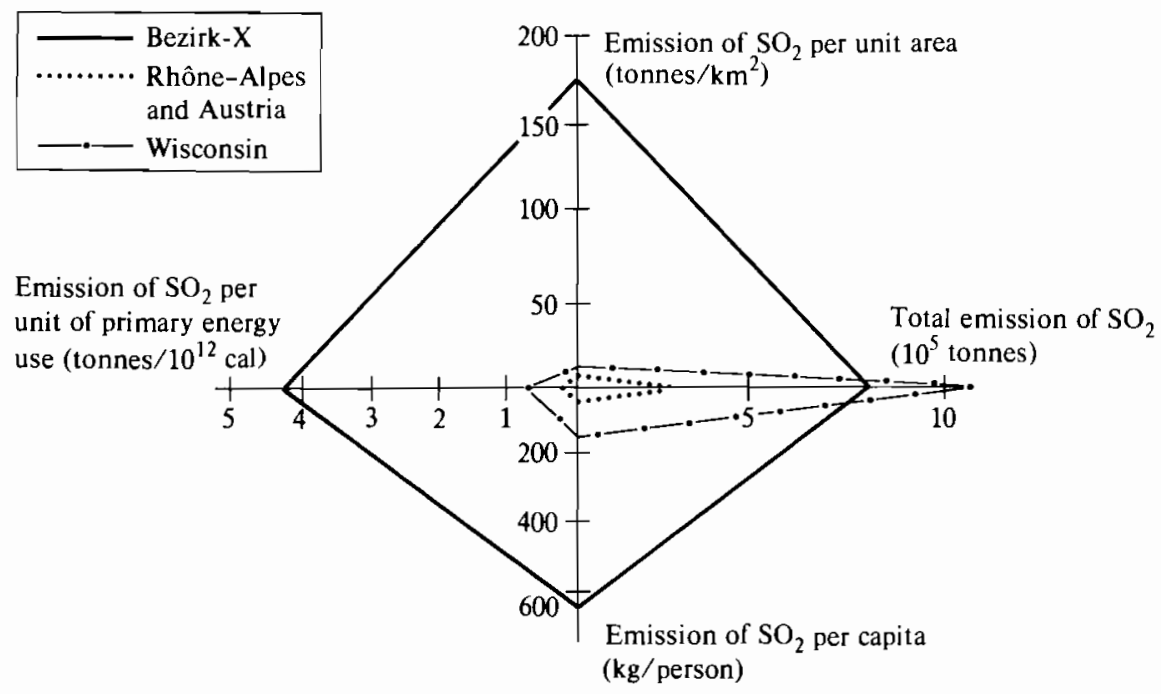

FIGURE 15.11 Levels of $\mathrm{SO}_{2}$ emission predicted by scenario $\mathrm{S} 1$ for the year 2025 (all regions).

industrialized region and relies on lignite for most of its energy, the problem of air pollution and related health hazards should play an important role in local energy planning.

\section{Human health and safety}

The parameters representing the quantified effects of energy systems on human health and safety in the year 2025 under the assumptions of scenario SI are shown in Figure 15.12. The measure "person-days lost" (PDL) is used to combine the effects of illness and death due to energy-related impacts. The quantified totals shown in the figure include damage to health and accidents suffered both by the general public and by people employed throughout the energy system from resource extraction to waste disposal. Unlike the figure showing the levels of $\mathrm{SO}_{2}$ emission, this figure illustrates that the only scale on which Bezirk- $\mathrm{X}$ has a higher value than any other region is that showing PDL per unit area. Air pollution is largely responsible for the high total PDL for Wisconsin. The large number of person-days lost per unit of energy use in Austria depends partly on a lack of data upon which to base predictions of improved conditions in the coal-mining industry, and is also affected by the large proportion of coal mined underground, since this is more dangerous than surface mining. 


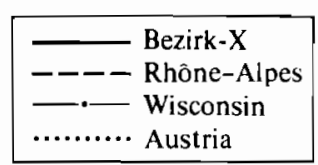

PDL per unit of primary energy use (PDL $/ 10^{12} \mathrm{cal}$ )

$2.2 \quad 2.0 \cdots 1.8 \cdots 1.6 \ldots 1.4 \quad 1.2 \quad 1.0<0.8$
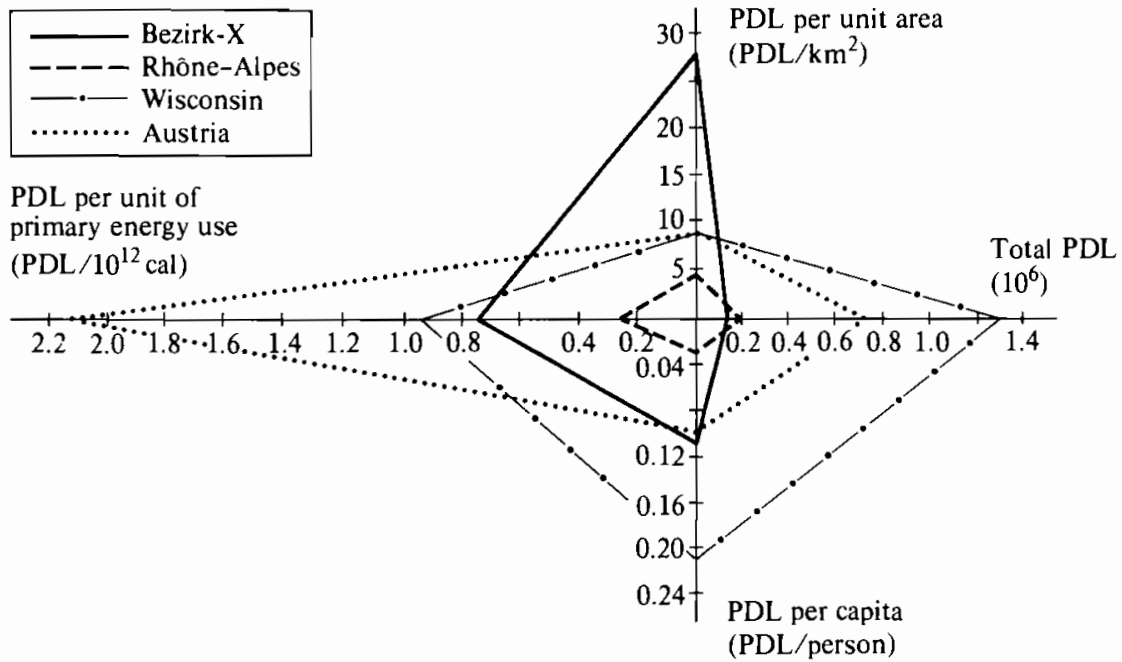

FIGURE 15.12 Parameters representing the effect of energy systems on human health in the year 2025 under the assumptions of scenario S1 (all regions). PDL denotes the number of person-days lost.

To put these numbers into perspective, it is interesting to compare the PDL per capita from Figure 15.12 with the PDL per capita resulting from all accidental fatalities in the USA. The probability of an accidental death (due to road accidents, falls, burns, drowning, firearm injuries, etc.) was 49 per 100,000 in the USA in 1974. This is equivalent to $2.9 \mathrm{PDL}$ per person per year*. The PDL per capita that scenario S1 suggests would result from energy use in Wisconsin in 2025 is therefore equivalent to $7 \%$ of the PDL per capita caused by fatal accidents at current levels. One interesting feature is that the dangers to health and safety do not seem to be distributed evenly over all population groups. For example, nearly $30 \%$ of the person-days lost in Wisconsin in 2025 under scenario $\mathrm{S} 1$ are associated with less than $1 \%$ of the total population- 53,000 elderly people who live in the industrialized Milwaukee area and have a previous history of heart or lung disease.

\section{Radioactive wastes}

The wastes produced during the reprocessing of nuclear fuel are highly radioactive and must be stored in isolation for long periods of time. The need to find a safe and reliable method for disposing of radioactive waste is one of the most

* This assumes that one accidental fatality is equivalent to 6000 PDL. 


\section{2}

pressing requirements for reducing the potential long-term risks associated with nuclear power.

The mass of radioactive waste produced annually per capita in each of the regions is shown in Figure 15.13 for all scenarios. The large commitment to nuclear power in the Rhône-Alpes scenario S1 and the Wisconsin scenario S2 is quite evident. Bezirk-X relies heavily on coal (lignite) for electricity, and nuclear power is only introduced after the year 2000 in scenarios S1 and S3, with no nuclear power at all in S2. The Wisconsin scenario S1 assumes a significant quantity of nuclear power but this is still only about one-third of the nuclear production assumed in Rhône-Alpes scenario S1. The hypothesized nuclearpowered electricity generation in the Rhône-Alpes region in 2025 is more than three times greater than the $83 \times 10^{9} \mathrm{kWh}$ (gross) produced by nuclear plants in the USA in 1973.

Radioactive wastes could cause problems at both global and regional levels. Accidents at reprocessing plants or waste storage units, or even during transportation could cause severe local radioactive contamination. An international commitment to nuclear power at the level of the Rhône-Alpes scenario S1 would

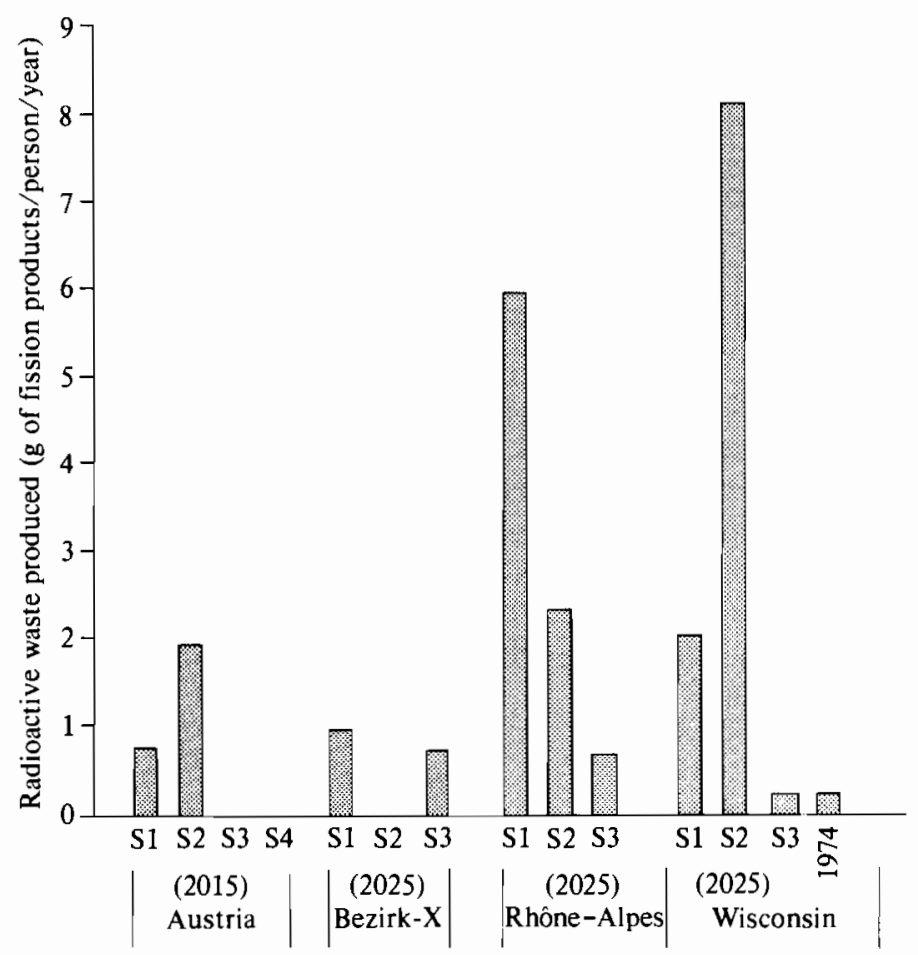

FIGURE 15.13 Amount of radioactive waste produced per capita in the years 2015 and 2025 in each of the regions for all scenarios. 
present a formidable waste management problem, which would require global cooperation for an acceptable long-term solution.

\section{CONCLUDING COMMENTS}

The preceding sections only touch on some of the more important results of our research. The papers presented in Chapter 16 of this volume and other publications arising from the project describe various parts of the study in more detail. One important analysis not described here is that of the relationship between the decision-making structure of a region and the formal models and methods of planning used within $i^{28}$. The energy system obviously depends to a large extent on the physical and economic characteristics of a region, but the social and administrative structure may also play an important role. For example, Wisconsin is a distinct political unit within the United States, and has its own legislative, judicial, and administrative apparatus. Many decisions relating to energy are made at the state level, although an even larger number of energy policies are the results of federal action. By contrast, the Rhône-Alpes "planning region" is a relatively recent creation, with no mechanism of self-government. The national or international roles of the regions and their ability to take independent action must always be borne in mind when considering the results obtained from the scenarios and the possible implementation of the policies discussed here.

This study was carried out with the aim of developing a greater understanding of the regions and their possible energy/environment futures, whatever they may be. We believe that this has been achieved and hope that our results will contribute to improved management of energy and environmental systems throughout the world.

\section{REFERENCES}

1 National Central Administration for Statistics. Statistical Yearbook of the German Democratic Republic, 1974, 1975, 1976, 1977, 1978, 1979. National Publication Company of the German Democratic Republic, Berlin. (Staatliche Zentralverwaltung für Statistik. Statistisches Jahrbuch der Deutschen Demokratischen Republik, 1974, 1975, 1976, 1977, 1978, 1979. Staatsverlag der Deutschen Demokratischen Republik, Berlin.)

2 Austrian Central Statistical Office. Statistical Yearbook for the Republic of Austria, 1972, 1973, 1974, 1975, 1976, 1977, 1978, 1979, 1980. Austrian National Press, Vienna. (Österreichisches Statistisches Zentralamt. Statistisches Handbuch für die Republik Österreich, 1972, 1973, 1974, 1975, 1976, 1977, 1978, 1979, 1980. Osterreichische Staatsdruckerei, Wien.)

3 Ministry of the Economy, Republic of France. Statistical Yearbook of France, 1974, 1975, 1976, 1977, 1978, 1979, 1980. National Institute of Statistics and Economic Studies, Paris. (Ministère de l'Économie. Republique Française. Annuaire Statistique de la France, 1974, 1975, 1976, 1977, 1978, 1979, 1980. Institut National de la Statistique et des Études Économiques (INSEE), Paris.) 
4 Regional Directorate of the National Institute of Statistics and Economic Studies. Operational basis of the Rhône-Alpes economy. Yearbook of Rhône-Alpes, 1974, 1977, 1978; Principal Results for 1973, 1976, 1977. (Direction Régionale de l'Institut National de la Statistique et des Études Économiques (INSEE). Points d'appui pour l'économie Rhône-Alpes. Annuaire Rhône-Alpes 1974, 1977, 1978; Principaux Résultats Statistiques en 1973, 1976, 1977.)

5 Wisconsin Legislative Reference Bureau. The State of Wisconsin Blue Book, 1971, 1973, 1975, 1977, 1979. State of Wisconsin, Madison, Wisconsin.

6 Dietmar Ufer. Personal communication to Robin L. Dennis on long-term energy planning in the German Democratic Republic. Leipzig, 1975.

7 B. Chateau and B. Lapillonne. Long-Term Forecasting of Energy Consumption: Towards a New Methodological Approach. Economic and Judicial Institute for the Study of Energy, Grenoble, France, 1976. (B. Chateau et B. Lapillonne. Prévisions à Long Terme de la Consommation d'Énergie: pour une Nouvelle Approche Méthodologique. Institut Économique et Juridique de l'Énergie, Grenoble, France, 1976.)

8 B. Chateau and B. Lapillonne. Long-Term Forecasting of Energy Demand: Methodological Propositions. National Center for Scientific Research, Paris, 1977. (B. Chateau et B. Lapillonne. La Prévision à Long Terme de la Demand d'Énergie: Propositions Methodologiques. Centre National de la Recherche Scientifique, Paris, 1977.)

9 Austrian Ministry of Trade, Commerce, and Industry. Energy Plan for 1976. Vienna, September 1976. (Osterreichisches Bundesministerium für Handel, Gewerbe und Industrie. Energieplan 1976. Wien, September 1976.)

10 Austrian Ministry of Trade, Commerce, and Industry. Energy Plan for 1980. Vienna, November 1980. (Österreichisches Bundesministerium für Handel, Gewerbe und Industrie. Energieplan 1980. Wien, November 1980.)

11 W.K. Foell (Ed.). Management of Energy/Environment Systems: Methods and Case Studies. Wiley, Chichester, UK, 1979.

12 W.K. Foell, J.W. Mitchell, and J.L. Pappas. The WISconsin Regional Energy (WISE) Model: A Systems Approach to Regional Energy Analysis. Report 56, Institute for Environmental Studies, University of Wisconsin-Madison, Madison, Wisconsin, 1975.

13 W.K. Foell, J.S. Buehring, W.A. Buehring, R.L. Dennis, M.E. Hanson, L.A. Hervey, A. Hölzl, K. Ito. R.L. Keeney, J.P. Peerenboom, E. Pönitz, J. Richter, and A. Toifelhardt. The Wisconsin-IIASA Set of Energy/Environment (WISE) Models for Regional Planning and Management: An Overview. RR-81-17, International Institute for Applied Systems Analysis, Laxenburg, Austria, 1981.

14 W.K. Foell, R.L. Dennis, M.E. Hanson, L.A. Hervey, A. Hölzl, J.P. Peerenboom, and E. Pönitz. Assessment of Alternative Energy/Environment Futures for Austria, 1977-2015. RR79-7, International Institute for Applied Systems Analysis, Laxenburg, Austria, 1979.

15 M.E. Hanson and J.W. Mitchell. A Model of Transportation Energy Use in Wisconsin: Demographic Considerations and Alternative Scenarios. Report 57, Institute for Environmental Studies, University of Wisconsin-Madison, Madison, Wisconsin, 1975.

16 M.E. Hanson. A Model of Personal Transportation Energy Use and Emissions in Wisconsin. Ph.D. Thesis, University of Wisconsin-Madison, Madison, Wisconsin, 1979.

17 W.A. Buehring, R.L. Dennis, and A. Hölzl. Evaluation of Health Effects from Sulfur Dioxide Emissions for a Reference Coal-Fired Power Plant. RM-76-23, International Institute for Applied Systems Analysis, Laxenburg, Austria, 1976.

18 R.L. Dennis. The Smeared Concentration Approximation Method: A Simplified Air Pollution Dispersion Methodology for Regional Analysis. RR-78-9, International Institute for Applied Systems Analysis, Laxenburg, Austria, 1978.

19 R.L. Dennis. An air pollution dispersion model for long-range policy analysis. Ecological Modelling 9(1980) 121-141.

20 J. Richter and W. Teufelsbauer. The Austrian Economy up to 1980: a Prognosis (Disaggregated 
into 31 Sectors) Made with the Help of the AUSTRIA II Input-Output Model. Report 19, Austrian Economic Chamber, Vienna, 1973. (J. Richter und W. Teufelsbauer. Österreichisches Wirtschaft bis 1980: Eine nach 31 Wirtschaftszweigen gegliederte Prognose mit Hilfe des Input-Output Modelles AUSTRIA II. Forschungsbericht 19, Bundeskammer der gewerblichen Wirtschaft, Wien, 1973.)

21 M.E. Hanson. Personal Transportation Energy Options. Report 80-103, Energy Research Center, University of Wisconsin-Madison, Madison, Wisconsin, 1980.

22 Energy System and Policy Research Group. The Potential Impact of the National Energy Plan on Wisconsin's Energy Future. University of Wisconsin-Madison, Madison, Wisconsin, 1977.

23 W.K. Foell, J.R. Huennekens, M.A. Lindsay, R.E. Stevenson, and A. TenWolde. Industrial Energy Use in Wisconsin: Consumption Patterns and Conservation Measures. Report 80-102, Energy Research Center, University of Wisconsin-Madison, Madison, Wisconsin, 1980.

24 J.R. Peerenboom, W.A. Buehring, W.K. Foell, M.E. Hanson, J.P. Peerenboom, and J.M. Lang. Alternative energy futures for Wisconsin. In W.K. Foell (Ed.), Proceedings of the 1978 Conference on Alternative Energy Futures for Wisconsin, 15-16 June 1978. Energy Research Center, University of Wisconsin-Madison, Madison, Wisconsin, 1978, pp. 66-79.

25 W.K. Foell and M.E. Hanson. Futurists and state energy policy: the Wisconsin story. Technological Forecasting and Social Change 18 (1980) $341-358$.

26 Carroll Wilson. Energy: Global Prospects 1985-2000. Report of the Workshop on Alternative Energy Strategies, McGraw-Hill, New York, 1977.

27 W.A. Buehring, W.K. Foell, and R.L. Keeney. Energy/Environment Management: Application of Decision Analysis. RR-76-14, International Institute for Applied Systems Analysis, Laxenburg, Austria, 1976.

28 S. Born, C. Cicchetti, R. Cudahy, J. Pappas, P. Hedrich, K. Lindner, D. Ufer, J. Martin, and D. Finon. Energy/Environment Models and their Relationship to Planning in Wisconsin, the German Democratic Republic, and Rhône-Alpes. RM-76-21, International Institute for Applied Systems Analysis, Laxenburg, Austria, 1976. Also appears in W.K. Foell (Ed.), Management of Energy/Environment Systems: Methods and Case Studies, Wiley, Chichester, UK, 1979, pp. 337-353, 405-443. 


\section{Issues Emerging from the Scenarios}

M.E. Hanson, A. Hölzl, E. Pönitz, L.A. Hervey, R. Dennis, and W.A. Buehring

\section{A THE POTENTIAL FOR ENERGY CONSERVATION*}

Energy conservation is one of the most important strategies available to policy makers in the management of regional energy/environment systems. Its importance is based on the fact that conservation can influence the development of energy/environment systems in accordance with social goals. Some major effects of conservation are:

1. Reduction of the environmental damage caused by energy-related activities

2. Reduction of energy costs

3. Provision of time and therefore flexibility in choosing among long-term energy options

It should be noted at the outset that the conservation discussed in the studies of the four regions does not imply a reduced standard of living or a reduction in the supply of goods and services. Although some would argue that the reduced provision of certain goods and services and changes in lifestyle are necessary and/or desirable methods of reducing energy use, conservation as defined here refers to technological and procedural changes that result in reduced demand for energy without reductions in goods and services unless otherwise noted.

The potential for conservation can be defined as the total reduction in energy use which is economically justified in terms of marginal costs being less than or equal to marginal benefits (in the broadest sense of the words) over the long run.

The exact value of this potential is a matter of debate, since it is possible to conserve energy beyond levels that are economically efficient. However, it was felt that the conservation measures considered within the regions studied did not

- By M.E. Hanson (International Institute for Applied Systems Analysis, Laxenburg, Austria, and University of Wisconsin-Madison, Madison, Wisconsin), A. Hölzl, and E. Pönitz (International Institute for Applied Systems Analysis, Laxenburg, Austria). 
exceed the bounds of economic efficiency. The conservation potentials defined here are the savings in energy use that result from particular technological and procedural changes expressed in terms of the scenarios for the regions. In many cases it would be possible to implement further measures for saving energy, but these are not considered here.

Conservation in this section is generally expressed in terms of end-use energy rather than primary energy. This presents some problems in that not all differences in end-use efficiencies are due to conservation. A shift from coal to an electric boiler appears to save end-use energy, but actually uses more primary energy. A related problem is that certain energy-saving measures, such as the cogeneration of heat and electricity by electric utilities, are not included in end-use analysis. However, adopting an end-use definition of consumption does not cause too much difficulty in this particular analysis because the cases with higher energy use, $\mathbf{S} 1$ and S2, include higher levels of electrification than the scenarios assuming lower levels of use, S3 and S4. Thus, energy conservation will always be underestimated rather than overestimated.

\section{REGIONAL ANALYSIS OF CONSERVATION POTENTIAL}

The potential for energy conservation depends on the particular circumstances of each of the regions. The greater the inefficiency or waste in the use of energy, the greater the potential and effectiveness of conservation as a management tool. The age of the buildings and equipment in place, the availability of replacement capital, the possibility of retrofitting, and the level of sheer waste are all factors which influence the potential for energy conservation.

There is clearly potential for saving energy in each of the four regions studied $^{1,2}$. The problem is not the existence of this potential, but the magnitude of the effort required to realize it. More specifically, the issue can be expressed as three questions.

1. What is the potential for energy conservation?

2. Are price and other signals to consumers and producers at levels which would make it possible to realize this potential?

3. If the signals are not at appropriate levels, what are the possibilities of adjusting them to these levels? In cases where regulation is applied, what options exist for setting or adjusting regulations?

These three questions will be discussed for each region separately, to deduce the potential for energy conservation within the different scenarios*. The potential for saving energy in specific sectors will then be considered in the light of the above questions.

\footnotetext{
* Again, it should be emphasized that the analysis considers only the part of the total conservation potential assumed in the different scenarios. This should not be considered to be the total potential for energy conservation.
} 


\section{Austria}

Figure 16.1 depicts the end-use energy requirements assumed in the four scenarios for Austria. Because both socioeconomic variables and conservation measures change between the scenarios, it is difficult to identify the effect of conservation alone. The difference between energy demand in S3 (the low energy use scenario) and S4 (the conservation case) is due to conservation measures in each of the sectors, with the caveat that $\mathrm{S} 4$ assumes more automobiles and a greater level of automotive travel than S3. The difference between S1 (the medium energy use scenario) and $\mathrm{S} 3$, on the other hand, is due to the assumption that the provision of goods and services will be less in S3 than in S1, i.e., fewer automobiles, smaller housing units with fewer appliances, and lower economic output. Finally, the difference in energy demand between the S1 and S2 (high energy use) cases is caused by differences in both conservation measures and the provision of goods

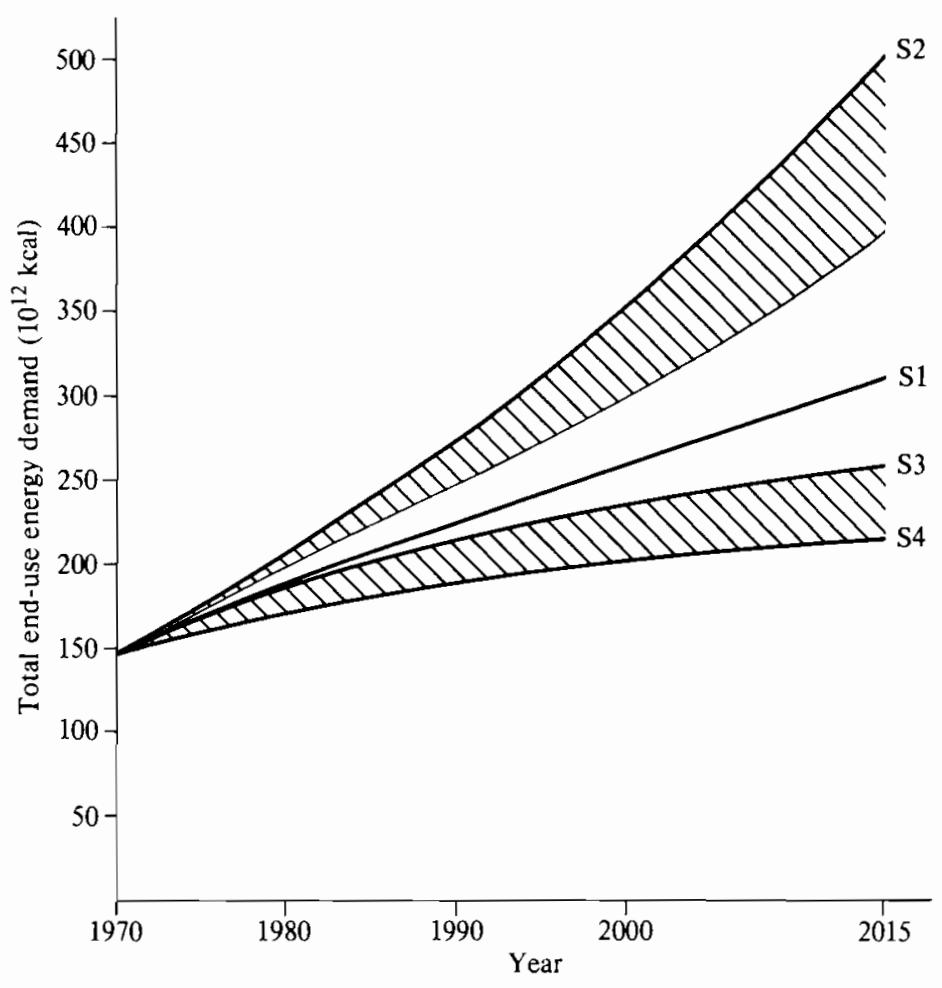

FIGURE 16.1 Total end-use energy demand, Austrian scenarios. The shaded areas represent the conservation potential. 
and services between the scenarios. The conservation potential identified by the scenarios, indicated by the cross-hatched areas in Figure 16.1, represents approximately $30 \%$ of the total end-use energy required by the S2 case in 2015 .

\section{Bezirk-X}

Figure 16.2 shows the total end-use energy demands suggested by the three scenarios for Bezirk-X in the German Democratic Republic. The differences between the scenarios are almost entirely due to differences in conservation, in particular the efficiency with which the region produces and transports its output. The only sector in which the production or amenity level differs between scenarios is transportation, where automobile ownership is greater in case S2 than in S1 and S3. A level of 1 car per household is reached by 2025 in the S2 case, as compared with 0.65 cars per household by the same date in the S1 and S3 scenarios. The cross-hatched area between scenarios S2 and S3 in Figure 16.2 represents the conservation potential identified in the scenarios; the remaining variation in energy demand is attributed to the different levels of automobile ownership. The conservation potential represents approximately $58 \%$ of the demand for energy in 2025 under scenario $\mathbf{S} 2$, a very large proportion of the total energy demand.

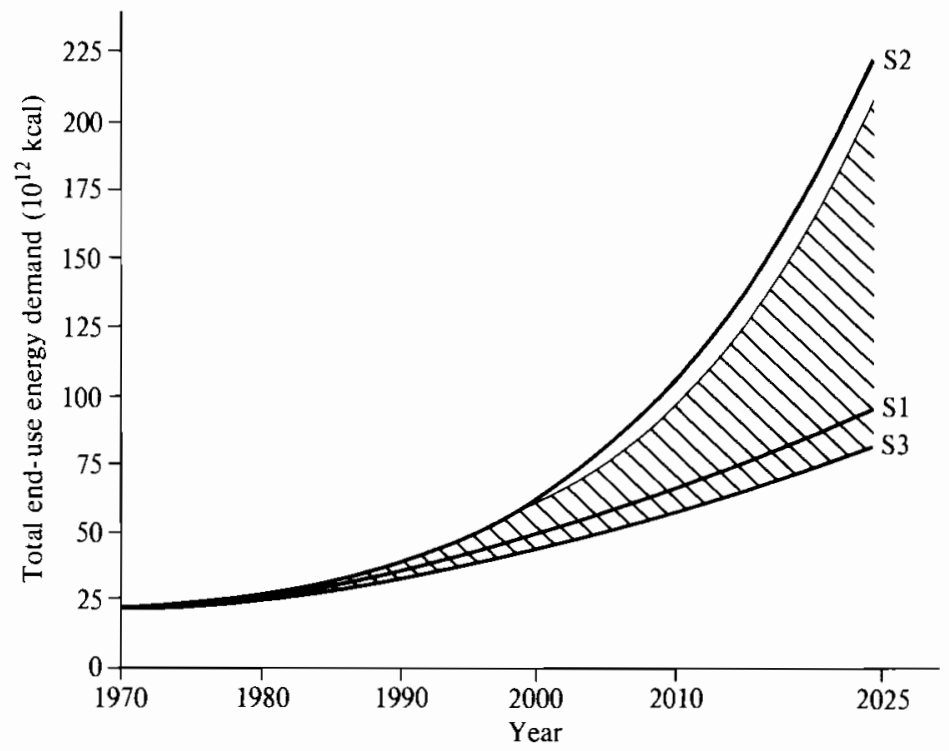

FIGURE 16.2 Total end-use energy demand, Bezirk-X scenarios. The shaded area represents the conservation potential. 


\section{Rhône-Alpes}

The total end-use energy demands suggested by the scenarios for the Rhône-Alpes region are shown in Figure 16.3. Scenarios S1 and S2 are broadly similar in terms of the level of goods and services, the main difference relating to patterns of housing and urban settlement. Scenario S2 assumes a dispersed urban pattern developing with time and a concomitant predominance of single-family homes, which comprise $80 \%$ of post- 1975 housing units. The level and mix of GRP (gross regional product) is identical in the two cases. The difference in energy demand between scenarios $\mathbf{S} 1$ and $\mathbf{S} 2$ is therefore entirely due to conservation measures.

Scenario S3 is quite different from the other two cases, in that both the level and the mix of GRP have been altered. The total GRP in 2025 under scenario S3 is $59 \%$ of the corresponding value for cases $\mathrm{S} 1$ and $\mathrm{S} 2$. Thus, the difference in end-use energy demand between S1 and S3 may be attributed to conservation

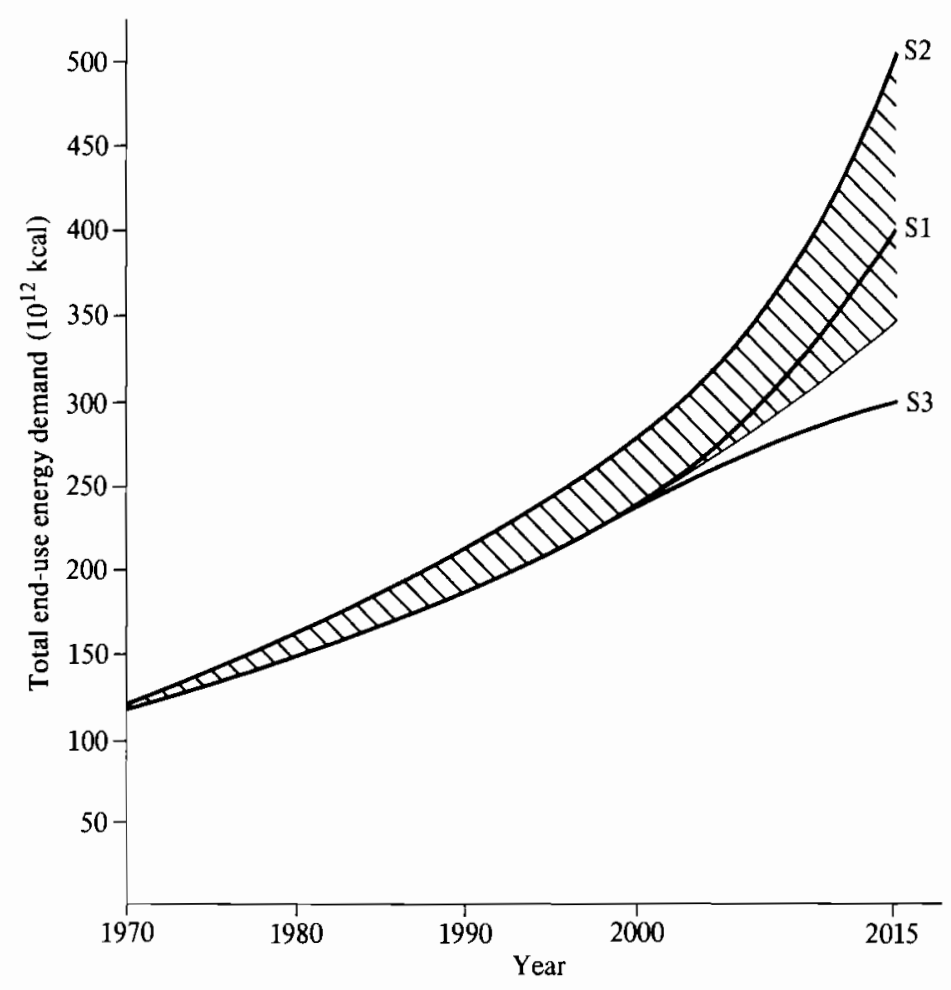

FIGURE 16.3 Total end-use energy demand, Rhône-Alpes scenarios. The shaded area represents the conservation potential. 
measures, as defined here, as well as to differences in the level and mix of goods, services, amenities, and lifestyle. The conservation potential represents $32 \%$ of total end-use demand in 2015 under scenario S2.

\section{Wisconsin}

The total primary energy demands suggested by the scenarios for Wisconsin are shown in Figure 16.4*. Because the total output of goods and services, their mix, and the number of automobiles per person are identical in each of the scenarios, the difference in energy demand is due entirely to conservation. However, the scenarios do assume different patterns of urban settlement and different ratios of single-family homes to apartments. The conservation potential within the scenarios is $49 \%$ of the 2025 energy demand from the S2 scenario. The effects of conservation measures are especially significant in the Wisconsin scenarios because the sources of energy employed in the higher energy use scenarios are

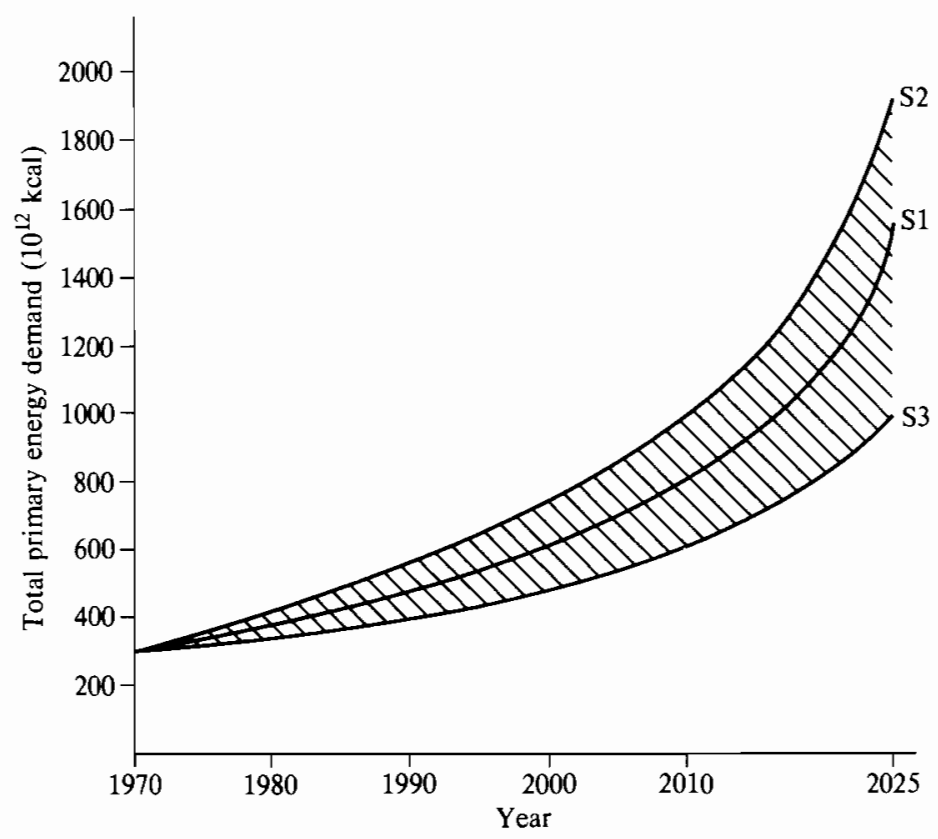

FIGURE 16.4 Total primary energy demand, Wisconsin scenarios. The shaded area represents the conservation potential.

* The Wisconsin figures are given in terms of primary energy to stress the importance of the inclusion of synthetic fuels. 
largely energy- and capital-intensive synthetic fuels (gas and petroleum from coal and shale) and electricity.

\section{PRICING POLICY}

The prices of energy in the GDR, the Rhône-Alpes region, and Wisconsin were felt to be at levels inappropriate to the stated goals of the regions ${ }^{1}$. The issue of whether energy prices corresponded to stated goals was not directly addressed in the study of Austria by Foell et $a l^{2}$.

At the time that the studies of the GDR, the Rhône-Alpes region, Wisconsin, and Austria were conducted, it was fair to say that energy prices were well below replacement or marginal cost. If those price levels had been maintained, it would have been difficult to achieve the conservation effects identified in the scenarios. Since these studies were made, however, energy prices have increased significantly in all four regions. It is too soon to judge whether the price increases experienced to date will be sufficient to realize the conservation potential identified in the scenarios, because the magnitude and speed of consumer response are not yet adequately known. However, each of the regions can expect further price increases due to the rapidly changing physical, technological, and political availability of resources.

\section{A SECTORAL ANALYSIS OF CONSERVATION POTENTIAL}

\section{Residential}

The residential sector accounts for $20-28 \%$ of total end-use energy in the regions. The most important single use is space heating, which accounts for approximately $70 \%$ of energy consumption in this sector. Water heating and, to a lesser degree, electrical appliances are additional targets for energy conservation.

The first issue is the thermal quality of the new housing units to be constructed. The basic policy choice, as in many cases, is whether to employ a regulatory approach, by imposing building codes, or whether to rely on market forces. A complicating factor is the relatively long lifetime of the housing units, which means that for economically efficient decisions it is necessary to anticipate fuel prices many years into the future. An individual is much more likely to base a decision on current energy prices, which may be at far from desirable levels. Improving the thermal quality of housing once it has been built is considerably more expensive than choosing an appropriate design before construction.

The choice between multi- or single-family units is another basic planning issue. Multi-unit dwellings are more energy-efficient due to shared internal walls, the possible use of district heat, and patterns of land use that reduce the energy needed for transportation.

Figure 16.5, based on the study of Austria, shows the results of an analysis of 


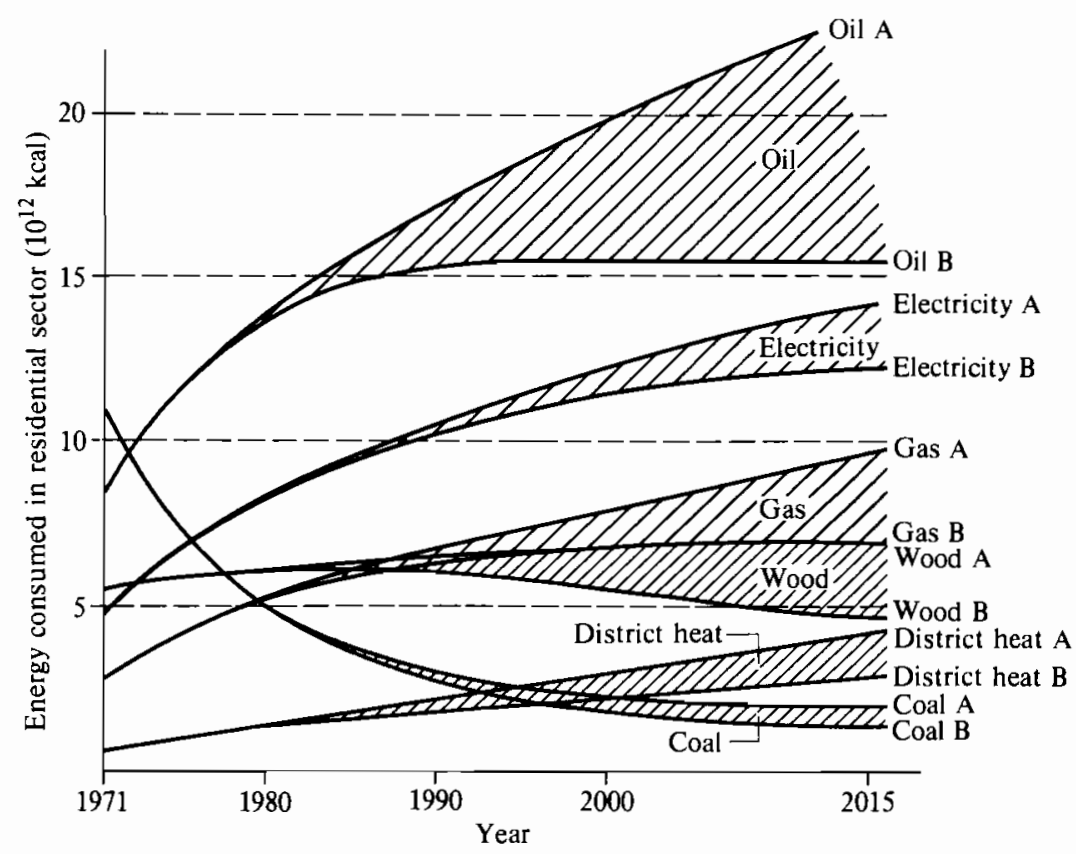

FIGURE 16.5 Comparison of the amount of each fuel consumed in the Austrian residential sector if present building practices were to continue (graphs $A$ ) with the amount of fuel consumed if improved standards of insulation had been introduced in 1971 (graphs B). The shaded area represents the conservation potential.

energy use in the residential sector. The figure compares the amount of each fuel consumed in the residential sector if present building practices were to continue with fuel consumption if improved standards of insulation had been introduced in 1971. This demonstrates both the importance of insulation in saving energy and the time lag between introduction of new regulations and significant reductions in fuel consumption.

\section{Commercial/service}

The commercial/service sector faces similar problems to the residential sector, in that space heating is the major use of energy in both. However, corporate or governmental bodies are the decision makers in this sector. One might expect corporate units to be more sensitive to price than individuals. Government bodies would perhaps be less sensitive than corporate units to price, but rather more easily regulated. 


\section{Industrial}

There are two broad methods by which energy may be conserved in the industrial sector: reducing the ratio of energy-intensive to less-energy-intensive industrial activities, and reducing the energy required for individual industrial processes. Although the proportion of energy-intensive activities assumed in the scenarios has been carefully identified, the analysis has concentrated on the possibility of reducing the energy-intensiveness of specific processes.

At the time of the regional studies, it was suggested that large reductions in industrial energy intensiveness would be possible with existing technology, with even greater advances accompanying the development of new technology. The question facing the market economies was not whether it was possible to reduce energy intensiveness, but whether industry would actually achieve these reductions. The GDR had to decide whether the individual branches of industry would achieve reductions in energy intensiveness by themselves or whether centralized directives were necessary.

Subsequent data and studies for Wisconsin have shown significant reductions in energy intensiveness. Overall industrial energy intensity in terms of Btu per dollar of shipments (in constant dollars) fell by $27 \%$ between 1971 and $1976^{3}$. Despite these gains in Wisconsin and despite achievements in industrial conservation in the other regions, conservation remains an important issue.

If government action is required, should that action take the form of taxes, incentives, or fuel use regulations? The normal reliance placed by market economies on the price mechanism has been severely limited in Wisconsin and the Rhône-Alpes region because the prices paid by industry for energy have historically been held at an artificially low level. In the Rhône-Alpes region this was a deliberate policy to maintain the competitive position of industry. In Wisconsin, natural gas and petroleum prices have been held artificially low by federal regulation, and these energy sources have been gradually decontrolled only in the last few years. In early 1981, petroleum controls, which were to have ended later in the year, were abruptly removed.

TABLE 16.1 Percentage of total end-use energy consumed in the industrial sector of each region in 1972.

\begin{tabular}{ll}
\hline Region & $\begin{array}{c}\text { Industrial share of } \\
\text { end-use energy (\%) }\end{array}$ \\
\hline Austria & 42 \\
Bezirk-X & 60 \\
Rhône-Alpes & 40 \\
Wisconsin & 28 \\
\hline
\end{tabular}


Energy conservation is particularly important in the industrial sector because of the large proportion of energy consumption that takes place in this sector. The percentages of total end-use energy consumed by industry in the four regions studied are shown in Table 16.1 for 1972.

Another issue raised by energy conservation in the industrial sector is the question of capital and investment. Housekeeping-type measures require little investment, while replacing older equipment or developing new technology requires a growing, financially sound industry. Thus strategies for conserving energy in stagnant industries and in growing industries may be quite different.

\section{Transportation}

The final sector to be considered in relation to energy conservation is transportation. In Wisconsin, transportation has a greater potential for energy conservation than any other sector, and there is also considerable scope for saving energy on transportation in the other three regions.

The central question concerning personal transportation, assuming a desire to reduce or limit liquid fuel consumption, is whether to pursue this objective via the price mechanism, with taxes on gasoline, or through legislation. The clear choice in the United States has been the regulatory route, with the Energy Policy and Conservation Act (EPCA) of 1975. This act sets an average fuel efficiency of 27.5 miles per gallon ( 8.6 liters per $100 \mathrm{~km}$ ) which must be achieved by the range of cars produced by each manufacturer in 1985 . This standard is being attained through gradual improvement every year.

The historical difficulties of the pricing approach are illustrated in Figure 16.6, which shows the economic incentives to own fuel-inefficient automobiles in Wisconsin. The real price of gasoline did not exceed the 1955 level significantly until 1979. The effect of the EPCA standards could be matched only by a very large tax increase or other mechanism raising the price of gasoline to at least $\$ 3.00$ and perhaps even to $\$ 4.00$ per gallon ${ }^{4}$. Gasoline prices in real terms would then have to increase roughly as fast as personal income if the effect were to be maintained. Anticipated consumer resistance has led to the adoption of the regulatory approach, despite the government revenue potential of the market/taxation solution. Austria, the GDR, and especially France have been more willing to use pricing as a means of conserving energy.

The fact that until recently incomes were rising more rapidly than automobile and gasoline prices in all of the regions suggests a related problem. With the increasing ownership and use of the automobile, towns and villages have become much more widely separated. Settlement patterns requiring higher energy use will present a far more difficult problem in the future than the fuel efficiency of automobiles does today.

Although freight transportation is controlled by a firm or branch of industry rather than an individual, the basic issue is still whether conservation measures 


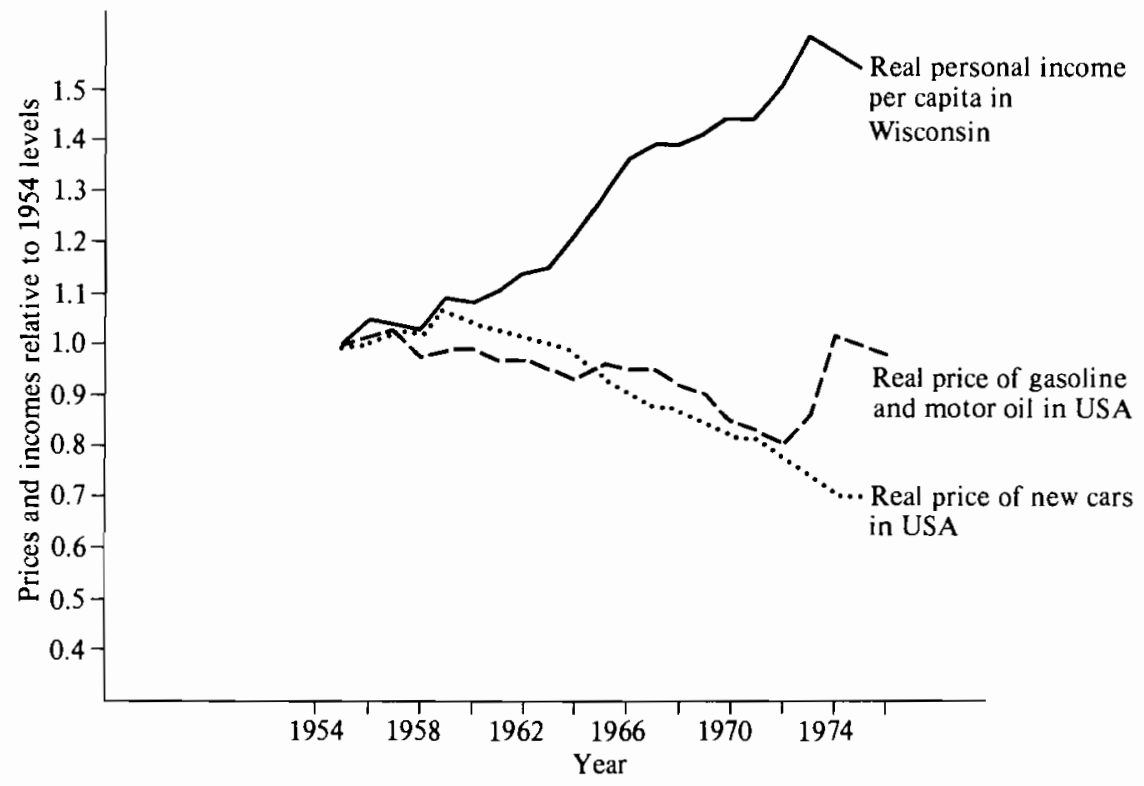

FIGURE 16.6 Changes in personal income in Wisconsin and the prices of gasoline, motor oil, and new cars in the USA between 1954 and 1976 relative to 1954 levels.

should be pursued via market or through regulatory mechanisms. In Austria and France freight transport by train is considerably more efficient than employing trucks, and the railroads are being subsidized to encourage their use. On the other hand, the construction of modern highways by the government provides a subsidy to the trucking industry, although it is not clear exactly how much is subsidized and how much is actually paid for by the industry. Nevertheless, it is possible to save energy by changing to a different mode of transport as well as by improving vehicle design. The responsiveness of industry to prices means that the pricing mechanism may well be more effective here than in the personal transportation sector.

\section{CONCLUDING OBSERVATIONS}

Energy conservation is attractive to all of the regions. The issue does not seem to be whether to conserve energy, but how much to conserve and how to do it. Since there are problems in pursuing any single strategy, the likely solution is a mix of regulatory and price mechanisms which will depend on the individual characteristics of the region concerned. In the light of the resource and environmental problems facing the regions, further analysis leading to the implementation of energy conservation measures seems more than warranted. 


\section{B ALTERNATIVE REGIONAL ENERGY SUPPLY STRATEGIES*}

The future development of each region--in terms of patterns of economic activity, transportation networks, and settlement policy-will depend greatly on the amounts and types of energy available. This section explores a number of possible energy strategies that could be used by the regions to meet future energy requirements. The particular strategies chosen by a given region will have many determinants, such as the relative costs of alternative energy sources, balance of payments considerations, the desire of a region to achieve energy independence, the presence of indigenous energy resources, and the importance given to the environmental effects of energy use.

The basic problem facing the regions is to choose a mix of energy sources for the future that is consistent with overall economic and social goals. Because conventional energy resources are limited both within the regions and globally, it is clear that patterns of energy use must change. In particular, it will be necessary to reduce the consumption of petroleum and gases in the near future. The questions currently facing decision makers include:

- What role will petroleum and gases play in future patterns of regional energy supply?

- How much substitution among energy sources is possible?

- How might conservation in various sectors affect the demand for energy in the regions?

- How can renewable resources contribute to supply?

This section examines a number of different energy supply strategies based on the scenarios developed for the four regions. The assumptions made in the scenarios make it possible to assess the role that petroleum, gases, coal, nuclear fuels, district heating, cogeneration, and renewable resources may play in future patterns of regional energy supply. Different energy sources are discussed in terms of the current supply pattern, the indigenous energy resources, and the conservation potential of each region.

\section{THE ROLE OF PETROLEUM AND GASES IN THE ENERGY FUTURES OF THE REGIONS}

The initial patterns of energy supply in Austria, the Rhône-Alpes region, and Wisconsin showed a heavy dependence on petroleum and gases. The GDR provided a complete contrast, with an almost total reliance on domestic lignite. As may be seen from Table 16.2, petroleum and gases met $67 \%$ of Austria's primary energy requirements in $1971,70 \%$ of the requirements in the Rhône-Alpes region

* By L.A. Hervey (International Institute for Applied Systems Analysis, Laxenburg, Austria). 
TABLE 16.2 Primary energy supply disaggregated by energy source in each of the four regions in $1970^{a}$.

\begin{tabular}{|c|c|c|c|c|}
\hline \multirow[t]{2}{*}{ Energy source } & \multicolumn{4}{|c|}{ Primary energy supply $\left(10^{12} \mathrm{kcal}\right.$ and as percentage of total) } \\
\hline & Austria & Bezirk-X & Rhône-Alpeș & Wisconsin \\
\hline $\begin{array}{l}\text { Petroleum } \\
\text { Gases } \\
\text { Coal }\end{array}$ & $\begin{array}{l}89.4(49.3) \\
31.5(17.5) \\
40.1(22.1)\end{array}$ & $\begin{array}{c}5.5(3.7) \\
2.0(1.3) \\
143.0^{b}(95.0)\end{array}$ & $\begin{array}{c}85.3(64.0) \\
8.2(6.2) \\
17.2(12.9)\end{array}$ & $\begin{array}{r}114.7(39.9) \\
90.3(31.4) \\
80.7(28.1)\end{array}$ \\
\hline Nuclear power & - & - & - & 0.1 \\
\hline Hydropower & $13.0(7.2)$ & - & $22.5(16.9)$ & $1.6(0.6)$ \\
\hline Other & $7.0(3.9)$ & - & - & - \\
\hline Total & $181.0(100)$ & $150.5(100)$ & $133.2(100)$ & $287.4(100)$ \\
\hline
\end{tabular}

${ }^{a}$ The 1971 value was used for Austria.

${ }^{b}$ Approximately half of the coal produced in Bezirk-X in 1970 was exported.

in 1970 , and $71 \%$ of Wisconsin's energy needs in 1970 . In contrast, these fuels provided only $5 \%$ of the primary energy in Bezirk-X in 1970*.

Is it possible for these patterns to persist in the future? Because they do not have substantial indigenous petroleum and gas resources, the current marked dependence on these fuels is an important issue in Wisconsin, the Rhône-Alpes region, and Austria. In the GDR, too, there is concern about maintaining energy autonomy, in the face of an anticipated expansion of the (petroleum-dependent) transportation sector.

The economic growth and personal consumption patterns assumed in the regional scenarios lead to increases in total primary energy demand by factors of 1.4-3.4 in Austria, 1.1-1.4 in Bezirk-X, 4.0-6.4 in the Rhône-Alpes region, and 2.8-5.8 in Wisconsin over the period studied. Doubling or tripling the total energy requirement would have a dramatic effect on the demand for petroleum and gases, particularly when one considers the initial importance of these fuels in Austria, the Rhône-Alpes region, and Wisconsin. Given current estimates of petroleum and gas resources and production rates, it is unlikely that these fuels will be able to meet the proportion of regional energy demand in the future that has been common in the past.

\section{STRATEGIES FOR REDUCING PETROLEUM DEMAND THROUGH FUEL SUBSTITUTION}

Because of its indigenous lignite resources, the GDR is concentrating on the efficient exploitation of this fuel. In Wisconsin and Austria, coal is also attracting

\footnotetext{
* In the case of Bezirk-X, primary energy includes coal produced for export. In 1970 approximately
} half of the coal mined in the region was exported either directly or after conversion to briquettes. 
increasing attention as a major energy option. The production of synthetic fuels from coal imported from other states is a possibility that has been discussed widely within Wisconsin, while in Austria the proximity of nations with large coal resources has generated interest in strategies involving the large-scale importing of coal, for instance by means of a coal-slurry pipeline between Poland and Austria. Coal is considered a less attractive prospect in the Rhône-Alpes region: here, planners are considering expansion of nuclear-based electricity generation, partly from a desire to achieve energy independence.

The supply strategies developed in the scenarios for the four regions therefore examined the possibility of reducing petroleum demand by substituting other fuels for liquid hydrocarbons, as follows:

1. Austria. Elimination of petroleum as a primary fuel for electricity production; use of coal to relieve pressure on petroleum supplies in the industrial, commercial, and residential sectors.

2. Bezirk-X. Phasing out of petroleum combustion in all sectors except transportation; petroleum to be replaced by coal and coal-based district heat.

3. Rhône-Alpes. Reduction of petroleum imports through rapid nuclearbased electrification.

4. Wisconsin. Substitution of petroleum by coal or coal-based synthetic fuels.

\section{Effectiveness of the conventional fuel substitution strategies}

The implementation of these strategies in the regional scenarios did not give consistently encouraging results, as indicated in Table 16.3. Despite measures designed to reduce dependence on petroleum in Bezirk-X (scenario S1), the annual

TABLE 16.3 Evolution of the primary demand for petroleum in the regions over time.

\begin{tabular}{llccc}
\hline Region & Scenario $^{a}$ & \multicolumn{3}{l}{ Primary petroleum demand $\left(10^{12} \mathrm{kcal}\right)$} \\
\cline { 3 - 5 } & & 1970 & 2000 & 2025 \\
\hline Austria & $\mathrm{S4}^{\prime}$ & $89.4^{b}$ & 92.3 & $68.5^{c}$ \\
Bezirk-X & $\mathrm{S} 1$ & 5.5 & 13.95 & 32.1 \\
Rhône-Alpes & $\mathrm{S} 1$ & 85.3 & 130.2 & 159.1 \\
Wisconsin & $\mathrm{S} 1$ & 114.7 & $168.8^{d}$ & $91.8^{d}$ \\
\hline
\end{tabular}

\footnotetext{
${ }^{a}$ Scenario S4' is a sensitivity study of the S4 case, which examines the potential for reductions in petroleum consumption through shifts to other fuels.

b 1971 value.

c 2015 value.

${ }^{d}$ These figures refer only to the demand for primary petroleum, not for synthetic petroleum produced from coal. Wisconsin's total petroleum requirements, including synthetics, was predicted to be $189.5 \times 10^{12} \mathrm{kcal}$ for the year 2000 and $356.3 \times 10^{12} \mathrm{kcal}$ for 2025 .
} 
primary energy demand for this fuel more than doubled between 1970 and 2000 and increased by a factor of six between 1970 and 2025. The corresponding scenario for the Rhône-Alpes region showed that the primary demand for petroleum increased $53 \%$ between 1970 and 2000 and $87 \%$ between 1970 and 2025.

The difficulty in replacing petroleum may be better understood if the demands for this fuel are analyzed by sector, as shown in Table 16.4. The figures reveal that a large proportion of the petroleum is used in the transportation sector, which is unaffected by the Bezirk-X coal strategy and the Rhône-Alpes nuclear-based electrification strategy. In the Rhône-Alpes region the potential for electricity to replace petroleum in the residential sector is limited; although it is assumed that most new homes will be heated by electricity, it was considered uneconomical to install electrical heating in pre-1971 homes heated by fossil fuels, which remain in the housing stock throughout the period covered by the scenarios. Increasing the use of electricity in the Rhône-Alpes industrial sector was constrained by the existence of processes for which electricity cannot efficiently replace conventional fuels, such as steam production and large kiln operation, and by the need to maintain a supply of feedstocks. The substantial increases in primary requirements for petroleum in Bezirk-X and the Rhône-Alpes region, despite the fuel substitution schemes, emphasize the need for innovative fuel substitutions in the transportation and industrial sectors.

In the Wisconsin scenarios coal-based synthetic fuels were used to produce liquid fuels suitable for transportation and industry, and this made it possible to reduce the primary requirements for petroleum in the next century to pre-1970 levels. However, the success of this strategy depends on the speed with which coal-mining and conversion facilities can be expanded. Large-scale use of synthetic fuels also implies a willingness to accept the primary energy losses and other disadvantages associated with conversion processes.

The coal substitution strategy examined for Austria also reduces the primary requirements for petroleum at the end of the period studied to pre-1971 levels.

TABLE 16.4 End-use demand for petroleum disaggregated by sector in each region in the year 2000 .

\begin{tabular}{|c|c|c|c|c|}
\hline \multirow[t]{2}{*}{ Sector } & \multicolumn{4}{|c|}{ End-use petroleum demand $\left(10^{12} \mathrm{kcal}\right.$ and as percentage of total) } \\
\hline & $\begin{array}{l}\text { Austria } \\
\text { (S4) }\end{array}$ & $\begin{array}{l}\text { Bezirk-X } \\
\text { (S1) }\end{array}$ & $\begin{array}{l}\text { Rhône-Alpes } \\
\text { (S1) }\end{array}$ & $\begin{array}{l}\text { Wisconsin } \\
\text { (S1) }\end{array}$ \\
\hline Industrial & $23.1(27)$ & $0.5(4)$ & $45.7(39)$ & $8.2(4)$ \\
\hline Commercial & $19.7(23)$ & - & $2.1(2)$ & $13.9(7)$ \\
\hline Residential & $15.6(18)$ & - & $32.1(27)$ & $35.3(19)$ \\
\hline Transportation & $28.2(33)$ & $12.0(96)$ & $37.3(32)$ & $129.2(69)$ \\
\hline Total & $86.6(100)$ & $12.5(100)$ & $117.2(100)$ & $186.6(100)$ \\
\hline
\end{tabular}


However, as in the case of Wisconsin, this success must be qualified. It is not certain whether capital, labor, financing, and other requirements could be provided quickly enough to meet worldwide demand should a large-scale switch from petroleum to coal take place. Also, it must be stressed that the coal substitution strategy was tested by means of a sensitivity study based on the Austrian energy scenario with the lowest demand (S4); here petroleum conservation measures were assumed in all sectors, including transportation. End-use petroleum demand grew very slowly during the period covered by the scenario, and therefore on an absolute basis the quantity of petroleum substituted by coal in the industrial, commercial, and residential sectors in the sensitivity study was quite small. This implies that conservation measures are also necessary if a petroleum shortfall is to be avoided through a coal substitution strategy.

\section{STRATEGIES FOR REDUCING PETROLEUM DEMAND THROUGH CONSERVATION}

\section{Conservation measures in the end-use sectors}

A comparison of S1 (base case) and S3 (conservation case) end-use demands for petroleum at the end of the period considered by the scenario indicates the potential for saving petroleum through conservation measures in the regions. S3 demands for petroleum were $16 \%$ lower than S1 demands at the end of the period studied in Austria, 45\% lower in Bezirk-X, 45\% lower in the Rhône-Alpes region, and $34 \%$ lower in Wisconsin. Table 16.5 indicates the end-use sectors in each region which were able to achieve the greatest savings in petroleum.

Except for Bezirk-X, where little petroleum was used by industry, each of the regions was able to achieve petroleum savings of $30-60 \%$ in the industrial sector by making industry less energy intensive*. The transportation sector also proved

TABLE 16.5 Percentage reduction in end-use petroleum demand in each sector on comparing scenario $\mathrm{S} 1$ with scenario $\mathrm{S} 3$ at the end of the period studied.

\begin{tabular}{llccc}
\hline Sector & \multicolumn{4}{l}{ Percentage reduction in end-use petroleum demand (S1 $\rightarrow$ S3) } \\
\cline { 2 - 5 } & Austria $^{a}$ & Bezirk-X & Rhône-Alpes & Wisconsin \\
\hline Industrial & 35 & - & 47 & 45 \\
Commercial & 32 & - & - & 52 \\
Transportation & 31 & 43 & 58 & 26 \\
Residential & 27 & - & 10 & 19 \\
\hline
\end{tabular}

${ }^{a}$ In this case scenario S1 (base) is compared with scenario $\$ 4$ (strict conservation).

\footnotetext{
* In Austria a considerable amount of petroleum was also saved through a shift to gases.
} 
to have a considerable capacity for petroleum savings in all of the regions, mainly through improvements in the efficiency of consumption, shifts to more efficient methods of freight transportation, and increased emphasis on mass transit. In the Austrian transportation sector, for example, 4.4 million tonnes ( 31 million barrels) of petroleum would be saved annually by improving the fuel consumption of automobiles from 8.9 liters $/ 100 \mathrm{~km}$ (26.4 miles per gallon) to 7.0 liters $/ 100 \mathrm{~km}$, (33.5 miles per gallon) by 2015 . In the Rhône-Alpes region a $60 \%$ reduction in end-use demand for petroleum in the transportation sector was achieved in the conservation scenario, as compared with the high energy use scenario, by emphasizing train rather than truck transport for freight, by improving the fuel economy of trucks (from $710 \mathrm{kcal} /$ ton-km to $600 \mathrm{kcal} /$ ton-km) and cars, and by developing the mass transit sector. In Wisconsin, the total annual saving of petroleum in the transportation sector by 2025 was estimated at 40 million barrels: $30 \%$ of this was achieved by improved fuel efficiency in automobiles and another $60 \%$ by increased rail transportation of freight. The savings in the Bezirk-X transportation sector are due to a decrease in the use of cars with a concomitant increase in mass transit. Savings in petroleum in the residential and commercial sectors cannot be attributed solely to conservation measures; shifts to alternative energy sources also play an important role in reducing petroleum demand.

\section{Petroleum conservation through district heating and cogeneration strategies}

The use of district plants to provide low-temperature space and water heating in the residential and commercial sectors has attracted attention as a method of heating that both decreases primary energy requirements and minimizes air pollution. The firing efficiencies in large district heating plants can reach $70-80 \%$, as compared with $40-65 \%$ achieved by coal- or oil-fired central heating units in the home. However, a scheme of this nature requires much cooperation between home owners in residential areas and businesses in commercial districts, and for this reason is often difficult to implement.

The GDR is currently the only region of the four studied in which a significant fraction of end-use energy is supplied by district heat. The pattern of state ownership in the GDR appears to encourage the development of this energy strategy; the scenarios stress the increasing importance of coal-fired district heating in the GDR and make it possible to assess the associated savings in primary energy. In the base case scenario (S1) the absolute amount of end-use demand met by district heat in the residential sector grew by a factor of 5 between 1970 and 2025 , increasing from $0.4 \times 10^{15} \mathrm{cal}$ ( $5 \%$ of total residential end-use demand in 1970) to $2.3 \times 10^{13} \mathrm{cal}$ (30\% of residential end-use demand in 2025). District heating plants are more efficient than home units, leading to a saving of $36 \%$ in primary energy requirements. On this basis, scenario S1 suggests that $3.0 \times 10^{15}$ cal could be saved in 2025 by using district heating plants rather than 
home furnaces for space and water heating. This is the equivalent of nearly 1 million tonnes of lignite. The difference in the efficiencies of district plants and on-site commercial units leads to a reduction of $24 \%$ in the primary energy required by the commercial sector. The use of district heat in the commercial sector in the final year of the base case scenario (S1) produced primary energy savings of $3.2 \times$ $10^{15} \mathrm{cal}$, or the equivalent of an additional million tonnes of lignite. The overall effect of district heating in the medium energy use (base case) scenario was therefore to reduce the total annual primary energy requirements of the commercial and residential sectors in 2025 by approximately $30 \%$ of the value expected if individual furnaces had been used.

Although the industrial cogeneration of electricity and process heat and the combined generation of electricity and district heat at power plants were not explicitly treated in the scenarios, the energy-saving potential of these processes is becoming increasingly apparent* While the separate production of electricity and steam for industrial processes commonly has an efficiency of about $30-38 \%$, cogeneration can be carried out at an efficiency of approximately $60 \%$. It is often noted that the additional fuel required to generate electricity in the cogeneration process in an industrial plant is only half that required to produce the same amount of electricity in a conventional power plant. Though the potential savings in primary energy that would result from widespread implementation of the cogeneration strategy are enormous, large institutional barriers currently hinder the required cooperation between industry, public utilities, and government in countries such as the USA. Combined electricity and district heat plants face similar difficulties. Should these obstacles disappear in the coming decades, cogeneration and combined heat-electricity plants could form an important part of a strategy to conserve petroleum in densely populated areas such as Austria and the Rhône-Alpes. These techniques also have the advantage of keeping environmental damage to a minimum.

\section{STRATEGIES FOR REDUCING PETROLEUM DEMAND THROUGH DEVELOPMENT OF RENEWABLE RESOURCES}

Another possible method of reducing petroleum consumption involves the use of renewable resources, such as solar power. Although there are many estimates of the speed of penetration of solar technologies into the energy market, they are surrounded by uncertainties. It must be stressed that in most cases only firstgeneration designs for solar power units exist, and these are mainly in the pilot testing stages. Significant advances are expected in the development of improved heat-transfer fluids, mass production of photovoltaic cells, and storage

\footnotetext{
* Industrial cogeneration generally involves the production of high-pressure steam, the expansion of this steam through a turbine to generate electricity, and the use of the resulting waste heat in industrial processes. District heating refers to the use of exhaust heat from thermal power plants to supply low-temperature heat for room heating and hot water.
} 
technologies, but it is impossible to predict when any breakthrough will occur. The crucial issue of costs cannot be resolved either, due to lack of operational experience with prototype plants, and uncertainty about the future prices of competitive energy sources. Even as the technologies become more mature, their use in a given region will depend to a large extent on local parameters such as meteorological conditions, availability of land, and integration with existing energy supply systems.

The conservation scenarios proposed for Bezirk-X, the Rhône-Alpes region, and Wisconsin assumed active development of solar power in the residential and commercial sectors, as well as to a more limited extent in the electricity-generating industry. These assumptions were not meant to be a prediction of technological progress, but were included as a means of assessing the impact of a given rate of solar development on sectoral end-use energy demands and total end-use energy demands over a period of 50-60 years. The assumptions made about the use of solar power in the conservation scenarios may be summarized as follows:

Bezirk-X. From 1980 onward, a steadily growing percentage of newly constructed homes will contain solar heating units; $50 \%$ of one- and two-family homes constructed in 2025 will make use of solar technology.

Rhône-Alpes. Housing units built after 1975 will make greater use of solar power than was assumed in Bezirk-X. An increasing proportion of new homes will have solar space and water heating: for single houses, this proportion will increase from $5 \%$ of the houses built between 1975 and 1985 to $30 \%$ of the houses built between 1985 and 2000 , rising to $75 \%$ of all houses built after 2010 ; for apartments, this proportion will increase from $30 \%$ of the units built between 1985 and 2000 to $60 \%$ of the units built between 2000 and 2010 , rising to $70 \%$ of all units built after 2010. In the commercial sector, solar collectors will supply more than $40 \%$ of end-use energy by 2025 .

Wisconsin. An increasing proportion of new housing units will make use of solar power. The number of newly constructed homes equipped with solar units will rise from $5 \%$ in 1980 to $50 \%$ in 2000 , this proportion remaining constant up until 2025. The commercial sector will use solar energy as a substitute for natural gas and petroleum, and in the electricity sector $30 \%$ of the power generated in 2025 will be supplied by solar plants.

Given these assumptions, how much of the end-use demands and electricity generation requirements can be met by solar energy during the period covered by the scenarios?

In 2025 the solar contribution to end-use energy requirements in the residential sector, based on the above assumptions, would range from $5 \%$ in Bezirk-X to $17 \%$ in Wisconsin. The contribution of solar energy to total end-use energy (including solar-generated electricity consumed in the end-use sectors) would range from $3 \%$ in Bezirk-X to $12 \%$ in the Rhône-Alpes region. The assumptions 
suggest that solar electric plants could generate $7 \%$ of the electricity required in Bezirk-X in 2025, the corresponding figures for the Rhône-Alpes region and Wisconsin being $16 \%$ and $30 \%$, respectively. However, it must be kept in mind that the scenarios limited the utilization of solar power to new housing units, and that even during a 50-year period the turnover of buildings is slow. Should it become economic to refit existing buildings with solar equipment the impact of solar technology would be much greater. It must also be emphasized that the scenarios include only applications that are already possible, such as space and water heating; the picture could be radically altered if inexpensive mass production of the photovoltaic cell becomes feasible or if systems for producing intermediate temperatures for industry are developed.

\section{CONCLUSION}

Continued growth in energy demand could lead to severe problems in supply unless the current dependence on petroleum is reduced. Strategies examined in the regional scenarios indicated that conventional fuel substitutes, such as coal and nuclear power, have limited applicability in the transportation and industrial sectors. Synthetic fuels have a wider range of application, but there may be institutional limits to production on a very large scale. It would appear that petroleum-substitution strategies cannot be successful unless combined with strong conservation measures and the development of alternative sources of energy.

\section{AIR POLLUTION AND ENERGY*}

Air pollution is a topic of concern in all of the regions studied, and is receiving particular attention in Wisconsin, the GDR, and Austria. Wisconsin is attempting to maintain the quality of the air in its largest city, Milwaukee, in the face of urban expansion; the GDR is showing a strong interest in reducing the levels of sulfur dioxide $\left(\mathrm{SO}_{2}\right)$ in major cities and industrial areas; and Austria is in the process of limiting the emission of the most common air pollutants. It is clear that there is most concern over air pollution in the major urban centers, but there is also a need to maintain air quality in the more rural areas.

The major source of five of the six most common air pollutants (sulfur oxides $\mathrm{SO}_{x}$, nitrogen oxides $\mathrm{NO}_{x}$, carbon monoxide $\mathrm{CO}$, ozone $\mathrm{O}_{3}$, and hydrocarbons $\left.\mathrm{C}_{x} \mathrm{H}_{y}\right)^{* *}$ is the use of energy by man. There is also much concern about the global effects of the carbon dioxide $\left(\mathrm{CO}_{2}\right)$ emitted during combustion processes, but this supraregional problem will not be discussed here. There are, therefore, strong links between air pollution and energy, and the quality of the air in both urban and rural areas will continue to deteriorate unless direct measures are taken to reduce the pollution caused by energy use.

* By R.L. Dennis (International Institute for Applied Systems Analysis, Laxenburg, Austria.)

** The sixth common air pollutant is particulate matter. 


\section{IMPORTANCE OF AIR POLLUTION}

Air pollution is one of the greatest threats to human health and safety associated with energy systems ${ }^{1}$. The most common measure of the effect of a particular factor on human health is the number of person-days lost (PDL) as a result of this factor. When trying to quantify the effect of energy systems on human health, it is necessary to consider all of the processes from extraction of the fuels up to and including final use; the person-days lost in connection with a tonne of coal would therefore include those caused by mining accidents as well as those produced by air pollution following combustion. The regional analysis of health hazards is based on the number of person-days lost as a result of the production and use of the fuel consumed in each region, regardless of where these person-days were lost. At the beginning of the period studied, air pollution accounted for $57 \%$ of the PDL associated with energy used in Wisconsin, the corresponding figures for Bezirk-X and Austria being $47 \%$ and $14 \%$, respectively. At the same time, $93 \%$ of the person-days lost in Wisconsin as a result of energy use in the same region could be attributed to air pollution, with corresponding values of $47 \%$ for Bezirk$\mathrm{X}$ and $30 \%$ for Austria. This illustrates that the incidence of person-days lost through air pollution is much higher in the region of consumption than elsewhere. Scenario S1 suggests that, at the end of the period studied, the proportion of the energy-associated PDL caused by air pollution will rise to $60 \%$ for Wisconsin and $51 \%$ for Bezirk-X, and fall to $11 \%$ for Austria.

These values are based on the $\mathrm{SCA}^{5}$ method for calculating the local exposure to $\mathrm{SO}_{2}$. From this it is possible to deduce the local exposure to the sulfates produced by $\mathrm{SO}_{2}$ and then use health damage functions to estimate the level of mortality and degree of acute and chronic sickness caused as a result ${ }^{6-8}$.

These health damage functions have been subject to much criticism. Many believe that these functions are too uncertain to use or that they do not represent the real cause of the damage. Others believe that the effects included in these functions constitute only a very small proportion of the total hazard because only $\mathrm{SO}_{2}$ is considered. Nevertheless, reducing the calculated impact of air pollution on health by a factor of ten would still mean that air pollution is one of the greatest causes of ill-health connected with energy systems. Multiplying this figure by a factor of ten would make air pollution the greatest energy-related danger to human health and safety.

It should be noted that the effects of air pollution on health are considered "involuntary", unlike the "voluntary" occupational health and safety hazards for which a worker is supposedly compensated. Society and policy makers may attach quite different weights to these two classes of health hazard.

\section{AIR POLLUTION ISSUES}

The studies of the four regions suggest that there is a need for continuing concern about the connection between energy and air pollution. This concern may be 
expressed in terms of policies which either directly or indirectly influence the level of pollution in the regions.

Direct policy measures are designed to reduce the emission of pollutants and/or the levels of pollution (exposure) experienced by the public without changing the patterns of energy use or social habits. These direct measures may be divided into three groups:

1. Controlling the total volume of emissions

2. Changing the fuel mix

3. Changing the height at which pollutants are emitted

Indirect policy measures are concerned with controlling energy rather than air pollution, though they may affect the latter indirectly. Three examples are:

1. Urban development and form

2. Energy conservation

3. Fuel mix

These two types of measures are discussed in more detail below.

\section{DIRECT POLICY MEASURES}

\section{Controlling the total volume of emissions}

Emissions are generally controlled either by removal of the pollutant at the stack or by precleaning or pretreatment of the fuel.

Removal of gas at the stack is only economic for large plants producing a considerable amount of pollution. This means that the bulk of the control is concentrated in the supply sector (especially electricity production) and the largest industries. Smaller polluters are not controlled by this method.

Pretreatment of the fuel, such as desulfurization of oil, has the advantage that pollution is controlled in all sectors, though this does increase fuel costs. As with stack-gas removal, the greatest effect is seen in the supply sector (oil refineries and coal treatment facilities).

Both of these measures were used in the scenarios for Austria ${ }^{2}$. Three stages of control were defined:

Stage 1. New legislation reducing the maximum sulfur content of oil to limits set by the Ministry of Health and Environment to be implemented by 1981 (fuel pretreatment)*.

\footnotetext{
* The legislation originally called for the following limits to the sulfur content of oil: extra-light heating oil, $0.3 \%$; light heating oil, $0.8 \%$; medium heating oil, $1.5 \%$; heavy heating oil, $2.0 \%$. However, the standards that actually went into effect on 1 May 1981 are lower: extra-light heating oil, $0.5 \%$; light heating oil, $1.5 \%$; medium heating oil, $2.5 \%$; heavy heating oil, $3.5 \%$. Therefore Stage 1 overestimates the stringency of the $\mathrm{SO}_{2}$ emission control standards implemented in Austria.
} 
Stage 2. The present USA standard of $2.16 \mathrm{~kg}$ of sulfur dioxide emitted per million kcal of energy released to be applied to all sources of $\mathrm{SO}_{2}$, starting in 1985 and finishing in 2000 (stack-gas removal and some fuel pretreatment).

Stage 3. More stringent standard of $1.08 \mathrm{~kg}$ of sulfur dioxide emitted per million $\mathrm{kcal}$ of energy released to be implemented for all point sources in 2000 and completed by 2015 (stack-gas removal for large sources and fuel pretreatment for small sources).

The effect of these control measures on the level of emissions and the related damage to health was then analyzed; the results are shown in Figures 16.7 and 16.8. It is clear that each of the new standards produces a significant reduction in the total volume of $\mathrm{SO}_{2}$ emitted, but that implementation of the first stage of control produces a much greater effect on public health than any subsequent measure.

The main reason for this difference is that the measures suggested in stages 2 and 3 are not aimed at the sectors causing the most damage to health. Emissions from the residential and service sectors have a greater effect on exposure levels and hence on health in the urban areas than the industrial emissions which are the main target of the measures in stages 2 and 3 . The implication is that the removal of gas at the stack in large emitters can considerably reduce the amount of $\mathrm{SO}_{2}$ released, though the resulting improvement in public health may be much less significant.

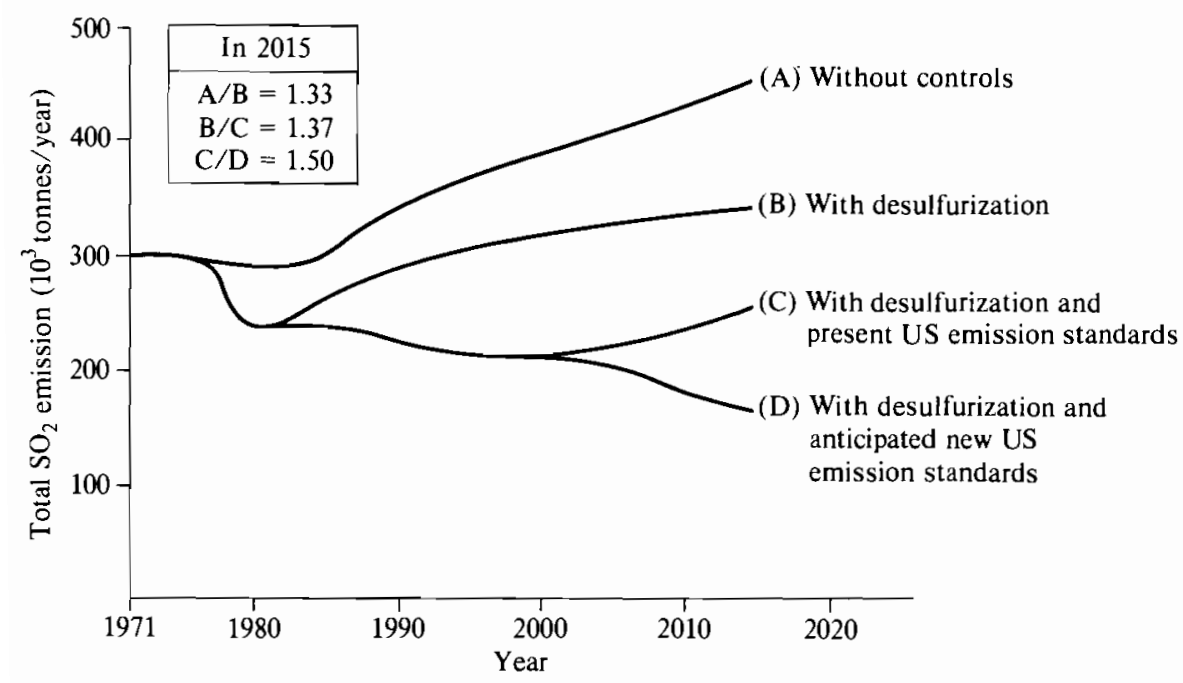

FIGURE 16.7 Effect of different $\mathrm{SO}_{2}$ regulations on the total volume of $\mathrm{SO}_{2}$ emitted in Austria (scenario S1). 


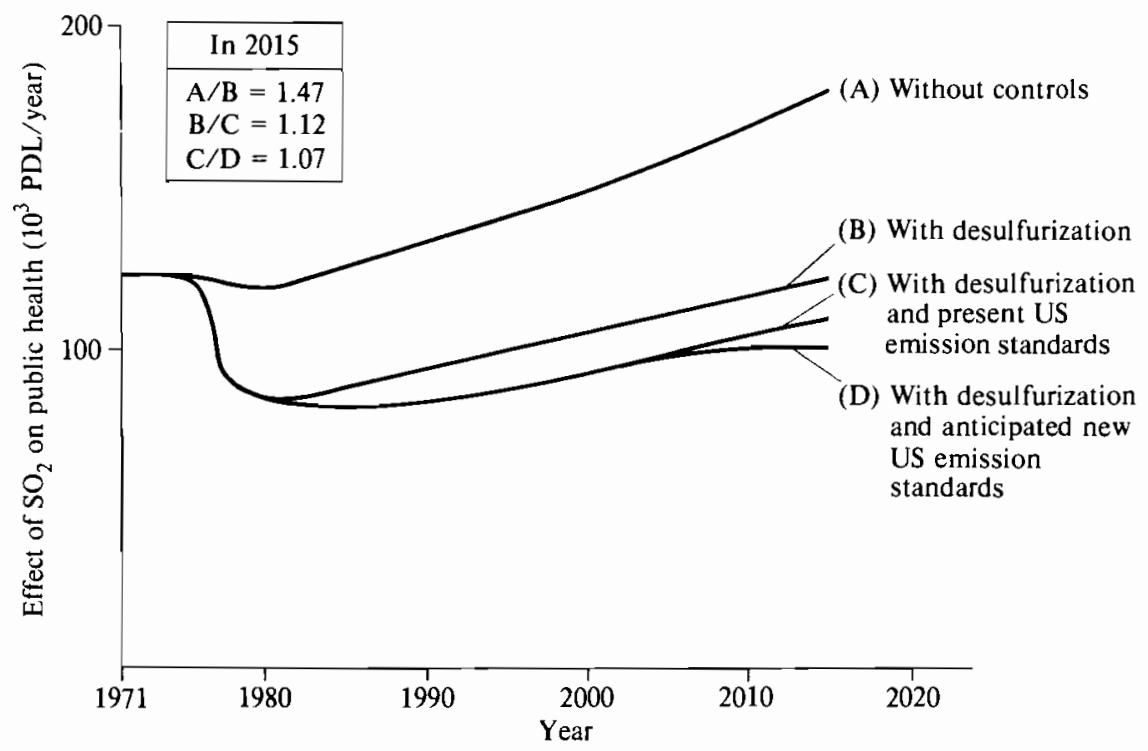

FIGURE 16.8 Effect of different $\mathrm{SO}_{2}$ regulations on public health in Austria (scenario S1).

It should be noted that Figure 16.8 assumes only local transport of air pollutants. This assumption is not strictly valid. There are sulfates being produced elsewhere (traveling considerable distances, and causing damage on Austrian territory) which are beyond the control of Austrian policy makers. In the Rhône-Alpes region and Wisconsin, however, since neither of these regions is downwind of any major source of sulfates, Figure 16.8 may be used as a reasonable guide to the effects of implementing the policies outlined above in these areas.

\section{Changing the fuel mix}

The discussion above suggests that it is important to control the emissions in the residential and commercial sectors if pollution damage to health is to be reduced. One common method of achieving this is based on the fact that the volume of pollutants produced per unit energy released is different for different fuels. It is therefore possible to reduce emissions without affecting consumption by changing the fuel mix in the residential and commercial sectors, e.g., by using natural gas rather than oil or coal for space heating. A switch from oil containing $1.2 \%$ sulfur to natural gas would reduce the emission of sulfur dioxide by $99.9 \%$, the emission of particulate matter by $36 \%$, the emission of carbon monoxide by $78 \%$, and that of carbon dioxide by $21 \%$, while producing the same amount of energy. 
This was one of the major strategies proposed to maintain the pollution levels in Milwaukee, Wisconsin, near the 1970 values, but was not adopted in the GDR scenarios because this region wishes to remain self-sufficient in energy.

As the availability of natural gas decreases, it will become necessary to make a decision about the best method of deploying this fuel among the sectors: its effect on air pollution in urban areas should certainly play a part in this decision. Similar considerations suggest that the increased use of synthetic gas may help to keep the damage to health through air pollution to a minimum.

\section{Changing the height at which pollutants are emitted}

There are two main methods of changing the height at which pollutants are emitted:

1. Increase the height of existing stacks

2. Use a central plant to supply heat, thereby replacing many chimneys relatively close to the ground with a much smaller number of tall stacks

Increasing the height of stacks has become quite common in the electricity supply sector as a means of reducing the local exposure to pollution by diluting the waste gases concerned. The average exposure to emissions from a stack $150 \mathrm{~m}$ high over an area of $1000 \mathrm{~km}^{2}$ is reduced by a factor of 3.3 on increasing the height of the stack ${ }^{5}$ to $300 \mathrm{~m}$. However, a study of the four regions shows that local exposure to the emissions from electrical power plants causes only a small proportion of the damage to health due to air pollution $(3 \%, 11 \%$, and $22 \%$ of the energy-related PDL in Austria, Wisconsin, and Bezirk-X, respectively)*.

Increasing the height of existing stacks is probably not very effective in reducing the impact of air pollution on human health. In addition to contributing to local pollution, the emissions from tall stacks may travel long distances with effects which are only now becoming apparent (see the results of the OECD's program on long-range transport of air pollutants ${ }^{9}$ or the study published by the Committee on Nuclear and Alternate Energy Systems in the USA ${ }^{10}$. One conclusion emerging from this work was that increasing the height of stacks is not an effective means of controlling air pollution, and in none of the regions studied was this option used.

The second method of reducing commercial and domestic (low-level) emissions is illustrated by the use of electricity rather than gas or coal for heating homes, or the introduction of large-scale district heating.

The use of electricity rather than fossil fuels in the home reduces low-level emissions because electricity causes no pollution at the point of end use. Pollution controls are also more easily applied to generating plants than to individual users.

* The figure for Bezirk-X is very high because it exports $57 \%$ of the electricity it produces, all of which is derived from coal. 
However, this solution is not ideal because the production of electricity is not a very efficient method of using primary energy, and for this reason it was only adopted in the Rhône-Alpes region, where there is great emphasis on electricity generated by nuclear or hydropower plants for other reasons.

District heating, on the other hand, was regarded as an excellent method both for reducing low-level pollution and for conserving energy. A study was carried out to examine the effect of a complete conversion to urban district heating in Bezirk-X on the levels of pollution experienced by the local population. Figure 16.9 shows the results of this investigation: the exposure to pollution produced by the residential sector would be reduced by a factor of ten on changing to district heating. In addition, since emission from this sector constitutes a large part of the total emission, human exposure to pollution from all sources would fall by a factor of 2.3--quite a significant reduction. District heating was therefore emphasized in the Bezirk-X scenarios.

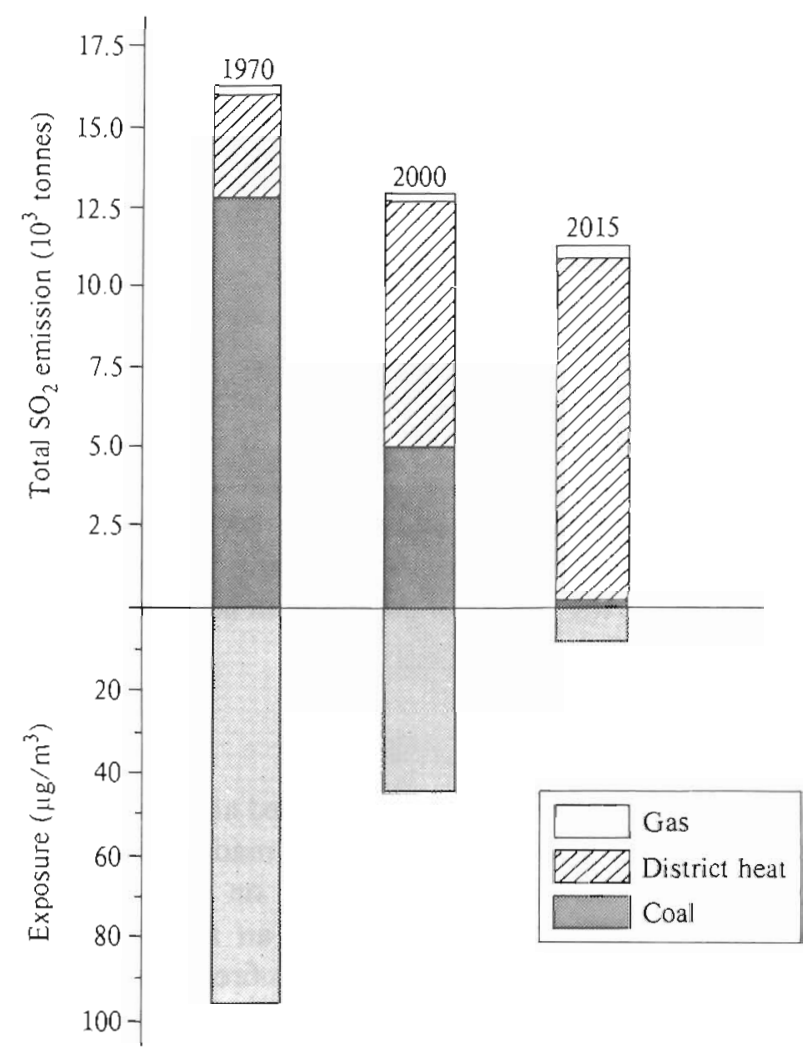

FIGURE 16.9 Effect of introducing district heating in the residential sector of the urban areas in Bezirk-X on $\mathrm{SO}_{2}$ emission and levels of exposure over time. 
Like increasing the height of chimneys, district heating is not the complete answer to pollution problems, but is both capable of reducing exposure levels in urban areas and more amenable to measures controlling the total emission of pollutants than other methods of heating.

\section{INDIRECT POLICY MEASURES}

\section{Urban development and form}

The use of land can dramatically affect the use of energy. More efficient land use generally leads to more efficient energy use and this may lead to a reduction in air pollution. For example, if dwellings are built very close together district heating becomes possible and air pollution levels fall, as discussed above. However, if there is no such change in methods of supplying energy the energy savings characteristic of dense urban areas are bought at the cost of increased exposure to air pollution. As an illustration, if Milwaukee, Wisconsin, with a density of 2250 people $/ \mathrm{km}^{2}$, were to compact to the same population density as Vienna (5000 people $/ \mathrm{km}^{2}$ ), the local exposure to air pollution would increase $80 \%$, assuming that the total volume emitted remained constant.

\section{Energy conservation}

Energy conservation not only saves energy but reduces the emission of pollutants in all sectors, thereby diminishing the hazard to health from energy-related activities. In the Austrian scenarios it was actually found that reduced energy use decreased the effect of pollution on human health more than imposing rigid limits on $\mathrm{SO}_{2}$ emission. The Bezirk-X conservation scenario with strict air pollution controls succeeded in keeping the impact of pollution on health constant over time.

\section{Fuel mix}

Changes in the fuel mix have already been discussed as a means of diminishing air pollution, but changes of this nature may also be made as a result of new energy policy. For example, a sensitivity study based on the Austrian scenario S4 examined the possibility of using coal to meet an anticipated shortfall in the petroleum supply. Converting petroleum- and gas-fired electricity plants to coalbased operation by 2015 would be expected to increase the emission of sulfur dioxide, particulate matter, nitrogen oxides, and carbon dioxide from these plants by $38 \%, 89 \%, 25 \%$, and $32 \%$, respectively. A return to coal is therefore not desirable from the point of view of air pollution. 


\section{FINAL OBSERVATIONS}

It is clear that a short summary like this cannot hope to cover all aspects of air pollution, but two points at least should be made:

1. Air pollution issues and energy issues are very closely related.

2. Air pollution is one of the major threats to human health and safety associated with energy systems.

However, while it is true that air pollution is responsible for a large proportion of the (involuntary) damage to health caused by energy systems, it is necessary to keep the effects of energy-related activities in perspective. The number of persondays lost through air pollution in each region in 1970 lies in the range $100,000-200,000$. However, 2860 pedestrians were severely injured in street accidents in Austria in 1974. Assuming that six months of lost time are associated with each incident, a total of 510,000 person-days were lost through this cause alone-more than double the number lost through air pollution.

Thus, while every effort should be made to minimize the damage to health caused by energy systems, these efforts should be consistent with those made to reduce the many other risks faced daily by every member of the population.

\section{ALTERNATIVE COAL STRATEGIES*}

This section examines the effects of various levels of coal use and considers different ways in which coal could be employed. The four regions have access to coals of greatly differing characteristics and quantities, they have different environmental constraints and regulatory procedures, and yet they all face a common problem: the degree to which they should rely on coal for future energy supply. Some of the broad issues are summarized below.

- What are the costs and effects of various levels of coal use and how much importance should be attached to these factors? The IIASA scenarios assume that coal will play a major role in energy supply in all regions, particularly Bezirk-X and $W$ isconsin ${ }^{1,2}$. Heavy reliance on coal in these regions may result in high costs and/or severe environmental damage.

- What are the important trade-offs between coal and other energy sources? Apart from conventional costs, other important aspects include the effects on the environment over various time scales. Coal may be used for generating electricity and, in the longer run, as a source of liquid and gaseous fuels; alternatively, nuclear power could be used instead of coal-based electricity.

\footnotetext{
* By W.A. Buehring, formerly at the International Institute for Applied Systems Analysis, Laxenburg, Austria, but now working for the Argonne National Laboratory, Argonne, Illinois.
} 
Assessing the relative advantages and disadvantages of these options can be a difficult task ${ }^{1 !}$.

- What is the geographical distribution of costs, impacts, and benefits of coal use? Bezirk-X and Wisconsin differ greatly in this respect, as the former produces its own coal while the latter does not. Thus, the effects of mining, cleaning, and transportation are "exported" to other regions by Wisconsin. Do decision makers in Wisconsin consider coal-mining fatalities in Illinois?

- Should future generations pay for the energy consumed in the regions today? In the case of coal, a nonrenewable resource is being consumed, and the effects of this consumption may be experienced over considerable periods of time. Some impacts occur before the actual use of the energy, e.g., during coal mining; other effects occur at about the time of combustion, e.g., water used for cooling; still others may not occur for long periods after the final use, e.g., certain effects of air pollution on health ${ }^{6,12}$ or of carbon dioxide $\left(\mathrm{CO}_{2}\right)$ on climate ${ }^{13}$. Are all these effects considered before important energy decisions are made?

- How should coal be used? How do the impacts per unit of end-use energy vary according to the method of use? For example, the models used to analyze the impacts of coal use in the IIASA scenarios indicate that the expected damage to health per unit of end-use energy supplied by coal depends quite heavily on whether it is burned in domestic furnaces or in a district heating plant. How should potential improvements in technology be taken into account?

- How can policy makers affect coal use? Tax incentives, environmental regulations, and other measures may be used to encourage or constrain coal use. For example, sulfur dioxide standards may affect the siting of energy facilities and the type of coal used ${ }^{14}$.

- What are the environmental effects of the various pollution control policies associated with different coal strategies, and how are the impacts and costs of coal use distributed among the groups of people affected? When constraints are imposed to improve certain aspects of energy production, other aspects may in fact deteriorate. For example, the use of sulfur dioxide removal systems in power plants increases solid waste and reduces plant efficiency, thereby causing other effects on the environment to increase per unit of end-use energy.

These questions were analyzed at various levels of detail in the IIASA regional studies. The analysis was not designed to resolve these problems, but rather to obtain information and suggest methodologies that may help planners to evolve the energy policy most suited to regional needs in the future.

The rest of this paper is devoted to (i) a brief discussion of the history and possible future of coal use in the four regions studied, (ii) a categorization of the 
effects of coal use, and (iii) methods for evaluating the trade-offs associated with alternative energy strategies.

\section{USE OF COAL IN THE FOUR REGIONS}

Coal is an important energy source in most of the scenarios considered for the four regions. The role of coal is strongly dependent on factors such as its price and availability, its physical characteristics, environmental impacts, and advantages and disadvantages when compared with other fuels. Only Bezirk-X has large coal reserves; the other three regions must import coal or coal derivatives.

The amount of primary energy derived from coal in each of the regions is indicated in Table 16.6 for all scenarios. The energy shown is the total for all types of coal, including lignite, subbituminous, and bituminous, or hard coal, and for all uses, including electricity generation, production of district heat and process steam, production of synthetic fuels, and direct uses. Bezirk-X used more coal than any other region in 1970 on both a per capita basis and an absolute energy scale; however, about half of this coal-derived energy was exported. Annual coal production in Bezirk-X is limited by the availability of resources to 1970 levels, and much less of the primary energy derived from coal in Bezirk-X is expected to leave the region in the later years of all scenarios. The use of coal in Austria remains approximately constant over the period considered in the IIASA scenarios; since total energy use is increasing, the fraction of the total energy requirement met by coal declines with time. Coal imports in the Rhône-Alpes region increase with time, but the percentage of total energy use based on coal does not increase in any scenario for this region, as indicated in Table 16.7. In the Wisconsin scenarios coal use increases at an average annual rate of 4-5\% between 1970 and 2025. This rapid growth implies that an increasing share of Wisconsin's total energy supply will be derived from coal in the future, as shown in Table 16.7.

Table 16.8 shows the uses to which coal is put in the four regions studied. The actual coal use in 1970 (1971 for Austria) is disaggregated by sector, and the corresponding results for the scenarios with the largest coal use (L) and smallest coal use (S) in 2025 (2015 for Austria) are also given. This table highlights the differences between the various regions and scenarios, showing the postulated importance of coal for industrial use in Austria, for district heat and process steam in Bezirk-X, for electricity generation in the Rhône-Alpes region, and for synthetic fuels in Wisconsin.

Table 16.8 also gives the percentage of the primary energy used for electricity generation derived from coal, for each scenario. These figures provide an indication of the degree to which coal use could be increased in a sector which is already a large consumer of coal in all regions. The scenarios for Austria, the 


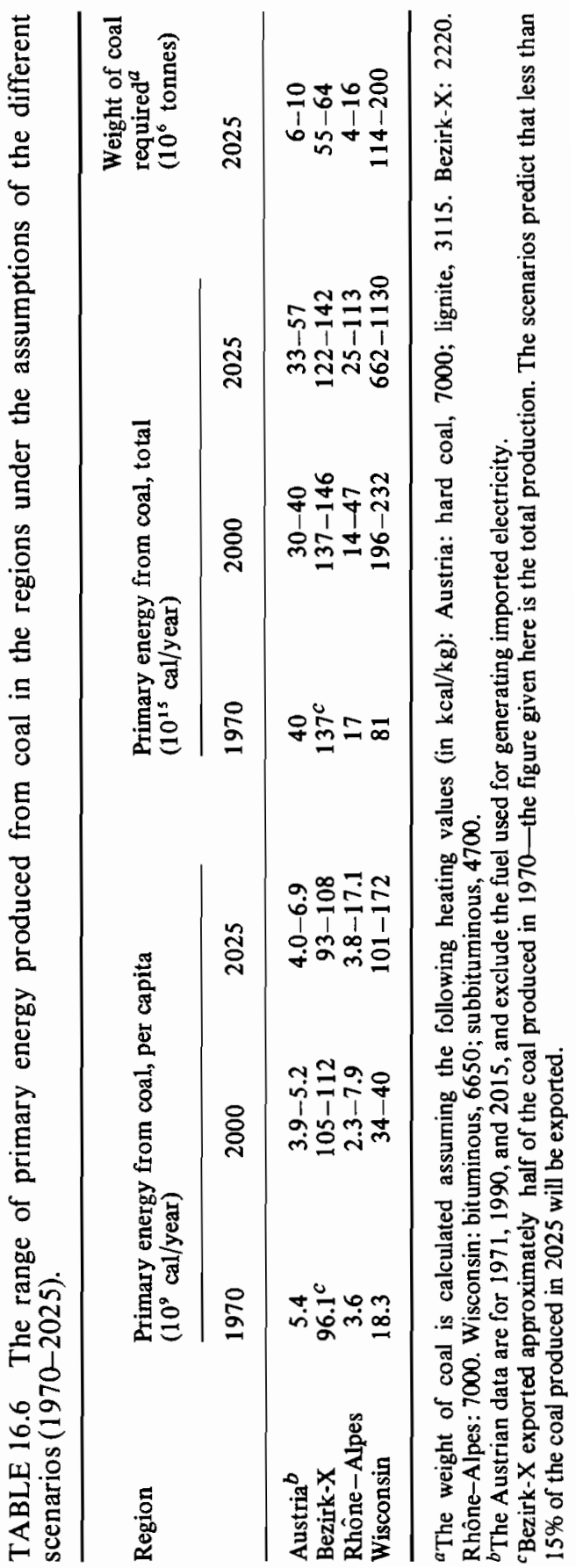


TABLE 16.7 Percentage of total primary energy use based on coal in the regions under the assumptions of the different scenarios (1970-2025).

\begin{tabular}{llrr}
\hline Region & \multicolumn{2}{c}{ Percentage of total primary energy use based on coal } \\
\cline { 2 - 4 } & 1970 & 2000 & 2025 \\
\hline Austria $^{2}$ & 22 & $12-15$ & $9-13$ \\
Bezirk-X & 89 & $88-90$ & $65-73$ \\
Rhône-Alpes & 13 & $3-12$ & $3-13$ \\
Wisconsin & 28 & $31-43$ & $46-74$ \\
\hline
\end{tabular}

${ }^{a}$ The Austrian data are for 1971,1990 , and 2015 , and exclude the fuel used for generating imported electricity.

Rhône-Alpes region, and, to a lesser degree, Wisconsin have the potential for significant increases in coal-based generation of electricity; of course, the extent to which coal is used for electricity generation depends on the relative cost and environmental effects of coal and its main competitors in this field. In contrast to the other three regions, Bezirk-X derives nearly all of its electricity from coal.

\section{EFFECTS OF COAL USE}

The effects of coal use can be classified in three ways:

1. According to the geographical area where the effect is experienced

2. According to the impact category, such as air, land, water, or human health and safety, in which the effect is experienced

3. According to the time when the effects are experienced relative to the end use of the energy

\section{Geographical location of effect}

The consumption of energy derived from coal in one region may affect people living in other regions. Examples of this include effects associated with fuel supply facilities situated outside the energy-consuming region, the emission of pollutants in areas remore from energy users (e.g., rural power plants), and the problem of air pollutants such as sulfates which have traveled considerable distances from the point of emission. There may even be global consequences, such as the possible climatological effects of large-scale carbon dioxide production. The effects of coal use in the various scenarios were quantified, and tabulated according to whether they occurred inside or outside the region of use.

Table 16.9 illustrates how policy changes can result in a different distribution of impacts. It compares the quantified effects of coal-based electricity generation on 


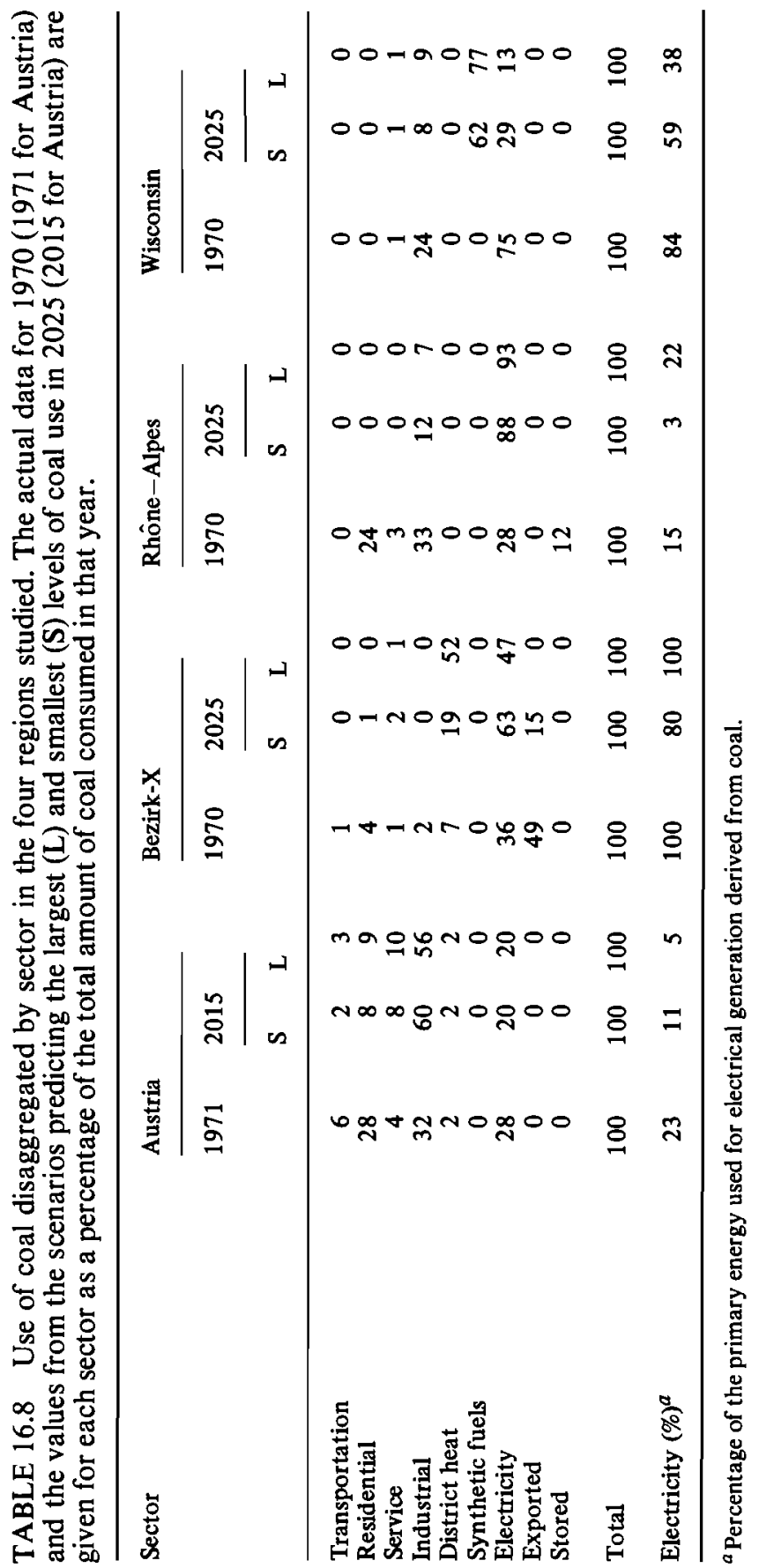


TABLE 16.9 Number of person-days lost through generation of electricity from coal in Wisconsin under a number of different assumptions ${ }^{a}$.

Class of PDL

Number of person-days lost through coal-based electricity generation (thousands)

\begin{tabular}{|c|c|c|c|c|}
\hline & \multicolumn{2}{|l|}{2025} & \multicolumn{2}{|c|}{ Cumulative total, $1970-2025$} \\
\hline & S1 & $\mathbf{S} 1^{\prime b}$ & S1 & $S 1^{\prime} b$ \\
\hline Occupational accidents & 47 & 46 & 1600 & 1600 \\
\hline Public accidents & 82 & 45 & 2600 & 1500 \\
\hline Occupational health & 0.3 & 0.4 & 100 & 100 \\
\hline Public health & 15 & 49 & 600 & 1600 \\
\hline Total (Wisconsin) ${ }^{c}$ & $144(28 \%)$ & $140(45 \%)$ & $4900(29 \%)$ & $4800(44 \%)$ \\
\hline
\end{tabular}

${ }^{a} 6000$ PDL are associated with each fatality or case of total disability. One PDL corresponds to an asthma attack or day of respiratory difficulty (caused by air pollution from the source under consideration) for elderly people suffering from heart and lung diseases. It is assumed that $62 \times 10^{9}$ $\mathrm{kWh}$ of electricity will be generated by coal-fired plants in 2025 , with a cumulative total of $2056 \times 10^{9} \mathrm{kWh}$ produced by this method between 1970 and 2025 .

${ }^{b}$ Scenario S1' differs from scenario $\mathrm{S} 1$ in that it assumes that sulfur dioxide controls are not imposed and that no western coal is available.

${ }^{c}$ The figure in parentheses represents the percentage of the person-days lost in connection with energy use in Wisconsin which actually occur within Wisconsin.

human health and safety from Wisconsin scenario S1 with the effects that would be produced if there were no control of $\mathrm{SO}_{2}$ emissions from power plants and no use of relatively low-sulfur coal from the western USA. It is assumed that approximately $25 \%$ of the coal used in $\mathrm{S} 1$ is from the western USA.

Eliminating control of $\mathrm{SO}_{2}$ and use of western coal increases the public health hazard in the year 2025 by an amount quantified at about 34,000 person-days lost (PDL), but the public accident PDL declines by approximately the same number. (This is approximately equivalent to six premature fatalities. To provide a basis for comparison, the total quantified PDL from all energy-related causes in 2025 is estimated to be $1,400,000$ for scenario S1.) The reduction in public accidents is the result of changing over to midwestern coal, which is transported over a much shorter distance than coal from the western USA. The increase in public health PDL is primarily caused by aggravated heart and lung disease in the elderly, caused by increased levels of air pollution. The overall change in quantified PDL is small, but the burden has shifted slightly from people who live outside Wisconsin (transportation accidents) to people who live in Wisconsin (air pollution effects on public health). The same general conclusions are also true for the cumulative totals (1970-2025) shown in Table 16.9. 


\section{Category of impact}

The second method of classification considers the domain, or category, (e.g., air, land, water, human health and safety, or national security). Some events may produce an effect in a number of domains. For example, coal-based generation of electricity results in the release of $\mathrm{SO}_{2}$, which in turn may affect air quality, agriculture, property values, and human health.

The relative levels of $\mathrm{SO}_{2}$ emitted in the four regions in 2025 under scenario $\mathrm{S} 1$ are illustrated in Figure 16.10 (Austria and the Rhône-Alpes region are very similar in this respect and are represented by the same graph). Coal is the main source of $\mathrm{SO}_{2}$. Four different indices are shown: total absolute emission, emission per unit area, emission per capita, and emission per unit of primary energy use. Wisconsin has the highest value for total emission, but Bezirk-X has the greatest value on the other three scales. The final impacts on the population or environment, e.g., health effects, depend on additional factors, such as the height at which gases are released and the levels of exposure experienced by the population.

\section{Time of occurrence of energy use and impacts}

Some energy-related effects occur long before the associated energy use, such as coal-mining accidents. Others, such as the damage to health caused by air pollution, may not appear for some time afterward. Still others, such as the possible global effects of large-scale release of carbon dioxide, may occur decades after the event. The IIASA scenarios associate these effects with the energy use that

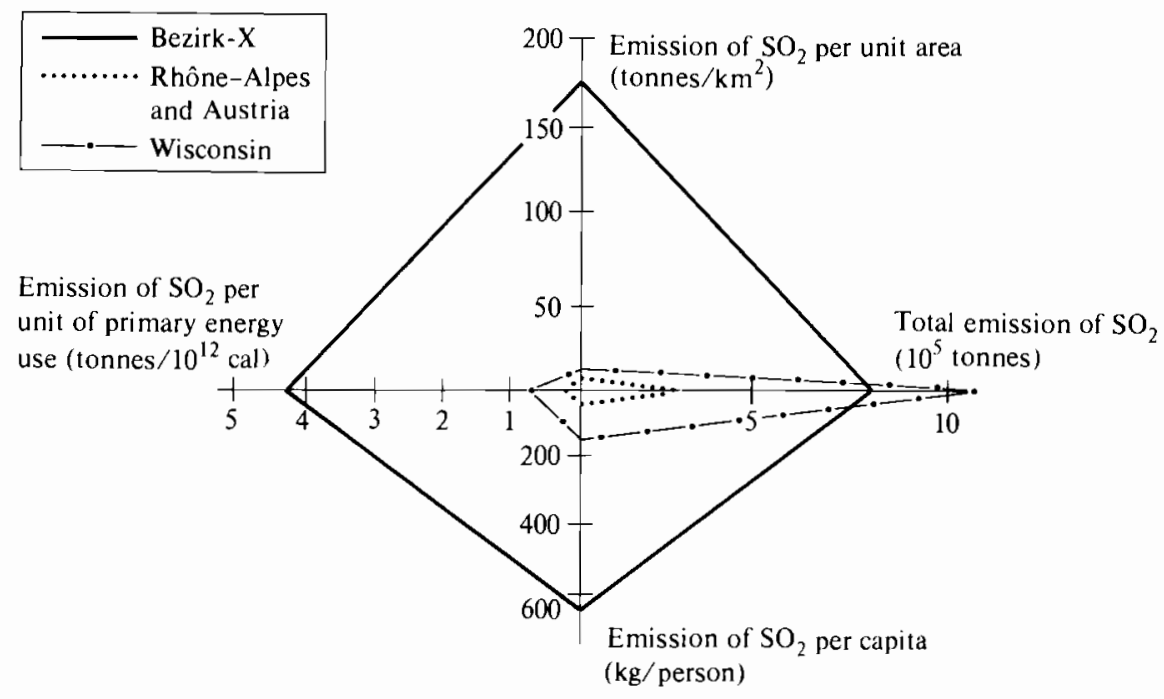

FIGURE 16.10 Levels of $\mathrm{SO}_{2}$ emission in 2025, scenario $\mathrm{S} 1$ (all regions). 
caused them and with the period during which that energy use occurred. Thus, the effects of coal use in 1970 could include mining accidents in 1969, miners' black lung disease in 1980, and the use of water for cooling in 1970.

\section{METHODS FOR EVALUATING ALTERNATIVE ENERGY STRATEGIES}

The acceptability of the various side-effects of using coal cannot be assessed without evaluating the consequences of alternative fuel strategies. Value judgments of the impacts and costs of the different strategies are necessary to determine the "best" course of action. For example, it must be decided whether it is a "good" policy to generate electricity from nuclear plants; whether coal is best used as a direct source of primary energy, as a source of synthetic fuels, as a means of providing district heat and process steam, or for generating electricity.

The relative merits of coal-based and nuclear electricity generation have been widely discussed in recent years (see, for example, refs. 15-17). The issues are complex and often controversial. Both technologies pose serious long-term problems, such as the management of radioactive waste and production of plutonium in nuclear plants and the possible climatic effects of large-scale release of carbon dioxide from coal-fired plants. The principal conclusion of a study by the US National Academy of Sciences ${ }^{13}$ was that "the primary limiting factor on energy production from fossil fuels over the next few centuries may turn out to be the climatic effects of the release of carbon dioxide".

For such evaluations it is not sufficient to quantify selected environmental impacts and costs. In an attempt to identify the value judgments involved, IIASA investigated whether formal preference analysis (multiattribute decision analysis) could help in selecting suitable policies ${ }^{18}$. Five individuals representing decision makers and policy analysts from three of the regions were asked to assess the relative importance of a number of measures quantifying the effects of energy systems (total fatalities, $\mathrm{SO}_{2}$ pollution, radioactive waste, and electricity generated). The results for each individual were then used to derive an order of preference for a number of strategies for electricity generation between 1970 and 2000; Table 16.10 indicates that the five individuals did not agree completely on the relative merits of the different strategies.

This brief study was not sufficiently detailed to serve as an aid in actual policy making; however, it did provide some insight into the potential usefulness of the technique and the features seen as "important". For example, all of the individuals considered the number of quantified fatalities to be one of the most important impacts of energy systems.

This experiment indicated that preference analysis can help to identify important issues and sensitize individuals to them, to generate and evaluate alternative strategies, and to isolate and resolve conflicts of judgment and preference between decision makers; it can be used as a means of communication between decision makers, and can identify subjects on which more information is required. 
TABLE 16.10 The relative merit of four strategies for electricity generation assessed for five individual "decision makers" using utility functions ${ }^{a}$.

\begin{tabular}{lllllll}
\hline Strategy & \multicolumn{3}{l}{ Expected utility } & & & \\
\cline { 2 - 5 } & A & B & C & D & E \\
\hline $\begin{array}{l}\text { Based mostly on coal; good pollution } \\
\quad \text { control }\end{array}$ & 0.53 & 0.56 & 0.76 & 0.62 & 0.65 \\
$\begin{array}{c}\text { Based mostly on nuclear power } \\
\begin{array}{l}\text { Based mostly on low-sulfur coal from } \\
\quad \text { distant mines }\end{array}\end{array}$ & 0.66 & 0.63 & 0.83 & 0.66 & 0.72 \\
$\begin{array}{c}\text { Based mostly on coal with less use of } \\
\text { electricity }\end{array}$ & 0.14 & 0.14 & 0.64 & 0.24 & 0.31 \\
\hline
\end{tabular}

${ }^{a}$ Taken from ref. 18.

${ }^{b}$ Expected utility is given on a scale of 0.0 to 1.0 ; the higher the expected utility, the greater the relative merit.

The alternative is to continue using informal qualitative methods to assess the relative merits of different energy strategies.

\section{CONCLUSION}

The IIASA scenarios lead to some general conclusions about the use of coal in the four regions studied:

- Because of its general availability for use both in its natural form and as a source of synthetic fuels, coal must be considered a potentially important source of energy in all of the regions studied.

- Regional energy policy should consider the fact that coal not only affects the environment near the point of combustion but also produces regional and global effects.

- The use of coal has particularly severe consequences for certain groups of people, such as underground miners and elderly people who already suffer from heart and respiratory ailments.

- The way in which coal is used can have a significant effect on the related impacts, e.g., burning coal in the residential and commercial sectors of populated areas may cause more damage to health than burning the same quantity of coal in a district heating plant.

- The evaluation of different energy strategies is a complex task that requires not only a consideration of quantified costs and impacts but also the use of value judgments.

- Regional policy concerning the use of coal should be developed rapidly as coal now appears likely to meet an increasing proportion of energy demand in several of the regions in the future. 


\section{REFERENCES}

1 W.K. Foell (Ed.). Management of Energy/Environment Systems: Methods and Case Studies. Wiley, Chichester, UK, 1979.

2 W.K. Foell, R.L. Dennis, M.E. Hanson, L.A. Hervey, A. Hölzl, J.P. Peerenboom, and E. Poenitz. Assessment of Alternalive Energy/Environment Futures for Austria: 1977-2015. RR-79-9, International Institute for Applied Systems Analysis, Laxenburg, Austria, 1979.

3 W.K. Foell, J.R. Huennekens, M.A. Lindsay, R.E. Stevenson, and A. TenWolde. Industrial Energy Use in Wisconsin: Consumption Patterns and Conservation Measures. Report 80-102, Energy Research Center, University of Wisconsin-Madison, Madison, Wisconsin, 1980.

4 M.E. Hanson. Personal Transportation Energy Options. Report 112, Institute for Environmental Studies, University of Wisconsin-Madison, Madison, Wisconsin, 1980.

5 R.L. Dennis. The SCA Method: A Simplified Air Pollution Dispersion Methodology for Regional Analysis. RR-78-9, International Institute for Applied Systems Analysis, Laxenburg, Austria, 1978.

6 W.K. Foell, J.S. Buehring, W.A. Buehring, R.L. Dennis, M.E. Hanson, L.A. Hervey, A. Hölzl, K. Ito, R.L. Keeney, J.P. Peerenboom, E. Pönitz, J. Richter, and A. Toifelhardt. The Wisconsin-IIASA Set of Energy/Environment (WISE) Models for Regional Planning and Management: An Overview. RR-81-17, International Institute for Applied Systems Analysis, Laxenburg, Austria, 1981.

7 W.A. Buehring, R.L. Dennis, and A. Hölzl. Evaluation of Health Effects from Sulfur Dioxide Emissions for a Reference Coal-Fired Power Plant. RM-76-23, International Institute for Applied Systems Analysis, Laxenberg, Austria, 1976.

8 J.F. Finklea, G.G. Akland, W.C. Nelson, R.I. Larsen, D.B. Turner, and W.F. Wilson. Health Effects of Increasing Sulfur Dioxide Emissions. US EPA in-house report, March 1975.

9 Organization for Economic Cooperation and Development (OECD). The OECD Program on Long-Range Transport of Air Pollutants. In-house document, OECD, Paris, 1979.

10 National Research Council, Committee on Nuclear and Alternate Energy Systems. Energy in Transition, 1985-2010. NTIS report CONS-3784-T1, US National Academy of Sciences and US Department of Energy, Washington, DC, 1979.

11 W.A. Buehring, W.K. Foell, and R.L. Keeney. Examining energy/environment policy using decision analysis. Energy Systems and Policy 2(1978) 341--367.

12 R.L. Dennis. Regional Air Pollution Impact: A Dispersion Methodology Developed and Applied to Energy Systems. RM-76-22, International Institute for Applied Systems Analysis, Laxenburg, Austria, 1976.

13 National Research Council, Panel on Energy and Climate (Roger R. Revelle, Chairman). Energy and Climate. US National A cademy of Sciences, Washington, DC, 1977.

14 Regional Studies Program, Argonne National Laboratory. National Coal Utilization Assessment-An Integrated Assessment of Increased Coal Use in the Midwest: Impacts and Constraints. ANL/AA-11, 1977.

15 Nuclear Energy Policy Study Group. Nuclear Power: Issues and Choices. Report to the Ford Foundation, Ballinger, Cambridge, MA, 1977.

16 S.M. Banager, B.R. Judd, and D.W. North. The Economic and Social Costs of Coal and Nuclear Electric Generation. Report prepared for the US National Science Foundation, Washington, DC, 1976.

17 D.L. Phung. Cost Comparison Between Base-Load Coal-Fired and Nuclear Plants in the Midterm Future (1985-2015). ORAU/IEA(M) 76-3, Institute for Energy Analysis, Oak Ridge, TN, 1976.

18 W.A. Buehring, W.K. Foell, and R.L. Keeney. Energy/Environment Management: Application of Decision Analysis. RR-76-14, International Institute for Applied Systems Analysis, Laxenburg, Austria, 1976. 


\title{
17 Retrospective Views from the Four Regions
}

\author{
Helmut Hirsch, Wolfgang Kluge, Dietmar Ufer, \\ Bertrand Chateau, and Charles Cicchetti
}

\section{THE AUSTRIAN SCENARIOS IN RETROSPECT*}

Since the creation of the Austrian scenarios, economic development in Austria has remained on a steady course; the economy has been stable, with low unemployment, moderate growth rates, and relatively low rates of inflation. Past trends have also been maintained in the energy sector. Imports are increasing and will soon meet $70 \%$ of total energy requirements. The need for conservation is increasingly recognized and has stimulated a great deal of research activity. Studies have concentrated on the efficiency of heating systems, the combined generation of steam and electricity, and the development of mass transport systems.

Although there appears to be considerable potential for saving energy through conservation, the implementation of such measures has proved difficult. In the case of combined generation of heat and electricity, institutional barriers account for some of the difficulty; the Austrian electric utilities are required to meet consumer demand for electricity, but their legal responsibility does not extend to district heating. In general it is difficult to implement national energy policies in Austria because energy is for the most part under the jurisdiction of the nine provincial governments.

Several strategies for meeting Austria's future energy requirements are currently under consideration; one possibility is that greater emphasis will be put upon coal**. The importing of large amounts of coal from Poland by means of a slurry pipeline has been discussed; however, for economic reasons the pipeline would need a capacity of 5 million tonnes annually and this currently appears to be in excess of Austria's energy requirements.

\footnotetext{
* By Helmut Hirsch (Federal Ministry for Trade, Commerce, and Industry, Vienna).

** Editors' note: The consumption of coal actually increased in Austria in 1979, after a long period of decline. The iron and steel industry and the small consumer sector were responsible for this increase, in the opinion of the Austrian Institute for Economic Research.
} 
The significance of Poland as a trading partner in the energy sector is also demonstrated by a recent contract under the terms of which Austria will import large amounts of electricity from Poland $(400-600 \mathrm{GWh}$ per year up to 1983 and $1600 \mathrm{GWh}$ per year between 1984 and 1999). This exchange is mutually advantageous, for Poland has a large trade deficit with Austria which it is interested in reducing. This trading balance goes some way toward ensuring that supplies will not be cut off in the short-to-medium term. Austria's trade with the Soviet Union is less satisfactory: Austria imports great quantities of natural gas from the USSR and currently has a related trade deficit. In an attempt to secure supplies of natural gas from several countries, the Austrian Mineral Oil Administration is conducting oil and gas exploration activities in Tunisia, Libya, Ireland, Canada, Egypt, and Norway.

Nuclear energy has been the center of much controversy in Austria during recent years. The Austrian electric utilities originally planned to construct three nuclear power stations and put them into operation by 1990 . A $700 \mathrm{MWe}$ boiling water reactor was built in $Z$ wentendorf, but public resistance has prevented it coming into service. A referendum held on 5 November 1978 resulted in a narrow majority against putting the $\mathrm{Z}$ wentendorf reactor into operation. Plans for constructing two additional $1300 \mathrm{MWe}$ nuclear plants have also been suspended. In the light of public opinion it is clear that alternatives to a large nuclear program must be considered.

Unconventional energy sources have been receiving increasing attention in Austria in recent years. Between 1974 and 1978 about 22 million schillings were spent in developing solar energy, and smaller amounts have been devoted to research on geothermal and wind energy. Although this is just a small fraction of the total money spent on nuclear research and development, it is considerably more than was allocated to the study of unconventional energy resources before 1974. Between 1976 and 1979 the area of solar collectors installed increased from approximately $2000 \mathrm{~m}^{2}$ to over $40,000 \mathrm{~m}^{2}$.

Austrian petroleum policy has been to expand its sources of this fuel, i.e., to import petroleum from as many different countries as possible. Austria also invests money in oil exploration throughout the world, with the expectation that it will have access to a share in any petroleum which is discovered. There appears to be a feeling among Austrian politicians that if petroleum supply is based on a sufficiently large number of sources there will be no problems during the period of time which they are considering. Perhaps some Austrian politicians also feel that, as a neutral country which enjoys good relations with many other nations, Austria may have some advantages when competing for oil on the world market.

Models and scenario-building methods such as those used in the IIASA study can be quite helpful in current energy planning in Austria. However, one must always be wary of extrapolating current trends or assumptions about development far into the future (to 2015 or 2025). It is illuminating to define some goals for the future within scenarios and then to analyze how a given set of policy measures 
may hinder or help the attainment of these goals; however, one must always bear in mind the need to make the various assumptions internally consistent and as explicit as possible. The large number of decision makers concerned with energy policy in Austria suggests that simulation games involving several participants would also be useful decision-making tools.

\section{THE GDR SCENARIOS IN RETROSPECT*}

During the past few years, intensive work has been carried out in the GDR on long-term energy planning. The precision of the planning has been increased and the planning horizon has been extended.

One important innovation has been a move from national level to district (Bezirk) level planning, and appropriate models have been developed for this purpose. Regional authorities are now responsible for the statistical registration of energy demand and can also exercise some influence upon energy supply strategies in their regions.

The institution of regional planning has demonstrated the need to coordinate regional plans with central plans. Regional plans are only acceptable if they conform to the provisions of the national plan, which is designed to reduce regional inequalities. For instance, the long-term per capita residential electricity demand calculated for all 15 districts of the GDR showed that the 1990 demand in one district was four times higher than in another district, although the districts had comparable economic and population structures. No explanation could be found for this large discrepancy. The problem of regional inequalities is being resolved through planning restrictions imposed on the regional authorities by the central planning agencies. It is hoped that in the future a more satisfactory correspondence between regional and central planning will be achieved.

Our collaboration with IIASA, especially in preparing for and attending the 1975 Three-Region Workshop, has yielded information that is of great value in energy planning. For instance, we fully agree with the conclusions presented at this workshop on the benefits of district heating, and we are going to continue to develop this energy technology in the GDR. Our reasons for doing so are fourfold. We want (1) to utilize our lignite in the most efficient way; (2) to protect the environment; (3) to offer the population a maximum of convenience; and (4) to help the economy. District heating is now being developed as rapidly as is economically viable: at the present time about $75 \%$ of all new flats are connected to district heating. Existing buildings are also being partially adapted to district heating during modernization. For greater economy, standardized district heat-

\footnotetext{
* By Wolfgang Kluge and Dietmar Ufer (Institute of Energetics, Leipzig). This section has been reprinted with the kind permission of John Wiley and Sons from pp. 69-72 of Management of Energy/Environment Systems: Methods and Case Studies, edited by W.K. Foell.
} 
ing/power stations with steam generators of 320 tonnes/h and $60 \mathrm{MW}$ turbines (and larger) have been developed and will become operational within the next few years.

Our interaction with IIASA also encouraged us to examine the potential for developing solar power in the GDR. We have concluded that the geographical situation of the GDR is such that solar power cannot be seriously considered as a major supply option in the near future; however, the production of lowtemperature heat for hot water and space heating seems promising, and the GDR has begun large-scale production of solar collectors. Despite our plans for the development of solar power, however, it appears that the contribution made to total primary energy requirements by this energy source by the year 2000 will be very small. Economic reasons underlie this rather pessimistic estimate. At present, the costs of supplying heat from solar energy are twice as high as the costs of supplying heat from oil and six times higher than the costs of supplying heat from lignite briquettes. The cost of solar collectors must be lowered and their efficiency increased if they are to become competitive with more conventional energy sources. In addition, efficient heat storage systems must be developed for times when solar energy is not available.

The application of the IIASA models to Wisconsin, the Rhône-Alpes region, and Bezirk-X is very promising for long time horizons. However, for shorter horizons, such as the year 2000 , it is necessary to investigate the effect of the energy scenarios on the economy, as well as on the environment. Such an analysis would lead to decisions that serve society as a whole. Even the scenario that is best in terms of environmental control is worthless if the society is not able to pay for it.

A last note on the question of industrial energy intensiveness in the GDR. At the 1975 workshop there were vehement discussions about the great decreases in industrial energy intensiveness which were assumed to take place in the scenarios before 2025. In the GDR, an annual rate of decrease in energy intensiveness of $5 \%$ is used as a basis for planning for the next one to two decades: this corresponds to past trends. However, it is not possible to extrapolate beyond the year 1990 because, over longer periods of time, significant changes in economic structure may occur which could affect energy demand. Complex economic analyses would be necessary to make realistic estimates of industrial energy intensiveness for years after 1990.

Now let us turn to the environmental sphere. At the time that our collaborative venture with IIASA began, we were aware that environmental problems would have to be integrated into the energy models, but this had not yet been done. Therefore, this aspect of the IIASA research was of special interest to us. Two important environmental factors, the land used for open-pit lignite mining and its reclamation, and $\mathrm{SO}_{2}$ emissions and ground level concentrations (as criteria for air quality), have now been built into our model, and soon we expect to include water, as a limited resource, as a third environmental factor. The adverse effects 
of land use for mining have been almost completely eliminated in the GDR through a vigorous land reclamation program.

The work carried out by the IIASA team on pollution levels in the GDR has led us to compare the ground level $\mathrm{SO}_{2}$ exposures calculated by our own models with the exposures calculated by the IIASA models. The comparison revealed a good correspondence for low- and medium-level sources, but for point sources with tall stacks $(120 \mathrm{~m}$ or taller), the figures calculated by our models were larger than those calculated by the IIASA models. The explanation may lie in differences in the stack heights, differences in the meteorological conditions, or differences in the allocation of emissions from large point sources (lying 10-20 km from the city center) to the urban area.

As a next step, we studied large emitting sources in more detail, and disaggregated $\mathrm{SO}_{2}$ emissions in a district capital into those caused by industry, district heating, and low-level heating sources-classes similar to those used in the IIASA work. The emissions and resulting ambient concentrations associated with these sources were projected to 2025; then, in an extension of the IIASA sensitivity analysis of the environmental implications of district heating, the effect of a flue-gas desulfurization policy on pollution levels from industry and district heating emission sources was studied. The results indicated that, under our assumptions of primary energy supply, district heating and flue-gas desulfurization must be used in conjunction if air quality is to improve in the future. In presenting such findings to decision makers, it is very helpful to have evidence from other research teams, like IIASA's, as well as our own.

Finally, we have analyzed the economic implications of several $\mathrm{SO}_{2}$ emission control strategies. The costs of improving the ambient air quality in urban areas by increasing the stack heights of urban sources and neighboring large point sources were compared with the costs of stack-gas desulfurization and conversion to district heating. It was found that increasing the stack heights of district heating plants outside the urban area from 180 to $300 \mathrm{~m}$ would be effective in improving air quality, but this would not be feasible because some of the stacks would interfere with air traffic. Although stack-gas desulfurization is more costly than increasing stack heights, it is the only solution in cases like this. For existing plants within an urban area, stack-gas desulfurization is preferred to increases in stack heights for environmental reasons, all costs being equal. A change to district heating from a combined cycle plant situated $20 \mathrm{~km}$ from the city center is clearly a cost-effective way of reducing exposure from industrial emitters situated in the urban area. For new power plants over $30 \mathrm{~km}$ from a city center, it is more economical to ensure that stacks are sufficiently tall $(300 \mathrm{~m})$ than to use stack-gas desulfurization.

As these remarks suggest, our collaboration with the IIASA regional energy/environment management study has proved to be of notable relevance to our own planning. The IIASA work has underscored our interest in the expansion of district heating networks and the integration of environmental factors into 
energy planning, and encouraged the development of the solar option. Our planning is now reaching new levels of precision through a regional focus on energy demand and supply, through specification of sources of pollution, and through the testing of pollution control strategies.

\section{THE RHONE-ALPES SCENARIOS IN RETROSPECT*}

Since the scenarios were written in 1975, several significant changes have occurred in the economic and energy sectors of France. First, the Rhône-Alpes region, and France as a whole, has been experiencing rising unemployment and low economic growth. Growth in GNP has averaged 3\% annually, instead of the $5.5 \%$ annual growth rate assumed in the scenarios. The industries most affected include the steel industry and the textile industry. In the energy sector, the ambitious national nuclear development program, which called for six new $1000 \mathrm{MW}$ plants per year, has been delayed by 18 months, mostly for technical reasons. This should not have major consequences since a slowing in the growth of electricity demand accompanied the slowing of economic growth. At the same time, however, research priorities have shifted from the development of nuclear technologies to energy conservation measures. Important studies have been conducted on the recovery of waste heat from conventional and nuclear power plants for use in district heating in the residential sector and for provision of process heat in the industrial sector. New standards for equipment efficiency and building insulation in the residential, commercial, and industrial sectors are also being implemented.

Several institutional changes have also occurred in the energy sector since 1975. Two new bodies, the Agency for Energy Conservation and the Commission for Solar Energy, have been set up. Concurrent with the creation of these agencies, there has been increased interest in the local determination of energy policies. Energy matters in France are under the jurisdiction of the central government, and regional authorities do not possess real decision-making power in this sphere. However, in the past three to four years local authorities have acquired more "bargaining power". The Agency for Energy Conservation, for instance, has a budget which is allocated at the regional level for the promotion of waste heat recovery, for the study of power plants for the combined production of electricity and heat, and for similar activities. The regional representative of the energy conservation agency has authority to make the allocations, and his dynamism determines to a great degree the freedom of a region in pursuing its own energy strategies. Perhaps such developments indicate the beginning of a new type of decision-making at the regional level in France.

\footnotetext{
* By Bertrand Chateau (Institute for the Economic and Judicial Study of Energy, Grenoble). This section has been reprinted with the kind permission of John Wiley and Sons from pp. 117-118 of Management of Energy/Environment Systems: Methods and Case Studies, edited by W.K. Foell.
} 
Turning to the usefulness of the scenarios, it is necessary first to distinguish the areas in which they are applicable to the real decision-making process. The scenario approach may be used to reveal when disruptions are likely to occur, and to explore policies which could be implemented to avoid such disruptions. The long time horizon of the scenarios-the year 2025-is also appropriate for the formulation of research and development strategies. The time scale makes it possible to build a consistent energy/economic future and to identify the actions that would have to be taken to reach such a future.

On the other hand, the scenario approach cannot be used to make predictions. It also has limited usefulness for short- or medium-term decision-making. Finally, it is very important to avoid the pitfalls of extrapolating the trends of the past 10-15 years to the period 2000-2025. For example, it is clear that if new solar technologies or other innovations were introduced during the next few years it could greatly affect the energy situation in 2025 . If it were possible to produce inexpensive solar cells in the next 20 years, the energy picture for the next 50 years would change completely.

If a scenario stressing strong development of nuclear power were to be written today, it would be important to include construction of combined power plants. It seems likely that in France such plants will be built more and more frequently, and, in addition, existing plants may be converted for the coproduction of electricity and steam or heat. The results of studies carried out in the Rhône-Alpes region indicate that the steam or heat that could be produced by nuclear plants is almost competitive with the steam or heat produced from conventional fuels (oil or coal). Last year, a consulting commission convened by the Ministry of Industry held numerous hearings on the topic of heat recovery and combined heat and power production, and, although a real policy decision has not yet been made, their conclusions were largely in favor of the development of such combined plants.

\section{THE WISCONSIN SCENARIOS IN RETROSPECT*}

Comparisons between the GDR, the Rhône-Alpes region, Austria, and Wisconsin suggest that $W$ isconsin has perhaps the furthest to go in improving its efficiency of energy use, strengthening its conservation policies, and reducing its rates of energy growth. Since the Wisconsin scenarios were written in 1975, some progress has been made in these areas; many ideas for energy-related reforms in Wisconsin have grown out of interactions with our colleagues in the GDR and the Rhône-Alpes during the three-region study.

Energy use in Wisconsin has been marked by high growth during the 1960s, leveling off in the 1970s. The growth experienced during the 1960s can be traced

* By Charles Cicchetti (Wisconsin Public Service Commission). This section has been reprinted with the kind permission of John Wiley and Sons from pp. 164-166 of Management of Energy/Environment Systems: Methods and Case Studies, edited by W.K. Foell. 
to several factors. First, the cost of end-use energy fell by $50 \%$ between 1960 and 1970. Second, the implementation of environmental protection measures began during the 1960s; improved pollution control required increases in energy use. Finally, in the early 1960s Wisconsin industries were highly energy intensive. All of these factors contributed to the dramatic growth in energy use in the period 1962-1970.

This exponential growth did not continue into the 1970s, however. The tradeoff between increased energy use and environmental protection did not result in continued high rates of growth in energy use. The mix of industries also shifted toward those that are less energy intensive. In fact, since the oil embargo of 1973-1974, there has been virtually no increase in energy consumption in Wisconsin. In some years there has been a modest $2-3 \%$ increase in electricity consumption, but this has been offset by decreases in the use of natural gas. This is a great change from the $7-10 \%$ annual increases in electricity consumption experienced in the early 1970s. In the light of these developments, the projections of continued exponential growth made in the Wisconsin base case scenario seem to be outdated. Wisconsin has actually set itself the goal of reducing its energy use by $10 \%$ by 1985 .

One way in which it is hoped that this goal will be achieved is through government regulations designed for energy conservation. In suggesting areas in which reforms were needed, Wisconsin's collaboration with the GDR and the Rhône-Alpes region produced several tangible benefits. For instance, we learned from the French that our technique of pricing electricity was counterproductive. Not only did the French bring to our attention the diseconomy of charging customers less when they buy electricity in bulk, but they also suggested a better pricing mechanism. Following their example, Wisconsin is now adopting a system of marginal cost pricing for electricity-i.e., it is instituting a time-of-day variation in tariffs. At the present time, $40 \%$ of Wisconsin's electricity is sold during high demand hours on a time-of-day pricing system. Also, in a pioneering US effort, it is planned to install residential "time-of-day" meters or load management systems in the city of Milwaukee within one or two years. The natural gas pricing system is also being changed according to the principle of marginal cost pricing.

Our interactions with representatives from the GDR made us aware of the potential of district heating, and we have decided that district heating, as a concept, should be encouraged. We require electric utilities to continue to sell steam to industrial users; new plants built to replace decommissioned plants are also required by state regulations to sell steam to industries. Whenever any new coal-burning plant is built, all potential industrial users in the surrounding service area must be asked if they would like to purchase the plant's waste heat. Because of the controversy currently surrounding the nuclear question, no decision has yet been made about the use of waste heat from nuclear power plants.

The use of waste heat to increase the temperature of drinking water by about $5^{\circ} \mathrm{C}$ is also under consideration in Wisconsin. The water is very cold, so there 
would be no health problem from bacteria connected with this scheme. Early studies have indicated that using waste heat in the drinking water system would reduce energy costs and bring tangible reductions in bills for water heating. Heat pumps have not been very practicable in Wisconsin up until now because of the coldness of the water. However, if the temperature of the drinking water were increased some engineers believe that efficient heat-pump systems would be feasible. The GDR's use of waste heat gave us a real impetus to utilize this energy source more fully in Wisconsin.

It has been asked which features of the research results were surprising. No one in Wisconsin was surprised that so much of the state's energy consumption was related to transportation, in comparison with the GDR and the Rhône-Alpes region. However, it was surprising to see how much more energy Wisconsin was using for domestic space heating, even after correcting for differences in degreedays, and excluding energy used in air conditioning. Part of the higher use is due to the greater size of Wisconsin housing units: there is more floor space per person in Wisconsin. But as we learned from the other regions, a much more important factor is the loss of heat through poor insulation. This realization convinced us that we ought to change the state's building codes. Wisconsin is now one of the few states in the United States with a complete building code that can actually be enforced. The Wisconsin Public Service Commission has also developed a set of pricing rules that will penalize people who do not improve the insulation in existing housing. Again, the impetus for these changes came from our new awareness of practices in the other regions.

The interregional comparisons also provided us with new insights into energy savings in the transportation sector. We were convinced of the savings that could be made if large cars were replaced by small cars, even if the distances traveled remained constant. On the basis of our recommendations, the governor of Wisconsin proposed a set of taxes and subsidies that would have made the purchase of new cars vary by as much as $\$ 1000$, depending on size. (At the time, a typical car in Wisconsin cost about $\$ 4000$.) Because Wisconsin is a major automobile manufacturer, these proposals were politically very risky - especially since most of the discounts would apply to European and Japanese cars and the taxes would be levied on American cars. As might be expected, the governor was not able to win legislative approval. Still, this serious attempt at policy change in the transportation sector resulted from ideas gained through interaction with representatives from the other regions. As a footnote, it is interesting that even without the benefit of federal regulations and state taxes, people in Wisconsin are beginning to buy smaller cars and reducing the distance they drive.

There have been several other events of significance in the energy field in Wisconsin since 1975. State legislation has been passed to give tax credits to people who install solar energy systems. The Public Service Commission has also passed a special set of tariffs for the electricity back-up systems needed for solar units. In industry, there has been a significant amount of energy conservation and 
conversion from natural gas, brought about largely by the oil embargo of 1973 and the gas shortage of 1976 . In the residential sector, voluntary conservation measures, such as lowering thermostats, are also being taken. The result of these activities has been the creation of a conservation bubble-i.e., Wisconsin now has excess energy supplies. However, this should not be understood to mean that we can return to "business as usual". Wisconsin is firmly committed to the goal of reducing energy consumption by $10 \%$ by 1985 . 

Appendixes 



\section{A The IIASA Conference on Management of Regional Energy/Environment Systems}

\section{THE PURPOSES AND STRUCTURE OF THE CONFERENCE}

The conference on which this book is based represented the culmination of the three-year IIASA research program on Management of Regional Energy/ Environment Systems. The objectives of the conference were (1) to summarize and discuss the project's substantive and methodological findings to date; (2) to discuss and appraise the methods used to analyze energy/environment policy in the countries with IIASA National Member Organizations (NMOs); and (3) to determine needs and priorities in policy analysis and planning of regional energy/environment systems.

The conference took the form of a four-day workshop attended by policy makers and policy advisors from IIASA NMO countries and various international organizations. The majority of these participants were individuals whose activities and responsibilities span both analysis and policy, and who have extensive experience in either energy or environmental areas. In general the conference did not stress mathematical developments, specific technical or economic theories, computer programs, etc., but rather concentrated on the applications, requirements, and results of these techniques, with particular emphasis on the conditions and constraints within which these methods could be applied in various countries.

There were four main inputs of information during the conference: papers were submitted by conference participants from 12 IIASA NMO countries; further papers were presented by the IIASA core research team on issues and findings emerging from the four case studies; working groups produced summary reports and recommendations on both substantive and methodological topics; and panel discussions on the various papers and reports took place. The papers given by the conference participants and those presented by the IIASA research team form Parts I and II of this volume, respectively. The reports of the working groups and summaries of the panel discussions are given in Appendixes B and C, respectively. 


\section{Working group reports and recommendations}

The conference participants were divided into four working groups to discuss needs and priorities in policy analysis and planning of regional energy/environment systems. The topics considered by the working groups were "Energy/ Economy Interactions"; "Environmental and Energy Strategies: Objectives, Uncertainties, and Constraints"; "Energy Conservation and Alternative Supply Strategies"; and "Embedding the Results of Energy and Environment Systems Analysis: Planning, Management, and the Real World". Each of the working groups drafted a brief report which classified and discussed the most important issues, proposed future approaches, and recommended priorities for future research in the area under study. These reports are presented in Appendix B.

\section{Conference panel discussions}

Appendix $\mathrm{C}$ contains summaries of panel discussions on three of the topics which had earlier been examined by the working groups, namely "Energy/Economy Interactions"; "Environmental and Energy Strategies: Objectives, Uncertainties, and Constraints"; and "Embedding the Results of Energy and Environment Systems Analysis: Planning, Management, and the Real World".

It is hoped that these Appendixes will provide the reader with a flavor of the discussions which took place during the conference and with some idea of the energy/environment issues which provoked the most debate. 


\section{B Reports of the Working Groups}

\section{REPORT OF THE WORKING GROUP ON ENERGY/ECONOMY INTERACTIONS*}

Most attempts at modeling energy systems, such as, for example, the IIASA work described during the conference, include only a one-way linkage between the economy and the energy sector. There are cases where such an approach might be satisfactory, but in general the distinction between the energy sector and the economy is artificial. Therefore, at least in long-term studies, the interrelationships between the energy sector and the rest of the economy should be explicitly incorporated in the models used. This does not mean that the IIASA studies presented during the conference are inconsequential, since they were intended more to identify the problems than to solve them. However, this approach is not very suitable for analyzing the impacts of various alternative measures. Since so many parameters are exogenous and their relationships are not clearly defined, it is difficult to evaluate the overall impact of measures which affect various parameters simultaneously.

The main problem with scenario writing is one of consistency: although the method is well suited to the consistent evaluation of policy measures, e.g., the imposition of sulfur controls on heating oil in the Austrian case study, it is difficult to guarantee consistency in the socioeconomic variables.

There was general agreement in the working group that there is no "optimal" model which will serve all purposes. The design of the model must be related to

\footnotetext{
* The members of the working group were: Lars Bergman (Sweden) who acted as joint chairman, Jean-Pierre Charpentier (International Atomic Energy Agency), Bertrand Chateau (France), Seppo Hannus (Finland), Alois Hölzl (International Institute for Applied Systems Analysis), Joseph Richter (Austria) who acted as joint chairman, and Frans Van Scheepen (Commission of the European Economic Community).
} 
the formulation of the problem. Specifically, it seems necessary to consider the following factors:

- The main characteristics of the region studied, such as its size and degree of "openness", the availability of domestic resources, the region's degree of development and its institutional framework

- The time horizon of the analysis

- The nature of disturbances to the system studied, e.g., whether caused by international changes or internal decisions

For example, if the world market price of oil were to increase, production costs in various countries would be affected in approximately the same way; thus, the relative competitiveness of these countries is not likely to be significantly affected by the price change. On the other hand, if one particular country were to independently follow a more costly energy production strategy, then the relative competitiveness of its energy-intensive industries would certainly be affected.

The problem of an appropriate level of aggregation or disaggregation was discussed in detail, and was perceived as basically involving two main types of trade-off decisions:

- Stability vs. information content; for example, in a highly aggregated input-output model, the coefficients are usually stable, but essential information about changes in the product mix of industry is lost

- Accuracy of results vs. expense of collecting the relevant information

In any analysis, the degree of aggregation chosen must match the aim of the study; for example, if we are concerned with energy, then the energy-intensive sectors should be isolated; if trade is the subject of interest, the major import-export sectors should be treated separately.

\section{REPORT OF THE WORKING GROUP ON ENVIRONMENTAL AND ENERGY STRATEGIES: OBJECTIVES, UNCERTAINTIES, AND CONSTRAINTS*}

\section{Introduction}

This working group identified the need for research in two major areasmethodology development and analysis and assessment programs.

\footnotetext{
* The members of the working group were: William Buehring (USA), Robin Dennis (International Institute for Applied Systems Analysis), Edgar Geißler (Federal Republic of Germany), Hugo Haider (Austria), John Hoover (USA) who acted as joint chairman, Wolfgang Kinzelbach (Federal Republic of Germany), Wolfgang Kluge (German Democratic Republic) who acted as joint chairman, Volkhurd Schulz (Federal Republic of Germany), and Julien Van Caeneghem (Commission of the European Economic Community).
} 
With regard to the development of methodology, inadequacies in both data and models constrain our ability to provide useful assessments and information to decision makers. While considerable research has been carried out on the development of air and water quality models, additional effort is needed to extend the methodologies to include chemical transformations. At the same time, it is necessary to provide simple methodologies that are useful in policy analysis. As other researchers have indicated, improved functions representing health and ecological damage are also needed. Although much work has been done on the behavior of pollutants in the individual media of air, water, and land, the working group felt that additional emphasis should be placed on multimedia methods for considering interactions between media and the synergistic effects of various pollutants. Better methodologies are needed to improve our understanding of the air-water interface. Examination of the results of the IIASA regional analysis program showed that various countries collect data in very different ways and on very different bases, making it difficult to carry out transnational comparisons of energy and environmental effects. Therefore, uniform energy and environmental data bases should be defined to promote the easy exchange of information and to make possible future regional comparisons. Further development of methodologies dealing with uncertainties is recommended. Moreover, if environmental evaluations of energy strategies are to be conducted in the future, more emphasis must be placed on the development and testing of appropriate evaluation models and methodologies. Specific approaches, such as cost-benefit analysis and preference or utility analysis, already exist, and further work in this general area is recommended.

Turning now to analysis, two major research areas were identified. During the past decade, a significant number of environmental standards have been defined and adopted throughout the world. A comprehensive review and evaluation of these standards should be undertaken. Particular emphasis should be placed on removing uncertainties in the information so that the standards are more rigorous and greater attention should be paid to more recent information. In addition, the need for further systemwide comparative studies was discussed. Past studies have in many cases emphasized modeling and forecasting. It was felt that future studies should be concerned with comparative evaluations of various regions using a case study approach. Emphasis should be placed on evaluations of the various energy and environmental policies used. The studies that could be considered include an evaluation of the effectiveness of standards, an evaluation of energy pricing programs, and so on. These studies, while analytically based, could be retrospective in nature rather than being oriented purely toward modeling.

\section{Multimedia methods and analysis}

During the last decade, major emphasis has been placed on the development of environmental standards and the development and application of environmental 
analysis methodologies. However, the focus in general has been on the pollution of one specific medium, such as air, with little or no consideration of interactive effects on other media. As an example, the stricter air pollution emission standards for power plants and the application of stack-gas scrubbers increase the generation of solid wastes, which are a potential source of water pollution; furthermore, trace elements released as air pollutants may, by deposition, become a potential source of water pollution.

There is a need for improved methodologies which consider the interactive effect between pollutants and analyze cross-media pathways. Moreover, environmental analysis should be more comprehensive and should consider multimedia effects.

While there is a need for research in this area, expertise already exists in many research institutes throughout the world. IIASA could serve as a forum for information exchange and for indicating likely directions for research.

\section{Improved single-medium techniques and effect relationships}

Environmental analysis today concentrates on the individual media, land, air, and water. Within each medium there can be many environmental trade-offs, but techniques or effect relationships (e.g., dose-response functions for plants) are still lacking, hindering a more relevant and complete analysis. Additionally, some of the techniques and effect relationships derived for a given medium need to be improved before a coupled, multimedia analysis can proceed. Pollutants originating from all types of sources (energy supply, transportation, agriculture, etc.) should be considered in the analysis.

In some cases, existing detailed models could be simplified; in other cases, new models should be developed. Methodological guidance would be very useful. Since so many models already exist, it would be useful to give priority to certain areas so that the appropriate models could be adapted for long-range planning purposes. The same is true for effect relationships, but in this case it would be more useful to concentrate on damage functions first.

The working group felt that specific attention should be given to the following areas of research:

1. Methodological guidance on the minimum amount of detail that a model can contain and still be useful for environmental analysis; in other words, how simple can a model be? How is simplicity related to the environmental questions asked?

2. Two media, air and water, merit special attention and scenario responsive models that take into account some locational detail are needed for both. For air, we need, first, to develop dispersion models for short-, medium-, and long-range transport and exposure to an equal level; we need to balance trade-offs, since the type of impact can be different in each case. 
Second, we require a better understanding of air chemistry in each of these ranges, especially for the sulfur oxides $\mathrm{SO}_{x}$ and nitrogen oxides $\mathrm{NO}_{x}$. For water, we need scenario responsive models for the location of energy facilities; the major concern here is to balance decisions on thermal discharge and water quality with trade-offs involving other media.

3. We need more detailed health and environment damage functions to quantify the effects of specific pollutants, such as $\mathrm{NO}_{x}, \mathrm{CO}$, and the heavy metals, and the extent of damage suffered by agricultural and other ecosystems.

The group felt that topic 1 above would be most appropriate for IIASA involvement, perhaps in conjunction with work already being carried out in IIASA's Resources and Environment research area. Topics 2 and 3 were considered to be subjects for general research, in which IIASA could act as a forum for discussion and identification of useful research directions.

\section{Development of methods for evaluating energy strategies from an environmental point of view}

It is desirable to have comprehensive methods that permit the evaluation and comparison of various energy strategies from the environmental point of view. The prerequisites of such comparisons are the identification of impacts and risks, and an understanding of the trade-offs between the impacts of alternative energy strategies. Effects that are already familiar from normal operations and accidents are of interest here. Several approaches, all implying the implicit or explicit establishment of value judgments, are possible. If a common quantifier of different types of impacts can be found, the judgment procedure becomes simple. If such a quantifier does not exist, the methods used must allow the intuitive consensus on the relative importance of different impacts to be formalized. In outline, the approach would be to set standards for any type of environmental pollution on the basis of a time-dependent cost-benefit analysis and to judge the various energy strategies by the degree to which they achieve or fall short of the standards.

The methodological tools required for these approaches fall within the existing research interests of IIASA and should be developed further. It might be useful to hold a workshop to compile and discuss existing methods.

\section{Setting of standards}

Environmental standards expressing minimum requirements or maximum doses should reflect information on quantified effects and also take into account the interrelationship of various pollutants.

In real life, the effects of many specific pollutants have not been quantified, and the procedures for setting standards are mainly based on compromises over the 
uncertainties. Specific standards for a given pollutant must take into account possible interactions with other pollutants, and also the behavior of the pollutant in other media.

Research which sets out to quantify the effects of various pollutants should be intensified in order to gradually reduce uncertainties and improve our knowledge of dose-effect relationships.

An inventory of pollutants resulting from various energy systems and other sources in the different media would be very helpful in the setting of standards. IIASA may have a role in collecting available information and in stimulating general research in this field.

\section{Uncertainties}

The working group perceived at least three different types of uncertainty:

1. Uncertainties in the original data, leading to a broad range of validity (or uncertainty) for results in analytical work. Methods for estimating such uncertainties are available; however, due to the complexity of systems, they usually cannot be executed in their analytical form, so numerical sensitivity analysis must be carried out. This type of analysis is in need of further improvement. From the results it would be possible to gain some insight into the areas of data collection and assembly which need attention.

2. Uncertainties regarding basic interdependences and relationships which, at present, cannot be formulated in an analytical way. It seems very doubtful that such uncertainties can be treated formally until more progress has been made with their conceptual formulation.

3. Uncertainties due to as-yet unknown effects, which may be expected from experience or which may be purely speculative.

In all of these cases it is necessary to decide on the relative weight and influence of the uncertainties, especially with regard to the decision makers. The working group concluded that significant research work could be done by IIASA in areas 1 and 2 above; in area 3, previous IIASA work, exemplified by the studies of Holling, should be continued.

\section{Systemwide comparative studies}

It is recommended that further studies should provide comparative assessments (via case studies) of the implementation of various energy and environmental policies and strategies. It is proposed that, rather than having a modeling and forecasting orientation, these studies should be retrospective in nature. Possible examples include evaluation of standard-setting procedures, evaluation of the Wisconsin marginal cost pricing program, and evaluation of the effectiveness 
of air quality policies. Questions of the following type should be answered in such studies:

1. What was the policy (e.g., pricing, standard setting)?

2. What was the environmental impact?

3. What initiated the administrative activity (e.g., energy conservation, environmental protection)?

4. What role was played by mathematical models and which models were used?

5. What were the impacts on other human activities?

6. What was the cost of the program?

7. How effective was the program?

\section{Data definition and collection}

When collecting data for the regional analysis, it was found to be extremely problematic and time-consuming to obtain comparable, relevant, and exact information. Therefore it was felt necessary to formulate something that might be called an "energy/environment" statistic. As there are, as yet, no guidelines for such a statistic, it was thought desirable that IIASA should implement a study on this topic, stressing the need for compatibility in the definitions of the relevant statistics.

The results of such a study could form the basis for a "recommendation" to all IIASA's NMO countries interested in setting up energy/environment statistics at the national level.

\section{REPORT OF THE WORKING GROUP ON ENERGY CONSERVATION AND ALTERNATIVE SUPPLY STRATEGIES*}

\section{Substantive statements}

Because of domestic supply limitations, increasing world prices, and longer-term supply uncertainties, a transition away from petroleum and natural gas will be necessary in the near future. Given current estimates of the resources and production rates of petroleum and natural gas, it is unlikely that these fuels can maintain their current share of the total energy supply in most regions.

Because of the combined economic, environmental, and energy benefits, energy conservation-defined here as more efficient use of energy —is the most attractive

\footnotetext{
* The members of the working group were: Eduard Fraunbaum (Austria), Mark Hanson (USA), Loretta Hervey (International Institute for Applied Systems Analysis), Antero Jahkola (Finland), Bruno Lapillonne (France), P.G. Schipper (The Netherlands), Gustave Speth (USA) who acted as joint chairman, and Dietmar Ufer (German Democratic Republic) who acted as joint chairman.
} 
method of reducing dependence on petroleum and natural gas. Moreover, the potential for energy conservation appears large. Though quantitative estimates are uncertain and vary from region to region, savings on the order of a quarter to a half of the growth in energy demand expected between now and 2020 appear possible, and even these estimates may be conservative. For all of these reasons, conservation should have high priority as a strategy for dealing with regional energy problems.

Energy conservation is possible in all sectors-residential and commercial, transportation and industry-but here regional variations will be quite important. Three particularly promising approaches involve the use of district heating, cogeneration, and heat pumps. To take maximum advantage of these approaches, however, certain institutional and technical issues need to be examined. These include the coupling of industrial systems with systems serving residential and other sectors, studies of land-use and housing patterns around energy facilities, and opportunities for enhanced thermal storage. Conservation can be achieved both by changes in prices-chiefly, by setting the prices of fuels at their social or replacement costs, and by tax incentives and disincentives-and by regulatory measures such as appliance, automobile, and building standards. In most cases, a combination of pricing and regulatory approaches will be appropriate. It appears highly likely that energy conservation, intelligently pursued, should have beneficial macroeconomic effects.

There are essentially three longer-term energy supply options: coal, nuclear energy, and renewable sources of energy. It seems that all three of these sources will be used in most regions in the years ahead. Both coal and nuclear energy, however, are linked with persistent environmental and social problems which will limit their expansion, and certain renewable energy technologies, such as biomass, could also cause environmental problems. If the issue of radioactive waste and other concerns associated with nuclear power could be successfully resolved, increased attention should be paid to the economic and nonproliferation benefits of once-through nuclear fuel cycles, such as those used in heavy water reactors, which (unlike current light water reactors) are relatively efficient in their use of uranium.

Because of their potential environmental and other benefits, energy strategies making the maximum possible use of renewable energy resources should receive high priority. Renewable resources-direct solar thermal energy, biofuels, photovoltaics, hydroelectric energy, and wind and wave energy-appear increasingly capable of fulfilling a major share of future energy needs, although renewable energy opportunities will vary widely from region to region. Though some of the promising renewable technologies are not at present economic and their introduction may cause institutional problems, several renewable options-such as solar heating, biomass, and hydroelectric energy - are already at or near commercial feasibility, and others, such as photovoltaic cells, have shown an encouraging decline in prices. Measures which should be considered to encourage the: 
development of renewable energy sources include reforming the prices of alternative fuels, providing commercial incentives in the forms of tax credits and other short-term subsidies, increasing research and development, and government purchases of solar equipment. It seems likely that, with sufficient support, renewable resources could constitute an important replacement source of energy later in this century; large-scale reliance on renewable resources is sufficiently promising that it should be actively pursued.

\section{Recommendations for future research}

There is a need for systematic international comparisons of conservation strategies in the form of case studies of the countries which have been most successful in implementing conservation measures. Such studies would consider technical questions, the circumvention of institutional barriers to conservation, and the identification of conservation potential in each sector. In addition, more investigation of the effects of pricing and regulatory measures on conservation is called for.

IIASA should become a forum for the discussion and dissemination of information about key issues in conservation and the development of renewable resources; these issues may include, for example, technical problems in thermal storage, and institutional constraints hindering the development of district heating. There is also a need for international comparisons and case studies on the effect on the competitiveness of solar energy of economic and institutional policies (such as subsidies to consumers). Finally, it is recommended that the problems connected with the integration of decentralized sources of energy, such as renewable resources, with centralized supply networks should receive more attention.

\section{REPORT OF THE WORKING GROUP ON EMBEDDING THE RESULTS OF ENERGY AND ENVIRONMENT SYSTEMS ANALYSIS: PLANNING, MANAGEMENT, AND THE REAL WORLD*}

\section{The role of regional energy systems analysis at IIASA}

There are three principal ways in which research such as that of IIASA's regional energy modeling group can help the international community. It can:

1. Share models with other analysts

2. Share the expertise of its core group with individual countries to help them solve their specific problems

\footnotetext{
* The members of the working group were: Oliviero Bernardini (Italy), Charles Cicchetti (USA) who acted as chairman, Wesley Foell (International Institute for Applied Systems Analysis), Lionel Johns (USA), Peter Middleton (Canada), Torgny Schütt (Sweden), Takao Tomitate (Japan), and Wolfgang Zehetner (Austria).
} 
3. Provide a formal setting for exchanging ideas and identifying policy options

IIASA, in fulfilling the role laid down in its charter, has several "client" communities for its products, including the academic community and national and regional policy makers. Greater efforts are required to tailor its products to the needs of these potential users. We make the following recommendations for IIASA publications:

1. Full research reports should be prepared for other analysts throughout the world.

2. National and regional policy advisors should receive an executive summary (no more than 100 and preferably only 10 pages long).

3. National and regional policy makers should receive a list of principal findings (surprises and recommendations) (no more than 10 and preferably only 2 pages long).

International meetings, with participants from non-NMO countries, should be encouraged. In addition, there should be an attempt to describe the problems encountered and the approaches used in transnational research.

The specific benefits of the work carried out by the IIASA regional energy modeling group may be summarized as follows:

1. A comparison of decision-making processes in four nations has been made.

2. The computer simulation approach has been transferred to other nations.

3. Policy options and their possible effects have been examined.

4. Simplified models have been provided that can be improved upon by scientists in other nations.

Quite apart from the significant scientific and policy-making contributions achieved, the working group felt that this IIASA work should be applauded as a pioneering example of East-West cooperative research.

Finally, the users of regional models should not expect them to replace decision makers or to produce hard answers (in terms of dollars or kilocalories, advice on timing or clear policy directions). Users should always consider:

1. The extent to which the models, assumptions, and variables are consistent with broader national or global values, constraints, etc.

2. The significance of extending the analyses very far into an uncertain future

3. The degree to which the model can be operated usefully without the inclusion of feedbacks (such as prices, investment data, etc.) 


\section{Summaries of the Panel Discussions}

\section{SUMMARY OF THE PANEL DISCUSSION ON ENERGY/ECONOMY INTERACTIONS*}

Mark Hanson (USA). One of the questions to be addressed during this panel discussion concerns the extent to which high energy costs or supply constraints will influence the economy, both in terms of overall rates of economic activity and of changes in the structure of the economy. In the IIASA case studies, energy growth and economic activity were not found to be tightly connected; however, as conservation potential is exploited a closer link may become evident. Other analyses, such as the CONAES study from the Committee on Nuclear and Alternative Energy Systems (sponsored by the National Research Council), have suggested that dramatic energy savings can be achieved with only small reductions in the growth of the economy; still others have argued that there is a very close relationship between energy use and economic activity, so that supply constraints and higher energy prices will inevitably slow down the economy. It will certainly be interesting to learn how this controversial question is viewed by the members of this international panel.

Lars Bergman (Sweden). A considerable amount of work has been done in this area in Sweden. One observation which has emerged from our research is that the interaction between the energy system and the economy differs according to the type of disturbance which is occurring. An international oil price increase affects the economy in quite a different way to domestic energy policy measures, at least in a small country like Sweden. We have also found that at the present time energy costs are still a very small fraction of total production costs. Thus an

\footnotetext{
* The participants in this discussion were: Lars Bergman (Sweden), John Brodman (International Energy Agency), Mark Hanson (USA) who acted as Moderator, Alois Hölzl (Austria), Josef Richter (Austria), and Takao Tomitate (Japan); Charles Cicchetti (USA) was an observer.
} 
increase in energy costs does not greatly affect overall economic productivity. In Sweden, where energy costs are 5-6\% of total production costs, a doubling of energy prices could be compensated for by fairly small productivity increases in sectors of the economy other than the energy sector. For this reason our studies suggest that a rise in energy costs would not greatly affect measures such as the GNP in Sweden.

However, energy policy measures or other changes in the energy system could have a considerable economic impact. For instance, in Sweden exports account for about $25 \%$ of the GNP, and a large fraction of total exports are highly energyintensive. Thus if Swedish policy makers alter the cost of energy, the competitiveness of the nation's export industries could be affected. Potentially, then, domestic energy policy in Sweden could have a significant impact on the structure of the economy.

If the growth in energy consumption is to be changed in Sweden, resources will have to be reallocated among various sectors of the economy. Although such measures would not have a great impact on the GNP, they could have a considerable effect on the everyday life of workers who would have to change their employment and possibly move to another region. This raises a question in my mind about the IIASA case studies. Was an attempt made to see how the four regions differed in their patterns of trade (i.e., the amounts traded and the energyintensiveness of the goods traded)?

Alois Hölzl (Austria). Our first three case studies centered upon regions, rather than nations, and the economies of these regions were naturally embedded within the larger national economies. The import-export activity of regions within a nation differs greatly from the activity of the nation as a whole. The fourth IIASA case study did focus upon a nation-Austria - but its exports are small except for steel and machinery. Swedish exports are certainly more energy-intensive than Austrian exports.

Josef Richter (Austria). I fully agree with the view that a moderate change in the price of energy (especially a change in the relative price of energy versus other factors of production) might lead to significant changes in the structure of the economy. It is important to distinguish between the situation in which one country alone is faced with an energy supply shortage or an energy price hike and a situation in which the nation's trading partners and competitors on the world market are also affected. If all western European countries simultaneously face an energy price shock, their competitive positions relative to one another may not be changed. However, their competitive positions relative to nations in parts of the world which are not so dependent on imports of primary energy and other raw materials may well be affected.

In order to study the impact of energy shortages or changes in relative prices it is of great importance to use a disaggregated approach. Such disturbances could significantly change the structure of the economy, though perhaps not the overall growth rate of the economy. A disaggregated model is needed in order to take into 
account changes within the economy. It is not sufficient to focus only upon aggregate measures such as gross domestic consumption or private consumption.

Takao Tomitate (Japan). In Japan, the price of crude oil is not expected to rise substantially in real terms until the middle of the 1980s. At the present time, the price of crude oil is not considered to be a serious constraint on the growth of Japan's economy. What is of more concern is the availability of a stable supply of energy and the location of energy supply facilities within Japan.

If one puts the Japanese economy into a world context, it becomes apparent that, ultimately, the biggest constraint on Japan's economic growth is the problem of future fluctuations in the world economy. If the present economic recession ends within one or two years, shortages in energy supply could create considerable pressure; this could cause the OPEC member countries to raise their crude oil prices. If the price rises more than $10 \%$ in real terms, the world economy will not be able to absorb it. The supply shortage structure may cause the world economy to undergo another short-term recovery-and-depression cycle after 1980. The relationship between the business cycle and the price of energy is thus very important.

Mark Hanson (USA). Because of Japan's dependence on the world economy, it appears that a regional economic model which is not linked to a more global economic model would have substantial shortcomings.

Takao Tomitate (Japan). At the present time there is no such comprehensive model in use in Japan. According to the projections which the Japanese government recently announced, Japan will have an economic growth rate of $6.1 \%$ during the next ten years and $4-5 \%$ thereafter. However, these projections rest on the very important assumption that the world economy will also show a healthy growth during this period, i.e., about $4 \%$ per year. If the world economy does develop in this manner there will be no problem for the Japanese economy. A comprehensive world economic model would be very useful in studying the links between Japan's economy and the world economy.

John Brodman (International Energy Agency). A national physical constraint on supply has a greater effect on economic activity than a price increase. The magnitude of the effects of supply constraints could be analyzed in the same way that the effects of a coal-miners' strike in the United States could be studied. Through an input-output type of analysis the decline in economic activity in the sectors that absorb the fuel shortages could be assessed. Then links to other economic sectors and the corresponding decline in their economic activity could be examined. Effects across regions could also be significant, as during the 1973 oil embargo. That is, if economic activity in one country falls, its demand for imports and production of exports can also fall, thus affecting its trading partners' economic activity. Actual physical shortages of energy do have a very big impact on economic activity.

Increases in the real price of energy are more complicated and are separate from the physical supply problem. Whether the price increase pertains to 
imported or domestic energy is an important question. The possibility of increasing the domestic supply of energy in response to an increase in the price of imported sources of energy must be assessed. In the case of Japan, a country which imports most of its energy, an increase in the price of imported oil theoretically should not reduce the Japanese gross domestic product (if you ignore management problems); however, there would be a one-shot fall in national income. Output would be unchanged, but real income for Japan would fall by the amount of extra money paid to exporting countries for oil imports. National income could continue to grow at the same rate, but because the growth starts from a lower base, the absolute annual increments would be smaller. This may be a little too theoretical for what goes on in the real world, because the adjustment process takes time and economic management problems must be solved.

The situation in a country which imports part of its oil, but which has some domestic energy supplies, is quite different. An increase in the price of imported oil could make it economic to develop domestic energy sources which previously were too expensive to exploit. In such a case a country could minimize the losses resulting from an energy price increase by developing domestic energy sources and thus internalizing part of the problem. This produces an internal shift in income shares from the non-energy-producing sector to the energy-producing sector. Of course, as long as some higher-cost sources of energy are imported, a drop in real income and an increase in the transfer of income to oil-exporting countries still occurs. However, these costs can be minimized through conservation and the development of alternative supplies. In a sense, development of higher-cost domestic supplies of energy is analogous to an increase in price, for it entails a decline in productivity for the resources which are employed domestically in the energy-producing sector. But on the other hand, conservation measures adopted to improve the efficiency of energy use are analogous to a decline in the real price of energy. An improvement in the efficiency of energy use helps to off set energy price increases in real terms.

One should also consider the policy problems which stem from increases in the international energy price. Many countries or regions are dependent to some degree on imported energy; as the price of their imported energy goes up, they must earn the money to pay for the higher-cost oil by exporting more. However, as long as the oil producers are not able to immediately spend all their oil revenues on increased imports of goods and services, the oil-importing countries are not able to increase their exports of goods and services. The resulting balance-ofpayments deficits put constraints on policy makers and perhaps lead them to take macroeconomic actions which lower the growth of GNP. This in turn lowers the demand for oil and softens the impact of the oil price increase on the balance of payments. As a number of countries simultaneously take such steps, the negative: impact on the GNP is magnified internationally. Thus, much of the impact of energy price increases on GNP results from policy actions.

Lars Bergman (Sweden). In Sweden an attempt has been made to estimate the 
economic impact of a zero-energy-growth strategy for the nation. This would entail reducing the annual growth in energy consumption from $2 \%$ to $0 \%$ between 1985 and 2000 . Our model simulations showed that this policy would lead to a slight decrease in the GNP growth rate, due to less-efficient resource allocation in the economy. However, the policy would not greatly influence growth in private consumption. The reduction in energy consumption would lead to a reduction in the growth of oil imports, and Sweden's balance of trade improved in the model simulation. Interestingly enough, the decrease in GNP was fully compensated for by a reduction in the export share of GNP.

I would like to make a further comment on the methods used in Sweden for research into energy policies for the future. My experience is based on the work of the Energy Commission, which prepared background material for governmental decisions about Swedish energy policy. With the aid of models, the Energy Commission has been able to make conditional predictions about the development of the economy and of energy consumption in the long run. The models used for this purpose are usually long-run equilibrium models suitable for long-term analyses. However, the problems faced by policy makers are usually of a completely different kind. They have to act in response to external shocks, such as the risk of oil price increases and public campaigns against nuclear power. The adjustment mechanisms which come into play in response to such shocks are very poorly understood, and models have not been developed which can describe the adjustment process. Model builders should pay much more attention to such phenomena, for long-run equilibrium analyses are not very useful for decision makers. Decision makers do not sit down and choose between various long-run equilibrium patterns, they have to make everyday decisions.

Mark Hanson (USA). I understand that in the study of the effects of zero energy growth on the Swedish economy, the energy growth was held at this level for fifteen years. From the response of the model, do you think that over a longer period of time, for instance 25 to 35 years, effects would become apparent which did not appear in the initial period, such as a slowing in economic growth?

Lars Bergman (Sweden). Yes, I think so. In any case one must consider the shadow price of energy under the constraint of zero energy growth. In the year 2000 , the shadow price of a safe and clean form of energy will range between three and nine times the production costs of energy. This also depends upon assumptions made about the substitutability of energy and other factors of production. At a given shadow price of energy, alternative energy sources which can be used at perhaps three times the production costs would be of interest.

Mark Hanson (USA). Mr. Richter, could you comment on the use of input-output models which include trade relations? How would you characterize the respective merits of input-output models and the equilibrium type of model?

Josef Richter (Austria). The input-output approach is extremely useful for many purposes, for it is possible to achieve consistency between the various sectors of the economy within the model, and it is possible to study the relatively 
big differences in energy-intensiveness between sectors. On the other hand it is very difficult to simulate short-run effects with the help of input-output analyses. The approach also requires a great deal of exogenous information, for instance about changes in technology. In a small country like Austria, it is often possible to obtain such information. Here many sectors are dominated by just a few firms, and the managers of such firms are often able to report on anticipated changes in technology during the next ten or fifteen years. This is not possible in large countries like the United States. An additional difficulty with the input-output approach is that it is difficult to simulate changes in relative prices and the effects of such changes. On the positive side, the input-output approach may play an important role in analyzing trade relations between countries.

Takao Tomitate (Japan). In Japan both input-output models and linear programming models are used. Input-output models are used mainly for projecting demands by sectors and by end-use, while linear programming models are used for studying the optimum distribution of energy. Currently, the biggest difficulty with the input-output approach lies in setting fixed coefficients, in the light of changes in the structure of industry and conservation measures.

Mark Hanson (USA). I would like to close the discussion with a general question. For a regional study in which the price of energy and constraints on energy supply are major questions, what methods should be used to model the economy in order to address these questions?

Charles Cicchetti (USA). The research team should decide at the outset whether it wishes to focus on a specific policy question of concern to a country or region. If a team tries to look at the totality of the problem area under consideration, it usually produces a model which is too superficial to handle specific policy questions. The scope of a study should be delineated at the beginning of the research effort.

\section{SUMMARY OF THE PANEL DISCUSSION ON ENVIRONMENTAL AND ENERGY STRATEGIES: OBJECTIVES, UNCERTAINTIES, AND CONSTRAINTS*}

William Buehring (USA). In the scenarios developed for the IIASA regional case studies, energy demand models provide information on energy requirements by fuel type and year; these data are then used as input to a set of environmental impact models, which calculate quantified impacts of various types, such as acres of land used, water consumption, radiation exposure, etc. The impact models produce a long "laundry list" of impact information, which of course we recognize is not complete. A final impact, such as acres of land used at a power plant,

\footnotetext{
- The participants in this discussion were: William Buehring (USA), Robin Dennis (IIASA) who acted as Moderator, John Hoover (USA), Peter House (USA), Wolfgang Kluge (German Democratic Republic), Peter Schipper (The Netherlands), and Torgny Schütt (Sweden); Edgar Geißler (Federal Republic of Germany) and John Brodman (International Energy Agency) were observers.
} 
represents quite a solid estimate. On the other hand, air pollution health effects are less certain, and it has only been possible for us to quantify part of the expected impact.

The next step in the analysis involves the assessment of the quantified impacts by means of utility functions within a preference model. Questions addressed during the assessment process include "which impacts are of most interest?", "which impacts are used as criteria for decisions?", "how may impacts be combined?", and "how may conflicting objectives be handled?" By actually interviewing decision makers and using those interviews to construct approximate preference models, we can learn what policies and assumptions are necessary and preferred by various individuals. We are, of course, very much aware that our methods of studying environmental impacts could be improved, and we hope to learn about approaches taken in other countries during the course of this panel discussion.

Torgny Schütt (Sweden). If one focuses upon the energy system, one must consider the economic, ecological, and environmental problems as well as the social impacts of using energy of various kinds and, conversely, of not using energy. I would like to discuss how the environmental and ecological effects of energy production and end-use have been studied in Swedish investigations.

It is first necessary to specify the decision-making body which would make use of the models. In Sweden the decision-making structure encompasses many levels, the top level being the parliament. Low down in the decision-making hierarchy, detailed dynamic models are used to study the dispersion of air pollutants and the impact of pollution on laboratory mice, etc. In this first research phase, one needs models both for conceptualizing and for numerical calculations; the knowledge gained at the end of this research phase should be transferred to the next level of decision making in easily understandable terms. It is my experience that political decision makers are not receptive to discussions about modeling per se, and require a fairly simple explanation of the findings of modeling exercises carried out at lower levels of the decision-making hierarchy. The complexity of the decision-making structure should always be kept in mind.

Many energy chains from production to end-use make up the energy system. The weak links in a given energy chain may have some critical effects on the environment, the economy, etc. One may concentrate on the critical impacts of special links in the energy system, just as if one were doing a bottleneck analysis of the system. This permits the description of the weak points in alternative energy chains.

In Sweden our experience has been that politicians feel that it is their role to assign weights to various impacts and to make decisions without revealing all their underlying motives. For politicians, decision making is in many ways an irrational process, often influenced by both an "official" set of standards and an "unofficial" set of standards.

The task of the researcher is to categorize impacts and to determine the types of 
information which national, regional, or local politicians require. Points of interest to the politicians include who or what is affected by the side-effects of the energy system (humans, the physical environment, property, etc.), the type of impact (loss of life, disablement, etc.), where the impacts occur (domestically or abroad), and when the impacts occur (immediately, or over a very long time span). It is exceedingly difficult to weight all of the different kinds of impacts associated with the energy system. How can one compare the death of one miner to the effects of air pollution on the general public? Should impacts occurring abroad be valued in the same way as domestic impacts, even if the value systems in other countries are very different? How much more severely should irreversible impacts be judged compared with those that disappear with time? The difficulty of attaching values to the impacts is compounded by the researcher's uncertainty in his description of the impacts. For instance, great uncertainty is attached to the estimation of the effects of a given dose of pollutant; these uncertainties require decisions to be made flexibly, always preserving our freedom to take new action when better information is available.

Environmental impacts which we have considered in studies in Sweden include risks to human life and health (such as injuries to coal miners, damage to public health from air pollution, radiation-induced cancers, etc.), effects on the physical environment, effects on the ecosystem, and climatic change. The impacts can occur on a local, regional, international, or global level. It is possible to develop a long list of impacts and to attempt to assign priorities to the impacts. However, it has been my experience on the Swedish Energy Commission that politicians prefer to weight the impacts themselves.

Peter House (USA). Energy/environment analysis at the federal level in the United States is tremendously complex. It is the task of the Department of Energy to set energy policy for the nation in a biannual national energy plan. Many agencies, such as the Council on Environmental Quality, provide input to this plan. Congress and the newspapers also contribute to the policy-making process. It is extremely difficult to pinpoint exactly who the policy makers are. The situation of the Office of Environment within the Department of Energy may in some respects be likened to "sitting in the middle of the enemy camp". The task of the Office of Environment is to ensure that environmental health and safety regulations are not broken, while the task of the Department of Energy as a whole is to "get energy on the street". In the context of this task the environmental regulations are often considered "barriers".

An additional complicating factor is that in the United States a large number of federal agencies, such as the Department of the Interior, the Department of Labor, and the Department of Agriculture, have environmental health and safety regulations. Often it happens that if one supports the development of a form of energy like hydropower, because it does not produce the pollutants ordinarily associated with combustion, one runs up against the endangered species laws or the wild and scenic rivers law. Such laws are hindering the exploitation of massive 
hydropower resources in the Pacific Northwest. Thus environmental concerns constitute a huge and very complex policy area.

Important organizational mechanisms have been created to coordinate interactions between all the agencies responsible for environmental problems. An "Environmental Issues Committee" has been set up in the Department of Energy, with representatives from several federal, state, and local agencies. The Committee previews new guidelines and standards before they are issued, to assure that the views of environmentalists as well as energy developers have been taken into consideration. The "Environmental Development Plan" constitutes another formal mechanism for consultation in the Department of Energy. In order to develop this plan, environmentalists sit down with technical staff and discuss the health and safety problems associated with new technologies, determine what kind of studies should be carried out to clarify the magnitude of these problems, and specify who will carry the studies out. The plan is developed for as long as a decade ahead and represents many millions of dollars of technology-specific research. Staff members from the Department of Energy also hold formal meetings at least once a month to evaluate research progress and to specify the types of information which are needed to write environmental impact statements and similar documents.

The Office of the Environment also keeps abreast of modeling efforts in the energy/environment sphere. Very large numbers of models have been built, and in fact it would seem that people are more interested in building models than using them. Everyone seems to want their own dispersion, land-use, or transportation model, and the duplication of effort is tremendously expensive.

I would like to conclude by mentioning some of the major issues which are currently facing the staff of the Department of Energy. The development of a trade-off methodology is an important concern. Trade-offs between nuclear power, fossil-fuel combustion, and solar power are often discussed, but because these energy sources present such totally different types of environmental problems, it is very difficult to analyze the trade-offs. A low level of research in the area of trade-off methodologies has been in progress for some time. A second issue of concern at the Department of Energy is the requirement of the Clean Air Act that a "balanced" approach be taken toward environmental control, rather than an approach which considers pollutants one at a time. For instance, with regard to fluidized-bed technologies, how does one balance the low solid-waste problem with the very large sulfate problem? A third important issue currently facing us is the usefulness of the damage functions used to calculate the effects of air pollution on health; in fact, it is the effects of pollution on health which seems to be of most concern to Congress.

John Hoover (USA). I find it very interesting that Dr. Schütt argued that decision makers do not like researchers to combine environmental impacts or to try to put values on them, and that, conversely, Dr. House identified a need for trade-off methodologies. I interpret this to mean that simple procedures are needed for 
identifying trade-offs between coal and nuclear power, and for combining air, water, social, and economic impacts. Dr. Schütt, do you think that if these methodologies were interpreted differently, they might be more acceptable to decision makers? Perhaps decision makers would find the methods more acceptable if they understood that the methods do not dictate what decisions to make, but rather help to eliminate bad decisions.

Torgny Schütt (Sweden). I agree that it would be desirable to have trade-off methodologies, but because so many political issues and value questions are involved, it is very difficult to create such a methodology. The work of the Swedish Energy Commission has made me realize that environmental problems must also be considered in an economic context. If researchers identify environmental problems they should also analyze the costs of mitigating them. This involves studying the likelihood of new technological developments and the costs of these technologies. But these questions are matters for political discussion.

Peter Schipper (The Netherlands). Similar questions are currently occupying us in The Netherlands. Domestic natural gas meets roughly half of all energy requirements in The Netherlands, the other half being supplied by imported oil. The household and commercial sectors are fueled by natural gas, and, in addition, $85 \%$ of the fuel requirements of the electricity sector are met by natural gas. Natural gas in The Netherlands is free of sulfur and does not create serious environmental problems. Environmental problems are connected mainly with industry, which is fueled in part by oil. But though large amounts of sulfur dioxide are produced by the oil refineries near Rotterdam, the quantities are small compared to the sulfur dioxide "imported" from Belgium and Germany. Thus the problem is international in scope.

As far as future energy supplies are concerned, it is expected that sufficient natural gas will be available for the household, commercial, and public sectors until about 2020. The main problems will arise in the electricity-producing sector and in industry. In the future the electricity sector might use a small amount of coal, perhaps eight million tonnes/year. It will be necessary to impose regulations for coal-fired power plants, covering both storage and waste disposal. However, the greatest problem will be in the industrial sector, where the largest future growth in energy demand is likely to occur. Currently there is overcapacity in the oil refineries and chemical processing industries, and unemployment is a very important policy issue. At the present time I think the problem of unemployment has higher priority than environmental concerns.

In our research in the energy sector, we have developed a reference energy system approach similar to that used at Brookhaven National Laboratory. We have tried to identify the environmental impacts occurring at each step of the energy chain, i.e., transportation, conversion, etc., and also to anticipate what energy/environmental protection technologies will be available in the future. We have been concerned with impacts to health, safety, and ecological systems, and have also tried to consider social and economic impacts. We have found that it is 
difficult to study damage to ecological systems, but that it is even more difficult to express such impacts in social and political terms. However, we found that the reference energy system approach provided a good basis for discussion, and we are planning to continue to use this approach in The Netherlands.

John Hoover (USA). I share quite a bit of the concern about models expressed earlier in this panel discussion. It has been my experience that there is a tendency to place one's faith in model results too quickly. I think it is important to doubt some of the procedures being used for analyzing trade-offs and combining impacts, although I recognize the need for such tools.

At Argonne National Laboratory we have tried to perform studies which will be directly useful to decision makers. However, in the seven years that I have been working in this field I have never really met a decision maker. As Peter House explained, decision making in the United States is very diffuse. There are many checks and balances and opportunities for everyone from private citizens to local, state, and federal officials to become involved. In the final analysis it is often unclear who actually makes policy.

To turn to another problem area, I think that the assumption of risk is a real source of conflict in the energy/environment sphere. The critical question is "who is going to benefit from the development of energy resources and who is going to accept the associated environmental and social effects?". In 1977 the National Academy of Sciences sponsored a coal forum which included a panel discussion of the local social and economic impacts associated with energy development. One case considered by the panel was the introduction of coal mining on a very large scale in rural areas of the Rocky Mountain States in the United States. The building of a coal-fired power plant in a small town requires a large construction force, perhaps 2000 people at the peak. There was great concern at the local level about supplying the necessary service infrastructure (e.g., schools, sewage, roads, hospitals) for this large increase in population. Because of the US tax structure, the money needed to build such facilities is very difficult to obtain in advance. At the conclusion of the panel discussion it appeared that the citizens of the Rocky Mountain States were willing to permit the development of the coal resources, provided that the risks associated with the costs of the public facilities were shared, i.e., that the costs were divided between the producers and the consumers of energy.

I would now like to comment on environmental constraints on energy use. It is noteworthy that as soon as compelling evidence about an environmental impact is available and a regulation is set the regulation quickly becomes a source of conflict. The Clean Air Act is a good example; the new source performance standards, nonattainment standards, air quality maintenance areas, prevention of significant deterioration areas, etc., potentially conflict with increased coal use. But equally important are environmental impacts that we know very little about, such as the effects of $\mathrm{CO}_{2}$ on health and ecological effects. As a private citizen I find this really frightening. We have very few techniques that help decision makers 
deal with uncertainties; this is a reason for emphasizing trade-off methodologies and mixed kinds of techniques that help us integrate over the unknowns.

Finally, I think that solutions to problems should be the object of more studies. In the United States a great deal of emphasis is placed on the delineation of problems, but few studies are directed toward the development of solutions, such as using the siting of smaller plants or the relocation of plants to relieve some of the environmental problems we face. It is necessary to evaluate the role of new technologies such as fluidized-bed techniques in solving solid waste problems, for instance. In the United States decision makers and the public want to learn how to deal with the problems which have been identified.

Wolfgang Kluge (GDR). Because the GDR has a central energy plan, the: problems we face in the energy/environment sphere are somewhat different from those brought up previously in the panel discussion.

I have been asked to comment on the approaches used at my Institute in the GDR to analyze energy/environment problems. The first step is to set forth realistic energy options related to the social goals of the country as a whole. It is necessary to consider energy demand, primary energy requirements, energy conservation measures, and so on. The next step is to calculate environmental effects, such as $\mathrm{SO}_{2}$ emissions, the amount of land used for open-cast mining, and water demand; it is then useful to compare these effects with resource options, and try to determine which energy options are good from the standpoint of the environment. At our Institute we also study ways of controlling environmental impacts and try to promote energy conservation measures, such as combined power and heat production and use of waste heat. We also try to calculate the costs of environmental protection measures.

The important points at which energy and the environment are linked include land use, water demand, air quality, and last but not least, the economy. As others have noted, the best option for protecting the environment is worthless if we are not able to pay for it.

There are several ways of resolving conflicts between energy production and environmental protection. If a plant is producing too much pollution, the first step is usually to implement emission control measures at the plant. In the case of nuclear power plants, attempts are made to site them in areas without human settlements. As for the damage caused to the landscape by open-cast mining, our objective is to mitigate the environmental impact through extensive landreclamation programs. Conflicts between central and local authorities over polluting plants have occurred at times in the GDR. For instance, local authorities in the city of Berlin successfully prevented the planned reconstruction of a gasproducing plant in the city, in order to protect the quality of the environment. Thus such conflicts are not always resolved to the advantage of the energy industry.

In the GDR several environmental factors constrain energy production and use. Because the nation does not have large water resources it is often necessary 
to recycle water. This involves the cleaning of water from open-cast mining, so that it can be used for other purposes. $\mathrm{SO}_{2}$ emissions are also important constraints. Finally, the land used for energy purposes constitutes an important economic problem and is also a social problem, in view of the density of the population in the GDR.

John Hoover (USA). It has been asked how the environmental impacts of energy systems compare in magnitude with those of non-energy systems. I cannot answer that question completely; however, six or seven years ago some very detailed air pollution studies were carried out for the Chicago metropolitan area to assist the city in developing its environmental control program. It was found that low-lying sources with short stacks, such as those used in the residential and commercial sectors, posed quite a large problem in terms of $\mathrm{SO}_{2}$ pollution. Power plants made a very small contribution to the pollution problem relative to the residential, commercial, and industrial sectors.

John Brodman (International Energy Agency). The environmental impacts of energy vs. nonenergy systems depend on the type of pollutant considered, the type of fuel being burned, and the area in which the combustion takes place. Electric utilities burning high-sulfur coal in the Four Corners area seem to be producing serious environmental impacts, but there are few other sources of pollution in the area. To give another type of example, there have been cases in the United States of certain companies actually buying up other polluting companies in order to obtain enough "air quality space" to continue their operations.

Edgar Geißler (FRG). I was surprised by the comments which Dr. Schütt made about Swedish politicians and their desire to attach weights to various environmental impacts themselves. Our experience in the Federal Republic has been quite different. The politicians are not interested in impacts expressed in units such as $\mu \mathrm{g} / \mathrm{m}^{3}$; they want to know how many people will be affected and in what way. The approach used in the IIASA studies, as described to us this morning, seems to be useful for those kinds of questions.

In the FRG, it is the mayor and the town council who decide whether their community will accept a fossil-fuel-fired plant or a nuclear power plant. And in the process of their deliberations they do not consider impacts expressed in units of $\mu \mathrm{g} / \mathrm{m}^{3}$. Perhaps decision making is different in our country, but there the reality of decision making is not as complicated as suggested by other panel discussants. The point where conflict arises is in setting standards. Disagreement occurs between various pressure groups, such as environmentalists and utilities, and the end result is usually a compromise. Once a standard is set the problem becomes one of compliance.

John Hoover (USA). In the United States there are opportunities for pressure groups to challenge a standard that has been passed, for instance through a court case. The authority of the Environmental Protection Agency is by no means absolute; many channels exist through which other actors can express their views.

Torgny Schütt (Sweden). I think that the complicated part of the process lies in 
arriving at an environmental standard. Here pressure groups of all persuasions come into the picture. Once the standard has been set the difficulty lies in differences of interpretation.

Perhaps I was a little too negative earlier in the discussion when I explained that while Swedish politicians are interested in accurate descriptions of environmental impacts (in terms of who will be affected, when, where, how severely, etc.), they are not interested in having researchers attach a weight or dollar value to these impacts. I did not mean to imply that researchers should always bow to the preferences of decision makers.

Perhaps you recall what a tremendous impact the model described in "The Limits to Growth" had. Many of the assumptions upon which the model was based have since been challenged, but nevertheless the model played an undeniably important role in opening up channels of communication and promoting discussion. The same is true for models attempting to rationalize decision making. These models promote communication and represent a useful conceptual framework, even if their underlying assumptions may be criticized on many grounds. The same is true for energy plans; it might not be possible to implement a plan, but the plan still plays a crucial role in the communication process. In Sweden the government has invested 300 million Swedish crowns per year in its energy research program. Many expected that the end product of the research would be some kind of hardware; but instead the main result was the communication of new ideas to the government and to society, and the stimulation of debate about priorities in the energy program; this I consider to be a very important aspect of research.

\section{SUMMARY OF THE PANEL DISCUSSION ON EMBEDDING THE RESULTS OF ENERGY AND ENVIRONMENT SYSTEMS ANALYSIS: PLANNING, MANAGEMENT, AND THE REAL WORLD*}

Wesley Foell (USA). In planning this conference we made a special effort to invite participants who could span analysis and decision making. From the content of the foregoing discussions, it appears that we have gotten that blend. As I listened to the views presented about modeling and decision making, I was concerned to hear so often comments like "Congress does not like models", and "politicians are wary of modeling and attempts at summing different types of impacts". This morning Professor Häfele made some statements about energy systems of the future which contained numbers with huge uncertainties associated with them. I wonder how the politicians referred to in our discussion can cope

\footnotetext{
* The participants in this discussion were: Charles Cicchetti (USA), Wesley Foell (USA) who acted as Moderator, György Földvary (Hungary), Edgar Geißler (Federal Republic of Germany), Peter Middleton (Canada), and Gustave Speth (USA); John Hoover (USA), Lionel Johns (USA), Torgny Schütt (Sweden), and Lars Bergman (Sweden) were observers.
} 
with the uncertainties connected with the IIASA models. Perhaps during this discussion we can consider priorities for making models more acceptable to decision makers. Should we try to reduce uncertainty in the model results? Or should we try to find a better way of coping with the subjectivity, the multiple objectives, and the multiple values of the people who are going to use the model results? The question before us really is "How can analytical results be embedded in the decision process?". Do we need more data, should we become better communicators, or should we try harder to get decision makers involved in the research process? I think our panel will be able to discuss these questions from a number of different perspectives.

Gustave Speth (USA). I work on the Council of Environmental Quality, a small advisory unit in the Executive Office of the President, whose function is to give policy guidance on environmental issues to the President and his White House advisors and to monitor the performance of other federal agencies in carrying out their duties in the environmental sphere.

From my vantage point it seems that the panel has been asked to generalize about extremely broad questions. For instance, serious estimates of total energy use in the United States in the year 2010 range from 70 to 140 quadrillion Btu. There are credible people who believe that energy use in the US can actually decrease over the next several decades and there are more people who believe that energy use will expand fairly dramatically. This huge uncertainty exists within the lifetimes of children alive today.

The question has been raised whether a broad systems analysis can be effective within a policy context. In general terms, the methodology is often not sophisticated enough and the data are not of sufficiently high quality to be directly relevant in a decision-making context. Decisions tend to be incremental and taken quickly, while the type of analysis we have been talking about takes a long time to carry out properly. In addition, decisions are very political, and the policy context shifts constantly. Six months ago in the US, every policy decision in the energy and environmental area was judged at least in part by its impact on jobs. Today inflation is one of the critical factors to consider.

Models such as those presented by W.K. Foell's group represent an excellent start in the difficult area of integrating many different types of information. However, several shortcomings must be noted. For instance, the solar material presented earlier in the conference really was quite dated; also, if all of the critical air pollutants had been considered in the model instead of just $\mathrm{SO}_{2}$, the approach would have become tremendously more complicated. In addition, nuclear power has been discussed as if it were just one thing, instead of three or four alternative fuel cycles which create different kinds of environmental impacts.

Perhaps these types of models are most useful for technical assistants to policy makers, to help them decide what is important. It is extremely helpful if analyses of these types can identify a critical issue which has not received enough attention and then move it in to the policy process. 
I think you are all aware that one type of analysis which has become part of the policy process in the US is the environmental impact statement. Decision makers are required by law to consider these statements and their conclusions. They are, however, quite different in scope from broad-gauged, multisectoral systems analyses.

The type of international research which has proved most useful to me is case studies of energy approaches which work in other countries. For instance, a number of studies have shown that Swedes use about half as much energy per capita as Americans, although their per capita income is comparable. Such studies are tremendously effective in government circles, because they suggest that per capita energy consumption can be drastically reduced without damaging the economy. Such studies permit one to assess the impact of different policies in basically similar societies.

Charles Cicchetti (USA). It has been my experience that complex models addressing tremendously complicated questions are least useful for decision making. If a question is narrow, it is more probable that a useful model can be developed to help in answering it. If the question and the choices are clearly defined, the modeling activity becomes much more purposeful. Researchers should always ask themselves whether they are modeling for modeling's sake, or whether they are modeling with a specific question in mind.

Much of the discussion today has implied that there is something wrong with decision making. In the United States our problem seems to be that many decision makers are lawyers. For this reason, energy questions are often addressed without consideration of elasticity on the demand side or substitution on the supply side. A second problem with decision making in the US is the general concensus that nothing should ever be done for the first time; another notion which damages decision making is the belief that nothing should ever be done until there is a crisis, i.e., that difficult and complex decisions should be postponed. The US President declared that the energy crisis is the moral equivalent of war, because the two times that the United States has moved in recent memory were during the Great Depression and World War II. The tendency in the United States is not to act until things get very much out of control. In my opinion, however, it is very difficult to try to make good decisions in a crisis atmosphere; when the situation has already deteriorated, choices become far more restricted.

On the other hand, academic research on policy questions is also not without problems. When academics confer, they often confess their ignorance about many questions; but when they talk to decision makers, they usually have the "answer". Except, of course, when they argue that they don't yet have the answer, but that they could get it with more time and much more money. In my opinion, one should never tell a politician or decision maker that one has the "answer". It is much more effective to try to narrow the decision down to two alternatives and explain what the alternatives are. In most cases the decision maker will be impressed by the analytic capacity of the researcher and at that point will ask for advice in making the final decision. 
Wesley Foell (USA). Mr. Földvary, Head of the Section on Regional Energy Economy within the National Power and Fuel Board of Hungary, has explained to me that analysis of energy/environment problems in Hungary is quite different from the approach adopted in the IIASA research.

György Földvary (Hungary). Hungary is a relatively small country with an area of 93,000 square kilometers and ten and a half million inhabitants. In Hungary, as in the GDR, the regions play an important role in implementing the country's medium- and long-range energy policies. ("Regions" in this context means counties and the largest human settlements.) The Ministry for Heavy Industry is not only responsible for the activities of energy-producing industries, electricity generation and distribution, and coal mining, but must also oversee the energy economy as a whole and its regional applications. In the National Planning Office the energy sector is treated as a subsystem of the national economy.

Recently, the Hungarian government created a new long-range national plan, with a time horizon of thirty years. According to this plan, responsibility for policy making in the energy sphere is delegated to the Ministry for Housing, Construction, and Urban Development, while actual implementation of the plan is carried out by the local authorities.

Within the hierarchical structure of the national plan, many subsystems are considered, e.g., the energy subsystem, the water subsystem, and the transport subsystem. Thus a systems approach is used in planning; a methodology has been developed for evaluating the goals which are set for the geographically defined socioeconomic microsystems of the country. The practical aims of the planning process include the provision of guidelines for investment by the local authorities and energy service companies and guidelines for allocation of energy sources to end-users when alternatives exist.

County and town councils also make complex energy supply studies, taking into account local natural resources, such as coal, natural gas, and geothermal energy. The studies also consider local agricultural and industrial development, the technological features of the local housing program for the next fifteen years, the availability of the labor force, and the volume and structure of energy consumption. Particular attention is paid to power stations which are planned to be used as sources of district heating for the residential and commercial sectors. Combined heat and power generation is viewed as one of the most promising forms of energy conservation. The results of the local studies are presented to local and central authorities and are considered in future decision-making activities.

I would now like to turn to the international aspects of the energy problem. Many regional energy problems should be tackled by groups of countries which are geographically close to one another and which have similar goals and constraints. Some good examples of joint ventures which promoted international energy trade are the trans-European oil pipeline which benefitted Hungary, Yugoslavia, and Czechoslovakia, and the Irongate complex of hydropower stations built on the Danube by Yugoslavia and Romania. In my opinion a promis- 
ing and ambitious goal for the IIASA research program would be to continue its work, recognizing the great potential for future international cooperation.

Peter Middleton (Canada). The consulting firm which I run in Canada undertakes policy-oriented research for the public sector, often using models as tools. In addition the firm provides services to private industries relating to investment and market decisions.

In my opinion the status of models in Canada is reasonably well-advanced. Statistics Canada, which collects data on a whole spectrum of industries and a wide variety of other topics, provides a solid basis for modeling activities. However, one must keep in mind that the quality of the data is directly proportional to the time invested by people filling out forms at the industry level. Canada also has a national input-output model and tables, and provincial models exist as well. Statistics Canada has recently attempted to derive information from the input-output model which would throw some light on environmental and energy impacts of human activities in Canada. A document on this research has been published very recently.

My own consulting firm is planning to cooperate with Statistics Canada on a project aimed at determining whether it is feasible to build factor-of-productionbased input-output tables. Such tables would give information of a different type to that obtained from input-output tables based on dollars or other currency units. It is hoped that the new type of table will provide a more accurate reflection of what is happening to the environment in terms of future sectoral requirements. The approach would in fact deal with actual processes. We are, of course, aware of the great difficulties involved in such a project, but we feel that the approach is worth investigating.

Several energy demand-and-supply models are also being used at the national level. The Department of Energy and Natural Resources, the National Energy Board, and several external organizations have such models. The use of both input-output models is illustrated most dramatically in the case of policy decisions about the Mackenzie Valley Pipeline. This pipeline, designed to supply both Canada and the United States with Alaskan and Canadian natural gas, is the largest privately financed project in history. The scale and complexity of this project required significant use of modeling to answer two critical questions, namely, whether there was actually a demand for the gas, and what the economic impact of investment in such a large project would be. There was considerable controversy among the modelers over both questions, but, significantly, the models were not used by parties which had a real vested interest in whether the pipeline would be built or not.

I would now like to turn to several micro-applications of models, which in our experience have often been more fruitful than macro-applications. For instance, one micro-application was undertaken to find out whether it was preferable from an energy and environmental perspective to burn solid waste, including paper, or to reclaim the paper. The study resulted in a policy which gave priority to paper 
recycling rather than to energy recovery. Other studies have looked at the impact of introducing new sources of energy on the environment, employment, and the economy. Another micro-application of a model involved an examination of the impact of restrictions on the type of bottles, containers, and packages which could be used.

Both micro- and macro-models can make an important contribution by clarifying the elements of the system under consideration. In the case of the Mackenzie Valley Pipeline, the models made an essential contribution in dealing with a situation of such complexity that it could not be handled manually or by nonnumerical methods. The macro-models were valuable in this case even though they often differed in their output and results. Micro-models are useful in sharply focused situations in which very specific questions need to be answered. Here the modeling approach can give hard answers, illustrating the consequences of different policy decisions. The questions which this discussion raises are, "what lies between the highly complex macro-approach and the very specific microapproach?", and "is regional modeling too specific to be considered a macroapproach?". Unfortunately, I have only raised these questions and not answered them.

Edgar Geißler (FRG). On the initiative of the Federal Ministry for Research and Development, twelve research centers embarked in 1973 on a joint effort to coordinate the vast number of different modeling and systems analysis studies in progress at the centers. A small central working group for applied systems analysis (ASA) has been established, and a study program focusing on four major areas-energy systems, raw materials, traffic systems, and communications systems - has been set up. As a member of this central group, a delegate of the nuclear research center at Jülich, I am involved in the energy part of the program.

By 1975 , at the latest, the element of exaggeration which often enters energy demand forecasts had become obvious to both decision makers and the public; since then opinions about studies of the future and related investigations have become a little ambiguous. When the objectives of such studies, for instance in the area of energy demand, are interpreted as energy forecasts, the public becomes wary. This may explain why even the Federal Ministry for the Economy, which is in charge of the Energy Program, showed some caution in publishing energy demand forecasts; these were formerly presented as components of the Program, but are now just appendixes to it. Decision makers have realized that one must look more carefully at the results and the way in which they were derived. Although this might contradict the usual ideas of analysts and experts in this field, decision makers believe that objectivity has not been achieved if there is only one result, or one number, or one curve; nor will they have much confidence in such unique results.

In the energy area, systems analysts have studied the potential of new technologies, especially those involving renewable resources. They have also studied in some detail the potential for energy conservation in different sectors of 
energy supply and final consumption. In addition, the potential of nuclear energy and the possibility of resolving related problems, such as the closing of the fuel cycle, have been analyzed. Recommendations for policy makers have been derived from this work, and there is evidence in published programs that the recommendations have been taken seriously. Policy makers have also shown interest in requesting systems analytical aid, usually on special problems rather than to deal with general questions.

Since the start of the systems analysis work, communication between analysts and decision makers has generally been good. But cooperation is also required, as well as the ability to understand that there are different views of reality and different approaches to the solution of real problems. Perhaps it is worth adding that the relationship between analysts and decision makers is sometimes disturbed when the analysts divulge their preliminary ideas or results prematurely to newspapers for publicity purposes.

Finally, for successful work in the field of systems analysis it is necessary to have a precise formulation of the questions to be studied. It makes no sense to develop general models in the hope that they will be appropriate for questions which may arise in the future. It has been my experience that models which address broad issues stimulate discussion, but often cannot be used to answer specific questions.

Wesley Foell (USA). I would like to ask Gustave Speth whether he feels that systems analysts could be more effective if they became actively involved in the policy-making process, using their models as tools to support their point of view-rather than sitting back in a disinterested way.

Gustave Speth (USA). I certainly did not wish to suggest that modeling efforts should be directed at corroborating conclusions which had been arrived at previously. However, when systems analysts come up with novel, innovative solutions, I do strongly urge that their points of view be forcefully presented in a policy context. I think that the staff of the Center for Environmental Studies at Princeton University has had a substantial impact on US policy, because it has briefed Congressmen, Senators, and agency officials about the conclusions of its technical work. The staff of the Center also publishes its results in a form understandable to the general public, not only in technical journals.

John Hoover (USA). I agree that analysts doing assessment work generally fail to take the appropriate steps to get their findings into the policy stream. But as a professional at Argonne National Laboratories I am in somewhat of a bind; I would like to ensure that our results are used, but at the same time I am aware that a funding contractor feels that he should have a say in the handling of research findings.

Lionel Johns (USA). In my opinion the step of taking one's research findings to a public forum and defending them is an extremely important intellectual exercise. The exercise prevents one from operating in a secure vacuum and leads one to identify the limitations of the model or program so that they are not misused. The presentation of research results in a policy domain also leads one to identify 
critical assumptions, especially those which have some uncertainty. A modeler should have the courage to clarify his model's limitations if he wishes to make policy recommendations.

Wesley Foell (USA). I understand that in Sweden there is quite an open forum for analyzing alternative energy futures. Are different technical tools used in this broad-ranging debate to reinforce one position versus another?

Torgny Schütt (Sweden). I don't think that "modelers" comprise a special group of researchers. Models range from dynamic or simulation models to conceptual models, which are perhaps especially useful to decision makers. It is more accurate to speak of "analysts" rather than modelers, and then to describe the context in which they are working.

I would now like to turn to the communication process between analysts and political decision makers. As in the Federal Republic of Germany, it often happens in Sweden that an official government report is communicated to a decision-making body both directly and through the mass media. Because the mass media are interested in "news", i.e., bad news, they tend to put a biased profile on the information. Through the public, the news is channeled back again to the decision maker. Thus it can happen that the decision maker gets two different, often conflicting, reports. This poses a real problem.

Lars Bergman (Sweden). The modeling work of the Energy Commission in Sweden has led to new insights and a better understanding of certain kinds of relationships. Unfortunately these findings have often been hidden in lengthy presentations of models. Perhaps the models have not had much influence because we have failed to point out what is really new and important.

Wesley Foell (USA). The discussion has indicated that the real impact of systems analysis may depend on active communication efforts. Do you think that this might represent a constraint for IIASA, which as an international institution is governed by so many different bodies?

Charles Cicchetti (USA). I think that it should be recognized that there are essentially two different kinds of analysis. In the first type of analysis one uses the first $10 \%$ of the time which it takes to address a problem to learn $90 \%$ of the information needed to resolve the problem. If an analyst uses this approach, he can consider many problems and issues, but he must be willing to make mistakes because the last $10 \%$ of information could change his answer. The other approach requires the analyst to do the full $100 \%$ of the work, to ensure that there will be no surprises after the first $90 \%$ of the research has been completed. This is the approach usually adopted at universities, and probably at IIASA too, because of its high standards and political constraints. IIASA's strength lies in carrying out research of high quality for decision makers in government positions who don't always have the luxury of doing long, detailed studies to provide as complete an answer as possible to very complex problems. It is, of course, very important that people in decision-making positions should understand the two types of studies; perhaps the most important part of the analysis is defining the question in terms of choices, not doing the actual modeling nor collecting the data for it. 



\section{Name Index}

An $\mathrm{n}$ following a page number indicates a footnote; a $\mathrm{t}$ indicates a table.

Bergman, L., 16, 155-173, 299n, 309-310, $312-313,329$

Bernadini, O., 18, 112-130, 307n

Blain, D., $71 \mathrm{n}$

Brodman, J., 311-312, 321

Buehring, W. A., 273-282, 300n, 314-315

Charpentier, J.-P., 299n

Chateau, B., 289-290, 299n

Cicchetti, C., 11, 290-293, 307n, 314, 324, 329

Ciechanowicz, W., 18, 143-153

Czipper, G., 18, 91-111

Darmstadter, J., 2

Dennis, R., 265-273, 300n

Finon, D., 62-80

Foell, W., 4, 7, 11, 203-245, 307n, $322-323,325,328,329$

Földvary, G., 18, 91-111, 325-326

Fraunbaum, E., 16, 20-34, 305n

Geissler, E., 16, 35-56, 300n, 321, 327-328

Haider, H., 300n
Hannus, S., 16, 57-61

Hanson, M., 246-256, 305n, 309, 311, 313,314

Hedrich, P., 16, 81-90

Hervey, L., 257-265, 305n

Hirsch, H., 284-286

Hölzl, A., 246-256, 299n, 310

Hoover, J., 300n, 317-318, 319-320, 321, 328

House, P., 17, 182-200, 316-317

Jahkola, A., 305n

Johns, L., 307n, 328-329

Kinzelbach, W., 300n

Kluge, W., 286-289, 300n, 320-321

Lapillonne, B., 305n

Lichtenberg, A., 2

Makowski, M., 18, 143-153

Mannus, S., 299n

Martin, J.-M., 62-80

Middleton, P., 307n, 326-327

Nekrasov, A., 174-181 
Pönitz, E., 246-256

Richter, J., 299n, 310-311, 313-314

Schipper, P., 305n, 318-319

Schippers, L., 2

Schulz, V., 300n

Schütt, T., 16, 155-173, 307n, 315-316, $318,321-322,329$

Speth, G., 305n, 323-324, 328

Thoss, R., 49
Tomitate, T., 17, 131-142, 307n, 311,314

Ufer, D., 16, 81-90, 286-289, 305n

Unk, E., 18, 91-111

Van Caeneghem, J., 300n

Van Schaepen, F., 299n

Wiik, K., 16, 35-56

Zehetner, W., 307n 


\section{Subject Index}

An $\mathrm{n}$ following a page number indicates a footnote; a $\mathrm{t}$ indicates a table. Page numbers in italic type indicate figures.

\section{Abatement Cost Feedback Model}

(ABATE) (USA), 191

Air pollution. See Pollutant emissions

Air pollution models

in FRG, 45-47, 46, 55-56

in Italy, 124

in Poland, 150-151

shortcomings of, 301

Air quality management

in Austria, 27-28

in FRG, 45-47

in GDR, 87-88, 88n

in Japan, 137-139

in Poland, 149-150

Analysis Report (AEAR) (USA), 183-184

Angewandte Systemanalyse (ASA), 44, 48

Assignment of Processes and Associated

Activities to Subnational Regions

Model (REGION) (USA), 192

Atomic power. See Nuclear energy

Austria

coal imports in, 284

economic activity forecasts for, 224-226, 225

electricity consumption in, $211 \mathrm{t}$

energy conservation measures in, 284 energy conservation potential, in residential sector of, 252-253,253 energy consumption in, 208, 209, 209t energy demand analysis in, 23-26 energy plans in, 21-22 energy policy principles in, 23 energy supply in, $22,257-258,258 \mathrm{t}$ energy supply analysis in, 26-27 environmental analysis in, 27-29 industrial sector in, 204, 206, 208t institutional structures and energy planning in, 20-21, 284 integration of decision making and analysis in, 29-30

map of, 205

petroleum policy of, 285

population char acteristics of, 204, 206t, 206

population forecasts for, 224,224

scenarios for, 216-217t

energy conservation potential in, $248-249,248$

energy consumption in, 226-227, $227 \mathrm{t}$

petroleum demand in, 259t, 260t, $261 \mathrm{t}$ 
A ustria, scenarios for (contd.) pollution control in, 267-268 solar power assumptions in, 264-265

transportation energy use projections for, 231

transportation system of, 204, 207t

Austria II model, 24, 26, 225, 225n

Base Case Scenario (S 1), 214, 216-223t, $224,227 \mathrm{t}, 229 \mathrm{t}, 231,237 \mathrm{t}, 238,240$, $241,242,259 \mathrm{t}, 261 \mathrm{t}, 268,269$

Bezirk-X. See also German Democratic Republic economic activity forecasts for, 224-226, 225

energy supply in, 257-258, 258t

features of, 204, 214

population forecasts for, 224,224

scenarios for, 218-219t

energy conservation potential in, 249,249

energy consumption in, 226, 227t petroleum demand in, 259t, 260t, $261 \mathrm{t}$

solar power assumptions in, 264-265

transportation energy use projections for, 231

Brookhaven Energy-Economy Input-Output Model (IO) (USA), 193, 195, 196

Brookhaven Energy System Optimization Model (BESOM) (USA), 193, 194, 195-196

Brookhaven National Laboratory (BNL) Modeling System, 182, 200, 318-319

Canada, energy modeling in, 326-327

Cause-effect relationships, 164

Coal

as electricity generation source, in regional studies, 212

environmental impacts of, 138,272

mining of, Austrian planning methods for, 26

as petroleum substitute, $258-261$

as primary energy source, in regional studies, 213, 236, 258t, 275, $276 \mathrm{t}, 277,277 \mathrm{t}$ sectoral use of, in regional studies, $278 \mathrm{t}$

Cogeneration plants, 180,181

definition of, $263 \mathrm{n}$

efficiency of, 263

institutional barriers to, 263

Commercial sector

energy conservation potential in, 253

energy demand analysis for

in Japan, 133

in regional scenarios, 232

petroleum demand of, in regional scenarios, 260t, 26 lt

solar power use in, in regional scenarios, 264-265

Conservation. See Energy conservation

Conservation Case Scenario (S4) for Austria, 216-217t, 227t, 229t, 231, $237 \mathrm{t}$

Council of Mutual Economic Assistance (CMEA), 84, 89, 90

Critical path method (CPM), 26

Damage functions, 302, 303, 317

Data bases

for demand coefficients, in USA, 188-189

for energy demand analysis, in Japan, 133

for energy end uses, in Italy, 119-120

for energy/environment analysis, in Sweden, 160

for environmental impact coefficients, 18

regionalized, in FRG, 48

Data Resources, Inc. (DRI) models, 17, $188,195-196$

Decision making and analysis, integration of. See Embedding

Decision models. See also Preference analysis

for economic/environmental policy coordination, in FRG, 55-56

for government and private industry policy analysis, in USA, 196-199

Degree-days, calculation of, 232t

Department of Energy (DOE) (USA), 182, $200,316,317$

Diffusion models, of air pollution, in FRG, $45-47,46$

District heat

and air pollution, 270-272, 271, 288 
definition of, $263 \mathrm{n}$

efficiency of, 262

energy conservation potential of, $262-263,306$

potential of, in FRG, 42

promotion of, in Wisconsin, 291

use of

in GDR, 262-263, 286-287

in Hungary, 96, 97-99, 98t

Dose. See Pollution dose

DRI. See Data Resources, Inc.

Dynamic equilibrium models, $157-158$

Econometric models

of economy

for Sweden, 157-159

for USA, 188, 189

of electricity sector, for France, 69

of energy demand, for USA, 189

of energy sector, for Italy, 120, 121

Economic activity, as forecasted in regional scenarios, 225

Elasticity. See Inferred elasticity

Electricité de France (EDF), 64, 68, 69

Electricity consumption

in Italy, 113

regional comparison of, $210,211 \mathrm{t}$

scenarios of, 236-237, 237t

Electricity sector planning methods

in Austria, 26-27

in France, 68-71

in FRG, 44-45

in Japan, 136

in USSR, 178,180

Embedding

approaches to, 18-19, 307-308, 322-329

in Austria, 29-30

in Finland, 61

in France, 71, 290

in FRG, 49-50

in GDR, 88-89

in Hungary, 107-110

in Japan, 140-141

in Sweden, 166-167, 167

in USA, 199-200

Emission standards

in Austria, 27

in France, 73n

in FRG, $27,45,55$ in Hungary, 107

in Japan, $137 \mathrm{t}$

in selected OECD countries, $137 \mathrm{t}$

in USA, 268

Emissions. See Pollutant emissions

End-use energy. See also Energy demand analysis

definition of, 226

in regional scenarios, $227 \mathrm{t}, 226-228$

End-use energy consumption

and energy conservation potential in regional scenarios, 248-252, 248, $249,250,251$

regional overview of, 209, 209t

Energy balance

in Austria, 26

in Finland, 60

in FRG, 37t, 41

in Italy, 119

in USSR, 177,180

Energy chain

and environmental impacts, 266

modeling of

in FRG, 44

in Poland, 143

Energy Commission of Sweden, 155, 163, $164,313,316$

Energy conservation, 305-307

and air pollution, 272

and cogeneration, 263, 306

definition of, 246-247

and district heating, 262-263, 306

effects of, 246

in France, 289

in Hungary, 100-101

in Italy, 126-127

in Japan, 132, 135

policy for, in USA, 183

potential for

in commercial sector, $253,261 \mathrm{t}$

in industrial sector, 254-255, 261, $261 \mathrm{t}$

in regional scenarios, 246-256, 248, $249,250,251$

in residential sector, 252-253, 253, $261 \mathrm{t}$

in transportation sector, 255-256, 261-262, 261t

promotion of, 306

and reduction of petroleum demand, 261-263, 261t 
Energy demand analysis, 16-17

in Austria, 23-26, 24t, 25t

in Finland, 58-59

in France, 67-75

in FRG, $41-43$

in GDR, 85-87

in Hungary, 105

in Italy, 121-122

in Japan, 133-135, 134t

in Poland, 145-147

in Sweden, 156-159

in USA, 187, 189, 197, 197-199

in USSR, 179

Energy/economy interactions analysis of, 299-300, 309-314

modeling of, $16,17,42,186 \mathrm{t}$

Energy intensiveness

and conservation in industrial sector, 254,261

definition of, 233

interregional comparison of, in industrial sector scenarios, 233-235, 234

reductions in

in GDR, 287

in Wisconsin, 254

Energy Plan

of GDR, 83

of Italy, 128

of Japan, 132

of USA, 182-183

Energy Policy and Conservation Act

(USA), 230-231, 255

Energy Production and Consumption

System Model (EPCS) (Poland),

144-149, 151-152, 148

Energy Prognosis Model (EPM) (Sweden), $158-160$

Energy Research and Development

Administration (ERDA) (USA),

182,200

Energy supply analysis, 17

in Austria, 26-27

in Finland, 59-60

in France, 67-75

in FRG, 43-45

in GDR, 85-87

in Hungary, 107

in Italy, 112-114, 121-122

in Japan, 134t, 135-136

in Poland, 147-149 in regional studies, $210,213,235-237$, 257-265

in Sweden, 160

in USA, 184-189

in USSR, 179-180

Energy supply scenarios

in Finland, 59-60

in Hungary, 107, 108-109t

in regional studies, 235-237, 257-265

Energy Systems Program Group at IIASA, 2

Energy Use Model (ENERGY) (USA), 192

Engineering models, 7

Ente Nazionale per l'Energia Ellectrica

(ENEL) (Italy). See National

Electrical Energy Agency

Environmental analysis, 17-18, 300-305, 314-322

in Austria, 27-29

in Finland, 60-61

in France, 75-77

in FRG, 45-49

in GDR, 87-88

in Hungary, 107

in Italy, 123-125

in Japan, 136-140

multi-media methods for, 301-302

in Poland, 149-151

in Sweden, 160-166

in USA, 189-193

in USSR, 180-181

Environmental impacts

categories of, 238

classification of, in Sweden, 162-163, $165 \mathrm{t}$

of electricity generation, in France, 71

of energy systems

in Sweden, 160-163, 162, 315-316

in USA, 185

on human health and safety, in regional scenarios, 240-241

of land use, in regional scenarios, 238,239

of nuclear energy, in France, 66, 76-77

of radioactive wastes, in regional scenarios, 241-243, 242

of sulfur dioxide emissions, in regional scenarios, 239-240

Environmental impact models

in Italy, 124

in Poland, 144, 150-151

in USA, 183, 189-193, 190 
Environmental impact studies

in France, 77

in Japan, 138

Environmental Protection Model (EP)

(Poland), 144, 150-151

Fast breeder reactors (France), 63, 63n, 67

Federal Republic of Germany (FRG) economic characteristics of, $36 \mathrm{t}$ energy balance of, $37 \mathrm{t}$ energy demand analysis in, 41-43 energy policy in, 35-41

energy supply in, $37 \mathrm{t}$ energy supply analysis in, 43-45

facility siting in, 39

institutional structures and energy planning in, 35

integration of decision making and analysis in, 49-50, 327-328

land-use density in, $38 \mathrm{t}$ physical characteristics of, $36 \mathrm{t}$

Finland

energy demand analysis in, 58-59 energy supply analysis in, 59-60 environmental analysis in, 60-61 integration of decision making and analysis in, 61

France transnational pollution in, 57

coal enterprises in, 63

electricity enterprises in, 64 emission standards in, 73n energy demand analysis in, 67-75 energy industry of, 63-67 energy sector models for, 67-75 energy supply analysis in, 67-75 environmental analysis in, 75-77 institutional structures and energy planning in, 64-66, 289 national plan of, 65,71 natural gas enterprises in, 63 nuclear power enterprises in, 64,66 petroleum enterprises in, 64

FRG. See Federal Republic of Germany

Fuel efficiency standards (USA), 255

Fuel option models, 136, 138

Gas. See also Natural gas use as electricity generation source, in regional studies, 212 as primary energy source, in regional studies, 210, 213, 257-258, 258t

Gas sector models, in France, 68

Gaz de France (GDF), 63, 68

GDR. See German Democratic Republic

Geothermal energy resources, in Hungary, 99

German Democratic Republic (GDR)

district heating in, 262-263, 286-287

energy consumption in, 208, 209, 209t, $210,210 t$

energy demand analysis in, 85-87

Energy Plan of, 83

energy sector of, 82

energy supply analysis in, $85-87$

energy system features of, 89-90

environmental analysis in, 87-88, $287-288,320-321$

government structure of, 84

industrial sector of, 204, 208t

institutional structures and energy planning in, $81-85,286$

integration of decision making and analysis in, 88-89

map of, 205

planning process in, $83-85,87$

population characteristics of, 204, 206t, 206

transportation system of, 204, 207t

Health damage functions, 266

Health impacts

of air pollution, 27, 268-269, 269

of coal-based electricity generation, $279,279 t$

interregional comparison of, 240-241, 241

High-energy scenario (S2), 214, 216-223t, $227 \mathrm{t}, 229 \mathrm{t}, 231,237 \mathrm{t}, 238,242$

Hungary

area of, $93 \mathrm{n}$

coal use in, $98 \mathrm{t}, 99$

district heat program in, 96, 97-99, 98t

energy conservation in, 100-101

energy demand analysis in, 105

energy planning process in, 325

energy supply in, 91-101

energy supply analysis in, 106, 107

energy supply scenarios of, 107

energy supply system modernization in, 91-99 


\section{Hungary (contd.)}

environmental analysis in, 107 geothermal analysis resources of, 99 integration of decision making and analysis in, 107, 110

National Physical Plan of, 101 natural gas program of, 93-96, 95t, 96t nuclear power plants of, $99 \mathrm{n}$ petroleum products use in, $97,98 \mathrm{t}$ socio-economic planning in, 102, 103 solar energy use in, 100 spatio-physical planning in, 101-110

Hydroelectric facilities, impact of (Austria), 20,29

Hydropower

as electricity generation source in Italy, 112

in regional studies, 210,212 as primary energy source, in regional studies, $210,213,258 \mathrm{t}$

IIASA. See International Institute for Applied Systems Analysis

Import dependence in Austria, 210, 235-236, 257, 258

in France, 36

in FRG, 36

in GDR, 210, 235-236, 258

in Hungary, 107

in Japan, 132, 136

in Rhône-Alpes, 210, 235-236, 257, 258

in Sweden, 160

in USA, 183

in Wisconsin, 212, 235-236, 257, 258

Industrial sector

energy conservation potential of, 254-255

energy consumption of

in regional scenarios, 233-235, 234, $260 t$

in study regions, $254 \mathrm{t}$

energy demand analysis in (Japan), 133 structure of, in study regions, $208 \mathrm{t}$

Inferred elasticity

as assumed in regional scenarios, $228-229,229 t$

definition of, 228

Information systems. See also Data bases, $61,119-120$

INFORUM model (USA), 191, 192
Input-output models

Austria II model, 24, 26, 225, 225n

Brookhaven Energy-Economy Input-Output Model (USA), 193, 195,196

INFORUM model (USA), 191

level of aggregation in, 300

use of

in Canada, 326

in FRG, 42, 55-56

in Poland, 146, 147

in Sweden, 157

usefulness of, 313-314

Institut für Energetik (GDR). See Institute of Energetics

Institute Economique et Juridique de l'Energie (IEJE) (France). See Institute for the Economic and Judicial Study of Energy

Institute for the Economic and Judicial

Study of Energy (France), 72, 74n

Institute of Energetics (GDR), 83

Institute of Energy Economics (IEE)

(Japan), 132, 133, 135, 136, 138,

$138 \mathrm{n}, 139,140$

Institutional structures

impact of, on energy system planning

in Austria, 20-23

in France, 63-67, 289

in FRG, 35

in GDR, 81-85

in Italy, 114-1 18

in USA, 182

national overview of, 15-16

Insulation standards, 231-232, 253, 253, 292

International Fuel Cycle Evaluation Group (INFCE), 1

International Institute for Applied Systems Analy sis (IIASA) and methodology transfer, 61 and Regional Energy/Environmental Study, 3-10, 297-298

Italy

energy consumption in, 112-113

energy demand analysis in, 121-122

energy price determination in, 122-123

energy production in, 112

energy supply analysis in, 121-122

environmental impact analysis in, 114, 118 
environmental planning and management in, 123-125

institutional structures and energy/environment management in, $114-118,115$

Petroleum Plan of, 114

public resistance to power plant siting in, $124-125$

refinery capacity in, 113-114, 125

Japan

energy demand analysis in, 133-135, $134 t$

energy/economy interactions in, 311,312 energy planning aims in, 132

energy supply analysis in, 134t, $135-136$

environmental analysis in, 136-140

environmental issues in, 132

istitutional structures and energy planning in, 131-133

integration of decision making and analysis in, 140-141

KFA/STE model (FRG), 43, 43

Land use. See also Environmental impacts and air pollution exposure, 272 in regional scenarios, 238,239

Land Use Model (USA), 192

Lead content of gasoline (France), 75

LEMMA model (Sweden), 157-158, 159

Linear programming models, 44, 72, 136, 193,314

Liquid natural gas, potential penetration of, in Japan, 139

Liquid natural gas-oil competition model (Japan), 139

Low-energy scenario (S3), 214, 216-223t, $227 \mathrm{t}, 229 \mathrm{t}, 231,237 \mathrm{t}, 238,242$, $259 \mathrm{t}, 261 \mathrm{t}$

Market Orientation Program Planning Strategy (MOPPS) (USA), 182

Material Reserves Model (STOCKS) (USA), 191-192

Ministère Chargé de la Protection de la Nature et de l'Environnement (France). See Ministry for the Protection of Nature and the Environment
Ministry for the Protection of Nature and the Environment (France), 65, 66, $75,76,77$

Motor vehicles. See Transportation sector

MRI models (Poland), 145

Multi-attribute decision analysis. See Preference analysis

National Electrical Energy Agency (Italy), $115,117,126$

National Energy Plan (NEP) (USA), 182-183

National Physical Plan (Hungary), 18, 101

Natural gas use

in Hungary, 93-96, 95t, 96t

in Italy, 112

Net national output. See Economic activity

Netherlands, energy supply in, 318

Nitrous oxide emissions in Japan, 137-138, 137t in USA, 183

Non-linear programming models, use of, in France, 70

Nuclear energy

district heat from, 48

environmental impact of, 48, 76-77

referendum on

in Austria, 20, 285

in Sweden, 156

as source for electricity generation, in regional studies, 210,212

as source of primary energy, in regional studies, $210,213,258 \mathrm{t}$

use of,

in France, 66, 289, 290

in Italy, 113

in Rhône-Alpes region (France), 63

Nuclear power facilities construction of, in Hungary, 99n siting of, in France, 76-77

Objective function, $73,136,139,178-179$

Oil. See Petroleum

Oil Trade Model (Japan), 136

Optimization models, 17,44

of electricity company investments

(France), 69-70

of energy sector

in France, 67, 68, 72-75

in GDR, 85-87

in USA, 186t, 193-195 
Originator principle, 39

Person Days Lost. See also Health impacts and air pollution, 266, 273

definition of, $240,241 \mathrm{n}$

from electricity generation, $279 t$

Petroleum

consumption of

in FRG, 37t

in Hungary, 97, 98t

in Italy, 113

as electricity generation source, in regional studies, 212

lead content of (France), 75

as primary energy source in regional studies, $210,213,257-258,258 \mathrm{t}$. $259 \mathrm{t}$

sectoral demand for, in regional studies, $260,260 t$

sulfur content of

in Austria, 27, 267n

in France, 75

in Japan, 137

supply of, in future, 235-236, 258-261

Petroleum sector models (France), 67

PIES. See Project Independent Energy

Poland

Systems Model

electricity supply scenarios for, $147-149$

energy consumption analysis in, $145-147$

energy production analysis in, 147-149

energy system planning in, 151-152 environmental analysis in, 149-151

Pollutant emissions, 265-273

in Austria, 27, 28t

control of, in Italy, 123-124

modeling of

in FRG, 45-47, 46

in Poland, 150-151

Pollution dose, definition of (Poland), 149

Pollution dose-response relationships, 161, 302

Population characteristics, of study regions, 204, 224, 224

Preference analysis, 9, 71, 281-282, 282t, 315

Preferences, of decision makers (Sweden), $164,165,166,315-316$

Prescriptive models, 17
Price, of energy

in Italy, 122-123

and personal income (USA), 256

policies for, in study regions, 252, 254, 255

in USA, 198, 199, 291

Primary energy consumption

in Austria, 23, 208, 209t

conservation potential for, in Wisconsin scenarios, 251-252, 251

in FRG, 36, 37t

in study regions, 208, 209t

Primary energy supply. See also Energy supply an alysis

in study regions, 257-258, 258t

Production Optimization Model (POM) (GDR), 85-87

Project Independent Energy Systems model (PIES) (USA), 182, 183, $184-189,186 \mathrm{t}, 188,200$

Reference energy systems, 17-18, 318-319

Refinery capacity (Italy), 113-114, 125

Refinery model (Italy), 126

Renewable energy sources and energy conservation, 263-265, 306 in Italy, 120

promotion of, 306-307

in USA, 183

Residential sector

district heat use in, in GDR scenarios, 262-263

energy conservation potential of, in Austria, 252-253, 253

energy demand analysis of

in Japan, 133

in study regions, $231-232,232 \mathrm{t}$

in Sweden, 159, 159n

heating requirements of, in FRG, 42, 43

petroleum demand of, in regional scenarios, 260, 260t, 261t

solar energy potential in, 264-265

Residual Generation Model (RESGEN)

(USA), 192

Resource allocation model, 235

Rhône-Alpes region (France)

economic activity forecasts for, 224-226, 225, 289

electricity consumption in, $211 \mathrm{t}$ 
energy consumption in, 62, 208, 209, 209t, 259t

energy production in, 62

energy supply in, 257-258, 258t

industrial sector in, 204, 206, 208t

map of, 205

nuclear energy in, 63

population characteristics of, 62, 204, 206t, 206, 224, 224

scenarios for, 210-221t

energy conservation potential in, $250-251,250$

energy consumption in, 226-228, $227 \mathrm{t}$

petroleum demand in, 259-261, $259 \mathrm{t}, 260 \mathrm{t}, 261 \mathrm{t}$

solar power assumptions in, 264-265

transportation energy use projections

for, 230,231

transportation system of, 204, 207t

SCA method, 266

Scenarios

assumptions used in, for study regions, 224-226

for Austria, 216-217t

for Bezirk-X, 218-219t

energy conservation potential of, for study regions, 248-252, 248, $249,250,251$

as research tool, 5-6, 212-215, 299

for energy demand analysis, 16 , 226-235

for energy supply analysis, $235-237$

for environmental analysis, 237-243

in Finland, 58

in France, 69, 71-72

in FRG, 42-43

in Hungary, 107, 108-109t

in Japan, 133, 139

in Poland, 146, 147, 149, 152

in USA, 193

in USSR, 176-178, 180-181

results of, for study regions, 7-8, 226-243

for Rhône-Alpes, 220-221t, 290

for Wisconsin, 222-223t

Scenario S1. See Base Case Scenario

Scenario S2. See High-energy Scenario

Scenario S3. See Low-energy Scenario
Scenario S4. See Conservation Case Scenario

SEAS model. See Strategic Environmental Assessment System

Sensitivity studies, 6, 213, 215, 261

Service sector. See Commercial sector

Shadow prices, 179

Sibilla system (Italy), 126

Simulation models, 7

of economic development (Sweden), $157-158$

of energy/environment sectors, 7, 214

of energy policies (France), 71

of energy sector (USA), 186t, 189

of thermal water pollution (FRG), 47

Siting, of energy facilities

in France, 76-77

in FRG, 39, 47, 48

in Italy, 124-125

in Japan, 131

Sludge disposal, 183-184

Solar energy

assumptions about, in regional scenarios, 264

potential of, 263-265

and tax credits (Wisconsin), 292

use of

in GDR, 287

in Hungary, 100

in Italy, 120

in USA, 183

Solid Waste Recycling Model (SOLID

WASTE) (USA), 191

Spatio-physical planning (Hungary), 101-111

SRI-Gulf model (USA), 182, 186t, 196-199, 197, 200

Stack heights, and air pollution exposure, 270,288

Stanford Research Institution model. See SRI-Gulf model

Statistics Canada, 326

Strategic Environmental Assessment System (SEAS) (USA), 182, 183, $186 \mathrm{t}, 189-193,190$

Strategic Petroleum Reserve (USA), 183

Substitution Optimization Model (SOM) (GDR), 85, 87

Sulfur content, of fuel

in Austria, 27, 267n

in France, 75 
Sulfur content, of fuel (contd.)

impact of, on emissions, 269

in Italy, 123

in Japan, 137

Sulfur dioxide emissions. See also

Environmental impacts, Pollutant emissions

in Austrian scenarios, 268

control measures for, 267-268, 274, 288

exposure to, 266

and fuel mix, 272

in regional scenarios, 239-240, 240, 280

Sunshine Program (Japan), 132

Super-Phênix, 67

Supply conversion/allocation model

(Japan), 136

Sweden

decision-making system in, 161

energy demand analysis in, 156-159

energy/economy interactions in, 309-310, 312-313

energy policy in, 155-156

energy supply analysis in, 160

environmental analysis in, 160-166, 315-316

government studies of

energy/environment system in, $170-173$

integration of decision making and analysis in, 166-167, 315-316

parliamentary procedure in, 168,169

Sy stems Research Institute system of models (Poland), 143-152, 144

Tradeoff methodologies, $303,317,318$, 320

Transnational pollution, 57

Transportation Model (TRANSPORT), (USA), 192

Transportation sector

assumptions about, in regional scenarios, 230-231, 231

energy conservation potential of, 255-256

energy consumption of

in FRG, 41

in Japan, 135

in regional scenarios, 231

environmental impact of, in FRG, 41 petroleum demand in, in regional scenarios, $260 \mathrm{t}$

Transportation system, of study regions, $204,207 \mathrm{t}$

UMPLIS information system (FRG), 40

Uncertainty

and decision making, 322-323

as energy planning problem (Finland), 59

of environmental impact analysis

(Sweden), 163-164, 166

quantification of, 19

in standard-setting, 303-304

types of, 304

Union of Soviet Socialist Republics

(USSR)

energy demand analysis in, 178-179

energy economy analysis in, 174-177, 175

energy economy scenarios for, 177-178

energy supply analysis in, 179-180

environmental impact analysis in, 180-181

regional energy economy of modeling of, 178-180 planning of, 176-177

United States of America (USA)

Brookhaven models for, 193-195

DRI models for, 195-196

energy objectives of, 182-183

environmental analysis in, 185

gasoline prices in, 256

integration of decision making and analysis in, 184, 199-200, 316-317

National Energy Plan of, 182-183

PIES model for, 184-189

SEAS model for, 189-193

SRI-Gulf model for, 196-199

Utility functions, $282 t$

Value added. See also Economic activity as economic indicator, in regional scenarios, 225

in Finland, 58

in France, 69

Waste heat utilization (Japan), 139-140

Water quality management

in Austria, 28 
in FRG, 47-49

in Italy, 124

modeling of, 301

Wisconsin, State of (USA)

economic activity forecasts for, 224-226, 225

electricity consumption in, $211 \mathrm{t}$

energy consumption in, 208, 209, 209t

energy pricing mechanisms in, 291

energy supply in, 257-258, 258t

industrial sector in, 204, 206, 208t

map of, 205

population characteristics of, 204, 206t, 206, 224, 224 scenarios for, 222-223t

energy conservation potential in, 251-252, 251

energy consumption in, $226,227 \mathrm{t}$, 228,291

petroleum demand in, 259t, 260t, $261 \mathrm{t}$

solar power assumptions in, 264-265

transportation energy use projections

for, 231

transportation system of, 204, 207t

Workshop on Alternative Energy

Strategies (WAES), 2, 58, 236 

3 Management and Planning of Energy/Environment Systems in Austria E. G. Fraunbaum

4 Management and Planning of Energy/Environment Systems in the Federal Republic of Germany E. Geißler and K. Wiik

5 Management and Planning of Energy/Environment Systems in Finland

S. Hannus

6 Management and Planning of Energy/Environment Systems in France

$D$. Finon and $J,-M$. Martin

7 Management and Planning of Energy/Environment Systems in the German Democratic Republic $D$. Ufer and P. Hedrich

8 Management and Planning of Energy/Environment Systems in Hungary G. Czipper, G. Földvary, and E. Unk

9 Management and Planning of Energy/Environment Systems in Italy

O. Bernardini

10 Management and Planning of Energy/Environment Systems in Japan

\section{T. Tomitate}

11 Management and Planning of Energy/Environment Systems in Poland

W. Ciechanowicz and M. Makowski

12 Management and Planning of Energy/Environment Systems in Sweden

T. Schütt and L. Bergman

13 Management and Planning of Energy/Environment Systems in the Union of Soviet Socialist Republics A. S. Nekrasov

14 Management and Planning of Energy/Environment Systems in the United States of America $P$. House

Part II. A Retrospective Look at the Four IIASA Regional Analyses of Energy/Environment Systems

15 A Four-Region Overview W. K. Foell

16 Issues Emerging from the Scenarios M. E. Hanson, A. Hölzl, E. Pönitz, L. A. Hervey, R. Dennis, and W. A. Buehring

17 Retrospective Views from the Four Regions $H$. Hirsch, W. Kluge, D. Ufer, B. Chateau, and $C$. Cicchetti

Appendixes

Indexes 


\section{THE WILEY IIASA INTERNATIONAL SERIES ON APPLIED SYSTEMS ANALYSIS}

Conflicting Objectives in Decisions

Edited by David E. Bell, University of Cambridge; Ralph L. Keeney, Woodward-Clyde Consultants, San Francisco; and Howard Raiffa, Harvard University

Material Accountability: Theory, Verification, and Applications Rudolf Avenhaus, Nuclear Research Center Karlsruhe and University of Mannheim Adaptive Environmental Assessment and Management

Edited by C. S. Holling, Institute of Animal Resource Ecology, University of British Columbia

Organization for Forecasting and Planning: Experience in the Soviet Union and the United States

Edited by William R. Dill, New York University; and G. Kh. Popov, Moscow State University

Management of Energy/Environment Systems: Methods and Case Studies Edited by Wesley K. Foell, University of Wisconsin-Madison

Systems Analysis by Multilevel Methods: With Applications to Economics and Management

Yvo Dirickx, Twente University of Technology; and L. Peter Jennergren, Odense University

Connectivity, Complexity, and Catastrophe in Large-Scale Systems

John L. Casti, New York University

Pitfalls of Analysis

Edited by G. Majone and E. S. Quade, International Institute for Applied Systems Analysis

Control and Coordination in Hierarchical Systems

W. Findeisen, Institute of Automatic Control, Technical University, Warsaw;

F. N. Bailey, University of Minnesota; M. Brdyś, K. Malinowski, P. Tatjewski, and A. Woźniak, Institute of Automatic Control, Technical University, Warsaw

Computer Controlled Urban Transportation

Edited by H. Strobel, Institute for Transportation and Communication 'Friedrich List', Dresden, GDR

National Perspectives on Management of Energy/Environment Systems

Edited by Wesley K. Foell, University of Wisconsin-Madison; and Loretta A. Hervey, International Institute for Applied Systems Analysis, Laxenburg

\section{Forthcoming}

Mathematical Modeling of Water Quality

Gerald T. Orlob (USA)

The Electronic Oracle

D. Meadows and $\mathbf{J}$. Robinson (both of USA)

\section{JOHN WILEY \& SONS}

Chichester - New York - Brisbane - Toronto - Singapore

A Wiley-Interscience Publication 